\title{
WEST VALLEY DEMONSTRATION PROJECT SITE ENVIRONMENTAL REPORT CALENDAR YEAR 2001
}

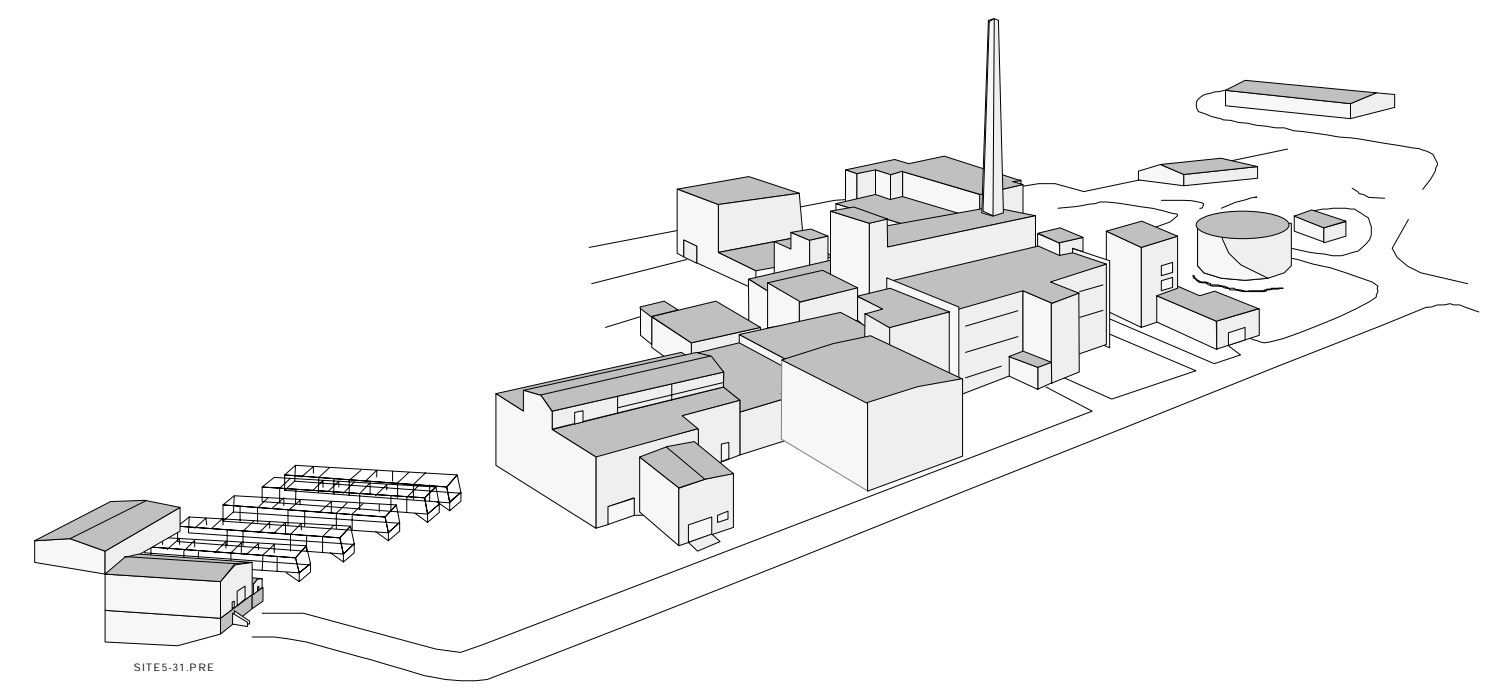

\section{WEST VALLEY NUCLEAR SERVICES COMPANY AND URS GROUP, INC.}
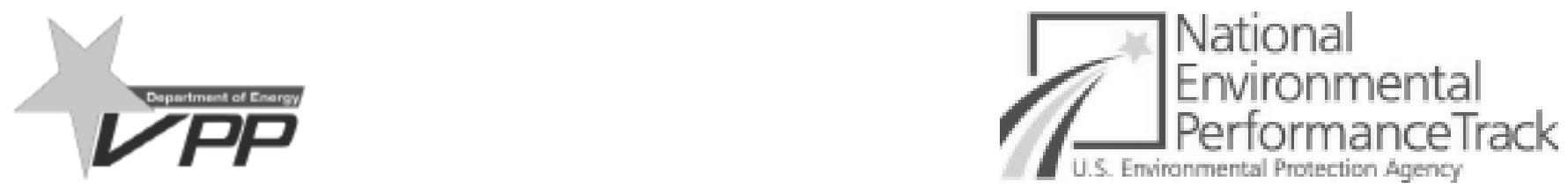

Prepared by: West Valley Nuclear Services Co. and URS Group, Inc.

Prepared for: U.S. Department of Energy

Ohio Field Office OH/WVDP

August 2002

10282 Rock Springs Road

Under: Contract DE-AC24-81NE-44139

West Valley, New York 14171-9799 



\author{
Department of Energy \\ Ohio Field Office \\ West Valley Demonstration Project \\ 10282 Rock Springs Road \\ West Valley, NY 14171-9799
}

To The Reader:

This report, prepared by the U.S. Department of Energy (DOE) Ohio Field Office West Valley Demonstration Project (OH/WVDP), summarizes the environmental protection program at the West Valley Demonstration Project (WVDP) for calendar year 2001. As has been the practice in prior years, this report is being made available to the public as soon as possible in advance of DOE's required release date of October 1, 2002.

Monitoring and surveillance of the WVDP facilities are conducted in order to verify that public health and safety and the environment are protected. The quality assurance protocols applied to the environmental monitoring program by the DOE ensure the validity and accuracy of the monitoring data. Also included in this report are groundwater and ambient air data from the New York State Energy Research and Development Authority's (NYSERDA) New York State-licensed Disposal Area (SDA).

Air, surface water, groundwater, soil, and biological samples collected and analyzed for radiological and nonradiological constituents are evaluated for indication of potential effects of activities at the WVDP. Monitoring of treated water effluents and facility ventilation system emissions verified that the dose received by off-site residents continues to be minimal.

Calculated doses to the hypothetical maximally exposed off-site individual from airborne and waterborne radiological releases in 2001 were less than one percent of the DOE limit. Radionuclide concentrations in biological samples were at levels near or statistically identical to background concentrations.

Nonradiological liquid effluent discharges are controlled and permitted through the New York State Pollutant Discharge Elimination System (SPDES). Discharges in 2001 were below regulatory limits with only one exception. Although this one release is not believed to have had a significant effect on the off-site environment, action was taken to prevent its recurrence. Refer to the Environmental Compliance Summary (ECS) section of the report for further discussion on this release.

The Project's continuing commitment to safety was recognized in 2001 when it was awarded the DOE Voluntary Protection Program Star of Excellence Award. In addition, the Project's continuing commitment to environmental responsibility was confirmed when the WVDP's status as a National Environmental Performance Track charter member was reaffirmed by the U.S. Environmental Protection Agency.

If you have any questions or comments about the information in this report, please contact the West Valley Nuclear Services Company (WVNSCO) Communication Department at (716) 942-4555 or complete and return the enclosed survey.

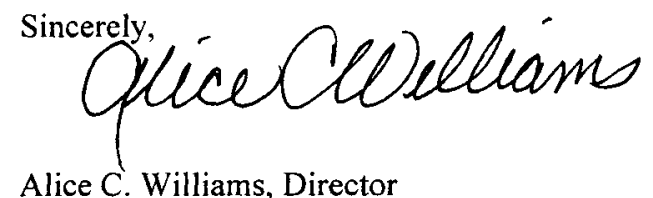

West Valley Demonstration Project 



\title{
West Valley Demonstration Project Site Environmental Report
}

for

\section{Calendar Year 2001}

\author{
Prepared for the U.S. Department of Energy \\ Ohio Field Office \\ West Valley Demonstration Project Office \\ under contract DE-AC24-81NE44139
}

\author{
August 2002 \\ West Valley Nuclear Services Co. \\ 10282 Rock Springs Road \\ West Valley, New York 14171-9799
}


This page intentionally left blank 


\section{Preface}

Environmental monitoring at the West Valley Demonstration Project (WVDP) is conducted by the West Valley Nuclear Services Company (WVNSCO), under contract to the U.S. Department of Energy (DOE). The data collected provide an historical record of radionuclide and radiation levels and chemical data from natural and manmade sources in the survey area. The data also document the chemical and radiological quality of the groundwater on and around the WVDP and in the air and water released by the WVDP. Meteorological data are also presented.

It is the policy of the WVDP to conduct all activities, including design, construction, testing, start-up, commissioning, operation, maintenance, and decontamination and decommissioning, in a manner that is appropriate to the nature, scale, and environmental effects of these activities. The WVDP is committed to full compliance with applicable federal and New York State legislation and regulations for the protection of the environment, to continual improvement, to the prevention and/or minimization of pollution, and public outreach, including stakeholder involvement.

This report represents a single, comprehensive source of off-site and on-site environmental monitoring data collected during 2001 by environmental monitoring personnel. The environmental monitoring program and results are discussed in the body of this report. The monitoring data are presented in the appendices. Appendix A contains maps of on-site and off-site sampling locations. Appendix $B$ is a summary of the site environmental monitoring schedule. Appendices $C$ through $J$ contain summaries of data obtained during 2001 and are intended for those readers interested in more detail than is provided in the main body of the report. Appendix $K$ lists laws and regulations pertaining to the WVDP. Appendix L provides groundwater monitoring data from the New York State-licensed Disposal $\operatorname{Area}(S D A)$.

Requests for additional copies of the 2001 Site Environmental Report and questions regarding the report should be referred to the WVDP Communications Department, 10282 Rock Springs Road, West Valley, New York 14171 (telephone: 716-942-4555). Additional Project information is available on the internet at http://www.wv.doe.gov. 
This page intentionally left blank

$i v$ 


\section{SUMMARY OF CHANGES TO THE 2001 WVDP SITE ENVIRONMENTAL REPORT FROM THE 2000 SITE ENVIRONMENTAL REPORT}

This report, prepared by the U.S. Department of Energy (DOE) West Valley Demonstration Project office, summarizes the environmental protection program at the West Valley Demonstration Project (WVDP) for calendar year (CY) 2001. Monitoring and surveillance of the facilities used by the DOE for the WVDP are conducted in order to protect public health and safety and the environment. The quality assurance protocols applied to the environmental monitoring program by the DOE ensure the validity and accuracy of the monitoring data. Also included in this report are groundwater and ambient air data from the New York State Energy Research and Development Authority's (NYSERDA) New York Statelicensed Disposal Area (SDA).

Changes in content for the 2001 annual Site Environmental Report are summarized below. The overall organization of the report is the same as that of the 2000 Site Environmental Report.

\section{REVISIONS AND ADDITIONS}

- The Executive Summary, Introduction, and Environmental Compliance Summary have been updated to describe implementation of the environmental monitoring program, special topics of importance, and status of regulatory compliance in CY 2001. The table of permits at the end of the Environmental Compliance Summary was updated to reflect those in effect in CY 2001.

- The section describing the purpose of the report was moved from the Introduction to the beginning of the Executive Summary. Summaries of compliance with DOE Orders 5400.5 and 435.1 were added to the Environmental Compliance Summary, as was a new section entitled Environmental Issues and Actions.

- Data and text were updated throughout the report to reflect results from the CY 2001 environmental monitoring program. Tables, graphs, maps, and references also were updated. The format for numerical data was standardized throughout to present standard units first, followed by metric units in parentheses.

- Chapter 1 summarizes 2001 activities at the WVDP, including vitrification, tank cleaning and characterization, preparation for spent fuel shipping, construction of the remote-handled waste facility, and environmental management of waste, liquid releases, and airborne emissions. All graphs were updated to include 2001 performance results.

- Chapter 2 includes a discussion of 2001 radiological results of sampling of air emissions and water effluents as compared to DOE concentration guides (as applicable). Results from air, water, soil, and biological samples taken from other on-site, near-site, and community locations are compared with results from background locations in order to evaluate effects of site activities. The current status of nonradiological monitoring on-site is also discussed. Special environmental evaluations done in 2001 are discussed. These include iodine emissions from the main stack, mercury at the low-level waste treatment facility, dose to biota, monitoring of contamination near the main process building, and monitoring of ambient air near preparation areas for soil shipments. 
- $\quad$ Chapter 3 was updated to summarize and discuss results of the 2001 groundwater monitoring program, including continued monitoring, characterization, and mitigation of the strontium-90 plume on the north plateau. Figures were updated to reflect monitoring results in CY 2001.

- Chapter 4 provides an assessment of dose to the general public resulting from exposure to radiation and radionuclides released by the Project to the surrounding environment in 2001. Dose calculations were updated to reflect monitoring results from CY 2001. A new section entitled Dose to Biota: Aquatic and Terrestrial Wildlife and a table summarizing the evaluation of dose to biota were added to the report.

- $\quad$ Chapter 5 was updated to summarize the assessments of the environmental monitoring program under the WVDP quality assurance program. A new section entitled Data Verification and Validation was added.

- Maps in Appendix A were revised in a standardized format and updated to reflect the 2001 environmental monitoring program. A new map, detailing environmental sampling points between five and ten kilometers from the WVDP, was added.

- Changes in the environmental monitoring program in CY 2001 are summarized at the beginning of Appendix B.

- Appendices C, D, E, F, G, H, I, and L - the tables summarizing CY 2001 data for water, sediment, soil, air, groundwater, biological samples, State Pollutant Discharge Elimination System (SPDES) samples, direct radiation monitoring, meteorological monitoring, and NYSERDA samples — were updated with CY 2001 results.

- $\quad$ There were no errata or corrigenda from the 2000 Site Environmental Report.

\section{SPECIAL ISSUES}

- $\quad$ Construction of the Remote-Handled Waste Facility continued in CY 2001.

- Ambient air in the NDA was monitored while soils for shipment were being moved from rolloffs to gondola cars.

- $\quad$ Low-level radioactive waste shipments continued in CY 2001.

- $\quad$ Spent fuel was removed from the FRS and prepared for shipping.

- Work to mitigate the gross beta plume on the north plateau continued.

- A contamination incident near the main process building was investigated and corrective actions were taken.

- Vitrification was almost completed. Cleaning and characterization of waste tanks continued in CY 2001. 


\section{ERRATA and CORRIGENDA}

\section{West Valley Demonstration Project \\ Site Environmental Report}

Calendar Year 2000

A transcription error was identified in the 2000 Site Environmental Report in Table D-24 (p. D-22). The June 2000 gross alpha value for location AFGRVAL, which read 6.13 $\pm 1.00 \mathrm{E}-15$, should be $0.61 \pm 1.00 \mathrm{E}-15$.

This change resulted in the aforementioned value no longer being bolded and the bolding being applied to the October value (1.33 $\pm 1.22 \mathrm{E}-15)$. This change caused no effect on evaluations throughout the report.

Any questions or comments about the corrigenda noted here may be directed to the Manager of Public and Employee Communications, John D. Chamberlain, West Valley Nuclear Services Company, at (716) 942-4610. 



\section{Table of Contents}

PREFACE

iii

EXECUTIVE SUMMARY

EXE-1

Purpose of This Report

EXE-1

Project Description EXE-1

Compliance EXE-2

Environmental Monitoring Program EXE-2

Surface Water Monitoring EXE-3

Soil and Stream Sediments EXE-4

Groundwater Monitoring EXE-4

Air Monitoring EXE-5

Vegetation, Meat, and Milk EXE-5

Game Animals EXE-5

Program Quality EXE-6

Safety and Environmental Management EXE-6

Notable 2001 Events EXE-6

Conclusion EXE-7

\section{INTRODUCTION}

INT-1

Information in This Report

INT-1

History of the West Valley Demonstration Project

INT-2

Description of the West Valley Demonstration Project INT-3 General Environmental Setting INT-5

Location of the West Valley Demonstration Project INT-5

Socioeconomics INT-5

Climate INT-6

Biology INT-6 Geology and Groundwater Hydrology INT-6

Environmental Monitoring Program INT-7

Monitoring and Sampling INT-7

Permits and Regulations INT-7

Exposure Pathways Monitored at the West Valley Demonstration Project INT-8

Water and Sediment Pathways INT-8

Groundwater Pathways INT-9

Air Pathways INT-9

Atmospheric Fallout INT-9 


\section{Table of Contents}

\section{Introduction (concluded)}

Food Pathways

INT-10

Direct Radiation Measurement

INT-10

Meteorological Monitoring

INT-10

Quality Assurance and Control

INT-10

Safety Management System

INT-10

ENVIRONMENTAL COMPLIANCE SUMMARY

ECS-1

Compliance Program

ECS-1

Compliance Status

ECS-2

Radiation Protection of the Public and the Environment (DOE Order 5400.5)

ECS-2

Radioactive Waste Management (DOE Order 435.1)

ECS-2

Resource Conservation and Recovery Act

ECS-2

Clean Air Act

Emergency Planning and Community Right-to-Know Act

ECS-8

Clean Water Act

Safe Drinking Water Act

ECS-13

Toxic Substances Control Act

ECS-13

National Environmental Policy Act

ECS-14

Migratory Bird Treaty Act

ECS-15

Current Achievements and Program Highlights

ECS-15

Phase II Vitrification

ECS-15

Integrated Safety Management System

ECS-15

STAR Status

ECS-16

U.S. EPA National Environmental Achievement Track

ECS-16

Environmental Management System

ECS-16

Environmental Issues and Actions

ECS-17

Closed Landfill Maintenance

ECS-17

Release of Materials Containing Residual Radioactivity

ECS-17

Flood Protection: Water-Supply Dam Repairs

ECS-17

Completion of the WVDP and Closure of the WNYNSC

ECS-17

Low-Level Radioactive Waste Shipment

ECS-18

On-Site Contamination Event

ECS-18

Project Assessment Activities in 2001

ECS-18 


\section{Table of Contents}

CHAPTER 1. ENVIRONMENTAL PROGRAM INFORMATION

Introduction $1-1$

Radiation and Radioactivity

Measurement of Radioactivity

Measurement of Dose

Environmental Monitoring Program Overview

Data Reporting

Changes in the 2001 Environmental Monitoring Program

Vitrification Overview

2001 Activities at the WVDP

Vitrification $1-8$

Tank Cleaning and Characterization

Decontamination and Decommissioning

Preparation for Spent Fuel Shipping

Remote-Handled Waste Facility Construction

Environmental Management of Aqueous Radioactive Waste

Environmental Management of Airborne Radioactive Emissions

Environmental Management of Radiological Exposure

Unplanned Radiological Releases

NRC-Licensed Disposal Area Interceptor Trench and Pretreatment System

Waste Minimization Program

Pollution Prevention Awareness Program

Waste Management

Low-Level Waste Shipping Program

National Environmental Policy Act Activities

Self-Assessments

Occupational Safety and Environmental Training

Voluntary Protection Program STAR Status

Environmental Management System Implementation

Integrated Safety Management System Implementation

Performance Measures

Radiation Doses to the Maximally Exposed Off-Site Individual

SPDES Permit Limit Exceptions

Waste Minimization and Pollution Prevention

Spills and Releases

Vitrification 


\section{Table of Contents}

CHAPTER 2. ENVIRONMENTAL MONITORING $2-1$

Routine Monitoring Program $2-1$

Sampling Program Overview 2-1

Radiological Monitoring: Surface Water $2-2$

Low-Level Waste Treatment Facility Sampling Location 2-3

Northeast Swamp and North Swamp Sampling Locations $2-4$

Other Surface Water Sampling Locations 2-4 South Plateau Sampling Locations $2-7$

Standing Pond Water Sampling Locations $2-9$

Off-Site Surface Water Sampling Locations

Drinking Water Sampling Locations

Radiological Monitoring: Sediments __ 2-12

Radiological Monitoring: Air ___ 2-14

On-Site Ventilation Systems $2-14$

Perimeter and Remote Air Sampling $2-17$

Fallout Pot Sampling $2-20$ Off-Site Surface Soil Sampling 2-20

Radiological Monitoring: Food Chain __ 2-20

Fish

2-20

Venison

2-21

Beef

2-22

Milk

2-22

Vegetables, Fruit, and Forage

2-22

Direct Environmental Radiation Monitoring ___ 2-22

On-Site Radiation Monitoring

$2-22$

Perimeter and Off-Site Radiation Monitoring

$2-23$

Confirmation of Results

2-24

Meteorological Monitoring ___ 2-24

Nonradiological Monitoring: Surface Water ___ 2-25

Nonradiological Monitoring: Drinking Water____ 2-26

Nonradiological Monitoring: Air __ 2-26

Special Monitoring __ 2-27

Iodine Emissions From the Main Stack ___ 2-27

Mercury at the Low-Level Waste Treatment Facility __ 2-27

Dose to Biota ___ 2-28

Monitoring of Contamination Near the Main Process Building __ 2-28

Monitoring of Ambient Air in the NDA for Soil Shipments __ 2-28 


\section{Table of Contents}

CHAPTER 3. GROUNDWATER MONITORING

Groundwater Monitoring Program Overview 3-1

Geologic History of the West Valley Site 3-1

Surface Water Hydrology of the West Valley Site $3-2$

Hydrogeology of the West Valley Site 3-2

Kent Recessional Sequence

Lavery Till 3-2

Sand and Gravel and Till-Sand Units

Routine Groundwater Monitoring Program 3-5

Monitoring Well Network $3-5$

Groundwater Monitoring Program Highlights 1982 Through 2001 3-8

Annual Analytical Trigger Level Review 3-8

Results of Routine Groundwater Monitoring 3-9

Long-Term Trends of Gross Beta and Tritium at Selected Groundwater Monitoring Locations 3-10

North Plateau Seeps 3-11

North Plateau Well Points 3-13

Results of Radioisotopic Sampling 3-13

Results of Monitoring at the NDA 3-13

Volatile and Semivolatile Organic Compounds Sampling 3-14

1,1-Dichloroethane 3-14

Dichlorodifluoromethane 3-14

1,2-Dichloroethylene 3-14

1,1,1-Trichloroethane 3-14

Tributyl Phosphate 3-15

Special Groundwater Monitoring 3-15

Gross Beta Plume on the North Plateau 3-15

Permeable Treatment Wall 3-16

Northeast Swamp Drainage Monitoring 3-16

North Plateau Groundwater Quality Early Warning Monitoring 3-16

Investigation of Chromium and Nickel in the Sand and Gravel Unit and Evaluation of Corrosion in Groundwater Monitoring Wells 3-17

Ten-Year Sampling Pump Inspections 3-17 


\section{Table of Contents}

CHAPTER 4. RADIOLOGICAL DOSE ASSESSMENT

Introduction 4-1

Sources of Radiation 4-1

Exposure Pathways 4-2

Land Use Survey 4-2

Radioactive Vitrification Operations ____ 4-3

Dose Assessment Methodology ____ 4-3

Measurement of Radionuclide Concentrations in Liquid and Air Releases ___ 4-5

Measurement of Radionuclide Concentrations in Food __ 4-5

Comparison of Near-Site and Background Environmental Media Concentrations ___ 4-7

Predicted Dose From Airborne Emissions __ 4-7

Maximum Dose to an Off-Site Individual ___ 4-8

Collective Population Dose ___ 4-9

Predicted Dose From Waterborne Releases __ 4-10

Maximum Dose to an Off-Site Individual ___ 4-11

Collective Dose to the Population __ 4-11

Calculated Dose From Local Foodstuff Tests ____ 4-11

Fish ___ 4-11

Milk ___ 4-11

Beef ___ 4-12

Venison ___ 4-12

Produce (Corn, Beans, and Apples)___ 4-12

Predicted Dose From All Pathways ___ 4-12

Risk Assessment___ 4-13

Dose to Biota: Aquatic and Terrestrial Wildlife ___ 4-13

Summary ___ 4-15

CHAPTER 5. QUALITY ASSURANCE _ 5-1

Organizational Responsibilities ___ 5-1

Program Design __ 5-1

Responsibility ___ 5-1

Planning ___ 5-1

Control of Design, Procedures, Items, and Documents __ 5-2

Documentation _ 5-2

Corrective Action __ 5-2

Audits _ـ 5-2 


\section{Table of Contents}

Chapter 5 (concluded)

Procedures 5-2

Quality Control in the Field $5-2$

Field Duplicates 5-3

Field Blanks $5-3$

Trip Blanks 5-3

Environmental Background Samples $5-3$

Quality Control in the Laboratory 5-3

Standards 5-4

Spikes $5-4$

Blanks 5-4

Duplicates $5-4$

Crosschecks 5-4

Personnel Training $5-5$

Recordkeeping $5-5$

Chain-of-Custody Procedures 5-6

Audits and Appraisals 5-6

Self-Assessments 5-6

Lessons Learned Program 5-7

Data Management and Data Validation $5-7$

Data Verification and Validation 5-7

Data Assessment and Reporting 5-7

Summary 5-8

APPENDIX A. Maps A-1

APPENDIX B. 2001 Environmental Monitoring Program B-i

APPENDIX C. Summary of Water, Sediment, and Soil Monitoring Data C-1 APPENDIX D. Summary of Air Monitoring Data D-1 APPENDIX E. Summary of Groundwater Monitoring Data ___ E-1 APPENDIX F. Summary of Biological Data __ F-1 APPENDIX G. Summary of Nonradiological Monitoring Data G-1 APPENDIX H. Summary of Direct Radiation Monitoring Data H-1 APPENDIX I. Summary of Meteorological Data __ I-1 APPENDIX J. Summary of Quality Assurance Crosscheck Analyses_ J-1 APPENDIX K. Environmental Regulations, Standards, and Orders_ K-1 APPENDIX L. Summary of NYSERDA Groundwater Monitoring Data L-1

$x i$ 


\section{Table of Contents}

REFERENCES and BIBLIOGRAPHY

$\mathrm{R} \& \mathrm{~B}-1$

GLOSSARY

GLO-1

ACRONYMS and ABBREVIATIONS

A\&A-1

UNITS OF MEASURE and UNIT PREFIXES

UOM-1

SCIENTIFIC NOTATION and CONVERSION CHART

UOM-2

DISTRIBUTION

DST-1

ACKNOWLEDGMENTS

ACK-1 


\section{Table of Contents}

\section{List of Figures}

1. Location of the Western New York Nuclear Service Center

INT-4

1-1. Annual Average Exposure at the CPC-WSA (DNTLD24)

1-2. Annual Average Exposure at the Drum Cell (DNTLD36)

1-3. Annual Effective Dose Equivalent to the Maximally Exposed Off-Site Individual

1-4. Yearly SPDES Permit Exceptions

1-5. Percentage of Waste Reduction Exceeding Goals

1-6. Number of Immediately Reportable Spills or Releases

1-7. Number of Curies Transferred to the Vitrification Facility

2-1. Fifteen-Year Trends of Gross Alpha, Gross Beta, and Tritium Concentrations at Sampling Location WNSP006

2-2. Fifteen-Year Trends of Gross Alpha, Gross Beta, and Tritium Concentrations at Sampling Location WNNDADR

2-3. Fifteen-Year Trends of Gross Alpha, Gross Beta, and Tritium Concentrations at Sampling Location WFFELBR

2-4. Sixteen-Year Trends of Cesium-137 in Stream Sediments at Two Locations Upstream and Three Locations Downstream of the WVDP

2-5. Comparison of Cesium-137 With Naturally Occurring Potassium-40 Concentrations in 2001 at Downstream Sampling Location SFTCSED

2-6. Fifteen-Year Trends of Gross Alpha and Gross Beta Activity at the Main Stack Sampling Location (ANSTACK)

2-7. Fifteen-Year Trends of Gross Alpha and Gross Beta Concentrations at the Rock Springs Road Sampling Location (AFRSPRD) $2-18$

2-8. Eighteen-Year Trends of Environmental Radiation Levels at Perimeter TLDs

2-9. Estimated Iodine-129 Releases From the WVDP Main Plant Stack $2-28$

3-1. Geologic Cross Section Through the North Plateau 3-3

3-2. Geologic Cross Section Through the South Plateau 3-3

3-3. North Plateau Gross Beta Plume Area: Fourth-Quarter 2001 Results 3-12

3-4. Annualized Average Strontium-90 Concentrations at WNSWAMP $3-17$

3-5. Eleven-Year Trends of Averaged Gross Beta Concentrations at Selected Locations in the Sand and Gravel Unit 3-18 


\section{Table of Contents}

List of Figures (continued)

3-6. Eleven-Year Trends of Averaged Gross Beta Concentrations at Selected Locations in the Sand and Gravel Unit $3-18$

3-7. Sixteen-Year Trends of Averaged Gross Beta Concentrations at Selected Locations in the Sand and Gravel Unit 3-19

3-8. Eleven-Year Trends of Averaged Tritium Concentrations at Selected Locations in the Sand and Gravel Unit

3-9. Eleven-Year Trends of Averaged Tritium Concentrations at Selected Locations in the Sand and Gravel Unit $3-20$

3-10. Sixteen-Year Trends of Averaged Tritium Concentrations at Selected Locations in the Sand and Gravel Unit

3-11. Eleven-Year Trends of 1,1-DCA at Selected Locations in the Sand and Gravel Unit $3-21$

3-12. Eleven-Year Trends of Dichlorodifluoromethane at Selected Locations in the Sand and Gravel Unit

3-13. Eleven-Year Trends of 1,2-DCE-t and 1,1,1-TCA at Well 8612 in the Sand and Gravel Unit $3-22$

3-14. Trends of Tributyl Phosphate at Selected Locations in the Sand and Gravel Unit $3-22$

4-1. Comparison of Annual Background Radiation Dose to the Dose From 2001 WVDP Effluents

4-2. Effective Dose Equivalent From Liquid and Airborne Effluents to a Maximally Exposed Individual Residing Near the WVDP $4-13$

4-3. Collective Effective Dose Equivalent From Liquid and Airborne Effluents to the Population Residing Within 50 miles $(80 \mathrm{~km})$ of the WVDP $4-14$

A-1. West Valley Demonstration Project Base Map A-3

A-2. On-Site Surface Water and Soil/Sediment Sampling Locations A-4

A-3. Off-Site Surface Water and Soil/Sediment Sampling Locations A-5

A-4. On-Site Air Monitoring and Sampling Points ___ A-6

A-5. Off-Site Air and Fallout Sampling Points ___ A-7

A-6. Active WVDP Groundwater Monitoring Points ___ A-8

A-7. North Plateau On-Site Groundwater Monitoring Network ___ A-9

A-8. South Plateau On-Site Groundwater Monitoring Network

A-9. Near-Site Drinking Water and Biological Sampling Points

A-10. Location of On-Site Thermoluminescent Dosimeters (TLDs) A-12

A-11. Location of Off-Site Thermoluminescent Dosimeters (TLDs) Within 5 Kilometers of the WVDP _ A-13 


\section{Table of Contents}

List of Figures (continued)

A-12. Environmental Sampling Points Between 5 and 10 Kilometers From the WVDP

A-14

A-13. Environmental Sampling Points More Than 10 Kilometers From the WVDP A-15

A-14. Projected 2001 Population by Sector Within 80 Kilometers of the WVDP A-16

E-1. $\mathrm{pH}$ in Groundwater Samples From the Sand and Gravel Unit E-24

E-2. Conductivity of Groundwater Samples From the Sand and Gravel Unit E-24

E-3. Gross Alpha in Groundwater Samples From the Sand and Gravel Unit E-25

E-4. Gross Beta in Groundwater Samples From the Sand and Gravel Unit E-25

E-4a. Gross Beta in Groundwater Samples From the Sand and Gravel Unit (Magnified Scale of Fig. E-4) E-26

E-4b. Gross Beta in Groundwater Samples From the Sand and Gravel Unit (Magnified Scale of Fig. E-4a)

E-5. Tritium in Groundwater Samples From the Sand and Gravel Unit ___ E-27

E-6. pH of Groundwater Samples From the Till-Sand Unit ___ E-27

E-7. Conductivity of Groundwater Samples From the Till-Sand Unit ___ E-27

E-8. Gross Alpha in Groundwater Samples From the Till-Sand Unit ___ E-28

E-9. Gross Beta in Groundwater Samples From the Till-Sand Unit ___ E-28

E-10. Tritium in Groundwater Samples From the Till-Sand Unit______ E-28

E-11. pH of Groundwater Samples From the Weathered Lavery Till Unit_____ E-28

E-12. Conductivity of Groundwater Samples From the Weathered Lavery Till Unit ___ E-29

E-13. Gross Alpha in Groundwater Samples From the Weathered Lavery Till Unit ___ E-29

E-14. Gross Beta in Groundwater Samples From the Weathered Lavery Till Unit ___ E-29

E-14a. Gross Beta in Groundwater Samples From the Weathered Lavery Till Unit (Magnified Scale of Fig. E-14)

E-15. Tritium in Groundwater Samples From the Weathered Lavery Till Unit______ E-30

E-16. pH of Groundwater Samples From the Unweathered Lavery Till Unit___ E-30

E-17. Conductivity of Groundwater Samples From the Unweathered Lavery Till Unit ___ E-30

E-18. Gross Alpha in Groundwater Samples From the Unweathered Lavery Till Unit ___ E-30

E-19. Gross Beta in Groundwater Samples From the Unweathered Lavery Till Unit ____ E-31

E-20. Tritium in Groundwater Samples From the Unweathered Lavery Till Unit ___ E-31

E-21. pH of Groundwater Samples From the Kent Recessional Sequence ______ E-31

E-22. Conductivity of Groundwater Samples From the Kent Recessional Sequence ___ E-31

E-23. Gross Alpha in Groundwater Samples From the Kent Recessional Sequence ____ E-32

E-24. Gross Beta in Groundwater Samples From the Kent Recessional Sequence ___ E-32

E-25. Tritium in Groundwater Samples From the Kent Recessional Sequence ___ E-32 


\section{Table of Contents}

List of Figures (concluded)

H-1. 2001 Average Yearly Gamma Exposure Rates Around the WVDP

H-6

H-2. 2001 Average Yearly Gamma Exposure Rates on the WVDP H-6

I-1. Wind Frequency Rose: 10-Meter at the Regional Monitoring Station I-3

I-2. Wind Frequency Rose: 10-Meter at the Primary Monitoring Station

I-3. Wind Frequency Rose: 60-Meter at the Primary Monitoring Station I-5

I-4. Calendar Year 2001 Weekly Precipitation I-6

I-5. Calendar Year 2001 Cumulative Precipitation I-6 


\section{Table of Contents}

\section{List of Tables}

Compliance Tables:

West Valley Demonstration Project 2001 Air Quality Noncompliance Episodes

ECS-20

West Valley Demonstration Project 2001 NPDES/SPDES Permit Limit Noncompliance

Episodes ECS-20

Release of Property Containing Residual Radioactive Material ECS-20

Status of EPCRA Reporting in 2001 ECS-21

Reportable Chemicals Above Threshold Planning Quantities Stored at the WVDP in 2001 ECS-21

West Valley Demonstration Project Environmental Permits ECS-22

2-1. 2001 Gross Alpha Concentrations at Surface Water Sampling Locations $2-5$

2-2. 2001 Gross Beta Concentrations at Surface Water Sampling Locations $2-5$

2-3. 2001 Gross Alpha Concentrations at Off-Site, Perimeter, and On-Site Ambient Air Sampling Locations

2-4. 2001 Gross Beta Concentrations at Off-Site, Perimeter, and On-Site Ambient Air Sampling Locations $2-19$

3-1. 2001 Groundwater Sampling and Analysis Agenda 3-6

4-1. Potential Local Off-Site Exposure Pathways Under Existing WVDP Conditions 4-3

4-2. Summary of Annual Effective Dose Equivalents to an Individual and Population From WVDP Releases in 2001 4-6

4-3. Evaluation of Dose to Aquatic and Terrestrial Biota 4-16

4-4. WVDP Radiological Dose and Release Summary 4-17 


\section{Table of Contents}

\section{List of Tables (continued)}

C-1. Total Radioactivity of Liquid Effluents Released From Lagoon 3 (WNSP001) in 2001 C-3

C-2. Comparison of 2001 Lagoon 3 (WNSP001) Liquid Effluent Radioactivity Concentrations With Department of Energy Guidelines C-4

C-3. 2001 Radioactivity Concentrations and pH in Surface Water: Facility Yard Drainage (WNSP005)

C-4. 2001 Radioactivity Concentrations in Surface Water: Downstream of the WVDP at Frank's Creek (WNSP006)

C-5. 2001 Radioactivity Concentrations in Surface Water: Sewage Treatment Facility (WNSP007)

C-6. 2001 Radioactivity Concentrations in Surface Water: French Drain (WNSP008) C-7

C-7. 2001 Radioactivity Concentrations and pH in Surface Water: Northeast Swamp (WNSWAMP)

C-8. 2001 Radioactivity Concentrations in Surface Water: North Swamp (WNSW74A) C-9

C-9. 2001 Radioactivity Concentrations and pH in Surface Water: Frank's Creek East of the SDA (WNFRC67)

C-10. 2001 Radioactivity Concentrations and pH in Surface Water: Erdman Brook (WNERB53) $\mathrm{C}-10$

C-11. 2001 Radioactivity Concentrations and pH in Surface Water: Cooling Tower Basin (WNCOOLW) C-11

C-12. 2001 Radioactivity Concentrations and $\mathrm{pH}$ in Surface Water: SDA Drainage (WNSDADR) C-11

C-13. 2001 Radioactivity Concentrations and pH in Surface Water: Waste Tank Farm Underdrain (WN8D1DR) C-12

C-14. 2001 Radioactivity Concentrations in Surface Water: Drum Cell Drainage (WNDCELD) C-12

C-15. 2001 Radioactivity Concentrations, pH, and Conductivity: Environmental Laboratory Potable Water (WNDNKEL)

C-16. 2001 Radioactivity Concentrations, pH, and Conductivity: Maintenance Shop Potable Water (WNDNKMS)

C-17. 2001 Radioactivity Concentrations, pH, and Conductivity: Main Plant Potable Water (WNDNKMP)

C-18. 2001 Radioactivity Concentrations and Water Quality Parameters: Utility Room Potable Water (WNDNKUR)

C-19. 2001 Radioactivity Concentrations and Water Quality Parameters: Storage and Disposal Area Drainage (WNNDADR) C-16

C-20. 2001 Radioactivity Concentrations, NPOC, and TOX in Groundwater at the NDA Interceptor Trench (WNNDATR) C-17 


\section{Table of Contents}

List of Tables (continued)

C-21. 2001 Radioactivity Concentrations and Water Quality Parameters in Surface Water at the Standing Water (WNSTAW-Series) Sampling Locations

C-22. 2001 Radioactivity Concentrations, pH, and Conductivity in Surface Water Upstream of the WVDP in Buttermilk Creek at Fox Valley (WFBCBKG)

C-23. 2001 Radioactivity Concentrations, pH, and Conductivity in Surface Water Downstream of the WVDP in Buttermilk Creek at Thomas Corners Bridge (WFBCTCB)

C-24. 2001 Radioactivity Concentrations and $\mathrm{pH}$ in Surface Water Downstream of the WVDP in Cattaraugus Creek at Felton Bridge (WFFELBR)

C-25. 2001 Radioactivity Concentrations in Surface Water Upstream of the WVDP in Cattaraugus Creek at Bigelow Bridge (WFBIGBR)

C-26. 2001 Radioactivity Concentrations, pH, and Conductivity in Potable Well Water Around the WVDP

C-27. 2001 Surface Water Quality at Locations WFBCBKG, WNSP006, WNSWAMP, and WNSW74A

C-28. 2001 Radioactivity Concentrations and Metals Concentrations in On-Site Soils/Sediments C-23

C-29. 2001 Radioactivity Concentrations in Surface Soil Collected at Air Sampling Stations Around the WVDP $\mathrm{C}-24$

C-30. 2001 Radioactivity Concentrations in Stream Sediments Around the WVDP $\mathrm{C}-25$

D-1. 2001 Airborne Radioactive Effluent Totals Released From the Main Ventilation Stack (ANSTACK)

D-2. Comparison of 2001 Main Stack (ANSTACK) Exhaust Radioactivity Concentrations With Department of Energy Guidelines

D-3. 2001 Airborne Radioactive Effluent Totals From the Vitrification System (HVAC) Ventilation Stack (ANVITSK)

D-4. 2001 Airborne Radioactive Effluent Totals From the Seismic Sampler (ANSEISK) for the Vitrification System (HVAC) Ventilation Stack

D-5. 2001 Airborne Radioactive Effluent Totals From the 01-14 Building Ventilation Exhaust (ANCSSTK)

D-6. 2001 Airborne Radioactive Effluent Totals From the Contact Size-Reduction Facility Ventilation Stack (ANCSRFK)

D-7. 2001 Airborne Radioactive Effluent Totals From the Supernatant Treatment System Ventilation Stack (ANSTSTK)

D-8. 2001 Airborne Radioactive Effluent Totals From the Container Sorting and Packaging Facility Ventilation Stack (ANCSPFK) D-10 


\section{Table of Contents}

\section{List of Tables (continued)}

D-9. 2001 Airborne Radioactive Effluent Totals From the Former Low-Level Waste Treatment Facility Hot Side Ventilation (ANLLWTVH)

D-10. 2001 Airborne Radioactive Effluent Totals From the New Low-Level Waste Treatment Facility Ventilation (ANLLW2V)

D-11. 2001 Airborne Radioactive Effluent Totals From the Laundry Change Room (ANLAUNV)

D-12. 2001 Radioactivity Concentrations in Airborne Particulates at the Lag Storage Area Air Sampler (ANLAGAM)

D-13. 2001 Radioactivity Concentrations in Airborne Particulates at the NDA Air Sampler (ANNDAAM)

D-14. 2001 Airborne Radioactivity Concentrations at the SDA Trench 9 Air Sampler (ANSDAT9)

D-15. 2001 Airborne Radioactive Effluent Totals From Outdoor Ventilation Enclosures/Portable Ventilation Units

D-16. 2001 Airborne Radioactivity Concentrations at the Rock Springs Road Air Sampler (AFRSPRD)

D-17. 2001 Radioactivity Concentrations in Airborne Particulates at the Dutch Hill Air Sampler (AFBOEHN)

D-18. 2001 Radioactivity Concentrations in Airborne Particulates at the Fox Valley Air Sampler (AFFXVRD)

D-19. 2001 Radioactivity Concentrations in Airborne Particulates at the Bulk Storage Warehouse Air Sampler (AFBLKST)

D-20. 2001 Radioactivity Concentrations in Airborne Particulates at the Route 240 Air Sampler (AFRT240)

D-21. 2001 Radioactivity Concentrations in Airborne Particulates at the Thomas Corners Road Air Sampler (AFTCORD)

D-22. 2001 Radioactivity Concentrations in Airborne Particulates at the West Valley Air Sampler (AFWEVAL)

D-23. 2001 Radioactivity Concentrations in Airborne Particulates at the Springville Air Sampler (AFSPRVL)

D-24. 2001 Airborne Radioactivity Concentrations at the Great Valley Background Air Sampler (AFGRVAL)

D-25. 2001 Radioactivity Concentrations in Airborne Particulates at the Nashville Background Air Sampler (AFNASHV)

D-26. 2001 Radioactivity and $\mathrm{pH}$ in Fallout: Dutch Hill (AFDHFOP) D-24

D-27. 2001 Radioactivity and pH in Fallout: Rain Gauge (ANRGFOP) D-24 


\section{Table of Contents}

List of Tables (continued)

D-28. 2001 Radioactivity and pH in Fallout: Route 240 (AF24FOP)

D-25

D-29. 2001 Radioactivity and pH in Fallout: Thomas Corners Road (AFTCFOP) ___ D-25

D-30. 2001 Radioactivity and pH in Fallout: Fox Valley Road (AFFXFOP) ___ D-26

E-1. Groundwater Monitoring Network: Super Solid Waste Management Units ___ E-3

E-2. 2001 Contamination Indicator and Radiological Indicator Results: Sand and Gravel Unit ___ E-7

E-3. 2001 Contamination Indicator and Radiological Indicator Results: Lavery Till-Sand Unit ___ E-11

E-4. 2001 Contamination Indicator and Radiological Indicator Results: Weathered Lavery Till Unit

E-5. 2001 Contamination Indicator and Radiological Indicator Results: Unweathered Lavery Till

Unit

E-6. 2001 Contamination Indicator and Radiological Indicator Results: Kent Recessional Sequence E-14

E-7. 2001 Contamination Indicator and Radiological Indicator Results: North Plateau Seep Monitoring Locations

E-8. 2001 Contamination Indicator and Radiological Indicator Results: North Plateau Well Points

E-9. 2001 Detections of Volatile Organic Compounds at Selected Groundwater Monitoring Locations E-15

E-10. 2001 Tributyl Phosphate Sampling Results at Selected Groundwater Monitoring Locations E-16

E-11. 2001 Metals Sampling Results E-16

E-12. 2001 Sampling Parameters at Early Warning Monitoring Wells E-17

E-13. 2001 Alpha-, Beta-, and Gamma-Emitting Radioisotopic Results for Selected Groundwater Monitoring Locations E-18

E-14. Practical Quantitation Limits E-20

F-1. 2001 Radioactivity Concentrations in Milk F-3

F-2. 2001 Radioactivity Concentrations in Meat F-4

F-3. 2001 Radioactivity Concentrations in Food Crops F-5

F-4. 2001 Radioactivity Concentrations in Fish Flesh From Cattaraugus Creek F-6

G-1. West Valley Demonstration Project State Pollutant Discharge Elimination System (SPDES) Sampling Program G-3

G-2. 2001 SPDES Results for Outfall 001 (WNSP001): Water Quality G-5

$x x i$ 


\section{Table of Contents}

\section{List of Tables (continued)}

G-3. 2001 SPDES Results for Outfall 001 (WNSP001): Metals G-7

G-4. 2001 SPDES Results for Outfall 001 (WNSP001): Organics G-9

G-5. 2001 SPDES Results for Outfall 007 (WNSP007): Water Quality and Iron G-11

G-6. 2001 SPDES Results for Outfall 008 (WNSP008): Water Quality G-12

G-7. 2001 SPDES Results for Sums of Outfalls 001, 007, 008, and Outfall 116: Water Quality G-13

G-8. 2001 Annual/Semiannual SPDES Results for Outfall 001: Water Quality, Metals, and Organics

G-9. 2001 Annual SPDES Results for Outfall 007: Water Quality G-15

G-10. 2001 Annual SPDES Results for Outfall 008: Water Quality G-15

H-1. Summary of 2001 Quarterly Averages of Off-Site TLD Measurements H-3

H-2. Summary of 2001 Quarterly Averages of On-Site TLD Measurements $\mathrm{H}-4$

H-3. 3rd-Quarter 2001 TLD Results and Instantaneous Exposure Rate Readings With a HighPressure Ion Chamber (HPIC) at Each Monitoring Location H-5

I-1. Site Precipitation Collection Data I-7

I-2. Annual Temperature Summary at the 10-Meter Primary Meteorological Tower I-8

I-3. Annual Barometric Pressure Summary $\mathrm{I}-8$

J-1. Comparison of Radiological Results With Known Results of Crosscheck Samples From the DOE Environmental Measurements Laboratory Quality Assessment Program 54; EML-613 QAP 0103; June 2001

J-2. Comparison of Radiological Results With Known Results of Crosscheck Samples From the DOE Environmental Measurements Laboratory Quality Assessment Program 55; EML-615 QAP 0109; December 2001

J-3. Comparison of Results From Crosscheck Samples Analyzed for Water Quality Parameters as Part of the EPA's 2001 Discharge Monitoring Report - Quality Assurance Study 21 for the National Pollutant Discharge Elimination System

K-1. Department of Energy Radiation Protection Standards and Derived Concentration Guides $\mathrm{K}-3$

K-2. Environmental Regulations, Orders, and Standards $\mathrm{K}-4$ 


\section{Table of Contents}

List of Tables (concluded)

L-1. 2001 Contamination Indicator Results at SDA Monitoring Wells L-3

L-2. 2001 Radiological Indicator Results at SDA Monitoring Wells L-5

L-3. 2001 Radioisotopic Results at SDA Monitoring Wells L-7

xxiii 
This page intentionally left blank

xxiv 


\section{EXECUTIVE SUMMARY}

\section{Purpose of This Report}

This annual environmental monitoring report is published to inform Project stakeholders about environmental conditions at the West Valley Demonstration Project (WVDP). (See stakeholder in the Glossary [p. GLO-10].) In accordance with DOE Order 231.1, Environment, Safety, and Health Reporting, the report summarizes the environmental monitoring data gathered during the year in order to characterize the performance of the WVDP's environmental management system, confirm compliance with standards and regulations, and highlight significant programs.

\section{Project Description}

The West Valley Demonstration Project(WVDP), the site of a U.S. Department of Energy (DOE) environmental cleanup activity operated by West Valley Nuclear Services Co. (WVNSCO), is in the final stages of stabilizing the high-level radioactive waste that remained at the site after commercial nuclear fuel reprocessing had been discontinued. The Project is located in Western New York State, about 30 miles south of Buffalo, within the New York State-owned Western New York Nuclear Service Center (WNYNSC).
In addition to high-level waste solidification, ongoing work activities at the WVDP during 2001 included:

- preparing spent nuclear fuel for shipment to Idaho

- shipping low-level waste off-site for disposal

- constructing a facility where large high-activity components can be safely packaged for disposal

- packaging and removing expended materials from the vitrification facility

- preparing environmental impact statements for future activities

- removing as much of the residual waste in the high-level waste tanks as was technically feasible

- monitoring the environment and managing contaminated areas within the Project facility premises

$A$ reader opinion survey has been inserted in this report. If it is missing, please contact the Communications Department at (716) 9424555. Additional Project information is available on the internet at http://www.wv.doe.gov.

EXE - 1 
- flushing and rinsing high-level waste-solidification facilities.

\section{Compliance}

Management at the WVDP continued to provide strong support for environmental compliance in 2001. DOE Orders and applicable state and federal statutes and regulations are integrated into the Project's compliance program. Highlights of the 2001 compliance program were as follows:

- No notices of violation or inspection findings from any environmental regulatory agencies were received by the WVDP in 2001.

- Inspections of hazardous waste activities by the New York State Department of Environmental Conservation (NYSDEC) verified Project compliance with the applicable regulations.

- The Project continued to monitor specific waste management areas at the site in order to comply with the Resource Conservation and Recovery Act (RCRA) §3008(h) Administrative Order on Consent.

- The Project also met the requirements of the Emergency Planning and Community Right-toKnow Act (EPCRA) by collecting information about hazardous materials used at the Project and making this information available to the local community.

- The State Pollutant Discharge Elimination System (SPDES) permit currently identifies four permitted liquid outfalls at the Project. A SPDES permit application was submitted to NYSDEC in 2000 to cover process changes and storm water runoff. A permit modification is expected in 2002.

- In accordance with the Site Treatment Plan developed under the Federal Facility Compliance
Act, all calendar year 2001 milestones for the characterization, treatment, and disposition of mixed waste at the WVDP were completed.

- Among other pollution-prevention accomplishments, waste minimization goals for 2001 were met or exceeded in all but one of the waste categories set in the one-year goals statement. Although low-level radioactive waste generation did not meet the established goal of an $80 \%$ reduction, generation was reduced by $70 \%$.

\section{Environmental Monitoring Program}

Throughout the first four years of vitrification, specific and sustained attention was given to environmental monitoring and assessment of effluents from changing site operations. Project environmental scientists continued in 2001 to sample and measure effluent air and water, groundwater, surface streams, soil, sediment, vegetation, meat, milk, and game animals, and to record environmental radiation measurements. More than 12,000 samples were collected in 2001 in order to assess the effect of site activities on public health, safety, and the environment.

The Project's environmental monitoring network is evaluated and updated to ensure that all the locations and sample types that would be sensitive to process-related changes are monitored. Samples are tested for radioactivity and/or nonradioactive substances using approved laboratory procedures. Both the laboratory test results and direct measurement data are reviewed at several stages for quality and are compared with historical data from the same locations, with background data, and with data from similar locations.

The environmental data are entered into a controlled database and are automatically compared with upper and lower acceptance values. Data 
points falling outside these values are brought to the attention of WVDP scientists for further investigation. WVDP scientists assess all data points and evaluate trends at each location.

Doses to the public are calculated using approved computer modeling codes. Dose calculations determine the impacts of air and water releases and from the consumption of game animals and locally grown food.

Surface Water Monitoring. Surface water is routinely sampled on the Project premises by four automatic samplers: Timed composite samples are collected at Frank's Creek where it exits the Project, at two other on-site points where water flows off-site, and at a surface drainage point near the former radioactive waste disposal areas. Onsite samples also are collected periodically at nine other points of drainage from facility areas. The data from these samples are used to determine the type, amount, and probable origin of both radiological and nonradiological contaminants.

Radiological Releases. The largest single source of radioactivity released to surface waters from the Project is the discharge from the low-level waste treatment facility through the lagoon 3 outfall. The treated effluent water flows into Erdman Brook, which joins Frank's Creek just before exiting the Project's fenced area. Five treated batches totaling approximately 8.4 million gallons were released periodically over the course of thirty-three days in 2001. In 2000, 11.5 million gallons were released. The difference can be attributed to a lag in batch releases of water from facility cleanup processes along with less precipitation in 2001 than in 2000.

The combined average concentration of all radionuclides in liquid releases from lagoon 3 in 2001 was approximately $33 \%$ of the DOE derived concentration guide (DCG), which is used to evalu- ate liquid process discharges. (See Chapter 1 [p. 1-5] for an explanation of DCGs.) The average radioactivity concentrations from 1997 through 2000 were $22 \%, 23 \%, 32 \%$, and $34 \%$ of the DCG, respectively. The major contributors to the total combined liquid effluent in 2001 were strontium90, cesium-137, and uranium-232.

Seepage of contaminated groundwater from the north plateau was another source of gross beta and strontium-90 radioactivity in surface water. Drainage from the north plateau eventually flows into Frank's Creek. (See location WNSWAMP on Fig. A-2 in Appendix A [p. A-4].) This drainage point has been carefully monitored since the contaminated seep was identified in 1993. A groundwater recovery and treatment system currently is being used to reduce the migration of strontium-90 to surface water on the north plateau. The average strontium-90 concentration at WNSWAMP, which originates from pre-Project operations, increased in 2001 from the concentration in 2000 . The increase in the strontium-90 concentrations in 2001 at this northeast swamp drainage is thought to be linked to a combination of decreased groundwater dilution due to less precipitation in 2001 than in 2000 and increases in groundwater activity surfacing in the ditch upstream of WNSWAMP. Nonetheless, the total quantity of radioactivity released, and the associated dose to an off-site individual from this radioactivity, were about $10 \%$ lower than in 2000 .

The WVDP is evaluating a pilot-scale permeable treatment wall that was installed in 1999 to treat contaminated groundwater on the north plateau. A subsurface trench filled with ion-exchange media, installed in the eastern lobe of the plume, removes contaminants from the groundwater as it flows through the trench. (See Chapter 3 [p. 316] for additional discussion of this technology.) 
Dose Assessment. Estimated dose to the maximally exposed off-site individual from the liquid pathway was estimated to be 0.035 mrem -0.014 mrem attributable to Project effluents from lagoon 3 and an additional contribution of $0.021 \mathrm{mrem}$ from the north plateau drainage.

Nonradiological Releases. Nonradiological contaminants, measured at three outfalls and calculated at one monitoring point, were, with one exception, below the New York SPDES permit limits. (The one exception was an elevated lead concentration from a groundwater drain system, which was subsequently capped off.) (See SPDES-Permitted Outfalls [p. ECS-10].)

Soil and Stream Sediments. Surface soil is collected annually near the ten air sampler locations in order to track long-term deposition. Sediments from off-site creeks are collected annually from three downstream and two upstream locations. Soil from three on-site drainage areas is also sampled annually in order to track waterborne movement of contaminants.

Surface soil samples in 2001 showed little change from previous years. Except for one area that historically has shown average cesium- 137 concentrations higher than background values, the concentrations of radionuclides normally present in soil from both worldwide fallout and from Project air emissions at near-site locations are close to or indistinguishable from concentrations from background locations.

Because of pre-Project releases from nuclear fuel reprocessing activities, the concentrations of cesium-137 in downstream creek sediments have been historically higher than concentrations in the upstream sediments. However, in 1998 and 1999 sediment samples at one downstream location showed a marked decrease in cesium-137, when compared with historical values, after an unusu- ally high June 1998 flood. The calendar year 2000 samples returned to a level of cesium-137 that is consistent with historical values. Samples collected at this location in 2001 are at a level slightly below samples collected in 2000. The sixteen-year graph of cesium-137 in sediments (Fig. 2-4 [p. 2-13]) indicates no upward trends at either upstream or downstream points.

Groundwater Monitoring. Groundwater samples were collected as scheduled from sixtyfive on-site locations in 2001. Computerized screening of the groundwater data accelerated identification and evaluation of changes. Monitoring activities in 2001 included gathering more detailed information about the north plateau strontium- 90 contamination. Additional monitoring wells were installed in 2001 to improve the definition of subsurface and groundwater conditions. The calendar year 2001 groundwater program continued to indicate that strontium- 90 is still the major contributor to elevated gross beta contamination in the plume on the north plateau. The concentrations of other isotopes were below the DCG levels usually applied to surface water.

In addition to collecting samples from wells, groundwater was routinely collected from seeps on the bank above Frank's Creek along the northeastern edge of the north plateau. Results of radiological analyses indicate that gross beta activity from the north plateau plume has not migrated to these seepage areas.

Site groundwater also is tested for a number of nonradiological constituents. In 2001 there were no statistically remarkable changes in the concentrations measured.

Calendar year 2001 sample results from near-site residential water-supply wells were within the historical range of values measured for these wells. 
Air Monitoring. WVDP airborne radiological emissions in 2001 included emissions from six routinely operated permitted exhaust points and four exhausts excluded from permitting because of their low emission potential.

Six air samplers on the perimeter of the WNYNSC and four in more distant locations continuously collect samples of air at the average human breathing height. The samples are tested for radioactivity carried by airborne particles. Samples also are collected for tritium and iodine-129 at two of the ten locations, the Rock Springs Road sampler near the site and the Great Valley background sampler.

Radiological Releases. As anticipated, radioactive releases from the Project in 2001 were far below the most restrictive limits that ensure public health and safety, even with an on-site release that took place in the fall of 2001. (See Unplanned Radiological Releases in Chapter 1 [p. 1-11].) Operating the vitrification process at a reduced capacity resulted in radiological air releases that were less in 2001 than those noted in calendar years 1999 and 2000.

Although several fission products contribute to airborne radiological releases, the most significant continued to be iodine-129, a long-lived radionuclide that exists in gaseous form at the high temperatures of the vitrification process. Iodine- 129 is not fully removed during treatment of the air effluent. The calendar year 2001 levels of gaseous iodine-129 emissions were lower than 2000 levels.

Gross radioactivity (airborne particulate) in air samples from around the perimeter was within the historical range of radioactivity measured at remote background locations or nearby communities. Gross radioactivity at the nearest perimeter sampler remained the same in 2001 as in 2000. Concentrations in samples from three on-site ambient air samplers and two portable samplers lo- cated near waste storage facilities operated during 2001 also were far below any applicable limits.

Dose Assessment. The dose from air emissions in calendar year 2001 was about $0.05 \%$ of the Environmental Protection Agency (EPA) radionuclide emissions standard of 10 millirem (mrem) per year effective dose equivalent to the maximally exposed off-site individual. (In 1999 the dose from these emissions was about $0.11 \%$ and in 2000 the dose was about $0.08 \%$.) Approximately $63 \%$ of the total 2001 calculated airborne dose to the maximally exposed off-site individual was attributable to iodine-129 emissions.

Nonradiological Releases. Nitrogen oxides, nonradiological byproducts of the vitrification process, are monitored as part of the emission-control process. The WVDP continues to monitor nitrogen oxides and sulfur dioxide emissions as a condition of the New York State Facility Air permit. The monitoring demonstrates that emissions are well below the 99-ton cap for each. No opacity or permit limits were exceeded in 2001.

Vegetation, Meat, and Milk. Test results from near-site samples of beans, apples, corn, hay, beef, and milk were consistent with results noted in previous years. When near-site samples were compared with background samples, no site-related effects were noted.

Game Animals. Fifty fish specimens from Cattaraugus Creek were collected in 2001 for testing. Ten of these were from below the Springville dam, including species that migrate up from Lake Erie. Two semiannual sample sets of ten fish each were collected downstream of Buttermilk Creek, which receives Project liquid effluents, and two sets were collected upstream. These samples represent sportfishing species and bottom-feeding indicator species. Testing for gamma-emitting isotopes and 
strontium-90 showed a slight statistical difference in median concentrations of strontium- 90 between upstream (background) fish and downstream fish collected above the dam. (See gamma isotopic in the Glossary [p. GLO-4].) No statistical differences were noted between cesium-137 concentrations in upstream and downstream fish.

Three samples of venison from near-site (WNYNSC) whitetail deer were tested for gamma-emitting isotopes and strontium-90. Control deer samples from locations more than thirty miles away from the site also were collected in 2001. Low levels of radioactivity from strontium90 , cesium-137, and naturally occurring potassium40 were detectable in both control and near-site deer samples. Although results vary from year to year, data from the last ten years show no statistical differences between radionuclide concentrations in near-site and control venison samples. In 2001 public access to the WNYNSC for deer hunting was curtailed due to security restrictions.

\section{Program Quality}

The WVDP environmental monitoring program is designed to produce high-quality, reliable results. To maintain this standard, each scientist must give continuous attention to the details of sample handling, following approved collection and analysis procedures and data review. Formal self-assessments were performed, and the environmental laboratory also continued the practice of analyzing radiological crosscheck samples sent from a national laboratory. Of 117 radiological crosscheck analyses performed at both the on-site Project laboratory and the off-site commercial service laboratory, $117(100 \%)$ were within the control limits. Off-site laboratories address data deficiencies under approved quality assurance programs.

Test results from the crosscheck program, selfassessments, and comparisons of co-located sample measurements taken by independent agencies such as the New York State Department of Health (NYSDOH) and NYSDEC indicate that high quality standards are being met.

The WVNSCO Environmental Affairs and Quality Assurance departments also periodically conducted and documented reviews of program activities in 2001 .

In addition, in August and September 2001 the DOE Ohio Field Office conducted a surveillance of a discharge from lagoon 3 to evaluate whether the WVDP procedures for discharge of liquid plant effluent are being effectively implemented to ensure compliance with the Site SPDES permit. (See Audits and Appraisals [p. 5-6] in Chapter 5.)

\section{Safety and Environmental Management}

In 2001 the WVDP continued to demonstrate its commitment to an all-inclusive approach to safety through implementation of its Integrated Safety Management System (ISMS). As an integral part of the ISMS, the site-wide work review group reviewed work plans, identified environmental safety and health concerns, and specified practices to ensure that work was performed safely. The Environmental Management System (EMS) was coordinated with other safety management and work planning processes through the integrated environmental, health, and safety management program. (See Environmental Management System [EMS] Implementation and Integrated Safety Management System [ISMS] Implementation in Chapter 1 [p. 1-16] for a more detailed discussion of these management systems at the WVDP.)

\section{Notable 2001 Events}

In 1999 WVNSCO was recommended for STAR status, the highest safety award given within the 
DOE. This award, received in early 2000 , was granted in recognition of superior health and safety performance by contractor management and employees. In 2001 this award was reconfirmed by the DOE in their bestowing of the Star of Excellence on WVNSCO for an outstanding safety record.

The WVDP also was recognized in 2000 by induction into the EPA's National Environmental Performance Track. The WVDP was accorded Charter Member status as one of the first facilities to receive this award.

In May 2001 the WVDP was visited by EPA representatives who toured the facilities and reviewed the WVDP environmental management system. Their assessment confirmed that the WVDP meets the Performance Track Program Criteria.

The WVDP is one of only two DOE sites to hold both the EPA's highest award for environmental sustainability and the DOE's STAR award.

\section{Conclusion}

The West Valley Demonstration Project conducts extensive monitoring of on-site facilities and the surrounding environment. This program fulfills federal and state requirements to assess the effect of Project activities on public health and safety and the environment. In 2001 the predicted dose from the Project via all pathways was $0.04 \mathrm{mrem}$, or $0.04 \%$ of the 100 -mrem DOE limit.

In addition to demonstrating compliance with environmental regulations and directives, evaluation of data collected in 2001 continued to indicate that Project activities pose no threat to public health or safety or the environment. 
This page intentionally left blank

EXE - 8 


\section{INTRODUCTION}

\section{Information in This Report}

Individual chapters in this report provide information on compliance with regulations, general information about the monitoring program and significant activities in 2001, summaries of the results of radiological and nonradiological monitoring, calculations of radiation doses to the population within 50 miles $(80 \mathrm{~km})$ of the site, and information about practices that ensure the quality of environmental monitoring data. Graphs and tables illustrate important trends and concepts. The bulk of the supporting data is found in the appendices following the text. Page numbers refer the reader to the appendices, figures, and graphs cited in the text.

Appendix A contains maps showing on-site and off-site sampling locations.

Appendix B summarizes the calendar year 2001 environmental monitoring program at the on-site (i.e., on the Western New York Nuclear Service Center [WNYNSC]) and off-site locations. Samples are designated by a coded abbreviation indicating sample type and location. (A complete listing of the codes is found in the index to Appendix B [pp. B-v through B-vii].) Appendix B lists the kinds of samples taken, the frequency of collection, the parameters analyzed, the location of the sampling points, monitoring and reporting requirements, and a brief rationale for the monitoring activities conducted at each location.

Appendices $\mathrm{C}$ through I summarize radiometric, chemical analytical, and physical data from air, surface water, groundwater, fallout in precipitation, sediment, soils, biological samples (meat, milk, food crops, and fish), and direct radiation measurements and meteorological monitoring.

Appendix $\mathrm{J}$ provides data from the comparison of results of analyses of identically prepared samples (crosscheck samples) by both the WVDP and independent laboratories. Radiological concentrations and chemical water quality parameters in crosscheck samples of air, water, soil, and vegetation are reported here.

Appendix K provides a list of radiation protection standards set by the Department of Energy (DOE) that are most relevant to the operation of the WVDP. It also lists federal and state laws and regulations that affect the WVDP.

Appendix L contains groundwater monitoring data for the New York State-licensed disposal area (SDA), provided by the New York State Energy Research and Development Authority (NYSERDA). 
Acronyms, often used in technical documents to speed up the reading process, are listed in a separate section at the back of this report. (See the Acronyms and Abbreviations section.) Although using acronyms can be a practical way of referring to agencies or systems with unwieldy names, having to look up rarely used acronyms can defeat the purpose of using them. Accordingly, full names of agencies and systems have been used in this report where it will help the reader. However, acronyms that the reader is apt to recognize (e.g., DOE, EPA, NRC, NYSERDA) or that are used often in this report (e.g.,WVDP, WNYNSC) are spelled out only at the beginning of sections. Other information that may be helpful is found in the References and Bibliography, Glossary, Units of Measure, Unit Prefixes, Scientific Notation, and Conversion Chart sections at the back of this report.

\section{History of the West Valley Demonstration Project}

In the early 1950s interest in promoting peaceful uses of atomic energy led to the passage of an amendment to the Atomic Energy Act that allowed the Atomic Energy Commission to encourage commercialization of nuclear fuel reprocessing as a way of developing a civilian nuclear industry. The Atomic Energy Commission made its technology available to private industry and invited proposals for the design, construction, and operation of reprocessing plants.

In 1961 the New York State Office of Atomic Development acquired 3,345 acres (1,354 ha) near West Valley, New York and established the Western New York Nuclear Service Center . Davison Chemical Co., together with the New York State Atomic Research and Development Authority, which later became NYSERDA, constructed and began operating a nuclear fuel reprocessing plant under a co-license issued by the Atomic Energy Commission (later the Nuclear Regulatory Commission [NRC]).

Nuclear Fuel Services, Inc. (NFS) was formed by Davison Chemical Co. to operate the plant as a commercial facility. NFS leased the property at the WNYNSC and in 1966 began operations to recycle fuel from both commercial and federally owned reactors.

In 1972, while the plant was closed for modifications and expansion, new and more rigorous safety regulations were imposed. Most of the changes concerned the disposal of high-level radioactive liquid waste and the prevention of earthquake damage to the facilities. NFS decided that compliance with the new regulations was not economically feasible and in 1976 notified NYSERDA that it would not continue in the fuel-reprocessing business.

Numerous studies followed the closing, leading eventually in 1980 to the passage of Public Law 96-368, the West Valley Demonstration Project Act, which authorized the DOE to demonstrate a method for solidifying the 600,000 gallons (2.3 million liters) of liquid high-level waste that remained at the West Valley site. Congress anticipated that the technologies developed at West Valley would be used at other facilities in the United States.

Under the original agreement between NFS and New York State, the state was ultimately responsible for both the radioactive wastes and the facility. The WVDP Act specifically provides that the facilities and the high-level radioactive waste onsite shall be made available (by the state of New York) to the DOE without the transfer of title for as long as required to complete the Project. The facility's NRC license was amended in 1981 to allow the DOE cleanup to proceed at the Project under a Memorandum of Understanding. Although

INT - 2 
the lead agency for the WVDP is the DOE, under the Memorandum of Understanding the DOE and the NRC each have specific responsibilities related to the WVDP.

The former West Valley Nuclear Services Company, Inc., a subsidiary of Westinghouse Electric Corporation, was chosen by the DOE to be the management and operating contractor for the West Valley Demonstration Project. Site operations began at the WVDP in March 1982. (The West Valley Nuclear Services Company [WVNSCO], a unit of the Westinghouse Environmental Services Company [in 2002, the Energy and Environmental Division of Washington Group International], is the management and operating contractor for the WVDP.)

The high-level waste, contained in underground storage tanks, had separated into two layers - a liquid supernatant and a settled sludge layer. Various subsystems were constructed that permitted the successful startup in May 1988 of the integrated radwaste treatment system (IRTS). The system removed most of the radioactivity from the liquid supernatant, allowing the major portion of the liquid to be treated as low-level waste. Treatment of the supernatant liquid from the highlevel waste tanks through the IRTS was completed in 1990.

The next step in the process, washing the sludge with water to remove soluble constituents, began in late 1991 and was completed in 1994. (See Vitrification Overview [p. 1-6] in Chapter 1 for a more detailed description.) In 1995, the contents of the high-level waste tanks were combined and the subsequent mixture washed a final time. Vitrification of the high-level waste residues began in July 1996. In June 1998 the WVDP successfully completed the first phase of the vitrification campaign. Currently the WVDP is conducting the second phase of vitrification, which involves removing and solidifying the high-level residuals (heels) remaining in the tanks, and is planning for future decommissioning of vitrification and support facilities.

\section{Description of the West Valley Demonstration Project}

The purpose of the WVDP is to solidify the highlevel radioactive waste left at the site from the original nuclear fuel reprocessing activities, develop suitable containers for holding and transporting the solidified waste, arrange transportation of the solidified waste to a federal repository, dispose of any Project low-level and transuranic waste resulting from the solidification of high-level waste, and decontaminate and decommission the Project facilities.

At the end of CY 2001, most of the high-level waste had been solidified in glass in 264 stainless steel canisters and stored in a shielded cell. In order to continue the Project mission, several projects are under way:

Spent Fuel Shipping. The original operator at the site, Nuclear Fuel Services, Inc., had accepted 750 spent fuel assemblies for reprocessing before discontinuing operations in 1975. These spent fuel assemblies were stored in the on-site fuel pool. During an early 1980 shipping campaign, 625 of the spent fuel assemblies were returned to the utilities that owned them. During 2001 the remaining 125 assemblies, which continued to be stored at the WVDP, were prepared for transport to the Idaho National Engineering and Environmental Laboratory (INEEL) for interim storage. After removing the spent fuel, the WVDP initiated work to drain and decontaminate the fuel pool.

Waste Management. Part of the DOE's cleanup mission at the West Valley site is the disposal of low-level radioactive waste that is generated 


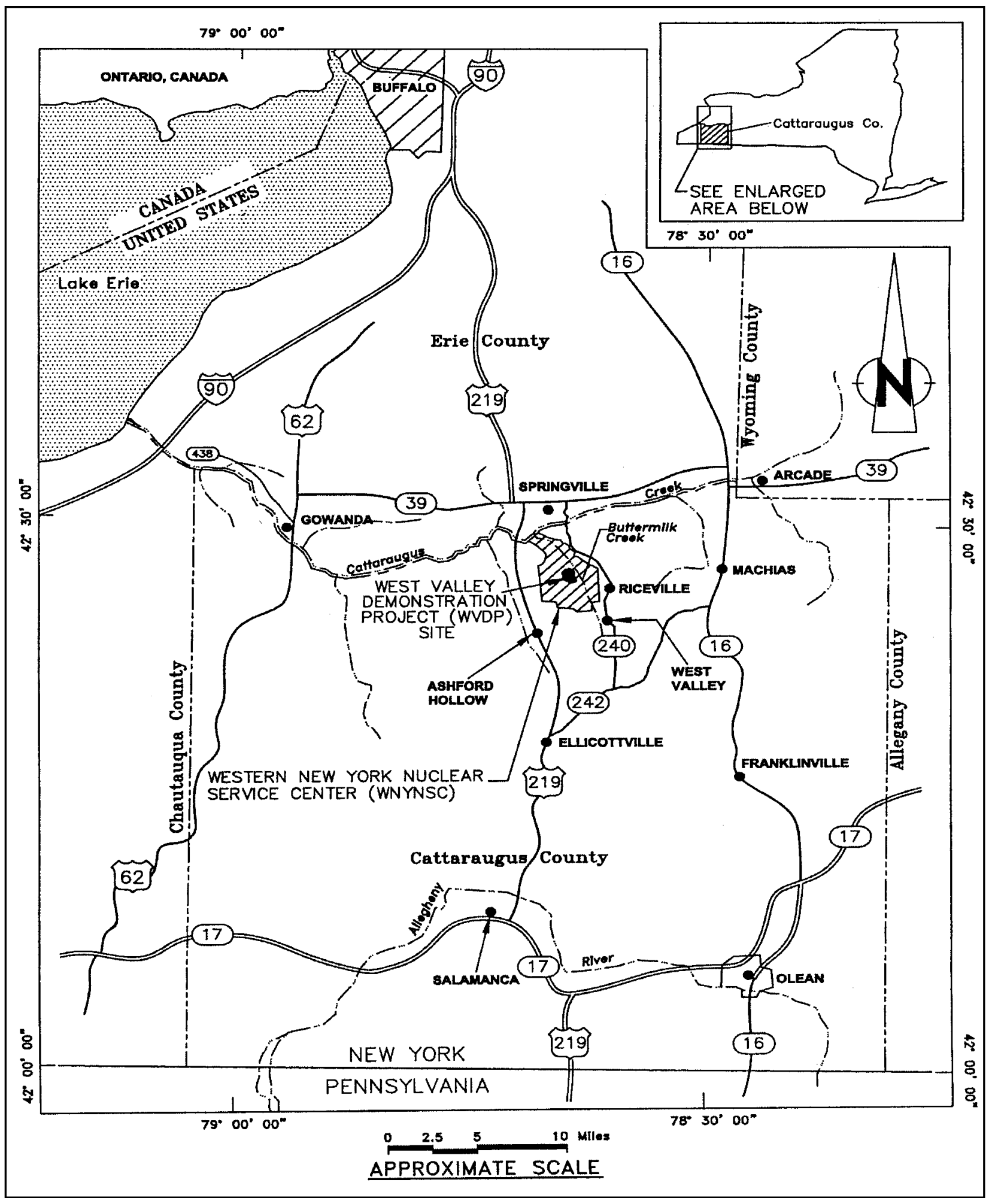

Figure 1. Location of the Western New York Nuclear Service Center

$$
\text { INT - } 4
$$


through WVDP operations. Stored wastes resulting from cleanup activities are being shipped offsite for disposal. The WVDP has refurbished the 1.8-mile $(2.9-\mathrm{km})$ railroad spur that enters the Project premises and is now shipping low-level waste directly from the site.

Vitrification Expended Materials Processing. As materials used in vitrification are expended they are inventoried, identified, sorted, classified, cleaned, size-reduced (as needed), packaged, and removed from the facility. The vitrification facility itself will be decommissioned after high-level waste processing is complete.

High-Level Waste Tank Closure. Liquid high-level waste processing is expected to be completed in 2002. The underground waste tanks will be closed following decisions on long-term site management.

Remote-Handled Waste. A remote-handled waste facility is under construction on-site. It will be used to prepare higher activity wastes for shipment and disposal.

Environmental Monitoring. Site-wide environmental monitoring and management of contaminated areas will continue to ensure the safety of the public and the environment.

Facility Closure Projects. To complete the West Valley Demonstration Project Act, the facilities used to solidify the high-level waste will be decommissioned in accordance with long-term management decisions.

\section{General Environmental Setting}

The geography, socioeconomics, climate, ecology, and geology of the region are principal factors in assessing possible effects of site activities on the surrounding population and environment and are an integral consideration in the design and structure of the environmental monitoring program.

Location of the West Valley Demonstration Project. The WVDP is located in northern Cattaraugus County about 30 miles $(50 \mathrm{~km})$ south of Buffalo, New York (Fig. 1 [facing page]). The WVDP facilities occupy a security-fenced area of about 200 acres ( 80 ha) within the WNYNSC. This fenced area is referred to as the Project premises.

The WVDP is situated on New York State's Allegheny plateau at an approximate average elevation of 1,300 feet $(400 \mathrm{~m})$. The communities of West Valley, Riceville, Ashford Hollow, and the village of Springville are located within approximately 5 miles $(8 \mathrm{~km})$ of the Project. Several roads and a railway pass through the WNYNSC, but the public does not have access to the WNYNSC. Hunting, fishing, and human habitation on the WNYNSC generally are prohibited. A NYSERDA-sponsored program to control the deer population, initiated in 1994, continued through 2000. Limited access to the WNYNSC was given to local hunters, and community response has been favorable. Due to security concerns, hunting on the WNYNSC was canceled for the season in the fall of 2001.

Socioeconomics. The WNYNSC lies within the town of Ashford in Cattaraugus County. The nearby population, approximately 9,200 residents within 6.2 miles $(10 \mathrm{~km})$ of the Project, relies primarily on an agricultural economy. No major industries are located within this area.

The land immediately adjacent to the WNYNSC is used principally for agriculture and arboriculture. Cattaraugus Creek is used locally for swimming, canoeing, and fishing. Although some water to irrigate nearby golf course greens and tree farms is taken from Cattaraugus Creek, no public water 
supply is drawn from the creek downstream of the WNYNSC before the creek flows into Lake Erie south of Buffalo, New York. Water from Lake Erie is used as a public drinking-water supply.

Climate. Although there are recorded extremes of $98.6^{\circ} \mathrm{F}\left(37^{\circ} \mathrm{C}\right)$ and $-43.6^{\circ} \mathrm{F}\left(-42^{\circ} \mathrm{C}\right)$ in Western New York, the climate is moderate, with an average annual temperature (1971-2000) of $48^{\circ} \mathrm{F}$ $\left(8.9^{\circ} \mathrm{C}\right)$. Rainfall is relatively high, averaging about 41 inches $(104 \mathrm{~cm})$ per year. As in 2000, precipitation in 2001 remained below average, totaling about 31 inches $(79 \mathrm{~cm})$. Precipitation is evenly distributed throughout the year and is markedly influenced by Lake Erie to the west and, to a lesser extent, by Lake Ontario to the north. Regional winds are generally from the west and south at about $9 \mathrm{mph}(4 \mathrm{~m} / \mathrm{sec})$.

Biology. The WNYNSC lies within the northern deciduous forest biome, and the diversity of its vegetation is typical of the region. Equally divided between forest and open land, the site provides a habitat especially attractive to white-tailed deer and various indigenous birds, reptiles, and small mammals. No species on the federal endangeredspecies list are known to be present on the WNYNSC.

Geology and Groundwater Hydrology. The WVDP site is located on the west shoulder of a steep-sided glacially scoured bedrock valley that is filled with a sequence of glacial sediments. (See Figs. 3-1 and 3-2 [p. 3-3] in Chapter 3, Groundwater Monitoring.) The WVDP site is bordered by two stream valleys (Frank's Creek and Quarry Creek) and divided by a third stream valley (Erdman Brook) into two portions, the north and south plateaus. (See Figs. A-6 through A-8 [pp. A-8 through A-10] in Appendix A.)

The uppermost layer of glacial sediments on the south plateau consists of a silty clay till, the Lavery till. The Lavery till does not transmit significant quantities of water except where it is exposed at the ground surface, where weathering has fractured the near-surface sediments. Groundwater flow in the weathered till has both a vertically downward component and a horizontal component to the northeast. Groundwater flow in the unweathered portion of the till, beneath the exposed weathered till, is predominantly downward.

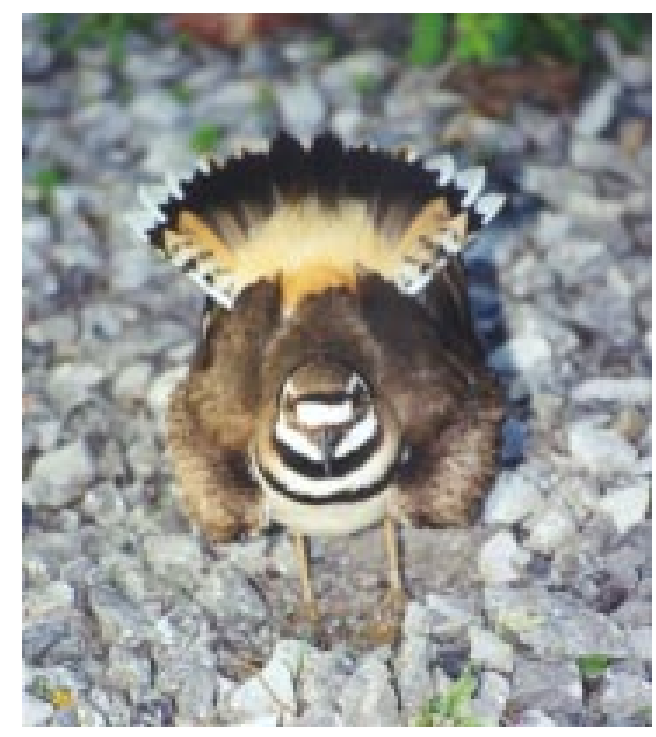

A Killdeer (charadrius vociferus) protects her nest.

On the north plateau a permeable alluvial sand and gravel layer overlies the less permeable glacial sequence of sediments (i.e., the Lavery till, the Kent recessional sequence, and the Kent till). Groundwater flow in the sand and gravel unit of the north plateau is predominantly horizontal, towards the northeast, discharging to seeps and streams along the plateau's edge and via evapotranspiration. (See evapotranspiration in the Glossary [p. GLO-4].)

Within the Lavery till on the north plateau is a silty, sandy unit of limited extent, the Lavery till-sand. Gradients indicate that groundwater flows east- 
southeast. Surface discharge points have not been observed.

The Kent recessional sequence that underlies the Lavery till beneath both north and south plateaus is composed of silt and silty sand with localized pockets of gravel. Groundwater flow in the Kent recessional sequence is also toward the northeast with discharge to Buttermilk Creek.

\section{Environmental Monitoring Program}

The WVDP's environmental monitoring program began in February 1982. The primary program goal is to detect changes in the environment resulting from Project or pre-Project activities and to assess the effect of any such changes on the human population and the environment surrounding the site facilities.

The monitoring network and sample collection schedule have been structured to accommodate specific biological and physical characteristics of the area. Among the several factors considered in designing the environmental monitoring program were the kinds of wastes and other byproducts resulting from the processing of high-level waste; possible routes that radiological and nonradiological contaminants could follow into the environment; geologic, hydrologic, and meteorologic site conditions; quality assurance standards for monitoring and sampling procedures and analyses; and the limits and standards set by federal and state governments and agencies. When new processes and systems become part of the Project, appropriate additional monitoring is provided. As processes are completed, unnecessary monitoring may be eliminated from the program.

Monitoring and Sampling. The environmental monitoring program consists of on-site effluent monitoring and on- and off-site environmental sur- veillance in which samples are measured for both radiological and nonradiological constituents. (See the Glossary [pp. GLO-3 and GLO-4] for more detailed definitions of effluent monitoring and environmental surveillance.) Monitoring and surveillance include both the continuous recording of data and the collecting of soil, sediment, water, air, and other samples at specific times.

Monitoring and sampling of environmental media provide two ways of assessing the effects of Project or pre-Project activities. Monitoring generally is a continuous (or periodic) process of measurement that allows rapid detection of any changes in the levels of constituents that could affect the environment. Sampling is the collection of media at specific times; sampling is slower than direct monitoring in indicating changes in constituent levels because the samples must be analyzed in a laboratory to obtain data. However, sample analysis allows much smaller quantities of radioactivity or chemical concentrations to be detected.

Permits and Regulations. Data gathering, analysis, and reporting to meet stringent federal and state requirements and standards are an integral part of the monitoring program. The current program meets the requirements of DOE Orders 5400.1 (General Environmental Protection Program), 5400.5 (Radiation Protection of the Public and Environment), and 231.1 (Environment, Safety, and Health Reporting), and DOE Regulatory Guide DOE/EH-0173T (Environmental Regulatory Guide for Radiological Effluent Monitoring and Environmental Surveillance). The environmental monitoring program also supports requirements of the 3008(h) Administrative Order on Consent.

The WVDP holds a State Pollutant Discharge Elimination System (SPDES) permit as required by the New York State Department of Environmental Conservation (NYSDEC), which regulates 
liquid effluent discharges containing nonradiological pollutants. The SPDES permit identifies the outfalls where liquid effluents are released to surface water drainage systems and specifies the sampling and analytical requirements for each outfall. It also specifies that concentrations of radionuclides at these outfalls must meet the requirements of DOE Orders 5400.1 and 5400.5.

Radiological air emissions must comply with the National Emission Standards for Hazardous Air Pollutants (NESHAP) regulations. Depending upon the potential to emit radionuclides, some radiological emission points must be permitted by the Environmental Protection Agency (EPA).

In addition, the site operates under state-issued air discharge permits for nonradiological plant emissions.

For more information about air and SPDES permits see the Environmental Compliance Summary (pp. ECS-6 through ECS-13). Environmental permits are listed at the back of the Environmental Compliance Summary (pp. ECS-22 and ECS-23).

\section{Exposure Pathways Monitored at the West Valley Demonstration Project}

The major near-term pathways for potential movement of contaminants away from the site are by surface water drainage and airborne transport. For this reason the environmental monitoring program emphasizes the collection of air and surface water samples.

Samples are collected on-site from locations such as plant ventilation stacks, various water effluent points, and surface water drainage locations. Analyses of samples of air, water, soils, and biota from the environment surrounding the site would detect radioactivity that might reach the public from site releases. Extensive groundwater monitoring addresses the subsurface pathway.

Water and Sediment Pathways. Process waters are treated through filtration and ion-exchange in a liquid-treatment facility, the LLW2. The treated water is sent to a series of on-site holding lagoons for testing before being discharged through a single outfall. (The locations of the lagoons are noted on Fig. A-2 [p. A-4] in Appendix A.) Samples of this process water and the effluent at two other discharge points are collected in accordance with permit requirements.

The samples are analyzed for radiological parameters, including gross alpha and gross beta, tritium, strontium-90, and gamma-emitting radionuclides, and for nonradiological parameters, including $\mathrm{pH}$. Additional analyses of composite samples determine metals content, solids, biochemical oxygen demand, nitrates, nitrites, ammonia, sulfate, organic chemicals, and specific radionuclides.

In general, surface water samples are collected regularly and analyzed, at a minimum, for gross alpha and gross beta radioactivity, tritium, and $\mathrm{pH}$. Selected samples are analyzed for conductivity, chlorides, metals, volatile organic compounds, and other parameters. Potable water on the site is analyzed monthly for radioactivity and annually for chemical constituents. Residential drinking water wells located near the site are sampled annually and analyzed for gross alpha and gross beta radioactivity, tritium, gamma-emitting radionuclides, $\mathrm{pH}$, and conductivity.

Off-site surface waters, primarily from Cattaraugus Creek and Buttermilk Creek, are sampled upstream of the Project for background radioactivity and downstream to measure possible Project contributions. Sediments deposited downstream of the facility and at upstream background locations are 
collected annually and analyzed for gross alpha, gross beta, and specific radionuclides. (See Appendix C [pp. C-3 through C-25] for water and sediment data summaries.)

Groundwater Pathways. Groundwater discharge at the WVDP site occurs as springs or seeps along stream channels, direct discharge to streams, evapotranspiration, vertical groundwater migration to underlying strata, and discharge to artificial draining systems and lagoons. All of these discharges vary with the seasons. Discharge from springs and seeps is highest during the spring. Evapotranspiration is at a maximum during the summer. Groundwater discharge is, in general, lowest during the winter because the ground surface is frozen, which minimizes recharge.

Routine monitoring of groundwater includes sampling for contamination and radiological indicator parameters ( $\mathrm{pH}$ and conductivity, and gross alpha, gross beta, and tritium) and for specific analytes of interest such as volatile organic compounds, semivolatile organic compounds, metals, and radionuclides at selected monitoring locations. (See Table E-1 [pp. E-3 through E-6] in Appendix E.)

Air Pathways. Permitted effluent air emissions are continuously monitored for alpha and beta activity. Alarms indicate any unusual rise in radioactivity. Air particulate sampling filters, which are retrieved and analyzed weekly for gross radioactivity, are also composited quarterly and analyzed for strontium-90 and specific gamma- and alpha-emitting radionuclides.

Iodine-129 and tritium also are measured in effluent ventilation air at some locations. At two of the effluent locations silica gel-filled columns are used to collect water vapor that is then distilled from the desiccant and analyzed for tritium. The distillates are analyzed weekly. Six permanent samplers at effluent locations contain activated charcoal ad- sorbent that is analyzed for iodine-129; the charcoal is collected weekly and composited for quarterly analysis.

Off-site sampling locations include those considered most representative of background conditions and those most likely to be downwind of airborne releases. Among the criteria used to position offsite air samplers are prevailing wind direction, land usage, and the location of population centers. Off-site air is continuously sampled at ten locations. Background samplers are located far from the site in Great Valley and Nashville, New York. Nearby-community samplers are in Springville and West Valley, New York. (See Figs. A-12 and A13 [pp. A-14 and A-15] in Appendix A for these four off-site air sampling locations.) Six samplers are located on the perimeter of the WNYNSC. (See Fig. A-5 [p. A-7] in Appendix A.) Samples from these locations are analyzed for parameters similar to the effluent air samples. (See Appendix D [pp. D-3 through D-26] for air monitoring data summaries.)

Atmospheric Fallout. An important contributor to environmental radioactivity is atmospheric fallout. Sources of fallout include earlier atmospheric testing of nuclear weapons and residual radioactivity from accidents such as that which occurred at Chernobyl in the Ukraine.

Four site perimeter locations and one on-site location currently are monitored for fallout using pottype collectors that are sampled every month. Long-term fallout is assessed by analyzing soil collected annually at each of the six perimeter and four off-site air samplers. Three additional on-site soil samples are taken annually. (See Appendix D [pp. D-24 through D-26] for fallout data summaries and Appendix C [pp. C-23 and C-24] for soil data summaries.) 
Food Pathways. A potentially significant pathway for radioactivity to reach humans is through consuming produce, meat, and milk from domesticated farm animals raised near the WVDP and game animals and fish that live in the vicinity of the WVDP. Animal and fish samples from potentially affected areas are gathered and analyzed for radionuclide content in order to reveal any longterm trends. Fish are collected along Cattaraugus Creek at several locations downstream of the WVDP. Venison is sampled from deer whose range include the WNYNSC. Control samples of both fish and venison are collected from background areas outside WVDP influence. Beef, milk, hay, and produce samples also are collected at nearby farms and at selected locations well away from WVDP influence. (See Appendix F [pp. F3 through F-8] for biological data summaries.)

Direct Radiation Measurement. Direct penetrating radiation is measured using thermoluminescent dosimeters (TLDs) located on- and off-site. Measurement points within the site are placed near selected waste management units and around the inner security fence. Other locations are around the site perimeter and access road and at background locations remote from the WVDP. Forty-three measurement points were used in 2001. The TLDs are retrieved quarterly and are processed by an off-site service to obtain the integrated gamma exposure. (See Appendix H [pp. H-3 through H-6] for a summary of the direct radiation data.)

\section{Meteorological Monitoring}

Meteorological data are continuously gathered and recorded at meteorological towers on-site and a nearby regional location south of the WNYNSC. Wind speed and direction, barometric pressure, temperature, dewpoint, and rainfall are measured on-site. Wind speed and direction are measured at the regional tower. These data are valuable for modeling both airborne dispersion and long-term hydrologic trends. In the event of an emergency, immediate access to the most recent meteorological data is indispensable for predicting the path and concentration of any materials that become airborne. (See Appendix I [pp. I-3 through I-8] for meteorological data summaries.)

\section{Quality Assurance and Control}

The work performed by and through the on-site Environmental Laboratory is regularly reviewed by several agencies for accuracy and compliance with applicable regulations. Assessments of the laboratory routinely focus on proper recordkeeping and reporting, timely calibration of equipment, training of personnel, adherence to accepted procedures, and general laboratory safety.

The Environmental Laboratory also participates in quality assurance crosscheck programs administered by federal agencies. (See Appendix J [pp. J-3 through J-7] for a summary of crosscheck performance.) The performance of outside laboratories contracted to analyze WVDP samples also is regularly assessed.

Environmental monitoring management continues to strengthen the formal self-assessment program, developing and implementing new strategies and procedures for ensuring high-quality data. Experienced senior scientists and specialists in varying disciplines follow an annual schedule of self-assessments, produce formal reports with recommended corrective actions, and track the actions as they are completed.

\section{Safety Management System}

The WVDP has a safety management system in place which has been validated by the DOE Ohio Field Office. The safety management system in- 
tegrates all safety programs, including environmental protection, to ensure that Project work can be safely and efficiently performed. As a continuation of this effort, the WVDP applied for the DOE Voluntary Protection Program STAR designation, reserved for companies that have demonstrated sustained excellence in their safety and health program. STAR status for the WVDP was announced in early 2000.

The WVDP also was recognized as a top environmental leader in 2000 and was accepted into the EPA's National Environmental Performance Track. The WVDP was awarded charter member status as part of the first group of applicants.

To qualify for the award the WVDP had to demonstrate that it voluntarily has adopted and implemented an environmental management system, has attained previous specific environmental achievements, has made a commitment to achieve four future goals, and has a sustained record of environmental compliance.

The WVDP is one of only two DOE sites to hold both the EPA's highest award for environmental achievement and the DOE's STAR award for excellence in safety and health.

In 2001 the WVDP continued the achievement level and practices worthy of a National Environmental Performance Track and STAR-designated site. 
This page intentionally left blank

INT -12 


\section{ENVIRONMENTAL COMPLIANCE SUMMARY Calendar Year 2001}

\section{Compliance Program}

The West Valley Demonstration Project (WVDP) is currently focusing on several goals that will lead to eventual site closure. Processing of the highlevel liquid waste into durable, solid glass is almost complete, and the WVDP is now working on removing and vitrifying residual radioactivity remaining in the high-level waste tanks. In addition, the WVDP is shipping low-level waste, constructing a remote-handled waste facility, actively managing on-site groundwater contamination, preparing for the shipment of spent nuclear fuel, and cleaning up facilities not presently used in anticipation of eventual closure.

The activities in progress at the WVDP are regulated by various federal and state laws that protect the public, workers, and the environment.

The U.S. Department of Energy (DOE), the federal agency that oversees the WVDP, established its policy concerning environmental protection in DOE Order 5400.1, General Environmental Protection Program. This Order lists the regulations, laws, and required reports that are applicable to DOE-operated facilities. DOE Order 231.1, Environment, Safety, and Health Reporting, requires the preparation of this annual site environmental report, which is intended to summarize environ- mental data gathered during the calendar year, describe significant environmental programs, and document WVDP compliance with environmental regulations.

The major federal environmental laws and regulations that apply to the West Valley Demonstration Project are the Resource Conservation and Recovery Act (RCRA), the Clean Air Act (CAA), the Emergency Planning and Community Rightto-Know Act (EPCRA, enacted as Title III of the Superfund Amendments and Reauthorization Act [SARA]), the Clean Water Act (CWA), the Safe Drinking Water Act (SDWA), the Toxic Substances Control Act (TSCA), and the National Environmental Policy Act (NEPA). These laws are administered primarily by the U.S. Environmental Protection Agency (EPA) and the New York State Department of Environmental Conservation (NYSDEC) through state programs and regulatory requirements such as permitting, reporting, inspecting, and self-auditing.

In addition, because the emission of radiological and nonradiological materials from an active facility cannot be completely prevented, the EPA, NYSDEC, and the DOE have established standards for such emissions that are intended to protect human health and the environment. The WVDP applies to NYSDEC and the EPA for per- 
mits that allow the site to release limited amounts of radiological and nonradiological constituents through controlled and monitored discharges into water and air in concentrations that have been determined to be safe for humans and the environment. In general, the permits describe the discharge points, specify management and reporting requirements, list the limits on those pollutants likely to be present, and define the sampling and analysis schedule. A summary of permits may be found on pp. ECS-22 and ECS-23.

\section{Compliance Status}

The following summary describes WVDP compliance with DOE Orders 5400.5 and 435.1 and federal and state laws and regulations that are applicable to the Project.

\section{Radiation Protection of the Public and the En-} vironment (DOE Order 5400.5). DOE Order 5400.5 was issued in February of 1990 to establish standards and requirements for protection of the public and the environment against undue risk from radiation resulting from activities of the DOE and DOE contractors. Objectives of the Order were to ensure that (1) operations are conducted so that radiation exposures to members of the public are maintained within the limits established in the Order, (2) potential exposures to members of the public are as far below the limits as is reasonably achievable, (3) routine and non-routine releases are monitored and dose to the public is assessed, and (4) the environment be protected from radioactive contamination to the extent practical.

This report summarizes radiological releases from the WVDP in 2001, presents estimates of dose to the public and the environment in 2001, and compares these values with release and dose standards established by DOE Order 5400.5. (See Appendix K [p. K-3].) In 2001, both releases and estimates of dose to the public were well within applicable limits.

Radioactive Waste Management (DOE Order 435.1). DOE Order 435.1 was issued in July of 1999 to ensure that all DOE radioactive waste - including high-level waste, transuranic waste, low-level waste, and the radioactive component of mixed waste - is managed in a manner that (1) protects the public from exposure to radiation from radioactive materials, (2) protects the environment, (3) protects workers, and (4) complies with applicable federal, state, and local laws and regulations, as well as applicable Executive Orders and other DOE directives. Compliance with the Order was required by July of 2000 .

The WVDP prepared an Implementation Plan for DOE Order 435.1 and submitted the plan to the DOE in June of 2000. The WVDP Radioactive Waste Acceptance Program, a formal document describing how radioactive waste is managed at the WVDP, was issued in July of 2000. Both the Implementation Plan and the Radioactive Waste Acceptance Program were updated in 2001.

Resource Conservation and Recovery Act (RCRA). RCRA was enacted to ensure that hazardous wastes are managed in a manner that protects human health and the environment. RCRA and its implementing regulations govern the generation, treatment, storage, and disposal of hazardous waste. RCRA regulations mandate that generators take responsibility for ensuring the proper treatment, storage, and disposal of their wastes. The EPA is the federal agency responsible for issuing guidelines and regulations for the proper management of solid and hazardous waste (including mixed [radioactive and hazardous] waste).

In New York, the EPA has delegated the authority to enforce these regulations to NYSDEC. In 
addition, the U.S. Department of Transportation (DOT) is responsible for issuing guidelines and regulations for the labeling, packaging, and spillreporting provisions for hazardous and mixed wastes while in transit.

A Part A Permit Application (for interim status) is required for a facility that treats or stores large quantities of hazardous waste for more than 90 days or disposes of hazardous waste at that facility. The facility must apply for a permit from the EPA (or authorized state). The Part A Permit Application defines the treatment processes to be used, the design capacities, the location of hazardous waste storage units, the design and operating criteria for disposal units, and the hazardous wastes to be managed.

In 1984 the DOE notified the EPA of hazardous waste activities at the WVDP and identified the WVDP as a generator of hazardous waste. In June 1990 the WVDP filed a RCRA Part A Hazardous Waste Permit Application with NYSDEC for storage and treatment of hazardous wastes and has been operating under interim status since then.

The WVDP updates its RCRA Part A Permit Application as changes to the site's interim-status waste-management operations occur. An updated Part A Permit Application was submitted to NYSDEC on March 6, 2001. On November 13, 2001, NYSDEC responded that the RCRA Part A modifications met the requirements for changes to interim status treatment and storage operations at the WVDP.

Hazardous Waste Management Program. Hazardous wastes at the WVDP are managed in accordance with Title 6 of the Official Compilation of Codes, Rules, and Regulations of the State of New York (6 NYCRR) Parts 370 - 374 and 376. To dispose of hazardous wastes generated from on-site activities, the WVDP uses New York State-permitted transporters (pursuant to 6 NYCRR Part 364) to ship RCRA-regulated wastes to permitted or authorized treatment, storage, or disposal facilities (TSDFs). Using these services, the WVDP shipped approximately 1.3 tons ( 1.18 metric tons) of nonradioactive hazardous waste to off-site TSDFs in 2001.

Off-site hazardous waste shipments and their receipt at designated treatment, storage, or disposal facilities are documented by signed manifests that accompany the shipment. If the signed manifest is not returned by the TSDF to the WVDP within the regulatory limit of forty-five days from shipment, an exception report must be filed with NYSDEC and it must be confirmed that the waste was received by the TSDF. One exception report was completed in February 2001 for a November 2000 shipment. (Confirmation of the shipment had been made, however, the signed copy of the manifest was not received until after the forty-fiveday requirement.)

Hazardous waste activities must be reported to NYSDEC each year through the submittal of the facility's annual Hazardous Waste Report. This report summarizes the hazardous waste activities for the previous year, specifies the quantities of waste generated, treated, and/or disposed, and identifies the TSDFs used. The annual Hazardous Waste Report for calendar year 2001 was submitted to NYSDEC by March 1, 2002.

In addition, a hazardous waste reduction plan must be filed every two years and updated annually. This plan documents efforts to minimize the generation of hazardous waste and was first submitted to NYSDEC in 1990. The most recent Annual Status Report for the Hazardous Waste Reduction Program was updated in June 2001 and submitted to NYSDEC. 
An annual inspection to assess compliance with hazardous waste regulations was conducted by NYSDEC on March 29, 2001. No deficiencies were noted.

Nonhazardous, Regulated Waste Management Program. The WVDP shipped approximately 125 tons (113 metric tons) of nonradioactive, nonhazardous material off-site to solid waste management facilities in 2001. Of this amount, 2.1 tons (1.9 metric tons) were recycled or reclaimed. Some of the recycled materials were lead-acid batteries, nonhazardous oils such as motor oil, hydraulic oil, and compressor oil, and spent lamps, which were recycled at off-site authorized reclamation and recycling facilities. Lead-acid batteries and spent lamps are managed as universal wastes. (See universal wastes [p. GLO-10].) The WVDP also shipped approximately 893 tons $(810$ metric tons) of digested sludge and untreated wastewater from the site sanitary and industrial wastewater treatment facility to the Buffalo Sewer Authority for treatment.

Mixed Waste Management Program. Mixed waste contains both a radioactive component, regulated under the Atomic Energy Act, and a hazardous component, regulated under RCRA. Both the EPA and NYSDEC oversee mixed waste management at the WVDP.

The Federal Facility Compliance Act (FFC Act) of 1992, an amendment to RCRA, required DOE facilities to prepare plans for treating their mixed waste inventories and to update these plans annually to account for development of treatment technologies, capacities, and changes in mixed waste inventories. Each plan was approved by the respective state agency or the EPA after consultation with other affected states and after consideration of public comments.
The WVDP's plan comprises two volumes: The Background Volume provides information on each mixed waste stream and information on the preferred treatment method for the waste. The Plan Volume contains proposed schedules for treating the mixed waste to meet the land disposal restriction (LDR) requirements of RCRA.

The DOE and NYSDEC entered into a consent order on September 3, 1996 that requires the completion of the milestones identified in the Plan Volume. The WVDP began implementing its site treatment plan immediately and updates it annually to bring waste stream, inventory, and treatment information current to September 30 , the end of the DOE fiscal year. A draft update of the fiscal year 2001 activities was presented to DOE for review and comment in October 2001. DOE comments were incorporated into the update and forwarded to NYSDEC before the due date of February 15, 2002.

Shipments of mixed waste to off-site TSDFs for treatment and disposal are documented via uniform Hazardous Waste Manifests. In 2001 the WVDP made four mixed waste shipments. A total of 12.7 tons (11.5 metric tons) were shipped off-site for treatment and disposal.

RCRA $\$ 3008(h)$ Administrative Order on Consent. The DOE and NYSERDA entered into a RCRA §3008(h) Administrative Order on Consent with NYSDEC and the EPA in March 1992. The Consent Order required NYSERDA and the DOE's West Valley Demonstration Project Office (OH/WVDP) to conduct RCRA-facility investigations (RFIs) at solid waste management units (SWMUs) to determine if there had been a release or if there is a potential for release of RCRA-regulated hazardous constituents from SWMUs. The final RFI reports were submitted in 1997, completing the investigative activities associated with the Consent Order. As a result of 
the RFIs, no corrective actions were required. Groundwater monitoring as specified in the RFI reports continued to be a significant portion of the WVDP groundwater monitoring program during 2001. The WVDP also continued to monitor SWMUs and to comply with the requirements of the RCRA $\S 3008(\mathrm{~h})$ Administrative Order on Consent. (Monitoring results are detailed in Chapter 3.)

Waste Minimization and Pollution Prevention. The WVDP continued a long-term program to minimize the generation of low-level radioactive waste, mixed waste, hazardous waste, industrial waste, and sanitary waste and to promote affirmative procurement as directed by Executive Order 13101 (Greening the Government Through Waste Prevention, Recycling, and Federal Acquisition) and Executive Order 13148 (Greening the Government Through Leadership in Environmental Management), which promote the Affirmative Procurement Program and RCRA §6002, Federal Procurement. The Affirmative Procurement Program specifies responsibilities and direction for federal agencies in acquiring recycled and environmentally preferable products and services designated by the EPA in Title 40, Protection of Environment, Code of Federal Regulations (40 CFR) Part 247. West Valley Nuclear Services Co. (WVNSCO) reports its challenges and successes associated with the purchase and use of these materials and services to the DOE each year.

For purposes of waste reduction tracking, on-site waste streams are separated into either waste from sources directly associated with the vitrification process or into other nonvitrification sources. See Chapter 1 (p. 1-12) for a detailed discussion of waste minimization activities from all sources in 2001 .

Underground Storage Tanks Program. RCRA regulations also cover the use and management of underground storage tanks and establish minimum design requirements to protect groundwater resources from releases. The regulations, specified in 40 CFR Part 280, require underground storage tanks to be equipped with overfill protection, spill prevention, corrosion protection, and leak detection systems. New tanks must comply with regulations at the time of installation.

New York State also regulates underground storage tanks through two programs, petroleum bulk storage (6 NYCRR, Parts 612 - 614) and chemical bulk storage (6 NYCRR, Parts 595 - 599). The state registration and minimum design requirements are similar to those of the federal program except that petroleum tank fill ports must be colorcoded using American Petroleum Institute standards to indicate the product being stored.

A 550-gallon double-walled steel underground storage tank, upgraded in 1998 to bring it into compliance with the most recent EPA requirements (40 CFR Part 280.21), is used to store diesel fuel for the supernatant treatment system/permanent ventilation system standby power unit. This tank is equipped with aboveground piping, an upgraded interstitial leak detection system, and a high-level warning device and meets the state requirements of 6 NYCRR Parts 612 - 614. This is the only underground petroleum-storage tank currently in use at the WVDP.

A former underground petroleum-storage tank, closed in place before the New York State underground storage tank program closure requirements were implemented in 1985, was removed in 1997. Testing of soils from the tank excavation had shown evidence of earlier petroleum leakage, and on March 19, 1999 the DOE and NYSDEC executed a Stipulation Agreement Pursuant to Section 17-0303 of the Environmental Conservation Law and Section 176 of the Navigation Law for mitigation of the petroleum contamination. 
A bioventing system, installed in August 1999 to remediate localized petroleum-contaminated soils, stimulates natural in situ biodegradation of petroleum hydrocarbons in the soil by providing an abundant oxygen supply to existing soil microorganisms within the contaminated soil zone.

This system continued operating during 2001, except during required maintenance. It is checked daily by site operations personnel, and the combined effluent airflow from the extraction wells is monitored weekly for total volatile organic compounds (VOCs) using a photoionization detector.

The system was assessed in August 2001. Results of this assessment indicated that the system is meeting its intended purpose of providing an oxygen supply to stimulate biodegradation of contaminants present in the subsurface soils. A report was transmitted to NYSDEC in September 2001.

There are no underground bulk chemical storage tanks at the WVDP.

New York State-Regulated Aboveground Storage Tanks. The state of New York regulates aboveground petroleum bulk storage under 6 NYCRR Parts 612 - 614, and aboveground hazardous bulk chemical storage under 6 NYCRR Parts 595 - 599. These regulations require secondary containment, external gauges to measure the current reserves, monthly visual inspections of petroleum tanks, and documented daily, annual, and five-year inspections of chemical tanks. Documentation relating to these periodic inspections is maintained by the WVDP and is available for regulatory agencies to review. Petroleum tank fill ports also must be color-coded and chemical tanks must be labeled to indicate the product stored.

WVDP registration at the end of 2001 included nine aboveground petroleum tanks and eleven aboveground chemical storage tanks. Three of the petroleum tanks contain No. 2 fuel oil, one contains unleaded gasoline, and the remainder contain diesel fuel. The Quality Assurance department inspects the aboveground petroleum tanks every month.

Nine of the chemical storage tanks are used as needed to contain nitric acid or nitric acid mixtures. Sodium hydroxide and anhydrous ammonia are stored in the remaining two tanks. All of the tanks are equipped with gauges and secondary containment systems except the anhydrous ammonia tank, which does not require secondary containment. (Any release of the contents of the anhydrous ammonia tank would be in gaseous form; thus, secondary containment is unnecessary.) The WVDP is in compliance with the most recent requirements to upgrade chemical bulk storage tanks that went into effect in December 1999.

Medical Waste Tracking. Medical waste poses a potential for humans to be exposed to infectious diseases and pathogens from contact with human bodily fluids. Medical evaluations, inoculations, and laboratory work at the on-site Health Services office regularly generate potentially infectious medical wastes that must be tracked in accordance with NYSDEC requirements (6 NYCRR Part 364.9).

The WVDP has retained the services of a permitted waste hauler and disposal firm to manage these medical wastes. Medical wastes are sterilized with an autoclave by the disposal firm to remove the associated hazard and then disposed. Eleven pounds $(5 \mathrm{~kg}$ ) of medical waste consisting of dressings, protective clothing such as rubber gloves, and needles, syringes, and other sharps were generated and disposed in 2001.

Clean Air Act (CAA). The CAA, including Titles I through VI, establishes a framework for the EPA to regulate air emissions from both stationary and 
mobile sources. These amendments mandate that each state establish a program to permit the operation of sources of air pollution. In 1996 NYSDEC amended 6 NYCRR Parts 200, 201, 231, and 621 to implement the requirements of the new EPA Clean Air Act Title V permitting processes.

In New York State, either the EPA or NYSDEC issues permits for stationary sources that emit regulated pollutants, including hazardous air pollutants. Sources requiring permits are those that emit regulated pollutants from a particular source (e.g., a stack, duct, vent, or other similar opening) if the pollutants are in quantities above a predetermined threshold. WVDP radiological emissions are regulated by the EPA. All other air pollutants are regulated by NYSDEC.

Radiological Emissions. Air emissions of radionuclides from point sources at the WVDP are regulated by the EPA under the National Emission Standards for Hazardous Air Pollutants (NESHAP) regulations, 40 CFR Part 61, Subpart $\mathrm{H}$, National Emission Standards for Emission of Radionuclides Other Than Radon From Department of Energy Facilities. The WVDP currently has permits for six radionuclide sources, including the slurry-fed ceramic melter and the vitrification heating, ventilation, and air conditioning (HVAC) system.

Other less significant sources of radionuclide emissions, such as those from the on-site laundry, do not require permits. Non-point radiological sources of air emissions such as lagoons also do not require permits. Emissions from all these sources are quantified for reporting to the EPA. The WVDP reports the radionuclide emissions from its non-permitted and permitted sources to the EPA annually in accordance with NESHAP regulations. Calculations to demonstrate compliance with NESHAP radioactive dose limits showed calendar year 2001 doses to be less than $0.1 \%$ of the 10 millirem standard. (See Table 4-2 [p. 46].)

Nonradiological Emissions. Nonradiological point sources of air emissions are regulated by NYSDEC. Major-source facilities are required by 6 NYCRR Part 201 to file a Title V Permit Application unless emissions are capped below operating limits. The WVDP submitted and has received NYSDEC approval of a capping plan for $\mathrm{NO}_{\mathrm{x}}$ and $\mathrm{SO}_{2}$.

The WVDP opted to file a State Facility Permit Application for the site. A State Facility Permit modification to incorporate sitewide air emission sources was submitted in December 1997 and approved June 1, 2000. Annual $\mathrm{NO}_{\mathrm{x}}$ and $\mathrm{SO}_{2}$ emissions under the updated permit are capped at 99 tons each. A DOE compliance surveillance performed in August 2001 verified that all conditions of this permit were being met.

The permit describes the conditions of the $\mathrm{NO}_{\mathrm{x}}$ and $\mathrm{SO}_{2}$ capping plan and the operational conditions for the boilers, melter, cold chemical facility, and the vitrification HVAC system. In July 1999 NYSDEC granted the WVDP a waiver of quarterly submissions of $\mathrm{NO}_{\mathrm{x}}$ and $\mathrm{SO}_{2}$ emission totals. The WVDP is required to submit only an annual site emission report, in January, that contains $\mathrm{NO}_{\mathrm{x}}$ and $\mathrm{SO}_{2}$ emission totals. The 2001 certification reported 4.81 tons of $\mathrm{NO}_{\mathrm{x}}$ and 0.06 tons of $\mathrm{SO}_{2}$, which were well below the 99-ton cap for each category.

The WVDP also conducts cylinder gas audits every quarter but is no longer required to conduct relative accuracy test audits of the melter off-gas $\mathrm{NO}_{\mathrm{x}}$ analyzers. A summary of quarterly cylinder gas audit results are incorporated in the annual site emission report. 
The air permits that were in effect at the WVDP in 2001 are included on the West Valley Demonstration Project Environmental Permits table (pp. ECS-22 and 23). There were no air permit or regulatory exceedances in 2001. (See also the West Valley Demonstration Project 2001 Air Quality Noncompliance Episodes table [p. ECS-20].)

Emergency Planning and Community Rightto-Know Act (EPCRA). EPCRA was designed to create a working partnership between industry, business, state and local governments, public health and emergency response representatives, and interested citizens. The Act is intended to address concerns about the effects of chemicals used, stored, and released in local communities.

Executive Order 12856, Federal Compliance with Right-to-Know Laws and Pollution Prevention Requirements, requires all federal agencies to comply with the following EPCRA provisions: planning notification (Sections 302 - 303), extremely hazardous substance (EHS) release notification (Section 304), material safety data sheet (MSDS)/ chemical inventory (Sections 311 - 312), and toxic release inventory (TRI) reporting (Section 313). The WVDP continued to comply with these provisions in 2001. (See also the Status of EPCRA Reporting table [p.ECS-21].)

- WVDP representatives participated in semiannual meetings of the Cattaraugus County Local Emergency Planning Committee (EPCRA Sections 302 - 303). WVDP representatives also attended meetings held by the Cattaraugus and Erie County Emergency Management Services concerning WVDP and other local emergency planning activities. Area hospitals and the West Valley Volunteer Hose Company continued to participate in on-site training drills and in information exchanges concerning hazardous-substance management at the WVDP.
- Compliance with all EPCRA reporting requirements was maintained and all required reports were submitted within the required time frame. There were no releases of extremely hazardous substances at the WVDP that triggered the release notification requirements of Section 304 of EPCRA.

- Under EPCRA Section 311 requirements, the WVDP reviews information about reportable chemicals every quarter. If a hazardous chemical that was not previously reported is present on-site in an amount exceeding the threshold planning quantity, an MSDS and an updated hazardous chemical list are submitted to the state and local emergency response groups. This supplemental reporting ensures that the public and the emergency responders have current information about hazardous chemicals at the WVDP. No new chemicals were added to the hazardous chemicals list in 2001 and no additional EPCRA Section 311 notifications were required.

- Under EPCRA Section 312 regulations, the WVDP submits annual reports to state and local emergency response organizations and fire departments that specify the quantity, location, and hazards associated with chemicals stored on-site. Fourteen reportable chemicals above threshold planning quantities were stored at the WVDP in 2001. (A list of reportable chemicals is provided on p. ECS-21.)

- Under EPCRA Section 313 the WVDP provides information about releases to all environmental media of EPA-listed toxic release inventory chemicals that are used at or above specified regulatory thresholds at the WVDP. TRI reports are filed for the preceding year. In 2001 the WVDP used one chemical above the regulatory reporting threshold amount of 10,000 lbs. - nitric acid. Thus, the TRI report for this chemical will be filed with the EPA by July 1, 2002. 
Clean Water Act (CWA). Section 404 of the CWA regulates the development of areas in and adjacent to the waters of the United States. Supreme Court interpretations of Section 404 have resulted in the inclusion of certain non-isolated wetlands in the regulatory definition of waters of the United States. Section 404 regulates the disposal of solids, in the form of dredged or fill material, into these areas by granting the U.S. Army Corps of Engineers the authority to designate disposal areas and issue permits for these activities. Executive Order 11990, Protection of Wetlands, directs federal agencies to "avoid to the extent possible the long and short term adverse impacts associated with the destruction or modification of wetlands and to avoid direct or indirect support of new construction in wetlands wherever there is a practical alternative." (Article 24 of the New York State Environmental Conservation Law also contains requirements for the protection of freshwater wetlands.)

In addition, Section 401 of the CWA requires applicants for a federal license or permit pursuant to Section 404 to obtain certification from the state that the proposed discharge complies with effluent and water quality-related limitations, guidelines, and national standards of performance identified under Sections 301 - 303, 306 - 307, and 511(c) of the CWA. The EPA has delegated administration of this program to New York State.

Wetlands. Jurisdictional wetlands are defined in Section 404 of the Clean Water Act as those satisfying specific technical criteria related to vegetation, soils, and hydrologic conditions. The WVDP notifies the U.S. Army Corps of Engineers and NYSDEC of proposed actions that could affect wetland units not specifically exempted from regulation or notification.

A wetlands assessment in August 1998 identified and delineated jurisdictional wetlands regulated under the Clean Water Act, Section 404, and/or those wetlands that may be regulated by the state of New York under Article 24 of the Environmental Conservation Law. The 375-acre (152-ha) assessment area covered a portion of the Western New York Nuclear Service Center (WNYNSC), including the entire 200-acre (80-ha) WVDP and adjacent parcels north, south, and east of the WVDP premises. The assessment also supported the requirements of Executive Order 11990 and updated a 1993 investigation. Fifty-nine jurisdictional wetlands ranging in size from 0.01 to 8.6 acres, a total of approximately 39 acres (16 ha) of wetland, were identified. This wetland delineation was submitted to the U.S. Army Corps of Engineers for verification of the wetland boundaries. Verification was obtained in November 1999.

Additional jurisdictional wetlands were assessed in a 150-foot corridor along both sides of the railroad spur from the southern fenced boundary of the Project premises to the intersection with Fox Valley Road in August and September 1999. Twenty-three separate wetland units ranging in size from 0.01 to 4.7 acres, a total of approximately 12 acres ( 5 ha), were identified.

In December 1999 a Joint Application for Permit was submitted to NYSDEC and the U.S. Army Corps of Engineers for activities in Buttermilk Creek and in or near the wetlands associated with the railroad spur. These activities included repairs to the culvert that carries the railroad over Buttermilk Creek and improvements to portions of the railside storm water drainage system. In April 2000 an Individual Dredge and Fill Permit was obtained from the Army Corps of Engineers and a Water Quality Certification and Freshwater Wetlands permit was obtained from NYSDEC for these activities.

An additional wetland unit at the foot of the Lake No. 1 dam was delineated in August 2000 to verify 
permitting requirements for improvements to the dam. NYSDEC and the Corps of Engineers reviewed the wetland mapping and the associated information and subsequently determined that these improvements were not within their permitting jurisdiction. The improvements were completed in 2001. The purpose of the railroad spur and dam improvements was to facilitate off-site shipment of spent nuclear fuel.

Storm Water Discharge Permit. Section 402 of the CWA generally regulates disposal of liquids and, as amended, authorizes the EPA to regulate discharges of pollutants to surface water through a National Pollutant Discharge Elimination System (NPDES) permit program. The EPA has delegated this authority to the state of New York, which issues State Pollutant Discharge Elimination System (SPDES) permits for discharges to surface water.

Surface water runoff from precipitation can become contaminated with pollutants from industrial process facilities, material storage and handling areas, access roads, or vehicle parking areas. To protect the environment, aquatic resources, and public health, Section 402(p) of the CWA requires that a storm water discharge permit application containing facility-specific information be submitted to the permitting authority. NYSDEC, the permitting authority in New York State, uses this information to ascertain the potential for pollution from storm water collection and discharge systems and to determine appropriate permitting requirements.

In April 1996 the WVDP obtained storm water characterization data through sampling and analysis and submitted an application for a modification of the SPDES permit to address overall site storm water discharges.
A permit application that updates the site storm water and process water discharges, including those associated with the construction and operation of the new Remote-Handled Waste Facility (RHWF) and with the operation of the site's refurbished railroad spur, was submitted to NYSDEC in September 2000. The permit modification is not expected until 2003.

A draft modified SPDES permit was issued by NYSDEC on December 11, 2001 for public comment. This modification includes a new effluent limit for mercury at outfall 001 and authorizes increased flows from the north plateau groundwater treatment project.

SPDES-Permitted Outfalls. Point-source liquid effluent discharges to surface waters of New York State are permitted through the New York SPDES program. The WVDP has four SPDES-permitted compliance points for discharges to Erdman Brook and Frank's Creek.

- Outfall 001 (WNSP001) discharges treated wastewater from the low-level waste treatment facility (LLWTF) and the north plateau groundwater recovery system. (See North Plateau Groundwater Recovery System [p. ECS-12] and Chapter 3, Special Groundwater Monitoring [p. 3-15].) The treated wastewater is held in lagoon 3, sampled and analyzed, and periodically released after notifying NYSDEC. In 2001 the treated wastewater from the LLWTF was discharged at WNSP001 in five batches totaling 8.4 million gallons (31.9 million liters) for the year. The annual average concentration of radioactivity at the point of release was approximately $33 \%$ of the DOE derived concentration guides (DCGs). None of the individual releases exceeded the DCGs. (See derived concentration guide in the Glossary [p. GLO-2] and in Chapter 1 [p. 1-5].) 


\section{WVDP SPDES Permit Limit Exceptions 1982-2001}

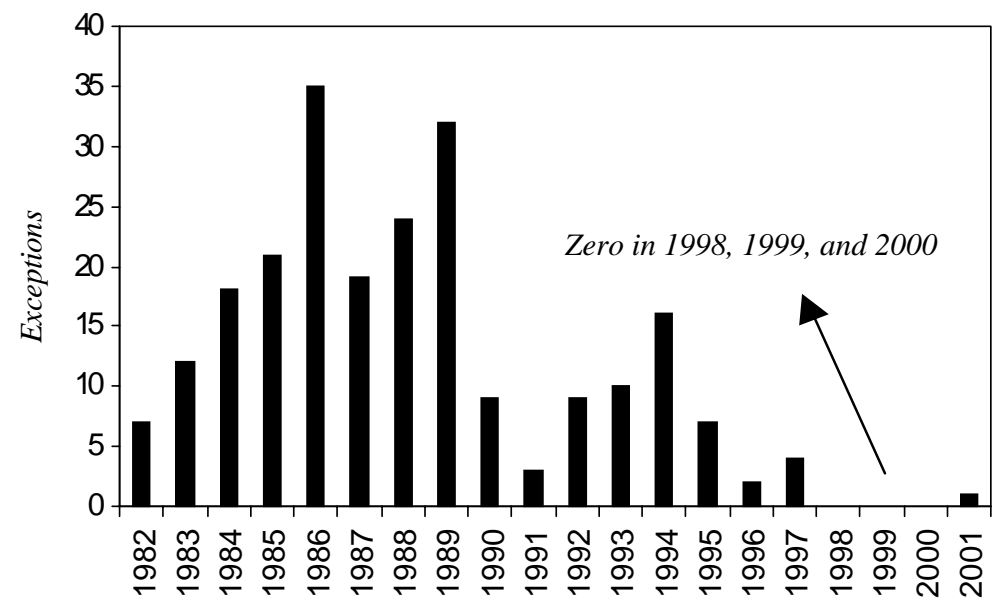

(TDS) and flow measurements from upstream sources are used to calculate the amount of augmentation water and flow needed to maintain compliance with SPDES-permitted TDS limits.

As shown on the chart above, the annual number of exceptions to the discharge concentration limits specified in the site's SPDES permit have been substantially reduced, especially when compared to the peak of thirty-five exceptions noted in 1986. In 2001 one exception was recorded at the french drain outfall
- Outfall 007 (WNSP007) discharges the effluent from the site sanitary and industrial wastewater treatment facility, which treats sewage and various nonradioactive wastewaters from physical plant systems (e.g., water plant production residuals and boiler blowdown). The average daily flow at WNSP007 in 2001 was 18,000 gallons $(68,100$ liters).

- Outfall 008 (WNSP008) discharges groundwater and surface water runoff directed from the northeast side of the site's LLWTF lagoon system through a french drain. The average daily flow at WNSP008 in 2001 was 1,790 gallons $(6,770$ liters) until it was capped off in May 2001.

- Monitoring point 116, located in Frank's Creek, represents the confluence of discharge from outfalls 001,007, and 008; base stream flow; wet weather flows (e.g., surface water runoff); groundwater seepage; and augmentation water (untreated water from the site reservoirs). This is not a physical outfall but a location where the combination of source-flow inputs is used to calculate values for determining compliance with SPDES permit limits during discharge of lagoon 3. Before discharge of lagoon 3, sample data for total dissolved solids
008 due to an elevated concentration of lead. The elevated concentration was believed to be caused by silt accumulation and reduced flow typical of an aging groundwater drain system. (See also p. ECS-20.)

In March 2001 NYSDEC conducted its annual facility inspection. At the request of the inspector, the SPDES outfalls, the sanitary and industrial wastewater treatment facility, and the LLWTF were observed. No deficiencies were noted during the inspection.

SPDES Permit Modifications. In March 1996 a SPDES permit application was submitted to NYSDEC to increase the average flow of effluent from the north plateau groundwater recovery system from approximately 2.6 million gallons $(9.8$ million liters) a year to approximately 10.5 million gallons (39.7 million liters) a year. (See North Plateau Groundwater Recovery System [p. ECS12].)

In 1999 increasing concentrations of total mercury were observed in process water collected in the LLWTF. The source of the mercury was determined to be process water from the liquid waste 
treatment system evaporator. (The evaporator is used to reduce the volumes of liquid waste generated during processing of high-level radioactive waste.)

A draft SPDES permit modification addressing both mercury and the proposed flow increase from the north plateau groundwater recovery system was issued for public comment in December 2001. A final permit addressing these changes is expected in 2002.

North Plateau Groundwater Recovery System. In November 1995 the WVDP installed a groundwater recovery system to mitigate the movement of strontium- 90 contamination in the groundwater northeast of the process building. Three recovery wells, installed near the leading edge of the groundwater plume, collect contaminated groundwater from the underlying sand and gravel unit. The groundwater is then treated at the low-level waste treatment building (LLW2) using ion-exchange to remove strontium-90. After the groundwater is processed, it is discharged to lagoon 4 or 5 of the LLWTF. Approximately 25 million gallons (96 million liters) of groundwater have been processed through the system since its inception, including about 3.4 million gallons (13 million liters) in 2001 .

In 1999 the Project installed a pilot-scale permeable treatment wall (PTW) to test this in situ passive technology for treating contaminated groundwater. Analytical data collected from within and around the wall indicate that a portion of the contaminated groundwater in this area is entering and being treated by the PTW. Based on the results of a detailed evaluation in early 2001, additional soil borings and monitoring wells were installed to further evaluate PTW performance and surrounding hydrogeologic conditions.

Petroleum- and Chemical-Product Spill Reporting. The WVDP has a Spill Notification and Re- porting Policy to ensure that all spills are properly managed, documented, and remediated in accordance with applicable regulations. This policy identifies the departmental responsibilities for spill management and the proper spill-control procedures. The policy stresses the responsibility of each employee to notify the main plant operations shift supervisor upon discovery of a spill. This first-line reporting requirement helps to ensure that spills are properly evaluated and managed.

Under a 1996 agreement with NYSDEC regarding petroleum spill-reporting protocol, the WVDP is not required to report spills of petroleum products of 5 gallons or less onto an impervious surface that are cleaned up within two hours of discovery. Petroleum-product spills of 5 gallons or less onto the ground are entered in a monthly petroleum spill log, which is submitted to NYSDEC by the fifteenth day of the following month. Spills of any amount that travel to waters of the state must be reported within two hours to the NYSDEC spill hotline and also are entered in the monthly $\log$. Spills of petroleum products that enter navigable waters of New York State are reported to the National Response Center within two hours of discovery. There were no spills to waters of the State at the WVDP in 2001.

The WVDP also reports spills or releases of hazardous substances in accordance with the reporting requirements of RCRA, the Comprehensive Environmental Response, Compensation, and Liability Act (CERCLA) if a reportable quantity has been exceeded, and the CAA, EPCRA, the CWA, and the Toxic Substances Control Act (TSCA). No chemical spills or releases exceeded reportable quantities and, thus, no reporting during calendar year 2001 was required.

In the event of a spill or release, all spills are cleaned up in a timely manner in accordance with the WVDP Spill Notification and Reporting Policy, 
thereby minimizing any effects on the environment. Debris generated during cleanup is characterized and dispositioned appropriately.

Safe Drinking Water Act (SDWA). The SDWA requires that each federal agency having jurisdiction over a federally owned or maintained public water system must comply with all federal, state, and local requirements regarding safe drinking water. Compliance with regulations promulgated under the SDWA in the state of New York is overseen by the New York State Department of Health (NYSDOH) through county health departments.

The WVDP obtains its drinking water from surface water reservoirs on the WNYNSC and is considered a non-transient, noncommunity public water supplier. The WVDP's drinking water treatment facility purifies the water by clarification, filtration, and chlorination before it is distributed on-site.

As an operator of a drinking water supply system, the WVDP routinely collects and analyzes drinking water samples to monitor water quality. The results of these analyses are reported to the Cattaraugus County Health Department, which also independently analyzes a sample of WVDP drinking water every month to determine bacterial and residual chlorine content. Analysis of the microbiological samples collected in 2001 produced satisfactory results and the free chlorine residual measurements taken throughout the distribution system were positive on all occasions, indicating proper disinfection.

The WVDP regularly tests the site's drinking water for lead and copper in accordance with EPA and New York State Department of Health (NYSDOH) regulations. NYSDOH regulations allow a facility to reduce sampling from once a year to once every three years if three consecutive annual sampling campaigns produce results below the action level. Because sampling for lead and copper in 1997, 1998, and 1999 indicated that all results were below the action levels for these metals, the next scheduled sampling for lead and copper will be in 2002 .

The Cattaraugus County Health Department conducted its annual inspection of the WVDP water supply system on November 8, 2001. No findings or notices of violation were issued.

Toxic Substances Control Act (TSCA). TSCA regulates the manufacture, processing, distribution, and use of chemicals, including asbestos-containing materials (ACM) and polychlorinated biphenyls (PCBs).

Asbestos-Containing Material (ACM). In 2001 the WVDP continued to maintain compliance with all TSCA requirements pertaining to asbestos by managing asbestos-containing material at the site in accordance with the Asbestos Management Plan (West Valley Nuclear Services Co., October $26,1999)$. The plan was prepared to ensure compliance with TSCA requirements and includes requirements for limiting worker exposure to $\mathrm{ACM}$ and for asbestos-abatement projects, maintenance activities, and periodic surveillance inspections (at least once every three years). The plan also identifies the inventory and status of on-site ACM.

Activities in 2001 included the repair or abatement of damaged/friable ACM, removal of approximately 760 linear feet of ACM insulation from abandoned lines, removal of approximately 3,438 square feet of ACM insulation from abandoned tanks, and the maintenance of signs and labels to warn workers of asbestos-containing material. All activities associated with ACM are completed by personnel who are certified by the New York State Department of Labor (NYSDOL). WVNSCO maintains an asbestos-handling license issued by NYSDOL. 
Polychlorinated Biphenyls (PCBs). Because PCBs are regulated as a hazardous waste in New York State, the WVDP continued in 2001 to manage radioactively contaminated $\mathrm{PCB}$ waste as mixed waste and nonradioactive PCB waste as hazardous waste. Details concerning PCB-contaminated radioactive waste management, including a description of the waste and proposed treatment technologies and schedules, can be found in section 3.1.5 of the Site Treatment Plan, Fiscal Year 2001 Update (West Valley Nuclear Services Co., February 6, 2002).

To comply with TSCA and the PCB regulations, all operations associated with PCBs comply with the PCB and PCB-Contaminated Material Management Plan. The WVDP also maintains an annual document log that details PCB use and appropriate storage on-site and any changes in storage or disposal status. The WVDP complies with the regulations for the disposal of PCBs, which conditionally allow radioactive and nonradioactive PCB wastes to be stored for more than one year (40 CFR Parts 750 and 761).

National Environmental Policy Act (NEPA). The National Environmental Policy Act, as amended, establishes a national policy to ensure that protection of the environment is included in federal planning and decision making (Title I). Its goals are to prevent or to eliminate potential damage to the environment that could arise from federal legislative actions or proposed federal projects.

Nationwide Management of Waste. In May 1997 DOE Headquarters issued the Final Waste Management Programmatic Environmental Impact Statement (EIS) to evaluate nationwide management and siting alternatives for the treatment, storage, and disposal of five types of radioactive and hazardous waste. The alternatives address waste generated, stored, or buried over the next twenty years at fifty-four sites in the DOE complex.
The Final Waste Management Programmatic EIS was issued with the intent of developing and issuing separate records of decision for each type of waste analyzed. In 1998 the DOE issued records of decision for transuranic and non-wastewater hazardous waste. In 1999 the DOE issued the record of decision for high-level radioactive waste. This decision specifies that the WVDP high-level vitrified waste will remain in storage on-site until it is accepted for disposal at a geologic repository.

On February 25, 2000 the DOE issued its record of decision for the management of low-level radioactive waste and mixed low-level waste, including West Valley's wastes. Hanford and the Nevada Test Site were identified as the designated national DOE disposal sites for these waste types (Volume 65, Federal Register, p. 10061 [65 FR 10061). In 2001 West Valley successfully completed the program approval process for access to the Nevada Test Site, and on July 17, 2001 received approval to ship. The WVDP subsequently completed two low-level waste shipments to the Nevada Test Site in 2001, which were the first West Valley low-level waste shipments made to a non-commercial disposal site.

Completion of the WVDP and Closure of the WNYNSC. The DOE and NYSERDA resumed efforts in 2001 to reach agreement on a preferred alternative and agency responsibilities for completion of the WVDP and closure or long-term management of the WNYNSC. Also in 2001, DOE formally initiated its plan to revise the scope of the existing EIS by splitting that scope into two separate documents: one EIS for near-term waste management and one EIS for final decommissioning and/or long-term site stewardship.

DOE published a Federal Register Notice of Intent (NOI) in March 2001 (66 FR 16447) formally announcing its rescoping plan and preparation of the waste management EIS. A draft of DOE's 
EIS for waste management is being prepared for public review and comment.

DOE also published an Advance NOI in November 2001 (66 FR 56090) announcing DOE's commitment to begin work on the decommissioning and/or long-term stewardship EIS.

Migratory Bird Treaty Act. The WVDP monitors Project activities to ensure continued compliance with the requirements of both the Migratory Bird Treaty Act and the Endangered Species Act. A New York State Fish and Wildlife License allows the WVDP to remove nests of migratory birds as needed to avoid the potential spread of radioactive contamination or to otherwise protect the health and safety of Project employees and visitors. The WVDP's license (DWP01-004) was received from NYSDEC on January 23, 2001 and was effective from January 1, 2001 through December 31, 2001. A depredation license renewal was filed with NYSDEC in December 2001.

The WVDP periodically updates its information about the potential for federally listed or proposed endangered or threatened species to be in the vicinity of Project activities. This was last done via correspondence with the U.S. Fish and Wildlife Service in June 1999. Their reply on June 21, 1999, reconfirmed that "except for occasional transient individuals" no plant or animal species protected under the Endangered Species Act were known to exist at the WVDP. In 2002 a request was forwarded to the U.S. Fish and Wildlife Service requesting an update of the status of endangered and threatened (or proposed candidate species) and critical habitats that may be present in the areas of Cattaraugus and Erie Counties in New York.

\section{Current Achievements and Program Highlights}

The WVDP's successful high-level waste vitrification program is one of only two such programs operating in the nation.

Phase II Vitrification. Phase II of vitrification, processing the high-level waste residuals (heels) in storage tank 8D-2, continued in 2001. Ten glass canisters were filled during this phase of operation, bringing the total number processed to 264 canisters since operations began in 1996.

Considerable progress has been made in the development and deployment of radiological instrumentation for remote surveying and sampling of the interior surfaces of the high-level waste tank 8D-2. This includes the use of beta/gamma detection systems, a gamma camera, neutron detectors, and use of a burnishing sampler tool. Access to the tank is through tank riser openings. These devices are moved within the tank using remote-controlled arms. Data acquired through the use of these devices will yield technical information about tank contents necessary for future decision making.

Additional noteworthy activities associated with the high-level waste include an acid flush of the vitrification waste header, an acid soak of tank $8 \mathrm{D}-4$, the development of a waste treatment plan to address isolation of sodium-bearing waste from high-level waste tanks 8D-1 and 8D-2, and reduction of radioactivity in the sodium-bearing waste by utilizing the supernatant treatment system and reducing the volume of residual waste via the liquid waste treatment system evaporator.

Integrated Safety Management System (ISMS). In August 2001 a self-assessment was conducted to confirm that the WVDP's integrated environmental, safety, and health management sys-

ECS - 15 
tem continued to function as verified in the DOE's annual review in February 2001. The WVDP continues to demonstrate its commitment to an allinclusive approach to safety through its safety programs and through ongoing efforts to strengthen its integrated safety management program by worker involvement in the safety program.

STAR Status. WVNSCO has reaffirmed its commitment to DOE's Voluntary Protection Program (VPP). During this reporting period, the annual VPP site evaluation was completed and submitted to DOE. WVNSCO also presented a workshop at the VPP Participants Association National Conference on our Interstate Zero Program. In addition, at the VPP Participants Association National Conference, WVNSCO was awarded DOE's Star of Excellence Award which is given to sites with outstanding safety records.

\section{U.S. EPA National Environmental Achieve-} ment Track. The WVDP was recognized as a top environmental leader in 2000 and was accepted into the EPA's National Environmental Achievement Track. The WVDP was awarded Charter Member status as part of the first group of applicants.

To qualify for the award the WVDP had to demonstrate that it voluntarily has adopted and implemented an environmental management system (EMS), has attained previous specific environmental achievements, has made a commitment to achieve four future goals, has a public outreach program, and has a sustained record of environmental compliance.

The WVDP's four commitments include:

- achieving a $62 \%$ reduction in hazardous waste generated over a three-year period from a baseline of $6,733 \mathrm{~kg} /$ year to $2,545 \mathrm{~kg} /$ year;

- reducing the generation of oily condensate wastewater from 1,600 gal/year to less than $100 \mathrm{gal} /$ year;
- removing 2,000 linear feet of asbestos; and

- reducing natural gas usage from 909,000 cubic feet per year to 800,000 cubic feet per year, and reducing electrical usage from 2,008,679 kilowatt hours per month to $1,800,000$ kilowatt hours per month.

In 2001 the WVDP made significant progress in these commitments by:

- completing the asbestos reduction goal in its entirety;

- achieving a hazardous waste reduction equivalent to $81 \%$ from the baseline of $6,733 \mathrm{~kg}$ for 2001 ;

- achieving the targeted annual goal for reduction of electrical usage; and

- realizing a cost avoidance of $3.3 \%$ for both electrical and gas usage as a result of installing the heating, ventilation, and air conditioning tracking database and optimizing all set points.

\section{Environmental Management System (EMS).} WVNSCO's environmental management system comprises procedures that provide the basic policy and direction for accomplishing work through proactive management, environmental stewardship, and the integration of appropriate technologies across all Project functions. Environmental management is integrated with other safety management and work planning processes at the WVDP through the integrated environmental, health, and safety management program.

The WVNSCO EMS satisfies the requirements of both the Code of Environmental Management Principles (CEMP) for federal agencies and International Organization for Standardization (ISO) 14001, Environmental Management Systems: Specifications for Guidance and Use, which are 
the two major frameworks for environmental management systems. The CEMP was developed by the EPA in response to Executive Order 12856, Federal Compliance with Right-to-Know Laws and Pollution Prevention Requirements. It embodies the principles and underlying performance objectives that are the basis for responsible environmental management. ISO 14001 is an EMS comparable to the CEMP.

\section{Environmental Issues and Actions}

Closed Landfill Maintenance. Closure of the on-site nonradioactive construction and demolition debris landfill (CDDL) was completed in August 1986. The landfill area was closed in accordance with NYSDEC requirements for this type of landfill, following a closure plan (Standish 1985) approved by NYSDEC. To meet routine post-closure requirements, the CDDL cover was inspected twice in 2001 and found to be in generally good condition. The grass cover on the clay and soil cap is routinely maintained and cut, and drainage is maintained to ensure that no obvious ponding or soil erosion occurs.

\section{Release of Materials Containing Residual} Radioactivity. The release of property containing residual radioactivity from DOE facilities is carefully controlled by DOE guidelines and procedures. In two special memoranda issued in January and July of 2000, the Secretary of Energy placed a moratorium on the release of contaminated materials and on the unrestricted release, for recycling, of metal from radiological areas within DOE facilities. The moratorium will remain in effect until directives clarifying the release criteria have been developed and implemented. Any transfer that places property (real property, structures, equipment, or scrap metal) containing radioactivity into public use is classified as a type of environmental release.
In keeping with DOE initiatives to expand environmental information provided to the public, certain details of transfers of property containing residual radioactivity are to be included in annual site environmental reports. The information provided should include, among other things, the type of material and the amount of residual radioactivity, the basis for releasing the property for public use (including release limits and when the property was released), the end use and cost savings associated with release of the property, and potential doses to individuals and the potential collective dose to the public associated with each release. The WVDP did not release any property classified per DOE Order 5400.5 as material containing residual radioactivity in 2001. (See also the Release of Property Containing Residual Radioactive Material table [p. ECS-20].)

\section{Flood Protection: Water-Supply Dam Re-} pairs. In 1998 an inspection by NYSDEC of the site's two water-supply reservoir dams and the emergency spillway showed that a localized area near dam \#1 had slumped and, although the dam was structurally sound, repairs were needed. Plans and permit applications for the repairs and improvements were filed with NYSDEC and the Corps of Engineers in October 2000. NYSDEC concurred with the plans and the Corps determined that no permit was required. Work began in the fall of 2000 and was completed in spring 2001. NYSDEC completed its inspection of the repairs to dam \#1 and no deficiencies were identified.

\section{Completion of the WVDP and Closure of the} WNYNSC. Although ongoing negotiations conducted between the DOE and NYSERDA to date have not resulted in agreement on long-term cleanup responsibilities, both parties remain committed to accomplishing important goals. These include shipping the 125 spent fuel assemblies to Idaho; completing high-level waste vitrification; and completing environmental impact statement 
analyses to support decisions on waste management, site decommissioning, and/or long-term stewardship. (See also p. ECS-14.) Other important Project goals include safely managing lowlevel waste, constructing the Remote-Handled Waste Facility, and managing contaminated groundwater on the north plateau.

Low-Level Radioactive Waste Shipment. An event involving low-level radioactive waste shipped from the WVDP to the Nevada Test Site occurred on July 30, 2001 in West Wendover, Nevada. A breach in one of the waste containers allowed some absorbent material to be released from the container. No release of radioactive material from the waste containers occurred. (See also Lowlevel Waste Shipping Program in Chapter 1 [p. 112].) As a result of this event, an internal (WVDP) and external (DOE) review of the incident was conducted to determine root causes and contributing causes and to identify corrective actions to prevent such events in the future. A corrective action plan was developed and determined to be acceptable to allow resumption of waste shipments to the Nevada Test Site.

On-Site Contamination Event. During routine radiation work surveys conducted in mid-November 2001, fixed radioactivity was found on-site in unexpected locations close to the main process building. The small spots of contamination were limited to an area immediately north, and to a lesser extent southeast, of the main plant stack. Upon discovery, the area involved was promptly isolated and decontaminated. On-site personnel were surveyed and no personnel contamination was found. Additionally, environmental monitoring data were checked and the data indicated that contamination did not spread off-site.

An extensive investigation was carried out to determine the origin of the contamination. Careful evaluation of radiological monitoring data, opera- tions records, and meteorological (weather) information helped to confirm that the contamination was the result of small amounts of cesium-137 from the waste tank farm ventilation system dissolved in condensed water vapor being released from the main plant stack during late September and early October 2001. Although the radioactivity release rate was too low to result in any stack monitoring alarms and the total amount of radioactivity released was well within regulatory limits, an unusual combination of ventilation process and weather conditions did result in an unexpected local deposition of radioactivity. (See Unplanned Radiological Releases in Chapter 1 [p. 1-11].) Corrective measures were put into effect to help prevent condensation of water vapor in process ventilation lines and to preclude recurrence of such an event in the future.

\section{Project Assessment Activities in 2001}

As the primary contractor for the DOE at the WVDP, WVNSCO maintains a comprehensive review program for proposed and ongoing operations. Assessments are conducted through formal surveillances and informal programs. Formal surveillances monitor compliance with regulations, directives, and DOE Orders. The informal program is used to identify issues or potential problems that can be corrected immediately.

The local DOE Project office and other agencies with responsibilities for the WVDP also independently review various aspects of the environmental and waste management programs, as discussed in preceding sections. In 2001 overall results reflected continuing, well-managed environmental programs at the WVDP. 


\section{Compliance Tables}

DOE Headquarters uses environmental compliance summary information from sites across the DOE complex to compile national environmental summary reports. The tables on the following pages were prepared to assist in this compilation.

ECS - 19 


\section{Status of EPCRA Reporting in 2001}

EPCRASection

EPCRA302-303

EPCRA 304

EPCRA311-312

EPCRA 313
Description of Reporting

Planning Notification

Extremely Hazardous Substance

Release Notification

Material Safety Data Sheet/Chemical Inventory

Toxic Release Inventory Reporting
Status

Yes

Not Required

Yes

Yes

\section{Reportable Chemicals Above Threshold Planning Quantities Stored at the WVDP in 2001}

Anhydrous ammonia

Ferric hydroxide slurry

Hydrogen peroxide solution (35\%)

Liquid nitrogen

Lubricating oils

Portland cement

Silicon dioxide
Zinc bromide solution

Diesel fuel \#2

Gasoline

Ion-exchange media

Nitric acid

Sodium hydroxide

Sulfuric acid

ECS - 21 


\section{West Valley Demonstration Project Environmental Permits}

\begin{tabular}{|c|c|c|c|}
\hline $\begin{array}{l}\text { Permit Name } \\
\text { and Number }\end{array}$ & $\begin{array}{c}\text { Agency/Permit } \\
\text { Type }\end{array}$ & Description & 2001 Changes \\
\hline
\end{tabular}

\begin{tabular}{|c|c|c|c|c|}
\hline $\begin{array}{l}\text { West Valley } \\
\text { Demonstration Project } \\
\text { RCRA Part A Permit } \\
\text { Application }\end{array}$ & $\begin{array}{l}\text { NYSDEC/Hazardous } \\
\text { Waste }\end{array}$ & $\begin{array}{l}\text { Provides interim status } \\
\text { under RCRA for treatment } \\
\text { and storage of hazardous } \\
\text { waste }\end{array}$ & $\begin{array}{l}\text { Application changes } \\
\text { include remote- } \\
\text { handled waste facility, } \\
\text { contact size-reduction } \\
\text { facility, storage in } \\
\text { tanks 8D-1 and 8D-2, } \\
\text { and additional storage } \\
\text { and treatment } \\
\text { capacity. }\end{array}$ & $\begin{array}{l}\text { No expiration date. } \\
\text { Received letter from } \\
\text { NYSDEC that Part A } \\
\text { application modification is } \\
\text { complete and meets the } \\
\text { regulatory requirements. }\end{array}$ \\
\hline $\begin{array}{l}\text { Article } 19 \text { State } \\
\text { Facility Air Permit } \\
90422-00005 / 00091\end{array}$ & NYSDEC/Air Emissions & $\begin{array}{l}\text { Sitewide permit includes: } \\
\text { - } 1 \text { boiler } \\
\text { - cold chemical solids } \\
\text { transfer system } \\
\text { - cold chemical vessel } \\
\text { vent system } \\
\text { - cold chemical vessel } \\
\text { dust collection hood } \\
\text { - vitrification facility } \\
\text { heating, ventilation, and air } \\
\text { conditioning (HVAC) } \\
\text { system } \\
\text { - vitrification off-gas } \\
\text { treatment system (melter) }\end{array}$ & None & $\begin{array}{l}\text { Effective } 6 / 1 / 00 . \text { No } \\
\text { expiration date. }\end{array}$ \\
\hline $\begin{array}{l}\text { Slurry-fed ceramic } \\
\text { melter (modification to } \\
\text { WVDP-687-01) } \\
\text { process building } \\
\text { ventilation }\end{array}$ & EPA/NESHAP & $\begin{array}{l}\text { Slurry-fed ceramic melter } \\
\text { radionuclide emissions }- \\
\text { main plant stack modified } \\
2 / 18 / 97\end{array}$ & None & $\begin{array}{l}\text { Permit approved 2/18/97. } \\
\text { No expiration date. } \\
\text { Request to modify } \\
\text { submitted to the EPA } 8 / 99\end{array}$ \\
\hline $\begin{array}{l}\text { Vitrification facility } \\
\text { HVAC system }\end{array}$ & EPA/NESHAP & $\begin{array}{l}\text { Vitrification facility HVAC } \\
\text { system for radionuclide } \\
\text { emissions }\end{array}$ & None & $\begin{array}{l}\text { Permit approved 2/18/97. } \\
\text { No expiration date. }\end{array}$ \\
\hline $\begin{array}{l}01-14 \text { building } \\
\text { ventilation system } \\
\text { (WVDP-187-01) }\end{array}$ & EPA/NESHAP & $\begin{array}{l}\text { Liquid waste treatment } \\
\text { system ventilation of } \\
\text { radionuclide emissions in } \\
\text { the } 01-14 \text { building }\end{array}$ & None & $\begin{array}{l}\text { Issued } 10 / 5 / 87 . \text { Modified } \\
5 / 25 / 89 . \text { No expiration } \\
\text { date. }\end{array}$ \\
\hline
\end{tabular}




\section{West Valley Demonstration Project Environmental Permits (concluded)}

\begin{tabular}{|c|c|c|c|c|}
\hline $\begin{array}{l}\text { Permit Name } \\
\text { and Number }\end{array}$ & $\begin{array}{c}\text { Agency/Permit } \\
\text { Type }\end{array}$ & Description & 2001 Changes & Status \\
\hline $\begin{array}{l}\text { Contact size-reduction } \\
\text { facility (WVDP-287- } \\
01 \text { ) }\end{array}$ & EPA/NESHAP & $\begin{array}{l}\text { Contact size-reduction and } \\
\text { decontamination facility } \\
\text { radionuclide emissions }\end{array}$ & None & $\begin{array}{l}\text { Issued } 10 / 5 / 87 \text {. No } \\
\text { expiration date. }\end{array}$ \\
\hline $\begin{array}{l}\text { Supernatant treatment } \\
\text { system/Permanent } \\
\text { ventilation system } \\
\text { (WVDP-387-01) }\end{array}$ & EPA/NESHAP & $\begin{array}{l}\text { Supernatant treatment } \\
\text { system ventilation for } \\
\text { radionuclide emissions }\end{array}$ & None & $\begin{array}{l}\text { Revised 1/1/97. No } \\
\text { expiration date. }\end{array}$ \\
\hline $\begin{array}{l}\text { Outdoor ventilated } \\
\text { enclosures (WVDP- } \\
587-01 \text { ) }\end{array}$ & EPA/NESHAP & $\begin{array}{l}\text { Ten portable ventilation } \\
\text { units for removal of } \\
\text { radionuclides }\end{array}$ & None & $\begin{array}{l}\text { Issued } 12 / 22 / 87 \text {. No } \\
\text { expiration date. }\end{array}$ \\
\hline $\begin{array}{l}\text { State Pollutant } \\
\text { Discharge Elimination } \\
\text { System } \\
\text { (NY-0000973) }\end{array}$ & NYSDEC/Water & $\begin{array}{l}\text { Covers discharges to } \\
\text { surface waters from } \\
\text { various on-site sources }\end{array}$ & $\begin{array}{l}\text { Renewed effective } \\
2 / 1 / 99 . \text { Expires } \\
\text { 2/1/04. Draft permit } \\
\text { modification issued } \\
\text { for public comment } \\
\text { on December } 11 \text {, } \\
2001 \text {. }\end{array}$ & $\begin{array}{l}\text { NYSDEC has prepared a } \\
\text { draft permit modification } \\
\text { for a groundwater recovery } \\
\text { system discharge increase. } \\
\text { Permit terms for } \\
\text { NYSERDA and DOE } \\
\text { responsibilities related to } \\
\text { storm water discharges are } \\
\text { being negotiated with } \\
\text { NYSDEC. }\end{array}$ \\
\hline $\begin{array}{l}\text { Buffalo Pollutant } \\
\text { Discharge Elimination } \\
\text { System } \\
(01-04-T R 096)\end{array}$ & $\begin{array}{l}\text { Buffalo Sewer } \\
\text { Authority/Sanitary } \\
\text { sewage and sewage } \\
\text { sludge disposal }\end{array}$ & $\begin{array}{l}\text { Permit issued to hauler of } \\
\text { waste from the wastewater } \\
\text { treatment facility }\end{array}$ & Renewed 6/30/01. & $\begin{array}{l}\text { Hauler must renew permit } \\
\text { by } 6 / 30 / 02 \text {. }\end{array}$ \\
\hline $\begin{array}{l}\text { Fill Discharge Permit } \\
(94-973-29(4))\end{array}$ & $\begin{array}{l}\text { U.S. Army Corps of } \\
\text { Engineers/Water }\end{array}$ & $\begin{array}{l}\text { Buttermilk Creek culvert } \\
\text { repairs and railroad spur } \\
\text { improvements }\end{array}$ & None & $\begin{array}{l}\text { Issued 4/27/00. Expires } \\
4 / 27 / 05 \text {. }\end{array}$ \\
\hline $\begin{array}{l}\text { Freshwater Wetlands } \\
\text { Permit and Water } \\
\text { Quality Certification } \\
(9-0422-00005 / 00093)\end{array}$ & NYSDEC/Water & $\begin{array}{l}\text { Buttermilk Creek culvert } \\
\text { repairs and railroad spur } \\
\text { improvements }\end{array}$ & None & $\begin{array}{l}\text { Issued 3/31/00. Expires } \\
\text { 4/1/05. }\end{array}$ \\
\hline $\begin{array}{l}\text { Chemical Bulk Storage } \\
(9-000158)\end{array}$ & $\begin{array}{l}\text { NYSDEC/Chemical } \\
\text { bulk storage tank }\end{array}$ & $\begin{array}{l}\text { Registration of bulk } \\
\text { storage tanks used for } \\
\text { listed hazardous chemicals }\end{array}$ & None & $\begin{array}{l}\text { Permit expires } 7 / 5 / 03 \text {. Will } \\
\text { renew before expiration. }\end{array}$ \\
\hline $\begin{array}{l}\text { Petroleum bulk storage } \\
(9-008885)\end{array}$ & $\begin{array}{l}\text { NYSDEC/Petroleum } \\
\text { bulk storage tank } \\
\text { registration }\end{array}$ & $\begin{array}{l}\text { Registration of bulk } \\
\text { storage tanks used for } \\
\text { petroleum }\end{array}$ & None & $\begin{array}{l}\text { Registration expires } \\
\text { 9/2/06. Will renew before } \\
\text { expiration. }\end{array}$ \\
\hline $\begin{array}{l}\text { Bird depredation } \\
\text { license (DWP01-004) }\end{array}$ & $\begin{array}{l}\text { New York State } \\
\text { Division of Fish and } \\
\text { Wildlife }\end{array}$ & $\begin{array}{l}\text { State license for the } \\
\text { removal of inactive nests of } \\
\text { migratory birds }\end{array}$ & License renewed. & $\begin{array}{l}\text { CY } 2001 \text { NYS license } \\
\text { expired 12/31/01. License } \\
\text { for } 2002 \text { became effective } \\
4 / 5 / 02 \text {. }\end{array}$ \\
\hline
\end{tabular}

\section{ECS - 23}


This page intentionally left blank

$$
\text { ECS - } 24
$$




\section{ENVIRONMENTAL PROGRAM INFORMATION}

\section{Introduction}

The high-level radioactive waste (HLW) presently stored at the Western New York Nuclear Service Center (WNYNSC) on the West Valley Demonstration Project (WVDP) premises is the byproduct of the reprocessing of spent nuclear fuel during the late 1960s and early 1970s, when the WNYNSC was leased by Nuclear Fuel Services, Inc. (NFS) for a commercial nuclear fuel reprocessing facility.

As the WNYNSC is no longer an active nuclear fuel reprocessing facility, the environmental monitoring program focuses on measuring radioactivity and chemicals associated with the residual by-products of NFS operations and the Project's high-level waste treatment and low-level waste management operations. The following information about the operations at the WVDP and about radiation and radioactivity will be useful in understanding the activities of the Project and the terms used in reporting the results of environmental testing measurements.

Radiation and Radioactivity. Radioactivity is a characteristic of some elements that have unstable atomic nuclei which spontaneously disintegrate or "decay" into atomic nuclei of another isotope or element. (See isotope [p. GLO-5] in the Glossary.) The nuclei decay until only a stable, nonradioactive isotope remains. Depending on the isotope, this process can take anywhere from less than a second to billions of years.

As atomic nuclei decay, radiation is released in three main forms: alpha particles, beta particles, and gamma rays. By emitting energy or particles, the nucleus moves toward a less energetic, more stable state.

Alpha Particles. An alpha particle, released by decay, is a fragment of a much larger nucleus. It consists of two protons and two neutrons (similar to the nucleus of a helium atom) and is positively charged. Compared to beta particles, alpha particles are relatively large and heavy and do not travel very far when ejected by a decaying nucleus. Alpha radiation, therefore, is easily stopped by a thin layer of material such as paper or skin. However, if radioactive material is ingested or inhaled, the alpha particles released inside the body can damage soft internal tissues because all of their energy is absorbed by tissue cells in the immediate vicinity of the decay. An example of an alphaemitting radionuclide is the uranium isotope with an atomic weight of 232 (uranium-232). Uranium232 is in the high-level waste mixture at the WVDP as a result of a thorium-based nuclear fuel reprocessing campaign conducted by NFS and has been previously detected in liquid waste streams. 


\section{Radioactivity}

Atoms that emit radiation are called radionuclides. Radionuclides are unstable isotopes that have the same number of protons as any other isotope of the element but different numbers of neutrons, resulting in different atomic masses. For example, the element hydrogen has two stable isotopes, $\mathrm{H}-1$ and $\mathrm{H}-2$ (deuterium), and one radioactive isotope, $\mathrm{H}-3$ (tritium). The numbers following the element's symbol identify the atomic mass, which is the number of protons plus neutrons in the nucleus. Thus, $H-1$ has one proton and no neutrons, H-2 has one proton and one neutron, and H-3 has one proton and two neutrons.

When radioactive atoms decay by emitting radiation, the daughter products that result may be either radioactive or stable. Generally, radionuclides with high atomic numbers, such as uranium-238 and plutonium-239, have many generations of radioactive progeny. For example, the radioactive decay of plutonium-239 creates uranium-235, thorium-231, protactinium-231, and so on through eleven progeny until only the stable isotope lead-207 remains.

Radionuclides with lower atomic numbers often have no more than one daughter. For example, strontium-90 has one radioactive daughter, yttrium-90, which finally decays into stable zirconium; cobalt-60 decays directly to stable nickel with no intermediate nuclide.

The time required for half of the radioactivity of a radionuclide to decay is referred to as the radionuclide's half-life. Each radionuclide has a unique half-life; both strontium-90 and cesium-137 have half-lives of approximately 30 years while plutonium-239 has a half-life of 24,400 years. Knowledge of radionuclide half-lives is often used to estimate past and future inventories of radioactive material. For example, a 1.0-millicurie source of cesium-137 in 2000 would have measured 2.0 millicuries in 1970 and will be 0.5 millicuries in 2030.

Radiation emitted by radionuclides may consist of electromagnetic rays such as $x$-rays and gamma rays or charged particles such as alpha and beta particles. A radionuclide may emit one or more of these radiations at characteristic energies that can be used to identify them.

\section{Background Radiation}

Background radiation is always present, and everyone is constantly exposed to low levels of such radiation from both naturally occurring and manmade sources. In the United States the average total annual exposure to low-level background radiation is estimated to be about 360 millirem (mrem) or 3.6 millisieverts $(\mathrm{mSv})$. Most of this radiation, approximately 295 mrem $(2.95 \mathrm{mSv})$, comes from natural sources. The rest comes from medical procedures, consumer products, and other manmade sources. (See Figure 4-1 [p. 4-2] in Chapter 4, Radiological Dose Assessment.)

Background radiation includes cosmic rays, the decay of natural elements such as potassium, uranium, thorium, and radon, and radiation from sources such as chemical fertilizers, smoke detectors, and televisions. Actual doses vary depending on such factors as geographic location, building ventilation, and personal health and habits. 
Beta Particles. A beta particle is an electron that results from the breakdown of a neutron in a radioactive nucleus. Beta particles are small compared with alpha particles, travel at a higher speed (close to the speed of light), and can be stopped by a material such as wood or aluminum less than an inch thick. If beta particles are released inside the body they do much less damage than an equal number of alpha particles. Because they are smaller and faster and have less of a charge, beta particles deposit energy in tissue cells over a larger volume than alpha particles. Strontium-90, a fission product, is an example of a beta-emitting radionuclide. (See fission [p. GLO-4] in the Glossary.) Strontium-90 is found in the stabilized supernatant.

Gamma Rays. Gamma rays are high-energy "packets" of electromagnetic radiation, called photons, that are emitted from the nucleus. They are similar to x-rays but generally have a shorter wavelength and therefore are more energetic than x-rays. If the alpha or beta particle released by the decaying nucleus does not carry off all the energy generated by the nuclear disintegration, the excess energy may be emitted as gamma rays. If the released energy is high, a very penetrating gamma ray is produced that can be effectively reduced only by shielding consisting of several inches of a heavy element, such as lead, or of water or concrete several feet thick. Although large amounts of gamma radiation are dangerous, gamma rays are also used in many lifesaving medical procedures. An example of a gamma-emitting radionuclide is barium-137m, a short-lived daughter product of cesium-137. Both barium-137m and cesium-137 are major constituents of the WVDP high-level radioactive waste.

Measurement of Radioactivity. The rate at which radiation is emitted from a disintegrating nucleus can be described by the number of decay events or nuclear transformations that occur in a radioactive material over a fixed period of time. This process of emitting energy, or radioactivity, is measured in curies $(\mathrm{Ci})$ or becquerels $(\mathrm{Bq})$.

The curie is based on the decay rate of the radionuclide radium-226 (Ra-226). One gram of radium-226 decays at the rate of 37 billion nuclear disintegrations per second $(3.7 \mathrm{E}+10 \mathrm{~d} / \mathrm{s})$, so one curie equals 37 billion nuclear disintegrations per second. One becquerel equals one decay, or disintegration, per second. (See the Scientific Notation section at the back of this report [UOM-2] or p. 1-5 of this chapter for information on exponentiation [i.e., the use of "E" to mean the power of 10].)

Very small amounts of radioactivity are sometimes measured in picocuries. A picocurie is one-trillionth (1E-12) of a curie, equal to 3.7E-02 disintegrations per second, or 2.22 disintegrations per minute.

Measurement of Dose. The amount of energy absorbed by the receiving material is measured in rads (radiation absorbed dose). A rad is $100 \mathrm{ergs}$ of radiation energy absorbed per gram of material. (An erg is the approximate amount of energy necessary to lift a mosquito one-sixteenth of an inch.) "Dose" is a means of expressing the amount of energy absorbed, taking into account the effects of different kinds of radiation.

Alpha, beta, and gamma radiation affect the body to different degrees. Each type of radiation is given a quality factor that indicates the extent of human cell damage it can cause compared with equal amounts of other ionizing radiation energy. Alpha particles cause twenty times as much damage to internal tissues as X-rays, so alpha radiation has a quality factor of 20 , compared to gamma rays, $x$-rays, or beta particles, all of which have a quality factor of 1 .

The unit of dose measurement to humans is the rem (roentgen-equivalent-man). The number of 
rem are equal to the number of rad multiplied by the quality factor for each type of radiation. Dose can also be expressed in sieverts. One sievert equals 100 rem.

\section{Environmental Monitoring Program Overview}

Exposure of human beings to radioactivity would be primarily through air, water, and food. At the WVDP all three pathways are monitored, but air and surface water pathways are the two primary means by which radioactive material can move off-site.

The geology of the site (types of soil and bedrock), the hydrology (location and flow of surface water and groundwater), and meteorological characteristics of the site (wind speed, patterns, and direction) are all considered in evaluating potential exposure through the major pathways.

The on-site and off-site monitoring program at the WVDP includes measuring the concentration of alpha and beta radioactivity, conventionally referred to as "gross alpha" and "gross beta," in air and water effluents. Measuring the total alpha and beta radioactivity from key locations, which can be done within a matter of hours, produces a comprehensive picture of on-site and off-site levels of radioactivity from all sources. For a DOE site such as the WVDP, frequent updating and tracking of the overall levels of radioactivity in effluents is an important tool in maintaining acceptable operations.

More detailed measurements are also made for specific radionuclides. Strontium-90 and cesium137 are measured because they have been previously detected in WVDP waste materials. Radiation from other important radionuclides such as tritium or iodine-129 is not sufficiently energetic to be detected by gross measurement tech- niques, so these must be analyzed separately using methods with greater sensitivity. Heavy elements such as uranium, plutonium, and americium require special analysis to be measured because they exist in such small concentrations in the WVDP environs.

The radionuclides monitored at the Project are those that might produce relatively higher doses or that are most abundant in air and water effluents. Because manmade sources of radiation at the Project have been decaying for more than thirty years, the monitoring program does not routinely include short-lived radionuclides, that is, isotopes with a half-life of less than two years, which would have less than $1 / 1,000$ of the original radioactivity remaining. (See Appendix B [pp. B-1 through B-44] for the schedule of samples and radionuclides measured and Appendix K, Table K-1 [p. K-3] for a listing of the half-lives of radionuclides measured in WVDP samples and related Department of Energy [DOE] protection standards, such as the derived concentration guides [DCGs]. See also the discussion of DCGs [facing page].)

Data Reporting. Because the decay of radioactive atoms is a random process, there is an inherent uncertainty associated with all measurements of environmental radioactivity. This can be demonstrated by repeatedly measuring the number of atoms that decay in a radioactive sample over some fixed period of time. The result of such an experiment would be a range of values for which the average value would provide the best indication of how many radioactive atoms were present in the sample.

However, in actual practice an environmental sample usually is measured for radioactivity only once. The inherent uncertainty of the measurement, then, stems from the fact that it cannot be known whether the result that was obtained from 


\section{Derived Concentration Guides}

A derived concentration guide (DCG) is defined by the DOE in DOE Order 5400.5 as the concentration of a radionuclide in air or water that, under conditions of continuous exposure by one exposure mode (i.e., ingestion of water, submersion in air, or inhalation) for one year, would result in an effective dose equivalent of 100 mrem $(1 \mathrm{mSv})$ to a "reference man." These concentrations - DCGs - are used as reference screening levels to enable WVDP personnel reviewing effluent and environmental data to decide if further investigation is needed. (See Table K-1, Appendix K [p. K-3] for a list of DCGs.)

For liquid effluent screening purposes, the percentages of the DCGs for all radionuclides present are summed. If the total is less than 100\%, then the effluent released complies with the DOE guideline. DCGs are also compared with radionuclide concentrations from these sources to verify that Best Available Technology standards for treatment of water are being met.

The DOE provides DCGs for airborne radionuclides in locations where members of the public could, over an extended period of time, breathe air containing contaminants. DCGs are only applicable to radionuclides in air breathed by members of the public. DCGs may be used as a basis for screening concentrations from air emission points.

DOE Orders require that the hypothetical dose to the public from facility effluents be estimated using specific computer codes. (See Dose Assessment Methodology [p. 4-3] in Chapter 4, Radiological Dose Assessment.) Doses estimated for WVDP activities are calculated using actual site data and are not related directly to summed DCG values. Dose estimates for liquid effluents are based on the product of radionuclide quantities released and the site-specific dose equivalent effects for that radionuclide. Although airborne DCGs are used for comparison purposes, the more stringent U.S. Environmental Protection Agency (EPA) National Emission Standards for Hazardous Air Pollutants (NESHAP) regulate Project airborne effluents at the point of release. For a consistent guide to relative concentrations, both air and water sampling results are compared with DCGs throughout this report.

one measurement is higher or lower than the "true" value.

The term confidence interval is used to describe the range of measurement values above and below the test result within which the "true" value is expected to lie. This interval is derived statistically. The width of the interval is based primarily on a predetermined confidence level, that is, the probability that the confidence interval actually encompasses the "true" value. The WVDP environmental monitoring program uses a 95\% confidence level for all radioactivity measurements and calculates confidence intervals accordingly.
The confidence interval around a measured value is indicated by the plus-or-minus ( \pm ) value following the result (e.g., $5.30 \pm 3.6 \mathrm{E}-09 \mu \mathrm{Ci} / \mathrm{mL}$ ), with the exponent of $10^{-9}$ expressed as "E-09." Expressed in decimal form, the number 5.30 $\pm 3.6 \mathrm{E}-09$ would be $0.00000000530 \pm 0.0000000036 \mu \mathrm{Ci} / \mathrm{mL}$. A sample measurement expressed this way is correctly interpreted to mean "there is a 95\% probability that the concentration of radioactivity in this sample is between 1.7E-09 $\mu \mathrm{Ci} / \mathrm{mL}$ and $8.9 \mathrm{E}-09 \mu \mathrm{Ci} / \mathrm{mL}$." (See also Scientific Notation [p. UOM-2] at the end of this report.) If the confidence interval for the measured value includes zero (e.g., $5.30 \pm 6.5 \mathrm{E}-09 \mu \mathrm{Ci}$ / $\mathrm{mL}$ ), the value is considered to be below the detec- 
tion limit. The values listed in tables of radioactivity measurements in the appendices include the confidence interval regardless of the detection limit value.

In general, the detection limit is the minimum amount of constituent or material of interest detected by an instrument or method that can be distinguished from background and instrument noise. Thus, the detection limit is the lowest value at which a sample result shows a statistically positive difference from a sample in which no constituent is present. (Maximum and minimum values in data sets showing positive results have been set in boldface type in the data appendices at the back of this report; the key to this convention is described at the beginning of each appropriate appendix.)

Nonradiological data conventionally are presented without an associated uncertainty and are expressed by the detection limit prefaced by a "lessthan" symbol $(<)$ if that analyte was not measurable. (See also Data Assessment and Reporting [p. 5-7] in Chapter 5, Quality Assurance.)

Changes in the 2001 Environmental Monitoring Program. Several modifications to the environmental sampling and surveillance network were made in 2001 to better reflect current facility status.

- Work is no longer being done in the former lowlevel waste treatment building. The building ventilation system and its air sampler (ANLLWTVH) have been shut down. Therefore no air samples were collected at this location during 2001.

- Water sampling at the waste tank farm underdrain (WN8D1DR) was discontinued in December 2001 at the direction of DOE. The location is not considered representative of the underground drainage system.
- The french drain water sampling point (WNSP008) was capped off in May 2001 to prevent the discharge of elevated levels of lead detected at this location. (See SPDES Permit Limit Exceptions [p. 1-18].)

- Due to a pending property sale, the community air sampler in West Valley (AFWEVAL) was relocated from a private residence to property of the West Valley Fire Department in November 2001.

- Monthly milk sampling was discontinued at location BFMCOBO in August 2001 when the local farmer stopped selling milk to commercial dairies and withdrew from the program.

See Appendix B for a summary of the program changes (p. B-iv) and the sample points and parameters measured in 2001 (pp. B-1 through B-44).

\section{Vitrification Overview}

High-level radioactive waste from NFS operations was originally stored in two of four underground tanks (tanks 8D-2 and 8D-4). The waste in 8D-2, the larger of the active tanks, had settled into two layers: a liquid - the supernatant - and a precipitate layer on the tank bottom - the sludge. To solidify the highlevel waste, WVDP engineers designed and developed a process of pretreatment and vitrification.

Pretreatment Accomplishments. The supernatant (in tank 8D-2) was composed mostly of sodium and potassium salts dissolved in water. Radioactive cesium in solution accounted for more than $99 \%$ of the total radioactivity in the supernatant. During pretreatment, sodium salts and sulfates were separated from the radioactive constituents in both the liquid portion of the high-level waste and the sludge layer in the bottom of the tank.

Pretreatment of the supernatant began in 1988. The integrated radwaste treatment system (IRTS) 
reduced the volume of the high-level waste needing vitrification by producing low-level waste stabilized in cement: The supernatant was passed through zeolite-filled ion exchange columns in the supernatant treatment system (STS) to remove more than $99.9 \%$ of the radioactive cesium. The resulting liquid was then concentrated by evaporation in the liquid waste treatment system (LWTS). This low-level radioactive concentrate was blended with cement in the cement solidification system (CSS) and placed in 71-gallon (269liter) steel drums. The cement-stabilized waste form has been accepted by the U.S. Nuclear Regulatory Commission (NRC).

The steel drums were stored in an on-site aboveground vault, the drum cell. (See Fig. A-1 [p. A-3].) Processing of the supernatant was completed in 1990, with more than 10,000 drums of cemented waste produced.

The sludge that remained was composed mostly of iron hydroxide. Strontium-90 accounted for most of the radioactivity in the sludge. Pretreatment of the sludge layer in high-level waste tank 8D-2 began in 1991. Five specially designed 50-footlong pumps were installed in the tank to mix the sludge layer with water to produce a uniform sludge blend and to dissolve the sodium salts and sulfates that would interfere with vitrification. After mixing and allowing the sludge to settle, processing of the wash water through the IRTS began. Processing removed radioactive constituents for later solidification into glass, and the wash water containing salt was then stabilized in cement.

Sludge washing was completed in 1994 after approximately 765,000 gallons (2.9 million liters) of wash water had been processed. About 8,000 drums of cement-stabilized wash water were produced. In January 1995, high-level waste liquid stored in tank 8D-4 was transferred to tank 8D-2. (Tank 8D-4 contained THOREX high-level radio- active waste, which had been produced by a single reprocessing campaign of a special fuel containing thorium that had been conducted from November 1968 to January 1969 by the previous facility operators.) The resulting mixture was washed and the wash water was processed. The IRTS processing of the combined wash waters was completed in May 1995.

In all, through the supernatant treatment process and the sludge wash process, more than 1.7 million gallons ( 6.4 million liters) of liquid had been processed by the end of 1995 , producing a total of 19,877 drums of cemented low-level waste. These drums are stored in the drum cell.

As one of the final steps, the ion-exchange material (zeolite) used in the IRTS to remove radioactivity was blended with the washed sludge before being transferred to the vitrification facility for blending with the glass-formers. In 1995 and early 1996 final waste transfers to high-level waste tank 8D-2 were completed in preparation for vitrification.

Preparation for Vitrification. Nonradioactive testing of a full-scale vitrification system was conducted from 1984 to 1989 . In 1990 all vitrification test equipment was removed to allow installation of shield walls for remote radioactive operations. The walls and shielded tunnel connecting the vitrification facility to the former reprocessing plant were completed in 1991. The slurry-fed ceramic melter was assembled, bricked, and installed in 1993, and the cold chemical building was completed, as was the sludge mobilization system that transfers high-level waste to the melter. This system was tested in 1994. Several additional major systems components also were installed in 1994: the canister turntable, which positions the stainless steel canisters as they are filled with molten glass; the submerged bed scrubber, which cleans gases produced by the vitrification process; and the transfer cart, which moves filled canisters to the storage area. 
Nonradiological testing ("cold" operations) of the vitrification facility began in 1995, and the first canister of nonradiological glass was produced. The WVDP declared its readiness to proceed with the necessary equipment tie-ins of the ventilation and utility systems to the vitrification facility building and tie-ins of the transfer lines to and from the high-level waste tank farm and the vitrification facility. In this closedloop system, the transfer lines connect to multiple common lines so that material can be moved among all the points in the system.

High-level waste vitrification began in 1996. Phase I, which saw the majority of the high-level liquid waste vitrified, was completed in mid-1998. Phase II, removing and vitrifying residual radioactivity, continued throughout 2001. (See Vitrification [below].)

\section{Activities at the WVDP}

The WVDP's environmental management system is an important factor in the environmental monitoring program and the accomplishment of its mission. Significant components, initiatives, and pertinent information about the work accomplished at the WVDP in 2001 are summarized below.

Vitrification. Solidification of the high-level waste in glass continued in 2001. The high-level waste mixture of washed sludge and spent zeolite from the ion-exchange process is combined in batches with glass-forming chemicals and then fed to a ceramic melter. The waste mixture is heated to approximately $2,000^{\circ} \mathrm{F}$ and poured into stainless steel canisters. Approximately 300 stainless steel canisters eventually will be needed to hold all of the vitrified waste. Each canister, 10 feet long by 2 feet in diameter, is filled with a uniform, highlevel waste glass that will be suitable for eventual shipment to a federal repository. During Phase I (June 1996 to June 1998) 210 canisters were filled. In 2001 more than 0.15 million curies of radioactivity were transferred to the vitrification facility and ten high-level waste canisters were produced. Since the beginning of vitrification in 1996 through calendar year 2001, 264 high-level waste canisters have been filled and more than 11 million cesium/strontium curies have been transferred to the vitrification facility and vitrified.

Tank Cleaning and Characterization. The recovery of the remaining waste has been challenging primarily due to the complex internal structural support system within the tanks. In 2001, two remotely operable tool deployment systems were installed in the main tank - tank 8D-2. From these two access points, remotely operated sluicers guided by video cameras were used to wash more than 80 percent of the tank's interior surfaces.

Several innovative characterization technologies deployed in tank 8D-2 include a burnishing sampler, a gamma camera, and a beta/gamma detection system. The burnishing sampler scours material from the tank surfaces and draws this residual material into a sample collection device for laboratory analysis. The gamma camera was used to map the tank interior for areas of cesium137 accumulation. The beta/gamma detector system was used to scan the vertical tank walls to determine levels of fixed surface contamination.

Decontamination and Decommissioning. Initial decontamination efforts in the main plant are focusing on the process mechanical cell and the general purpose cell to place the cells in a safer configuration for future facility decommissioning. After a readiness assessment was completed, decontamination and decommissioning (D\&D) work began in the process mechanical cell during September 2001. Additional D\&D projects completed during 2001 included decontamination of the acid recovery pump room and the decontamination, dismantlement, and packaging of a large glove box that was used during Nuclear Fuel Services reprocessing operations. 
Preparation for Spent Fuel Shipping. A significant achievement during 2001 was the loading of 125 spent nuclear fuel assemblies remaining from former fuel reprocessing operations into two specially designed casks for rail shipment to Idaho. The WVDP worked with the NRC to allow fullload shipments, resulting in one shipment instead of two. The casks are currently staged on-site, awaiting shipment to the Idaho National Engineering and Environmental Laboratory.

\section{Remote-Handled Waste Facility Construction.}

As part of project operations, various contaminated materials/components have been removed from the former Process Building and are in storage awaiting disposal. In addition, as efforts increase toward eventual decommissioning, additional materials and components will be removed from the Waste Tank Farm and the former Process Building. Before these waste materials can be shipped for disposal, they have to be characterized, sorted, processed as necessary, and packaged to meet regulatory requirements for transportation. The Remote-Handled Waste Facility (RHWF) is a new facility which will be used to process and package these highly contaminated, highactivity, solid radioactive wastes. Construction of the Remote-Handled Waste Facility started in September 2000 and continued throughout 2001 . The facility is currently scheduled to begin operations sometime in calendar year 2004.

Environmental Management of Aqueous Radioactive Waste. Water containing radioactive material from site process operations is collected and treated in the low-level waste treatment facility (LLWTF). (Water from the sanitary system, which does not contain added radioactive material, is managed in a separate system.)

The treated process water is held, sampled, and analyzed before it is released through a New York State Pollutant Discharge Elimination System (SPDES)-permitted outfall. In 2001, 8.4 million gallons (31.9 million liters) of water were treated in the LLWTF system, which includes the lowlevel waste treatment building (LLW2) and associated holding lagoons, and discharged through outfall 001, the lagoon 3 weir. The discharge waters contained an estimated 13.2 millicuries of gross alpha plus gross beta radioactivity. Comparable releases during the previous sixteen years averaged about 37 millicuries per year. The 2001 release was about $36 \%$ of this average. (See Radiological Monitoring: Surface Water, Low-level Waste Treatment Facility Sampling Location [p. 2-3] in Chapter 2.)

Approximately 0.11 curies of tritium were released in WVDP liquid effluents in 2001 - about $9 \%$ of the sixteen-year average of 1.30 curies.

Environmental Management of Airborne Radioactive Emissions. Ventilated air from the various points in the IRTS process (high-level waste sludge treatment, main plant and liquid waste treatment system, and the cement solidification system) and from other waste management activities is sampled continuously during operation for both particulate matter and for gaseous radioactivity. In addition to monitors that alarm if particulate matter radioactivity increases above pre-set levels, the sample media are analyzed in the laboratory for the specific radionuclides that are present in the radioactive materials being handled.

Air used to ventilate the facilities where radioactive material cleanup processes are operated is passed through filtration devices before being emitted to the atmosphere. These filtration devices are generally more effective for particulate matter than for gaseous radioactivity. For this reason, facility air emissions tend to contain a greater amount of gaseous radioactivity (e.g., tritium and iodine-129) than radioactivity associated with particulate matter (e.g., strontium-90 and cesium-137). However, gaseous radionuclide emissions still remain so far be- 

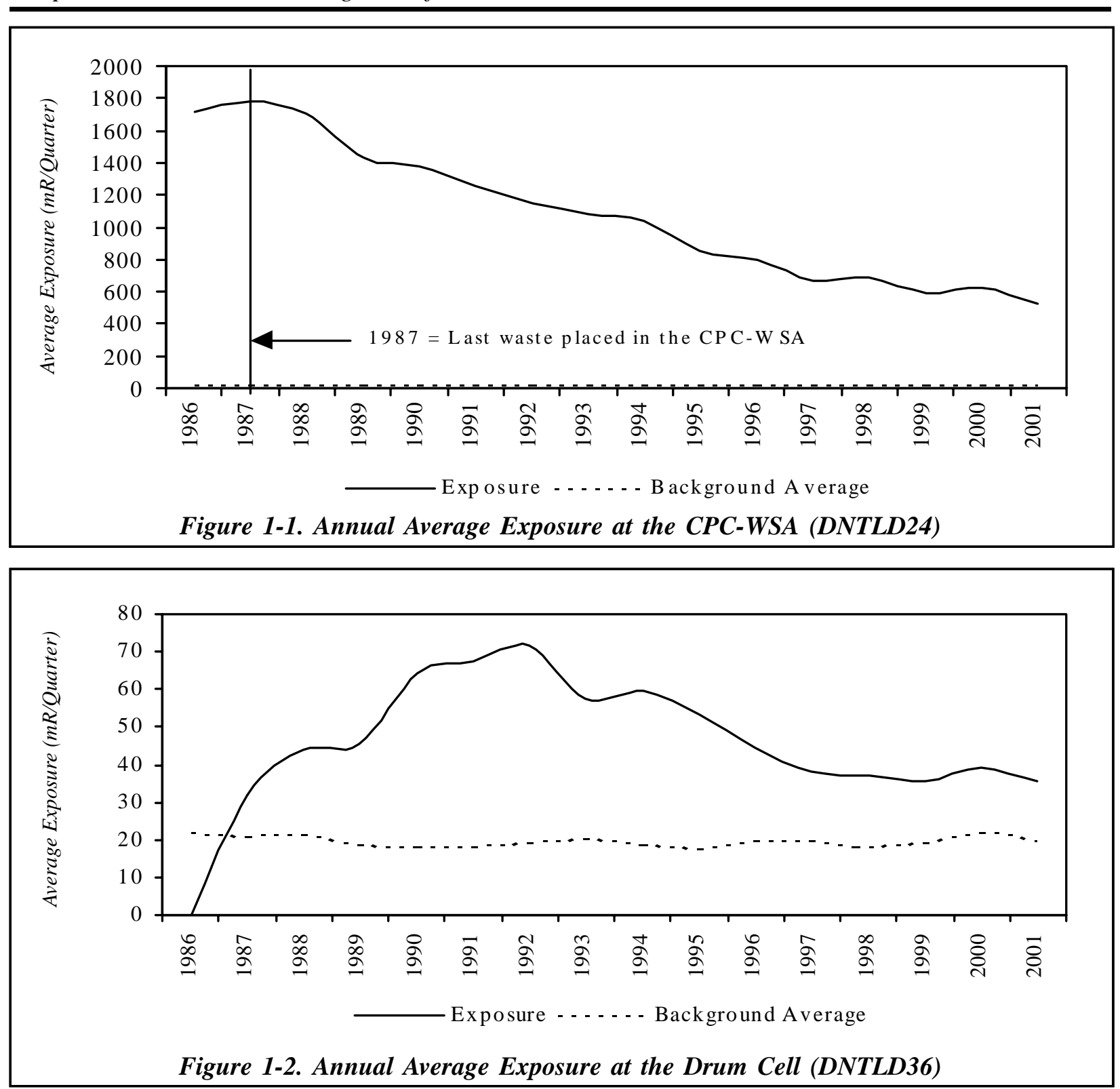

low the most restrictive regulatory limit for public safety that additional treatment technologies beyond that already provided by, for example, the vitrification off-gas treatment system, are not necessary.

Gaseous radioactivity emissions from the main plant in 2001 included approximately 26.5 millicuries of tritium (as hydrogen tritium oxide [HTO]) and 0.52 millicuries of iodine-129. (See Chapter 2 [p. 2-27] for a discussion of iodine-129 emissions from the main plant stack.) As expected, these 2001 values are quite low in comparison to values from 1997, a year in which the vitrification system was in operation for the entire year at a relatively high rate of production and tritium and iodine-129 emissions were 140 millicuries and 7.43 millicuries respectively.

Particulate matter radioactivity emissions from the main plant in 2001 - conservatively determined - 
included approximately 1.2 millicuries of gross beta-emitting radioactivity and 0.004 millicuries of gross alpha-emitting radioactivity. In 1997, betaemitting and alpha-emitting radioactivity emissions were 0.4 millicuries and 0.001 millicuries, respectively. The increase is suspected to be attributable to the changing character of the waste being vitrified (residuals in Phase II versus the bulk wastes of Phase I), increasing contributions to air emissions from D\&D activities, and a release from the main plant stack in the fall of 2001. (See Unplanned Radiological Releases [this page].)

\section{Environmental Management of Radiological} Exposure. Radiological exposures measured at on-site monitoring locations DNTLD24, located near the chemical process cell waste storage area (CPC-WSA), and DNTLD36, located near the drum cell, have shown steady decreases for several years. (See Fig. A-10 [p. A-12] for the locations of these two monitoring points.) Exposure data for these two monitoring locations are shown in Figures 1-1 and 1-2 (facing page).

The beginning of the long-term steady decrease in exposure at DNTLD24 correlates well with the cessation of placement of waste containers in the CPCWSA in 1987 and with the decay of the mix of isotopes in the stored waste. The decreases noted at DNTLD36 can be attributed to the cessation of the placement of waste drums in the drum cell as well as the decay of the mix of isotopes in the stored waste over time and to the revised stacking plan initiated in 1990, which changed the arrangement of waste and shield drums in the drum cell.

Unplanned Radiological Releases. There were no unplanned liquid radiological releases on-site or to the off-site environment from the Project in 2001.

During routine radiation work surveys conducted during mid-November 2001, fixed radioactivity was found on-site in unexpected locations close to the main process building. The small spots of contamination were limited to an area immediately north, and to a lesser extent southeast, of the main plant stack. Upon discovery, the area involved was promptly isolated and decontaminated or stabilized. On-site personnel were surveyed and no personnel contamination was found. Additionally, environmental monitoring data were checked and the data indicated that contamination did not spread off-site.

An extensive investigation was carried out to determine the origin of the contamination. Careful evaluation of radiological monitoring data, operations records, and meteorological (weather) information helped to confirm that the contamination was the result of the release of small amounts of cesium-137 from the waste tank farm ventilation system dissolved in condensed water vapor being released from the main plant stack during late September and early October 2001. The radioactivity release rate was too low to result in any stack monitoring alarms and the total amount of radioactivity released was well within regulatory limits. An unusual combination of ventilation process and weather conditions resulted in an unexpected local deposition of radioactivity. To help prevent recurrence of such an event in the future, operational procedures and system designs are being reviewed and modified to preclude condensation of water vapor in process ventilation systems.

\section{NRC-Licensed Disposal Area (NDA) Inter-} ceptor Trench and Pretreatment System. Radioactively contaminated n-dodecane in combination with tributyl phosphate (TBP) was discovered at the northern boundary of the NDA in 1983, shortly after the DOE assumed control of the WVDP site. Extensive sampling and monitoring through 1989 revealed the possibility that the n-dodecane/TBP could migrate. To contain migration of this subsurface radioactive organic con- 
taminant, an interceptor trench and liquid pretreatment system (LPS) were built.

The trench was designed to intercept and collect subsurface water, which could be carrying ndodecane/TBP, to prevent the material from entering the surface water drainage ditch leading into Erdman Brook. The LPS was installed to decant the n-dodecane/TBP from the water and to remove iodine- 129 from the collected water before its transfer to the low-level waste treatment facility. The separated n-dodecane/TBP would be stored for subsequent treatment and disposal.

As in previous years, no water containing ndodecane/TBP was encountered in the trench and no water or $\mathrm{n}$-dodecane/TBP was treated by the LPS in 2001. Approximately 147,000 gallons (556,000 liters) of radiologically contaminated water were collected from the interceptor trench and transferred to the LLWTF for treatment during the year. Results of surface and groundwater monitoring in the vicinity of the trench are discussed in Chapter 2 under South Plateau Sampling Locations (p. 2-7) and in Chapter 3 under Results of Monitoring at the NDA (p. 3-13).

Waste Minimization Program. The WVDP formalized a waste minimization program in 1991 to reduce the generation of low-level waste, mixed waste, and hazardous waste. This program is a comprehensive and continual effort to prevent or minimize pollution, with the overall goal of reducing health and safety risks, protecting the environment, and complying with all federal and state regulations. (See also the Environmental Compliance Summary, Waste Minimization and Pollution Prevention [p. ECS-5] and p. 1-18 of this chapter.)

Pollution Prevention Awareness Program. The WVDP's Pollution Prevention (P2) Awareness Program is a significant part of the Project's waste minimization program. The goal of the program is to make all employees aware of the importance of pollution prevention both at work and at home.

A crucial component of the P2 Awareness Program at the WVDP is the Pollution Prevention Coordinators group. This group communicates, shares, and publicizes prevention, reduction, reuse, and recycling information to all departments at the WVDP. The P2 coordinators identify and facilitate the implementation of effective sourcereduction, reuse, recycling, and procurement of recycled products. During 2001, an incentive program was developed and implemented to encourage employees to align their waste minimization and pollution prevention activities with the Department of Energy's P2 goals. This resulted in waste stream reduction/elimination, energy savings, and affirmative procurement with total cost savings and avoidances of more than $\$ 1,400,000$ with implementation costs of about $\$ 45,000$.

Waste Management. The WVDP continued reducing and eliminating waste generated by site activities. Reductions in the generation of low-level radioactive waste, mixed waste, hazardous waste, industrial wastes, and sanitary waste such as paper, plastic, wood, and scrap metal were targeted. Specific waste minimization achievements included the following items.

- Ninety-five percent of unused software stored in the warehouse was sent to a recycling vendor, with the remaining $5 \%$ donated to local schools.

- A portable steam cleaner was purchased to clean sewage grinder pumps. Use of this cleaner has reduced personnel exposure to chemicals, protected the environment, and avoided future costs of approximately $\$ 40,000$ for shipping 571,000 gallons of sewage off-site. 
- Minimum/maximum inventory limits were changed, reducing the quantity of laboratory materials on hand.

- More than 703 cubic feet of unused radiological supplies were transferred to other DOE facilities for use.

- More than nine metric tons of plastic and metal drums were emptied, cleaned, and either returned to the vendor for deposit or sold for recycling.

- More than 100 metric tons of scrap carbon and stainless steel were collected and sold to a metal recycling vendor.

- Activities associated with the vitrification expended materials program reduced waste material by more than 344 metric tons.

Low-Level Waste Shipping Program. Activities were initiated in 1997 to reduce the inventory of legacy low-level waste on-site. More than 125,000 cubic feet of waste have been safely shipped off-site since the program was instituted. The WVDP received approval to ship waste to the Nevada Test Site in July 2001, the only new generator to receive this certification.

A truck shipment of low-level radioactive waste from the WVDP was delayed on Monday, July 30, 2001 during a refueling stop in West Wendover, Nevada, when the driver noticed that some absorbent material appeared to have been released from a metal waste box. The shipment, consisting of two metal boxes and five high-integrity containers holding solid, low-level radioactive debris, was en route to the DOE's Nevada Test Site for disposal. The WVDP and local authorities were notified as were representatives from the DOE's Radiological Assistance Program. Radiological surveys of the materials and containers indicated that no radiologically contaminated materials were released. Uncontaminated, non-hazardous absorbent packing material had fallen through a small (one-inch) crack in the container. The damaged waste box and its contents were returned to the WVDP and the remaining containers continued on to the Nevada Test Site. This event resulted in no environmental release and no safety and health consequences. An investigation was carried out and corrective actions were put in place to prevent a recurrence.

National Environmental Policy Act Activities. Under the National Environmental Policy Act (NEPA), the Department of Energy is required to consider the overall environmental effects of its proposed actions or federal projects. The President's Council on Environmental Quality established a screening system of analyses and documentation that requires each proposed action to be categorized according to the extent of its potential environmental effect. The levels of documentation include categorical exclusions (CXs), environmental assessments (EAs), and environmental impact statements (EISs).

Categorical exclusions evaluate and document actions that will not have a significant effect on the environment. Environmental assessments evaluate the extent to which the proposed action will affect the environment. If a proposed action has the potential for significant effects, an environmental impact statement is prepared that describes proposed alternatives to an action and explains the effects.

Facility maintenance, decontamination and decommissioning activities, and minor projects that support high-level waste vitrification are documented and submitted for approval as categorical exclusions, although environmental assessments occasionally are necessary for larger-scale activities. 


\section{West Valley Citizen Task Force}

In addition to the public comment process required by the National Environmental Policy Act, the New York State Energy Research and Development Authority (NYSERDA), with participation from the DOE, formed the West Valley Citizen Task Force in January 1997. The mission of the Task Force is to provide advice on the completion of the West Valley Demonstration Project and cleanup, closure, and/or long-term management of the facilities at the site. The Task Force process has helped illuminate the various interests and concerns of the community, increased the twoway flow of information between the site managers and the community, and provided an effective way for the Task Force members to establish mutually agreed upon recommendations for the site managers to consider in their decision-making process.

In December 1988 the DOE published a Notice of Intent to prepare an environmental impact statement for the completion of the WVDP and closure of the facilities at the WNYNSC.

The draft environmental impact statement, which describes the potential environmental effects associated with Project completion and various site closure alternatives, was completed in 1996 and released without a preferred alternative for a sixmonth public review and comment period. Having met throughout 1997 and 1998 to review alternatives presented in the draft environmental impact statement, the Task Force (see inset [above]) issued the West Valley Citizen Task Force Final Report (July 29, 1998). This report provided recommendations and advice on the development of a preferred alternative. The Task Force continues to meet and discuss issues related to Project completion and site closure decision making.
Because the Nuclear Regulatory Commission (NRC) is authorized by the West Valley Demonstration Project Act to prescribe decommissioning criteria for the WVDP, from 1998 until early 2002 the NRC worked to develop those decommissioning criteria through a series of draft policy papers and public meetings.

In January 2002 the NRC announced that it was issuing its final policy statement establishing the criteria of its existing license termination rule as the decommissioning criteria for the WVDP. The final policy statement was issued February 1, 2002 (67 FR 5003).

After the federal administration change in 2001, the DOE and NYSERDA continued efforts to reach agreement on a preferred alternative and agency responsibilities for completion of the WVDP and closure and/or long-term management of the WNYNSC. Also in 2001, DOE formally initiated its plan to revise the scope of the existing EIS by splitting that scope into two separate documents. The decision-making process has been separated into two phases by revising the scope of the 1996 draft environmental impact statement. Re-scoping will allow two separate environmental impact statements - one EIS for nearterm waste management decision making and one EIS for final decommissioning and/or long-term stewardship decision making.

DOE published a Federal Register Notice of Intent (NOI) March 26, 2001 (66 FR 16447) formally announcing its rescoping plan and preparation of the waste management EIS. A draft EIS for waste management is being prepared for public review and comment.

DOE also published an Advance NOI on November 6, 2001 (66 FR 56090) announcing its commitment to begin work on the decommissioning and/or long-term stewardship EIS. 
Self-Assessments. Self-assessments continued to be conducted in 2001 to review the management and effectiveness of the WVDP environmental protection and monitoring programs. Results of these self-assessments are evaluated and corrective actions are tracked through to completion. Overall results of these self-assessments found that the WVDP continued to implement quality requirements and in some cases improve the quality of the environmental protection and monitoring program. (See the Environmental Compliance Summary [p. ECS-18] and Chapter 5, Quality Assurance [p. 5-6].)

\section{Occupational Safety and Environmental} Training. The safety of personnel who are involved in industrial operations under DOE cognizance is protected by standards mandated by DOE Order 5480.4, Environmental Protection, Safety, and Health Protection Standards, which directs compliance with specific Occupational Safety and Health Act (OSHA) requirements. This act governs diverse occupational hazards ranging from electrical safety and protection from fire to the handling of hazardous materials. The purpose of OSHA is to maintain a safe and healthy working environment for employees.

Hazardous waste operations and emergency response regulations require that employees at treatment, storage, and disposal facilities, who may be exposed to health and safety hazards during hazardous waste operations, receive training appropriate to their job function and responsibilities. The WVDP environmental, health, and safety training matrix identifies the specific training requirements for such employees.

The WVDP provides the standard twenty-fourhour hazardous waste operations and emergency response training. (Emergency response training includes spill response measures and controlling contamination of groundwater.) In 2001, the

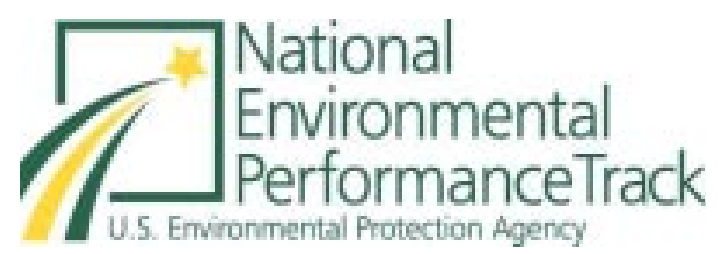

The National Environmental Performance Track is designed to recognize and encourage top environmental performers - those who go beyond compliance with regulatory requirements to attain levels of environmental performance and management that benefit people, communities, and the environment.

The logo identifies those facilities that qualify for Achievement Track membership. Achievement Track facilities can participate in a peer exchange network to share experience, benchmark each other's performance, share information on successful practices and strategies, and receive recognition for their work at state and local levels. The WVDP was awarded charter membership in this program.

WVDP implemented a 40-hour training program for hazardous waste operations and emergency response to meet the additional OSHA training requirements of a cleanup site. The additional training will provide workers with information and techniques for working on decontamination and decommissioning.

Training programs also contain information on waste minimization, pollution prevention, and the WVDP environmental management program. Besides this standard training, employees working in radiological areas receive additional training on subjects such as understanding radiation and radiation warning signs, dosimetry, and respiratory protection. In addition, qualification standards for 
specific job functions at the site are required and maintained. These programs have evolved into a comprehensive curriculum of knowledge and skills necessary to maintain the health and safety of employees and ensure the continued compliance of the WVDP.

In 2001 the WVDP maintained a hazardous materials response team trained to respond to spills of hazardous materials. This team maintained its proficiency through classroom instruction and scheduled training drills.

Medical emergencies on-site are handled by the WVDP Emergency Medical Response Team. This team consists of on-site professional medical staff, volunteer New York State-certified emergency medical technicians, and main plant operators who are First Responders.

Any person working at the WVDP who has a personal photo badge receives general employee training that covers health and safety, emergency response, and environmental compliance issues. All visitors to the WVDP receive a site-specific briefing on safety and emergency procedures before being admitted to the site.

Voluntary Protection Program STAR Status. On May 5, 2000 the WVDP received Voluntary Protection Program (VPP) STAR status, the highest safety award given within OSHA or the DOE. This prestigious award was granted in recognition of the WVDP's excellent worker safety and health programs. (See also the Environmental Compliance Summary [p. ECS-16].)

During 2001, the WVDP reaffirmed its commitment to DOE's VPP. During this reporting period, the annual VPP site evaluation was completed and submitted to DOE. WVDP representatives presented a workshop at the VPP Participants Association National Conference on the Interstate
Zero Program (a program promoting zero on-thejob injuries). In addition, the WVDP was awarded DOE's Star of Excellence Award at this conference, which is given to sites with outstanding safety records.

\section{Environmental Management System (EMS)} Implementation. The project's environmental management system provides the basic policy and direction for work at the WVDP through procedures that support proactive management, environmental stewardship, and the integration of appropriate technologies throughout all aspects of the work at the WVDP.

The Project's environmental management system satisfies the requirements of the Code of Environmental Management Principles (CEMP) for federal agencies and International Organization for Standardization(ISO) 14001, Environmental Management Systems: Specification for Guidance and Use, which is being implemented worldwide. The CEMP was developed by the EPA in response to Executive Order 12856, Federal Compliance with Right-to-Know Laws and Pollution Prevention Requirements, in order to serve as the basis for responsible environmental management. Following the principles and performance objectives of the CEMP helps to ensure that a federal facility's environmental performance is proactive, flexible, cost-effective, and sustainable. The WVDP was awarded charter membership in the EPA's National Performance Track program for implementation of this EMS. (See inset on p. 1-15.)

\section{Integrated Safety Management System} (ISMS) Implementation. A plan to integrate environmental, safety, and health $(\mathrm{ES} \& \mathrm{H})$ management programs at the WVDP was developed and initiated at the WVDP during 1998. During development of the ISMS, the enhanced work planning program (EWP) was identified as an integral part of the ISMS and a site-wide work review group 
was established to review work plans, identify ES\&H concerns, and specify practices that ensure that work is performed safely.

Implementation of an ISMS at the WVDP, including the EWP, was verified by the DOE Ohio Field Office in November 1998. The most recent selfassessment by WVNSCO, performed in August 2001, verified that the ISMS continues to be effectively implemented at the WVDP. An annual ISMS review by the DOE occurred in October 2001 and confirmed the results of the WVNSCO self-assessment.

\section{Performance Measures}

Performance measures can be used to evaluate effectiveness, efficiency, quality, timeliness, productivity, safety, or other areas that reflect achievements related to organization or process goals and can be used as a tool to identify the need to institute changes.

The performance measures applicable to operations conducted at the WVDP, discussed here, reflect process performance related to wastewater treatment in the low-level waste treatment facility, the identification of spills and releases, the reduction in the generation of wastes, the potential radiological dose received by the maximally exposed off-site individual, and the transfer of high-level waste to the vitrification system.

\section{Radiation Doses to the Maximally Exposed} Off-Site Individual. One of the most important pieces of information derived from environmental monitoring program data is the potential radiological dose to an off-site individual from on-site activities. As an overall assessment of Project activities and the effectiveness of the as-low-as-reasonably achievable (ALARA) concept, the effective radiological dose to the maximally exposed offsite individual is an indicator of well-managed radiological operations. The effective dose equivalents for air effluent emissions, liquid effluent discharges, and other liquid releases (such as swamp drainage) from 1993 through 2001 are graphed in Figure 1-3 (below). Note

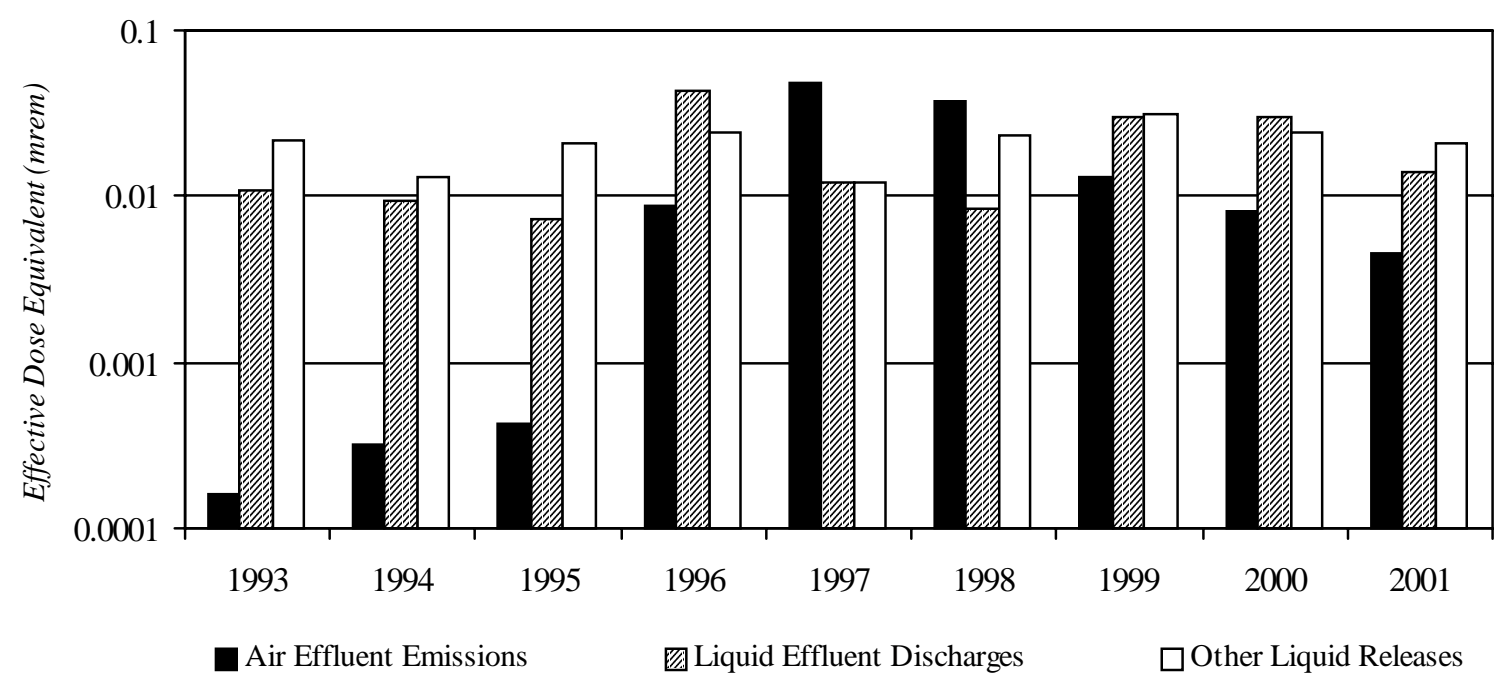

Figure 1-3. Annual Effective Dose Equivalent to the Maximally Exposed Off-Site Individual 


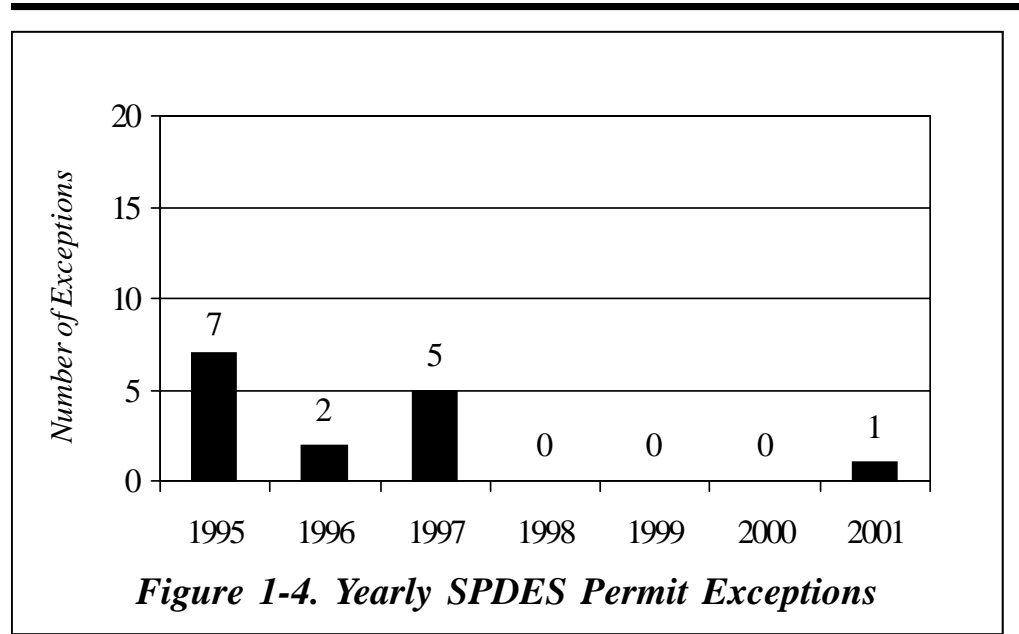

System (NPDES)/SPDES permitting and compliance was formed in 1995 to address the causes of these exceptions.

The Water Task Team's efforts produced three consecutive years with no permit limit exceptions. In 2001, one permit limit exception for total recoverable lead occurred at outfall 008 , the french drain for the LLWTF lagoon system. This exception was attributable to an increased lead concentration resulting from decreased flow and siltation

that the sum of these values is well below the DOE standard of 100 mrem per year. These consistently low results indicate that radiological activities at the site are well-controlled. (See also Table 4-2 [p. 4-6] in Chapter 4, Radiological Dose Assessment.)

SPDES Permit Limit Exceptions. Effective operation of the site wastewater treatment facilities is indicated by compliance with the applicable discharge permit limitations. Approximately sixty parameters are monitored regularly as part of the SPDES permit requirements. The analytical results are reported to NYSDEC via Discharge Monitoring Reports, required under the SPDES program.

Although the goal of the low-level waste treatment facility and wastewater treatment facility operations is to maintain effluent water quality consistently within the permit requirements, occasionally SPDES permit limit exceptions do occur. All SPDES permit limit exceptions are evaluated to determine their cause and to identify corrective measures.

A Water Task Team composed of WVDP personnel with expertise in wastewater engineering, treatment plant operations and process monitoring, and National Pollutant Discharge Elimination within this aging groundwater drain system. (See Fig. 1-4 [this page].)

Although exceptions are not always related to operating deficiencies, corrective actions may include improved operation or treatment techniques. In 1997 the WVDP notified NYSDEC of the presence of mercury in the influent wastewater to the LLWTF and of its likely presence at outfall 001 at concentrations below the detectable level of $0.2 \mu \mathrm{g} / \mathrm{L}$. In 1998 and 1999 an increase in the mercury concentration was observed in process wastewater from the liquid waste treatment system (LWTS) evaporator, water that is eventually treated at the LLWTF. The LWTS evaporator processes residual radioactive wastewater from the high-level radioactive waste processing and supernatant treatment operations.

During 2000 an engineering report and plans and specifications for a mercury pretreatment system, designed to remove mercury from the LWTS process water, were prepared by the WVDP and approved by NYSDEC. The system was subsequently installed and processing of LWTS wastewater through this system began in January 2001.

Waste Minimization and Pollution Prevention. In 2001 the WVDP continued its program 


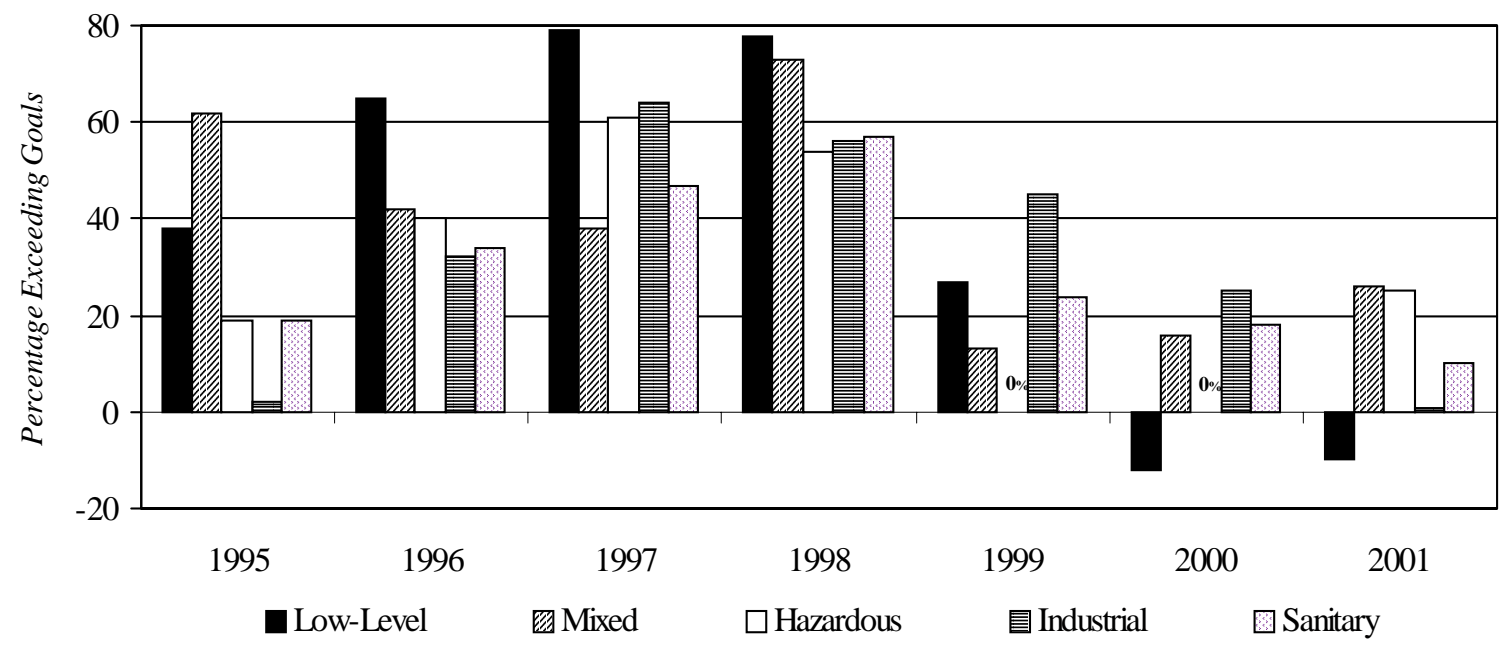

Figure 1-5. Percentage of Waste Reduction Exceeding Goals

of reducing and eliminating the amount of waste generated from site activities. Emphasis on good business practices, source-reduction, and recycling continued to reduce the generation of low-level radioactive waste, mixed waste, hazardous waste, industrial wastes, and sanitary wastes such as paper, glass, plastic, wood, and scrap metal. (See p. 1-12 for a list of specific waste minimization achievements.)

To demonstrate the effectiveness of the waste minimization program, a graph of the percentage of waste reduction achieved above the annual goal for each category is presented in Figure 1-5 (above) for calendar years 1995 through 2001.

The WVDP set the following cumulative nonvitrification waste-reduction goals for fiscal year 2001: an $80 \%$ reduction in the generation of lowlevel radioactive waste, a $71 \%$ reduction in the generation of mixed waste, a $42 \%$ reduction in the generation of hazardous waste, a 54\% reduction in the generation of industrial waste, and a $67 \%$ reduction in the generation of sanitary waste. The above goals were based on quantities of routine waste generated in 1993. (As of fiscal year
2001, all WVDP pollution prevention goals are in alignment with the DOE's pollution prevention goals, which are now based on a federal fiscal year.)

All but one of these goals were exceeded during fiscal year 2001. Low-level radioactive waste generation was reduced by $70 \%$, missing the established goal of $80 \%$ because the estimated goal set for 2001 was extremely aggressive. Mixed waste generation was reduced by $97 \%$, hazardous waste by $67 \%$, industrial waste by $55 \%$, and sanitary waste by $77 \%$.

A number of waste streams have been tracked over this period. Note that the low-level radioactive waste figures from 1995 include the volume of drummed waste produced in the cement solidification system. Hazardous waste and industrial waste volumes have been tracked separately for vitrification-related and nonvitrification-related waste streams since vitrification began in 1996. To maintain historical comparability, the percentages in Figure 1-5 include only the nonvitrification portions of these two waste streams. 


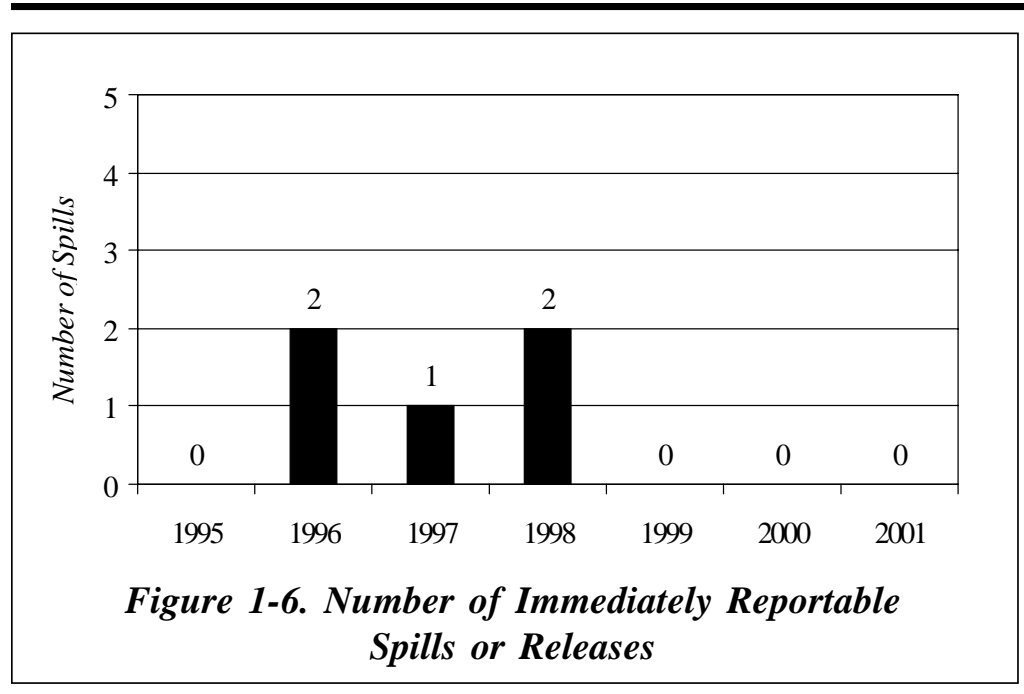

ure 1-6 (at left) is a bar graph of immediately reportable spills from 1995 to 2001 .

Prevention is the best means of protection against oil, chemical, and hazardous substance spills or releases. WVDP employees are trained in applicable standard operating procedures for equipment that they use, and best management practices have been developed that identify potential spill sources and measures that will reduce the potential for releases to occur. Spill

Spills and Releases. Chemical spills greater than the applicable reportable quantity must be reported immediately to NYSDEC and the National Response Center and other agencies as required. There were no reportable chemical spills during 2001.

Petroleum spills greater than 5 gallons - or of any amount that travel to waters of the state must be reported immediately to the NYSDEC spill hotline and entered in the monthly log. There were no reportable petroleum spills in 2001. Fig- training, notification, and reporting policies have also been developed to emphasize the responsibility of each employee to report spills immediately upon discovery. This first-line reporting helps to ensure that spills will be properly documented and mitigated in accordance with applicable regulations.

Vitrification. To safely solidify the high-level radioactive waste in borosilicate glass, the high-level waste sludge is transferred in batches from the tank, where it currently is stored, to the vitrification facility. After transfer, the waste is solidified

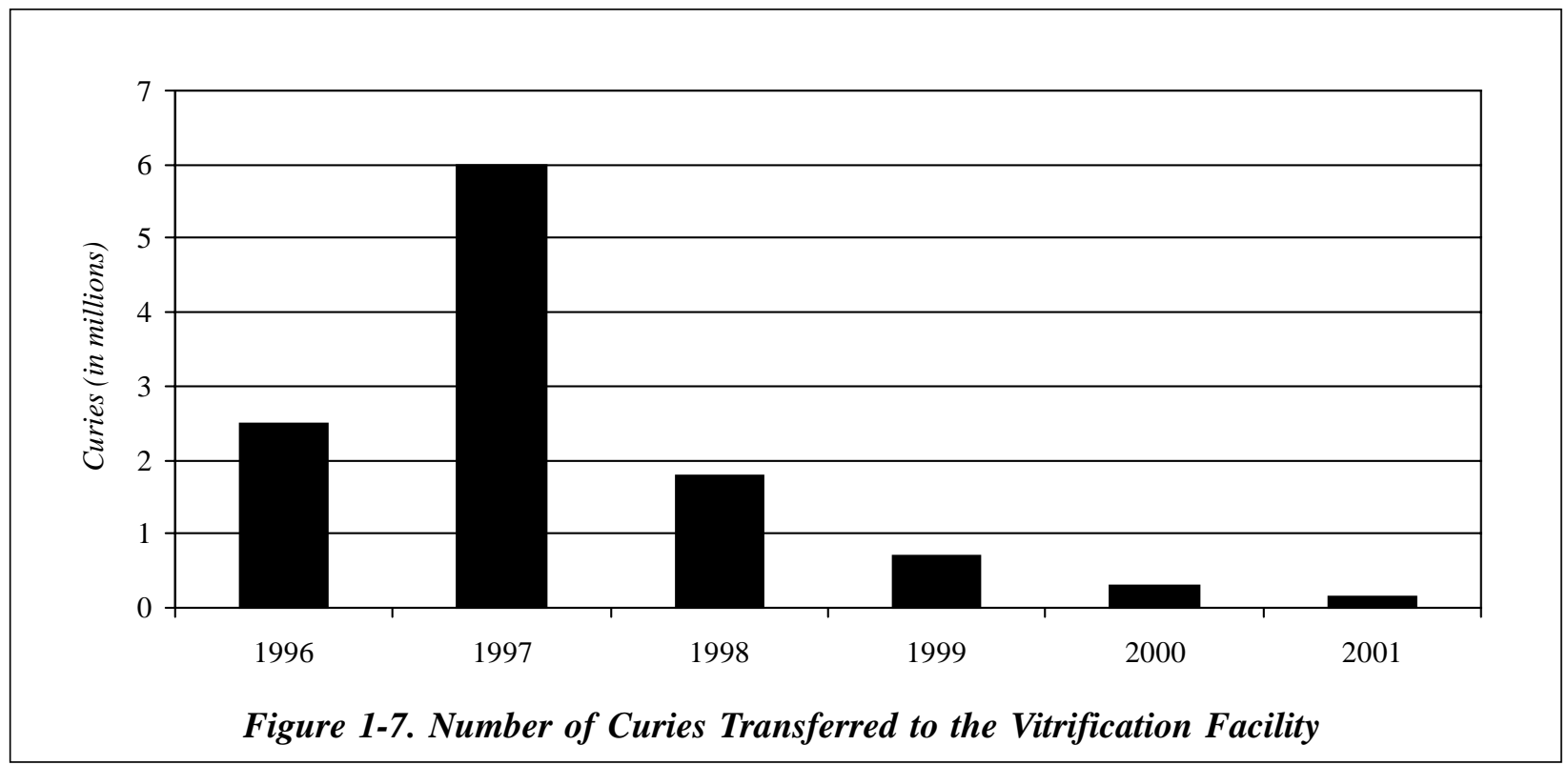


into a durable glass for safe storage and future transport to a federal repository. It is estimated that roughly 12 million curies of strontium and cesium radioactivity in the high-level waste eventually will be vitrified. (Radioactive cesium and strontium isotopes account for $98 \%$ of the longlived radioactivity.) To quantify the progress made toward completing the vitrification goal, Figure 17 (facing page) shows the number of curies transferred to the vitrification facility from 1996 through 2001.

On June 10, 1998, the WVDP marked completion of the Project's production phase (Phase I) of highlevel waste processing, during which 210 canisters were filled with solidified waste glass. Phase II, vitrifying the high-level waste residuals, began in 1998 and continued through 2001. An additional fifty-four canisters have been filled in Phase II, ten of which were filled in 2001. A total of 264 canisters of immobilized waste, containing more than 11.9 million curies, have been generated thus far in the vitrification process. 
This page intentionally left blank

$1-22$ 


\section{ENVIRONMENTAL MONITORING}

\section{Routine Monitoring Program}

Routine activities at the West Valley Demonstration Project (WVDP) can lead to the release of radioactive or hazardous substances that could affect the environment. Possible pathways for the movement of radionuclides or hazardous substances from the WVDP to the public include milk and food consumed by humans; forage consumed by animals; sediments, soils, groundwater, and surface water; and effluent air and liquids released by the WVDP.

The food pathway is monitored by collecting samples of beef, hay, milk, and produce at nearsite and remote locations, samples of fish upstream and downstream of the site, and venison samples from near-site deer and deer taken from background locations. Stream sediments are sampled upstream and downstream of the WVDP, and both on-site groundwater and off-site drinking water are routinely sampled. Direct radiation is monitored on-site, at the perimeter of the site, in communities near the site, and at background locations.

The primary focus of the monitoring program, however, is on surface water and air pathways, as these are the principal means of transport of radionuclides from the WVDP.
Liquid and air effluents are monitored on-site by collecting samples at locations where radioactivity or other regulated substances are released or might be released. Release points include water effluent outfalls and plant ventilation stacks.

Surface water samples are collected within the Project site from ponds, swamps, seeps, and drainage channels that flow through the Western New York Nuclear Service Center (WNYNSC) and then off-site into Cattaraugus Creek.

Both surface water and air samples are collected at site perimeter locations where the highest offsite concentrations of transported radionuclides might be expected. Samples are also collected at remote locations to provide background concentration data for comparison with data from on-site and near-site samples.

\section{Sampling Program Overview}

The complete environmental monitoring schedule is delineated in Appendix B. This schedule provides information on monitoring and reporting requirements and the types and extent of sampling and monitoring at each location. An explanation of the codes that identify the sample medium and the specific sampling or monitoring location is also found in Appendix B (p. B-iii). For example, a sample location code 
such as AFGRVAL indicates an air sample (A), offsite (F), at the Great Valley (GRVAL) sampling station. These codes are used throughout this report for ease of reference and to be consistent with the data reported in the appendices.

Surface Water Sampling Locations. Automatic samplers collect surface water at points along drainage channels within the WNYNSC that are most likely to show any radioactivity released from the site. These automatic samplers collect a 50milliliter $(\mathrm{mL})$ aliquot (about one-quarter of a cup of water) every half-hour. The aliquots are pumped into a large container where they are accumulated and mixed from which the composited subsamples are then collected.

The samplers operate on-site at four locations: WNSP006, the point in Frank's Creek where Project drainage leaves the security-fenced area; WNNDADR, the drainage point downstream of the Nuclear Regulatory Commission (NRC)-licensed disposal area (NDA); WNSWAMP, the northeast swamp drainage; and WNSW74A, the north swamp drainage.

Off-site automatic samplers collect surface waters from Buttermilk Creek at a background station upstream of the site (WFBCBKG), from Buttermilk Creek downstream of the site at Thomas Corners Road bridge (WFBCTCB), the last monitoring point before Buttermilk Creek leaves the WNYNSC, and from Cattaraugus Creek at Felton Bridge (WFFELBR). Grab samples are collected at several other surface water locations both on-site and off-site, including a background location on Cattaraugus Creek at Bigelow Bridge (WFBIGBR).

Figure A-2 (p. A-4 in Appendix A) shows the locations of the on-site surface water monitoring points. Figure A-3 (p. A-5) shows the locations of the off-site surface water monitoring points.

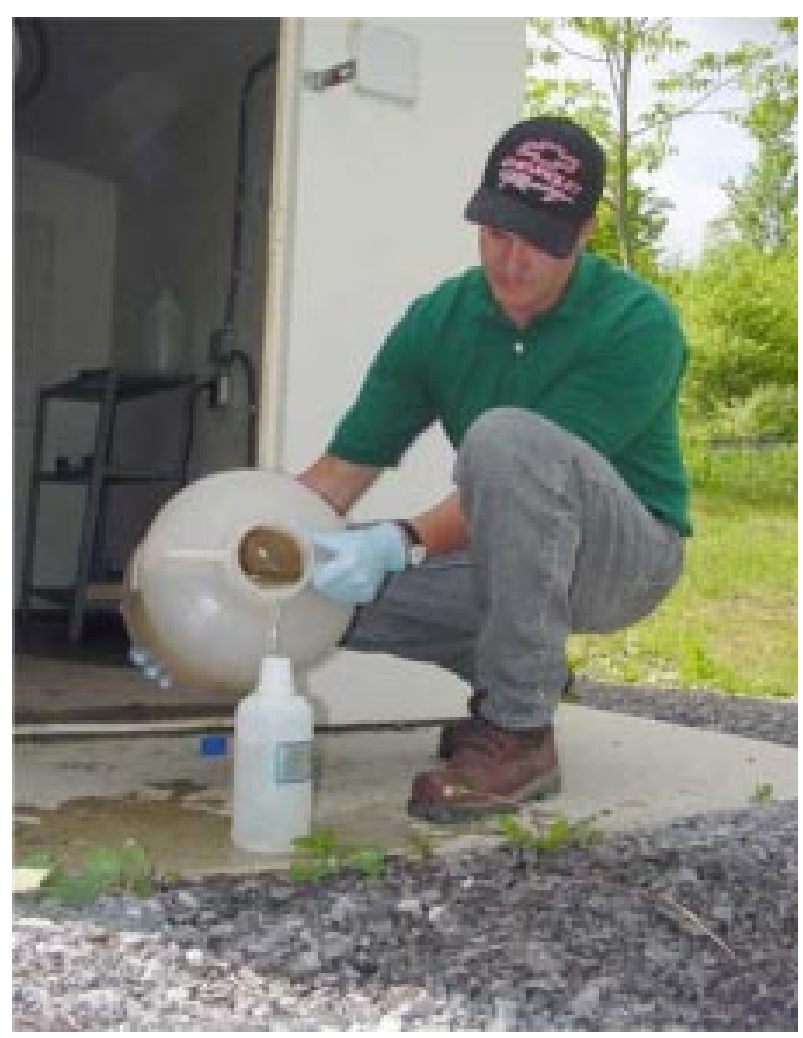

Collecting a Sample at a Stream Sampling Location

Air Sampling Locations. Air samplers are located on-site, at the perimeter of the site, and at points remote from the WVDP. Figure A-4 (p. A-6) shows the locations of the on-site air effluent monitors and samplers and the on-site ambient air samplers; Figures A-5, A-12, and A-13 (pp. A-7, A-14, and A-15) show the locations of the perimeter and remote air samplers.

Methods for monitoring and sampling air emission points and for sampling ambient air are described later in this chapter. (See On-site Ventilation Systems [p. 2-14] and Perimeter and Remote Air Sampling [p. 2-17].)

\section{Radiological Monitoring: Surface Water}

The WVDP site is drained by several small streams. (See Surface Water Hydrology of the 
West Valley Site in Chapter 3 [p. 3-2] and Figs. A-2 [p. A-4] and A-3 [p. A-5].) Frank's Creek flows along and receives drainage from the south plateau. As Frank's Creek flows northward, it is joined by a tributary, Erdman Brook, which receives effluent from the low-level waste treatment facility. On the north plateau, beyond the Project fence line, the north and northeast swamp areas and Quarry Creek drain into Frank's Creek.

Frank's Creek continues past the WVDP perimeter and flows across the WNYNSC, where it enters Buttermilk Creek. Radionuclide concentrations in Buttermilk Creek are monitored upstream and downstream of the WVDP. Further downstream, Buttermilk Creek leaves the WNYNSC and enters Cattaraugus Creek, which is also monitored for radionuclide concentrations both upstream and downstream of the point where the creek receives effluents from the WVDP.

Three liquid effluent locations (one process release point from the low-level waste treatment facility and two natural drainages from the northeast and north swamps) are primary contributors to site dose estimates. (See Chapter 4, Radiological Dose Assessment, Table 4-2 [p. 4-6] for an estimate of the dose attributable to these waterborne effluents.)

\section{Low-Level Waste Treatment Facility Sam-} pling Location. The discharge from the low-level waste treatment facility (LLW2) through the lagoon 3 weir (WNSP001 on Fig. A-2 [p. A-4]) into Erdman Brook, a tributary of Frank's Creek, is the largest single source of radioactivity released to surface waters from the Project. There were five batch releases totaling about 8.4 million gallons (31.9 million liters) in 2001. Composite samples were collected near the beginning and end of each discharge and one effluent grab sample was collected during each day of discharge. Samples were analyzed for gross alpha and gross beta radioactivity, for gamma-emitting radionuclides, and for spe- cific radionuclides as noted in Appendix B (p. B-7). The total amounts of radioactivity from specific radionuclides in the lagoon 3 effluent are listed in Appendix C, Table C-1 (p. C-3). The annual average concentration of each radionuclide is divided by its corresponding Department of Energy (DOE) derived concentration guide (DCG) in order to determine what percentage of the DCG was released. (DOE standards and DCGs for radionuclides of interest at the WVDP are found in Appendix K, Table K-1 [p. K-3].) As a DOE policy, the sum of the percentages calculated for all radionuclides released should not exceed $100 \%$.

The combined annual average of radionuclide concentrations from the lagoon 3 effluent discharge weir in 2001 was approximately $33.3 \%$ of the DCGs. (See Table C-2 [p. C-4].) This is comparable to the average concentration over the last six years of approximately $31 \%$.

The low-level waste treatment facility was designed to efficiently remove strontium- 90 and cesium-137, the more prevalent of the long-lived fission products in WVDP wastewaters. Other radionuclides are also removed to a lesser extent by the low-level waste treatment facility. For example, one other major contributor to the total combined DCG in lagoon 3 effluent is uranium-232, which averaged about $11 \%$ of its DCG in 2001. Uranium-232 and other uranium isotopes are found in WVDP liquid waste because they were present in the nuclear fuel that was once reprocessed at the site. Variations in liquid effluent radionuclide ratios continue to reflect the dynamic nature of the waste streams being processed through the low-level waste treatment facility.

(Outfall WNSP001, the lagoon 3 weir, is monitored also for nonradiological parameters under the New York State Pollutant Discharge Elimination System [SPDES] program. See Nonradiological Monitoring: Surface Water [p. 2-25].) 
Northeast Swamp and North Swamp Sampling

Locations. The northeast and north swamp drainages on the site's north plateau conduct surface water and emergent groundwater off-site.

The northeast swamp sampling location (WNSWAMP) monitors surface water drainage from the northeastern portion of the site's north plateau. The north swamp sampling point (WNSW74A) monitors drainage to Quarry Creek from the northern portion of the north plateau. (See Fig. A-2 [p. A-4].) Waters from the northeast swamp drainage run into Frank's Creek downstream of location WNSP006, the point in Frank's Creek where Project drainage leaves the securityfenced area. (See Other Surface Water Sampling Locations [this page].)

Samples from WNSWAMP and WNSW74A are collected weekly and analyzed for radiological parameters. Concentrations of all radiological parameters detected at WNSWAMP and WNSW74A, other than gross beta and strontium-90, were less than $1 \%$ of the respective DCGs for these parameters. The maximum and minimum gross alpha and gross beta results from WNSWAMP and WNSW74A are noted on Tables 2-1 and 2-2 (facing page). Complete data from these two locations are found in Tables C-7 and C-8 (pp. C-8 and $\mathrm{C}-9$ in Appendix C). An upward trend in gross beta concentrations at WNSWAMP, first noted in 1993, continued through 2001. Gross beta activity at this location is largely attributable to strontium90. (See Special Groundwater Monitoring [p. 315].)

Strontium-90 concentrations at WNSWAMP in 2001 averaged $2.38 \mathrm{E}-06 \mu \mathrm{Ci} / \mathrm{mL}(88.1 \mathrm{~Bq} / \mathrm{L})$. (See Chapter 3, Fig. 3-4 [p. 3-17] for a graph of the annualized average strontium-90 concentration at WNSWAMP in 2001.) Even though waters with elevated strontium-90 concentrations drain from WNSWAMP into Frank's Creek, wa- ters collected from Cattaraugus Creek downstream at the first point of access by the general public (WFFELBR) were not significantly different from those at the background location, WFBIGBR, which is upstream of the location where site drainage enters Cattaraugus Creek. (See Off-Site Surface Water Sampling Locations [p. 2-9].) Also, the maximum concentration of strontium-90 in surface water exiting the WNYNSC through Buttermilk Creek (WFBCTCB) was less than the water quality standard of $8 \mathrm{pCi} / \mathrm{L}$ applicable to surface water drinking water supplies, such as Lake Erie.

\section{Other Surface Water Sampling Locations.} Samples taken from a point in Frank's Creek (WNSP006), from the sanitary and industrial wastewater treatment facility discharge (WNSP007), are routinely monitored for radiological parameters. Point WNSP008, subsurface drainage from the perimeter of the low-level waste treatment facility storage lagoons, was also monitored until May of 2001, when it was capped off because of slightly elevated lead results. (See Fig. A-2 [p. A-4].) Discharges from WNSP001, WNSP007, and WNSP008 leave the site through point WNSP006. Radiological results of analyses from WNSP006, WNSP007, and WNSP008 are summarized in Tables C-4, C-5, and C-6 (pp. C-6 and C-7). Samples from these points also are monitored for nonradiological parameters as part of the site's SPDES program. (See Nonradiological Monitoring: Surface Water [p. 2-25].)

WNSP006. WNSP006 is located more than 2.5 miles $(4.0 \mathrm{~km})$ upstream from Thomas Corners Road, which is the last monitoring point before Buttermilk Creek leaves the WNYNSC and before the public has access to the creek waters. Samples from WNSP006 are retrieved weekly and composited both monthly and quarterly and are analyzed for the same radionuclides as the effluent samples from WNSP001. 
Table 2-1

2001 Gross Alpha Concentrations at Surface Water Sampling Locations

Location $\quad \begin{gathered}\text { Number of } \\ \text { Samples }\end{gathered}$
Sa

Off-Site

$\begin{array}{llrr}\text { WFBCBKG } & 12 & <3.67 \mathrm{E}-10 \text { to } 1.30 \mathrm{E}-09 & <1.36 \mathrm{E}-02 \text { to } 4.81 \mathrm{E}-02 \\ \text { WFBCTCB } & 12 & 6.28 \mathrm{E}-10 \text { to } 1.40 \mathrm{E}-09 & 2.32 \mathrm{E}-02 \text { to } 5.17 \mathrm{E}-02 \\ \text { WFBIGBR } & 12 & <8.36 \mathrm{E}-10 \text { to } 1.30 \mathrm{E}-09 & <3.09 \mathrm{E}-02 \text { to } 4.79 \mathrm{E}-02 \\ \text { WFFELBR } & 12 & <1.16 \mathrm{E}-09 \text { to } 7.41 \mathrm{E}-09 & <4.30 \mathrm{E}-02 \text { to } 2.74 \mathrm{E}-01 \\ & & & \\ \text { On-Site } & & & \\ & & & \\ \text { WNNDADR } & 12 & <8.79 \mathrm{E}-10 \text { to } 1.63 \mathrm{E}-09 & <3.25 \mathrm{E}-02 \text { to } 6.02 \mathrm{E}-02 \\ \text { WNSP006 } & 52 & 9.20 \mathrm{E}-10 \text { to } 1.07 \mathrm{E}-08 & 3.40 \mathrm{E}-02 \text { to } 3.97 \mathrm{E}-01 \\ \text { WNSW74A } & 52 & <1.15 \mathrm{E}-09 \text { to } 3.39 \mathrm{E}-09 & <4.26 \mathrm{E}-02 \text { to } 1.25 \mathrm{E}-01 \\ \text { WNSWAMP } & 52 & <1.01 \mathrm{E}-09 \text { to } 4.15 \mathrm{E}-09 & <3.74 \mathrm{E}-02 \text { to } 1.54 \mathrm{E}-01\end{array}$

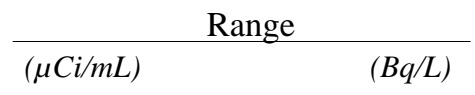

Annual Average

$$
(\mu \mathrm{Ci} / \mathrm{mL})
$$

$(B q / L)$

Table 2-2

\section{Gross Beta Concentrations at Surface Water Sampling Locations}

Location $\quad \begin{gathered}\text { Number of } \\ \text { Samples }\end{gathered}$

Off-Site

$\begin{array}{llrr}\text { WFBCBKG } & 12 & <1.21 \mathrm{E}-09 \text { to } 2.72 \mathrm{E}-09 & <4.47 \mathrm{E}-02 \text { to } 1.00 \mathrm{E}-01 \\ \text { WFBCTCB } & 12 & 3.71 \mathrm{E}-09 \text { to } 1.26 \mathrm{E}-08 & 1.37 \mathrm{E}-01 \text { to } 4.68 \mathrm{E}-01 \\ \text { WFBIGBR } & 12 & 1.36 \mathrm{E}-09 \text { to } 3.72 \mathrm{E}-09 & 5.02 \mathrm{E}-02 \text { to } 1.38 \mathrm{E}-01 \\ \text { WFFELBR } & 12 & 1.88 \mathrm{E}-09 \text { to } 6.52 \mathrm{E}-09 & 6.96 \mathrm{E}-02 \text { to } 2.41 \mathrm{E}-01\end{array}$

On-Site

$\begin{array}{llrr}\text { WNNDADR } & 12 & 1.52 \mathrm{E}-07 \text { to } 3.30 \mathrm{E}-07 & 5.62 \mathrm{E}+00 \text { to } 1.22 \mathrm{E}+01 \\ \text { WNSP006 } & 52 & 1.27 \mathrm{E}-08 \text { to } 1.62 \mathrm{E}-07 & 4.70 \mathrm{E}-01 \text { to } 6.01 \mathrm{E}+00 \\ \text { WNSW74A } & 52 & <3.80 \mathrm{E}-09 \text { to } 3.36 \mathrm{E}-08 & <1.40 \mathrm{E}-01 \text { to } 1.24 \mathrm{E}+00 \\ \text { WNSWAMP } & 52 & 2.36 \mathrm{E}-06 \text { to } 8.65 \mathrm{E}-06 & 8.74 \mathrm{E}+01 \text { to } 3.20 \mathrm{E}+02\end{array}$

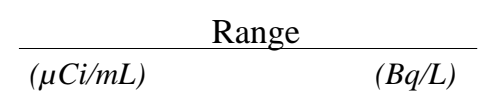

$(\mu \mathrm{Ci} / \mathrm{mL})$

$\begin{array}{ll}0.39 \pm 1.40 \mathrm{E}-09 & 1.44 \pm 5.18 \mathrm{E}-02 \\ 0.75 \pm 1.70 \mathrm{E}-09 & 2.78 \pm 6.29 \mathrm{E}-02 \\ 0.44 \pm 3.01 \mathrm{E}-09 & 0.16 \pm 1.11 \mathrm{E}-01 \\ 0.35 \pm 2.02 \mathrm{E}-09 & 1.31 \pm 7.48 \mathrm{E}-02\end{array}$

$1.55 \pm 2.81 \mathrm{E}-02$
$2.87 \pm 3.17 \mathrm{E}-02$
$1.15 \pm 3.91 \mathrm{E}-02$
$8.29 \pm 5.18 \mathrm{E}-02$

$\begin{array}{ll}4.18 \pm 7.60 \mathrm{E}-10 & 1.55 \pm 2.81 \mathrm{E}-02 \\ 7.76 \pm 8.56 \mathrm{E}-10 & 2.87 \pm 3.17 \mathrm{E}-02 \\ 0.31 \pm 1.06 \mathrm{E}-09 & 1.15 \pm 3.91 \mathrm{E}-02 \\ 2.24 \pm 1.40 \mathrm{E}-09 & 8.29 \pm 5.18 \mathrm{E}-02\end{array}$

\author{
$\frac{\text { Annual Average }}{(\mu \mathrm{Ci} / \mathrm{mL})}$ \\ $\frac{\text { Annual Average }}{(\mu \mathrm{Ci} / \mathrm{mL})}$
}

$\begin{array}{ll}1.84 \pm 1.25 \mathrm{E}-09 & 6.82 \pm 4.63 \mathrm{E}-02 \\ 7.84 \pm 1.51 \mathrm{E}-09 & 2.90 \pm 0.56 \mathrm{E}-01 \\ 2.20 \pm 1.27 \mathrm{E}-09 & 8.15 \pm 4.71 \mathrm{E}-02 \\ 3.96 \pm 1.83 \mathrm{E}-09 & 1.47 \pm 0.68 \mathrm{E}-01\end{array}$

$\begin{array}{lr}1.90 \pm 0.07 \mathrm{E}-07 & 7.04 \pm 0.26 \mathrm{E}+00 \\ 4.40 \pm 0.41 \mathrm{E}-08 & 1.63 \pm 0.15 \mathrm{E}+00 \\ 1.22 \pm 0.44 \mathrm{E}-08 & 4.51 \pm 1.64 \mathrm{E}-01 \\ 4.79 \pm 0.04 \mathrm{E}-06 & 1.77 \pm 0.01 \mathrm{E}+02\end{array}$

$2-5$

WVDP Site Environmental Report

Calendar Year 2001 
The average gross alpha and gross beta data from location WNSP006 and the maximum and minimum results are noted in Tables 2-1 and 2-2 (p. 25) for comparison with sampling results from other on- and off-site surface water locations. As shown in Table 2-2, gross beta results for WNSP006 are generally higher than those at downstream and background locations. Figure 2-1 (below) shows the fifteen-year trends of gross alpha, gross beta, and tritium concentrations at location WNSP006. Fluctuations over this period reflect variable concentrations in treated WVDP liquid effluent being released from the site.

Many of the constituents detected at low levels in effluent from WNSP001 were not detectable downstream at location WNSP006. Except for gross beta and strontium-90, all constituents that were detected were found at concentrations lower than $1 \%$ of the respective DCG. The highest monthly concentration of strontium-90 at WNSP006 in 2001 was 2.80E-08 $\mu \mathrm{Ci} / \mathrm{mL}(1.04 \mathrm{~Bq} / \mathrm{L})$, which is less than $3 \%$ of its DCG $(1 \mathrm{E}-06 \mu \mathrm{Ci} / \mathrm{mL})$.
Average concentrations in 2001 for the radiological parameters monitored at WNSP007 (gross alpha, gross beta, tritium, and cesium-137) and at WNSP008 (gross alpha, gross beta, and tritium) were also at small percentages of their respective DCGs.

Concentrations observed farther downstream at Felton Bridge (WFFELBR), the sampling location that represents the first point of public access to surface waters leaving the WVDP site, continue to be close to or indistinguishable from background.

WNSP005 and WNCOOLW. Sampling point WNSP005, which monitors drainage from land on the east side of the main plant, and WNCOOLW, which monitors facility coolant water, are sampled monthly for gross alpha, gross beta, and tritium concentrations. WNCOOLW also is sampled quarterly for gamma isotopes, including cesium-137. Radiological data for WNSP005 and WNCOOLW are found in Tables C-3 and C-11 (pp. C-5 and C-11).

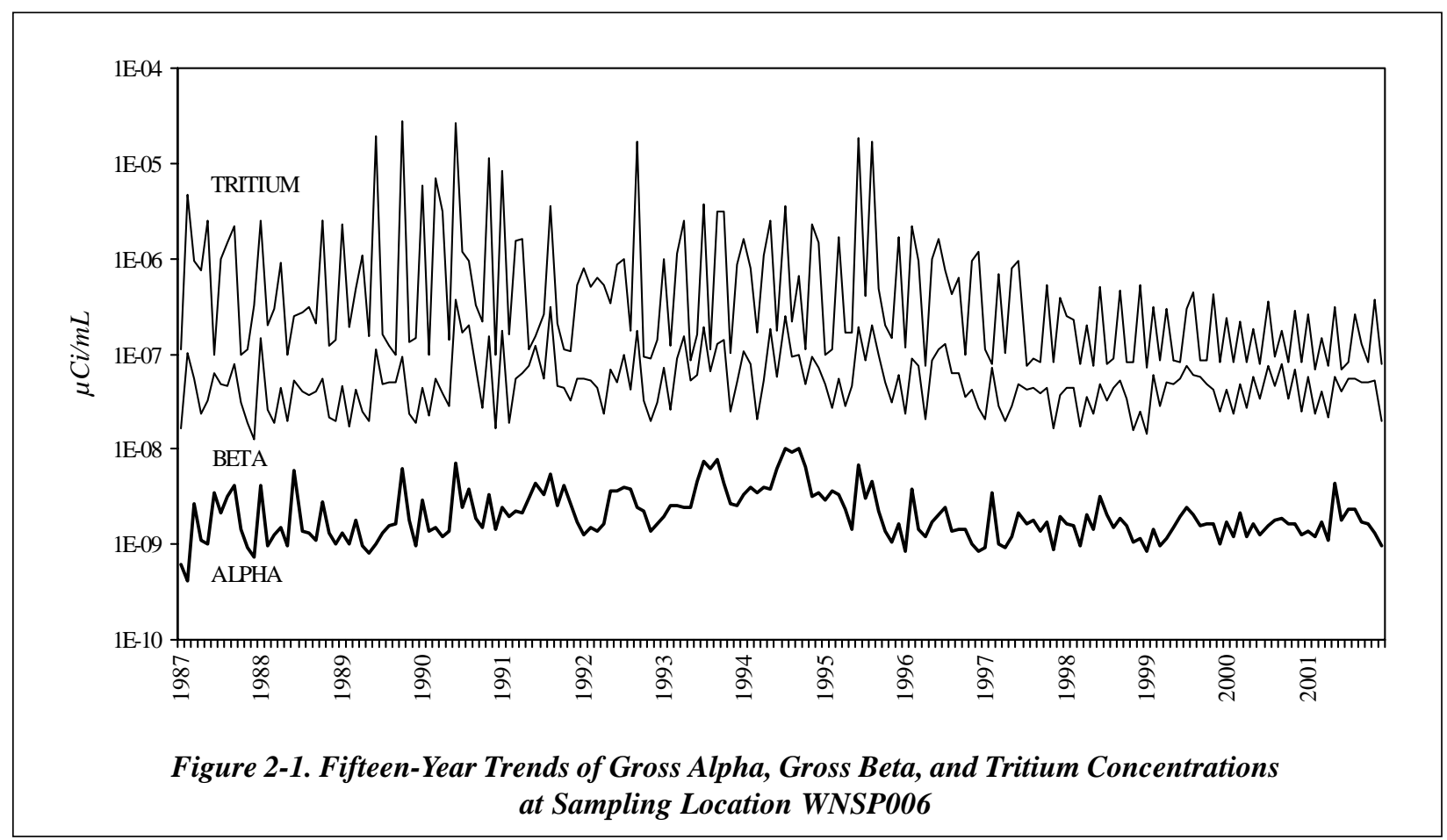


Average gross alpha and tritium concentrations for both locations were below detection levels in 2001. Average gross beta concentrations at WNSP005 and WNCOOLW were considerably lower than the strontium-90 DCG $(<20 \%$ and $<1 \%$, respectively). Average cesium-137 concentrations at WNCOOLW were below detection levels in 2001.

$W N 8 D 1 D R$. This sampling point is at the access to a storm sewer manhole that originally collected surface and shallow groundwater flow from the high-level waste tank farm area. In July 1993 the access was valved off from the original high-level waste tank farm drainage area to prevent collected waters from rising freely to the surface. Although samples from this location are not thought to be representative of either local groundwater or surface water, weekly sampling for gross alpha, gross beta, and tritium continued through 2001. A monthly composite was analyzed for gamma radionuclides and strontium-90. Sampling at WN8D1DR was discontinued in December 2001.

Average gross alpha, tritium, and cesium- 137 concentrations at WN8D1DR were all below detection levels in 2001. Although gross beta activity was detected, if gross beta concentrations were assumed to be completely attributable to strontium-90, they would account for only $1.1 \%$ of the strontium-90 DCG. Radiological data for WN8D1DR are found in Table C-13 (p. C-12).

South Plateau Sampling Locations. Two inactive underground radioactive waste disposal areas, the Nuclear Regulatory Commission (NRC)-licensed disposal area (NDA) and the state-licensed disposal area (SDA), lie on the south plateau of the site. (The SDA is managed by the New York State Energy and Research Development Authority [NYSERDA].) The drum cell, an aboveground structure used to store approximately 19,000 drums of processed low-level radioactive waste, is located nearby. Surface waters, which flow from the south to the north, are routinely monitored at several points around these areas. (See Fig. A-2 [p. A-4].) In addition to the routine samples collected by the WVDP, samples are collected and analyzed by the New York State Department of Health (NYSDOH) at the two stream sampling points that receive drainage from the south plateau, WNFRC67 and WNERB53.

NRC-Licensed Disposal Area. Sampling point WNNDATR is a sump at the lowest point in the collection trench system constructed along the northeastern and northwestern sides of the NDA that intercepts groundwater from the NDA. If radiological or nonradiological contamination were to migrate through the NDA, it would most likely be first detected in samples from WNNDATR. Monthly samples from WNNDATR are taken under the auspices of the environmental monitoring program and quarterly samples under the auspices of the groundwater monitoring program.

Surface water drainage downstream of the NDA is monitored at WNNDADR. Further downstream, water from sampling point WNERB53 in Erdman Brook, which represents surface waters from the NDA before they join with drainage from the main plant and lagoon areas, also is monitored. Some drainage from western and northwestern portions of the SDA also passes through sampling points WNNDADR and WNERB53.

Monthly results from WNNDATR, the sump in the interceptor trench, are in Table C-20 (p. C17) and quarterly results are listed under "NDATR" in Tables E-4, E-11, and E-13 (pp. E12, E-16, and E-18, respectively). Results from WNNDADR, surface water drainage downstream of the NDA, are in Table C-19 (p. C-16), and results from WNERB53, the sampling location even further downstream of the NDA, are in Table C-10 (p. C-10). Parameters monitored at 
these three NDA sampling locations include gross alpha, gross beta, tritium, iodine-129, and cesium-137.

Gross alpha and gross beta results from WNNDADR are included in Tables 2-1 and 2-2 (p. 2-5) for comparison with results from other surface water locations. In addition, fifteen-year trends of gross alpha, gross beta, and tritium concentrations at WNNDADR are plotted in Figure 2-2 (below). Allowing for seasonal variations, gross alpha and gross beta concentrations have been relatively stable over this time period, whereas tritium concentrations have been decreasing.

Gross Alpha. Gross alpha results from water samples taken at WNNDATR, WNNDADR, and WNERB53 in 2001 were indistinguishable from background results from Buttermilk Creek upstream of the site (WFBCBKG).

Gross Beta. Gross beta results at all three locations were elevated with respect to background, but even the maximum concentration, at WNNDADR, was less than 35\% of the DCG for strontium-90 in water $(1 \mathrm{E}-06 \mu \mathrm{Ci} / \mathrm{mL})$. The maximum result at Erdman Brook (WNERB53), further downstream of the NDA, was less than $4 \%$ of the strontium-90 DCG. Gross beta activity at these locations is attributable largely to strontium90. Residual soil contamination from past waste burial activities is thought to be the source of the activity. The NDA is thought to be the predominant source of gross beta activity observed at WNNDATR. Water collected at this location is treated prior to discharge at WNSP001.

Tritium. Although tritium concentrations at WNNDATR and WNNDADR were also elevated with respect to background values (those from WNERB53 were not), the maximum concentrations from both WNNDATR and WNNDADR were less than $1 \%$ of the DCG for tritium in water $(2 \mathrm{E}-03 \mu \mathrm{Ci} / \mathrm{mL})$. Allowing for seasonal variations, tritium concentrations seem to be generally decreasing at both WNNDATR and WNNDADR.

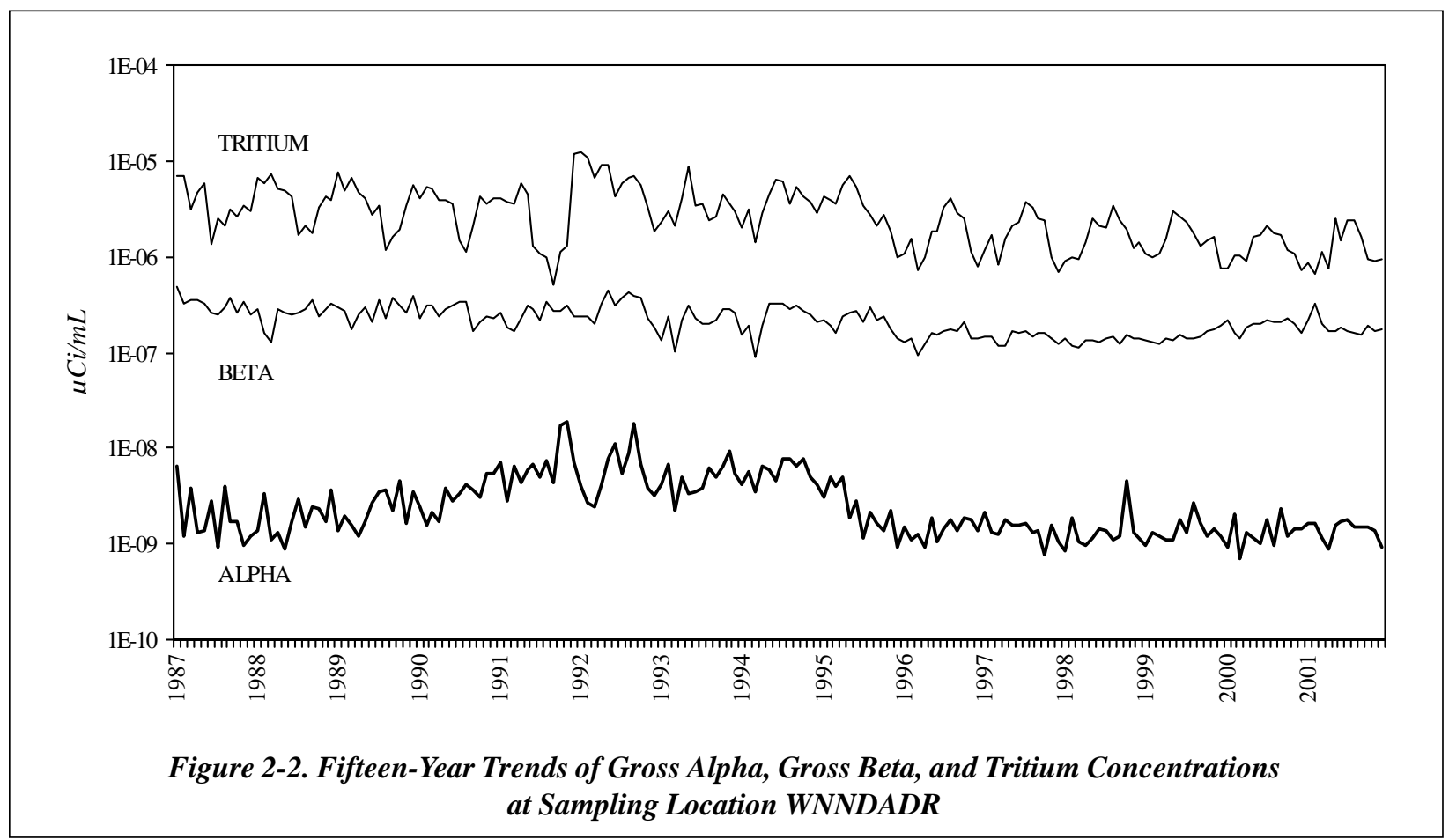


Since the half-life of tritium is slightly longer than twelve years, decreasing tritium concentrations may be partially attributable to radioactive decay.

Iodine-129. A key indicator of possible migration of nonradiological organic contaminants from the NDA would be iodine-129, which is soluble in water and is known to travel with the organic contaminants present in the NDA. Iodine-129 concentrations at WNNDADR and WNNDATR in 2001 were statistically indistinguishable from background concentrations.

Cesium-137. No cesium-137 activity was detected at either WNNDATR or WNNDADR in 2001.

Total Organic Halides. Total organic halides (TOX) measurements are used as a screening mechanism to detect the presence of certain organic compounds and associated radionuclides. Average TOX concentrations at both WNNDATR and WNNDADR, although lower in 2001 than in 2000 , remained within the range of historical values at these locations. (See also Results of Monitoring at the NDA in Chapter 3 [p. 3-13].)

New York State-Licensed Disposal Area. Point WNSDADR is used to monitor drainage from trench covers on the southwestern area of the SDA. Immediately south of the SDA, and upstream of WNSDADR, sampling point WNDCELD is used to monitor surface drainage from the area around the drum cell. (See Fig. A2 [p. A-4].) To the northeast, sampling point WNFRC67, in Frank's Creek, is used to monitor drainage downstream of the drum cell and the eastern and southern borders of the SDA. Results from WNSDADR, WNDCELD, and WNFRC67 are in Tables C-12 (p. C-11), C-14 (p. C-12), and C-9 (p. C-10), respectively.

Gross beta results at WNFRC67 and WNDCELD and tritium results at WNSDADR were elevated with respect to background measurements at WFBCBKG. Even so, maxima were all $1 \%$ or less of the respective DCG $(1 \mathrm{E}-06 \mu \mathrm{Ci} / \mathrm{mL}$ as strontium- 90 for gross beta and $2 \mathrm{E}-03 \mu \mathrm{Ci} / \mathrm{mL}$ for tritium). All other radiological results in calendar year 2001 at sampling points WNSDADR, WNDCELD, and WNFRC67 were statistically indistinguishable from background.

Standing Pond Water Sampling Locations. In addition to samples from moving water (streams or seeps), samples from ponds within the WNYNSC are also collected and tested annually for various radiological and water quality parameters to confirm that no major changes are occurring in standing water within the Project environs.

Four ponds near the site were tested in 2001. For comparison, a background pond 14.1 kilometers (8.8 mi) north of the Project was also tested. (See Figs. A-2, A-3, and A-13 [pp. A-4, A-5, and A15] for the locations of the five ponds and Table C-21 [p. C-18] for a summary of sampling results.) Although the gross beta result at standing water pond WNSTAW4 was elevated with respect to background, all other gross alpha, gross beta, and tritium results were statistically the same as concentrations at the background pond. If all gross beta activity at WNSTAW4 were attributable to strontium-90, it would constitute less than $1 \%$ of the strontium-90 DCG $(1 \mathrm{E}-06 \mu \mathrm{Ci} / \mathrm{mL})$.

\section{Off-Site Surface Water Sampling Locations.}

Samples of surface water are collected at four off-site locations, two on Buttermilk Creek and two on Cattaraugus Creek. Off-site surface water and sediment sampling locations are shown on Fig. A-3 (p. A-5). Tables 2-1 and 2-2 (p. 2-5) list the ranges and annual averages for gross alpha and gross beta activity at off-site surface water locations, which may be compared with data from on-site locations. 
Fox Valley Road and Thomas Corners Bridge Sampling Locations. Buttermilk Creek is the major surface drainage from the WNYNSC. Two surface water monitoring stations are located on Buttermilk Creek, one upstream of the WVDP at Fox Valley Road (WFBCBKG) and one downstream of the WVDP at Thomas Corners bridge (WFBCTCB). The Thomas Corners bridge sampling location is also upstream of Buttermilk Creek's confluence with Cattaraugus Creek. The Thomas Corners bridge sampling location represents an important link in the pathway to humans because dairy cattle have access to the water here.

Samples collected every week are composited monthly and analyzed for tritium, gross alpha, and gross beta radioactivity. A quarterly composite is analyzed for gamma-emitting radionuclides and strontium-90. Quarterly samples from WFBCBKG, the background location, also are analyzed for specific radionuclides as noted in Appendix B (p. B-29) and the results are used as a base for comparison with results of samples from site effluents.
Table C-22 (p. C-19) lists radionuclide concentrations at the Fox Valley Road background location; Table C-23 (p. C-20) lists radionuclide concentrations downstream of the site at Thomas Corners bridge.

Gross alpha, tritium, and cesium-137 concentrations at Thomas Corners bridge were statistically the same as background concentrations in 2001. Gross beta and strontium-90 concentrations at Thomas Corners bridge, however, were elevated in comparison to background and may be attributed to small amounts of radioactivity moving from the site, principally during periods of lagoon discharge via Frank's Creek.

The highest gross beta concentration at Thomas Corners bridge was $1.26 \mathrm{E}-08 \mu \mathrm{Ci} / \mathrm{mL}(0.47 \mathrm{~Bq} /$ $\mathrm{L})$. If compared to the most conservative guideline for beta emitters in water (strontium-90 at $1 \mathrm{E}-06 \mu \mathrm{Ci} / \mathrm{mL}[37 \mathrm{~Bq} / \mathrm{L}]$ ), gross beta concentrations at Thomas Corners bridge would be less than $2 \%$ of the DCG. The highest strontium- 90 concentration was $5.41 \mathrm{E}-09 \mu \mathrm{Ci} / \mathrm{mL}(0.20 \mathrm{~Bq} / \mathrm{L})$, less than $1 \%$ of the DCG.

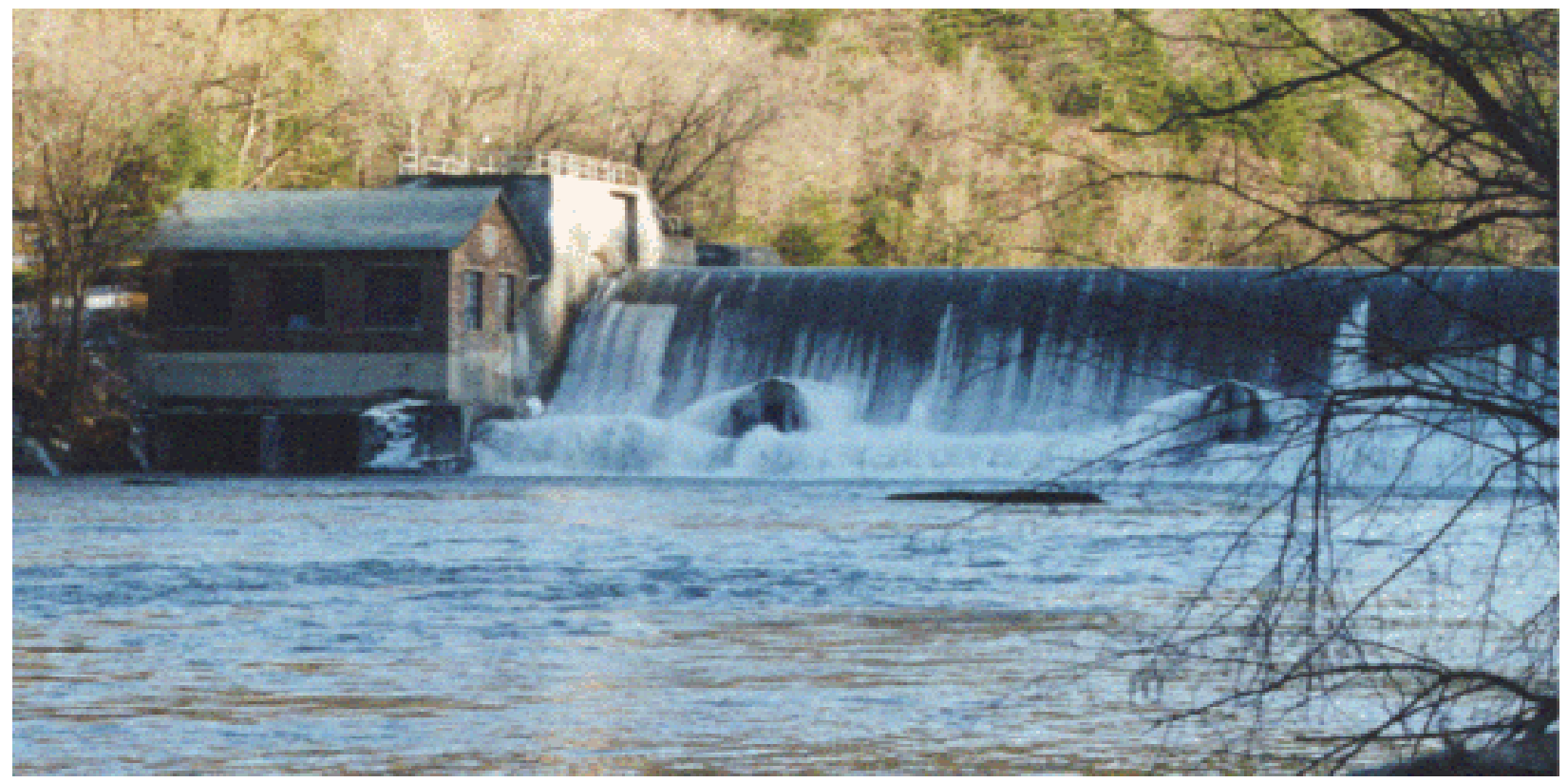

Springville Dam on Cattaraugus Creek 
Cattaraugus Creek at Felton Bridge and Bigelow Bridge Sampling Locations. Buttermilk Creek flows through the WNYNSC and then offsite, where it joins with Cattaraugus Creek. An automated sampler is located on Cattaraugus Creek at Felton Bridge (WFFELBR), just downstream of the point where Buttermilk Creek enters. Samples are collected weekly and analyzed for gross alpha, gross beta, and tritium concentrations. A chart recorder registers the stream depth during the sampling period so that a flow-weighted weekly sample can be proportioned into a monthly composite, which is analyzed for gross alpha, gross beta, tritium, strontium-90, and gamma-emitting radionuclides. (See Table C-24 [p. C-20].)

Background samples are collected monthly from Cattaraugus Creek at Bigelow Bridge (WFBIGBR), which is upstream of the point where Buttermilk Creek enters Cattaraugus Creek. These samples are analyzed for concentrations of gross alpha, gross beta, tritium, strontium-90, and gamma-emitting radionuclides. (See Table C-25 [p. C-21].)
No statistically significant differences were noted between results of analyses for gross alpha, tritium, strontium-90, and cesium-137 at either the upstream or downstream sampling locations. However, gross beta concentrations at Felton Bridge (WFFELBR) were higher than those at the background location at Bigelow Bridge (WFBIGBR). The highest gross beta concentration at Felton Bridge in 2001 was $7.79 \mathrm{E}-09 \mu \mathrm{Ci} / \mathrm{mL}(0.29 \mathrm{~Bq} /$ $\mathrm{L})$, which is about $1 \%$ of the DCG for strontium90. Figure 2-3 (below) shows gross alpha, gross beta, and tritium results over the past fifteen years in Cattaraugus Creek samples taken at Felton Bridge. For the most part, tritium concentrations represent method detection limits and not detected radioactivity. (Method detection limit values are levels below which the analytical measurement could not detect any radioactivity. See Data Reporting in Chapter 1 [p. 1-4].) Taking into account seasonal fluctuations, gross beta activity appears to have remained relatively constant at this location since 1987.

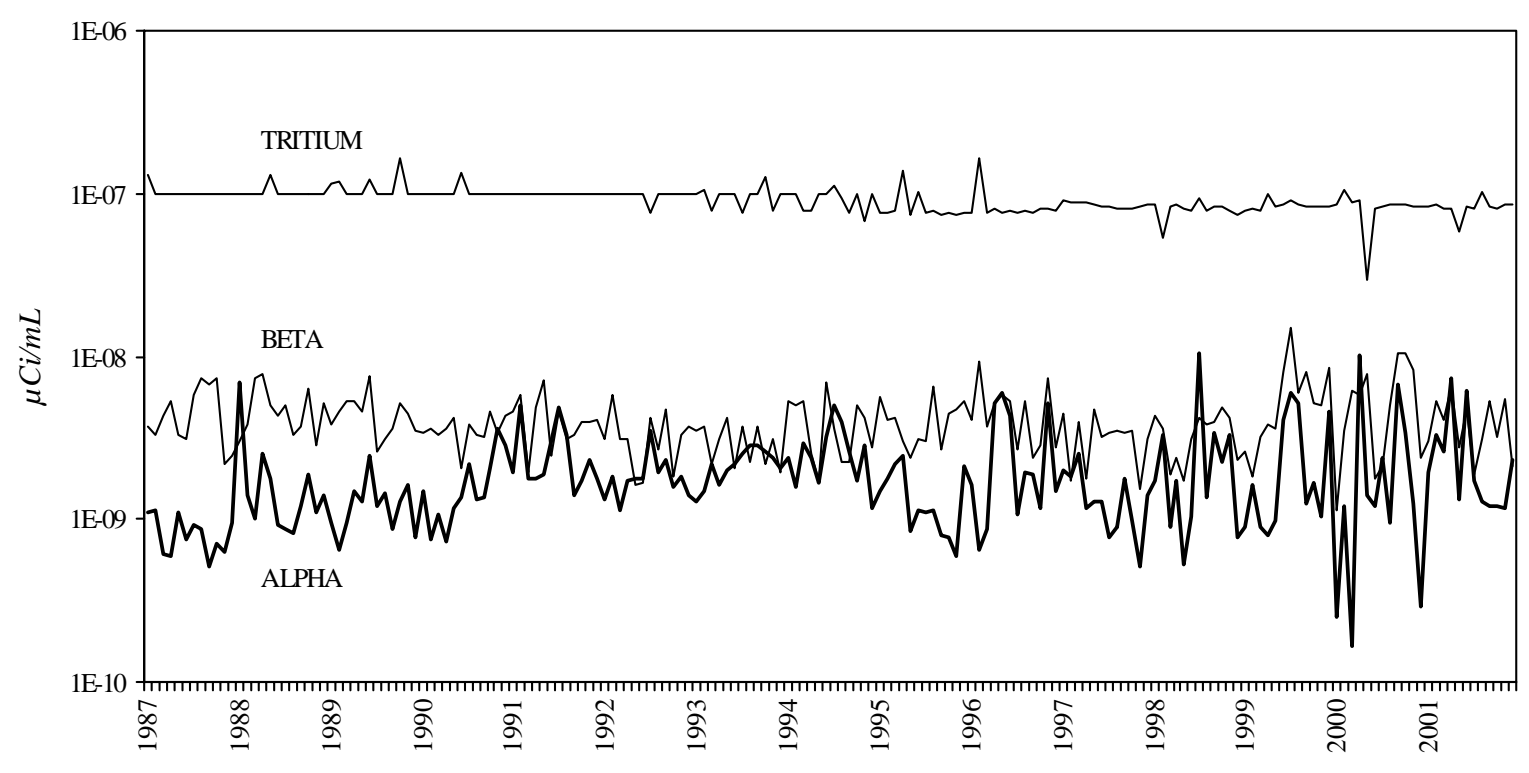

Figure 2-3. Fifteen-Year Trends of Gross Alpha, Gross Beta, and Tritium Concentrations at Sampling Location WFFELBR 
Drinking Water Sampling Locations. Drinking water (potable water) is sampled both off-site (near the WVDP) and on-site. Off-site drinking water samples are taken from wells that represent the nearest unrestricted use of groundwater near the Project; none of these wells draw from groundwater units underlying the site. Drinking water and utility water for the Project are drawn from two on-site surface water reservoirs.

Off-Site Wells. Nine off-site private, residential wells between 0.9 miles $(1.5 \mathrm{~km})$ and 4.3 miles $(7 \mathrm{~km})$ from the facility were sampled for radiological parameters in 2001. A tenth private well, 18 miles (29 $\mathrm{km})$ south of the site, provides a background sample. Sampling locations are shown in Figures A-9, A-12, and A-13 (pp. A-11, A-14, and A-15) in Appendix A. Results from the sampling are presented in Table C-26 (p. C-21). Radiological results in 2001 were within the range of historical values.

On-Site Drinking and Utility Water. On-site drinking water sources were also monitored for radionuclides at four locations: the Environmental Laboratory (WNDNKEL); the maintenance shop (WNDNKMS); the main plant (WNDNKMP); and the utility room (WNDNKUR). Monthly samples were analyzed for gross alpha, gross beta, and tritium concentrations. Results of analyses of samples from site locations were compared with those from the entry point location at the utility room, which serves as a control comparison sampling location for these drinking water samples. No differences between control values and those from site locations were noted. (See Appendix C, Tables C-15 through C-18 [pp. C-13 through C-15].)

\section{Radiological Monitoring: Sediments}

Particulate matter in streams can adsorb radiological constituents in liquid effluents, settle on the bottom of the stream as sediment, and subsequently be eroded or resuspended, especially during periods of high stream flow. These resuspended sediments may provide a pathway for radiological constituents to reach humans either directly via exposure or indirectly through the food pathway.

On-Site Sediments. Sediment samples are taken from the same locations as surface water samples and are identified as sediment samples by the "SN" prefix. (See Appendix B [p. B-iii].) Sediments are collected on-site at the three points where liquid effluents leaving the site are most likely to be radiologically contaminated: Frank's Creek where it leaves the security fence (SNSP006); the north swamp (SNSW74A); and the northeast swamp (SNSWAMP). Figure A-2 (p. A-4) shows the onsite sediment sampling locations. (Note that swamp sediment samples may be partially composed of soils.) Results from radiological analyses of these samples are listed in Table C-28 (p. C-23). As expected, gross beta, cesium-137, strontium-90, and certain alpha isotopic results were higher at the above three sediment sampling points than at the background sampling points.

Off-Site Sediments. Sediments are collected offsite at three locations downstream of the WVDP: Buttermilk Creek at Thomas Corners Road (SFTCSED), Cattaraugus Creek at Felton Bridge (SFCCSED), and Cattaraugus Creek at the Springville dam (SFSDSED). The first two sampling points are located at automatic water samplers. The other is behind the Springville dam, where water would be expected to transport and deposit sediments that had adsorbed radionuclides from the site. Locations upstream of the WVDP are Buttermilk Creek at Fox Valley Road (SFBCSED) and Cattaraugus Creek at Bigelow Bridge (SFBISED). The two upstream locations provide background data for comparison with downstream points. Figure A-3 (p. A-5) shows the off-site sediment sampling locations. 


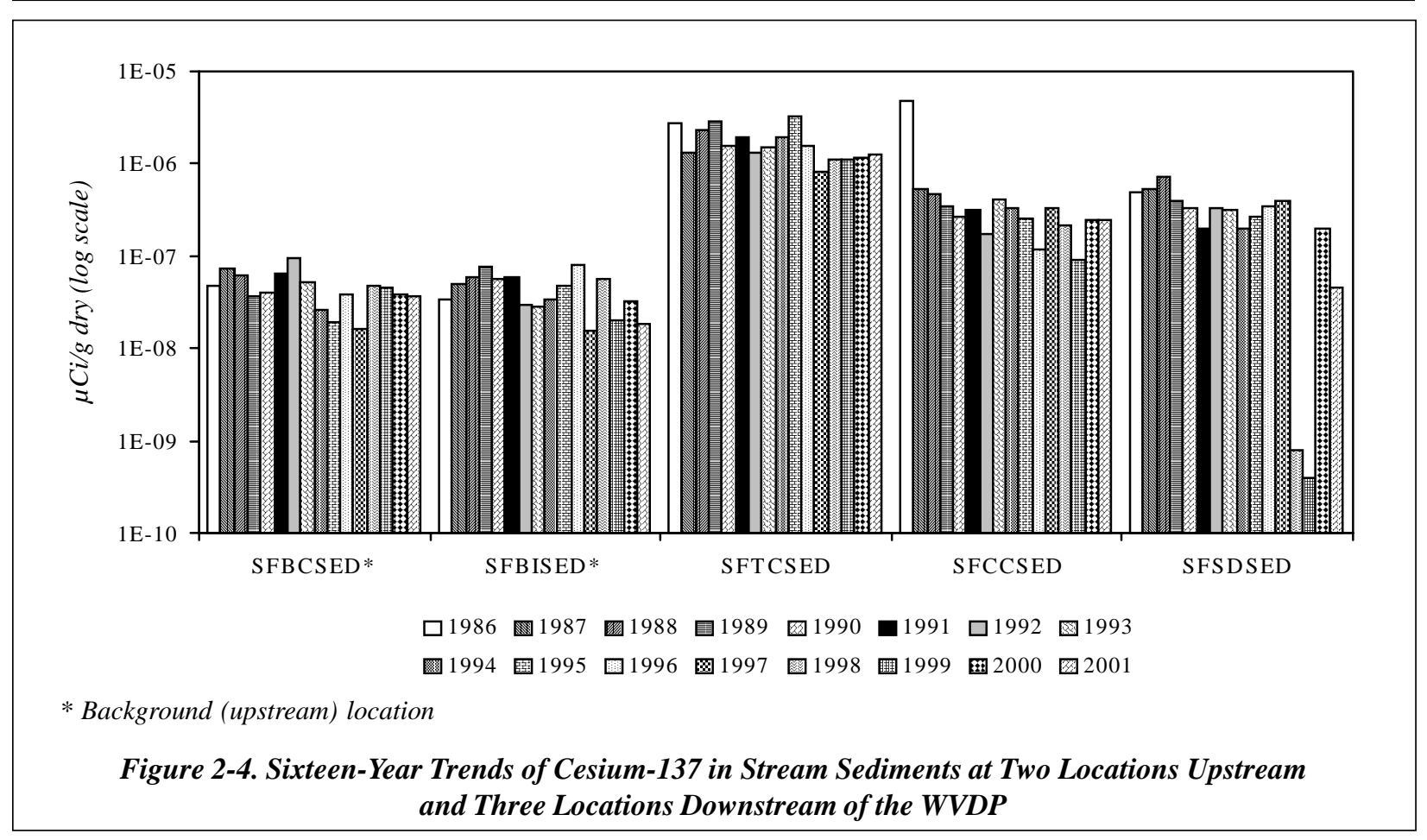

Most radiological results from downstream sediment sampling sites were statistically the same as those from background locations. However, sediments from Buttermilk Creek near Thomas Corners, the sampling location immediately downstream of the site, contained gross beta, strontium-90, and cesium-137 concentrations statistically higher than background. Sediments from Cattaraugus Creek by Felton Bridge also contained elevated cesium137 concentrations, consistent with historical results at this site. A comparison of annual averaged cesium-137 concentrations from 1986 through 2001 for the five off-site sampling locations is illustrated in Figure 2-4 (above). As the figure indicates, cesium-137 concentrations are relatively stable at the two background locations (SFBCSED and SFBISED) and are either stable or declining at the three locations downstream of the WVDP (SFTCSED, SFCCSED, and SFSDSED).

Although cesium-137 activity historically is elevated in downstream Cattaraugus Creek sediments, relative to upstream sediments (see Appendix C, Table

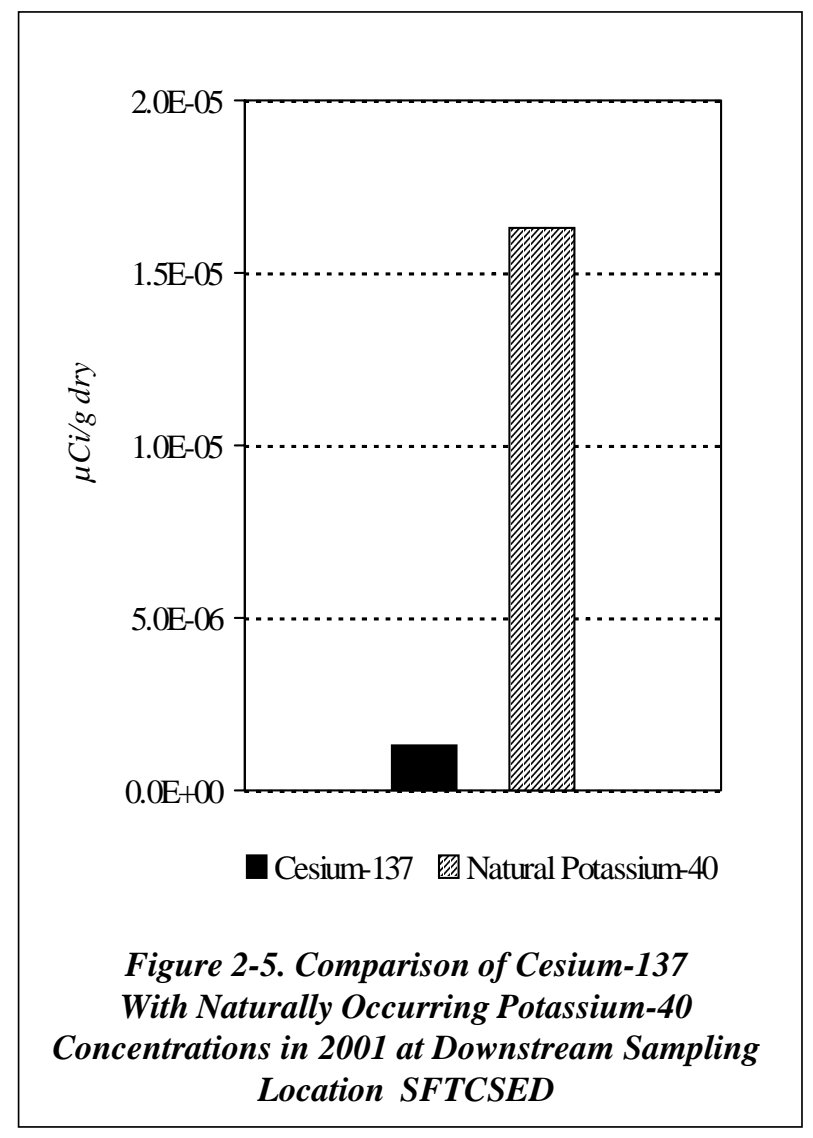
$2-13$ 
C-30 [p. C-25]), the levels are far lower than those of naturally occurring gamma emitters such as potassium-40. (See Fig. 2-5 [p. 2-13], which is a graphic comparison of cesium-137 to potassium40 at the downstream location nearest the WVDP, Buttermilk Creek at Thomas Corners Road SFTCSED.)

\section{Radiological Monitoring: Air}

Permits obtained from the U.S. Environmental Protection Agency (EPA) allow air containing small amounts of radioactivity to be released from plant ventilation stacks during normal operations. The air released must meet criteria specified in the National Emission Standards for Hazardous Air Pollutants (NESHAP) regulations to ensure that the environment and the public's health and safety are protected. Dose-based comparisons of WVDP emissions against NESHAP criteria are presented in Chapter 4, Radiological Dose Assessment.

Unlike NESHAP dose criteria, the DOE DCGs are expressed in units of $\mu \mathrm{Ci} / \mathrm{mL}$ and therefore can be directly compared with concentrations of radionuclides in WVDP air emissions. DOE standards and DCGs for radionuclides of interest at the WVDP are found in Appendix K, Table K-1 (p. K-3).

Radiological parameters measured in air emissions include concentrations of gross alpha and gross beta, tritium, strontium- 90 , cesium-137, and other radionuclides. When comparing concentrations with dose limits for screening purposes, gross alpha and beta radioactivities are assumed to come from americium-241 and strontium-90, respectively, because the dose effects for these radionuclides are the most limiting for major particulate emissions at the WVDP.

On-Site Ventilation Systems. The exhaust from each EPA-permitted fixed ventilation system on- site is continuously filtered, monitored, and sampled as it is released to the atmosphere. Because concentrations of radionuclides in air emissions are quite low, a large volume of air must be sampled at each point in order to measure the quantity of specific radionuclides released from the facility. Specially designed sampling nozzles continuously remove a representative portion of the exhaust air, which is then drawn through very fine glass fiber or membrane filters to trap particulates. Sensitive detectors continuously monitor these filters and provide readouts of alpha and beta radioactivity levels.

Separate sampling units on the ventilation stacks of the permitted systems contain another glass fiber filter that is removed every week and tested in the laboratory. These filters are analyzed routinely for the parameters delineated in Appendix $\mathrm{B}$ of this report.

Special samples also are collected in order to monitor gaseous (non-particulate) emissions of radioactivity. For example, six of the sampling systems contain an activated carbon cartridge that collects gaseous iodine-129, and at two locations water vapor is collected by trapping moisture in silica gel desiccant columns. The trapped water is distilled from the silica gel desiccant and analyzed for tritium. Figure A-4 (p. A-6) shows the locations of on-site air monitoring and sampling points.

The Main Plant Ventilation Stack. The main ventilation stack (ANSTACK) is the primary source of airborne releases at the WVDP. This stack, which vents to the atmosphere at a height of more than 60 meters (approximately $200 \mathrm{ft}$ ), releases filtered ventilation from several facilities, including the liquid waste treatment system, the analytical laboratories, and off-gas from the vitrification system.

Samples from the main plant stack are collected weekly and analyzed for gross alpha, gross beta, 


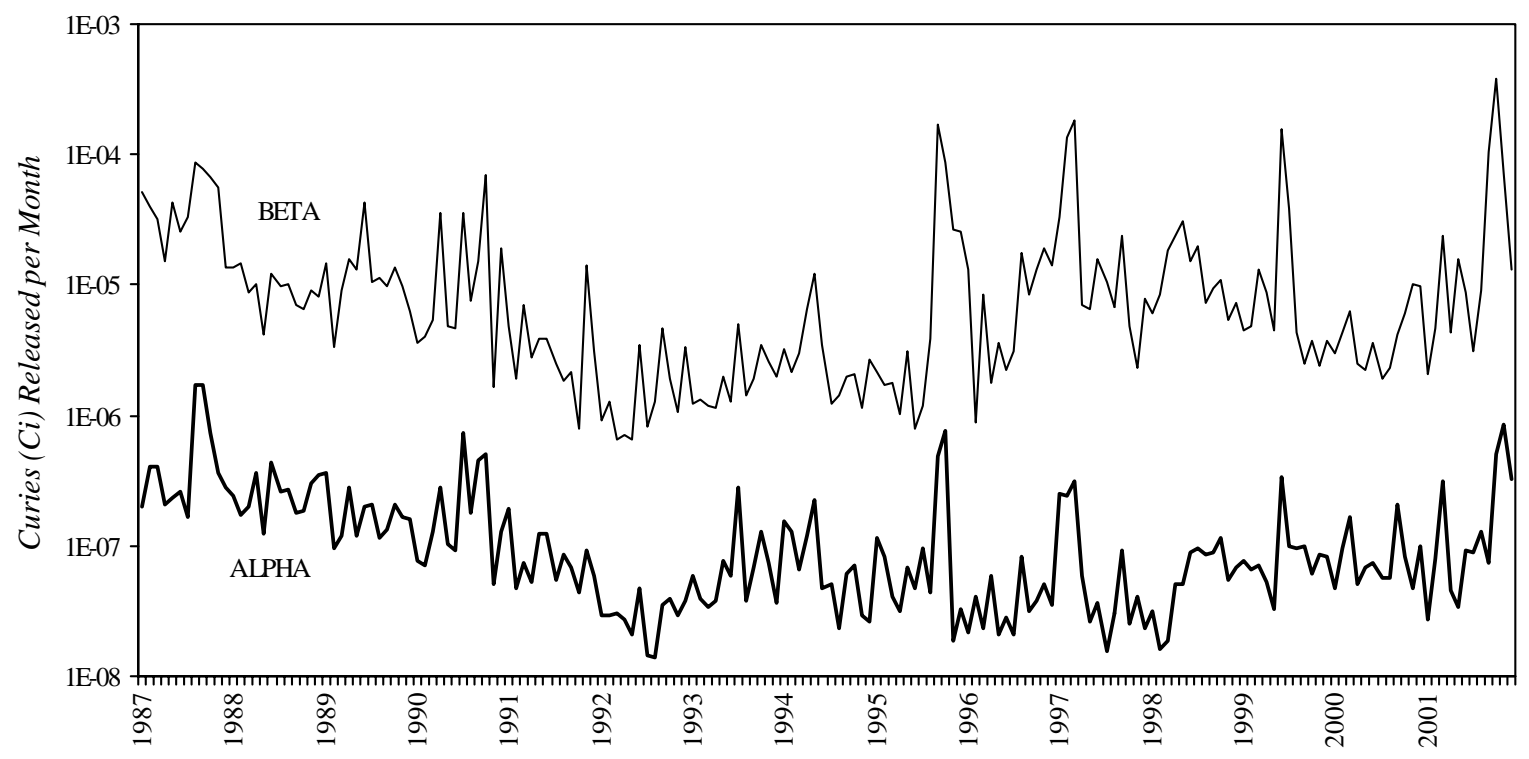

Figure 2-6. Fifteen-Year Trends of Gross Alpha and Gross Beta Activity at the Main Stack Sampling Location (ANSTACK)

and tritium concentrations. Weekly filters are composited quarterly and analyzed for strontium90, gamma-emitting radionuclides, total uranium, uranium isotopes, plutonium isotopes, and americium-241. Charcoal cartridges collected weekly are composited quarterly and analyzed for iodine129. In addition, filters from the main plant ventilation stack are routinely analyzed for strontium- 89 and cesium- 137 as part of operational-safety monitoring.

Monthly and quarterly total curies released from the main stack in 2001 are summarized in Table D-1 (p. D-3). Total curies released, annual averages, and a comparison of total curies released with the applicable DCGs are summarized in Table D-2 (p. D-4). As in previous years, 2001 results show that average radioactivity levels at the point of discharge from the stack were already below concentration guidelines for airborne radioactivity in an unrestricted environment. Airborne concentrations from the stack to the site boundary are further reduced via dispersion by a factor of more than 200,000. Results from air samples taken just outside the site boundary confirm that WVDP operations had no discernible effect on off-site air quality. (See Perimeter and Remote Air Sampling [p. 2-17].)

Figure 2-6 (above) shows the gross alpha and gross beta curies released per month from the main stack during the past fifteen years. The figure indicates a steady five-year downward trend in both gross alpha and gross beta activity from 1987 to mid-1992 and a stabilization through mid-1995. Previtrification transfers of cesium-loaded zeolite from waste tank 8D-1 to 8D-2 began in late 1995, and airborne releases increased.

In June 1998 the WVDP completed the first phase of high-level waste vitrification, processing the bulk of the waste in tank 8D-2. In the latter part of 1998 the focus of the vitrification program shifted to the second phase, vitrifying the high-level waste residuals in the tank. Phase II vitrification continued throughout 2001. 
Since radioactive vitrification operations began in mid1996, the radionuclide concentrations in air emissions have fluctuated while generally remaining higher than concentrations before vitrification began. In general, concentrations of gross beta, tritium, iodine-129, and cesium-137 have decreased during the second phase of vitrification. Gross alpha, strontium-90, and alpha isotopic concentrations, however, have shown slight increases during phase II. This phenomenon is thought to be partially attributable to the changing character of the waste being vitrified (residuals in phase II versus the bulk wastes of phase I). The changing radionuclide distribution may also reflect the increasing contribution to air emissions from decontamination of waste tanks, transfer lines, and main plant cells, in preparation for site closure.

Vitrification Heating, Ventilation, and Air Conditioning (HVAC) Sampling System. Sampling point ANVITSK and the seismically protected backup sample point ANSEISK monitor emissions from the vitrification HVAC system. (Off-gas ventilation from the vitrification system itself is released through the main plant stack.)

Radioactivity concentrations were monitored at ANVITSK and ANSEISK before actual radioactive vitrification began in July 1996. The previtrification levels provide a baseline for comparison with concentrations of radionuclides in emissions during vitrification. Results from 2001 are found in Tables D-3 and D-4 (pp. D-5 and D-6). Concentrations of radionuclides measured during 2001 were indistinguishable from background values.

Other On-Site Air Sampling Systems. Sampling systems similar to those of the main stack monitor airborne effluents from the 01-14 building ventilation stack (ANCSSTK), the contact size-reduction facility ventilation stack (ANCSRFK), the supernatant treatment system ventilation stack (ANSTSTK), and the container sorting and packaging facility ventilation stack (ANCSPFK). (See Fig. A-4 [p. A-6].)
Tables D-5 through D-8 (pp. D-7 through D-10) show monthly totals of gross alpha and beta radioactivity and quarterly total radioactivity released for specific radionuclides at each of these sampling locations. Samples from these locations (ANCSSTK, ANCSRFK, ANSTSTK, and ANCSPFK) occasionally showed detectable concentrations of gross radioactivity as well as specific beta- and alpha-emitting radionuclides, but none approached any DOE effluent limitations.

Two other operations are routinely monitored for airborne radioactive releases: the low-level waste treatment facility ventilation system (ANLLW2V), which came on-line in 1998, and the contaminated clothing laundry ventilation system (ANLAUNV). (Although one additional monitoring point [ANLLWTVH, the sampler for radioactive operations at the former low-level waste treatment ventilation] is listed as part of the routine sampling program, the location and sampler are no longer in use and the point may be deleted from the program. No samples were collected in 2001.)

The low-level waste treatment facility ventilation point and the laundry ventilation system are sampled for gross alpha and gross beta radioactivity. These emission points are not required to be permitted because the potential magnitude of the emissions is so low. Although only semiannual grab sampling is required to verify the low level of emissions, both points are sampled continuously while discharging to the environment. Data for these facilities are presented in Tables D-9 through D-11 (pp. D-11 and D-12). Results from these calendar year 2001 samples were well below DOE effluent limitations.

Permitted portable outdoor ventilation enclosures (OVEs) are used occasionally to provide the ventilation necessary for the safety of personnel working with radioactive materials in areas outside permanently ventilated facilities. Air samples from 
OVEs are collected continuously while those emission points are discharging, and data from these units are included in annual airborne emission evaluations. (See Table D-15 [p. D-16].) Average discharges from OVEs were well below DOE guidelines for alpha and beta radioactivity in an unrestricted environment.

Three on-site air samplers collect samples of ambient air in the vicinity of three on-site waste storage units - the lag storage area (ANLAGAM), the NDA (ANNDAAM), and the SDA (ANSDAT9). (See Fig. A-4 [p. A-6].) These samplers were put in place to monitor potential diffuse releases of radioactivity. Monitoring data from these locations are presented in Appendix D, Tables D-12 through D-14 (pp. D-13 through D-15).

With the exception of tritium results at ANSDAT9, radiological data sets for the three locations are statistically indistinguishable from results for background air monitoring locations at Great Valley (AFGRVAL) and Nashville (AFNASHV). Although tritium results at ANSDAT9 were elevated with respect to background, even the highest result $(2.80 \mathrm{E}-12 \mu \mathrm{Ci} / \mathrm{mL}[1.04 \mathrm{E}-04 \mathrm{~Bq} / \mathrm{L}])$ was less than $0.1 \%$ of the DOE DCG for tritium in air $(1 \mathrm{E}-07 \mu \mathrm{Ci} / \mathrm{mL})$.

Perimeter and Remote Air Sampling. Samples for radionuclides in air are collected continuously at six locations around the perimeter of the site and at four remote locations. Maps of perimeter and remote air sampling locations are found on Figures A-5, A-12, and A-13 (pp. A-7, A-14, and A-15).

The perimeter locations on Fox Valley Road (AFFXVRD), Rock Springs Road (AFRSPRD), Route 240 (AFRT240), Thomas Corners Road (AFTCORD), Dutch Hill Road (AFBOEHN), and at the site's bulk storage warehouse (AFBLKST) were chosen because they provide historical con- tinuity (as former NFS sampling locations) or because they represent the most likely locations for detecting off-site airborne concentrations of radioactivity.

The remote locations provide data from nearby communities - West Valley (AFWEVAL) and Springville (AFSPRVL) - and from more distant background areas. Concentrations measured at Great Valley (AFGRVAL, 19 miles [30.9 km] south of the site) and Nashville (AFNASHV, 25 miles $[39.8 \mathrm{~km}]$ west of the site in the town of Hanover) are considered representative of regional background air.

At all locations airborne particulates are collected on filters for radiological analysis. Samplers maintain an average flow of approximately $1.4 \mathrm{ft}^{3} / \mathrm{min}$ (40 L/min) through a 47 -millimeter glass fiber filter. The sampler heads are set above the ground

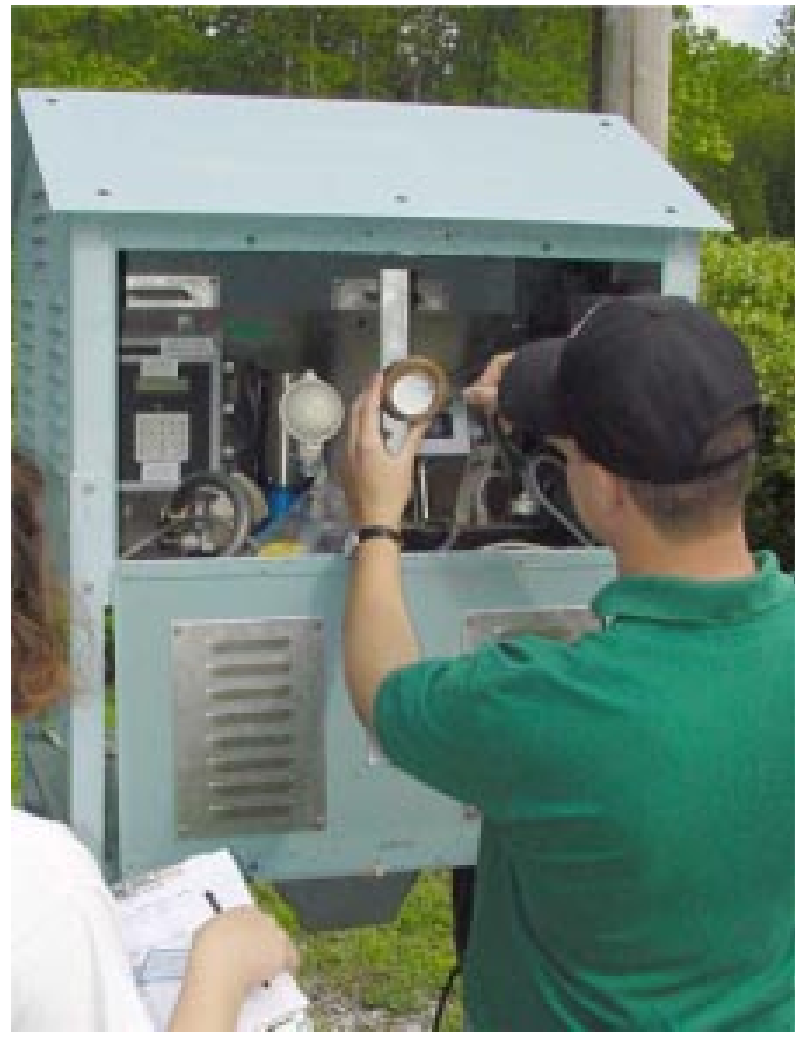

Changing an Air Filter at an Air Sampling Station 
at the height of the average human breathing zone. Filters are collected weekly and analyzed after a seven-day "decay" period to remove interference from short-lived naturally occurring radionuclides. After weekly sample filters are measured for gross alpha and gross beta concentrations, they are combined in a quarterly composite consisting of thirteen weekly filters. The composite is analyzed for specific alpha-emitting, beta-emitting, and gamma-emitting radionuclides.

At two locations, the nearest perimeter location in the predominant downwind direction (Rock Springs Road) and the primary background location (Great Valley), desiccant columns are used to collect airborne moisture for tritium analysis and charcoal cartridges are used to collect samples for iodine129 analysis.

Trends of gross alpha and gross beta concentrations at the Rock Springs Road location are shown in Figure 2-7 (below). Within a range of seasonal and weekly fluctuations, the concentrations have been relatively constant over the past fifteen years. The gross alpha and gross beta ranges and annual averages for each of the off-site sampling points are noted on Tables 2-3 and 2-4 (facing page). All gross alpha averages were below detection levels. Gross beta results from samples taken at two near-site communities and from the site perimeter were statistically the same as those from the background samplers, suggesting that there is no adverse site influence on the air quality at these near-site locations. Gross beta concentrations at all off-site and perimeter locations averaged about $1.88 \mathrm{E}-14 \mu \mathrm{Ci} / \mathrm{mL}$, which is about $0.2 \%$ of the DCG for strontium- 90 in air $(9 \mathrm{E}-12 \mu \mathrm{Ci} / \mathrm{mL})$. The highest average gross beta concentration $(1.97 \mathrm{E}-14 \mu \mathrm{Ci} / \mathrm{mL}$ [about $0.22 \%$ of the DCG]) was at Boehn Road.

Additional radionuclide data from these samplers are provided in Tables D-16 through D-25 (pp. D17 through D-23).

Although low levels of tritium, strontium-90, iodine-129, and cesium-137 were detected in emis-

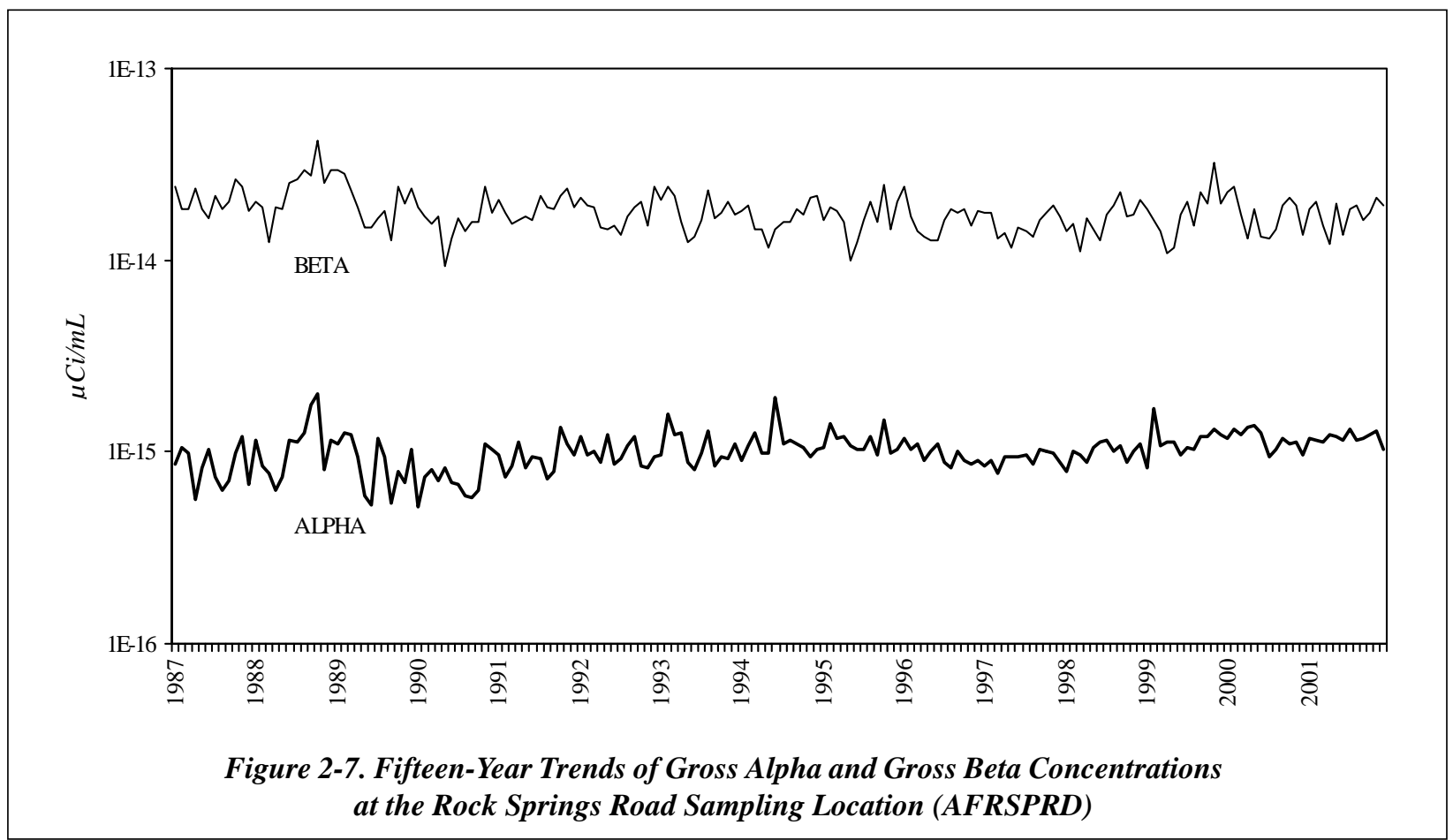


Radiological Monitoring: Air

Table 2-3

2001 Gross Alpha Concentrations at Off-Site, Perimeter, and On-Site Ambient Air Sampling Locations

$\begin{array}{lr}\text { Location } & \begin{array}{r}\text { Number } \\ \text { Samp }\end{array} \\ & \\ \text { AFBLKST } & 52 \\ \text { AFBOEHN } & 52 \\ \text { AFFXVRD } & 52 \\ \text { AFGRVAL } & 52 \\ \text { AFNASHV } & 52 \\ \text { AFRSPRD } & 52 \\ \text { AFRT240 } & 52 \\ \text { AFSPRVL } & 52 \\ \text { AFTCORD } & 52 \\ \text { AFWEVAL } & 52 \\ \text { ANLAGAM } & 52 \\ \text { ANNDAAM } & 52 \\ \text { ANSDAT9 } & 52\end{array}$

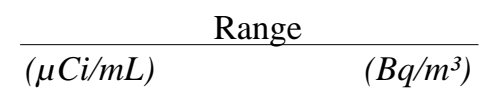

$<6.50 \mathrm{E}-16$ to $2.54 \mathrm{E}-15$ $<8.24 \mathrm{E}-16$ to $2.30 \mathrm{E}-15$ $<8.44 \mathrm{E}-16$ to $3.18 \mathrm{E}-15$ $<8.93 \mathrm{E}-16$ to $2.84 \mathrm{E}-15$ $<7.76 \mathrm{E}-16$ to $2.70 \mathrm{E}-15$ $<7.33 \mathrm{E}-16$ to $2.14 \mathrm{E}-15$ $<7.68 \mathrm{E}-16$ to $2.22 \mathrm{E}-15$ $<8.58 \mathrm{E}-16$ to $2.32 \mathrm{E}-15$ $<9.09 \mathrm{E}-16$ to $2.49 \mathrm{E}-15$ $<8.42 \mathrm{E}-16$ to $2.27 \mathrm{E}-15$ $<6.60 \mathrm{E}-16$ to $2.18 \mathrm{E}-15$ $<6.31 \mathrm{E}-16$ to $1.93 \mathrm{E}-15$ $<8.15 \mathrm{E}-16$ to $2.01 \mathrm{E}-15$
$<2.41 \mathrm{E}-05$ to $9.39 \mathrm{E}-05$ $<3.05 \mathrm{E}-05$ to $8.52 \mathrm{E}-05$ $<3.12 \mathrm{E}-05$ to $1.18 \mathrm{E}-04$ $<3.30 \mathrm{E}-05$ to $1.05 \mathrm{E}-04$ $<2.87 \mathrm{E}-05$ to $9.98 \mathrm{E}-05$ $<2.71 \mathrm{E}-05$ to $7.91 \mathrm{E}-05$ $<2.84 \mathrm{E}-05$ to $8.22 \mathrm{E}-05$ $<3.18 \mathrm{E}-05$ to $8.57 \mathrm{E}-05$ $<3.36 \mathrm{E}-05$ to $9.21 \mathrm{E}-05$ $<3.11 \mathrm{E}-05$ to $8.40 \mathrm{E}-05$ $<2.44 \mathrm{E}-05$ to $8.05 \mathrm{E}-05$ $<2.34 \mathrm{E}-05$ to $7.13 \mathrm{E}-05$ $<3.02 \mathrm{E}-05$ to $7.43 \mathrm{E}-05$
Annual Average

$(\mu \mathrm{Ci} / \mathrm{mL}) \quad\left(\mathrm{Bq} / \mathrm{m}^{3}\right)$

$\begin{array}{ll}0.50 \pm 1.19 \mathrm{E}-15 & 1.85 \pm 4.39 \mathrm{E}-05 \\ 0.77 \pm 1.23 \mathrm{E}-15 & 2.83 \pm 4.54 \mathrm{E}-05 \\ 0.67 \pm 1.23 \mathrm{E}-15 & 2.48 \pm 4.54 \mathrm{E}-05 \\ 0.64 \pm 1.24 \mathrm{E}-15 & 2.35 \pm 4.60 \mathrm{E}-05 \\ 0.68 \pm 1.25 \mathrm{E}-15 & 2.52 \pm 4.61 \mathrm{E}-05 \\ 0.48 \pm 1.19 \mathrm{E}-15 & 1.79 \pm 4.41 \mathrm{E}-05 \\ 0.74 \pm 1.27 \mathrm{E}-15 & 2.72 \pm 4.70 \mathrm{E}-05 \\ 0.68 \pm 1.24 \mathrm{E}-15 & 2.51 \pm 4.58 \mathrm{E}-05 \\ 0.72 \pm 1.23 \mathrm{E}-15 & 2.66 \pm 4.55 \mathrm{E}-05 \\ 0.69 \pm 1.26 \mathrm{E}-15 & 2.54 \pm 4.67 \mathrm{E}-05 \\ 7.85 \pm 9.20 \mathrm{E}-16 & 2.90 \pm 3.41 \mathrm{E}-05 \\ 6.97 \pm 8.96 \mathrm{E}-16 & 2.58 \pm 3.32 \mathrm{E}-05 \\ 0.59 \pm 1.22 \mathrm{E}-15 & 2.18 \pm 4.50 \mathrm{E}-05\end{array}$

Table 2-4

\section{Gross Beta Concentrations at Off-Site, Perimeter, and On-Site Ambient Air Sampling Locations}

Location $\quad \begin{gathered}\text { Number of } \\ \text { Samples }\end{gathered}$

$\begin{array}{ll}\text { AFBLKST } & 52 \\ \text { AFBOEHN } & 52 \\ \text { AFFXVRD } & 52 \\ \text { AFGRVAL } & 52 \\ \text { AFNASHV } & 52 \\ \text { AFRSPRD } & 52 \\ \text { AFRT240 } & 52 \\ \text { AFSPRVL } & 52 \\ \text { AFTCORD } & 52 \\ \text { AFWEVAL } & 52 \\ \text { ANLAGAM } & 52 \\ \text { ANNDAAM } & 52 \\ \text { ANSDAT9 } & 52\end{array}$

$$
\begin{aligned}
& \text { Range } \\
& (\mu \mathrm{Ci} / \mathrm{mL}) \quad\left(B q / \mathrm{m}^{3}\right)
\end{aligned}
$$

$$
\begin{array}{rr}
\text { 8.49E-15 to } 4.22 \mathrm{E}-14 & 3.14 \mathrm{E}-04 \text { to } 1.56 \mathrm{E}-03 \\
\text { 9.10E-15 to } 4.93 \mathrm{E}-14 & 3.37 \mathrm{E}-04 \text { to } 1.82 \mathrm{E}-03 \\
4.80 \mathrm{E}-15 \text { to } 4.36 \mathrm{E}-14 & 1.78 \mathrm{E}-04 \text { to } 1.62 \mathrm{E}-03 \\
6.43 \mathrm{E}-15 \text { to } 4.33 \mathrm{E}-14 & 2.38 \mathrm{E}-04 \text { to } 1.60 \mathrm{E}-03 \\
<1.93 \mathrm{E}-15 \text { to } 4.32 \mathrm{E}-14 & <7.15 \mathrm{E}-05 \text { to } 1.60 \mathrm{E}-03 \\
\text { 5.62E-15 to } 3.89 \mathrm{E}-14 & 2.08 \mathrm{E}-04 \text { to } 1.44 \mathrm{E}-03 \\
6.70 \mathrm{E}-15 \text { to } 4.09 \mathrm{E}-14 & 2.48 \mathrm{E}-04 \text { to } 1.51 \mathrm{E}-03 \\
7.13 \mathrm{E}-15 \text { to } 4.48 \mathrm{E}-14 & 2.64 \mathrm{E}-04 \text { to } 1.66 \mathrm{E}-03 \\
8.34 \mathrm{E}-15 \text { to } 4.39 \mathrm{E}-14 & 3.09 \mathrm{E}-04 \text { to } 1.62 \mathrm{E}-03 \\
6.48 \mathrm{E}-15 \text { to } 4.43 \mathrm{E}-14 & 2.40 \mathrm{E}-04 \text { to } 1.64 \mathrm{E}-03 \\
7.75 \mathrm{E}-15 \text { to } 4.97 \mathrm{E}-14 & 2.87 \mathrm{E}-04 \text { to } 1.84 \mathrm{E}-03 \\
<1.28 \mathrm{E}-15 \text { to } 4.08 \mathrm{E}-14 & <4.74 \mathrm{E}-05 \text { to } 1.51 \mathrm{E}-03 \\
7.78 \mathrm{E}-15 \text { to } 4.82 \mathrm{E}-14 & 2.88 \mathrm{E}-04 \text { to } 1.78 \mathrm{E}-03
\end{array}
$$

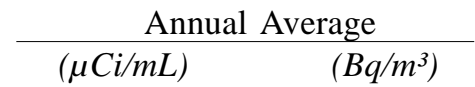

$\begin{array}{ll}1.88 \pm 0.33 \mathrm{E}-14 & 6.95 \pm 1.22 \mathrm{E}-04 \\ 1.97 \pm 0.33 \mathrm{E}-14 & 7.31 \pm 1.22 \mathrm{E}-04 \\ 1.93 \pm 0.33 \mathrm{E}-14 & 7.15 \pm 1.23 \mathrm{E}-04 \\ 1.92 \pm 0.34 \mathrm{E}-14 & 7.11 \pm 1.24 \mathrm{E}-04 \\ 1.93 \pm 0.34 \mathrm{E}-14 & 7.15 \pm 1.24 \mathrm{E}-04 \\ 1.76 \pm 0.32 \mathrm{E}-14 & 6.51 \pm 1.20 \mathrm{E}-04 \\ 1.86 \pm 0.33 \mathrm{E}-14 & 6.88 \pm 1.23 \mathrm{E}-04 \\ 1.89 \pm 0.33 \mathrm{E}-14 & 6.98 \pm 1.23 \mathrm{E}-04 \\ 1.87 \pm 0.33 \mathrm{E}-14 & 6.92 \pm 1.21 \mathrm{E}-04 \\ 1.83 \pm 0.33 \mathrm{E}-14 & 6.75 \pm 1.22 \mathrm{E}-04 \\ 2.01 \pm 0.27 \mathrm{E}-14 & 7.44 \pm 0.99 \mathrm{E}-04 \\ 1.78 \pm 0.25 \mathrm{E}-14 & 6.59 \pm 0.94 \mathrm{E}-04 \\ 1.89 \pm 0.33 \mathrm{E}-14 & 7.01 \pm 1.22 \mathrm{E}-04\end{array}$


sions from the main stack on-site, results for these radionuclides at near-site locations were indistinguishable from background values, confirming that site releases have a negligible effect on near-site air quality.

Fallout Pot Sampling. Short-term fallout samples are analyzed for radionuclide concentrations each month at four of the perimeter air sampler locations and at one on-site location near the rain gauge outside the Environmental Laboratory. (See Figs. A-4 and A-5 [pp. A-6 and A-7].) Monthly gross alpha, gross beta, potassium-40, and cesium-137 results are reported in nanocuries per square meter $\left(\mathrm{nCi} / \mathrm{m}^{2}\right)$ and tritium results are reported in $\mu \mathrm{Ci} /$ $\mathrm{mL}$. Results from on-site and perimeter locations were similar to each other and to results noted in previous years. The low levels of tritium and cesium-137 released in main stack emissions did not measurably affect on-site or perimeter fallout pot samples in 2001. The data from these analyses and the $\mathrm{pH}$ in precipitation are summarized in Tables D-26 through D-30 (pp. D-24 through D-26).

Off-Site Surface Soil Sampling. In order to assess long-term fallout deposition, surface soil near the off-site air samplers is collected annually and analyzed for radioactivity. Samples were collected from ten locations: six near-site points on the perimeter of the WNYNSC, two in nearby communities, and two in locations 19 to 25 miles (30 to 40 $\mathrm{km}$ ) distant from the Project. Maps of the off-site surface soil sampling locations are on Figures A3, A-12, and A-13 (pp. A-5, A-14, and A-15).

Concentrations of gross alpha and beta radioactivity, strontium-90, cesium-137, plutonium-239/ 240 , and americium-241 were determined at all ten locations; concentrations of uranium isotopes and total uranium were determined at two perimeter locations and one background location. The measured concentrations of most site-related radionuclides in soils from the perimeter and com- munity locations (Table C-29 [p. C-24]) were statistically indistinguishable from normal regional background concentrations. Elevated gross beta concentrations were noted at Thomas Corners and at the Bulk Storage Warehouse, consistent with historical data from these soil sampling locations. In 2001, as in the past, cesium-137 concentrations from the Rock Springs Road location - northwest of the site-remained higher than background concentrations.

\section{Radiological Monitoring: Food Chain}

Each year food and forage samples are collected from locations near the site (Fig. A-9 [p. A-11]) and from remote locations (Figs. A-12 and A-13 [pp. A-14 and A-15] in Appendix A). Fish and deer are collected during periods when they would normally be taken by sportsmen for consumption. Most milk samples are collected monthly; beef is collected semiannually. Hay, corn, apples, and beans are collected at the time of harvest.

Fish. Fish are obtained under a collector's permit by electrofishing, a method that temporarily stuns the fish, allowing them to be netted for collection. Electrofishing allows more efficient species-selective control than sport fishing, with unwanted fish being returned to the creek essentially unharmed.

Fish are collected from three locations in Cattaraugus Creek: Two locations are downstream of WNYNSC drainage - one above the Springville dam (BFFCATC) and one below the Springville dam (BFFCATD) - and one location is upstream of the site (BFFCTRL). (See Figs. A-9 and A-13 [pp. A-11 and A-15].)

A total of fifty fish were collected from Cattaraugus Creek in 2001 for testing. Twenty were taken from the control location upstream of the site (BFFCTRL), ten the first half of the year and ten the second half 


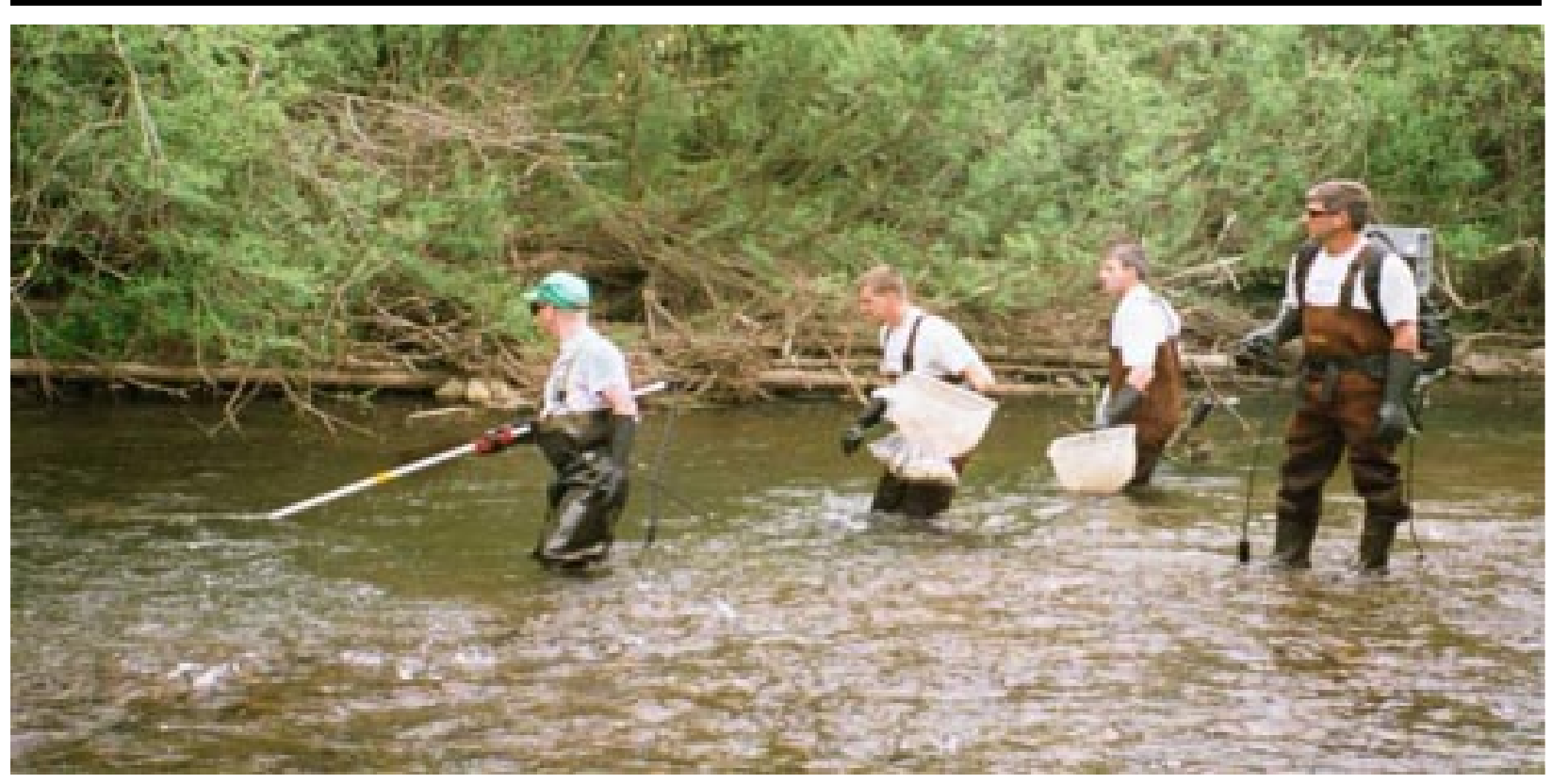

Electrofishing in Cattaraugus Creek

of the year. Twenty were taken immediately downstream of the site (BFFCATC) but above the Springville dam, ten the first half of the year and ten the second half of the year. The remaining ten fish were taken below the dam (BFFCATD), including species that migrate about 40 miles (more than 60 $\mathrm{km}$ ) upstream from Lake Erie.

The edible portion of each fish was analyzed for strontium-90 content and the gamma-emitting radionuclide cesium-137. (See Table F-4 [pp. F-6 through F-8] in Appendix F for a summary of the results.)

Strontium-90 results from fish above the Springville dam (at BFFCATC) were elevated in comparison with the background samples (from BFFCTRL), however, results from below the dam (BFFCATD) were not. Strontium-90 concentrations at both locations were within the range of historical results.

Cesium-137 concentrations were not higher than background concentrations at either of the down- stream sampling locations (BFFCATC or BFFCATD).

Venison. Venison from vehicle-deer accidents around the WNYNSC and from deer collected far from the site in the towns of Wellsville, Humphrey, and Freedom, New York was analyzed for tritium, naturally occurring potassium-40, strontium-90, and cesium-137 concentrations. (See Figs. A-9, A-12, and A-13 [pp. A-11, A-14, and A-15].) Results from these samples are shown in Table F-2 (p. F-4) in Appendix F.

No tritium was detected in any of the samples, however, strontium-90 and cesium-137, radionuclides of concern in WVDP effluents, were detected in both near-site and control samples. Although results vary from year to year, data from the last eleven years show no statistical differences between concentrations of these radionuclides in near-site and control samples.

For the last seven years, during the large-game hunting season, hunters were allowed access to 
designated areas within the WNYNSC, excluding the WVDP premises, in a controlled hunting program established by NYSERDA. The hunt was canceled in 2001 because of heightened security concerns. However, data from previous hunts have shown that concentrations of radioactivity in deer flesh have been very low, indicating that Project activities have little or no effect on the local herd.

Beef. Beef samples are taken semiannually from both near-site and remote locations (Figs. A-9 and A-13 [pp. A-11 and A-15] in Appendix A) and are analyzed for tritium, potassium-40, strontium-90, and cesium-137. Results are presented in Table F-2 (p. F-4) in Appendix F. As with the deer samples, no tritium was detected and low levels of strontium-90 and cesium-137 were detected in both near-site and background samples. No significant differences were found between results for these radionuclides from near-site and background samples.

Milk. Monthly milk samples were taken from dairy farms near the site to the north and west downwind in the prevailing wind direction from the WVDP - and from farms more than 15 miles $(25 \mathrm{~km})$ from the site and used as control locations. Annual milk samples were collected at two near-site farms to the south and east of the site. The locations of the near-site and remote sampling points are shown in Figure A-9 (p. A-11) and Figure A-13 (p. A-15) in Appendix A.

The monthly samples from each location were composited into single quarterly samples for analysis. These quarterly composites and annual samples were analyzed for tritium, potassium-40, strontium-90, iodine-129, and cesium-137. Results are presented in Table F-1 (p. F-3) in Appendix F. Near-site sample results were indistinguishable from background control sample results.

Vegetables, Fruit, and Forage. Sweet corn, beans, apples, and hay were collected at near-site and back- ground locations at harvest time. Sampling locations are shown on Figures A-9 (p. A-11), A-12 (p. A14), and A-13 (p. A-15) in Appendix A. Samples were analyzed for tritium, potassium-40, cobalt-60, strontium-90, and cesium-137. Results are presented in Table F-3 (p. F-5) in Appendix F.

Low levels of strontium-90 were noted in both background and near-site samples. Radionuclide results, including strontium-90, for near-site samples were statistically the same as measurements from background samples.

\section{Direct Environmental Radiation Monitoring}

This was the eighteenth full year in which direct penetrating radiation was monitored at the WVDP. Thermoluminescent dosimeters (TLDs) are placed at each monitoring location for one calendar quarter (three months) and are then processed to obtain the integrated gamma radiation exposure at that location.

Monitoring points are located on-site at the waste management units, at the site security fence, around the WNYNSC perimeter and the access road, and at background locations remote from the WVDP (Figs. A-10 through A-13 [pp. A-12 through A-15]). The identification numbers associated with each location were assigned in chronological order of original installation. (See TLD Locations and Identification Numbers [p. 2-23].)

Quarterly and annual averages of TLD measurements at off-site and on-site locations are noted in Appendix H, Tables $\mathrm{H}-1$ and $\mathrm{H}-2$ (pp. $\mathrm{H}-3$ and $\mathrm{H}-4$ ). The results of measurements in 2001 show typical seasonal variations and are similar to results from previous years.

On-Site Radiation Monitoring. Table H-2 (p. $\mathrm{H}-4$ ) shows the average quarterly exposure rate at each on-site TLD. The on-site monitoring point 
with the highest dose readings was location \#24. Sealed containers of radioactive components and debris from the plant decontamination work are stored nearby. This storage area is well within the WNYNSC boundary, just inside the WVDP fenced area, and is not accessible by the public.

The average exposure rate at location \#24 was about 523 milliroentgens $(\mathrm{mR})$ per quarter $(0.24$ $\mathrm{mR} / \mathrm{hr}$ ) during 2001, slightly lower than the exposure rate noted at this location in 2000 (0.29 $\mathrm{mR} / \mathrm{hr}$ ). Exposure rates at this location are gradually decreasing because the radioactivity in the materials stored nearby is decaying. (See Fig. 1-1 [p. 1-10] in Chapter 1.)

The average penetrating radiation exposure rate in 2001 at locations 100 to 400 feet ( 30 to $120 \mathrm{~m}$ ) distant from the integrated radwaste treatment storage building - the drum cell - including TLDs \#18, \#32, \#34, \#35, \#36, and \#43, was $0.02 \mathrm{mR/}$ $\mathrm{hr}$, about the same as in 2000. Exposure rates around the drum cell are above background levels (approximately $0.01 \mathrm{mR} / \mathrm{hr}$ ) because the building contains drums filled with decontaminated supernatant mixed with cement. (See also Fig. 1-2 [p. 1-10] in Chapter 1.) The drum cell and the surrounding TLD locations are well within the WNYNSC boundary and are not accessible by the public.

Perimeter and Off-Site Radiation Monitoring. Table H-1 (p. H-3) lists the average quarterly exposure rate at each off-site TLD location. The perimeter TLDs (TLDs \#1-16 and \#20) are located in the sixteen compass sectors around the

\section{TLD Locations and Identification Numbers}

Perimeter of the WNYNSC
Perimeter of the WVDP security fence
On-site sources or waste management units
(Note: Some TLDs monitor more than one
waste management unit.)

Near-site communities

Background
$1-16,20$

$24,26-34$

18, 32-36, 43 (drum cell)

18, 19, 33, 42, 43 (SDA)

24 (component storage, near WVDP security fence)

25 (maximum measured exposure rate at the closest point of public access)

38 (main plant and, in previous years, the cement solidification system)

39 (parking lot security fence closest to the vitrification facility)

40 (high-level waste tank farm)

21 (Springville)

22 (West Valley)

17 (Five Points Landfill in Mansfield)

23 (Great Valley)

37 (Nashville)

41 (Sardinia) 


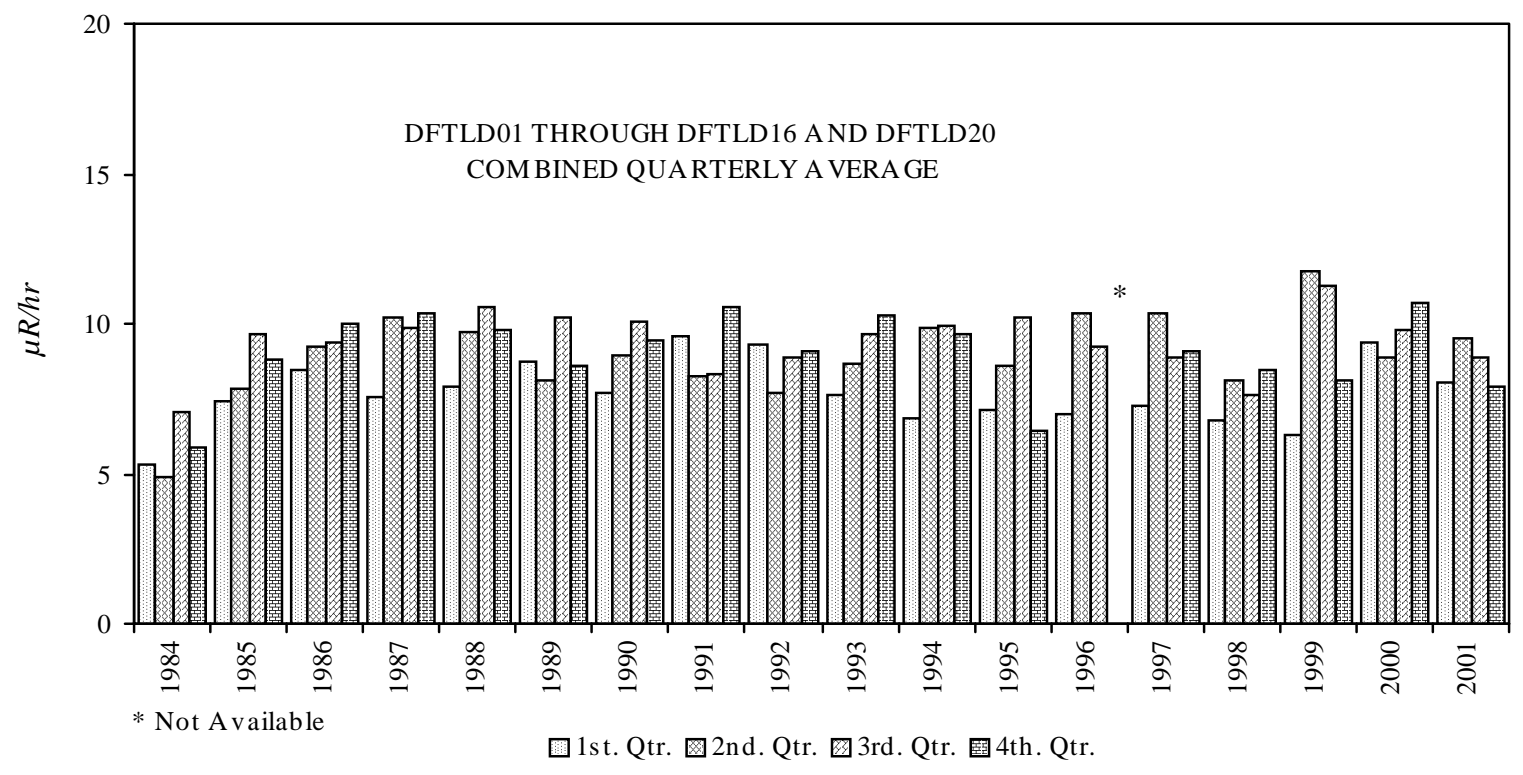

Figure 2-8. Eighteen-Year Trends of Environmental Radiation Levels at Perimeter TLDs

facility near the WNYNSC boundary. Results from the background and community TLDs were essentially the same as results from the perimeter TLDs. The perimeter TLD quarterly averages (expressed in microroentgen per hour $[\mu \mathrm{R} / \mathrm{hr}]$ ) shown on Figure 2-8 (p. 2-24) indicate seasonal fluctuations but no long-term trends. The quarterly average of the seventeen WNYNSC-perimeter TLDs was $18.9 \mathrm{mR}$ per quarter $(8.6 \mu \mathrm{R} / \mathrm{hr})$ in 2001, slightly lower than in 2000.

Confirmation of Results. The performance of the environmental TLDs is confirmed periodically using a portable high-pressure ion chamber (HPIC) detection system. In the third quarter of 2001 the HPIC was taken to each of the forty-three environmental TLD locations and instantaneous exposure rate readings (in $\mu \mathrm{R} / \mathrm{hr}$ ) were obtained. These readings and the comparable third-quarter environmental TLD results are listed in Table H-3 (p. H-5). The TLD results include the entire third quarter of 2001; the HPIC results were collected over a period of less than 30 minutes.
Because the measurements are made with different systems and over differing periods of time, they are not directly comparable. Even so, the average relative percent difference between the two sets of measurements was less than $11 \%$, indicating good agreement between these two different measurement methods. (Guidance in American National Standards Institute [ANSI] N545-1975, the standard for environmental dosimetry, uses less than $30 \%$ total uncertainty as a performance specification for TLD measurements.)

\section{Meteorological Monitoring}

Meteorological monitoring at the WVDP provides representative and verifiable data that characterize the local and regional climatology of the site. These data are used primarily to assess potential effects of routine and nonroutine releases of airborne radioactive materials and to develop dispersion models used to calculate the effective dose equivalent to off-site residents. Since dispersive capabilities of the atmosphere are dependent upon 
wind speed, wind direction, and atmospheric stability (which is a function of the difference in temperature between two elevations), these parameters are closely monitored and are available to the emergency response organization at the WVDP.

The on-site 197-foot (60-m) meteorological tower (Fig. A-1 [p. A-3]) continuously monitors wind speed, wind direction, and temperature at both the 197-foot (60-m) and 33-foot (10-m) elevations. In addition, an independent, remote 33-foot (10-m) meteorological station, located approximately 5 miles $(8 \mathrm{~km})$ south of the site on a hillcrest on Dutch Hill Road, continuously monitors wind speed and wind direction. (See Fig. A-12 [p. A-14].) Dewpoint, precipitation, and barometric pressure are also monitored on-site.

The two meteorological locations supply data to the primary digital and analog data acquisition systems located within the Environmental Laboratory. On-site systems are provided with either uninterruptible or standby power backup in case of site power failures. In 2001 the on-site system data recovery rate (time valid data were logged versus total elapsed time) was approximately 95.6\%. Regional data at the 33-foot (10-m) elevation are shown on Figure I-1 (p. I-3). Figures I-2 and I-3 (pp. I-4 and I-5) illustrate the mean wind speed and wind direction at the 33- and 197foot (10-m and 60-m) elevations on the on-site tower during 2001.

Weekly and cumulative total precipitation data are illustrated in Figures I-4 and I-5 (p. I-6) in Appendix I. Precipitation in 2001 was approximately 31 inches $(78.8 \mathrm{~cm})$, about $24 \%$ below the annual average of 41 inches $(104 \mathrm{~cm})$.

Documentation such as meteorological system calibration records, site log books, and analog strip charts are stored in protected archives. Meteoro- logical towers and instruments are examined three times per week for proper function and are calibrated semiannually and/or whenever instrument maintenance might affect calibration.

\section{Nonradiological Monitoring: Surface Water}

Liquid discharges are regulated under the State Pollutant Discharge Elimination System (SPDES). The WVDP holds a SPDES permit that identifies the outfalls where liquid effluents are released to Erdman Brook (Fig. A-2 [p. A-4]) and specifies the sampling and analytical requirements for each outfall. The current SPDES permit (effective June 1995) was administratively renewed without changes by the New York State Department of Environmental Conservation (NYSDEC) and was issued to the WVDP in September 1998 with an effective date of February 1, 1999 and an expiration date of February 1, 2004. The conditions and requirements of the SPDES permit are summarized in Table G-1 (pp. G-3 and G-4) in Appendix $\mathrm{G}$. The permit identifies four outfalls:

- outfall WNSP001, discharge from the low-level waste treatment facility

- outfall WNSP007, discharge from the sanitary and industrial wastewater treatment facility

- outfall WNSP008, groundwater effluent from the perimeter of the low-level waste treatment facility storage lagoons

- outfall 116, a sampling location in Frank's Creek that represents the confluence of outfalls WNSP001, WNSP007, and WNSP008 as well as storm water runoff, groundwater surface seepage, and augmentation water. Samples from upstream sources are used to calculate total dissolved solids at this location and to demonstrate compliance with the SPDES permit limit for this param- 


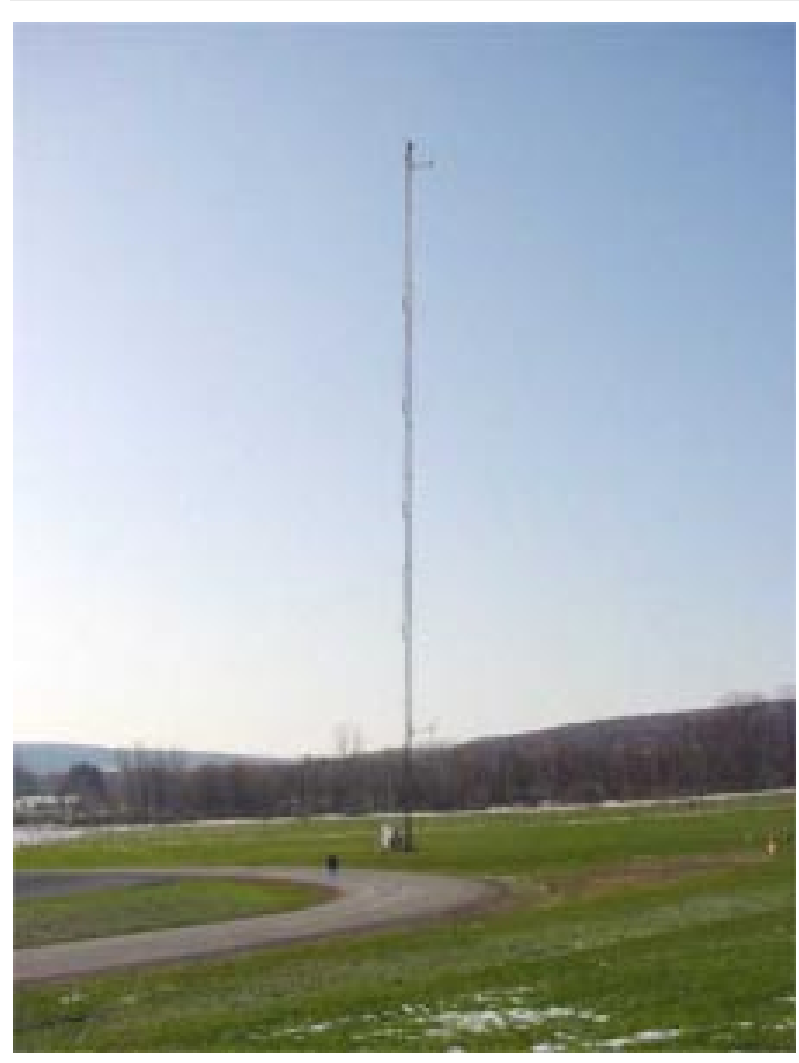

On-Site Meteorological Tower

eter. (Outfall 116 is referred to as a "pseudo-monitoring" point on the SPDES permit. See p. GLO7 in the Glossary.)

Some of the more significant features of the SPDES permit are the requirements to report fiveday biochemical oxygen demand $\left(\mathrm{BOD}_{5}\right)$, total dissolved solids, iron, and ammonia data as flowweighted concentrations and to apply a net discharge limit for iron. The net limit allows the Project to account for the iron that is naturally present in the site's incoming water. The flowweighted limits apply to the flow-proportioned sum of the Project effluents.

The SPDES monitoring data for 2001 are displayed in Tables G-2 through G-10 (pp. G-5 through G15). The WVDP reported one permit exceedance in 2001. In April 2001, total recoverable lead at
WNSP008 exceeded the daily maximum permit limit $(0.006 \mathrm{mg} / \mathrm{L})$. The elevated lead concentration was thought to be attributable to siltation and reduced flow typical of an aging groundwater drain. The WNSP008 drain pipe was sealed in May 2001. (See also SPDES-Permitted Outfalls [pp. ECS-10 and ECS-11] in the Environmental Compliance Summary.)

As part of the routine monitoring program, one set of grab samples at WNSP006 (Frank's Creek at the security fence), WNSWAMP (northeast swamp drainage), WNSW74A (north swamp drainage), and WFBCBKG (Buttermilk Creek at Fox Valley) were taken in 2001. These samples were screened for organic constituents and selected anions, cations, and metals. Results of these measurements for all of these locations are found in Table C-27 (p. C-22).

\section{Nonradiological Monitoring: Drinking Water}

Site drinking water is monitored to verify compliance with EPA and New York State Department of Health (NYSDOH) regulations. (See Safe Drinking Water Act [p. ECS-13] in the Environmental Compliance Summary.) Samples are collected annually and analyzed for nitrate, fluoride, and metals concentrations. Sampling and analysis for copper and lead are conducted according to Cattaraugus County Health Department guidance. The 2001 monitoring results indicated that the Project's drinking water met NYSDOH, EPA, and Cattaraugus County Health Department drinking water quality standards.

\section{Nonradiological Monitoring: Air}

Nonradiological air emissions and plant effluents are permitted under NYSDEC and EPA regulations. (The regulations that apply to the WVDP 
are listed in Table K-2 [p. K-4] in Appendix K. The New York State Facility Air Permit held by the WVDP is described in the West Valley Demonstration Project Environmental Permits table [p. ECS22] in the Environmental Compliance Summary.)

The nonradiological air permits are for emissions of regulated pollutants that include particulates, ammonia, nitrogen oxides, and sulfur dioxide. Emissions of oxides of nitrogen and sulfur are each limited to 99 tons per year and are reported to NYSDEC annually. Nitrogen oxide emissions from the vitrification off-gas system are continuously monitored. All other nitrogen oxides and sulfur dioxide emissions data are calculated using process knowledge and fuel usage information. Nitrogen oxides emissions for 2001 were approximately 4.81 tons; sulfur dioxide emissions were approximately 0.06 tons, well below the 99ton limit. Compliance with New York State and EPA opacity requirements is verified by certified visible-emissions observers.

\section{Special Monitoring}

Special monitoring comprises sampling and analyses not covered by the routine environmental monitoring program but that address items of environmental interest. Special monitoring programs are used to verify and/or track these items.

Iodine Emissions From the Main Stack. When radioactive vitrification operations began in 1996, emission rates of radioactive isotopes of iodine increased at the main stack. The increase occurred because gaseous iodine is not as efficiently removed by the vitrification process off-gas treatment system as are most other radionuclides. Iodine-129 is a long-lived radionuclide that has always been present in main stack emissions.

Iodine- 129 continued to be monitored closely during 2001. In 2001 the total quantity of iodine-129 released from the main plant stack continued to decline, reflecting the lower quantities of waste being processed in the final stages of the vitrification process. (See Fig. 2-9 [p. 2-28]). For more information on the off-site effective dose from airborne emissions see Predicted Dose from Airborne Emissions (p. 4-7) in Chapter 4.

Mercury at the Low-Level Waste Treatment Facility. In 1999, increasing concentrations of total mercury were observed in process water collected from the low-level waste treatment facility. A primary source of the mercury was determined to be the effluent from the liquid waste treatment system (LWTS). At that time, New York State water quality standards were modified, defining toxicity-based standards that, in some cases, were several orders of magnitude lower than previous standards.

In 2000, equipment was put into place to reduce mercury concentrations in effluent from the LWTS. Using EPA guidance, site personnel developed and implemented procedures for collecting representative samples of ambient and effluent water for low-level mercury analysis. Subcontracts were established with new analytical service laboratories that could analyze samples for mercury to much lower levels than previously available.

During 2001, samples were collected from various locations within the low-level waste treatment facility and from the effluent of the new mercury treatment system associated with the LWTS. These samples were analyzed using the new services for low-level mercury analysis (EPA's Method 1631). Sample collection and evaluation of results are ongoing.

In December 2001 a draft of a revised SPDES permit for the Site was issued for review and comment. One of the proposed changes to the SPDES 


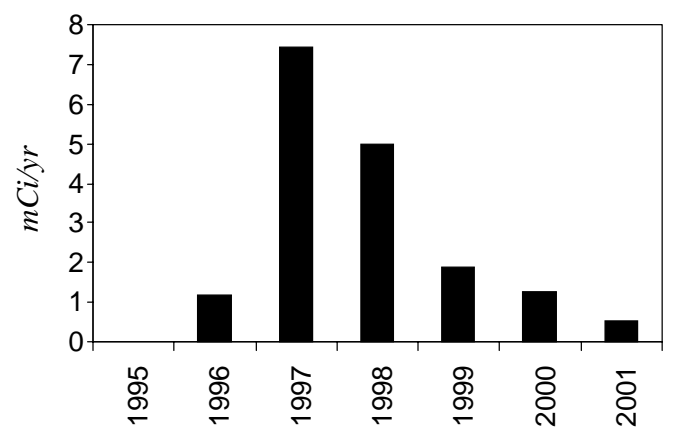

Figure 2-9. Estimated Iodine-129 Releases from the WVDP Main Plant Stack

permit is a protocol for evaluating mercury concentrations at process points upstream of the lagoon 3 discharge (outfall 001, sampling point WNSP001) and at WNSP001 itself. The new SPDES permit is expected to be finalized in 2002. (See the Environmental Compliance Summary [p. ECS-11].)

Dose to Biota. DOE Order 5400.5 includes a limit of $1 \mathrm{rad}$ per day for aquatic animals from exposure to radionuclides from DOE activities. Recommended exposure thresholds for terrestrial plants and terrestrial animals ( $1 \mathrm{rad}$ per day and $0.1 \mathrm{rad}$ per day, respectively) have also been proposed.

In 2001, dose to biota was assessed using the recent guidance from the DOE. The calculated results were found to be within the thresholds. A detailed description of the evaluation and the results of the study may be found in Chapter 4 of this document. (See Dose to Biota: Aquatic and Terrestrial Wildlife [p. 4-13].)

\section{Monitoring of Contamination Near the Main}

Process Building. During routine radiation work surveys conducted in mid-November 2001, small spots of fixed radioactivity were found on-site in an area immediately north, and to a lesser extent southeast, of the main plant stack. Upon discovery, the area involved was promptly isolated and decontaminated and/or stabilized. On-site personnel were surveyed and no personnel contamination was found. Additionally, environmental monitoring data were checked and the data indicated that contamination had not spread off-site.

An investigation, including an evaluation of radiological monitoring data, a review of operations records, and a review of meteorological information, was carried out to determine the origin of the contamination. It was determined that the contamination was the result of small amounts of cesium137 from the waste tank farm ventilation system dissolved in condensed water vapor being released from the main plant stack during late September and early October 2001.

Although the radioactivity release rate was too low to result in any stack monitoring alarms and the total amount of radioactivity released was well within regulatory limits, an unusual combination of ventilation process and weather conditions resulted in an unexpected local deposition of radioactivity. (See Unplanned Radiological Releases in Chapter 1 [p. 1-11] for a more detailed discussion of this event.)

Monitoring of Ambient Air in the NDA for Soil Shipments. Waste soils with the potential to contain radiological contamination were staged and packaged for shipping on the south plateau of the WVDP during the summer of 2001. In order to detect radionuclides associated with particulates in ambient air that could be attributable to the soils, two special air samplers, one east and one west of the NDA, were set up and run continuously from mid-May through November 2001 while the soil was being prepared for shipping.

The air samplers were identical to those used in the routine monitoring program and the samples 
were collected and analyzed as routine samples. Samples were collected weekly and analyzed onsite for gross beta and gross alpha activity. When shipping was completed, sampling was discontinued. The weekly air filters from each sampler were assembled into a single composite and each composite was analyzed off-site for the same suite of radionuclides as routine particulate air samples.

When data were evaluated, no differences were noted between results from the special samplers and results from the background samplers. It was concluded that the soil shipping activity had no detectable effect on ambient air on the south plateau. 
This page intentionally left blank

$$
2-30
$$




\section{GROUNDWATER MONITORING}

\section{Groundwater Monitoring Program Overview}

Groundwater at the West Valley Demonstration Project (WVDP) is monitored according to a comprehensive program developed to comply with all applicable state and federal regulations. The monitoring program also meets requirements of Department of Energy (DOE) Order 5400.1 to obtain data for determining baseline conditions of groundwater quality and quantity, to provide data that will allow the early detection of groundwater contamination, to identify existing and potential groundwater contamination sources and maintain surveillance of these sources, and to provide data upon which decisions can be made concerning the integrity of existing disposal areas and the management and protection of groundwater resources.

Current groundwater monitoring activities at the WVDP are summarized in two primary documents - the Groundwater Monitoring Plan (West Valley Nuclear Services Co., September 27, 2001) and the Groundwater Protection Management Program Plan (West Valley Nuclear Services Co., May 2, 2000). The Groundwater Monitoring Plan outlines the WVDP's plans for groundwater characterization, current groundwater sampling requirements, and support of long-term monitoring requirements identified in the Resource Conser- vation and Recovery Act (RCRA) facilities investigation (RFI) and DOE programs. The Groundwater Protection Management Program Plan provides additional information regarding protection of groundwater from on-site activities.

\section{Geologic History of the West Valley Site}

The Western New York Nuclear Service Center (WNYNSC) comprises approximately 3,345 acres (1,354 ha) and is located on the Allegheny Plateau near the northern border of Cattaraugus County in Western New York. The 200-acre (80ha) WVDP site is located on the WNYNSC. Beneath the WNYNSC site is a sequence of Holocene (recent age) and Pleistocene (ice age) sediments filling a steep-sided valley incised in the bedrock. The bedrock is composed of shales and interbedded siltstones of the upper Devonian Canadaway and Conneaut Groups that dip southward at about $5 \mathrm{~m} / \mathrm{km}$ (Rickard, 1975).

The Pleistocene sediments overlying the bedrock typically consist of a sequence of three glacial tills of Lavery, Kent, and possibly Olean age. The tills are separated by stratified fluvio-lacustrine deposits. In the northern part of the site the Lavery till is capped by coarse-grained alluvial-fluvial deposits. 
Repeated glaciations of the ancestral bedrock valley occurred between 24,000 and 15,000 years ago (Albanese et al., 1984), ending with the deposition of up to 130 feet $(40 \mathrm{~m})$ of Lavery till. Post-Lavery outwash and alluvial fans, including the sand and gravel unit that covers the northern portion of the WVDP site, were deposited on the Lavery till between 15,000 and 14,200 years ago (LaFleur, 1979).

A summary of the site hydrology is presented below. Hydrologic conditions of the site are more fully described in Environmental Information Document, Volume III: Hydrology, Part 4 (West Valley Nuclear Services Co., Inc., March 1996) and in the RCRA Facility Investigation Report: Introduction and General Site Overview (West Valley Nuclear Services Co., Inc., July 1997).

\section{Surface Water Hydrology of the West Valley Site}

The WNYNSC lies within the Cattaraugus Creek watershed, which empties into Lake Erie about 27 miles $(43 \mathrm{~km})$ southwest of Buffalo. Buttermilk Creek, a tributary of Cattaraugus Creek, drains most of the WNYNSC and all of the WVDP site.

The WVDP site, located on the WNYNSC, is contained within the smaller Frank's Creek watershed. Frank's Creek, a tributary of Buttermilk Creek, forms the eastern and southern boundary of the WVDP; Quarry Creek, a tributary of Frank's Creek, forms the northern boundary. (See Fig. A-1 [p. A-3].)

Another tributary of Frank's Creek, Erdman Brook, bisects the WVDP into a north and south plateau. The main plant, waste tanks, and lagoons are located on the north plateau. The drum cell, the U.S. Nuclear Regulatory Commission (NRC)licensed disposal area (NDA), and the New York State-licensed disposal area (SDA) are located on the south plateau.

\section{Hydrogeology of the West Valley Site}

The WVDP site area is underlain by a sequence of glacial tills comprised primarily of clays and silts separated by coarser-grained interstadial sediments. Because the bottommost layer, the Kent till, is less permeable than the other geological units and does not provide a pathway for contaminant movement from the WVDP, it is not discussed here.

The sediments above the Kent till - the Kent recessional sequence, the Lavery till and the intraLavery till-sand, and the surficial sand and gravel - are generally regarded as containing all of the potential routes for the migration of contaminants (via groundwater) from the WVDP site. (Figs. 31 and 3-2 [facing page] show the relative locations of these sediments on the north and south plateaus.) The Lavery till, the Kent recessional sequence, and the Kent till are common to both the north and south plateaus.

Kent Recessional Sequence. The Kent recessional sequence consists of a fine-grained lacustrine unit of interbedded clay and silty clay layers locally overlain by coarse-grained glacial sands and gravels. These deposits underlie the Lavery till beneath most of the site, pinching out along the southwestern margin of the site where the walls of the bedrock valley intersect the sequence.

Groundwater flow in the Kent recessional sequence is predominantly to the northeast, toward Buttermilk Creek. Hydraulic conductivity testing completed during the last several years indicates a mean value of $2 \mathrm{E}-01 \mathrm{ft} /$ day $(8 \mathrm{E}-05 \mathrm{~cm} / \mathrm{sec})$ or 2.6 in/day. Recharge comes from the overlying Lavery till and in flow from the bedrock in the southwest, and discharge is to Buttermilk Creek.

Lavery Till. The Lavery till is predominantly an olive-gray, silty clay glacial till with scattered lenses 
Hydrogeology of the West Valley Site

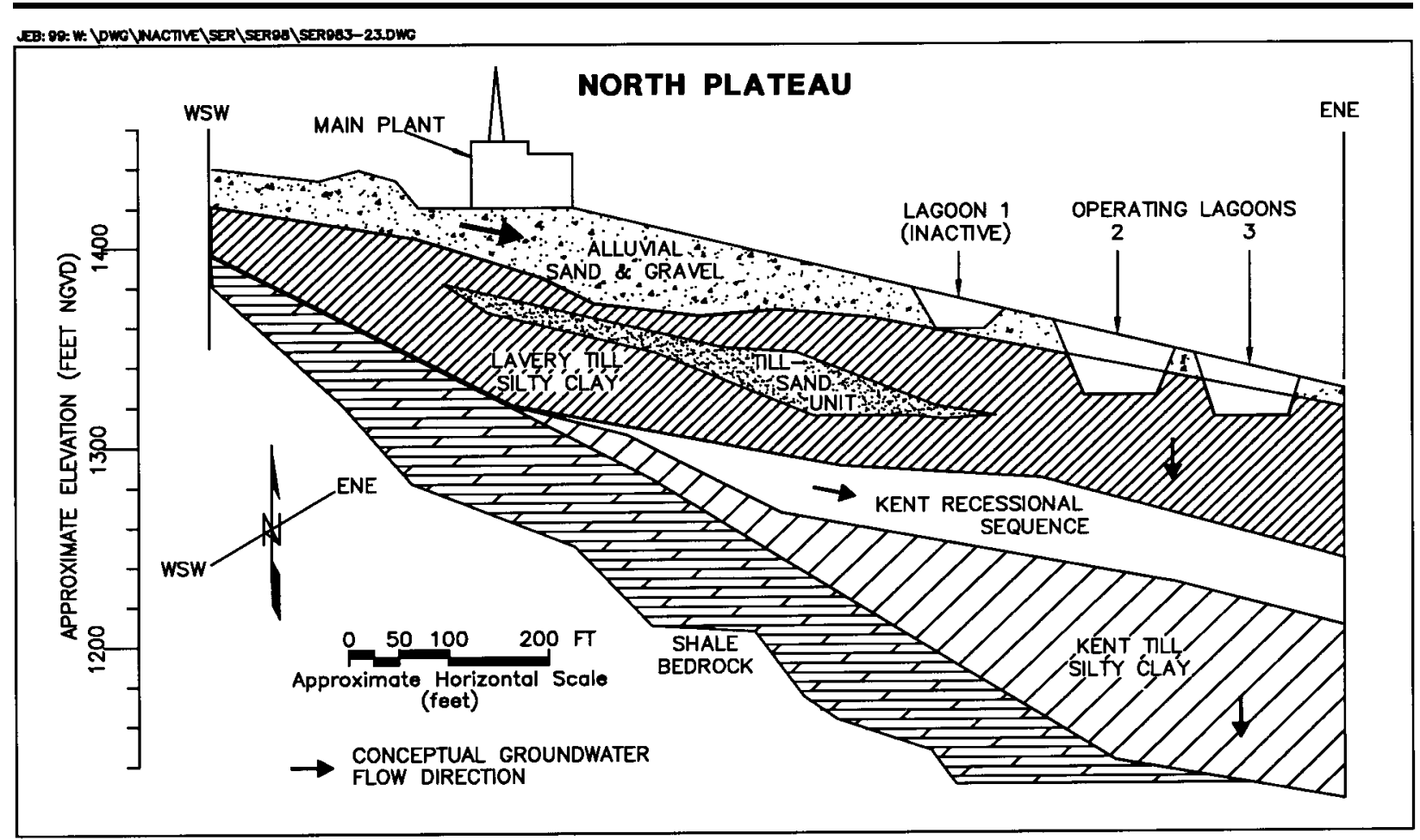

Figure 3-1. Geologic Cross Section Through the North Plateau (Vertical Exaggeration Approx. 2:1)

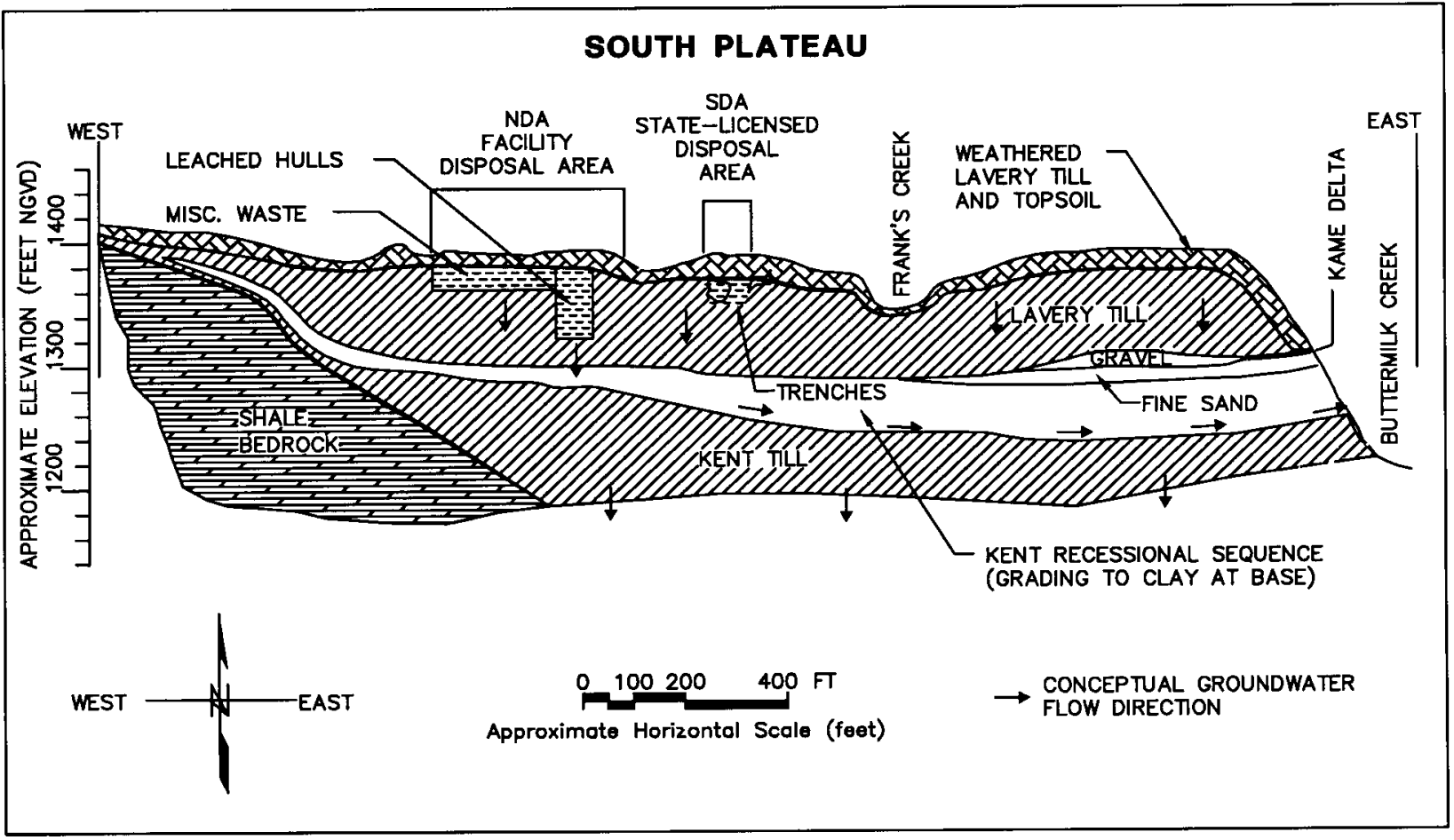

Figure 3-2. Geologic Cross Section Through the South Plateau (Vertical Exaggeration Approx. 2.5:1)

$$
3-3
$$

WVDP Site Environmental Report 
of silt and sand. It underlies both the north and south plateaus and ranges up to 130 feet $(40 \mathrm{~m})$ in thickness beneath the active areas of the site, slightly increasing northeastward towards Buttermilk Creek and the center of the bedrock valley.

Hydraulic head distributions in the unweathered Lavery till indicate that groundwater flow is predominantly vertically downward at a relatively slow rate, toward the underlying Kent recessional sequence. Hydraulic conductivity testing in the Lavery till during the last several years indicates a mean value of $1 \mathrm{E}-04 \mathrm{ft} / \mathrm{day}(1 \mathrm{E}-07 \mathrm{~cm} / \mathrm{sec})$ or $0.001 \mathrm{in} /$ day. Some wells have produced hydraulic conductivity values as high as $3 \mathrm{E}-04 \mathrm{~cm} / \mathrm{s}$, which may indicate the presence of sand lenses within the till.

On the south plateau, the upper zone of the Lavery till is exposed at the ground surface and is weathered and fractured to a depth of 3 to 16 feet $(0.9$ to $4.9 \mathrm{~m}$ ). This layer is referred to as the weathered Lavery till and is unique to the south plateau. The weathered Lavery till has been oxidized to a brown color and contains numerous dessication cracks and root tubes.

Groundwater flow in the weathered till has both horizontal and vertical components. This enables the groundwater to move laterally across the south plateau before moving downward into the unweathered Lavery till or discharging to nearby incised stream channels. Hydraulic conductivity testing in the weathered Lavery till completed during the last several years indicates a mean value of $5 \mathrm{E}-02 \mathrm{ft} /$ day $(2 \mathrm{E}-05 \mathrm{~cm} / \mathrm{sec})$ or $0.6 \mathrm{in} /$ day. The highest conductivities are associated with the dense fracture zones found within the upper 7 feet ( $2 \mathrm{~m}$ ) of the unit.

On the north plateau, where the main plant, waste tanks, and lagoons are located, the weathered till layer is much thinner or nonexistent and the un- weathered Lavery till is immediately overlain by the sand and gravel unit.

Sand and Gravel and Till-Sand Units. The sand and gravel unit and the Lavery till-sand are unique to the north plateau. The sand and gravel unit is a silty sand and gravel layer composed of younger Holocene alluvial deposits that overlie older Pleistocene-age glaciofluvial deposits. Together these two layers range up to 41 feet (12.5 $\mathrm{m})$ in thickness near the center of the plateau and pinch out along the northern, eastern, and southern edges of the plateau, where they have been truncated by the downward erosion of stream channels.

Depth to groundwater within the sand and gravel unit varies from 0 to 16 feet ( 0 to $5 \mathrm{~m}$ ), being deepest generally beneath the central north plateau (beneath the main plant facilities) and intersecting the ground surface farther north toward the security fence.

Groundwater in this unit generally flows northeastward across the plateau towards Frank's Creek. Groundwater near the northwestern and southeastern margins of the sand and gravel layer also flows radially outward toward Quarry Creek and Erdman Brook, respectively. There is minimal groundwater flow downward into the underlying Lavery till. The mean hydraulic conductivity is 16.4 feet/day (6E-03 cm/sec) or $200 \mathrm{in} /$ day, based on testing completed during the last several years.

Within the unweathered Lavery till on the north plateau is another unit, the Lavery till-sand. Onsite investigations from 1989 through 1990 identified this thin sandy unit of limited areal extent and variable thickness within the Lavery till, primarily beneath the southeastern portion of the north plateau. Groundwater flow through this unit is in an east-southeast direction. Surface discharge locations have not been observed. The mean hydrau- 
lic conductivity of $3.8 \mathrm{feet} / \mathrm{day}(1 \mathrm{E}-03 \mathrm{~cm} / \mathrm{sec})$ or $46 \mathrm{in} /$ day for this unit is based on testing completed during the last several years.

\section{Routine Groundwater Monitoring Program}

The purpose of groundwater monitoring at the WVDP is to detect changes in groundwater quality within the five different hydrogeologic units previously described: the sand and gravel, the weathered Lavery till, the unweathered Lavery till, the Lavery till-sand, and the Kent recessional sequence. In 2001, a total of 65 groundwater monitoring locations were sampled. These locations included 59 monitoring wells (including driven well points), five groundwater seepage points, and one sump manhole.

Monitoring Well Network. Table E-1 (Appendix E [pp. E-3 through E-6]) lists the eleven super solid waste management units (SSWMUs) monitored by the well network, the hydraulic position of each well relative to the waste management unit, the geologic unit monitored, and the analytes measured in 2001. (See super solid waste management unit in the Glossary [p. GLO-10].) Note that monitoring of certain wells, marked by an asterisk, is required by the RCRA $§ 3008(\mathrm{~h})$ Administrative Order on Consent for the WVDP.

Figures A-7 and A-8 (pp. A-9 and A-10) show the boundaries of ten of the SSWMUs at the WVDP. (Twenty-one additional wells in an eleventh SSWMU monitor the SDA and are the responsibility of the New York State Energy Research and Development Authority [NYSERDA]. Locations of NYSERDA wells are shown on Fig. A-8 [p. A-10] in Appendix A. The SDA, a closed radioactive waste landfill, is contiguous with the Project premises, but the WVDP is not responsible for the facilities or activities relating to it. Under a joint agreement with the DOE,
NYSERDA contracts with the Project to obtain specifically requested technical support in SDArelated matters. Groundwater monitoring results from the SDA are reported in this document in Appendix L [pp. L-3 through L-11] but are not discussed here.)

Table E-1 (pp. E-3 through E-6) identifies the hydraulic positions of monitoring locations relative to the SSWMUs. The wells monitoring a given hydrogeologic unit (e.g., sand and gravel, weathered Lavery till) also are arranged in a generalized upgradient to downgradient order based upon their location within the entire hydrogeologic unit. The hydraulic position of a well relative to a SSWMU (upgradient or downgradient) does not necessarily match that same well's position within its hydrogeologic unit. For example, a well that is upgradient in relation to a SSWMU may be located at any position within a hydrogeologic unit within the boundaries of the WVDP, depending on the geographic position of the SSWMU relative to the hydrogeologic unit. In general, the following text and graphics refer to the hydraulic position of monitoring wells within their respective hydrogeologic units, thus providing a site-wide perspective rather than a perspective centered on SSWMUs. Information provided in Appendix E (pp. E-7 through E-19) also follows this convention.

Potentiometric (water level) measurements also are collected from the wells listed in Table E-1 in conjunction with the quarterly analytical sampling schedule. (See Table 3-1 [p. 3-6].) Groundwater elevation data are used to produce groundwater contour maps, which delineate flow directions and gradients, and long-term trend graphs, which illustrate seasonal fluctuations and other changes in the groundwater system. In 2001, water levels were routinely measured at 42 locations in addition to those that were sampled. 


\section{Table 3-1 \\ 2001 Groundwater Sampling and Analysis Agenda}

\author{
Analyte Group \\ Contamination Indicator \\ Parameters (I) \\ Radiological Indicator \\ Parameters (RI) \\ Volatile Organic \\ Compounds (V) \\ Semivolatile Organic \\ Compounds (SV)
}

NYCRR Appendix 33 Metals (M33)

Special Monitoring Parameters

for Early Warning Wells (SM)

Radioisotopic Analyses:

alpha-, beta-, and gamma-

emitters (R)

Strontium-90 (S)

\section{Description of Parameters ${ }^{I}$}

$\mathrm{pH}$, specific conductance

(field measurement)

Gross alpha, gross beta,

tritium

NYCRR Appendix 33 Volatile Organic Compounds (VOCs)

(See Table E-14 [p. E-20].)

NYCRR Appendix 33 Semivolatile Organic Compounds (SVOCs) and tributyl phosphate (TBP) (See Table E-14 [p. E-20].)

Antimony, arsenic, barium, beryllium, cadmium, chromium, cobalt, copper, lead, mercury, nickel, selenium, silver, thallium, tin, vanadium, zinc

Aluminum, iron, manganese

C-14, Sr-90, Tc-99, I-129, Cs-137, Ra-226, Ra-228, U-232, U-233/234, U-235/236, U-238, total uranium

Sr-90

\section{Location of Sampling Results in Appendix $E$}

Tables E-2 through E-8 (pp. E-7 through E-15)

Tables E-2 through E-8 (pp. E-7 through E-15)

Table E-9

(p.E-15)

Table E-10

(p.E-16)

Table E-11

(pp.E-16 and E-17)
Table E-12

(p.E-17)

Table E-13

(pp. E-18 and E-19)

Table E-13

(pp.E-18 and E-19)

2001 Quarterly Monitoring Schedule:

1st Qtr - December 1, 2000 to February 28, 2001

2nd Qtr - March 1, 2001 to May 31, 2001

3rd Qtr - June 1, 2001 to August 31, 2001

4th Qtr-September 1, 2001 to November 30, 2001

${ }^{1}$ Analysis completed for selected active monitoring locations only. See Table E-1 (pp. E-3 through E-6) for the analytes assigned to each monitoring location.

$$
3-6
$$




\section{Groundwater Sampling Methodology}

Groundwater samples are collected from monitoring wells using either dedicated Teflon ${ }^{\circledR}$ well bailers or bladder pumps. (Dedicated bailers are equipped with Teflon ${ }^{\circledR}$-coated stainless steel leaders.)

The method of collection depends on well construction, water depth, and the water-yielding characteristics of the well. Bailers are used in low-yield wells; bladder pumps are used in wells with good water-yielding characteristics.

To ensure that only representative groundwater is sampled, three well volumes are removed (purged) from the well before the actual samples are collected. If three well volumes cannot be removed because of limited recharge, pumping or bailing the well to dryness provides sufficient purging. Conductivity and $\mathrm{pH}$ are measured before sampling and, if sufficient water is still available, after sampling to confirm the geochemical stability of the groundwater during sampling.

The bailer, a tube with a check valve at the bottom, is lowered into the well until it reaches the desired point in the water column. The bailer is lowered slowly to minimize agitation of the water column and is then withdrawn from the well with a sample and emptied into a sample container. The bailer, bailer line, and bottom-emptying device used to drain the bailer are dedicated to the well, that is, they are not used for any other well.

Bladder pumps use compressed air to gently squeeze a Teflon ${ }^{\circledR}$ bladder that is encased in a stainless steel tube located near the bottom of the well. When the pressure is released, new groundwater flows into the bladder. A series of check valves ensures that the water flows only in one direction. The operating air is always separated from the sample and is expelled to the surface by a separate line.

Bladder pumps reduce mixing and agitation of the water in the well. Each bladder pump system is dedicated to an individual well to reduce the likelihood of sample contamination from external materials or cross contamination. The air compressor and pump control box can be used from well to well because they do not contact the sample or the inside of the well.

Immediately after the samples are collected they are put into a cooler and returned to the Project's Environmental Laboratory. The samples are preserved with chemicals, if necessary, and stored under controlled conditions to minimize chemical and/or biological changes after sample collection. The samples are then either packaged for expedited delivery to an off-site contract laboratory or kept in controlled storage to await on-site testing. A strict chain-of-custody protocol is followed for all samples collected by the WVDP. 
Surface water elevation measurements are also collected at eleven locations on the north plateau where the water table in the sand and gravel unit intersects the ground surface in the form of standing water. Surface water elevation measurements taken at these locations are correlated with groundwater elevation measurements taken at monitoring wells and are used routinely to help define groundwater flow-direction and gradients in the sand and gravel unit in areas where monitoring well coverage is sparse or nonexistent.

\section{Groundwater Monitoring Program Highlights} 1982 Through 2001. The groundwater monitoring program is designed to support DOE Order 5400.1 requirements and the RCRA §3008(h) Administrative Order on Consent for the WVDP. In general, the content of the program is dictated by these requirements in conjunction with current operating practices and historical knowledge of previous site activities.

- Groundwater monitoring at the WVDP began in 1982 with the monitoring of tritium in the sand and gravel unit in the area of the lagoon system.

- By 1984 twenty wells in the vicinity of the main plant and the NDA provided monitoring coverage.

- Fourteen new wells, a groundwater seep location, and the french drain outfall were added in 1986 to monitor additional site facilities.

- In 1990 ninety-six new wells were installed for data collection for the environmental impact statement and RCRA facility investigations.

- A RCRA facility investigation expanded-characterization program was conducted during 1993 and 1994 to fully assess potential releases of hazardous wastes or constituents from on-site SSWMUs. This investigation, which consisted of two rounds of sampling for a wide range of radio- logical and chemical parameters, provided valuable information regarding the presence or absence of groundwater contamination near each SSWMU and was also used to guide later monitoring program modifications.

- In 1993 monitoring results indicated elevated gross beta activity in groundwater in the sand and gravel unit on the north plateau. Subsequent investigation of this area delineated a plume of contamination with a southwest to northeast orientation. (See Special Groundwater Monitoring [p. 3-15] for more detail.)

- Long-term monitoring needs were the focus of a 1995 groundwater monitoring program evaluation. After a comprehensive assessment, the number of sampling locations was reduced from ninety-one to sixty-five and analytical parameters were tailored for each sampling location, for a more focused, efficient, and cost-effective program.

- In 1996 several groundwater seep monitoring locations on the northeast edge of the north plateau were added to the monitoring program.

- From 1996 through 2001, in response to current sampling results and DOE and RCRA monitoring requirements, wells to be monitored, analytes, and sampling frequencies were modified.

Annual Analytical Trigger Level Review. A computerized data-evaluation program using "trigger levels" for chemical and radiological analytes was instituted in 1995. These pre-set levels - conservative values for chemical or radiological concentrations - were developed to identify and expedite a prompt focus on any anomalies in monitoring results. These values are based on regulatory limits, detection limits, or statistically derived levels. Trigger levels are reviewed and updated every year, if necessary, using all pre-existing data as well as the current year's data. The trigger 
levels were updated before the start of the firstquarter 2001 groundwater monitoring.

Upper and lower trigger levels for groundwater elevation measurements were introduced in 1999. These levels are used to identify field measurement anomalies, allowing prompt investigation and remeasurement, if necessary. Groundwater-elevation trigger levels were updated before the start of the first-quarter 2001 groundwater monitoring.

\section{Results of Routine Groundwater Monitoring}

Each component of the groundwater monitoring program is completed in accordance with regulatory protocols. These components include locating and installing wells, collecting groundwater samples, incorporating quality assurance methods, and evaluating data.

The tables in Appendix E (pp. E-7 through E-19) group the results of groundwater monitoring according to the five hydrogeologic units monitored: the sand and gravel unit, the Lavery till-sand unit, the weathered Lavery till unit, the unweathered Lavery till unit, and the Kent recessional sequence. These tables contain the results of sampling for the radiological and nonradiological analyte groups noted on Table 3-1 (p. 3-6). In addition, Table E14 (pp. E-20 through E-22) lists the practical quantitation limits (PQLs) for individual New York Official Compilation of Codes, Rules, and Regulations (NYCRR) Title 6, Appendix 33 analytes. (The PQL is the lowest level of an analyte that can be measured within specified limits of precision during routine laboratory operations [New York State Department of Environmental Conservation, 1991].)

Appendix E tables also provide each well's hydraulic position relative to other wells within the same hydrogeologic unit. Wells identified as UP

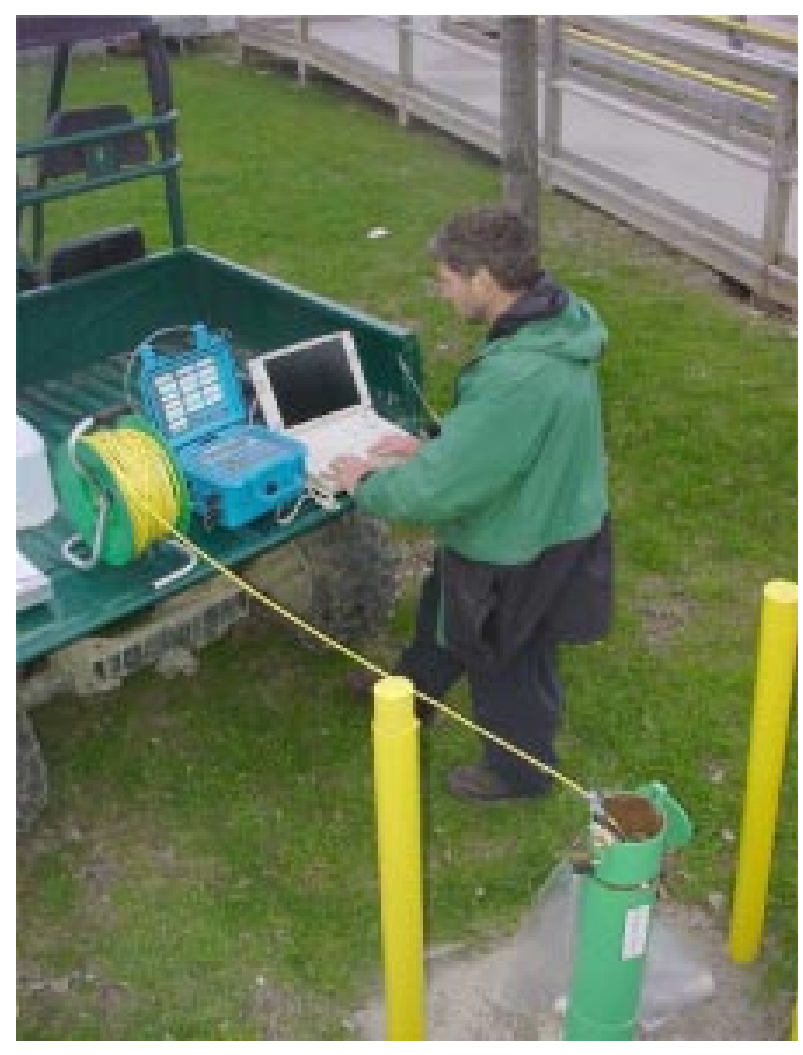

Using a Datalogger to Record Hydraulic Conductivity Data From an On-Site Monitoring Well

refer to either background wells or wells that are upgradient of other wells in the same hydrogeologic unit. Wells identified as DOWN are downgradient of other wells in that unit. In each table wells are presented from upgradient to furthest downgradient. Grouping the wells by hydraulic position provides the basis for presenting the groundwater monitoring data in the tables and figures in this report. (See Table 3-1 [p. 3-6] for the quarterly groundwater monitoring schedule.)

High-Low graphs. Graphs showing the range of values for contamination and radiological indicator parameters ( $\mathrm{pH}$, conductivity, gross alpha, gross beta, and tritium) have been prepared for all active monitoring locations in each geologic unit. (See Appendix E [pp. E-24 through E-32].) These highlow graphs allow results for all wells within a given 
hydrogeologic unit to be compared to each other. All of the high-low graphs present the upgradient wells on the left side of the figure. Downgradient locations are plotted to the right according to their relative position along the groundwater flow path.

On the high-low graphs depicting nonradiological contamination indicator results ( $\mathrm{pH}$ and conductivity), the upper and lower tick marks on the vertical bar indicate the highest and lowest measurements recorded during 2001 for a particular well. The middle tick represents the arithmetic mean of all 2001 results for that well. The vertical bar indicates the total range of the data set for each monitoring location during the year.

On the high-low graphs depicting radiological indicator results (gross alpha, gross beta, and tritium), the middle tick is again used to represent the arithmetic mean of all 2001 results. However, the upper and lower tick marks on the vertical bar indicate the upper and lower ranges of the pooled error terms for all 2001 results. This format illustrates the relative amount of uncertainty associated with the radiological measurements. By displaying the uncertainty together with the mean, a more realistic perspective is obtained. (See also Data Reporting [p. 1-4] in Chapter 1, Environmental Program Information.) On magnified-scale graphs, markers for some locations cannot be shown because the magnitude of the concentration is larger than the upper range of the graph.

The analytical results for gross alpha, gross beta, and tritium, even if below the minimum detectable concentrations, were used to generate the highlow graphs. Thus, negative values were included. This is most common for the gross alpha analyses, where sample radiological counting results may be lower than the associated background.

The wells used to provide background values are noted on each graph. All of the geologic units ex- cept the sand and gravel unit use a single well for background. In previous years well NB1S was used as the single background reference well for the sand and gravel unit. However, in 1997 the collective monitoring results from three upgradient wells (301, 401, and 706) were substituted for NB1S to use for comparison with other sand and gravel wells as a way of better representing the natural spatial variability within this geologic unit. Both the DOE and the New York State Department of Environmental Conservation (NYSDEC) have accepted the use of this collective background reference instead of well NB1S.

Trend-Line graphs. Trend-line graphs have been used at monitoring locations that have historically shown radiological concentrations above background values for volatile and semivolatile organic compound (VOC or SVOC) concentrations above practical quantitation limits. Graphs are included for gross beta and tritium at selected groundwater monitoring locations $(104,105,111,408,501$, $502,801,8603,8604$, and 8605) and for the VOCs 1,1-dichloroethane (1,1-DCA) at wells 803, 8609, and 8612; dichlorodifluoromethane (DCDFMeth) at wells 803 and 8612;1,2-dichloroethylene (1,2DCE-t) and 1,1,1-trichloroethane (1,1,1-TCA) at well 8612; and tributyl phosphate (TBP) at wells 111 and 8605. (See Volatile and Semivolatile Organic Compounds Sampling [p. 3-14].)

Long-Term Trends of Gross Beta and Tri-
tium at Selected Groundwater Monitoring Locations. Figures 3-5 through 3-10 (pp. 3-18 through 3-20) show the trends of gross beta and tritium concentrations at selected monitoring locations in the sand and gravel unit. These specific groundwater monitoring locations were selected for trending because they have shown elevated or rising levels of gross beta concentrations, with some also showing elevated levels of tritium. Results are presented on a logarithmic scale to allow locations having widely differing concentrations 
to be compared to the average background concentrations plotted on each graph.

Gross Beta. The groundwater plume of gross beta activity in the sand and gravel unit on the north plateau (Fig. 3-3 [p. 3-12]) continues to be monitored closely. The source of the plume's activity can be traced to the subsurface beneath the southwest corner of the former process building. In 2001, ten wells $(104,105,111,408,501,502,801,8603$, 8604 , and 8605) showed gross beta concentrations that exceeded the DOE derived concentration guide (DCG) for strontium-90 $(1.0 \mathrm{E}-06 \mu \mathrm{Ci} /$ $\mathrm{mL}$ ). Lagoon 1, formerly part of the low-level waste treatment facility, has been identified as a source of the gross beta activity at wells 8605 and 111. The gross beta concentrations at well 8605 have been slowly but steadily decreasing over the past several years while concentrations at 111 continued to fluctuate within historical levels. Contamination observed at SP11 is believed to be attributable to re-infiltration of contaminated water that has surfaced from the strontium- 90 groundwater plume.

- Figures 3-5 and 3-6 (p. 3-18) show gross beta concentrations in wells 104, 105, 111, 408, 501, 502, and 801 over the last eleven years. As in previous years, samples from well 408 continued to show the highest gross beta concentrations of all the wells within the north plateau gross beta plume area. Gross beta results for well 408 were slightly higher in 2001 than in 2000.

Gross beta at well 111 was slightly higher in 2001 than in 2000. Wells 501, 502, and 801 showed slight increases relative to 2000 , and wells 104 and 105 showed somewhat greater increases relative to 2000 values.

- Figure 3-7 (p. 3-19) is a graph of gross beta concentrations at sand and gravel unit monitoring locations 8603, 8604, and 8605. After several years of increases in gross beta concentrations in well
8604 , the trend showed relatively minor fluctuations during 1996 through 2001. Results from well 8603 showed a steady upward trend until early 2000 , with only slight fluctuations since then.

Tritium. Tritium in sand and gravel wells also is routinely monitored as part of the groundwater program.

- Figure 3-8 (p. 3-19) shows the tritium concentrations in wells $111,408,501$, and 502 over the eleven-year period that the WVDP's current groundwater monitoring program has been in place. The figure indicates that tritium concentrations in these wells show slight decreases or relatively consistent trends.

- Figure 3-9 (p. 3-20) shows tritium concentrations in wells 104, 105 and 801 over the past eleven years. Well 801 shows a general decrease until 2000 and a slight increase for 2001; wells 104 and 105 show a slight decrease over the past two to three years.

- Figure 3-10 (p. 3-20) shows sixteen-year trends of tritium concentrations at monitoring locations 8603, 8604, and 8605. Wells 8603 and 8604 indicate gradually declining trends in tritium; 8605 shows a significant decrease over time.

North Plateau Seeps. Analytical results of sampling for radiological parameters from the sand and gravel unit seepage monitoring locations were compared with the results from GSEEP, a seep monitored since 1991 that has not been affected by the gross beta plume. (Seep monitoring locations are noted on Figs. A-6 and A-7 [pp. A-8 and A-9].)

Gross Beta. Radiological monitoring results continue to indicate that the gross beta groundwater plume has not migrated to these seepage areas. With the exception of SP11, gross beta concen- 


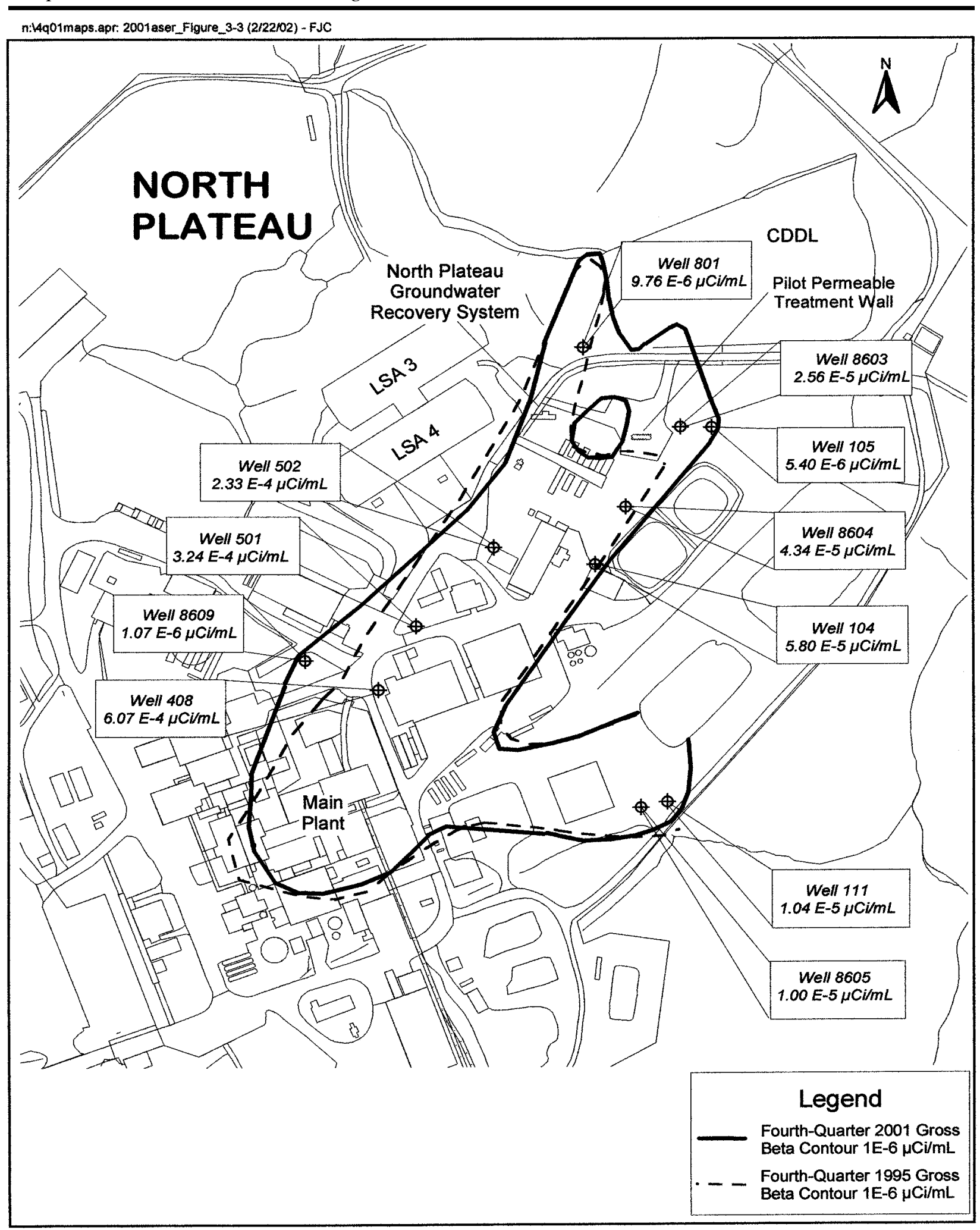

Figure 3-3. North Plateau Gross Beta Plume Area: Fourth-Quarter 2001 Results

$$
3-12
$$


trations from all seep monitoring locations were less than or similar to GSEEP concentrations during 2001. The gross beta concentration at SP11 shows a slightly increasing trend since early 1999 and somewhat steeper increases during the second half of 2001. Although somewhat greater than values typically obtained at GSEEP, it is still well below the strontium-90 DCG. (See Table E-7 [p. E-14].)

Gross Alpha. Gross alpha concentrations at all of the seep sampling locations were very low - generally below the associated uncertainty or less than the detection limit.

Tritium. Tritium concentrations at the seeps remained similar in magnitude or were less than concentrations at GSEEP. Tritium concentrations in the north plateau seeps, including GSEEP, are slightly above the levels reported in background wells of the sand and gravel unit. The concentrations are similar to those seen in sand and gravel unit wells monitoring the lagoon areas of the north plateau but are still far below the DCG for tritium.

The north plateau seep monitoring locations are inspected periodically and repaired as necessary to maintain optimum seepage flow. This ensures the quality, quantity, and representativeness of the groundwater samples. The conditions at all seep monitoring locations are checked during routine sampling and during the annual inspection of groundwater monitoring equipment.

North Plateau Well Points. Seven well points were installed in 1990 downgradient of the process building and were sampled annually between 1993 and 1996 for radiological indicator parameters. This area east of the process building and west of inactive lagoon 1 appears to be an area of localized contamination and is routinely monitored for contamination indicator and radiological indicator parameters. Data from these seven well points were used to supplement data collected from groundwater monitoring wells. Four well points were removed from the sampling program in 1997 because sufficient coverage was provided by active monitoring wells.

Sampling at well points A, C, and H (Fig. A-6 [p. A-8]) monitors tritium concentrations in the area east of the process building and fuel receiving and storage facility (FRS) and west of inactive lagoon 1. Samples from these three locations have yielded concentrations of tritium that, while elevated with respect to historical monitoring of wells in the area, are well below the DCG of $2.0 \mathrm{E}-03 \mu \mathrm{Ci} / \mathrm{mL}$. (See Table E-8 [p. E-15].) Data from downgradient monitoring wells have not indicated similarly elevated levels of tritium.

Results of Radioisotopic Sampling. Groundwater samples for radioisotopic analyses are collected regularly from selected monitoring points in the sand and gravel unit and the weathered Lavery till. (See Table E-13 [pp. E-18 and E-19].) Results in 2001 were generally similar to historical findings. Strontium-90 remained the major contributor to elevated gross beta activity in the plume on the north plateau, as indicated by the similarity between strontium- 90 trends and gross beta trends in wells showing elevated gross beta results.

Carbon-14, technetium-99, and iodine-129, which have been detected at several monitoring locations at concentrations above background levels, contribute very small percentages to total gross beta concentrations. These detections have occurred at locations within the gross beta plume and downgradient of inactive lagoon 1 and the NDA. None of the concentrations of carbon-14, technetium-99 or iodine-129 have been above DCGs, and gross beta analyses continue to provide surveillance on a quarterly basis.

Results of Monitoring at the NDA. A trench system was constructed along the northeast and 
northwest sides of the NDA to collect groundwater that may be contaminated with a mixture of ndodecane and tributyl phosphate. (See also Chapter 1, Environmental Program Information, NRC-Licensed Disposal Area [NDA] Interceptor Trench and Pretreatment System [p. 1-11].) There were no monitoring results in 2001 that indicated the presence of TBP or n-dodecane in groundwater in the vicinity of the NDA. Groundwater levels are monitored quarterly in and around the trench to ensure that an inward gradient is maintained, thereby minimizing the likelihood for outward migration of potentially contaminated groundwater.

Gross beta and tritium concentrations in samples from location NDATR, a sump at the lowest point of the interceptor trench, and from well 909 (Fig. A-6 [p. A-8]), which is downgradient of NDATR, continued to be elevated with respect to background monitoring locations on the south plateau but were still well below the DCGs.

NDATR. During 2001 gross beta concentrations at NDATR were slightly higher than those seen during 2000, but tritium, while still higher than at other NDA monitoring locations, declined and then leveled off during recent years.

Well 909. Radiological indicator results have historically fluctuated at this location but, in general, upward long-term trends in both gross beta and tritium are discernible at well 909, although the trends show a decrease and then a leveling off during 2000 and 2001. Gross beta concentrations from well 909 are considerably higher than at NDATR. Residual soil contamination near well 909 is the suspected source of elevated gross beta concentrations at well 909.

\section{Volatile and Semivolatile Organic Compounds Sampling}

Volatile and semivolatile organic compounds were sampled at specific locations (wells 8612, 8609, 803, and seep sampling location SP12 [Fig. A-6, p. A-8]) that have shown historical results above their respective practical quantitation limits. (See Table E-14 [pp. E-20 through E-22] for a list of PQLs.) Other monitoring locations are sampled for volatile and/or semivolatile organic compounds because they are downgradient of locations that have shown positive results or to comply with the RCRA §3008(h) Administrative Order on Consent.

1,1-Dichloroethane. Trends in concentrations of the compound 1,1-DCA from 1991 through 2001 are illustrated in Figure 3-11 (p. 3-21). Concentrations of 1,1-DCA at well 8612 have decreased over the past six years. The compound was not detected at wells 8609,803 , or groundwater seep SP12 during 2001. (See Table E-9 [p. E-15].)

Dichlorodifluoromethane. Trends of DCDFMeth concentrations are shown in Figure 3-12 (p. 3-21). DCDFMeth was detected at wells 803 and 8612 during 2001 at levels below the PQL.

1,2-Dichloroethylene. Positive detections of 1,2-DCE-t were first noticed at well 8612 (Fig. 313 [p. 3-22]) in 1995. Concentrations of 1,2-DCEt during 2001 were slightly higher than those measured during 2000.

1,1,1-Trichloroethane. The compound 1,1,1TCA was detected in wells 8609 and 8612 during 2001 at levels below the PQL but was not detected in well 803 or in seep SP12. (See Table E9 [p. E-15] for a summary of concentrations at these locations and Fig. 3-13 [p. 3-22] for a graph of 1,1,1-TCA concentrations at well 8612.) 
The VOCs 1,1-DCA, DCDFMeth, and 1,1,1-TCA are often found in combination with each other and with 1,2-DCE-t. In well 8612 each of these three compounds first exhibited an increasing trend that, over the past few years, was then followed by a decreasing trend. It is expected that 1,2DCE-t will exhibit similar behavior, and routine monitoring will evaluate future trends.

Tributyl Phosphate. Concentrations of tributyl phosphate were detected in 2001 groundwater samples from well 8605, near former lagoon 1, at concentrations similar to or less than those in 2000. TBP also was detected in well 111, which is next to and downgradient of well 8605 , but at levels much lower than those at well 8605. (See Fig. 314 [p. 3-22] and Table E-10 [p. E-16].)

The ongoing detection of TBP in this localized area may be related to previously detected low, positive concentrations of iodine-129 and uranium-232 in wells 111 and 8605 , as noted in previous annual site environmental reports. The presence of these three contaminants may reflect residual contamination from liquid waste management activities in the former lagoon 1 area during earlier nuclear fuel reprocessing. Future trends of TBP will be evaluated as part of the routine groundwater monitoring program.

\section{Special Groundwater Monitoring}

Gross Beta Plume on the North Plateau. Elevated gross beta activity has been detected in groundwater from the surficial sand and gravel unit in areas north and east of the building where Nuclear Fuel Services, Inc. (NFS) reprocessed nuclear fuel (Fig. 3-3 [p. 3-12]). In December 1993 elevated gross beta concentrations were detected in surface water at former sampling location WNDMPNE, located near the edge of the plateau. This detection initiated a subsurface investigation in 1994. Groundwater and soil were sampled using a Geoprobe ${ }^{\circledR}$, a mobile sampling system. The investigation was used to estimate the extent of the gross beta plume beneath and downgradient of the process building. The gross beta plume delineated in 1994 was approximately 300 feet wide and 800 feet long.

The highest gross beta concentrations in groundwater and soil were near the southeast corner of the process building. For the 1994 study, the maximum concentration in groundwater was $3.6 \mathrm{E}-03 \mu \mathrm{Ci} / \mathrm{mL}$, and the maximum concentration in soil was $2.4 \mathrm{E}-02 \mu \mathrm{Ci} / \mathrm{g}$. Strontium-90 and its daughter product, yttrium-90, were determined to be the isotopes responsible for most of this elevated gross beta activity (West Valley Nuclear Services Co., Inc., 1995).

In 1995 the north plateau groundwater recovery system (NPGRS) was installed to minimize the advance of the gross beta plume. The NPGRS is located near the leading edge of the main lobe of the plume where groundwater flows preferentially towards the edge of the plateau. The NPGRS consists of three extraction wells (RW-01, RW-02, and RW-03) that recover the contaminated groundwater which is then treated by ion exchange to remove strontium-90. Treated water is transferred to lagoon 4 or 5, then to lagoon 3, and ultimately is discharged to Erdman Brook.

The north plateau groundwater recovery system operated successfully throughout 2001 , processing about 3.4 million gallons ( 13 million liters). The system has recovered and processed approximately 25 million gallons (96 million liters) since November 1995.

As a result of recommendations from a 1997 external review of WVDP response actions on the north plateau, more attention was given in 1998 to the core area of the plume, determined to be beneath and immediately downgradient of the former process building. A summary report, 1998 
Geoprobe ${ }^{\circledR}$ Investigation in the Core Area of the North Plateau Groundwater Plume (West Valley Nuclear Services Co., Inc., June 1999) discusses groundwater and soil sampling data in the core area and compares radiological sampling results with the 1994 data. The 1998 study verified that strontium-90 is the predominant beta-emitter in groundwater and saturated soil within the north plateau groundwater plume. The report also noted that while the overall distribution of strontium- 90 in groundwater within the plume was similar to 1994, concentrations detected in 1998 samples were generally lower than in the 1994 samples due to radioactive decay and continuing migration and dispersion of the plume.

Permeable Treatment Wall. A pilot-scale permeable treatment wall (PTW) was completed in the fall of 1999 in the eastern lobe of the north plateau strontium- 90 groundwater plume in order to test this passive, in situ remediation technology. The PTW is a trench constructed in the subsurface and backfilled with clinoptilolite, a medium selected for its ability to adsorb strontium-90 ions from groundwater. The PTW extends vertically downward through the sand and gravel unit to the top of the underlying Lavery till and is approximately 30 feet long and 10 feet wide.

Monitoring and evaluation of water levels and radiological concentrations upgradient, within, and downgradient of the PTW continued during 2001 in order to assess its effectiveness. Additional test borings and monitoring well installations were completed in the vicinity of the PTW during the fall of 2001 in order to obtain improved definition of hydrogeologic conditions. Hydraulic testing in the new wells is planned for early 2002. These new data will be used to evaluate the performance of the pilot PTW.

Northeast Swamp Drainage Monitoring. Routine surface water sampling during 2001 contin- ued to monitor radioactivity levels in surface water flowing through the outlet location WNSWAMP. (See Appendix C, Table C-7 [p. C-8].) Gross beta and strontium- 90 concentrations continued to fluctuate due to seasonal effects. The annualized average strontium- 90 concentrations were consistent for the first five months and then steadily increased during the remainder of the year. (See Fig. 3-4 [p. 3-17].) The increase is believed to be due to a natural concentrating effect resulting from belowaverage precipitation during the summer and fall months. (See Figures I-4 and I-5 [p. I-6] and Table I-1 [p. I-7] in Appendix I.)

Although the annualized averaged concentration of strontium-90 in surface water increased at sampling location WNSWAMP (on the WVDP premises), monitoring downstream at the first point of public access (WFFELBR) continued to show strontium-90 concentrations that were not significantly different from background (WFBIGBR) concentrations. (See also Northeast Swamp and North Swamp Sampling Locations [p. 2-4] in Chapter 2, Environmental Monitoring.)

\section{North Plateau Groundwater Quality Early} Warning Monitoring. This monitoring is important because water recovered by the NPGRS ultimately is discharged through outfall 001. Quarterly monitoring results from three wells $(116,602 \mathrm{~A}$, and 502) in the vicinity of the NPGRS are assigned to identify concentrations that may affect compliance with SPDES effluent limits. Routine results for two of the wells, 116 and 602A, are used to monitor groundwater in the area affected by NPGRS drawdown. The third well, 502, is directly upgradient of the NPGRS and is sampled for additional metals not routinely analyzed under the current groundwater monitoring program. Analytical results of sampling of well 502 for additional metals can be found in Table E-12 (p. E-17 in Appendix E). 


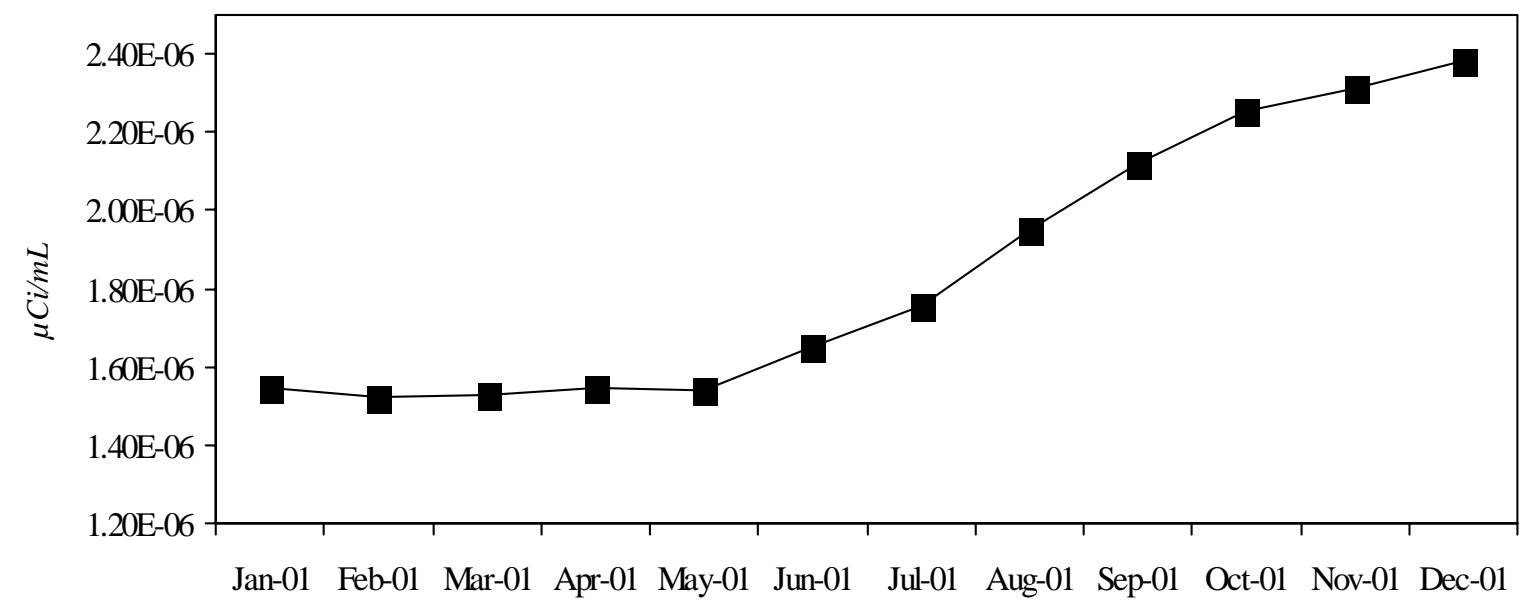

- Strontium-90

Figure 3-4. Annualized Average Strontium-90 Concentrations at WNSWAMP

Investigation of Chromium and Nickel in the Sand and Gravel Unit and Evaluation of Corrosion in Groundwater Monitoring Wells. A 1997 and 1998 study of the effect of modifying sampling equipment and methodology on the concentrations of chromium and nickel in samples of groundwater from the sand and gravel unit noted that such modifications did produce decreases in chromium and nickel concentrations. This supported the hypothesis (which is well documented in the technical literature) that the apparently elevated concentrations were not representative of actual groundwater conditions but were caused by the release of metals from subsurface corrosion of stainless steel well materials (West Valley Nuclear Services, Inc. and Dames \& Moore, June 1998).

To ensure continued monitoring well integrity and the collection of high-quality samples representative of actual groundwater conditions, approximately three-fourths of the stainless steel wells monitoring the sand and gravel unit were inter- nally inspected for corrosion during 2001. Wells containing corrosion were cleaned using simple brushing and purging techniques. Cleaned wells were reinspected to verify that corrosion had been removed. Long-term corrosion management will include annual inspections of selected wells.

Ten-Year Sampling Pump Inspections. Dedicated bladder pumps were installed in many WVDP monitoring wells in 1991. (See Groundwater Sampling Methodology [p. 3-7].) Pumps in all actively sampled wells were removed and inspected during 2001 in order to evaluate conditions after ten years of use. All pumps were found to be in good, serviceable condition and future maintenance will be based on observations made during routine quarterly sampling activities. 


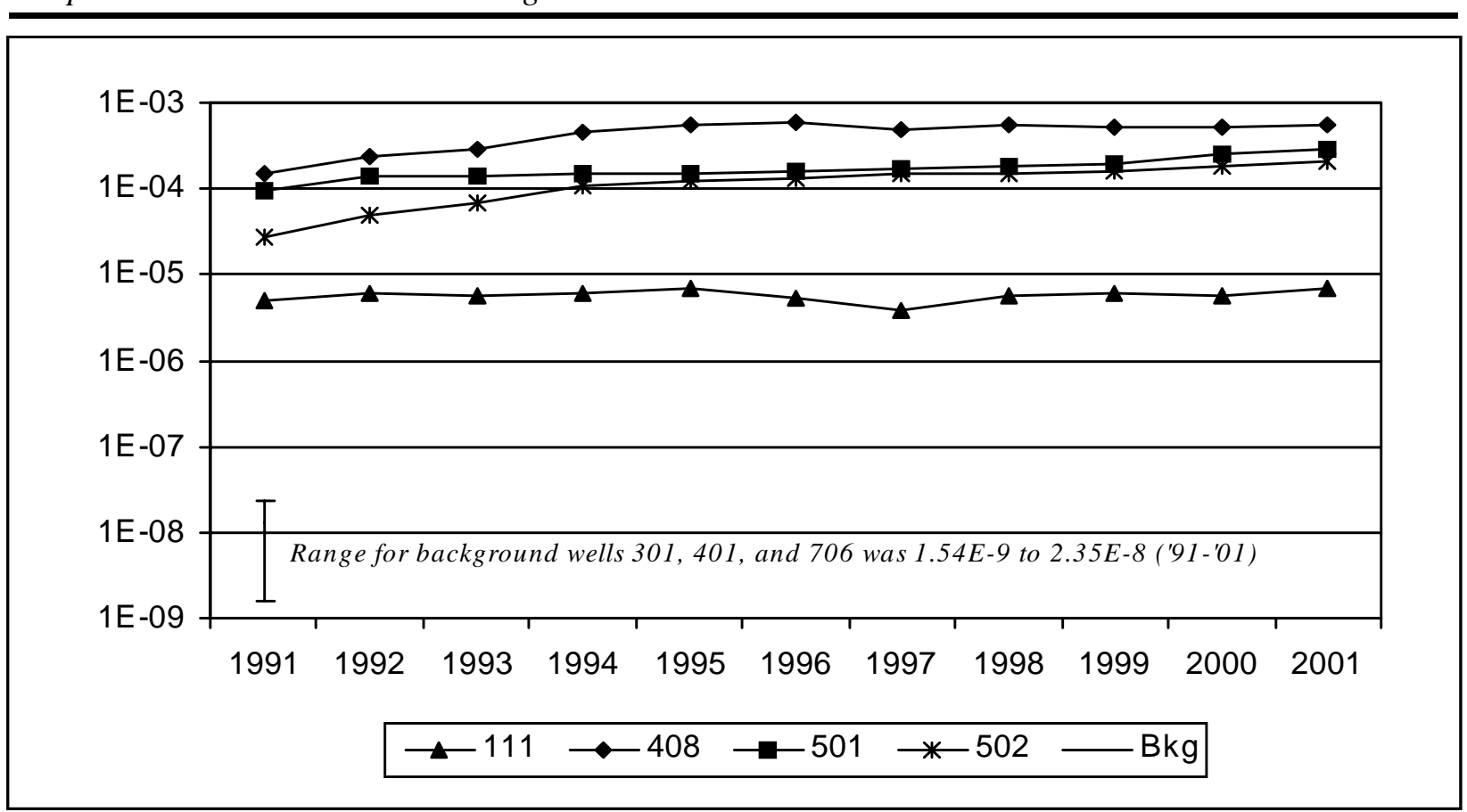

Figure 3-5. Eleven-Year Trends of Averaged Gross Beta Concentrations ( $\mu \mathrm{Ci} / \mathrm{mL})$ at Selected Locations in the Sand and Gravel Unit

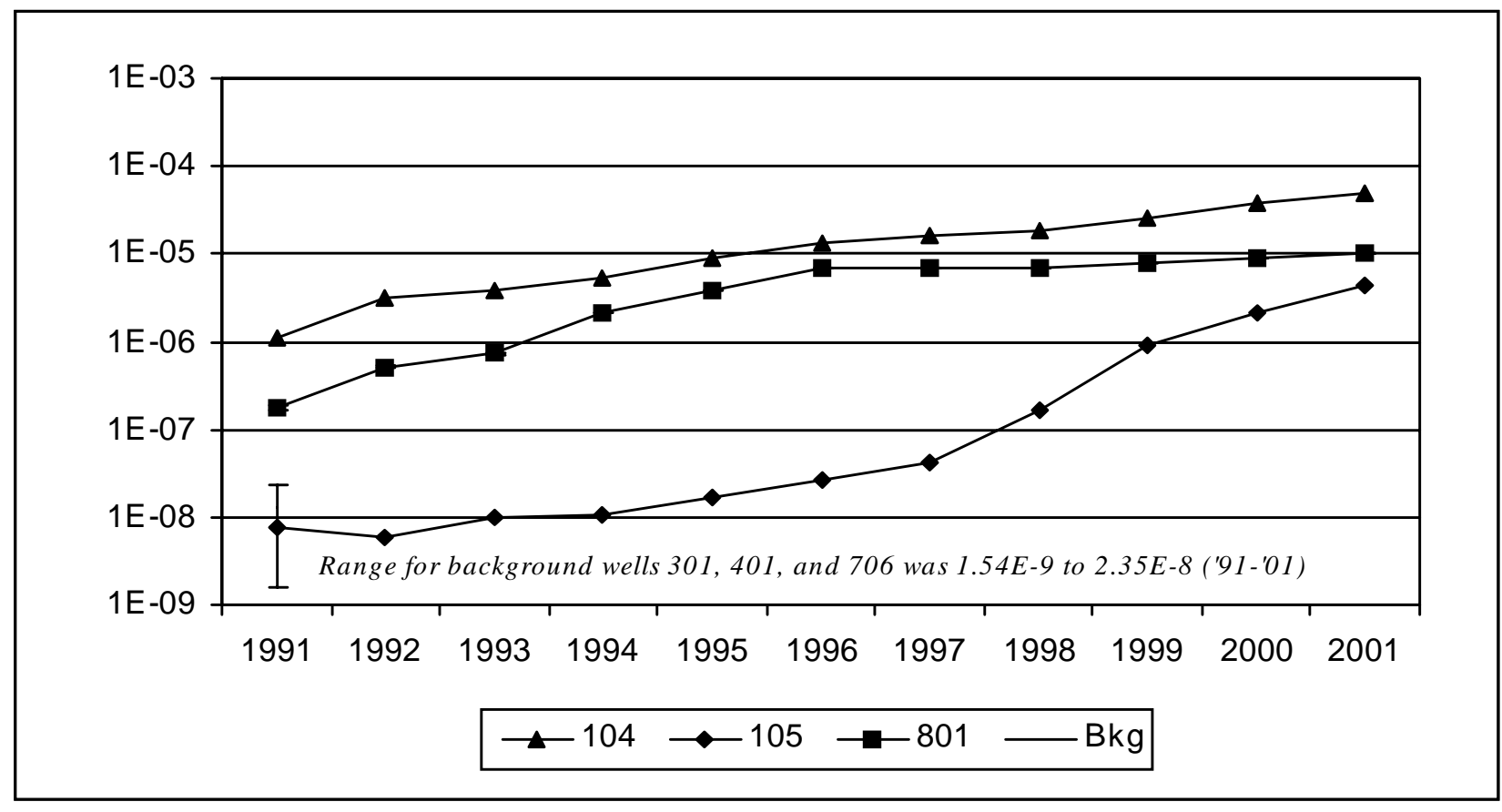

Figure 3-6. Eleven-Year Trends of Averaged Gross Beta Concentrations ( $\mu \mathrm{Ci} / \mathrm{mL})$ at Selected Locations in the Sand and Gravel Unit 


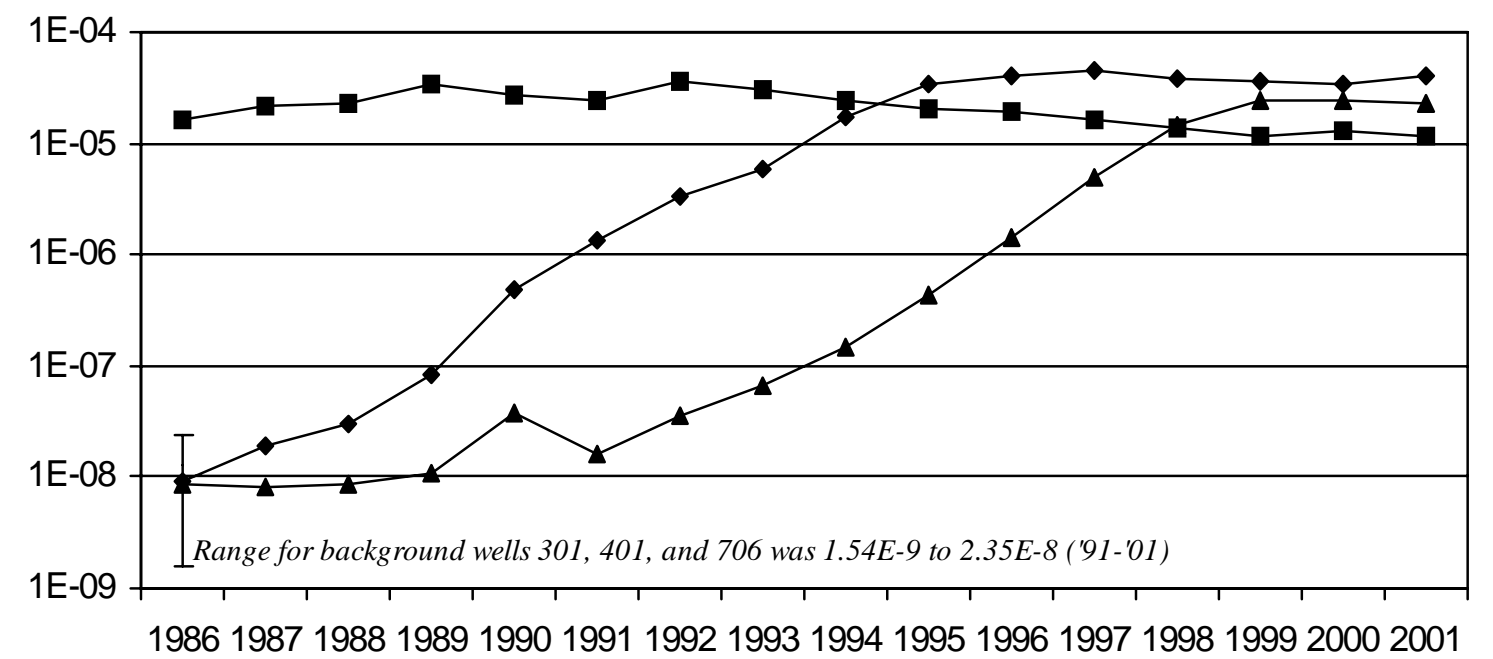

$$
\multimap-8603 \multimap-8604 \multimap-8605 \multimap B k g
$$

Figure 3-7. Sixteen-Year Trends of Averaged Gross Beta Concentrations ( $\mu$ Ci/mL) at Selected Locations in the Sand and Gravel Unit

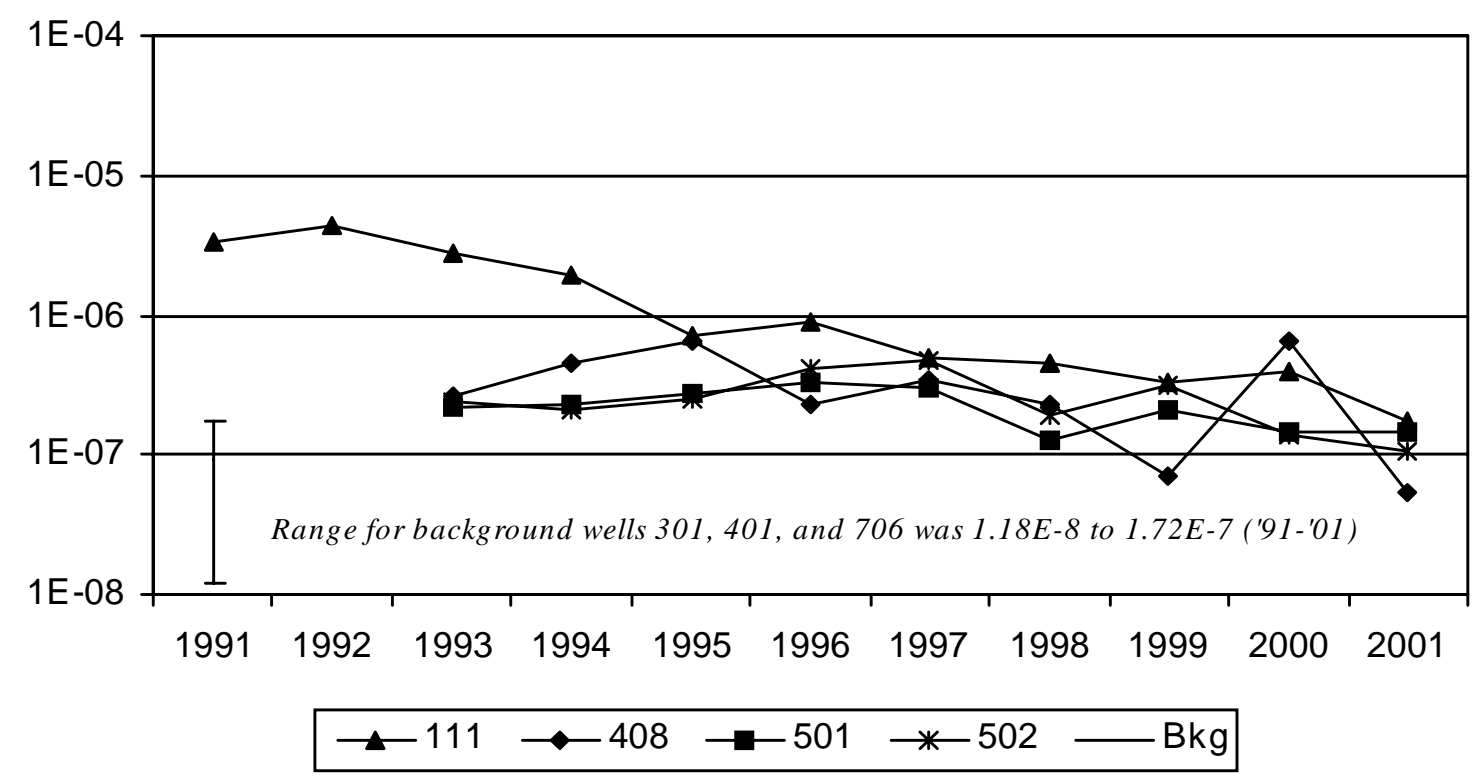

Figure 3-8. Eleven-Year Trends of Averaged Tritium Concentrations ( $\mu \mathrm{Ci} / \mathrm{mL})$ at Selected Locations in the Sand and Gravel Unit 


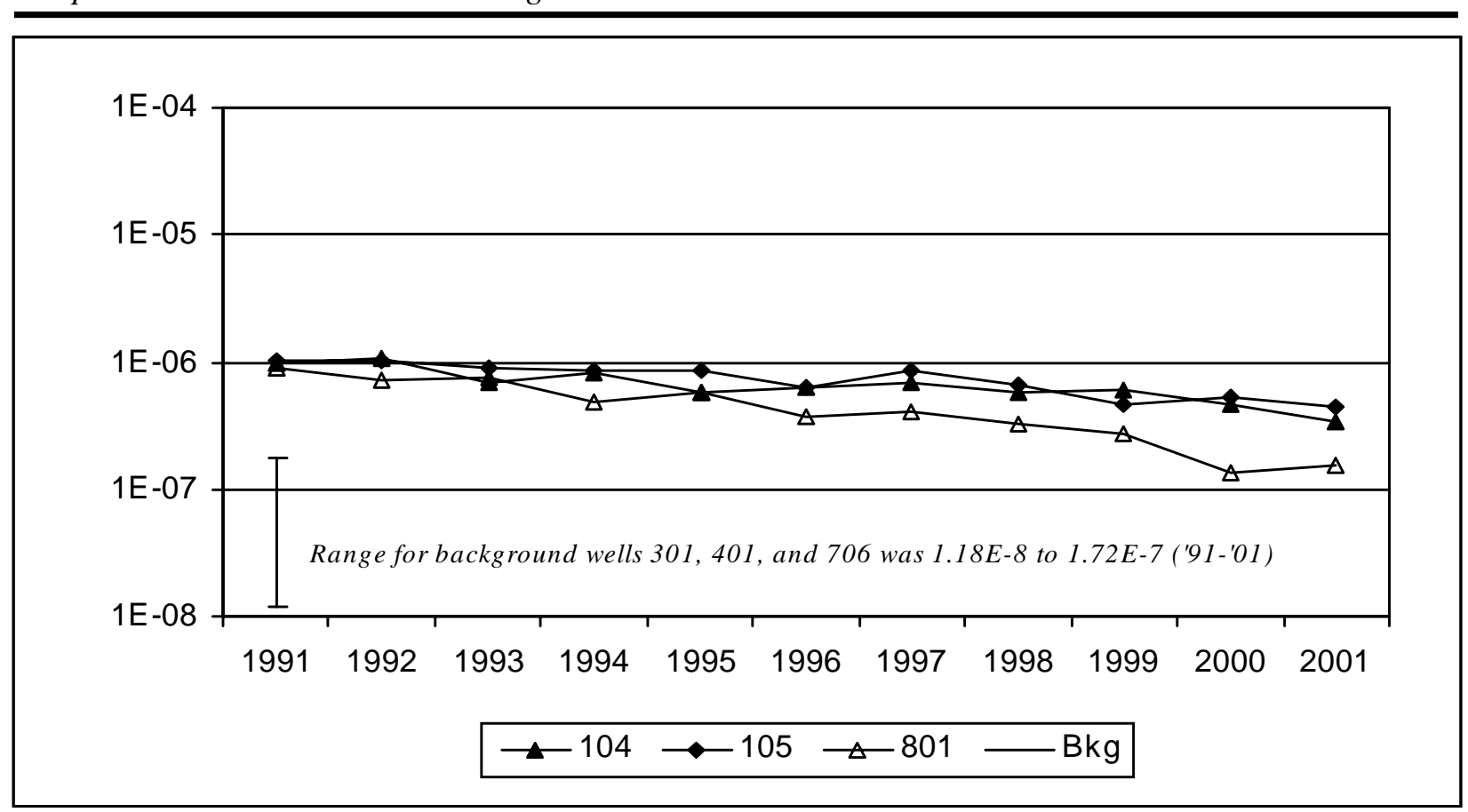

Figure 3-9. Eleven-Year Trends of Averaged Tritium Concentrations ( $\mu$ Ci/mL) at Selected Locations in the Sand and Gravel Unit

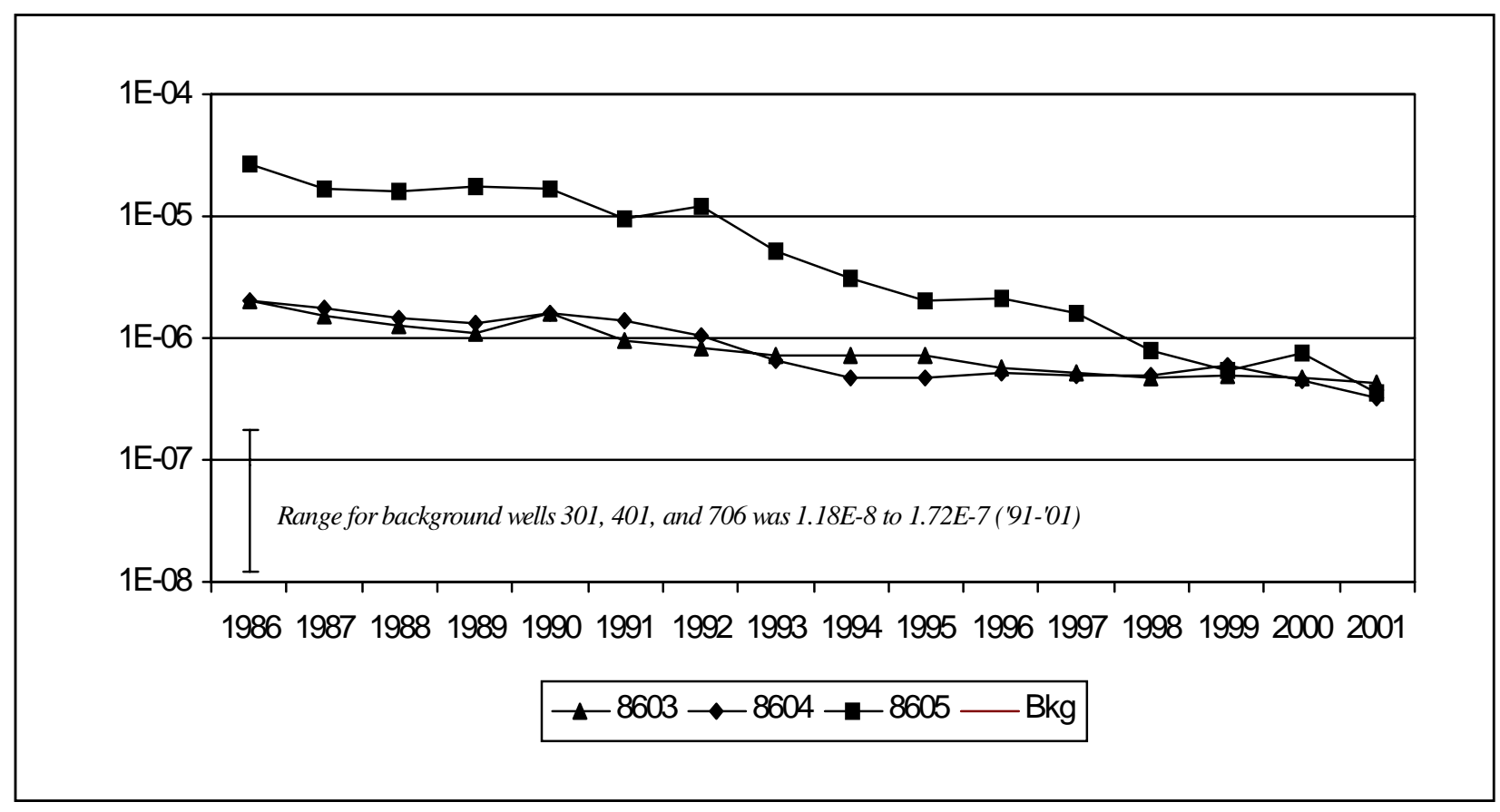

Figure 3-10. Sixteen-Year Trends of Averaged Tritium Concentrations $(\mu \mathrm{Ci} / \mathrm{mL})$ at Selected Locations in the Sand and Gravel Unit 


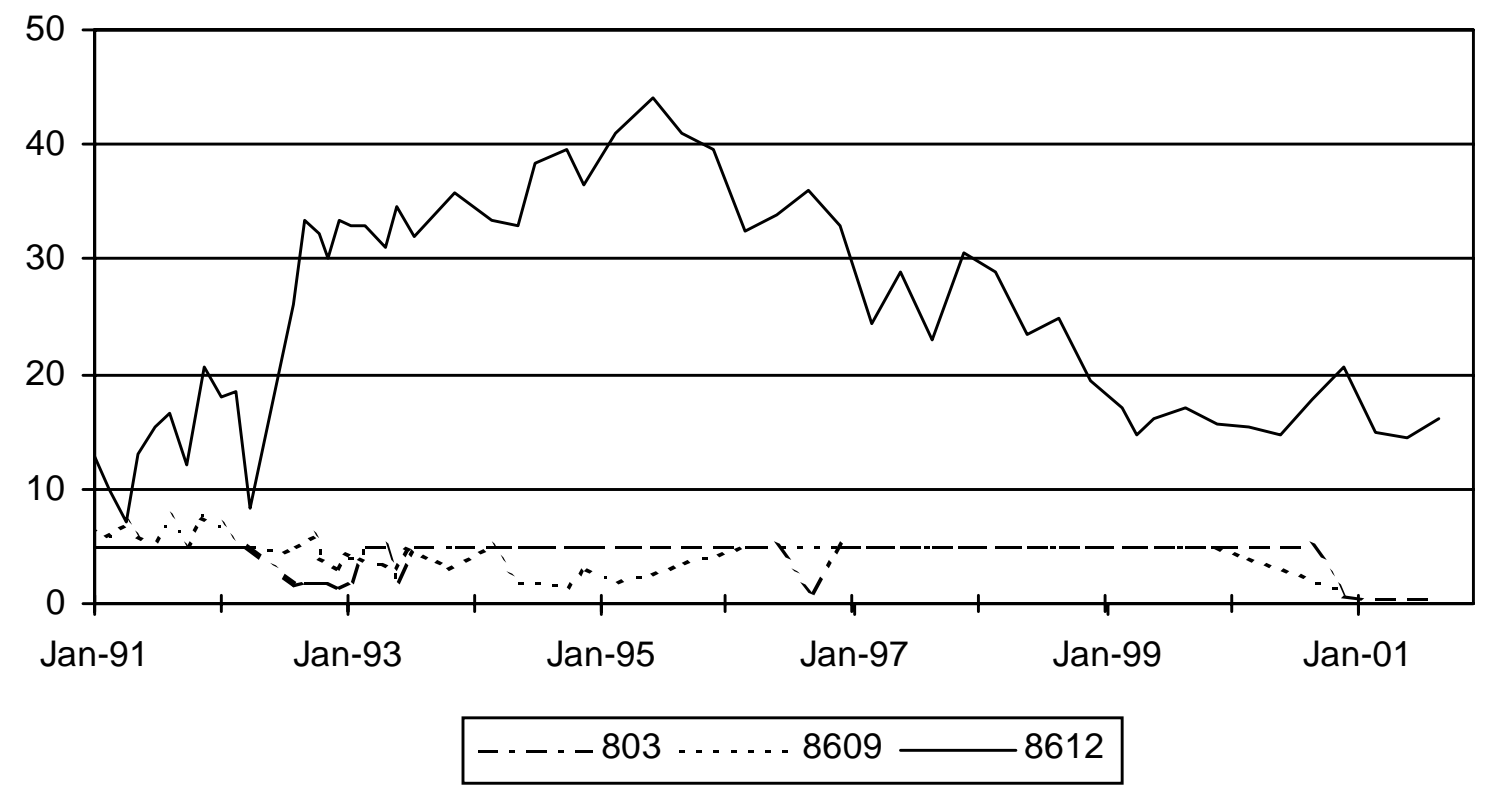

Figure 3-11. Eleven-Year Trends of 1,1-DCA $(\mu \mathrm{g} / \mathrm{L})$ at Selected Locations in the Sand and Gravel Unit

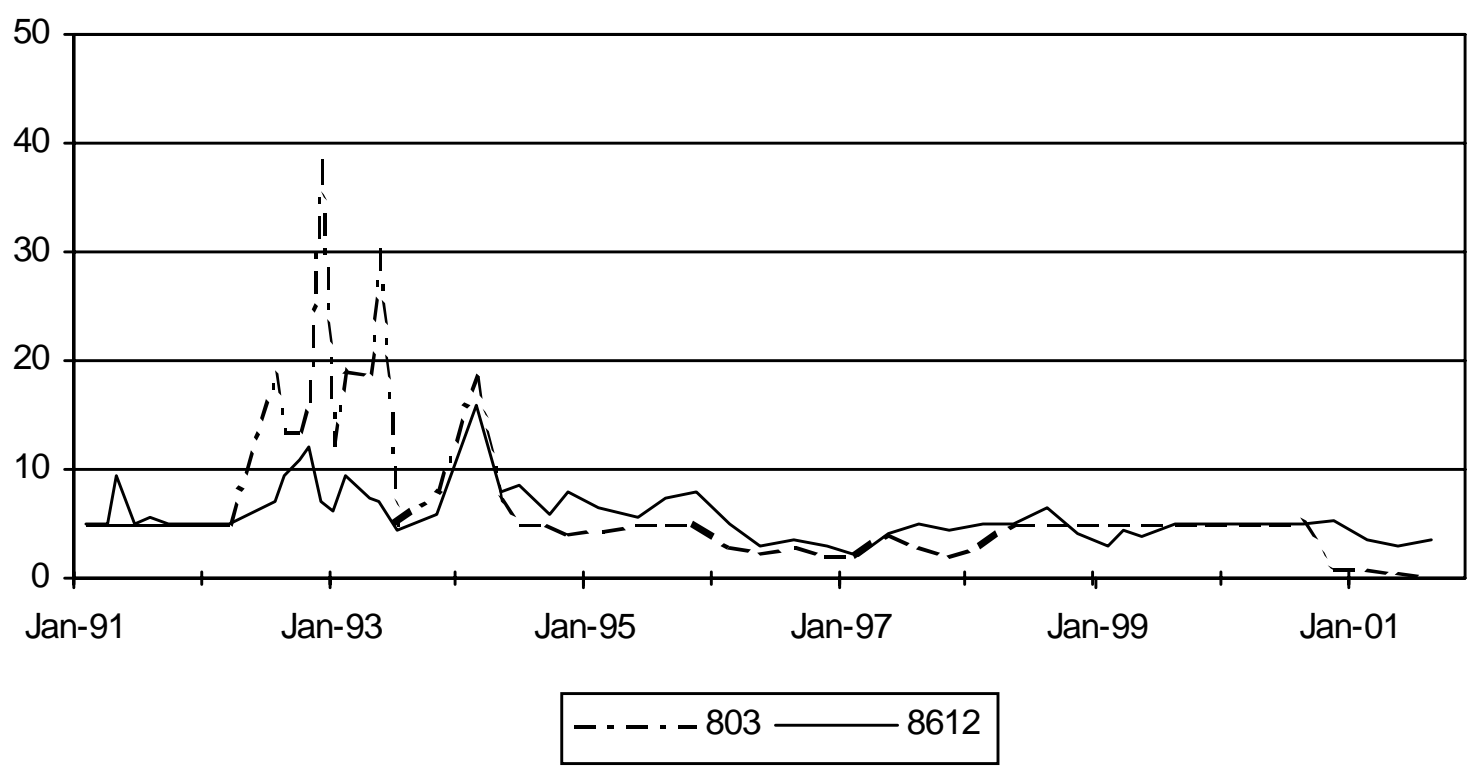

Figure 3-12. Eleven-Year Trends of Dichlorodifluoromethane $(\mu \mathrm{g} / \mathrm{L})$ at Selected Locations in the Sand and Gravel Unit

WVDP Site Environmental Report 


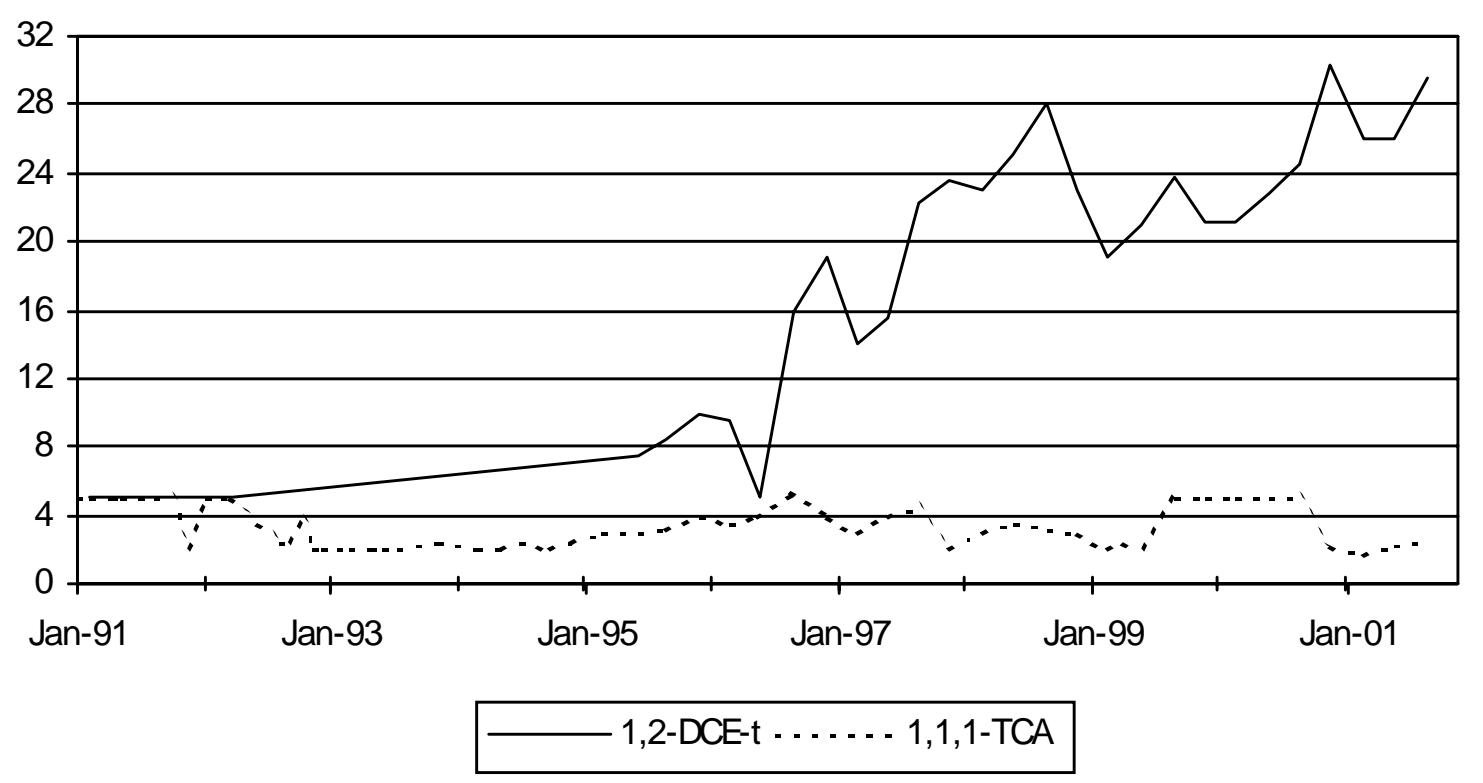

Figure 3-13. Eleven-Year Trends of 1,2-DCE-t and 1,1,1-TCA $(\mu \mathrm{g} / \mathrm{L})$ at Well 8612 in the Sand and Gravel Unit

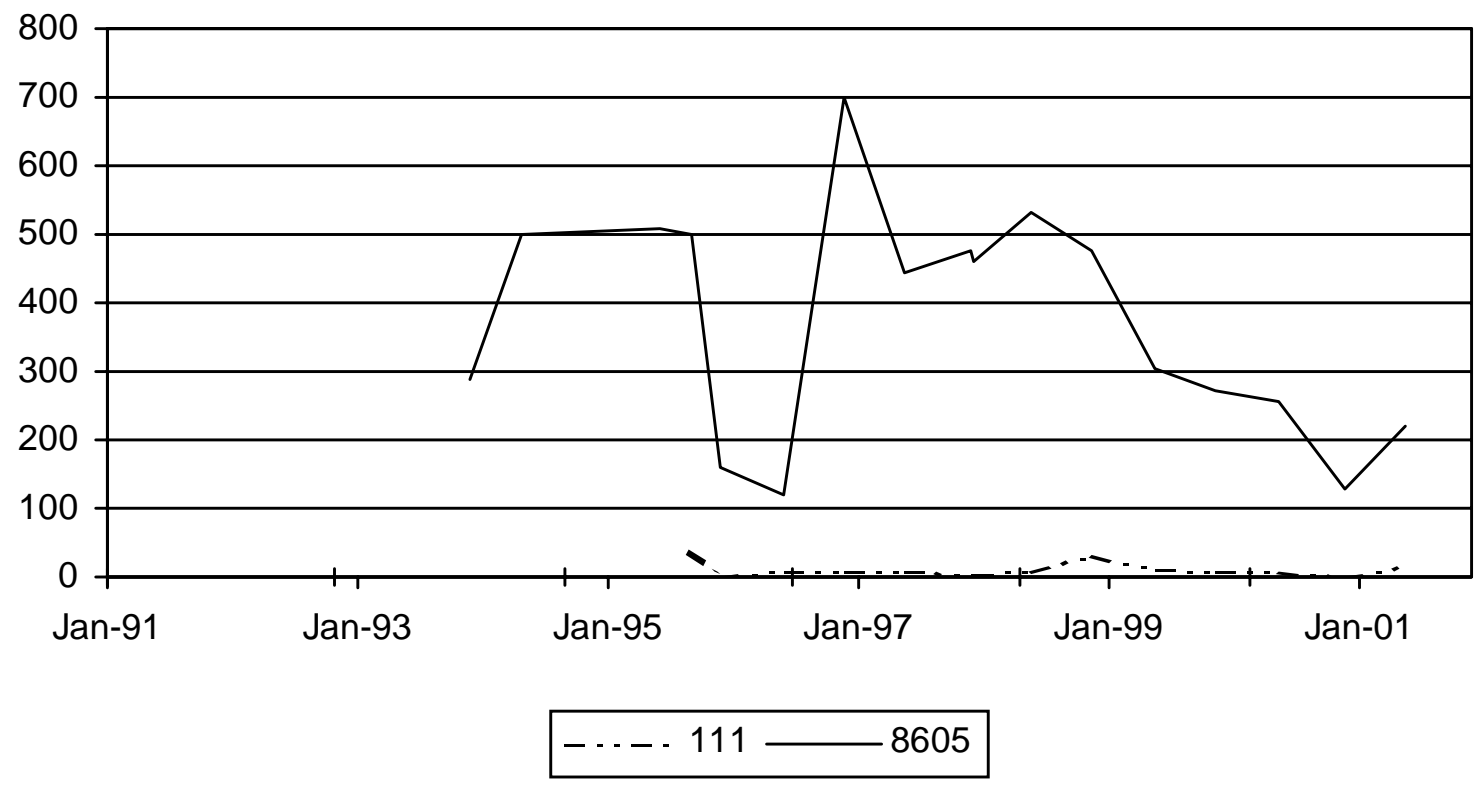

Figure 3-14. Trends of Tributyl Phosphate ( $\mu \mathrm{g} / \mathrm{L})$ at Selected Locations in the Sand and Gravel Unit 


\section{RADIOLOGICAL DOSE \\ ASSESSMENT}

\section{Introduction}

Each year the potential radiological dose to the public that is attributable to operations and effluents from the West Valley Demonstration Project (WVDP) is assessed to verify that no individual could credibly have received a dose exceeding the limits established by the regulatory agencies. The results of these conservative dose calculations demonstrate that the potential maximum dose to an off-site resident was well below permissible standards and was consistent with the as-low-as-reasonably achievable (ALARA) philosophy of radiation protection.

This chapter describes the methods used to estimate the dose to the general public resulting from exposure to radiation and radionuclides originating at the Project during calendar year 2001. The resulting estimated doses are compared directly with current radiation standards established by the U.S. Department of Energy (DOE) and the U.S. Environmental Protection Agency (EPA) for protection of the public. These values are also compared with the annual dose the average resident of the U.S. receives from natural background radiation and to doses reported in previous years for the Project.

Sources of Radiation. Members of the public are routinely exposed to different sources of ionizing radiation from both natural and manmade sources. Figure 4-1 (p. 4-2) shows the relative contribution to the annual dose in millirem from these sources in comparison with the estimated calendar year 2001 maximum individual dose from the WVDP. The National Council on Radiation Protection and Measurements (NCRP) Report 93 (1987b) estimates that the average annual effective dose equivalent received by an individual living in the U.S. is about $360 \mathrm{mrem}(3.6 \mathrm{mSv})$ from both natural and manmade sources of radiation.

While most of the radiation dose received by the general public is natural background radiation, manmade sources of radiation also contribute to the average dose. Such sources include diagnostic and therapeutic $x$-rays, nuclear medicine, fallout residues from atmospheric nuclear weapons tests, effluents from nuclear fuel-cycle facilities, and consumer products such as smoke detectors and cigarettes.

As can be seen in Figure 4-1 (p. 4-2), natural sources of radiation contribute $295 \mathrm{mrem}(2.95 \mathrm{mSv})$ and manmade sources contribute $65 \mathrm{mrem}(0.65 \mathrm{mSv})$ of the total annual U.S. average dose of $360 \mathrm{mrem}$ $(3.60 \mathrm{mSv})$. The WVDP contributed a very small amount $(0.040 \mathrm{mrem}[0.00040 \mathrm{mSv}])$ to the total annual manmade radiation dose to the maximally exposed off-site individual (MEOSI) residing near the WVDP. This is much less than the average dose 
received from using consumer products and is insignificant compared to the federal standard of 100 mrem allowed from any DOE site operations in a calendar year or the 295 mrem received annually from natural sources. The dose from WVDP operations also is small compared to the average additional dose an airline crew member typically receives from cosmic radiation ( $200 \mathrm{mrem} /$ year).

\section{Exposure Pathways}

The radionuclides present at the WVDP site are residues from the reprocessing of commercial nuclear fuel during the 1960s and early 1970s. A very small fraction of these radionuclides is released off-site during the year through ventilation systems and liquid discharges. These releases make a negligible contribution to the radiation dose to the surrounding population through several exposure pathways.

An exposure pathway consists of a way for a source of contamination or radiation to be transported by environmental media to a receptor where exposure to contaminants may occur. For example, a member of the public could be exposed to low concentrations of radioactive particulates carried by prevailing winds.
The potential pathways of exposure from Project emissions are inhalation of gases and particulates, ingestion of locally grown food products, ingestion of fish, beef, and deer tissues, and exposure to external penetrating radiation emitted from contaminated materials. The drinking water pathway is excluded from calculations of potential maximum dose to individuals because surveys revealed that local residents do not use Cattaraugus Creek as a source of drinking water. Table 4-1 (facing page) summarizes the potential exposure pathways for the local off-site population.

\section{Land Use Survey}

Periodic surveys of local residents provide information about local family sizes, sources of food, and gardening practices. Information from the most recent survey, conducted in early 2002, was used to confirm the locations of the nearest residences and other population parameters. These parameters are required for computer models that are used for the annual dose assessments. (See the discussion of Dose Assessment Methodology [ facing page] for more information on the computer models used.)

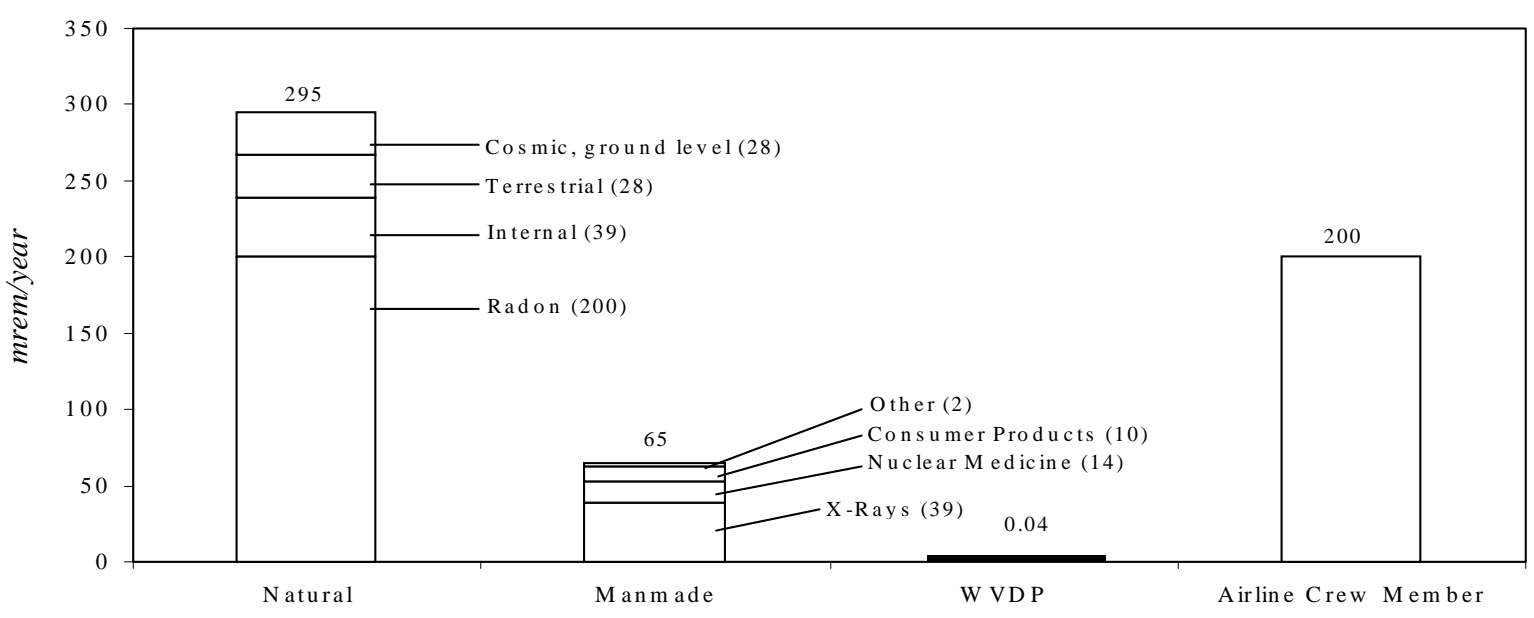

Figure 4-1. Comparison of Annual Background Radiation Dose to the Dose From 2001 WVDP Effluents 
Dose Assessment Methodology

\section{Table 4-1}

\section{Potential Local Off-Site Exposure Pathways Under Existing WVDP Conditions}

\section{Exposure Pathway and Transporting Medium}

Inhalation: gases and particulates in air (included)

Ingestion: cultivated crops

(included)

Ingestion: surface and groundwater (excluded)

Ingestion: fish, beef, venison, and milk (included)

External exposure: radiation emanating from particulates and gases from air or surface water (included)

\section{Reason for Inclusion/Exclusion}

Off-site transport of contaminants from WVDP stacks or resuspended particulates from soils or water

Local agricultural products irrigated with contaminated surface or groundwater; foliar deposition and uptake of airborne contaminants

No documented use of local surface water or downgradient groundwater wells as drinking water by local residents

Fish exposed to contaminants in water or sediments may be consumed; beef, venison, and milk consumption following deposition of transported airborne and surface water contaminants

Transport of air particulates and gases to offsite receptors; transport of contaminants in surface water and direct exposure during stream use and swimming

\section{Radioactive Vitrification Operations}

The start of radioactive vitrification operations in July 1996 resulted in expected increases of radioactive emissions from the main plant stack. Specifically, the release rate of iodine-129 increased from a 1993 to 1995 average of 25 microcuries $(\mu \mathrm{Ci})$ per year to $1,200 \mu \mathrm{Ci}$ in 1996 and $7,430 \mu \mathrm{Ci}$ in 1997 as a result of the processing of the highlevel waste.

In 1998 the yearly release of iodine-129 fell to $4,970 \mu \mathrm{Ci} / \mathrm{yr}$ due to the completion of Phase I of vitrification; in 1999 the total iodine-129 release was $1,900 \mu \mathrm{Ci}$. The iodine- 129 levels continued to decrease in calendar year 2000 - to $1,260 \mu \mathrm{Ci}$, a level consistent with reduced vitrification activity. In calendar year $2001,520 \mu \mathrm{Ci}$ of iodine- 129 were released. (See Chapter 2, Special Monitoring, [p. 2-27] for a discussion of iodine-129 emissions from the main plant stack.)

\section{Dose Assessment Methodology}

The potential radiation dose to the general public from activities at the WVDP is evaluated by using a two-part methodology applied in a manner consistent with the requirements in DOE Order 5400.5. The first part uses the measurements of radionuclide concentrations in liquid and air released from the Project to determine annual total effect. The second part uses measurements of 


\section{Ionizing Radiation}

Radiation can be damaging if, in colliding with other matter, the alpha or beta particles or gamma rays knock electrons loose from the absorber atoms. This process is called ionization, and the radiation that produces it is referred to as ionizing radiation because it changes an electrically neutral atom, in which the positively charged protons and the negatively charged electrons balance each other, into a charged atom called an ion. An ion can be either positively or negatively charged. Various kinds of ionizing radiation produce different degrees of damage.

\section{Potential Effects of Radiation}

The biological effects of radiation can be either somatic or genetic. Somatic effects are restricted to the person who has been exposed to radiation. For example, sufficiently high exposure to radiation can cause clouding of the lens of the eye or loss of white blood cells.

Radiation also can cause chromosomes to break or rearrange themselves or to join incorrectly with other chromosomes. These changes may produce genetic effects and may show up in future generations. Radiation-produced genetic defects and mutations in the offspring of an exposed parent, while not positively identified in humans, have been observed in some animal studies.

The effect of radiation depends on the amount absorbed within a given exposure time. The only observable effect of an instantaneous whole-body dose of $50 \mathrm{rem}(0.5 \mathrm{~Sv})$ might be a temporary reduction in white blood cell count. An instantaneous dose of 100-200 rem (1-2 Sv) might cause additional temporary effects such as vomiting but usually would have no long-lasting side effects. Assessing biological damage from low-level radiation is difficult because other factors can cause the same symptoms as radiation exposure. Moreover, the body is able to repair damage caused by low-level radiation.

The effect most often associated with exposure to relatively high levels of radiation appears to be an increased risk of cancer. However, scientists have not been able to demonstrate with certainty that exposure to low-level radiation causes an increase in injurious biological effects, nor have they been able to determine if there is a level of radiation exposure below which there are no biological effects.

\section{Health Effects of Low-Level Radiation}

Radionuclides entering the body through air, water, or food are distributed in different organs of the body. For example, isotopes of iodine concentrate in the thyroid. Strontium, plutonium, and americium isotopes concentrate in the skeleton. When inhaled, uranium and plutonium isotopes remain in the lungs for a long period of time. Some radionuclides such as tritium, carbon-14, or cesium-137 are distributed uniformly throughout the body. Thus, depending on the radionuclide, some organs may receive quite different doses. Moreover, at the same dose levels, certain organs (such as the breast) are more prone to developing a fatal cancer than other organs (such as the thyroid).

Because of the uncertainty and difficulty in measuring the incidence of increased cancer resulting from exposure to ionizing radiation, to be conservative, a linear model is used to predict health risks from low levels of radiation. This model assumes that there is a risk associated with all dose levels even though the body may effectively repair damage incurred from low levels of alpha, beta, and gamma radiations.

$$
4-4
$$


radioactivity in food from locations near the Project boundaries to confirm the low impact of the totals.

Radiological dose is evaluated for all major exposure pathways, including external irradiation, inhalation, and ingestion of local food products. The dose contributions from each radionuclide and pathway combination are then summed to obtain the total dose estimates reported in Table 4-2 (p. 4-6).

\section{Measurement of Radionuclide Concentra-} tions in Liquid and Air Releases. Because of the difficulty of distinguishing the small amount of radioactivity emitted from the site from that which occurs naturally in the environment using actual measurements of environmental samples, computer codes are used to model the environmental dispersion of radionuclides emitted from on-site monitored ventilation stacks and liquid discharge points.

First, actual data from release-monitoring samples are collected, together with annual weather measurements and the latest demographic information. (See Appendices C, D, and I.) The effective dose equivalent (EDE) to the maximally exposed off-site individual and the collective EDE to the population within a 50 -mile $(80-\mathrm{km})$ radius are then calculated using conservative models that have been approved by the DOE and the EPA to demonstrate compliance with radiation standards. (See Radiation Dose [this page] and Units of Measurement [p. 4-8].)

\section{Measurement of Radionuclide Concentra-} tions in Food. The second part of the dose assessment is based on actual measurements of radioactivity in samples of foodstuffs grown in the vicinity of the WVDP and the comparison of these values with measurements of samples collected from locations well beyond the potential influence of site effluents. These measurements of environmental media show that the concentrations of

\section{Radiation Dose}

The energy released from a radionuclide is eventually deposited in matter encountered along the path of the radiation. The radiation energy absorbed by a unit mass of material is referred to as the absorbed dose. The absorbing material can be either inanimate matter or living tissue.

Alpha particles leave a dense track of ionization as they travel through tissue and thus deliver the most dose per unit-path length. However, alpha particles are not penetrating and must be taken into the body by inhalation or ingestion to cause harm. Beta and gamma radiation can penetrate the protective dead skin layer of the body from the outside, resulting in exposure of the internal organs to radiation.

Because beta and gamma radiations deposit much less energy in tissue per unit-path length relative to alpha radiation, they produce fewer biological effects for the same absorbed dose. To allow for the different biological effects of different kinds of radiation, the absorbed dose is multiplied by a quality factor to yield a unit called the dose equivalent. A radiation dose expressed as a dose equivalent, rather than as an absorbed dose, permits the risks from different types of radiation exposure to be compared with each other (e.g., exposure to alpha radiation compared with exposure to gamma radiation). For this reason, regulatory agencies limit the dose to individuals in terms of total dose equivalent.

radioactivity are small - usually near the analytical detection limits - thereby providing additional assurance that operations at the WVDP are not adversely affecting the public.

If any of the near-site food samples were to contain radionuclide concentrations that are statistically higher than the concentrations in control

$4-5$ 


\section{Table 4-2 \\ Summary of Annual Effective Dose Equivalents to an Individual and Population From WVDP Releases in 2001}

Exposure Pathways
Annual Effective Dose Equivalent

\begin{tabular}{|c|c|c|}
\hline & $\begin{array}{l}\text { Maximally Exposed } \\
\text { Off-Site Individual } \\
\text { mrem }(m S v)\end{array}$ & $\begin{array}{l}\text { Collective Effective } \\
\text { Dose Equivalent }{ }^{2} \\
\text { person-rem (person-Sv) }\end{array}$ \\
\hline Airborne Releases ${ }^{3}$ & 4.6E-03 (4.6E-05) & 5.9E-02 (5.9E-04) \\
\hline$\%$ EPA standard (10 mrem) & $0.046 \%$ & $N A$ \\
\hline \multicolumn{3}{|l|}{ Waterborne Releases ${ }^{4}$} \\
\hline Effluents only & $1.4 \mathrm{E}-02(1.4 \mathrm{E}-04)$ & $1.0 \mathrm{E}-02(1.0 \mathrm{E}-04)$ \\
\hline Effluents plus north plateau drainage & 3.5E-02 (3.5E-04) & $1.3 \mathrm{E}-01(1.3 \mathrm{E}-03)$ \\
\hline Total from all Pathways & 4.0E-02 (4.0E-04) & 1.9E-01 (1.9E-03) \\
\hline $\begin{array}{l}\% \text { DOE standard }(100 \mathrm{mrem})- \\
\text { air and water combined }\end{array}$ & $0.040 \%$ & \\
\hline $\begin{array}{l}\% \text { of natural background } \\
(295 \text { mrem; } 398,000 \text { person-rem })- \\
\text { received from air and water combined }\end{array}$ & $0.01 \%$ & $0.00005 \%$ \\
\hline Estimated Rn-220 5 & $2.2 \mathrm{E}-02(2.2 \mathrm{E}-04)^{6}$ & $7.2 \mathrm{E}-01(7.2 \mathrm{E}-03)$ \\
\hline
\end{tabular}

Exponents are expressed as " $E$ " in this report: a value of $1.2 \times 10^{-4}$ in scientific notation is reported as 1.2E-04 in the text and tables.

NA - Not applicable. Numerical regulatory standards are not set for the collective EDE to the population.

1 Modeled data estimates the maximum exposure to air discharges occurs at a residence 1.9 kilometers north-northwest of the main plant.

2 Population of 1.35 million within 80 kilometers of the site.

3 From atmospheric release non-radon point and diffuse sources. Calculated using CAP88-PC for individual and population. EPA and DOE limits for individual airborne dose are the same.

4 Calculated using methodology described in Manual for Radiological Assessment of Environmental Releases at the WVDP (Spector, 2000).

5 Estimated releases based on indicator measurements and vitrification processing values: dose estimates calculated using CAP88-PC.

6 Estimated dose from Rn-220 specifically excluded by rule from NESHAP totals. (See p. 4-9.)

$$
4-6
$$


samples, separate dose calculations would be performed to verify that the calculated foodstuff dose is within the dose range estimated by computer modeling. These calculated doses are not added to the computer-modeled estimates (Table 4-2 [facing page]) because the models already include contributions fromall environmental pathways.

Comparison of Near-Site and Background Environmental Media Concentrations. Both near-site and control (background) samples of fish, milk, beef, venison, and local produce are collected and analyzed for various radionuclides, including tritium, cobalt-60, strontium-90, iodine-129, and cesium-137. The measured radionuclide concentrations reported in Appendix F, Tables F-1 through F-4 (pp. F-3 through F-8) are the basis for comparing near-site and background concentrations.

If differences are found between near-site and background sample concentrations, the amount by which the near-site sample concentration exceeds background is used to calculate a potential maximum individual dose for comparison with dose limits and the dose from background alone. If no statistical differences in concentrations are found, then no further assessment is conducted.

The maximum potential dose to nearby residents from the consumption of foods with radionuclide concentrations above background is calculated by multiplying the net concentrations (concentration in a sample minus background concentration) by the maximum adult annual consumption rate for each type of food and the unit dose conversion factor for ingestion of the measured radionuclide. The consumption rates are based on site-specific data and recommendations in NRC Regulatory Guide 1.109 for terrestrial food chain dose assessments (U.S. Nuclear Regulatory Commission October, 1977). The internal dose conversion factors were obtained from Internal Dose Conversion Factors for Calculation of Dose to the Public
(DOE/EH-0071 [U.S. Department of Energy, July 1988]).

Note that foodstuffs are weighed when received at the laboratory and the percent moisture is determined from the difference between the mass of the dried sample weighed after preparation for radiological measurement and the original "wet" as-measured mass. Doses are calculated based on the reconstituted "wet" mass of the original sample as it would be before preparation as food.

\section{Predicted Dose From Airborne Emissions}

Airborne emissions of radionuclides are regulated by the EPA under the Clean Air Act and its implementing regulations. DOE facilities are subject to 40 CFR 61, Subpart H, National Emission Standards for Hazardous Air Pollutants (NESHAP). Subpart H constitutes the national emission standards for emissions of radionuclides other than radon from DOE facilities. The applicable standard for radionuclides is a maximum of $10 \mathrm{mrem}$ $(0.1 \mathrm{mSv})$ EDE to any member of the public in any year.

Releases of airborne radioactive materials from nominal ground level stacks ( 1 to 24 meters high) and from the main 60-meter stack are modeled using the EPA-approved CAP88-PC computer code (U.S. Environmental Protection Agency, March 1992). This air dispersion code estimates effective dose equivalents for the ingestion, inhalation, air immersion, and ground surface pathways. Site-specific data for non-radon radionuclide release rates in curies per year, wind data, and the current local population distribution are used as input parameters. Resulting output from the CAP88-PC code is then used to determine the total EDE to a maximally exposed individual and the collective dose to the population within a 50mile $(80-\mathrm{km})$ radius of the WVDP. 


\section{Units of Measurement}

The unit for dose equivalent in common use in the U.S. is the rem, which stands for roentgenequivalent-man. The international unit of dose equivalent is the sievert (Sv), which is equal to 100 rem. The millirem (mrem) and millisievert $(\mathrm{mSv})$, used more frequently to report the low dose equivalents encountered in environmental exposures, are equal to one-thousandth of a rem or sievert, respectively.

The effective dose equivalent (EDE), also expressed in units of rem or sievert, provides a means of combining unequal organ and tissue doses into a single "effective" whole body dose that represents a comparable risk probability. The probability that a given dose will result in the induction of a fatal cancer is referred to as the risk associated with that dose. The EDE is calculated by multiplying the organ dose equivalent by the organ-weighting factors developed by the International Commission on Radiological Protection (ICRP) in Publications 26 (1977) and 30 (1979). The weighting factor is a ratio of the risk from a specific organ or tissue dose to the total risk resulting from an equal whole body dose. All organ-weighted dose equivalents are then summed to obtain the EDE.

The dose from internally deposited radionuclides calculated for a fifty-year period following intake is called the fifty-year committed effective dose equivalent (CEDE). The CEDE sums the dose to an individual over fifty years to account for the biological retention of radionuclides in the body. The total EDE for one year of exposure to radioactivity is calculated by adding the CEDE to the dose equivalent from external, penetrating radiation received during the year. Unless otherwise specified, all doses discussed here are total EDE values, which include the CEDE for internal emitters.

A collective population dose is expressed in units of person-rem or person-sievert because the individual doses are summed over the entire potentially exposed population. The average individual dose can therefore be obtained by dividing the collective dose by the number in the population.

As reported in Chapter 2, Environmental Monitoring, the main 60-meter stack and several shorter stacks were monitored for radioactive air emissions during 2001. The activity that was released to the atmosphere from these emission points is listed in Tables D-1 through D-11 and D-15. (See Appendix D [pp. D-3 through D-12 and D-16].) Note that these tables include data from an onsite airborne release in the fall of 2001. (See Unplanned Radiological Releases in Chapter 1 [p. 1-11].) Applicable information from these tables was used as input to the CAP88-PC code.
Wind data collected from the on-site meteorological tower during 2001 were used as input to the CAP88-PC code. Data collected at the 60-meter and 10-meter heights were used in combination with the main plant stack and near-ground-level effluent release data, respectively.

\section{Maximum Dose to an Off-Site Individual.} Based on the non-radon airborne radioactivity released from all sources at the site during 2001, it was estimated that a person living in the vicinity of the WVDP could have received a total EDE of 


\section{Radon-220}

Radon-220 is a naturally occurring gaseous decay product of thorium-232 present in the airborne emissions from the WVDP main plant. Radon-220, also known as thoron, is associated with the THOREX-related thorium-232 and uranium-232 in the high-level waste.

As reported in Chapter 2 of the 1996 WVDP Site Environmental Report, thoron levels were observed to increase during startup of the 1996 high-level waste vitrification process. An estimate of the thoron released during each waste concentration cycle was developed and used to determine a theoretical annual release. During the vitrification phase an average of about 12 curies per day were released. In 2001, because of the substantially reduced number of concentration cycles, the average was a bit less than six and a half curies of thoron released per day.

Although large numbers of curies were released relative to other radionuclides, the calculated dose from thoron is quite small because of its short decay half-life and other characteristics. The NESHAP rule specifically excludes thoron from air emission dose calculations at the WVDP, so a dose estimate using CAP88-PC was calculated separately. The theoretical dose to the maximally exposed off-site individual (MEOSI) located 1.9 kilometers north-northwest of the site in 2001 would have been 0.022 mrem, and the collective dose to the population within an 80-kilometer radius would have been 0.72 person-rem. (See Table 4-2 [p. 4-6].) These theoretical doses are less than or about the same as doses from the manmade radionuclide WVDP effluents.

As the final stages of vitrification are completed, thoron releases are expected to decrease to below pre-vitrification levels. The figure presented here provides a relative indication of recent trends in the estimated annual thoron releases.

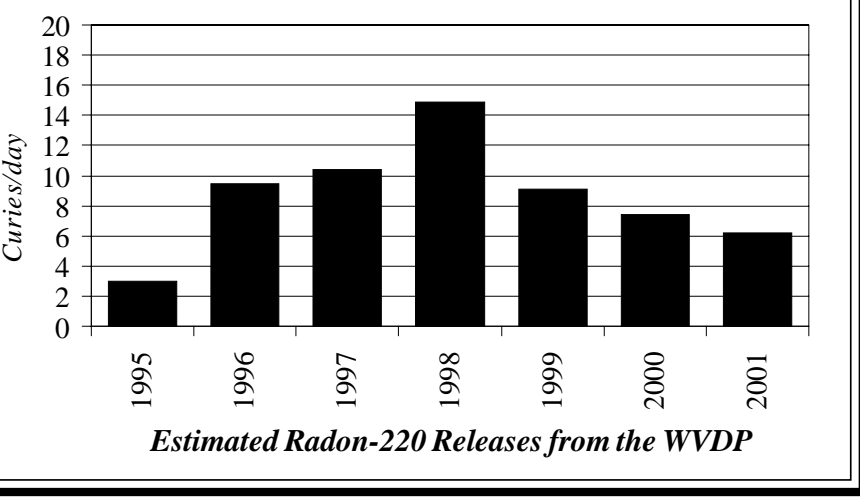

0.0046 mrem $(0.000046 \mathrm{mSv})$. The computer model estimates that this maximally exposed offsite individual was located 1.9 kilometers northnorthwest of the site and was assumed to eat only locally produced foods. Approximately $63 \%$ of the dose was from iodine- 129 .

The maximum total EDE of 0.0041 mrem $(0.000041 \mathrm{mSv})$ from the permitted stacks and vents is far below levels that could be directly measured at the exposed individual's residence. This dose is comparable to about eight minutes of natu- ral background radiation received by an average member of the U.S. population and is well below the $10 \mathrm{mrem}(0.1 \mathrm{mSv})$ NESHAP limit promulgated by the EPA and required by DOE Order 5400.5 .

Collective Population Dose. The CAP88-PC program was used to estimate the collective EDE to the population. Based upon the latest U.S. census population data collected in calendar year 2000 , 1.35 million people were estimated to reside within 50 miles $(80 \mathrm{~km})$ of the WVDP. This population received an estimated 0.059 person-rem $(0.00059$ 
person-Sv) total EDE from radioactive non-radon airborne effluents released from WVDP point and diffuse sources during 2001. The resulting average EDE per individual was 0.00004 mrem (0.0000004 mSv).

\section{Predicted Dose From Waterborne Releases}

Currently there are no EPA standards establishing limits on the radiation dose to members of the public from liquid effluents except as applied in 40 CFR 141 and 40 CFR 143, Drinking Water Guidelines (U.S. Environmental Protection Agency, 1984a; 1984b). The potable-water wells sampled for radionuclides are upgradient of the WVDP and therefore are not a potential source of exposure to radiation from Project activities.

Since Cattaraugus Creek is not used as a drinking water supply, a comparison of the predicted concentrations and doses with the EPA drinking water limits established in 40 CFR 141 and 40 CFR 143 is not truly appropriate (although the values in creek samples are well below the EPA drinking water limits). The estimated radiation dose was compared to the applicable guidelines provided in DOE Order 5400.5. The EDE to the maximally exposed off-site individual and the collective EDE to the population due to routine waterborne releases and natural drainage are calculated using dose conversion factors as tabulated in the WVDP Manual for Radiological Assessment of Environmental Releases at the WVDP (Spector, 2000).

Since the Project's liquid effluents eventually reach Cattaraugus Creek, which is not used directly as a source of drinking water, the most important individual exposure pathway is the consumption of fish from this creek by local sportsmen. It is assumed that a person may consume annually as much as 46 pounds $(21 \mathrm{~kg}$ ) of fish caught in the creek. Exposure to external radiation from shore- line or water contamination also is included in the model for estimating radiation dose. Population dose estimates assume that radionuclides are further diluted in Lake Erie before reaching municipal drinking water supplies.

The computer codes GENII version $1.485(\mathrm{~Pa}-$ cific Northwest Laboratory, 1982), which implements the models in U.S. NRC Regulatory Guide 1.109, and LADTAP II (Simpson and McGill, 1980) were used to calculate the site-specific unit dose factors for routine waterborne releases and dispersion of these effluents. Input data included local stream flow and dilution, drinking water usage, and stream usage factors. A detailed description of GENII is given in the WVDP Manual for Radiological Assessment of Environmental Releases at the WVDP (Spector, 2000).

Five planned batch releases of liquid radioactive effluents from lagoon 3 occurred during 2001. The radioactivity discharged in these effluents, listed in Appendix C, Table C-1 (p. C-3), was used with the unit dose factors to calculate the EDE to the maximally exposed off-site individual and the collective EDE to the population living within a 50mile $(80-\mathrm{km})$ radius of the WVDP.

In addition to the batch releases from lagoon 3 (WNSP001), effluents from the sewage treatment facility (WNSP007) and the french drain (WNSP008) are routinely released. The activities measured from these release points were included in the EDE calculations. The measured radioactivity concentrations from the sewage treatment facility and french drain are presented in Appendix C, Tables C-5 and C-6 (p. C-7).

Besides the three release points listed above, there are two natural drainage channels originating on the Project premises that have measurable concentrations of radioactivity in the water. These are drainages from the northeast swamp 
(WNSWAMP) and north swamp (WNSW74A). The measured radioactivity from these points is reported in Tables C-7 and C-8 (pp. C-8 and C9). Radioactivity measured at these drainage sample points is included in the EDE calculations for the maximally exposed off-site individual and the collective population.

There were no unplanned releases of waterborne radioactivity in 2001 .

Maximum Dose to an Off-Site Individual. Based on the radioactivity in liquid effluents released from the WVDP (lagoon 3, the sewage treatment plant, and the french drain) during 2001 an off-site individual could have received a maximum EDE of $0.014 \mathrm{mrem}(0.00014 \mathrm{mSv})$. Approximately $90 \%$ of this dose was from cesium-137. This 0.014 mrem $(0.00014 \mathrm{mSv})$ dose is negligible in comparison to the $295 \mathrm{mrem}(2.95 \mathrm{mSv})$ that an average member of the U.S. population receives in one year from natural background radiation.

The maximum off-site individual EDE due to drainage from the north plateau (north swamp and northeast swamp) is $0.021 \mathrm{mrem}(0.00021 \mathrm{mSv})$. The combined EDE to the maximally exposed individual from liquid effluents and drainage is $0.035 \mathrm{mrem}$ $(0.00035 \mathrm{mSv})$. This annual dose is somewhat less than the 2000 estimate and is negligible in comparison to the $295 \mathrm{mrem}(2.95 \mathrm{mSv})$ that an average member of the U.S. population receives in one year from natural background radiation.

Collective Dose to the Population. As a result of radioactivity released in liquid effluents from the WVDP (lagoon 3, the sewage treatment plant, and the french drain) during 2001, the population living within 50 miles $(80 \mathrm{~km})$ of the site received a collective EDE of 0.010 person-rem $(0.00010$ person-Sv). The collective dose to the population from the north plateau drainage is 0.12 personrem $(0.0012$ person-Sv). This estimate is based on a population of 1.35 million living within the 50mile $(80-\mathrm{km})$ radius. The resulting average EDE from lagoon 3 , the sewage treatment plant, the french drain, and north plateau drainage (north swamp and northeast swamp) per individual is $9.7 \mathrm{E}-05 \mathrm{mrem}$ (9.7E-07 mSv). This dose of 0.000097 mrem $(0.00000097 \mathrm{mSv})$ is an inconsequential addition to the dose that an average person receives in one year from natural background radiation.

\section{Calculated Dose From Local Foodstuff Tests}

Fish. Samples of fish were collected from Cattaraugus Creek from May 2001 through November 2001. Twenty fish were collected both at background locations upstream of the site and at locations downstream of the site above the Springville dam. Ten fish were collected at points downstream of the site below the dam. Edible portions of fish samples were analyzed for strontium- 90 and cesium-137, and the values were compared with background values. (See Table F-4 [pp. F-6 through F-8].)

Cesium-137 concentrations in fish collected downstream of the site but above the Springville dam were not statistically higher than background.

Strontium-90 in individual fish collected downstream of the site, above the Springville dam, was detectable at slightly above the average median control sample concentrations. The calculated maximum dose to an individual from consuming 46 pounds $(21 \mathrm{~kg})$ of near-site fish would be 0.01 mrem $(0.0001 \mathrm{mSv})$. This dose is roughly equivalent to the dose received every eighteen minutes from natural background radiation.

Milk. Milk samples were collected from various nearby dairy farms throughout 2001. Control samples were collected from farms 15 to 20 miles ( 25 to 30 $\mathrm{km}$ ) to the south and north of the WVDP. Milk samples were analyzed for tritium, potassium-40, 
strontium-90, iodine-129, and cesium-137. (See Table F-1 [p. F-3].) Nine near-site milk samples were collected and compared with eight background samples. Average values for tritium, strontium-90, iodine-129, and cesium-137 were either below detection limits or not statistically different from control concentrations. Naturally occurring potassium- 40 was used as an intrinsic reference point for the samples.

Beef. Near-site and control samples of locally raised beef were collected in 2001. These samples were analyzed for tritium, strontium-90, and cesium-137. Two samples of beef muscle tissue were collected from background locations and two from near-site locations. Individual concentrations of measured radionuclides in near-site samples were either below detection limits or not statistically different from concentrations at control locations. (See Table F-2 [p. F-4].)

Venison. Meat samples from three near-site and three control deer were collected during the fall of 2001. (See Table F-2 [p. F-4].) These samples were measured for tritium, strontium-90, cesium137, and other gamma-emitting radionuclides. Individual concentrations of measured radionuclides in near-site venison samples were either below detection limits or not statistically different from concentrations at control locations.

Produce (Corn, Beans, and Apples). Near-site and background samples of corn, beans, and apples were collected during 2001 and analyzed for tritium, potassium- 40 , cobalt-60, strontium- 90 , and cesium-137. (See Appendix F, Table F-3 [p. F5].) Individual concentrations of all the measured radionuclides in near-site produce samples were either below detection limits or not statistically different from concentrations at control locations.

See Appendix B (pp. B-37 through B-40) for the locations from which background biological samples are collected.

\section{Predicted Dose From All Pathways}

The potential dose to the public from both airborne and liquid effluents released from the Project during 2001 is the sum of the individual dose contributions. The calculated maximum EDE from all pathways to a nearby resident was $0.040 \mathrm{mrem}$ $(0.00040 \mathrm{mSv})$. This dose is $0.040 \%$ of the 100 mrem (1 mSv) annual limit in DOE Order 5400.5. The estimated dose from radon-220 to the same nearby resident was approximately $0.02 \mathrm{mrem}$.

The total collective EDE to the population within 50 miles $(80 \mathrm{~km})$ of the site was 0.19 person-rem (0.0019 person-Sv), with an average EDE of $0.00014 \mathrm{mrem}(0.0000014 \mathrm{mSv})$ per individual. The estimated radon-220 dose to the population was approximately 0.72 person-rem.

Table 4-2 (p. 4-6) summarizes the dose contributions from all pathways and compares the individual doses with the applicable standards. The low doses calculated using computer modeling are corroborated by the low or non-detectable doses calculated from local foodstuff test data.

Figure 4-2 (facing page) shows the calculated annual dose to the hypothetical maximally exposed individual over the last fourteen years. The estimated dose for 2001 ( $0.040 \mathrm{mrem})$ is lower than the annual dose reported for 2000 (0.061 mrem). The decrease in dose fraction from air emissions in 2001 is attributed to the continuing decrease in iodine-129 emissions. The lower dose from the liquid pathway is mostly the result of a lower volume of releases from the water treatment system. This decrease includes the continuing effect of the migration of the gross beta plume. (See Special Groundwater Monitoring in Chapter 3 [p. 315].) 
Dose to Biota: Aquatic and Terrestrial Wildlife

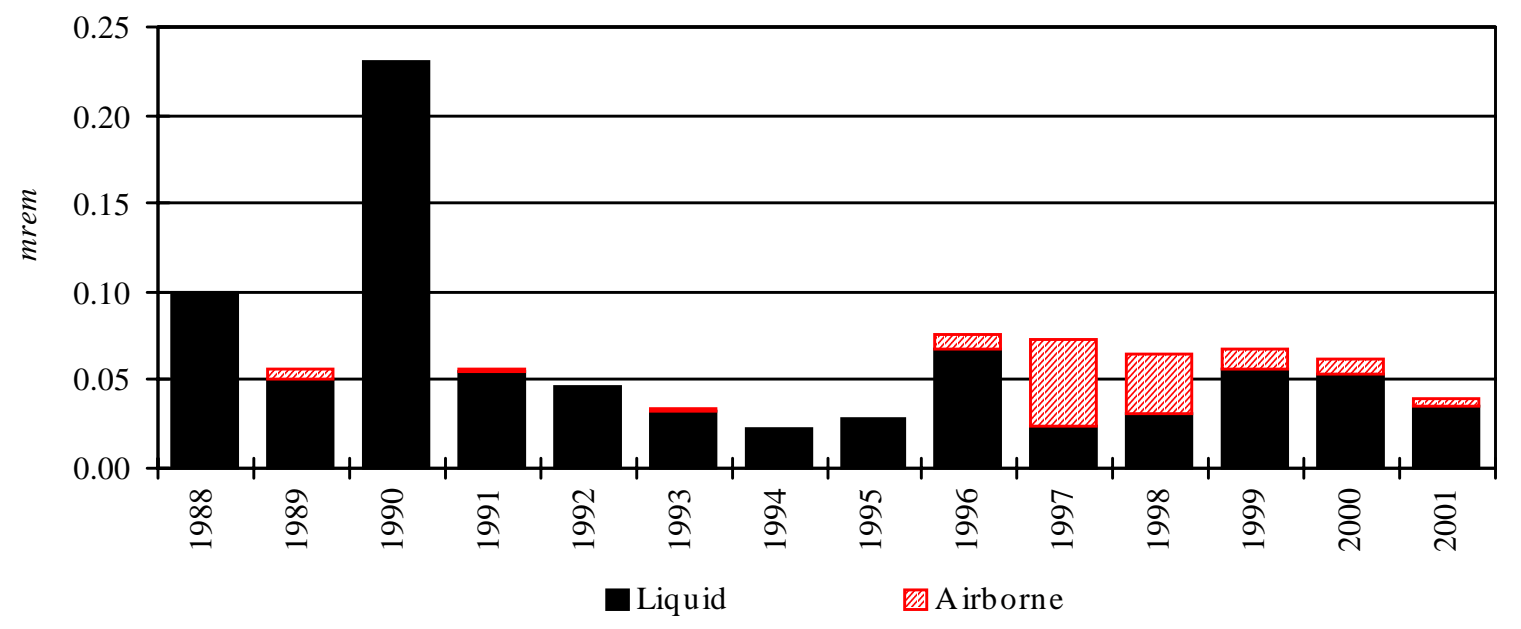

Figure 4-2. Effective Dose Equivalent from Liquid and Airborne Effluents to a Maximally Exposed Individual Residing Near the WVDP

Figure 4-3 (p. 4-14) shows the collective dose to the population over the last fourteen years. (See Fig. A-14 [p. A-16] for a map of the population sectors.) A five-year upward trend, primarily from an increase in vitrification activities, reversed in 1998 and then in 1999 through 2001 continued down towards previtrification levels.

As with the individual dose, a slight downward trend in collective dose from treated liquid effluents, directly linked to a noticeable decrease in the volume of water treated, was noted in 2001.

The overall radioactivity represented by these data confirm the continued inconsequential addition to the natural background radiation dose that the individuals and population around the WVDP receive from Project activities.

\section{Risk Assessment}

Estimates of cancer risk from ionizing radiation have been presented by the National Council on Radiation Protection and Measurements (1987b) and the National Research Council's Committee on Biological Effects of Ionizing Radiation (1990).

These reports estimate that the probability of fatal cancer induction to the public, averaged over all ages, ranges from 0.0001 to 0.0005 cancer fatalities/rem. The most recent risk coefficient of 0.0005 (International Commission on Radiological Protection 1991) was used to estimate risk to a maximally exposed off-site individual. The resulting estimated risk to this hypothetical individual from airborne and waterborne releases was a 0.000000020 probability of a cancer fatality (1 chance in 50 million). This risk is well below the range of 0.000001 to 0.00001 per year considered by the International Commission on Radiological Protection in Report 26 (1977) to be a reasonable level of risk for any individual member of the public.

\section{Dose to Biota: Aquatic and Terrestrial Wildlife}

Radionuclides from both natural and man-made sources may be found in environmental media such 


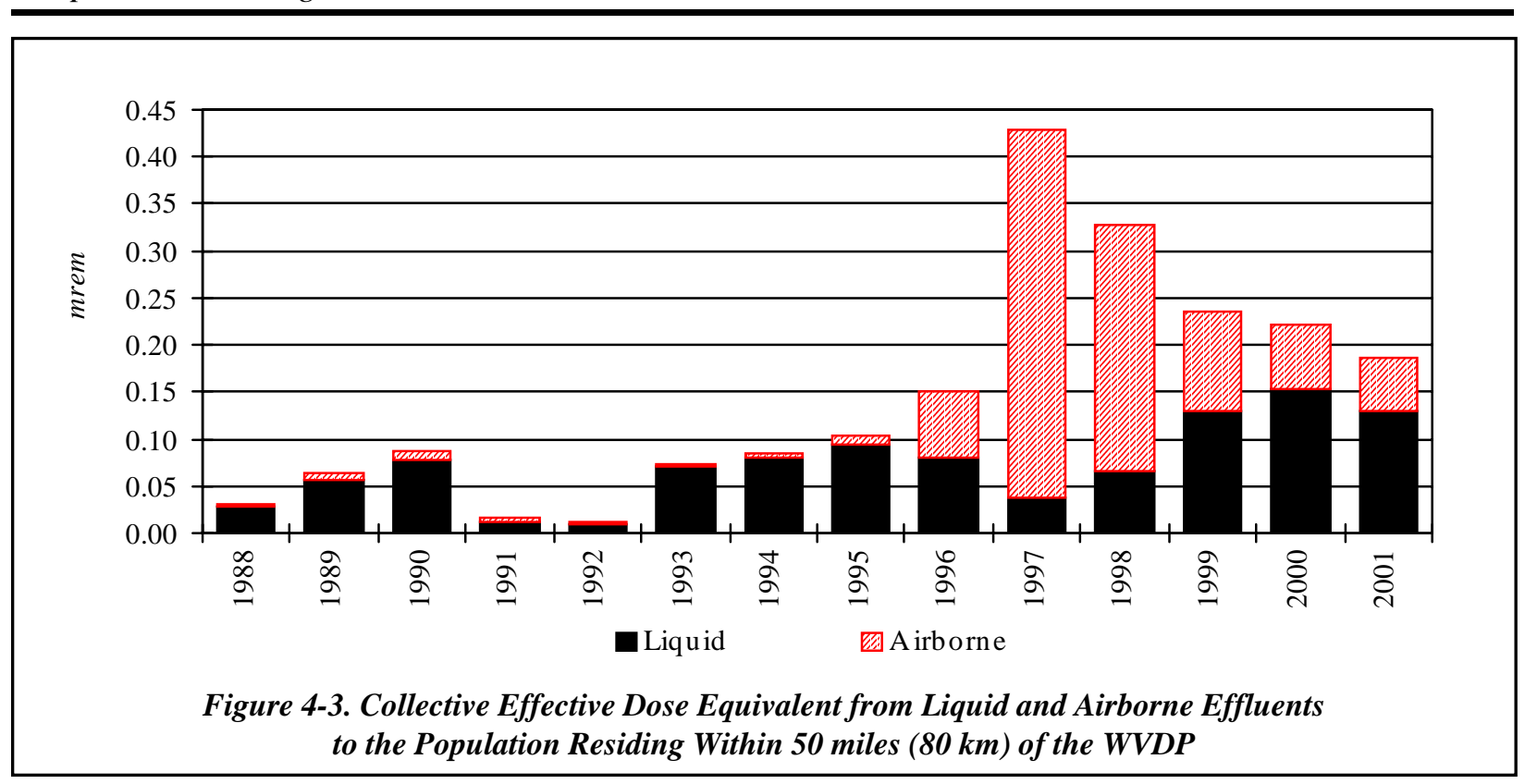

as water, sediments, and soils. In the past, it has been assumed that if radiological controls are sufficient to protect humans, other living things are also likely to be sufficiently protected. This assumption is no longer considered adequate, since populations of plants and animals residing in or near these media or taking food or water from these media may be exposed to a greater extent than are humans. For this reason, the DOE has prepared a technical standard which provides methods and guidance to be used to evaluate doses of ionizing radiation to populations of aquatic animals, terrestrial plants, and terrestrial animals.

Methods in this draft technical standard, A Graded Approach for Evaluating Radiation Doses to Aquatic and Terrestrial Biota (ENVR-0011, DOE, June 2000), were used in 2001 to evaluate radiation doses to aquatic and terrestrial biota within the confines of the Western New York Nuclear Service Center (WNYNSC), which includes the WVDP. Doses were assessed for compliance with the limit in DOE Order 5400.5 for aquatic animals ( 1 rad per day) and for compliance with the thresholds for terrestrial plants (also
$1 \mathrm{rad}$ per day) and for terrestrial animals ( $0.1 \mathrm{rad}$ per day), as proposed in ENVR-0011. Note that the absorbed dose unit (rad) is used for biota instead of the units used for indicating human risk (rem).

RAD-BCG, a calculation tool provided by the DOE for implementing ENVR-0011, was used to compare existing radionuclide concentration data from environmental sampling with biota concentration guide (BCG) limits. Data collected from surface waters, sediments, and soils on and around the WNYNSC over a ten-year period (1991 2000) were used in a baseline evaluation. For a more near-term assessment, a second evaluation was completed using surface water data from 2001 and sediment data from 1997 - 2001. (See Appendices $\mathrm{A}$ and $\mathrm{B}$ for maps and descriptions of monitoring and surveillance locations. Radionuclides analyzed for each medium at each location are listed in Appendix B. See Appendix C for a listing of results from these locations in 2001.)

Concentration data for radionuclides in each medium were entered to the calculation tool. The value for 
each radionuclide was automatically divided by the BCG in order to calculate a partial fraction for each nuclide for each medium. Partial fractions for each medium were added to produce a sum of fractions.

It was found that the isotopes with the highest sums of fractions - the radionuclides that contributed the largest component of both aquatic and terrestrial dose to biota - were strontium-90 and cesium-137. Per guidance in ENVR-0011, the populations of organisms most sensitive to strontium-90 and cesium-137 in this evaluation - that is, those populations residing on the WNYNSC that were most likely to be adversely affected via the aquatic and terrestrial pathways - were determined to be populations of the raccoon (aquatic dose) and the deer mouse (terrestrial dose). As such, this study does not pertain to pathways to humans, which are addressed elsewhere in this chapter. (See Dose Assessment Methodology [p. 4-3].)

The aquatic dose limit from DOE 5400.5 may be assumed to have been met if the sum of fractions for the water medium plus that for the sediment medium is less than 1.0. Similarly, proposed dose limits for both terrestrial plants and animals may be assumed to have been met if the sum of fractions for the water medium plus that for the soil medium is less than 1.0.

In accordance with the approach described in ENVR-0011, a general screening was first conducted using the maximum radionuclide concentrations from surface waters, sediments, and soils. Maximum radionuclide concentrations from the 10-year sampling database exceeded applicable general screening BCG limits for both aquatic and terrestrial evaluations, as did the concentrations from the 2001 surface water data and the more recent sediment data.

As recommended in ENVR-0011, a site-specific screening was then done using estimates of aver- age radionuclide concentrations derived from measurement series in surface waters, sediments, and soils. Average concentrations for each medium, applicable BCGs, partial fractions, and sums of fractions for the ten-year baseline study are tabulated in Table 4-3 (p. 4-16).

At the site-specific screening level for the full tenyear period, the sum of fractions for the aquatic system evaluation was 0.45 and that for the terrestrial system evaluation was 0.57 . The comparable sums of fraction using the more near-term data were 0.37 and 0.57 , respectively. The sum of fractions for each assessment was less than 1.0, indicating that applicable BCGs were met for both the aquatic and terrestrial evaluations. It was therefore concluded that populations of aquatic and terrestrial biota (both plants and animals) on the WNYNSC are not being exposed to doses in excess of the existing DOE dose standard for aquatic organisms and the recommended standards put forth in ENVR-0011 for terrestrial biota.

\section{Summary}

Predictive computer modeling of airborne and waterborne releases resulted in estimated hypothetical doses to the maximally exposed individual that were orders of magnitude below all applicable EPA standards and DOE Orders, which place limitations on the release of radioactive materials and dose to individual members of the public. The collective population dose also was assessed and found to be orders of magnitude below the natural background radiation dose. Additionally, it was determined that biota at the WVDP are exposed at a fraction of the suggested maximum radiation levels.

Based on the overall dose assessment, the WVDP was found to be in compliance with applicable effluent radiological guidelines and standards during calendar year 2001. Table 4-4 (p. 4-17) provides a summary of WVDP releases and calculated doses in specified DOE format. 


\section{Table 4-3 \\ Evaluation of Dose to Aquatic and Terrestrial Biota}

Based on average radionuclide concentrations in waters, sediments, and soils from ten years of monitoring, the sum of fractions for the aquatic system evaluation was 0.45 and that for the terrestrial system evaluation was 0.57 . Evaluations using more recent data - surface water data from 2001 and sediment data from 1997 - 2001 - resulted in aquatic and terrestrial sums of fractions of 0.37 and 0.57 , respectively. Each sum of fractions was less than 1.0, indicating that applicable biota concentration guides (BCGs) were met for both the aquatic and terrestrial evaluations. The calculated sum of fractions for aquatic organisms for the near-term assessment was less than the sum of fractions calculated for the 10-year baseline. It was therefore concluded, based on both long-term and near-term results, that populations of aquatic and terrestrial biota on the WNYNSC are not being exposed to doses in excess of the existing DOE limit for aquatic organisms (U.S. Department of Energy, February 1990) and the international standards for terrestrial organisms (International Atomic Energy Agency, 1992).

\section{Aquatic System Evaluation (Long-Term [10-Year] Data Set)}

\begin{tabular}{|c|c|c|c|c|c|c|c|}
\hline Nuclide & $\begin{array}{c}\text { Water } \\
\text { BCG* } \\
(\mathbf{p C i} / \mathbf{L})\end{array}$ & $\begin{array}{c}\text { Mean Water } \\
\text { Value } \\
(\text { pCi/L) }\end{array}$ & $\begin{array}{c}\text { Water } \\
\text { Partial } \\
\text { Fraction }\end{array}$ & $\begin{array}{l}\text { Sediment } \\
\text { BCG* } \\
(\mathbf{p C i} / \mathrm{g})\end{array}$ & $\begin{array}{c}\text { Mean Sediment } \\
\text { Value } \\
(\mathrm{pCi} / \mathrm{g})\end{array}$ & $\begin{array}{l}\text { Sediment } \\
\text { Partial } \\
\text { Fraction }\end{array}$ & $\begin{array}{c}\text { Water and } \\
\text { Sediment } \\
\text { Sum of Fractions }\end{array}$ \\
\hline Cesium-137 & 42.6 & 13.0 & $3.05 \mathrm{E}-01$ & 3,120 & 7.00 & $2.24 \mathrm{E}-03$ & 0.31 \\
\hline Strontium-90 & 278 & 37.1 & $1.33 \mathrm{E}-01$ & 582 & 1.76 & $3.02 \mathrm{E}-03$ & 0.14 \\
\hline All Others & NA & NA & $9.00 \mathrm{E}-03$ & NA & NA & $3.90 \mathrm{E}-04$ & $<0.01$ \\
\hline \multicolumn{3}{|c|}{ Sum of Fractions (Long-Term data) } & 4.47E-01 & & & $5.65 \mathrm{E}-03$ & 0.45 \\
\hline \multicolumn{7}{|c|}{ Sum of Fractions (Near-Term data) } & 0.37 \\
\hline \multicolumn{8}{|c|}{ Terrestrial System Evaluation (Long-Term [10-Year] Data Set) } \\
\hline Nuclide & $\begin{array}{l}\text { Water } \\
\text { BCG* }^{*} \\
(\mathbf{p C i} / \mathrm{L})\end{array}$ & $\begin{array}{c}\text { Mean Water } \\
\text { Value } \\
(\mathbf{p C i} / \mathbf{L})\end{array}$ & $\begin{array}{c}\text { Water } \\
\text { Partial } \\
\text { Fraction }\end{array}$ & $\begin{array}{c}\text { Soil } \\
\text { BCG* } \\
\text { (pCi/g) }\end{array}$ & $\begin{array}{l}\text { Mean Soil } \\
\text { Value } \\
(\mathbf{p C i} / \mathrm{g})\end{array}$ & $\begin{array}{c}\text { Soil } \\
\text { Partial } \\
\text { Fraction }\end{array}$ & $\begin{array}{c}\text { Water and } \\
\text { Soil } \\
\text { Sum of Fractions }\end{array}$ \\
\hline Cesium-137 & 599,000 & 13.0 & 2.17E-05 & 20.8 & 5.95 & $2.87 \mathrm{E}-01$ & 0.29 \\
\hline Strontium-90 & 54,500 & 37.1 & $6.81 \mathrm{E}-04$ & 22.5 & 6.26 & $2.78 \mathrm{E}-01$ & 0.28 \\
\hline All Others & NA & NA & $1.73 \mathrm{E}-05$ & NA & NA & $1.00 \mathrm{E}-03$ & $<0.01$ \\
\hline \multicolumn{3}{|c|}{ Sum of Fractions (Long-Term data) } & 7.20E-04 & & & $5.66 \mathrm{E}-01$ & 0.57 \\
\hline \multicolumn{6}{|c|}{ Sum of Fractions (Near-Term data) } & & 0.57 \\
\hline
\end{tabular}

* The BCGs are calculated values. Except for the sums of fractions, which are rounded to two significant digits, all values are expressed to three significant digits. 
Table 4-4

WVDP Radiological Dose and Release Summary

\section{WVDP Radiological Dose Reporting Table CY 2001}

\begin{tabular}{|c|c|c|c|c|}
\hline $\begin{array}{c}\text { Dose to the } \\
\text { Maximally Exposed } \\
\text { Individual }\end{array}$ & $\begin{array}{c}\text { \% of DOE } \\
\mathbf{1 0 0 - m r e m ~ l i m i t}\end{array}$ & $\begin{array}{c}\text { Estimated } \\
\text { Population Dose }\end{array}$ & $\begin{array}{c}\text { Population within } \\
\mathbf{5 0} \text { miles } \\
\text { 2000 Projection } \\
(\mathbf{1 9 9 0} \text { census })\end{array}$ & $\begin{array}{c}\text { Estimated Natural } \\
\text { Radiation Population } \\
\text { Dose }\end{array}$ \\
\hline $\begin{array}{cc}0.00040 \\
\mathrm{mrem} \quad(\mathrm{mSv})\end{array}$ & 0.040 & $\begin{array}{c}0.19 \\
\text { person-rem } \\
\text { (person-Sv) }\end{array}$ & $1,350,000$ & 398,000 \\
person-rem \\
\hline
\end{tabular}

\section{WVDP Radiological Atmospheric Releases ${ }^{+}$CY 2001 in Curies (Bq)}

\begin{tabular}{|c|c|c|c|c|c|c|c|c|c|c|}
\hline Tritium & Kr-85 & $\begin{array}{c}\text { Noble Gases } \\
\left(\mathbf{T}_{1 / 2}<40 \mathrm{dy}\right)\end{array}$ & $\begin{array}{c}\text { Short-Lived } \\
\text { Fission and } \\
\text { Activation } \\
\text { Products } \\
\left(\mathrm{T}_{1 / 2}<3 \mathrm{hr}\right)\end{array}$ & $\begin{array}{c}\text { Fission and } \\
\text { Activation } \\
\text { Products } \\
\left(\mathrm{T}_{1 / 2}>3 \mathrm{hr}\right)\end{array}$ & $\begin{array}{c}\text { Total } \\
\text { Radioiodine }\end{array}$ & $\begin{array}{c}\text { Total } \\
\text { Radiostrontium }\end{array}$ & $\begin{array}{c}\text { Total } \\
\text { Uranium* }\end{array}$ & $\begin{array}{c}\text { Total } \\
\text { Plutonium }\end{array}$ & \begin{tabular}{|c|} 
Total \\
Other \\
Actinides
\end{tabular} & $\begin{array}{c}\text { Other } \\
(\mathbf{R n - 2 2 0})\end{array}$ \\
\hline $\begin{array}{c}2.66 \mathrm{E}-02 \\
(9.83 \mathrm{E}+08)\end{array}$ & NA & NA & NA & $\begin{array}{c}7.89 \mathrm{E}-04 \\
(2.92 \mathrm{E}+07)\end{array}$ & $\begin{array}{c}5.30 \mathrm{E}-04 \\
(1.96 \mathrm{E}+07)\end{array}$ & $\begin{array}{c}3.28 \mathrm{E}-04 \\
(1.21 \mathrm{E}+07)\end{array}$ & $\begin{array}{c}3.02 \mathrm{E}-07 \\
(1.12 \mathrm{E}+04)\end{array}$ & $\begin{array}{c}1.11 \mathrm{E}-06 \\
(4.10 \mathrm{E}+04)\end{array}$ & $\begin{array}{c}2.12 \mathrm{E}-06 \\
(7.86 \mathrm{E}+04)\end{array}$ & $\begin{array}{c}2.27 \mathrm{E}+03 \\
(8.40 \mathrm{E}+13)\end{array}$ \\
\hline
\end{tabular}

\section{WVDP Liquid Effluent Releases ${ }^{+}$of Radionuclide Material CY 2001 in Curies (Bq)}

\begin{tabular}{|c|c|c|c|c|c|c|}
\hline Tritium & $\begin{array}{c}\text { Fission and } \\
\text { Activation } \\
\text { Products } \\
\left(\mathbf{T}_{1 / 2}>\mathbf{3} \mathbf{~ h r}\right)\end{array}$ & $\begin{array}{c}\text { Total } \\
\text { Radioiodine }\end{array}$ & $\begin{array}{c}\text { Total } \\
\text { Radiostrontium }\end{array}$ & $\begin{array}{c}\text { Total } \\
\text { Uranium** }\end{array}$ & $\begin{array}{c}\text { Total } \\
\text { Plutonium }\end{array}$ & $\begin{array}{c}\text { Total } \\
\text { Other } \\
\text { Actinides }\end{array}$ \\
\hline $1.20 \mathrm{E}-01$ & $\begin{array}{c}5.76 \mathrm{E}-03 \\
(2.13 \mathrm{E}+08)\end{array}$ & $\begin{array}{c}1.55 \mathrm{E}-04 \\
(5.73 \mathrm{E}+06)\end{array}$ & $\begin{array}{c}1.37 \mathrm{E}-01 \\
(5.09 \mathrm{E}+09)\end{array}$ & $\begin{array}{c}7.52 \mathrm{E}-04 \\
(2.78 \mathrm{E}+07)\end{array}$ & $\begin{array}{c}9.27 \mathrm{E}-06 \\
(3.43 \mathrm{E}+05)\end{array}$ & $\begin{array}{c}2.35 \mathrm{E}-05 \\
(8.70 \mathrm{E}+05)\end{array}$ \\
\hline
\end{tabular}

+ The WVDP air and water releases are from point sources and controlled liquid effluent releases, respectively.

$*$ Total uranium $($ grams $)=2.61 \mathrm{E}-01$

** Total uranium $($ grams $)=4.56 \mathrm{E}+02$

Note: These tables have been included to provide a standardized format for data collected from all Department of Energy sites. 
This page intentionally left blank

$$
4-18
$$




\section{QUALITY ASSURANCE}

The quality assurance (QA) program at the West Valley Demonstration Project (WVDP) provides for and documents consistency, precision, and accuracy in collecting and analyzing environmental samples and in interpreting and reporting environmental monitoring data.

\section{Organizational Responsibilities}

West Valley Nuclear Services Co. (WVNSCO) is contractually obligated to implement a quality assurance program at the WVDP. Managers of programs, projects, and tasks are responsible for determining and documenting the applicability of quality assurance requirements to their activities and for implementing those requirements. For example, Environmental Laboratory management and staff are directly responsible for carrying out sampling and analytical activities in a manner consistent with good quality assurance practices and for following approved procedures.

\section{Program Design}

The quality assurance rule 10 CFR Part 830.122, Quality Assurance Criteria (U.S. Department of Energy [DOE]), and DOE Order 414.1A, Quality Assurance (U.S. Department of Energy, 2001) provide the quality assurance program policies and requirements applicable to activities at the WVDP.
The integrated quality assurance program applicable to environmental monitoring at the WVDP also incorporates requirements from Quality Assurance Program Requirements for NuclearFacilities (American Society of Mechanical Engineers [ASMENQA1], 1989) and Specifications and Guidelines for Quality Systems for Environmental Data Collection and Environmental Technology Programs (American National Standards Institute and American Society for Quality Control [ANSI/ASQCE4-1994], 1994).

The quality assurance program focuses upon assigning responsibilities and upon thorough planning, specification, control, and documentation of all aspects of an activity in order to ensure the quality of both radiological and nonradiological monitoring data. The quality assurance program includes requirements in the areas listed below:

Responsibility. Responsibilities for overseeing, managing, and conducting an activity must be clearly defined. Personnel who verify that the activity has been completed correctly must be independent of those who performed it.

Planning. An activity must be planned beforehand and the plan followed. All activities must be documented. Similarly, purchases of any equipment or items must be planned, specified precisely, and verified for correctness upon receipt. 
Control of Design, Procedures, Items, and Documents. Any activity, equipment, or construction must be clearly described or defined and tested. Changes in the design must be tested and documented. Procedures must clearly state how activities will be conducted. Only approved procedures may be used. Equipment or particular items affecting the quality of environmental data must be identified, inspected, calibrated, and tested before use. Calibration status must be clearly indicated. Items that do not conform to requirements must be identified and separated from other items and the nonconformity documented.

Documentation. Records of all activities must be kept in order to verify what was done and by whom. Records must be clearly traceable to an item or activity.

Corrective Action. If a problem should arise the cause of the problem must be identified, a corrective action planned, responsibility assigned, and the problem remedied.

Audits. Scheduled audits and assessments must be conducted to verify compliance with all aspects of the quality assurance program and determine its effectiveness.

Subcontractor laboratories providing analytical services for the environmental monitoring program are contractually required to maintain a quality assurance program consistent with WVNSCO requirements.

\section{Procedures}

Those activities that affect the quality of environmental monitoring data are conducted according to approved procedures that clearly describe how the activity should be performed and what precautions are to be taken in connection with the activity. Any person performing an activity that could affect the quality of environmental monitor- ing data must be trained and must demonstrate proficiency in procedures applicable to the activity.

New procedures are developed each time an activity is added to the monitoring program. Procedures are reviewed periodically and updated when necessary. Documents are controlled so that only current procedures are used.

\section{Quality Control in the Field}

Quality control (QC), an integral component of environmental monitoring quality assurance, is a way of verifying that samples are being collected and analyzed according to established quality assurance procedures. Quality control ensures that sample collection and analysis are consistent and repeatable and is a means of tracking down possible sources of error. For example, sample locations at the WVDP are clearly marked in the field to ensure that future samples are collected in the same locations; collection equipment in place in the field is routinely inspected, calibrated, and maintained; and automated sampling stations are kept locked to prevent tampering and to ensure sample integrity. Samples are collected into certified precleaned containers of an appropriate material and capacity. Containers are labeled immediately with the pertinent information - date, time, person doing the collecting, and special field sampling conditions. Collection information is documented and kept as part of the record for that sample.

Chain-of-custody protocols are followed to ensure that samples are controlled and tracked for traceability. If necessary, samples are preserved as soon as possible after collection.

In order to assess quality problems that might be introduced by the sampling process, duplicate field samples, field blank samples, and trip blank samples are collected. Background samples are collected for baseline environmental information. 
Field Duplicates. Field duplicates are samples collected simultaneously for the same analyte at one location, after which they are treated as separate samples. If the sampling matrix is homogeneous, field duplicates provide a means of assessing the precision of collection methods. Field duplicates are collected at a minimum rate of one per twenty samples.

Field Blanks. A field blank is a sample of laboratory-distilled water that is put into a sample container at a field collection site and is processed from that point as a routine sample. Field blanks are used to detect contamination introduced by the sampling procedure. They are processed at a minimum rate of one per twenty samples.

If the same collection equipment is used for more than one site, a special form of field blank known as an equipment blank may be collected by pouring laboratory-distilled water through cleaned collecting equipment and into a sample container. Equipment blanks are collected to detect any cross-contamination that may be passed from one sampling location to another by the equipment. Many wells and surface water collection stations have dedicated collecting equipment that remains at that location; equipment blanks are not necessary at these locations.

Trip Blanks. Trip blanks are prepared by pouring laboratory-distilled water into sample bottles in the laboratory. The bottles are then placed into sample coolers where they remain throughout the sampling event. Trip blanks are collected in order to detect any volatile organic contamination that may be introduced from handling during collection, storage, or shipping. Trip blanks are prepared once per day when volatile organic samples are being collected.

Environmental Background Samples. To monitor each pathway for possible radiological contamination, samples of air, water, vegetation, meat, and milk are taken from locations remote from the site for comparison with samples from nearsite locations. Samples that are clearly outside site influence show ambient radiological concentrations and serve as backgrounds or "controls," another form of field quality control sample. Background samples provide baseline information to compare with information from near-site or on-site samples so that site influences can be evaluated.

\section{Quality Control in the Laboratory}

More than 12,000 samples were handled as part of site monitoring in 2001. Samples for routine radiological analysis were analyzed on-site, with the rest being sent to subcontract laboratories.

Off-site subcontract laboratories must maintain a level of quality control as specified in contracts with WVNSCO and are required to participate in all applicable crosscheck programs and to maintain all relevant certifications.

In order to monitor the accuracy and precision of data, laboratory quality control practices specific to each analytical method are clearly described in approved references or procedures. Examples of laboratory quality control activities at the WVDP include proper training of analysts, maintaining and calibrating measuring equipment and instrumentation, and processing samples in accordance with specific methods as a means of monitoring laboratory performance.

Analytical instruments and counting systems are calibrated at specified frequencies, and logs of instrument calibration and maintenance are kept. Calibration methods for each instrument are specified in procedures or in manufacturers' directions. Standards traceable to the National Institute of Standards and Technology (NIST) are used to calibrate counting and test instrumentation. 
Laboratory quality control samples consist of three general types: standards (including spikes), used to assess accuracy; blanks, to assess the possibility of contamination; and duplicates, to assess precision.

Standards. Laboratory standards are materials containing known concentrations of an analyte of interest such as a $\mathrm{pH}$ buffer or a plutonium-239 counting standard. Standards used at the WVDP for environmental monitoring activities are either NIST-traceable or reference materials from other nationally recognized sources.

At a minimum, one reference standard is analyzed for every twenty sample analyses. The results of the analyses are plotted on control charts, which specify acceptable limits. If the results lie within these limits, then analysis of actual environmental samples may proceed and the results are deemed usable.

Spikes. Another form of standard analysis is a laboratory spike. In a laboratory spike, a known amount of analyte is added to a sample or blank before the sample is analyzed. The percent recovery of the analyte indicates how much of the analyte of interest is being detected in the analysis of actual samples; hence, a spike also is an assessment of the accuracy of the method. Spike recoveries are recorded on control charts with documented acceptance limits.

Blanks. Laboratory blanks are prepared from a matrix similar to that of the sample but known to contain none of the analyte of interest. For instance, distilled water, taken through the same preparatory procedure as a sample, may serve as a laboratory blank for both radiological and chemical analyses of water samples. A positive result for an analyte in a blank indicates that something is wrong with the analysis and that corrective action should be taken. In general, one laboratory blank is processed daily or with each batch of samples for a given analyte.
A special form of laboratory blank for radiological samples is an instrument background count, which is a count taken of a planchet or vial containing no sample. The count serves three purposes: to determine if contamination is present in the counting instrument; to determine if the instrument is responding in an acceptable manner; and to determine the background correction that should be applied when calculating radiological activity in certain samples.

Environmental samples containing little or no radioactivity must be measured with very sensitive instruments. For example, gross alpha and gross beta measurements must be made with a low-background proportional counter. An instrument background count is taken before each day's counting or with each batch of twenty samples. Background counts are recorded on control charts with defined acceptance limits. An unacceptable count requires corrective action before analyses can proceed.

Duplicates. Duplicates are analyzed to assess precision in the analytical process. Laboratory duplicates are created by splitting existing samples before analysis; each split is treated as a separate sample. If the analytical process is in control, results for each split should be within documented acceptance criteria.

To further check the precision of environmental monitoring data, samples of air filters, water, milk, fish, vegetation, and sediments are split or separately collected and sent to the New York State Department of Health (NYSDOH) for independent measurement. (Co-located samples are listed in Appendix B of this report.) Results from NYSDOH are compared with WVDP results as an independent verification of environmental monitoring program data.

Crosschecks. As with standards, crosscheck samples contain a concentration of an analyte 
known to the agency conducting the crosscheck. However, the concentration is unknown to the participating laboratory. Crosscheck programs provide an additional means of testing accuracy of environmental measurements. WVNSCO participates in formal crosscheck programs for both radiological and nonradiological analyses.

The U.S. Department of Energy recommends that all organizations performing radiological analyses as part of effluent or environmental monitoring participate in the semiannual Environmental Measurements Laboratory (EML) Quality Assessment Program (QAP). This program is designed to test the quality of environmental measurements being reported to the DOE by its contractors.

Crosscheck samples for radiological constituents are analyzed by both the Environmental Laboratory on-site and by the subcontract laboratory. Results from radiological crosschecks are summarized in Appendix J, Tables J-1 and J-2 (pp. J-3 through J-6). A total of 117 radiological crosscheck analyses were performed by or for the WVDP and reported in 2001. All results $(100 \%)$ were within acceptance limits.

Two nonradiological crosscheck samples (from Environmental Research Associates) for the National Pollutant Discharge Elimination System (NPDES) Discharge Monitoring Report-Quality Assurance Study \#21 were analyzed for $\mathrm{pH}$ and residual chlorine by the WVDP wastewater facility laboratory. Twenty-one crosscheck samples were analyzed by an off-site vendor laboratory for additional parameters. Nonradiological crosscheck results are summarized in Appendix J, Table J-3 (p. J-7).

Results from both crosschecks analyzed at the WVDP were within acceptance limits (100\%). Of the twenty-one results reported by the vendor laboratory, twenty were within acceptance limits $(95.2 \%)$, for a combined $95.7 \%$ in control.
WVNSCO subcontracted laboratories are required to perform satisfactorily on crosschecks, defined as $80 \%$ of results falling within control limits. Crosscheck results that fall outside control limits are addressed by formal corrective actions in order to determine any conditions that could adversely affect sample data and to ensure that actual sample results are reliable.

\section{Personnel Training}

Anyone performing environmental monitoring program activities is trained in the appropriate procedures and qualified accordingly before carrying out the activity as part of the site environmental monitoring program.

\section{Recordkeeping}

Control of records is an integral part of the environmental monitoring program. Field data sheets, chain-of-custody forms, requests for analysis, sample-shipping documents, sample logs, bench logs, laboratory data sheets, equipment maintenance $\log s$, calibration logs, training records, crosscheck performance records, data packages, and weather measurements, in addition to other records, are maintained as documentation of the environmental monitoring program. All records pertaining to the program are routinely reviewed and securely stored.

A Laboratory Information Management System (LIMS) is used to log samples, print labels, store and process data, track quality control samples, track samples, produce sampling and analytical worklists, and generate reports. Subcontract laboratories, where possible, provide data in electronic form for direct entry into the LIMS. 


\section{Chain-of-Custody Procedures}

Chain-of-custody records begin with sample collection. Samples brought in from the field are transferred under signature from the sampler to the sample custodian and are logged at the sample receiving station, after which they are stored in a sample lockup before analysis or shipping. Samples sent off-site for analysis are accompanied by an additional chain-of-custody/analytical request form. Subcontract laboratories are required by contract to maintain internal chain-of-custody records and to store the samples under secure conditions.

\section{Audits and Appraisals}

In 2001, the WVNSCO Quality Assurance department conducted an audit of the Environmental Laboratory's practices and procedures. Areas of inquiry included: the documentation and reporting of environmental data; the management of environmental assessment and monitoring records; gross alpha and gross beta sample preparation; gross alpha and gross beta sample analysis; and general quality assurance/quality control compliance for the environmental monitoring program. No findings were noted, although two observations regarding program improvements were noted and corrective actions were identified and implemented.

In 2001, the Cattaraugus County Health Department conducted an annual inspection of the WVDP potable water supply system. No findings were identified.

The New York State Department of Environmental Conservation performed an inspection of WVDP's wastewater treatment facilities and SPDES discharge monitoring program in 2001. The inspection resulted in no reported findings or observations.
In 2001 the DOE's Ohio Field Office (DOE-OH) conducted a surveillance of a discharge from lagoon 3, State Pollutant Discharge Elimination System (SPDES) discharge point WNSP001. The purpose of the surveillance was to evaluate whether the WVDP procedures for the discharge of liquid effluent were being effectively implemented to ensure compliance with the Site SPDES permit. Relevant documents were reviewed and field and laboratory activities were observed. The surveillance report included two findings, four observations, one concern, and one noteworthy practice. Nothing was found to indicate that data had been compromised. Corrective actions were taken as appropriate. After reviewing SPDES exceptions since 1986 as part of this surveillance, DOE$\mathrm{OH}$ noted that WVNSCO staff has done a good job of significantly decreasing SPDES permit exceptions, with no exceptions in 1998, 1999, and 2000. (See Fig. 1-4, Yearly SPDES Permit Exceptions [p. 1-18].)

Any corrective actions generated as a result of internal or external program reviews are addressed and tracked to closure.

\section{Self-Assessments}

Routine self-assessments of the environmental monitoring program were conducted in 2001. The primary topics addressed by the assessment were: compliance with sampling requirements pertaining to the environmental monitoring program; compliance with quality assurance requirements pertaining to the environmental monitoring program; implementation of conduct of operations principles during environmental monitoring program activities; and animal control operations and reporting requirements.

No findings or observations were noted. Recommended actions were proposed to improve the program. Several good practices were identified. Nothing 
was found during the course of these routine selfassessments that would compromise the program in general or the data in this report.

\section{Lessons Learned Program}

Information from audits, appraisals, and selfassessments are shared with other departments through the WVDP Lessons Learned Program. The WVDP maintains this system in order to identify, document, disseminate, and use this information to improve the safety, efficiency, and effectiveness of all WVNSCO operations.

\section{Data Management and Data Validation}

Information about environmental monitoring program samples is maintained and tracked in the LIMS and includes location, date and time of collection, chain-of-custody transfer, shipping information, analytical results, and final validation status.

All software used to generate data is verified and validated before use. All analytical data produced in the Environmental Laboratory at the bench level are reviewed and signed off by a qualified person other than the one who performed the analysis. A similar in-house review is contractually required from subcontractor laboratories.

\section{Data Verification and Validation}

Analytical data from both on- and off-site laboratories are reviewed to verify proper documentation of sample processing and data reporting, and to determine the quality and usability of the data. A graded approach is applied that, based on the importance of a given data point, gives the right amount of attention to the details of each analysis. In the WVDP environmental program each data point is validated per standard procedures before it is approved for use.

Control measures such as chain-of-custody and sample identification numbering and collection dates are checked to make sure that the correct sample has been analyzed using the right test procedures. The analytical process log information may be reviewed to verify the number and accuracy of quality check samples and tests. Other quality requirements such as meeting minimum testing sensitivity and precision levels are checked for the data being examined.

Data not completely meeting requirements may be either flagged as estimates (useful, for example, as supporting information), or as rejected (not-tobe-used) data. When a sample does not provide a valid data point and analytical or calculation errors cannot be identified and corrected, a retest is often requested on either a remaining sample portion or a similar sample.

After validation is complete and accurate transcription into the WVDP environmental database is verified, the sample is approved and the associated data are available for assessment.

\section{Data Assessment and Reporting}

Validated radiological and nonradiological analytical data, field information, and historical project data are then integrated and evaluated to assess the specific data usability in determining presence or absence of analytical constituents and, if present, the levels of the constituents. Data problems identified at this level are further investigated and, if necessary, corrected.

Data from the environmental monitoring program are then processed in order to assess the effect, if 
any, of the site on the environment and the public. Data from each sampling location are compared to historical results from the same location, comparable background measurements, and (if applicable) regulatory or guidance standards.

- Radiological concentrations in liquid effluent releases or air emissions are compared with DOE derived concentration guides (DCGs) for release of water or air to an unrestricted environment. DCGs for specific radionuclides are listed in Table K-1 (p. K-3).

- Calculated doses from air emissions are compared with National Emissions Standards for Hazardous Air Pollutants (NESHAP) limits.

- Nonradiological releases from liquid effluents covered by the SPDES permit are compared with the limits specified in the permit. (See Table G-1 [pp. G-3 and G-4].)

- Data trends over time are assessed on a monthly basis and identified trends are investigated.

- Near-site radiological results are compared to results from background locations far from the site.

- Results from surface waters downgradient of the site are compared with results from upgradient locations.

Standard statistical methods are used to compare the data. Where possible, the underlying distribution of the data set is assessed before determining the appropriate statistical tests to be used.

Once the data have been evaluated, reports are prepared. Calculations summarizing the data, for instance, summing the total curies released from an effluent point, averaging the annual concentration of a radionuclide at a monitoring point, or pooling confidence intervals from a series of measurements, are made in accordance with formally approved procedures. Final data are reported as described elsewhere in this report. (See Data Reporting in Chapter 1 [p. 1-4] and the section on Scientific Notation at the back of this report [p. UOM-2].)

Before each technical report is issued, the document, including the data on which the report was based, is comprehensively reviewed by one or more persons who are knowledgeable in the necessary technical aspects of the field of work.

\section{Summary}

The multiple levels of scrutiny built into generating, validating, evaluating, and reporting data from the environmental monitoring program ensure that reliable data are reported. The quality assurance elements described in this chapter ensure that environmental monitoring data are consistent, precise, and accurate. The effectiveness of the monitoring program is evidenced by continuing favorable quality assurance assessments. 


\section{Appendix A Maps}

A - 1 
This page intentionally left blank

A - 2 


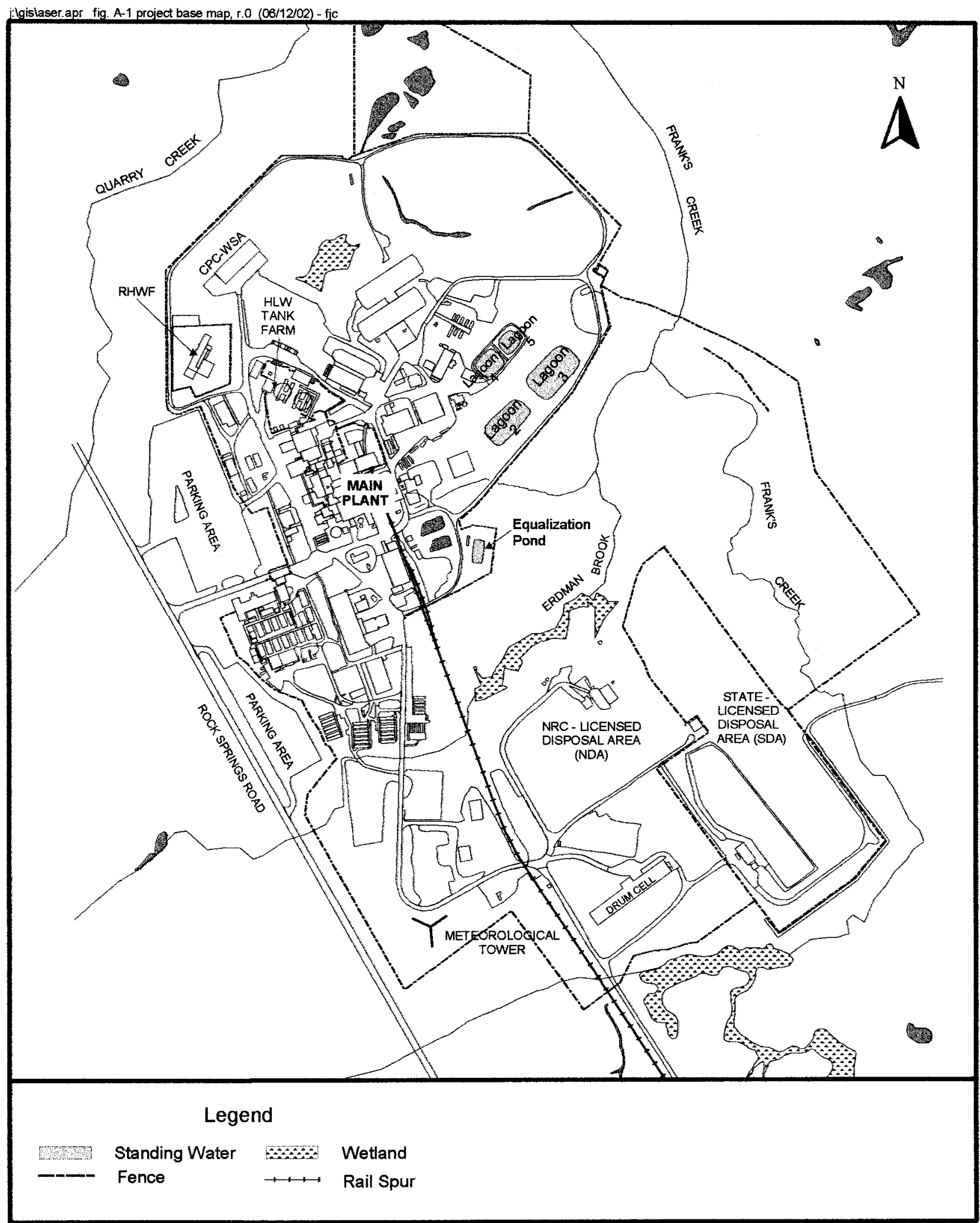

Figure A-1. West Valley Demonstration Project Base Map

A - 3 


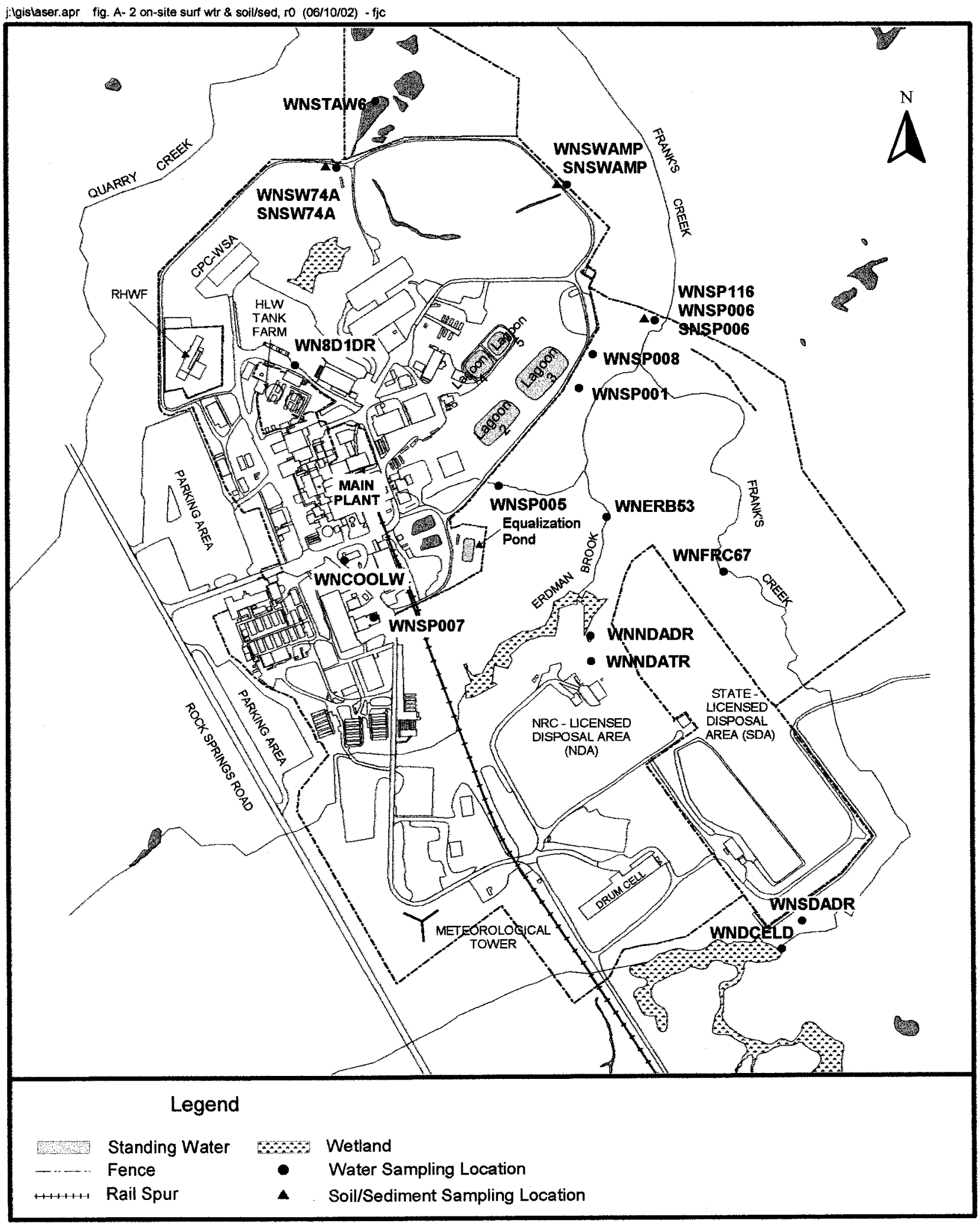

Figure A-2. On-Site Surface Water and Soil/Sediment Sampling Locations

$$
\text { A - } 4
$$




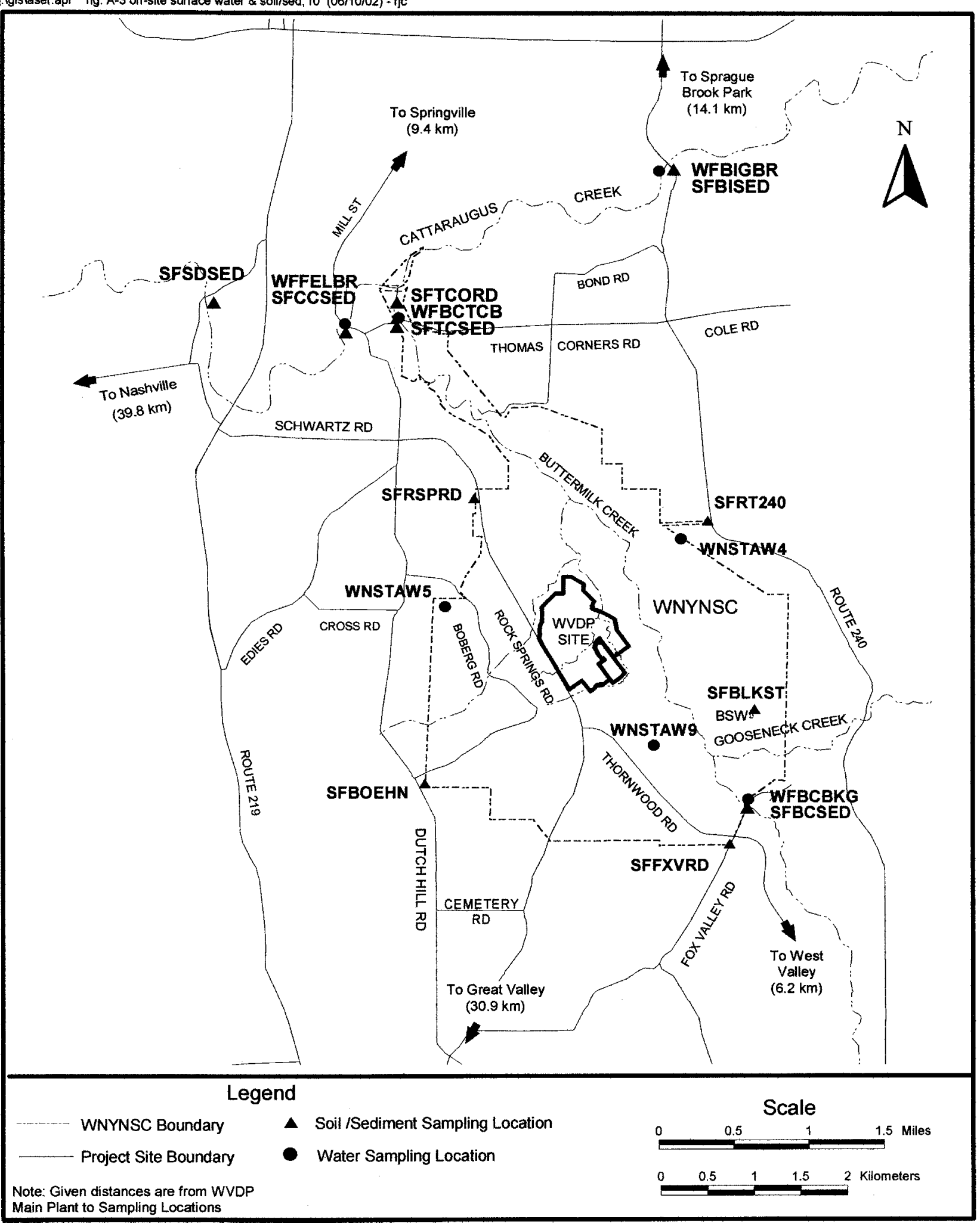

Figure A-3. Off-Site Surface Water and Soil/Sediment Sampling Locations

$$
\text { A - } 5
$$




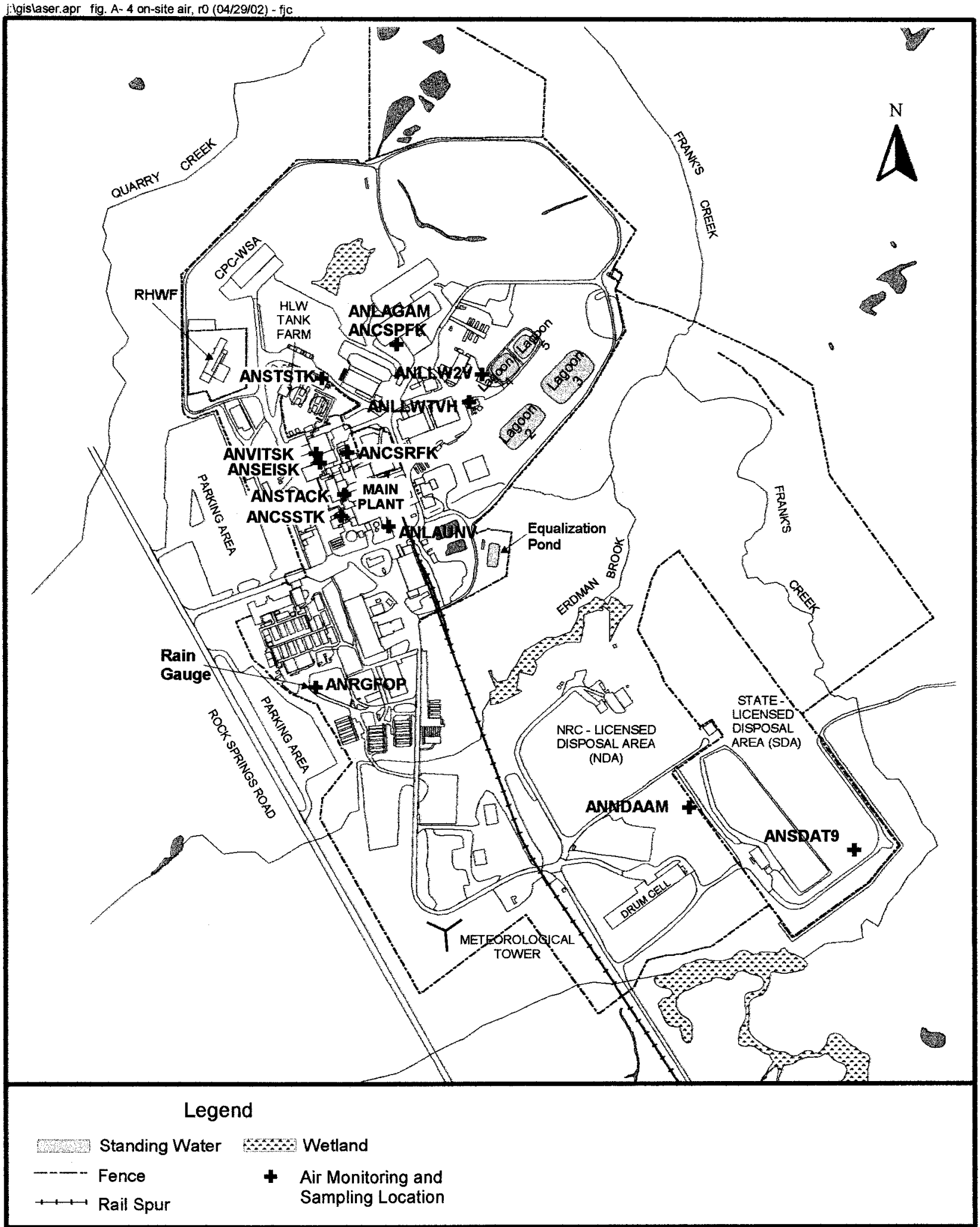

Figure A-4. On-Site Air Monitoring and Sampling Points

A - 6

WVDP Site Environmental Report

Calendar Year 2001 


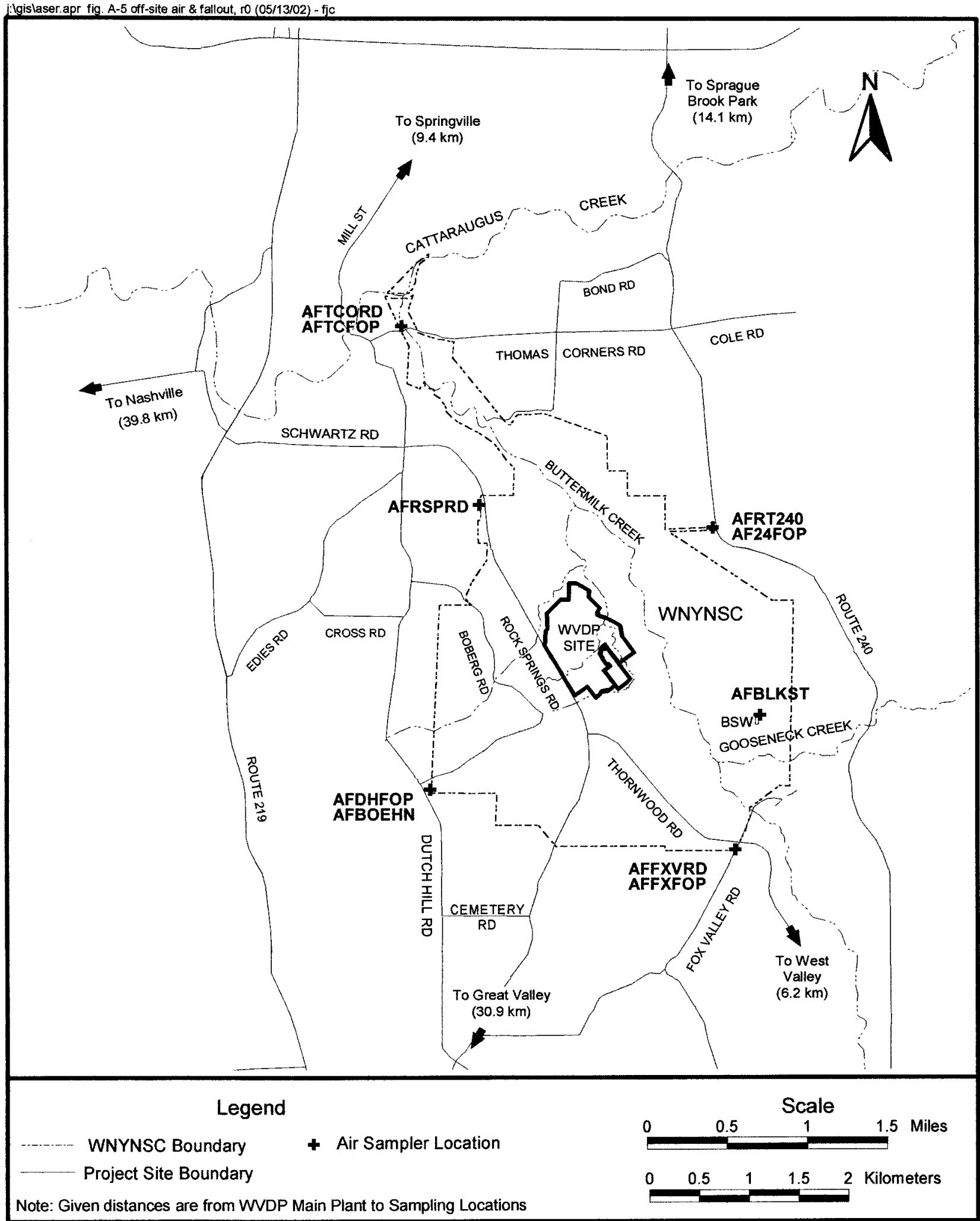

Figure A-5. Off-Site Air and Fallout Sampling Points

A - 7 


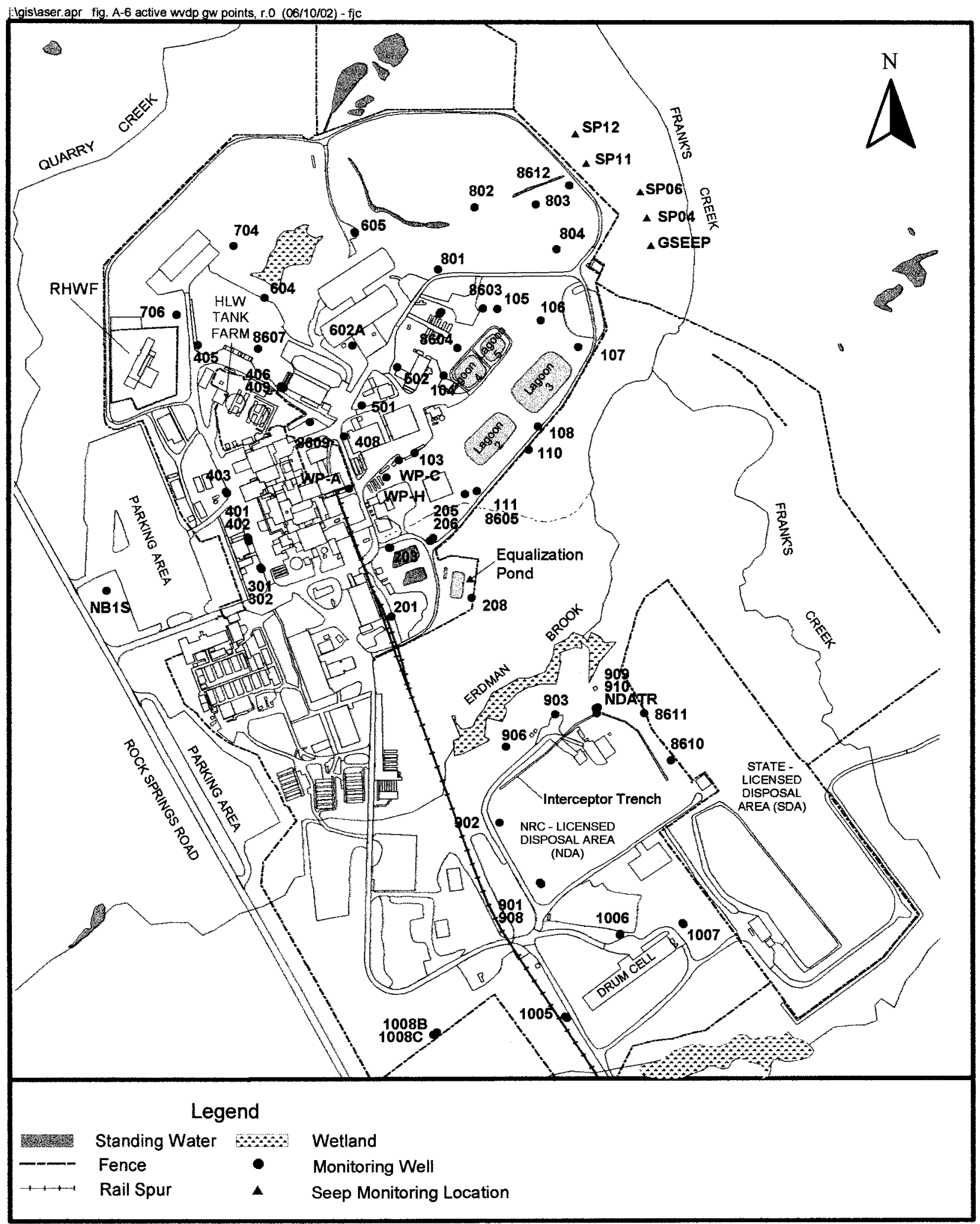

Figure A-6. Active WVDP Groundwater Monitoring Points

A - 8 


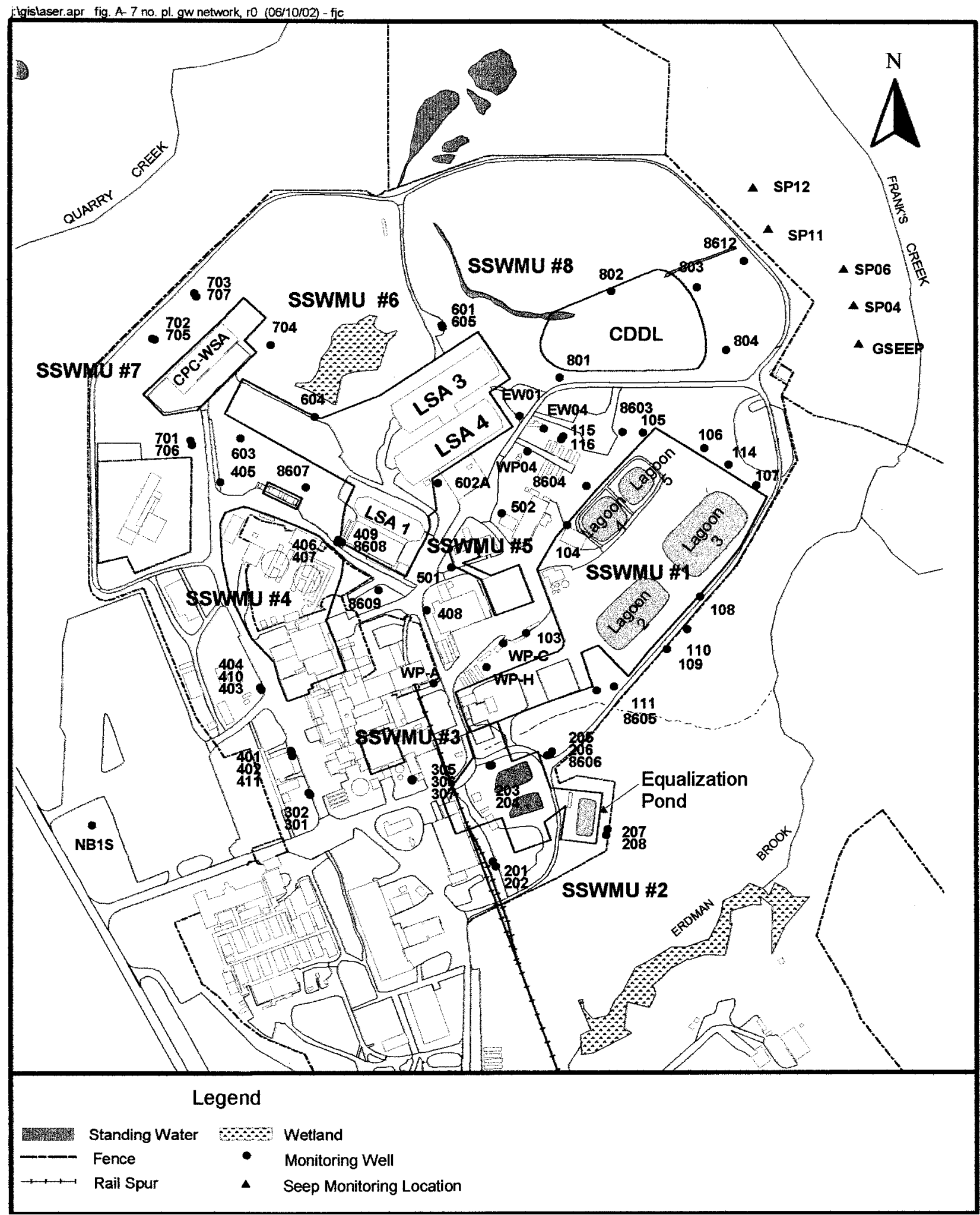

Figure A-7. North Plateau On-Site Groundwater Monitoring Network (Includes Wells Used for Water-Level Measurements)

A - 9

WVDP Site Environmental Report 


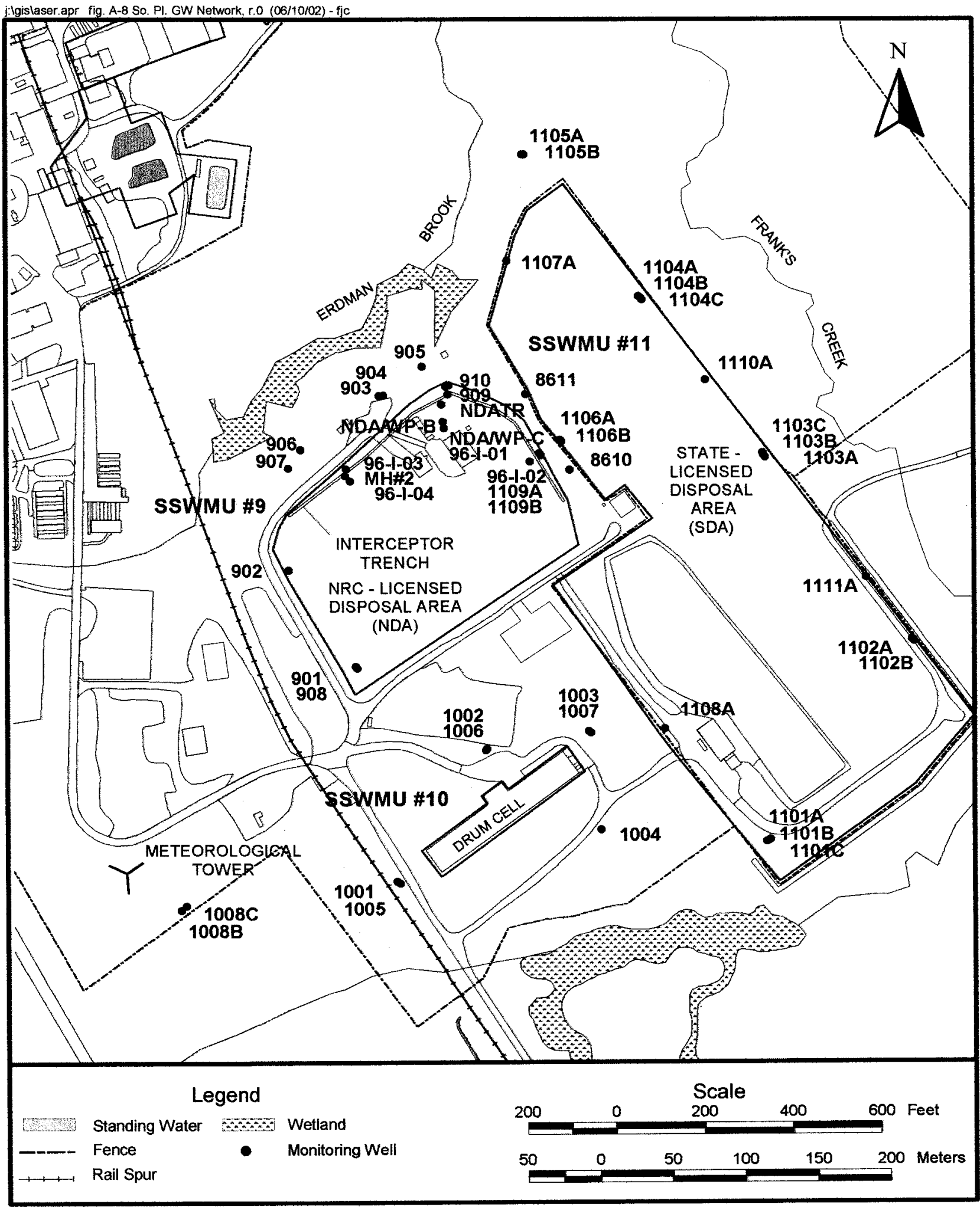

Figure A-8. South Plateau On-Site Groundwater Monitoring Network (Includes Wells Used for Water-Level Measurements [WVDP] and SDA Wells [NYSERDA])

$$
\text { A }-10
$$




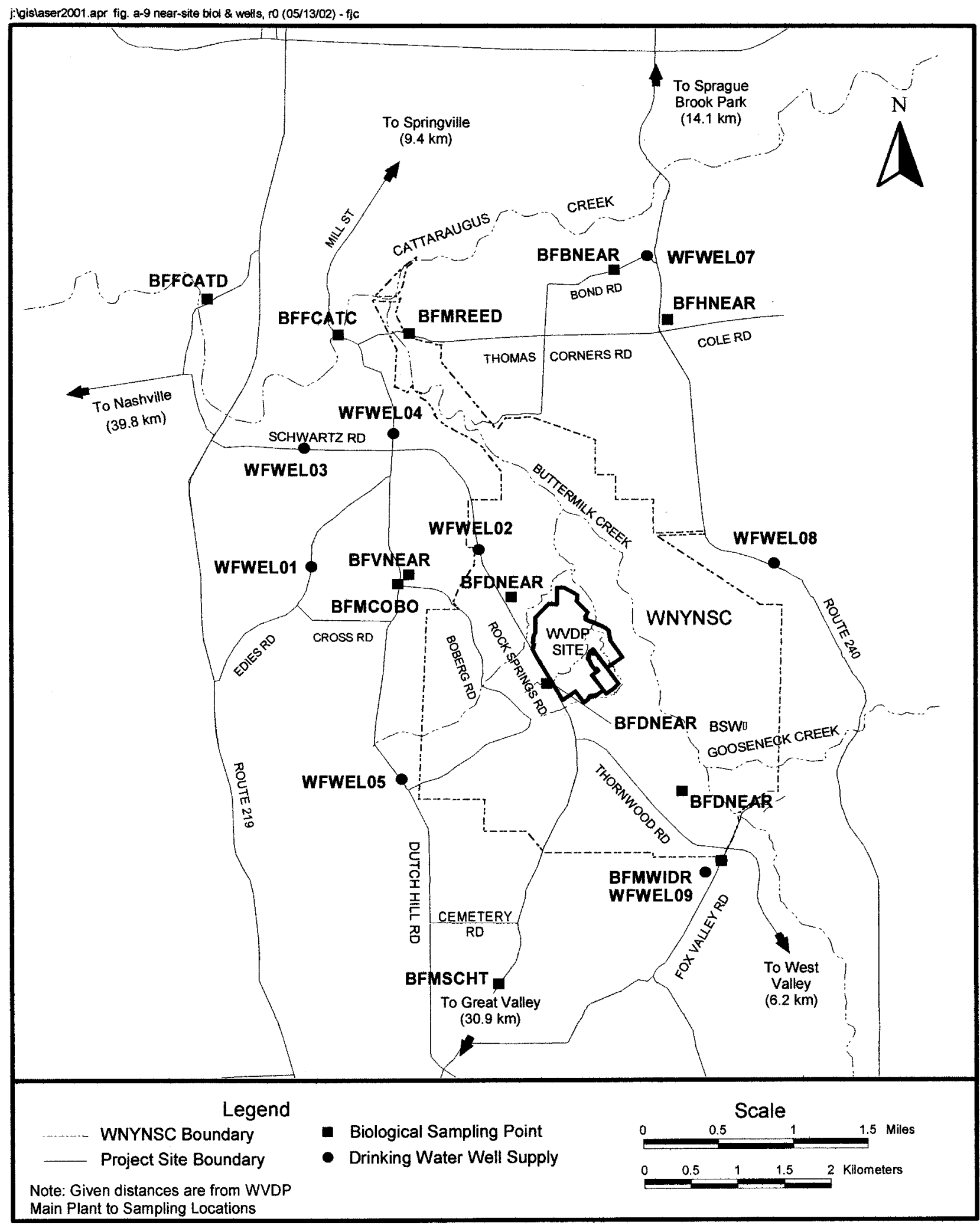

Figure A-9. Near-Site Drinking Water and Biological Sampling Points

$$
\text { A - } 11
$$


jigislaser.apr fig A-10 On-Site TLDs, r.o (06/10/02) - fjc

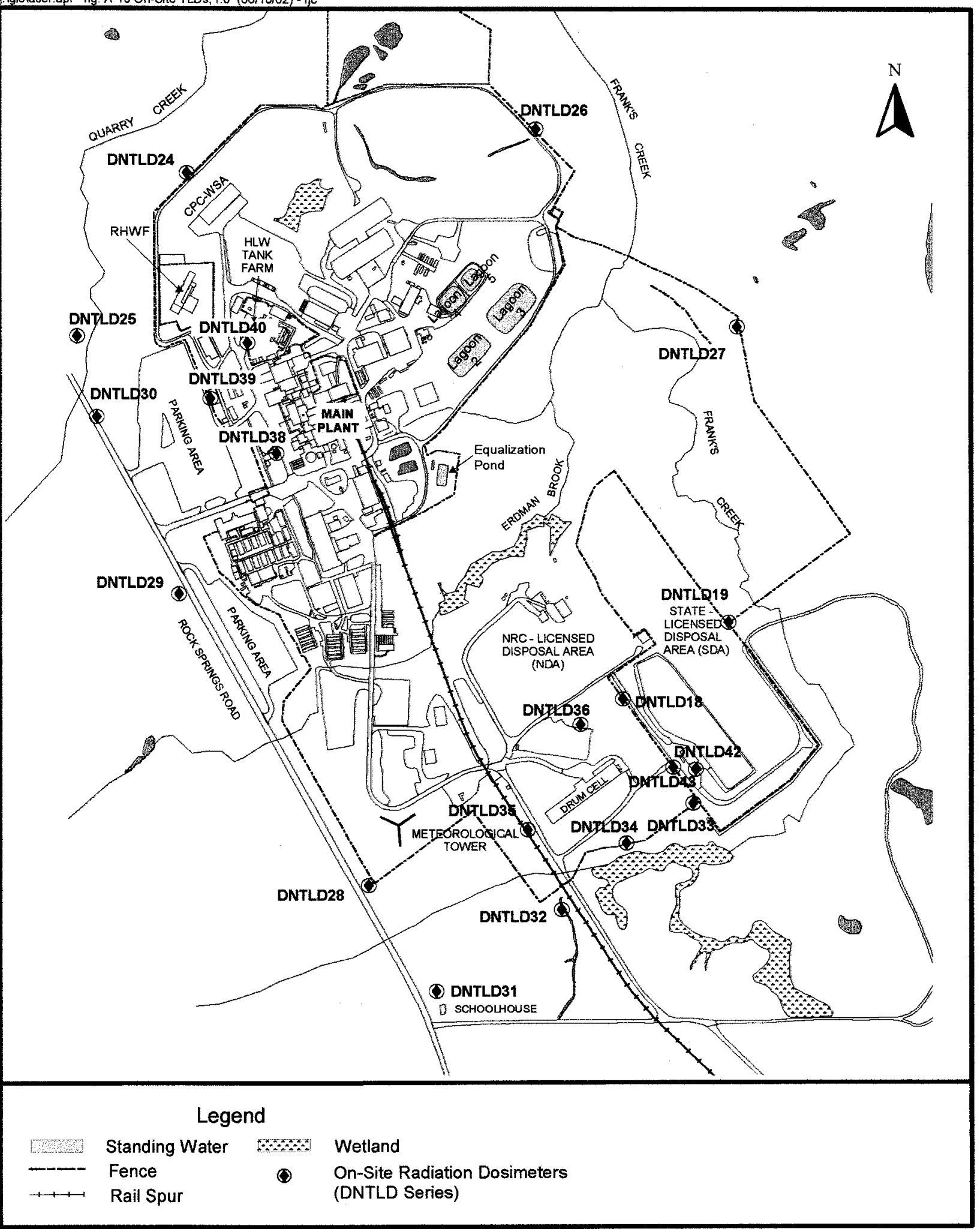

Figure A-10. Location of On-Site Thermoluminescent Dosimeters (TLDs)

A - 12 


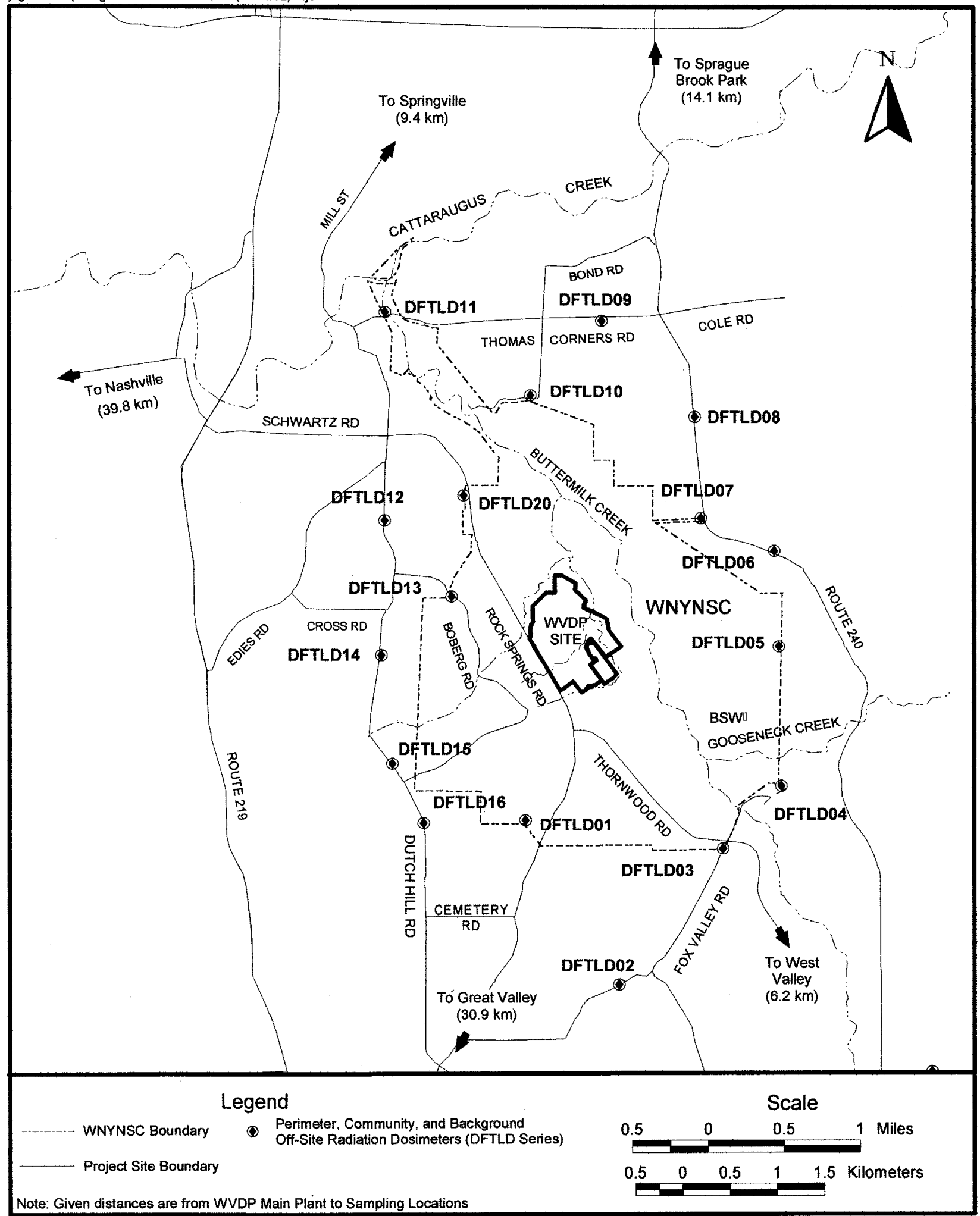

Figure A-11. Location of Off-Site Thermoluminescent Dosimeters (TLDs) Within 5 Kilometers of the WVDP

$$
\text { A }-13
$$




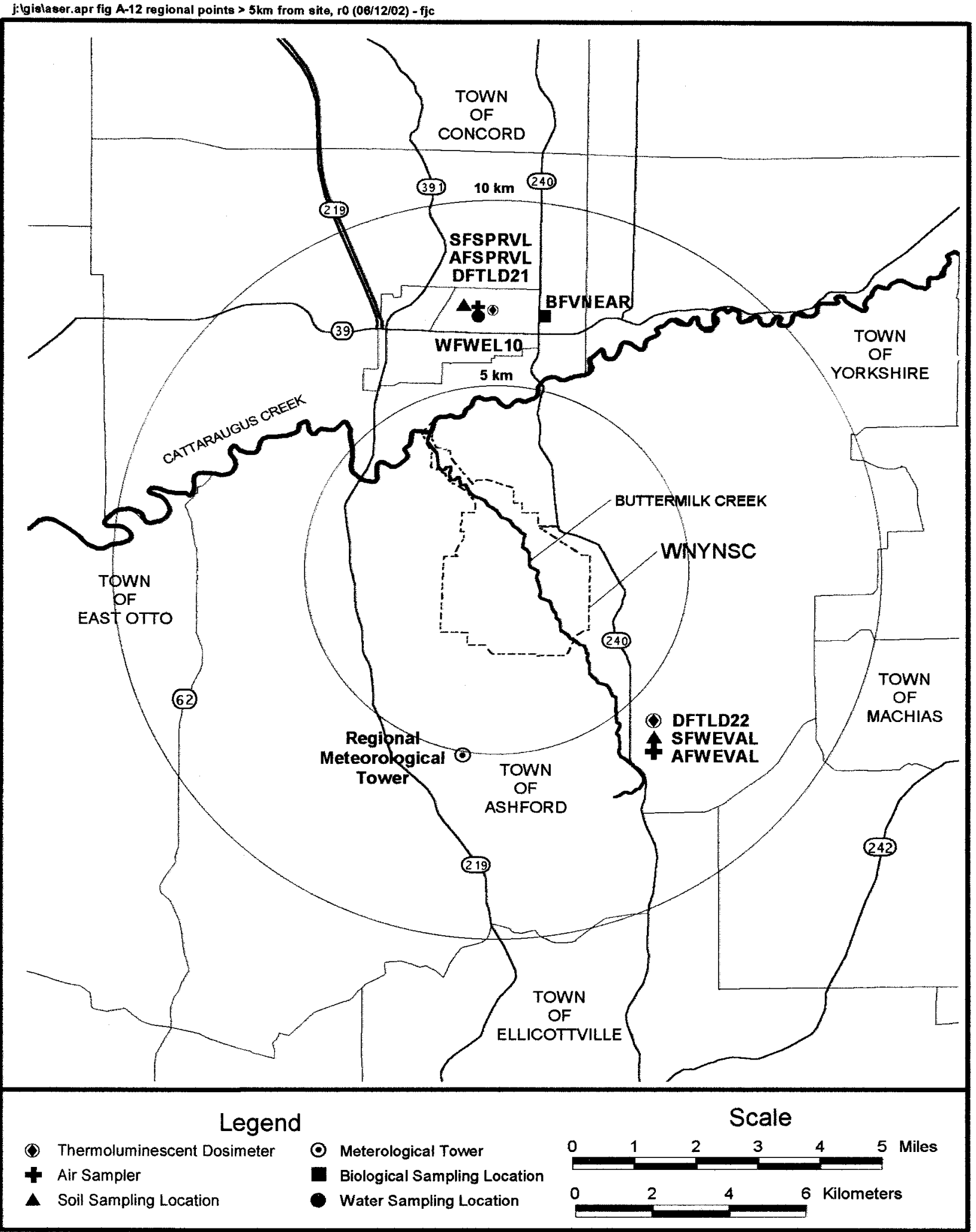

Figure A-12. Environmental Sampling Points Between 5 and 10 Kilometers From the WVDP

$$
\text { A - } 14
$$




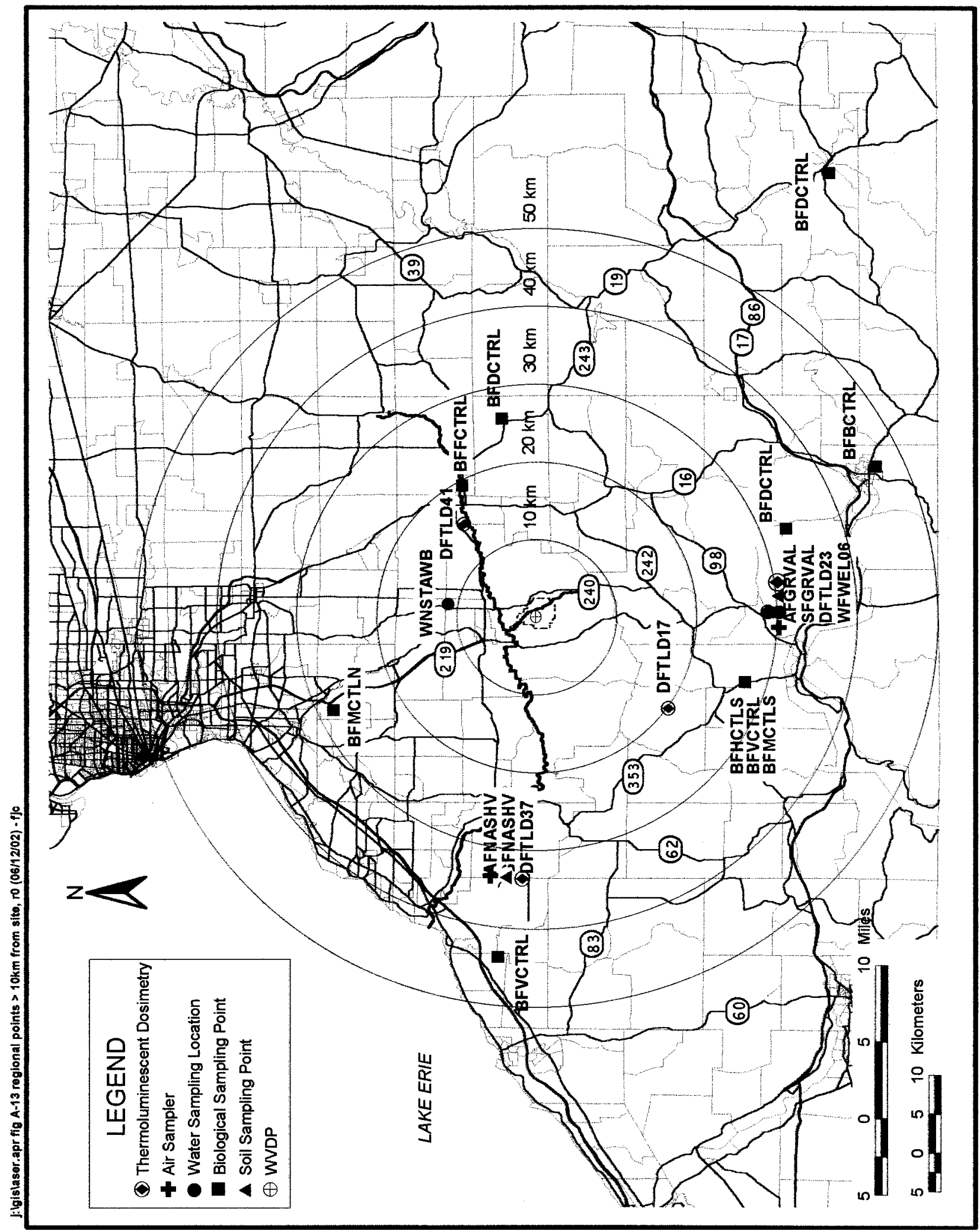

Figure A-13. Environmental Sampling Points More Than 10 Kilometers From the WVDP

A -15 


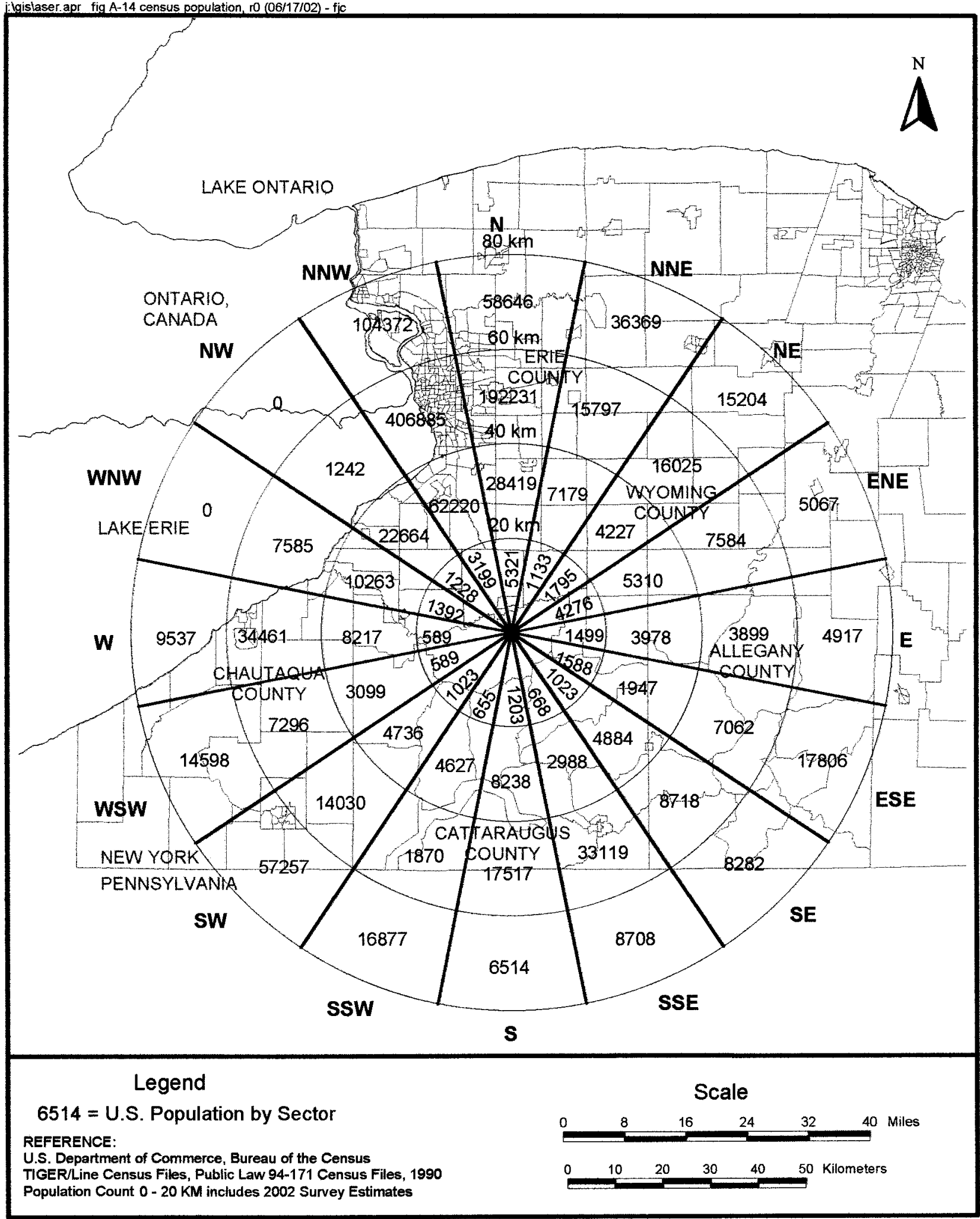

Figure A-14. Projected 2001 Population by Sector Within 80 Kilometers of the WVDP

WVDP Site Environmental Report

$$
\text { A - } 16
$$




\section{Appendix $B$ 2001 Environmental Monitoring Program}

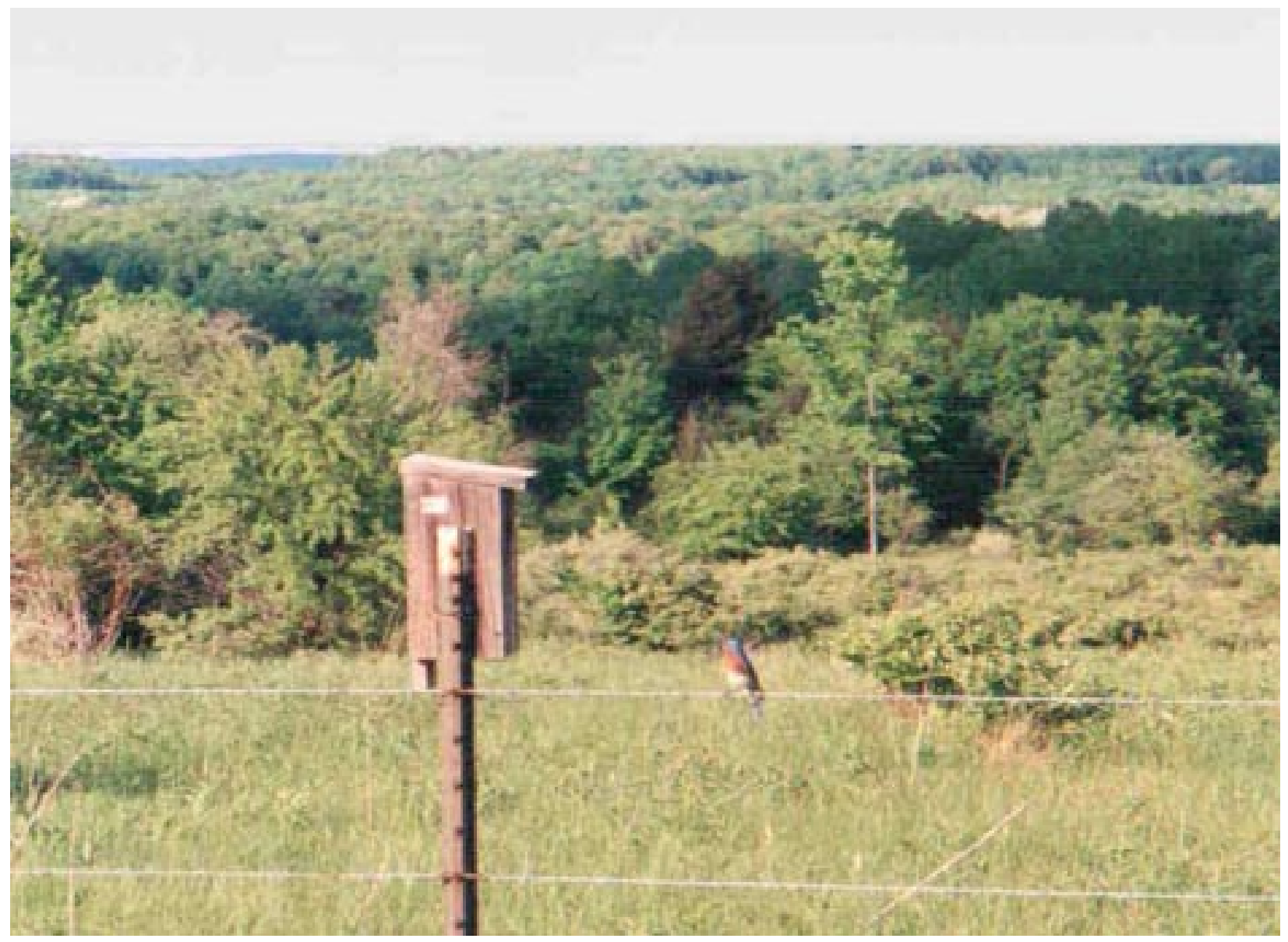

The WVDP Supports a Bluebird and Wood Duck Nesting-Box Program Sponsored by the Springville Field and Stream Club 
This page intentionally left blank

$B-i i$ 


\section{Environmental Monitoring Program}

The following schedule represents the West Valley Demonstration Project (WVDP) routine environmental monitoring program for 2001. This schedule met or exceeded the minimum program specifications needed to satisfy the requirements of DOE Order 5400.1. It also met the requirements of DOE 5400.5 and DOE/EH0173T. Specific methods and recommended monitoring program elements are found in DOE/EP-0096, $A$ Guide for Effluent Radiological Measurements at DOE Installations, and DOE/EP-0023, A Guide for Environmental Radiological Surveillance at U.S. Department of Energy Installations, which were the bases for selecting most of the schedule specifics. Additional monitoring was mandated by air and water discharge permits (40 CFR 61 and SPDES), which also required formal reports. Specifics are identified in the schedule under Monitoring/Reporting Requirements.

A computerized environmental data-screening system identifies analytical data that exceed pre-set limits. All locations are checked monthly for trends or notable results in accordance with criteria established in Documentation and Reporting of Environmental Monitoring Data (West Valley Nuclear Services Co., Inc., August 19, 1998). Reportable results are then described in a monthly trend analysis report together with possible causes and corrective actions, if indicated. A WVDP effluent summary report is transmitted with each monthly trend analysis report.

\section{Schedule of Environmental Sampling}

The index on pages B-v through B-vii is a list of the codes used to identify the various sampling locations, which are shown on Figures A-1 through A-13 (pp. A-3 through A-15 in Appendix A). The schedule of environmental sampling at the WVDP is found in this appendix on pages B-1 through B-44. Table headings in the schedule are as follows:

- Sample Location Code. Describes the physical location where the sample is collected. The code consists of seven or eight characters: The first character identifies the sample medium as Air, Water, Soil/Sediment, Biological, or Direct Measurement. The second character specifies oN-site or oFf-site. The remaining characters describe the specific location (e.g., AFGRVAL is Air oFf-site at GReat VALley). Distances noted at sampling locations are as measured in a straight line from the main stack on-site.

- Monitoring/Reporting Requirements. Notes the bases for monitoring the location, any additional references to permits, and the reports that are generated from the sample data. Routine reports cited in this appendix are the Effluent Summary Report (ESR), the Monthly Trend Analysis Report (MTAR), the Air Emissions Report (NESHAP), and the annual Site Environmental Report (SER).

- Sampling Type/Medium. Describes the collection method and the physical characteristics of the medium.

- Collection Frequency. Indicates how often the samples are collected or retrieved.

- Total Annual Sample Collections. Specifies the number of discrete physical samples collected annually for each group of analytes.

- Analyses Performed/Composite Frequency. Notes the type of analyses of the samples taken at each collection, the frequency of composite, and the analytes determined for the composite samples.

$B-i i i$

WVDP Site Environmental Report

Calendar Year 2001 


\section{Summary of Monitoring Program Changes in 2001}

Location Code

ANLLWTVH

WN8D1DR

WNSP008

AFWEVAL

BFMCOBO

\section{Description of Changes}

Decontamination and decommissioning activities are no longer being conducted in the former low-level waste treatment building. The building ventilation has been shut down and its sampler is currently inactive. No samples were collected in 2001.

Sampling at the waste tank farm underdrain was discontinued in December 2001 at the direction of the DOE.

The french drain sampling point was capped off in May 2001 to prevent the spread of low levels of lead detected at this location.

Due to a pending property sale, the community air sampler in West Valley was relocated from a private residence to the West Valley Volunteer Fire Department in November 2001.

Monthly milk sampling was discontinued in August 2001 when the local farmer stopped selling milk to commercial dairies and withdrew from the program.

$B-i v$ 


\section{Index of Environmental Monitoring Program Sample Points}

\begin{tabular}{lll}
\multicolumn{2}{l}{ Air Effluent and On-Site Ambient Air (Fig. A-4 [p. A-6]) } & \\
ANSTACK & Main Plant & B-1 \\
ANSTSTK & Supernatant Treatment System & B-1 \\
ANCSSTK & 01-14 Building & B-1 \\
ANCSRFK & Size-Reduction Facility & B-1 \\
ANCSPFK & Container Sorting and Packaging Facility & B-1 \\
ANVITSK & Vitrification Heating, Ventilation, and Air Conditioning & B-1 \\
ANSEISK & Seismic Sampler (Vitrification backup) & B-1 \\
OVEs/PVUs* & Outdoor Ventilated Enclosures/Portable Ventilation Units & B-3 \\
ANLLW2V & Low-Level Waste Treatment Ventilation & B-5 \\
ANLLWTVH** & Low-Level Waste Treatment Ventilation (radioactive operations) & B-5 \\
ANLAUNV & Contaminated Clothing Laundry Ventilation & B-5 \\
ANLAGAM & Lag Storage Area (ambient air) & B-5 \\
ANNDAAM & NDA Area (ambient air) & B-5 \\
ANSDAT9 & SDA Trench 9 (ambient air) & B-5
\end{tabular}

\section{Liquid Effluent and On-Site Water (Fig. A-2 [p. A-4])}

WNSP001

WNSP006

WNURRAW*

WNSP007

WNSWAMP

WNSW74A

WN8D1DR

WNSDADR

WNSP008

WNSP005

WNCOOLW

WNFRC67

WNERB53

WNNDADR

WNDCELD

WNNDATR

WNSTAW Series

WNDNK Series*
Lagoon 3 Weir Point

B-7

Facility Main Drainage

Utility Room Raw Water

Sanitary Waste Discharge

Northeast Swamp Drainage Point

North Swamp Drainage Point

Waste Farm Underdrain

SDA Run-Off

French Drain LLWTF Area

South Facility Drainage

Cooling Tower

Frank's Creek East

Erdman Brook

Disposal Area Drainage

Drum Cell Drainage

NDA Trench Interceptor Project

Standing Water

Site Potable Water
B-9

B-9

B-9

B-11

B-11

B-11

B-11

B-13

B-13

B-13

B-15

B-15

B-15

B-15

B-15

B-17

B-19

* Not detailed on map.

** The location and sampler are no longer in use. Deletion of this sampling point is in progress. No samples were collected in 2001.

$$
B-v
$$




\title{
Index of Environmental Monitoring Program Sample Points (continued)
}

\author{
On-Site Groundwater and Seeps (Figs. A-6 through A-8 [pp. A-8 through A-10]) \\ SSWMU \#1 Low-Level Waste Treatment Facility Wells $\quad$ B-21 \\ SSWMU \#2 Miscellaneous Small Units Wells $\quad$ B-21 \\ SSWMU \#3 $\quad$ Liquid Waste Treatment System Wells $\quad$ B-21 \\ SSWMU \#4 HLW Storage and Processing Tank Wells $\quad$ B-23 \\ SSWMU \#5 Maintenance Shop Leach Field Wells $\quad$ B-23 \\ SSWMU \#6 Low-Level Waste Storage Area Wells $\quad$ B-23 \\ SSWMU \#7 CPC Waste Storage Area Wells $\quad$ B-23 \\ $\begin{array}{llr}\text { SSWMU\#8 CDDL Wells } & \text { B-25 }\end{array}$ \\ SSWMU\#9 NDA Units Wells and NDATR $\quad$ B-25 \\ $\begin{array}{llr}\text { SSWMU \#10 IRTS Drum Cell Wells } & \text { B-25 }\end{array}$ \\ $\begin{array}{llr}\text { SSWMU\#11 SDA Unit Wells } & \text { B-27 }\end{array}$ \\ $\begin{array}{lll}\text { North Plateau Seeps } & \text { Northeastern Edge of North Plateau } & \text { B-27 }\end{array}$ \\ $\begin{array}{lll}\text { Well Points } & \text { Downgradient of Main Plant } & \text { B-27 }\end{array}$ \\ $\begin{array}{llr}\text { WNWNB1S } & \text { Former North Plateau Background Well } & \text { B-27 }\end{array}$
}

Off-Site Surface Water (Fig. A-3 [p. A-5])

$\begin{array}{llr}\text { WFBCTCB } & \text { Buttermilk Creek at Thomas Corners } & \text { B-29 }\end{array}$

$\begin{array}{llr}\text { WFFELBR } & \text { Cattaraugus Creek at Felton Bridge } & \text { B-29 }\end{array}$

$\begin{array}{lll}\text { WFBCBKG } & \text { Buttermilk Creek near Fox Valley (background) } & \text { B-29 }\end{array}$

$\begin{array}{lll}\text { WFBIGBR } & \text { Cattaraugus Creek at Bigelow Bridge (background) } & \text { B-29 }\end{array}$

Off-Site Drinking Water (Figs. A-9, A-12, and A-13 [pp. A-11, A-14, and A-15])

$\begin{array}{lll}\text { WFWEL Series } & \text { Private Local Wells } & \text { B-31 }\end{array}$

Off-Site Ambient Air (Figs. A-5, A-12, and A-13 [pp. A-7, A-14, and A-15])

$\begin{array}{llr}\text { AFFXVRD } & \text { Fox Valley Sampler } & \text { B-33 } \\ \text { AFTCORD } & \text { Thomas Corners Sampler } & \text { B-33 } \\ \text { AFRT240 } & \text { Route 240 Sampler } & \text { B-33 } \\ \text { AFSPRVL } & \text { Springville Sampler } & \text { B-33 } \\ \text { AFWEVAL } & \text { West Valley Sampler } & \text { B-33 } \\ \text { AFNASHV } & \text { Nashville Sampler (background) } & \text { B-33 } \\ \text { AFBOEHN } & \text { Dutch Hill Road Sampler } & \text { B-33 } \\ \text { AFRSPRD } & \text { Rock Springs Road Sampler } & \text { B-33 } \\ \text { AFGRVAL } & \text { Great Valley Sampler (background) } & \text { B-33 } \\ \text { AFBLKST } & \text { Bulk Storage Warehouse Sampler } & \text { B-33 }\end{array}$

$B-v i$

WVDP Site Environmental Report

Calendar Year 2001 


\section{Index of Environmental Monitoring Program Sample Points (concluded)}

Fallout, Sediment, and Soil (Figs. A-2 through A-5 [pp. A-4 through A-7], A-12, and A-13 [pp. A-14 and A-15])

$\begin{array}{llr}\text { AFDHFOP } & \text { Dutch Hill Fallout } & \text { B-35 } \\ \text { AFFXFOP } & \text { Fox Valley Fallout } & \text { B-35 } \\ \text { AFTCFOP } & \text { Thomas Corners Fallout } & \text { B-35 } \\ \text { AF24FOP } & \text { Route 240 Fallout } & \text { B-35 } \\ \text { ANRGFOP } & \text { Rain Gauge Fallout } & \text { B-35 } \\ \text { SF Soil Series } & \text { Air Sampler Area Soil } & \text { B-35 } \\ \text { SFCCSED } & \text { Cattaraugus Creek at Felton Bridge, Sediment } & \text { B-35 } \\ \text { SFSDSED } & \text { Cattaraugus Creek at Springville Dam, Sediment } & \text { B-35 } \\ \text { SFBISED } & \text { Cattaraugus Creek at Bigelow Bridge, Background Sediment } & \text { B-35 } \\ \text { SFTCSED } & \text { Buttermilk Creek at Thomas Corners, Sediment } & \text { B-35 } \\ \text { SFBCSED } & \text { Buttermilk Creek at Fox Valley Road, Background Sediment } & \text { B-35 } \\ \text { SNSoil Series: } & \text { On-Site Soils/Sediments } & \text { B-35 } \\ \text { SNSW74A } & & \text { B-35 } \\ \text { SNSWAMP } & & \text { B-35 } \\ \text { SNSP006 } & & \text { B-35 }\end{array}$

Off-Site Biological (Figs. A-9, A-12, and A-13 [pp. A-11, A-14, and A-15])

$\begin{array}{llr}\text { BFFCATC } & \text { Cattaraugus Creek Fish, Downstream } & \text { B-37 } \\ \text { BFFCATD } & \text { Cattaraugus Creek Fish, Downstream of Springville Dam } & \text { B-37 } \\ \text { BFFCTRL } & \text { Cattaraugus Creek Fish, Background } & \text { B-37 } \\ \text { BFMREED } & \text { NNW Milk } & \text { B-37 } \\ \text { BFMCOBO } & \text { WNW Milk } & \text { B-37 } \\ \text { BFMCTLS } & \text { Milk, South, Background } & \text { B-37 } \\ \text { BFMCTLN } & \text { Milk, North, Background } & \text { B-37 } \\ \text { BFMWIDR } & \text { Southeast Milk, Near-Site } & \text { B-37 } \\ \text { BFMSCHT } & \text { South Milk, Near-Site } & \text { B-37 } \\ \text { BFVNEAR* } & \text { Produce, Near-Site } & \text { B-39 } \\ \text { BFVCTRL* } & \text { Produce, Background } & \text { B-39 } \\ \text { BFHNEAR } & \text { Forage, Near-Site } & \text { B-39 } \\ \text { BFHCTLS } & \text { Forage, South, Background } & \text { B-39 } \\ \text { BFHCTLN } & \text { Forage, North, Background } & \text { B-39 } \\ \text { BFBNEAR } & \text { Beef, Near-Site } & \text { B-39 } \\ \text { BFBCTRL } & \text { Beef, Background } & \text { B-39 } \\ \text { BFDNEAR } & \text { Venison, Near-Site } & \text { B-39 } \\ \text { BFDCTRL } & \text { Venison, Background } & \text { B-39 }\end{array}$

Direct Measurement Dosimetry (Figs. A-10 through A-13 [pp. A-12 through A-15])

DFTLD Series $\quad$ Off-Site Direct Radiation $\quad$ B-41

DNTLD Series $\quad$ On-Site Direct Radiation $\quad$ B-43

* Near-site and background produce samples (corn, apples, and beans) are identified specifically as follows: corn = BFVNEAC and BFVCTRC; apples = BFVNEAAF and BFVCTRA; beans = BFVNEAB and BFVCTRB.

$$
B-v i i
$$




\section{Monitoring Program \\ On-Site Effluent Monitoring}

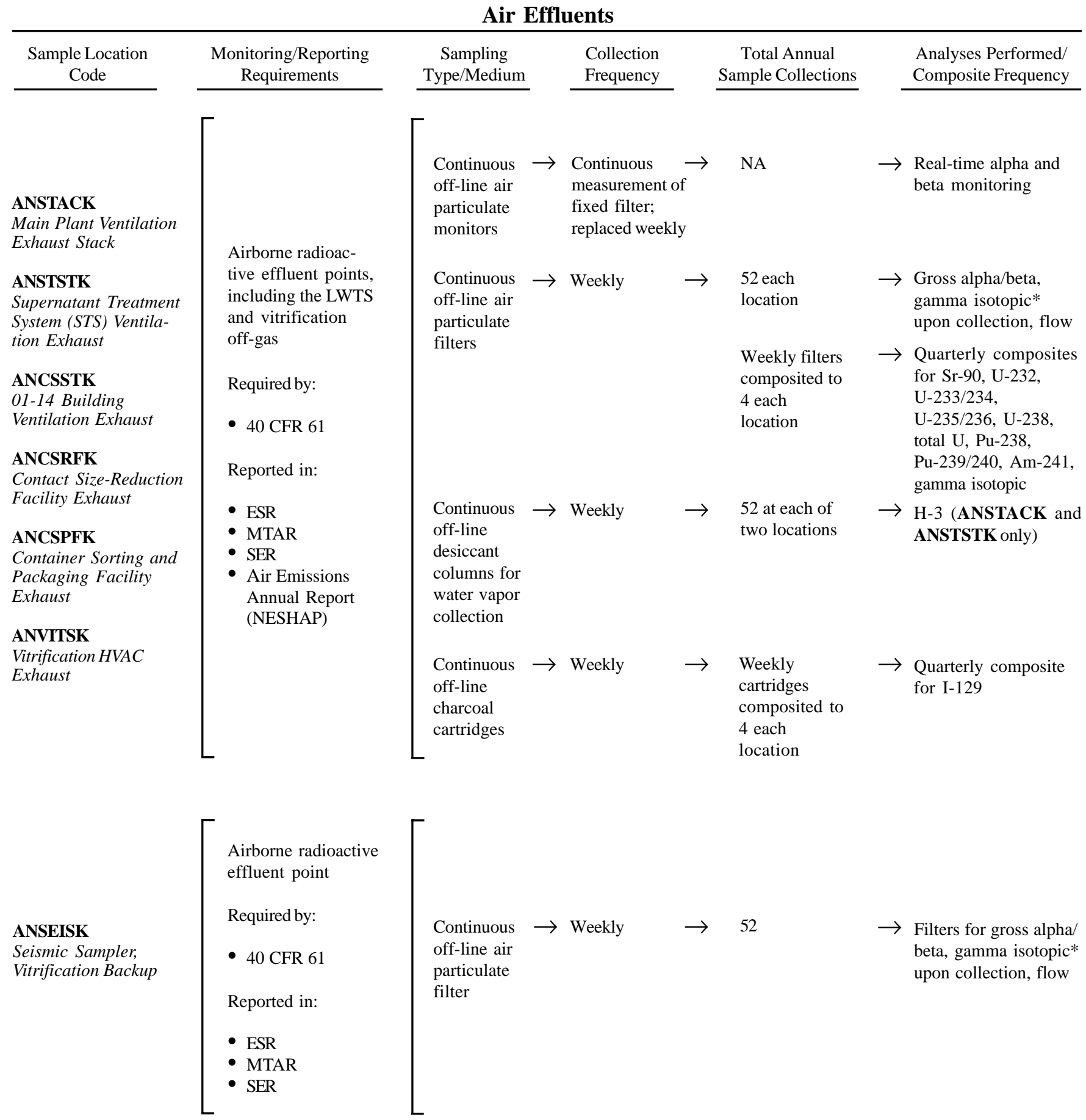

* Weekly gamma isotopic only if gross activity rises significantly.

NA - Not applicable.

$$
B-1
$$




\title{
Sampling Rationale
}

ANSTACK

ANSTSTK

ANCSRFK

ANCSPFK

ANVITSK

ANSEISK
DOE/EH-0173T, 3.0; DOE/EP-0096, 3.3

Monitors and samples HEPA-filtered ventilation from most process areas, including cell ventilation, vessel offgas, fuel receiving and storage (FRS), head end ventilation, and an analytical aisle. Requires continuous effluent monitoring per 40 CFR Subpart H, Section 61.93(b) because potential emissions may exceed the 0.1 mrem limit.

DOE/EH-0173T, 3.0; DOE/EP-0096, 3.3

Monitors and samples HEPA-filtered ventilation (permanent ventilation system [PVS]) from building areas involved in treatment of high-level waste supernatant. Requires continuous effluent monitoring per 40 CFR Subpart H, Section 61.93(b) because potential emissions may exceed the 0.1 mrem limit.

DOE/EH-0173T, 3.0; DOE-EP-0096, 3.3

Monitors and samples HEPA-filtered ventilation from the 01-14 building, which houses equipment used to treat the ceramic melter off-gas. Requires effluent monitoring per 40 CFR Subpart H, Section 61.93(b) to confirm that emissions are less than the 0.1 mrem limit.

DOE/EH-0173T, 3.0; DOE-EP-0096, 3.3

Monitors and samples HEPA-filtered ventilation from a process area where radioactive tanks, pipes, and other equipment are cut up with a plasma torch to reduce volume.

DOE/EH-0173T, 3.0; DOE-EP-0096, 3.3

Monitors and samples ventilation from lag storage area 4, the container sorting and packaging facility.

DOE/EH-0173T, 3.0; DOE-EP-0096, 3.3

Vitrification facility heating, ventilation, and air conditioning (HVAC) effluent exhaust stack. Sampler brought online in late 1995 when nonradioactive operations began. Radioactive operation began with the first high-level waste transfer in June 1996 and vitrification startup in July 1996. Monitors and samples HEPA-filtered ventilation from building areas involved in treatment of high-level waste supernatant. Requires effluent monitoring per 40 CFR Subpart H, Section 61.93(b) because potential emissions may exceed the 0.1 mrem limit.

DOE/EH-0173T, 3.0; DOE-EP-0096, 3.3

Vitrification system back-up filter for catastrophic-event monitoring in case the primary vitrification HVAC stack ventilation fails.

Sampling locations are shown on Figure A-4 (p. A-6).

\author{
WVDP Site Environmental Report
}




\section{Monitoring Program \\ On-Site Effluent Monitoring}

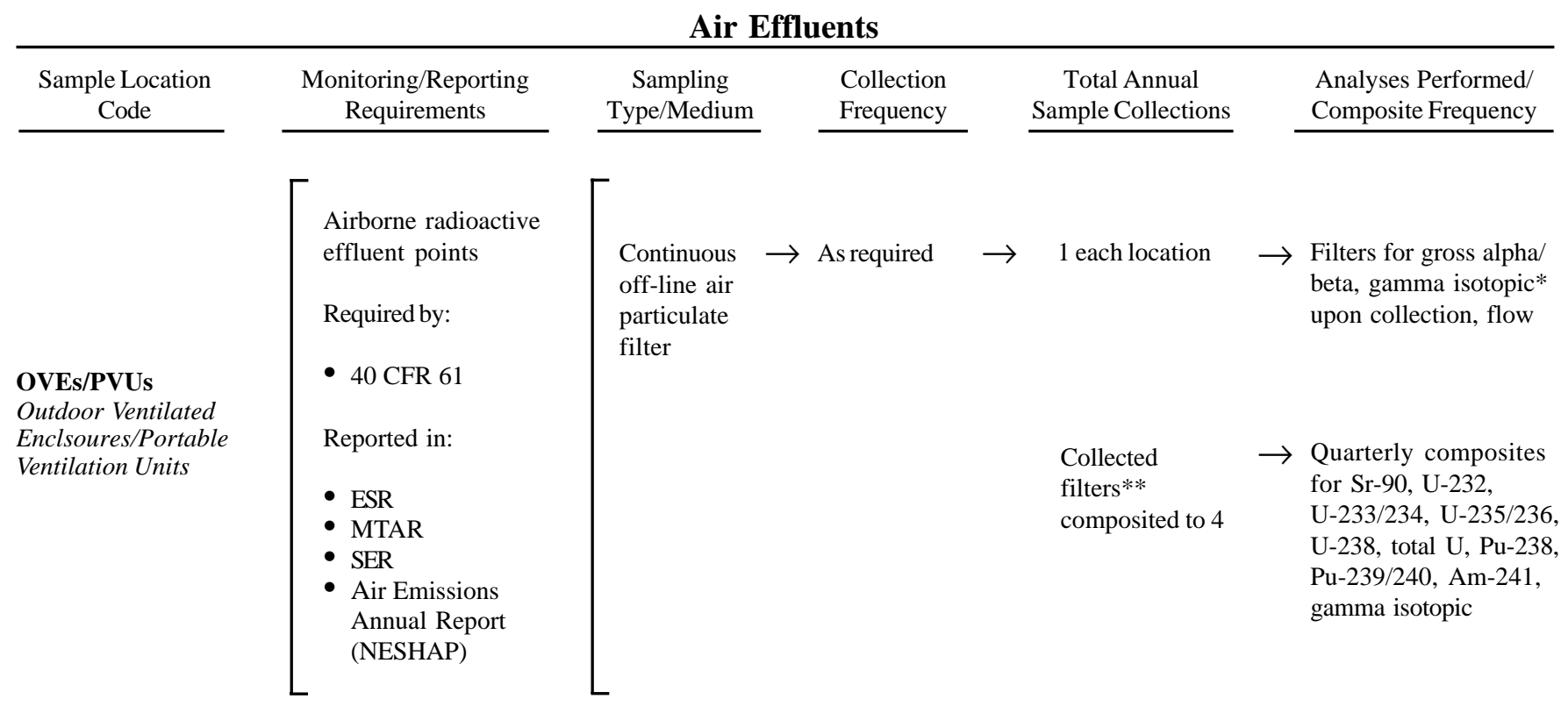

* Gamma isotopic only if gross activity rises significantly.

** If gross determination of individual filter is significantly higher than background, the individual sample would be submitted immediately for isotopic analysis.

$$
B-3
$$




\section{Sampling Rationale}

OVEs/PVUs

DOE/EH-0173T, 3.0; DOE/EP-0096, 3.3

Outdoor ventilated enclosures; portable ventilation units used for handling radioactive materials or for decontamination in areas not having containment ventilation. Emissions are monitored to confirm that they are below the 0.1 mrem limit.

Sampling locations are not shown on figures.

$$
B-4
$$




\section{Monitoring Program \\ On-Site Effluent Monitoring}

\section{Air Effluents and On-Site Ambient Air}

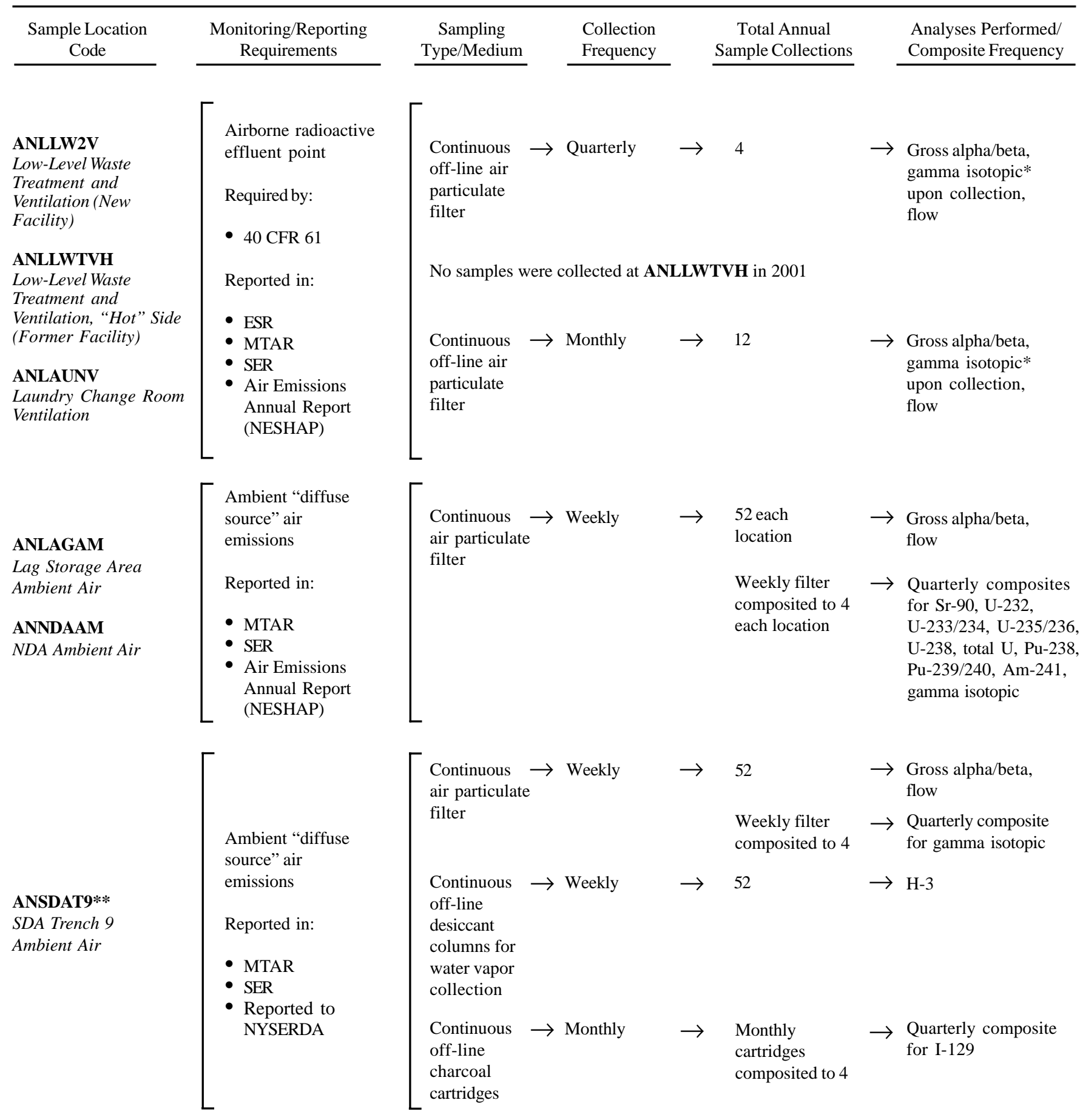

* Gamma isotopic only if gross activity rises significantly.

** Sampling frequency and analytical parameters as directed by NYSERDA.

$$
B-5
$$




\section{Sampling Rationale}

ANLLW2V DOE/EH-0173T, 3.0; DOE/EP-0096, 3.3

Samples ventilation exhaust from the new low-level waste treatment facility. System started up in April 1998.

ANLLWTVH DOE/EH-0173T, 3.0; DOE/EP-0096, 3.3

Samples radioactive side of ventilation exhaust from the former low-level waste treatment facility.

This location is being decommissioned and the sampler is no longer operating.

ANLAUNV DOE/EH-0173T, 3.0; DOE/EP-0096, 3.3

Samples ventilation from the contaminated clothing laundry.

Permission to delete this point from the monitoring program has been requested from the DOE on the basis that data from this point over years of monitoring have demonstrated compliance with NESHAP requirements.

ANLAGAM DOE/EH-0173T, 3.3.2

Monitors ambient air in the lag storage area, a possible diffuse source of air emissions.

ANNDAAM

DOE/EH-0173T, 3.3.2

Monitors ambient air in the NDA area, a possible diffuse source of air emissions.

ANSDAT9 DOE/EH-0173T, 3.3.2

Monitors ambient air by SDA trench 9, a possible diffuse source of air emissions. WVDP support of NYSERDA.

Sampling locations are shown on Figure A-4 (p. A-6).

$$
B-6
$$




\section{Monitoring Program \\ On-Site Effluent Monitoring}

\section{Liquid Effluents}

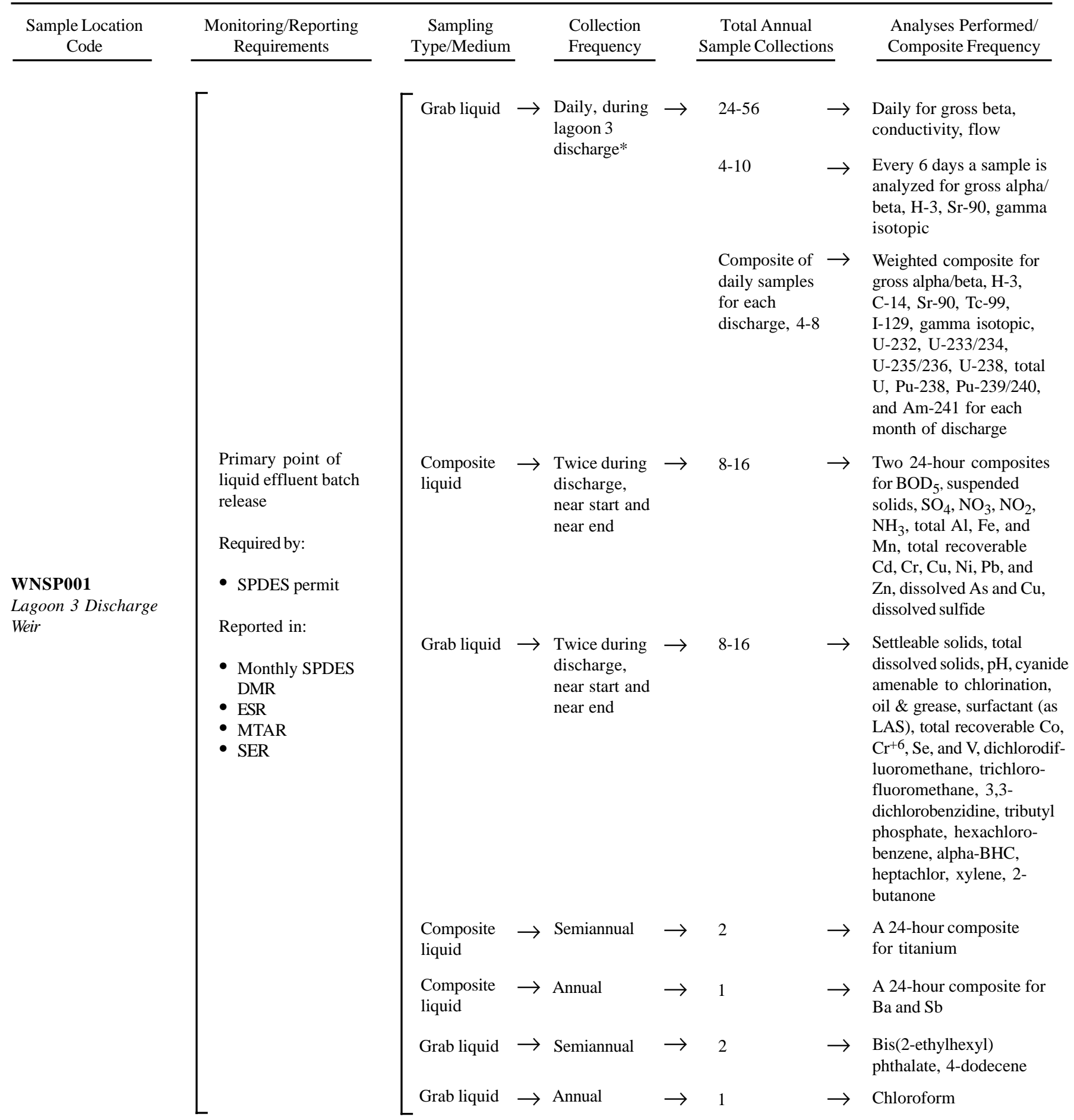

\footnotetext{
* Lagoon 3 is discharged four to eight times per year, as necessary, averaging six to seven days per discharge.
}

$$
B-7
$$




\section{Sampling Rationale}

WNSP001 DOE 5400.5; DOE/EH-0173T, 2.3.3; SPDES permit no. NY0000973

By DOE Order all liquid effluent streams from DOE facilities shall be evaluated and their potential for release of radionuclides addressed.

These requirements for radiological parameters are met by daily grab sampling during periods of lagoon 3 discharge. Sampling for chemical constituents is performed near the beginning and end of each discharge period to meet the site SPDES permit. Both grab samples and 24-hour composite samples are collected.

Sampling location is shown on Figure A-2 (p. A-4).

$$
B-8
$$




\section{Monitoring Program \\ On-Site Effluent Monitoring}

\section{Liquid Effluents}

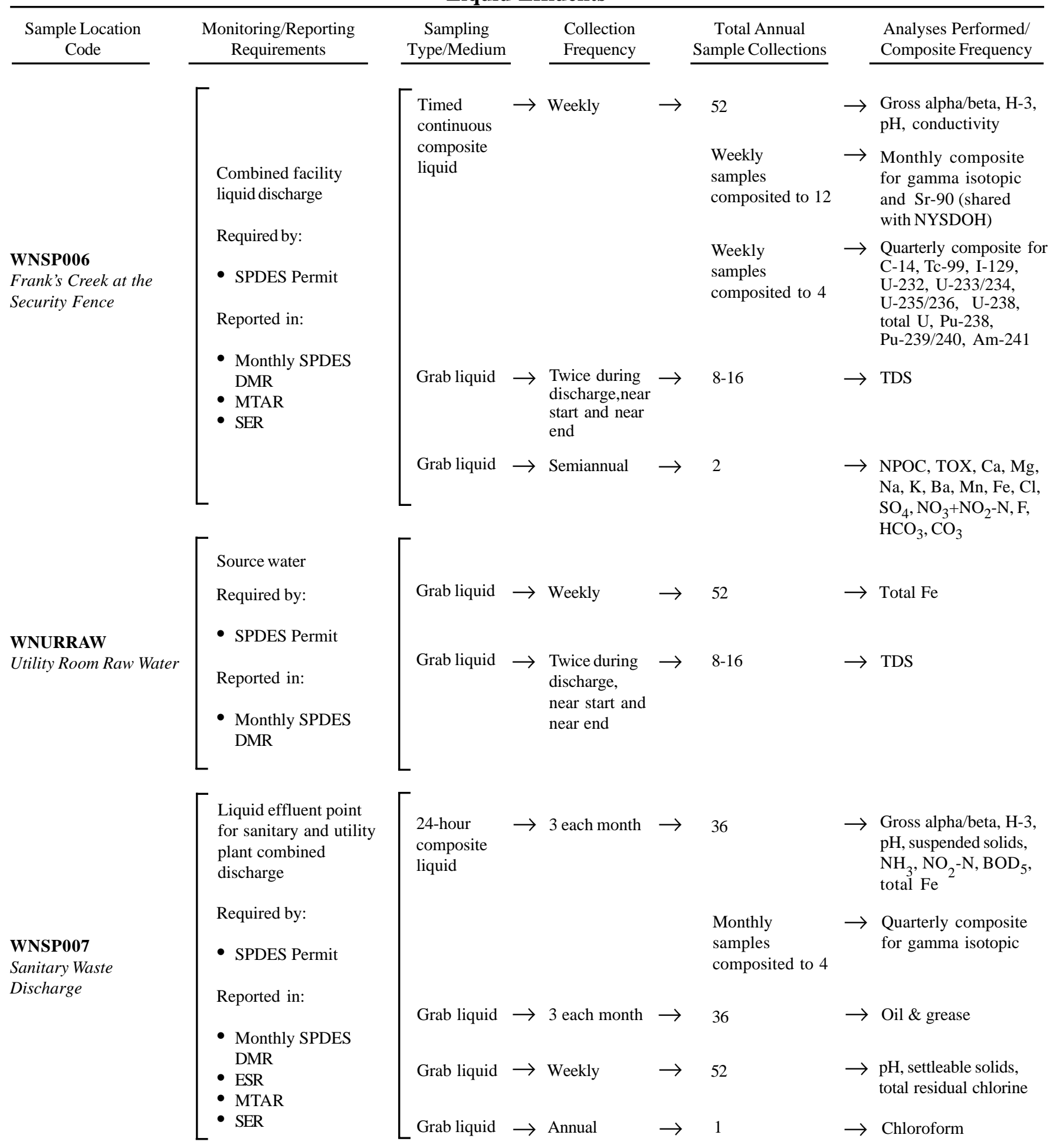

$$
B-9
$$




\section{Sampling Rationale}

WNSP006 DOE/EH-0173T, 5.10.1.1; SPDES permit no. NY0000973

By DOE Order all liquid effluent streams from DOE facilities shall be evaluated and their potential for release of radionuclides addressed.

In accordance with the WVDP SPDES permit no. NY0000973, outfall 116 (pseudo-monitoring point) uses flow data from WNSP006. Flow augmentation parameters (flow and total dissolved solids [TDS]) are monitored at location WNSP006; calculated TDS and flow data related to sample point WNSP006 are reported for pseudo-monitoring point 116 in the monthly SPDES Discharge Monitoring Report (DMR).

WNURRAW SPDES permit no. NY0000973

TDS is measured near the beginning and end of each lagoon 3 discharge. Results are used for outfall 116 calculations. (See WNSP006 above.)

WNSP007

DOE 5400.5; DOE/EH-0173T, 2.3.3

Sampling rationale is based on New York State SPDES permit no. NY0000973 and DOE 5400.5 criteria.

Sampling locations are shown on Figure A-2 (p. A-4). 


\section{Monitoring Program \\ Environmental Surveillance}

\section{On-Site Surface Water}

\begin{tabular}{|c|c|c|c|c|c|c|c|c|}
\hline $\begin{array}{l}\text { Sample Location } \\
\text { Code }\end{array}$ & $\begin{array}{c}\text { Monitoring/Reporting } \\
\text { Requirements }\end{array}$ & $\begin{array}{c}\text { Sampling } \\
\text { Type/Medium }\end{array}$ & & $\begin{array}{l}\text { Collection } \\
\text { Frequency }\end{array}$ & & $\begin{array}{c}\text { Total Annual } \\
\text { Sample Collections }\end{array}$ & & $\begin{array}{l}\text { Analyses Performed/ } \\
\text { Composite Frequency }\end{array}$ \\
\hline \multirow{4}{*}{$\begin{array}{l}\text { WNSWAMP } \\
\text { Northeast Swamp } \\
\text { Drainage }\end{array}$} & \multirow{4}{*}{$\begin{array}{l}\text { Site surface } \\
\text { drainage } \\
\text { Reported in: } \\
\text { - } \text { ESR } \\
\text { - MTAR } \\
\text { - SER }\end{array}$} & \multirow{3}{*}{$\begin{array}{l}\text { Timed } \\
\text { continuous } \\
\text { composite } \\
\text { liquid }\end{array}$} & \multirow[t]{3}{*}{$\rightarrow$} & \multirow[t]{3}{*}{ Weekly } & \multirow[t]{3}{*}{$\rightarrow$} & 52 & $\rightarrow$ & $\begin{array}{l}\text { Gross alpha/beta, } \mathrm{H}-3 \text {, } \\
\mathrm{pH}, \text { conductivity }\end{array}$ \\
\hline & & & & & & $\begin{array}{l}\text { Weekly samples } \\
\text { composited to } 12\end{array}$ & $2 \rightarrow$ & $\begin{array}{l}\text { Monthly composite for } \\
\text { gamma isotopic and Sr-90 } \\
\text { (shared with NYSDOH) }\end{array}$ \\
\hline & & & & & & $\begin{array}{l}\text { Weekly samples } \\
\text { composited to } 4\end{array}$ & $\rightarrow$ & $\begin{array}{l}\text { Quarterly composite } \\
\text { for C-14, I-129, U-232, } \\
\text { U-233/234,U-235/236, } \\
\text { U-238, total U, Pu-238, } \\
\text { Pu-239/240, Am-241 }\end{array}$ \\
\hline & & Grab liquid & $\rightarrow$ & Semiannual & $\rightarrow$ & 2 & $\rightarrow$ & $\begin{array}{l}\mathrm{NPOC}, \mathrm{TOX}, \mathrm{Ca}, \mathrm{Mg}, \\
\mathrm{Na}, \mathrm{K}, \mathrm{Ba}, \mathrm{Mn}, \mathrm{Fe}, \mathrm{Cl}, \\
\mathrm{SO}_{4}, \mathrm{NO}_{3}+\mathrm{NO}_{2}-\mathrm{N}, \mathrm{F}, \\
\mathrm{HCO}_{3}, \mathrm{CO}_{3}\end{array}$ \\
\hline \multirow{4}{*}{$\begin{array}{l}\text { WNSW74A } \\
\text { North Swamp Drainage }\end{array}$} & \multirow{4}{*}{$\begin{array}{l}\begin{array}{l}\text { Site surface } \\
\text { drainage }\end{array} \\
\text { Reported in: } \\
\text { - ESR } \\
\text { - MTAR } \\
\text { - SER }\end{array}$} & $\begin{array}{l}\text { Timed } \\
\text { continuous } \\
\text { composite }\end{array}$ & $\rightarrow$ & Weekly & $\rightarrow$ & 52 & $\rightarrow$ & $\begin{array}{l}\text { Gross alpha/beta, } \mathrm{H}-3 \text {, } \\
\mathrm{pH}, \text { conductivity }\end{array}$ \\
\hline & & liquid & & & & $\begin{array}{l}\text { Weekly samples } \\
\text { composited to } 12\end{array}$ & $\rightarrow$ & $\begin{array}{l}\text { Monthly composite for } \\
\text { gamma isotopic and } \mathrm{Sr}-90\end{array}$ \\
\hline & & & & & & $\begin{array}{l}\text { Weekly samples } \\
\text { composited to } 4\end{array}$ & $\rightarrow$ & $\begin{array}{l}\text { Quarterly composite } \\
\text { for C-14, I-129, U-232, } \\
\text { U-233/234,U-235/236, } \\
\text { U-238, total U, Pu-238, } \\
\text { Pu-239/240, Am-241 }\end{array}$ \\
\hline & & Grab liquid & $\rightarrow$ & Semiannual & $\rightarrow$ & 2 & $\rightarrow$ & $\begin{array}{l}\mathrm{NPOC}, \mathrm{TOX}, \mathrm{Ca}, \mathrm{Mg} \text {, } \\
\mathrm{Na}, \mathrm{K}, \mathrm{Ba}, \mathrm{Mn}, \mathrm{Fe}, \mathrm{Cl} \text {, } \\
\mathrm{SO}_{4}, \mathrm{NO}_{3}+\mathrm{NO}_{2}-\mathrm{N}, \mathrm{F}, \\
\mathrm{HCO}_{3}, \mathrm{CO}_{3}\end{array}$ \\
\hline \multirow{2}{*}{$\begin{array}{l}\text { WN8D1DR } \\
\text { High-Level Waste Farm } \\
\text { Underdrain }\end{array}$} & $\begin{array}{l}\text { Drains subsurface } \\
\text { water from HLW } \\
\text { storage tank area }\end{array}$ & \multirow[t]{2}{*}{ Grab liquid } & \multirow[t]{2}{*}{$\rightarrow$} & \multirow[t]{2}{*}{ Weekly } & \multirow[t]{2}{*}{$\rightarrow$} & 52 & $\rightarrow$ & $\begin{array}{l}\text { Gross alpha/beta, H-3, } \\
\text { pH }\end{array}$ \\
\hline & $\begin{array}{l}\text { Reported in: } \\
\text { - } \text { MTAR } \\
\text { - SER }\end{array}$ & & & & & $\begin{array}{l}\text { Weekly samples } \\
\text { composited to } 12\end{array}$ & $2 \rightarrow$ & $\begin{array}{l}\text { Monthly composite for } \\
\text { gamma isotopic and Sr-90 }\end{array}$ \\
\hline \multirow[b]{2}{*}{$\begin{array}{l}\text { WNSDADR } \\
\text { SDA Run-Off }\end{array}$} & $\begin{array}{l}\text { Surface water run-off } \\
\text { from south portion } \\
\text { of SDA } \\
\text { Required by: }\end{array}$ & & & & & & & \multirow[b]{2}{*}{$\begin{array}{l}\mathrm{pH} \text {, total suspended } \\
\text { solids, oil \& grease, flow, } \\
\text { gross alpha/beta, H-3, } \\
\text { gamma isotopic }\end{array}$} \\
\hline & $\begin{array}{l}\text { - Interim Measures } \\
\text { Compliance } \\
\text { Reported in: } \\
\text { - MTAR } \\
\text { - SER } \\
\text { - Reported to } \\
\text { NYSERDA }\end{array}$ & Grab liquid & $\rightarrow$ & Monthly & $\rightarrow$ & 12 maximum & $\rightarrow$ & \\
\hline
\end{tabular}

$$
B-11
$$




\section{Sampling Rationale}

WNSWAMP DOE/EH-0173T, 5.10.1.1

Northeast site surface water drainage; provides for sampling of uncontrolled surface waters from this discrete drainage path just before they leave the site's controlled boundary. Waters represent surface and subsurface drainages from the construction and demolition debris landfill (CDDL), old hardstand areas, and other possible north plateau sources of radiological or nonradiological contamination.

WNSW74A DOE/EH-0173T, 5.10.1.1

North site surface water drainage; provides for sampling of uncontrolled surface waters from this discrete drainage path just before they leave the site's controlled boundary. Waters represent surface and subsurface drainages from lag storage areas and other possible north plateau sources of radiological or nonradiological contamination.

WN8D1DR DOE/EH-0173T, 5.10.1.3

Monitors the potential influence on subsurface drainage surrounding the high-level waste tank farm. Sampling at WN8D1DR was discontinued in December 2001 at the direction of the DOE because the location is not considered representative of the underground drainage system.

WNSDADR NYSERDA interim measures compliance.

Sampling locations are shown on Figure A-2 (p. A-4).

$B-12$ 
2001 Monitoring Program

Environmental Surveillance

On-Site Surface Water

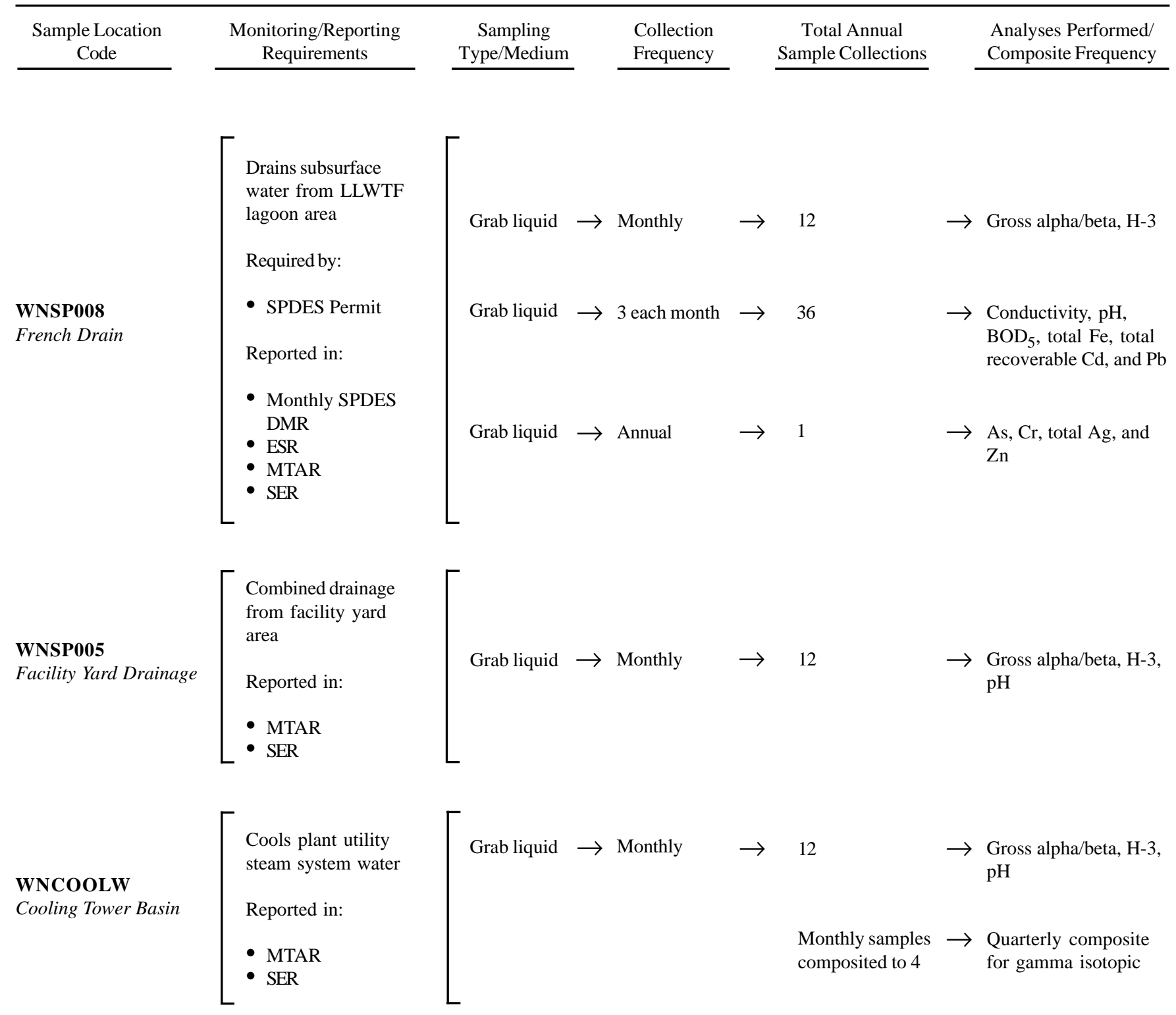

$$
B-13
$$




\section{Sampling Rationale}

WNSP008 DOE/EH-0173T, 5.10.1.3; SPDES permit no. NY0000973.

French drain of subsurface water from lagoon (LLWTF) area. The SPDES permit also provides for sampling of uncontrolled subsurface water from this discrete drainage path before these waters flow into Erdman Brook. Waters represent subsurface drainages from downward infiltration around the LLWTF and lagoon systems. This point would also monitor any subsurface spillover from the overfilling of lagoons 2 and 3. Sampling is of significance for both radiological and nonradiological contamination. This point was capped off in May 2001.

WNSP005 Facility yard surface water drainage; generally in accordance with DOE/EH-0173T, 5.10.1.1. Previously in accordance with SPDES permit no. NY0000973.

Provides for the sampling of uncontrolled surface waters from this discrete drainage path after outfall 007 discharge into the drainage and before these waters flow into Erdman Brook. Waters represent surface and subsurface drainages primarily from the main plant yard area. Historically, this point was used to monitor sludge pond and utility room discharges to the drainage. These two sources have been rerouted. Migration of residual site contamination around the main plant dictates surveillance of this point, primarily for radiological parameters.

WNCOOLW Facility cooling tower circulation water; generally in accordance with DOE/EH-0173T, 5.10.1.1.

Operational sampling carried out to confirm that radiological contamination is not migrating into the primary coolant loop of the high-level waste treatment facility and/or plant utility steam systems. Migration from either source might indicate radiological control failure.

Sampling locations are shown on Figure A-2 (p. A-4).

$B-14$ 
2001 Monitoring Program

Environmental Surveillance

On-Site Surface Water

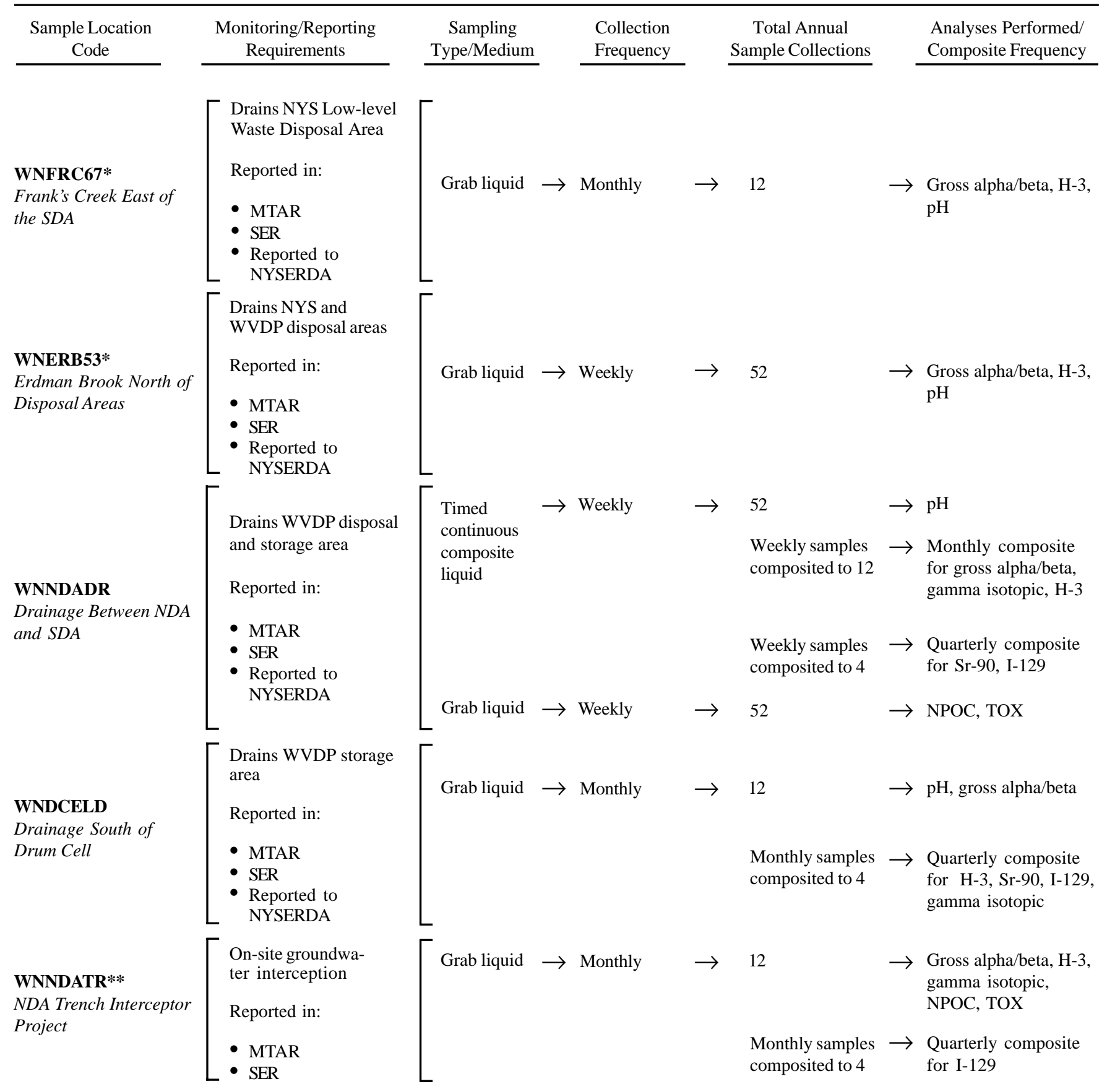

\footnotetext{
* Monthly sample also collected by NYSDOH

** Coordinated with Main Plant Operations
} 


\section{Sampling Rationale}

WNFRC67 DOE/EH-0173T, 5.10.1.1

Monitors the potential influence of both the SDA and drum cell drainage into Frank's Creek east of the SDA and upstream of its confluence with Erdman Brook.

WNERB53 DOE/EH-0173T, 5.10.1.1

Monitors the potential influence of the drainages from the SDA and the WVDP storage and disposal area into Erdman Brook upstream of its confluence with Frank's Creek.

WNNDADR $\quad$ DOE/EH-0173T, 5.10.1.1

Monitors the potential influence of the drainages from the SDA and the WVDP storage and disposal area into Lagoon Road Creek upstream of the creek's confluence with Erdman Brook.

WNDCELD

DOE/EH-0173T, 5.10.1.1

Monitors the potential influence of drum cell drainage into Frank's Creek south of the SDA and upstream of WNFRC67.

WNNDATR DOE 5400.1, IV.9

Monitors groundwater in the vicinity of the NDA interceptor trench project. The grab sample is taken directly from the trench collection system.

Sampling locations are shown on Figure A-2 (p. A-4).

$$
\text { B }-16
$$


2001 Monitoring Program

Environmental Surveillance

On-Site Surface Water

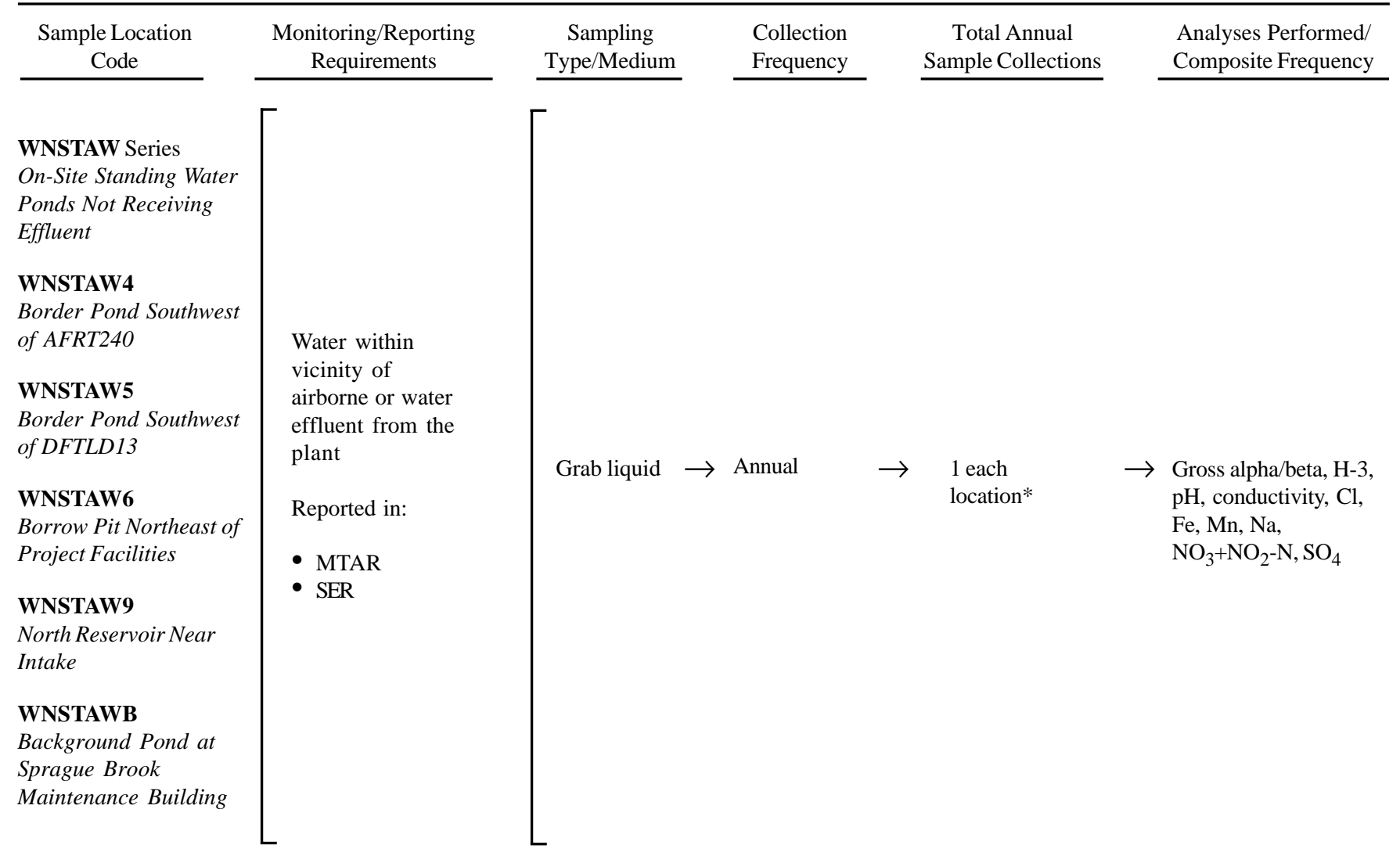

* Sampling depends upon on-site ponding conditions during the year.

$$
B-17
$$




\section{Sampling Rationale}

WNSTAW Series DOE/EH-0173T, 5.10.1.1

Monitoring of on- and off-site standing waters at locations listed below. Although none receive effluent directly, the potential for contamination is present except at the background location. Former collecting sites 1,2,3,7, and 8 were deleted from the monitoring program because they were either built over or are now dry.

WNSTAW4 Border pond located south of AFRT240. Chosen as a location for showing potentially high concentrations, based on meteorological data. This perimeter location is next to a working farm. Drainage extends through private property and is accessible by the public.

WNSTAW5 Border pond located west of Project facilities near the perimeter fence and DFTLD13. Chosen as a location for showing potentially high concentrations, based on meteorological data. Location is next to a private residence and potentially accessible by the general public.

WNSTAW6 Borrow pit northeast of Project facilities just outside the inner security fence. Considered the closest standing water to the main plant and high-level waste facilities.

WNSTAW9 North reservoir near intake. Chosen to provide data in the event of potentially contaminated site potable water supply. Location is south of main plant facilities.

WNSTAWB Pond located near the Sprague Brook maintenance building. Considered a background location; approximately 14 kilometers north of the WVDP.

Sampling locations are shown on Figures A-2, A-3, and A-13 (pp. A-4, A-5, and A-15).

\section{$B-18$}


2001 Monitoring Program

Environmental Surveillance

On-Site Potable Water

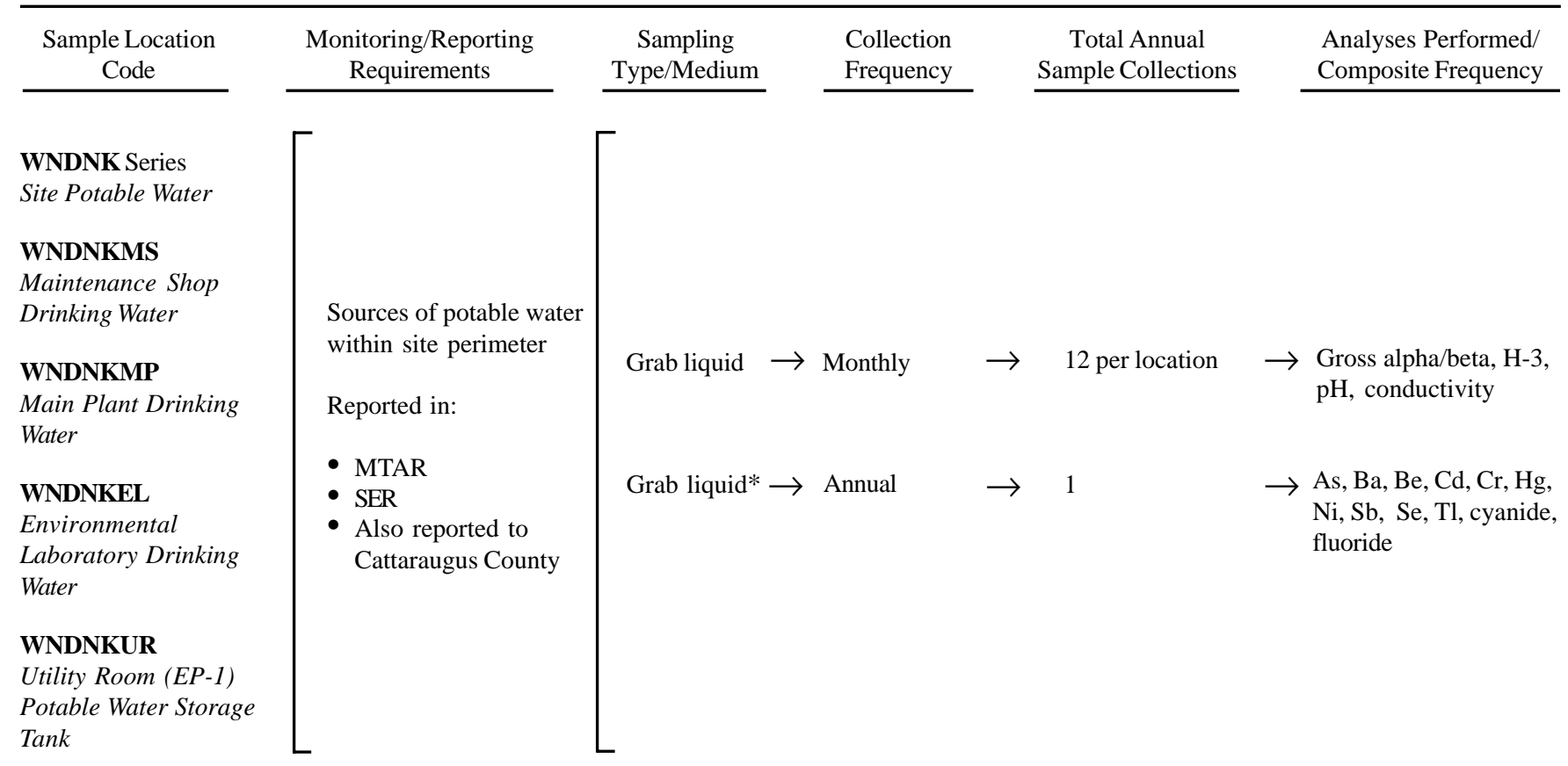

* WNDNKUR only. Sample for $\mathrm{NO}_{3}$ (as total nitrate) is collected by the Cattaraugus County Health Department. $\mathrm{Pb}$ and $\mathrm{Cu}$ also are sampled at this site based upon Cattaraugus County Health Department guidance.

$$
B-19
$$




\section{Sampling Rationale}

WNDNK Series Site drinking water; generally according to DOE/EH-0173T, 5.10.1.2

Potable-water sampling to confirm no migration of radiological and/or nonradiological contamination into the site's drinking water supply.

WNDNKMS Potable water sampled at the maintenance shop in order to monitor a point that is an intermediate distance from the point of potable water generation and that is used heavily by site personnel.

WNDNKMP Same rationale as WNDNKMS but sampled at the break room sink.

WNDNKEL Potable water sampled at the Environmental Laboratory.

WNDNKUR Sampled at the utility room potable water storage tank before the site drinking water distribution system. Sample location is entry point EP-1.

Sampling locations are within the site facilities and are not detailed on figures.

B - 20 
2001 Monitoring Program

Environmental Surveillance

On-Site Groundwater

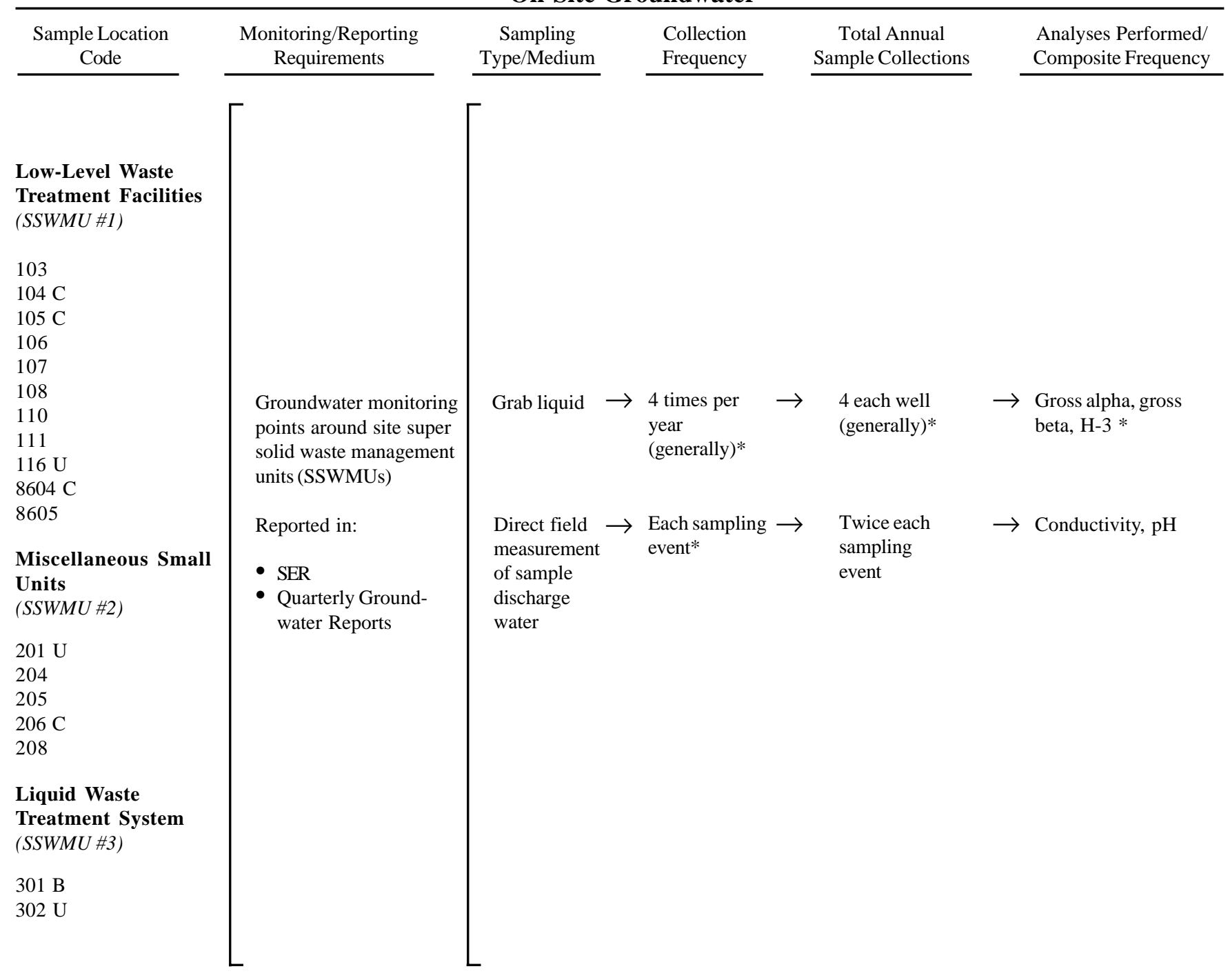

NOTE: "U" designates upgradient, "B" designates background, and "C" designates crossgradient wells. The remainder are downgradient.

* Sampling frequency and analytes vary from point to point. See Table 3-1 (p. 3-6) for a summary listing of all monitored analytes. See Table E-1 (Appendix E [p. E-3]) for a listing of analytes monitored at each location. See Appendix E for results from each location.

$$
B-21
$$




\title{
Sampling Rationale
}

\begin{abstract}
On-Site DOE Order 5400.1, IV.9; DOE/EH-0173T, 5.10.1.3; 40 CFR Parts 264 and 265, Subpart F
Groundwater

The on-site WVDP groundwater monitoring program provides for the determination of water quality, focusing on radiological and chemical surveillance of both active and inactive super solid waste management units (SSWMUs). In addition, using wells situated hydraulically upgradient (background) and downgradient of SSWMUs allows both detection of groundwater contamination and evaluation of the effects associated with the individual SSWMUs. Groundwater protection was addressed in the Groundwater Protection Management Program Plan, WVDP-091. Groundwater monitoring was detailed in the Groundwater Monitoring Plan, WVDP-239.
\end{abstract}

SSWMU \#1 Low-level waste treatment facilities, including four active lagoons - lagoons 2, 3, 4, and 5 - and an inactive, filledin lagoon - lagoon 1.

SSWMU \#2 Miscellaneous small units, including the sludge pond, the solvent dike, the paper incinerator, the equalization basin, and the kerosene tank.

SSWMU \#3 Liquid waste treatment system containing effluent from the supernatant treatment system.

Sampling locations are shown on Figures A-6 and A-7 (pp. A-8 and A-9).

B - 22 
2001 Monitoring Program

Environmental Surveillance

On-Site Groundwater

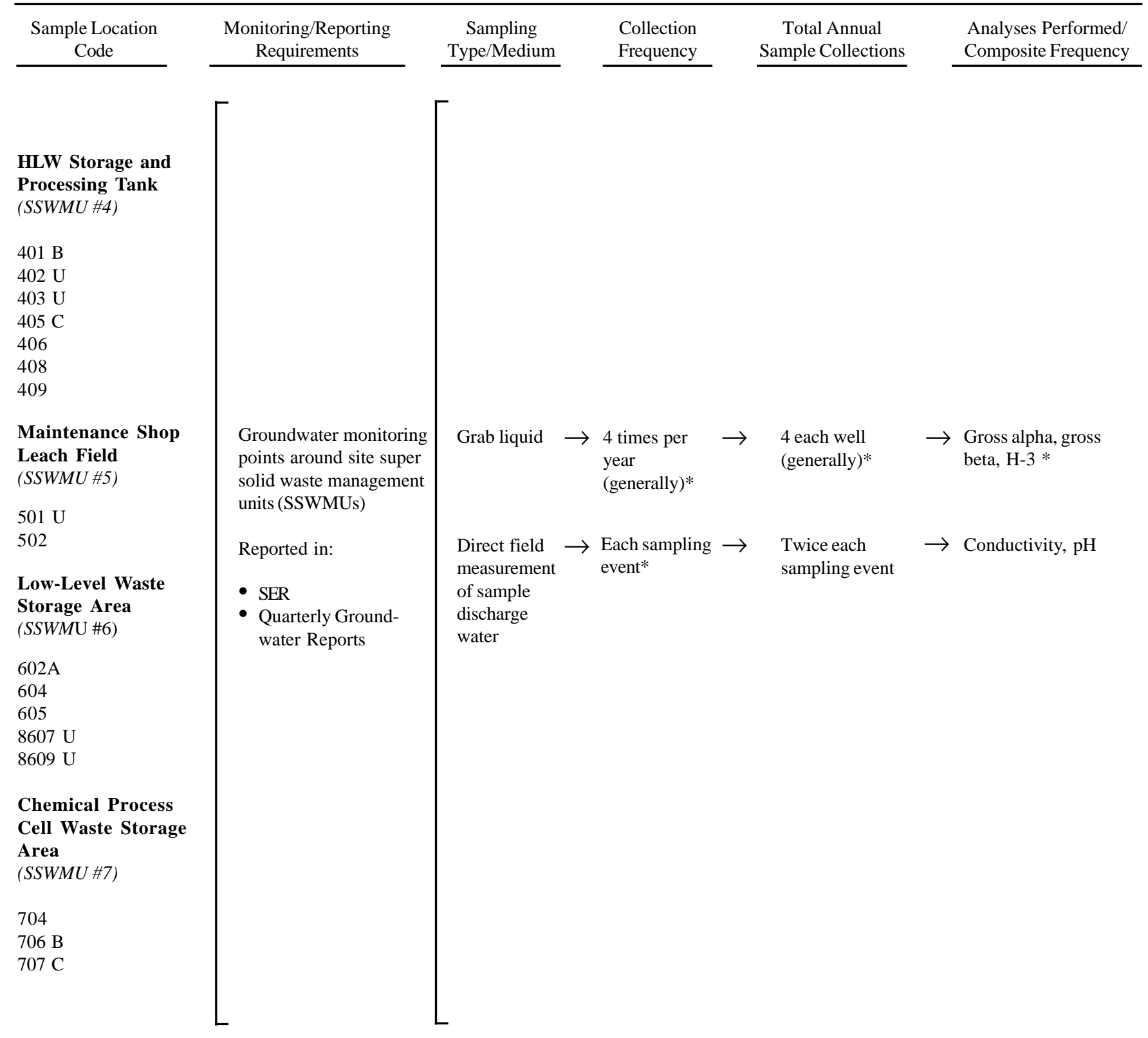

NOTE: "U" designates upgradient, "B" designates background, and "C" designates crossgradient wells. The remainder are downgradient.

* Sampling frequency and analytes vary from point to point. See Table 3-1 (p. 3-6) for a summary listing of all monitored analytes. See Table E-1 (Appendix E [p. E-3]) for a listing of analytes monitored at each location. See Appendix E for results from each location.

$$
\text { B }-23
$$




\title{
Sampling Rationale
}

\author{
On-Site \\ DOE Order 5400.1, IV.9; DOE/EH-0173T, 5.10.1.3; 40 CFR Parts 264 and 265, Subpart F \\ Groundwater \\ The on-site WVDP groundwater monitoring program provides for the determination of water quality, focusing on \\ radiological and chemical surveillance of both active and inactive super solid waste management units (SSWMUs). In \\ addition, using wells situated hydraulically upgradient (background) and downgradient of SSWMUs allows both detection \\ of groundwater contamination and evaluation of the effects associated with the individual SSWMUs. Groundwater \\ protection was addressed in the Groundwater Protection Management Program Plan, WVDP-091. Groundwater \\ monitoring was detailed in the Groundwater Monitoring Plan, WVDP-239. \\ SSWMU \#4 High-level waste storage and processing area, including the high-level radioactive waste tanks, the supernatant \\ treatment system, and the vitrification facility. \\ SSWMU \#5 Maintenance shop sanitary leach field, formerly used by NFS and the WVDP to process domestic sewage generated by \\ the maintenance shop. \\ SSWMU \#6 Low-level waste storage area; includes metal and fabric structures housing low-level radioactive waste being stored for \\ future disposal. \\ SSWMU \#7 Chemical process cell (CPC) waste storage area, which contains packages of pipes, vessels, and debris from \\ decontamination and cleanup of the chemical process cell in the former reprocessing plant.
}

Sampling locations are shown on Figures A-6 and A-7 (pp. A-8 and A-9).

\section{B - 24}


2001 Monitoring Program

Environmental Surveillance

On-Site Groundwater

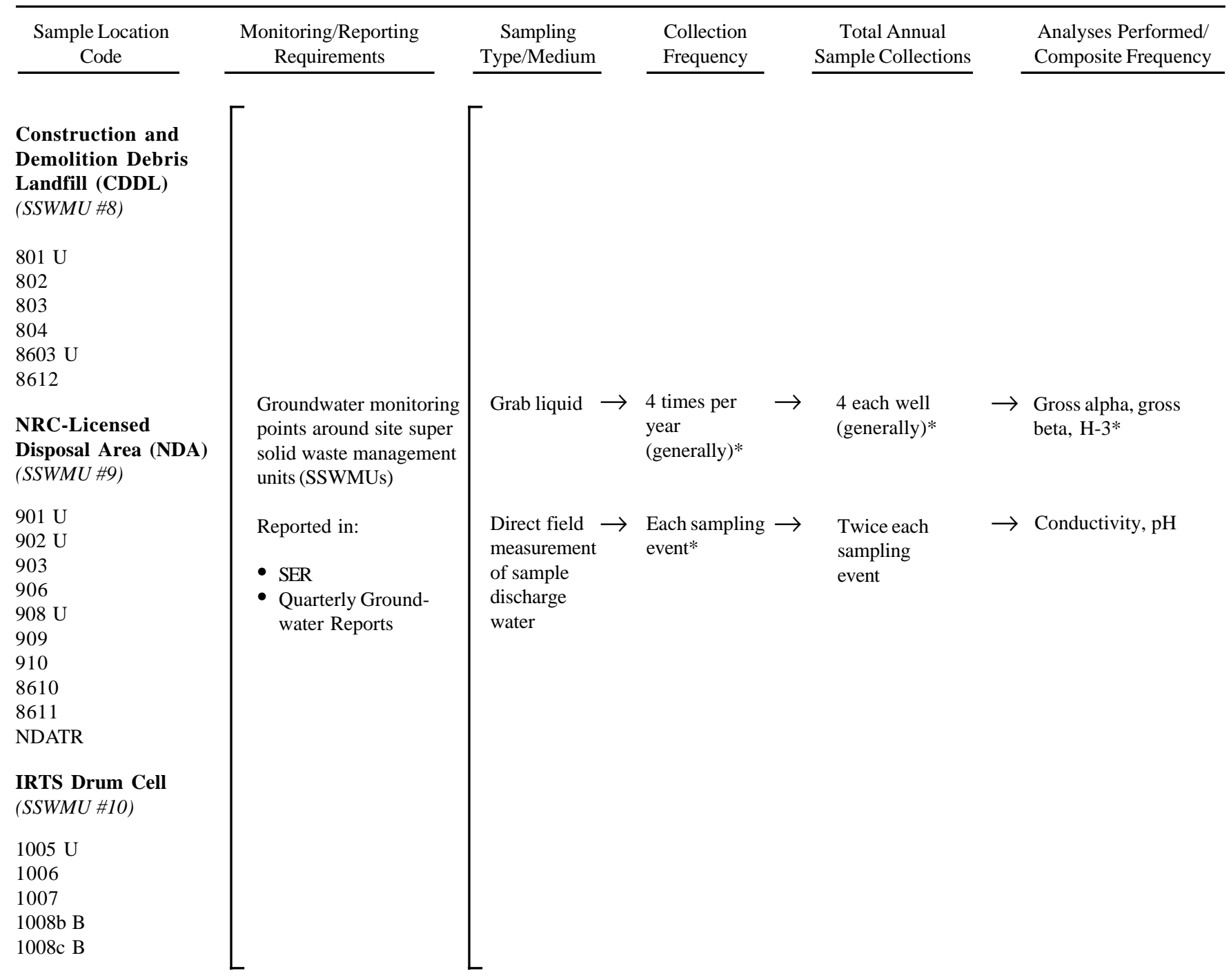

NOTE: "U" designates upgradient, "B" designates background, and "C" designates crossgradient wells. The remainder are downgradient.

* Sampling frequency and analytes vary from point to point. See Table 3-1 (p. 3-6) for a summary listing of all monitored analytes. See Table E-1 (Appendix E [p. E-3]) for a listing of analytes monitored at each location. See Appendix E for results from each location.

$$
B-25
$$




\title{
Sampling Rationale
}

\begin{abstract}
On-Site DOE Order 5400.1, IV.9; DOE/EH-0173T, 5.10.1.3; 40 CFR Parts 264 and 265, Subpart F
Groundwater

The on-site WVDP groundwater monitoring program provides for the determination of water quality, focusing on radiological and chemical surveillance of both active and inactive super solid waste management units (SSWMUs). In addition, using wells situated hydraulically upgradient (background) and downgradient of SSWMUs allows both detection of groundwater contamination and evaluation of the effects associated with the individual SSWMUs. Groundwater protection was addressed in the Groundwater Protection Management Program Plan, WVDP-091. Groundwater monitoring was detailed in the Groundwater Monitoring Plan, WVDP-239.

SSWMU \#8 The construction and demolition debris landfill (CDDL); used by NFS and the WVDP to dispose of nonhazardous and nonradioactive materials.

SSWMU \#9 The NRC-licensed disposal area (NDA); contains radioactive wastes generated by NFS and the WVDP. The NDA is bounded on its downgradient (northwest and northeast) perimeters by the interceptor trench, which is sampled at monitoring point NDATR.
\end{abstract}

SSWMU \#10 The integrated radioactive waste system (IRTS) treatment drum cell; stores cement-stablized low-level radioactive waste.

Sampling locations are shown on Figures A-6 through A-8 (pp. A-8 through A-10).

B - 26 
2001 Monitoring Program

Environmental Surveillance

\section{On-Site Groundwater and Seeps}

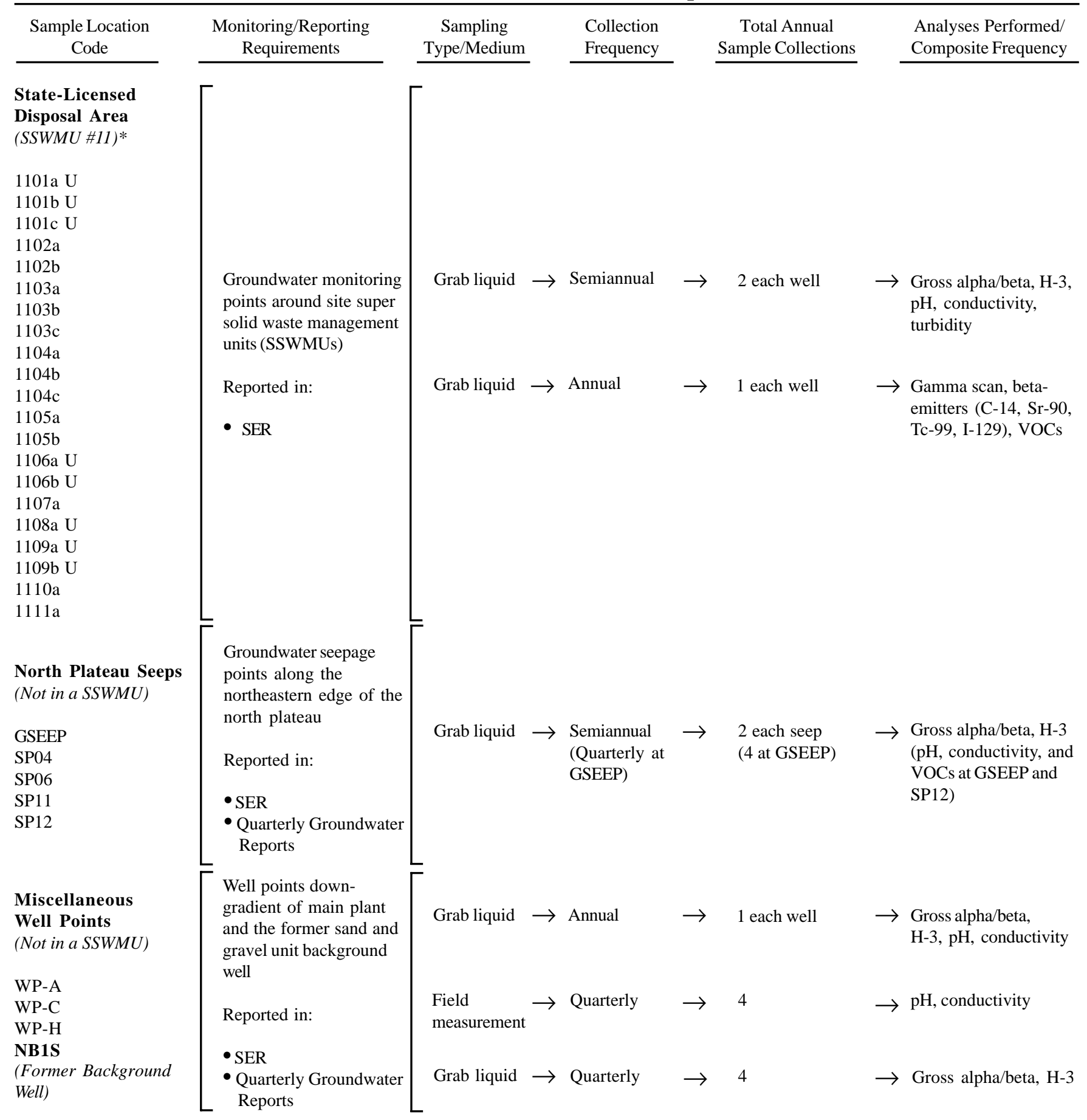

NOTE: "U" designates upgradient, "B" designates background, and "C" designates crossgradient wells. The remainder are downgradient.

* SSWMU \#11 is sampled by NYSERDA under a separate program.

$$
\text { B - } 27
$$




\title{
Sampling Rationale
}

\begin{abstract}
On-Site $\quad$ DOE Order 5400.1, IV.9; DOE/EH-0173T, 5.10.1.3; 40 CFR Parts 264 and 265, Subpart F
Groundwater

The on-site WVDP groundwater monitoring program provides for the determination of water quality, focusing on radiological and chemical surveillance of both active and inactive super solid waste management units (SSWMUs). In addition, using wells situated hydraulically upgradient (background) and downgradient of SSWMUs allows both detection of groundwater contamination and evaluation of the effects associated with the individual SSWMUs. Groundwater protection was addressed in the Groundwater Protection Management Program Plan, WVDP-091. Groundwater monitoring was detailed in the Groundwater Monitoring Plan, WVDP-239.
\end{abstract}

SSWMU \#11 The New York State-licensed disposal area (SDA) was operated by NFS as a commercial low-level disposal facility; it also received wastes from NFS reprocessing operations.

North Plateau Monitor groundwater emanating from the ground surface along the edge of the site's north plateau.

Seeps

Well Points Monitor groundwater of known subsurface contamination in the north plateau area. All well points are downgradient of the main plant.

WNWNB1S Former background well on the north plateau.

Sampling locations are shown on Figures A-6, A-7, and A-8 (pp. A-8, A-9, and A-10).

$$
B-28
$$


2001 Monitoring Program

Environmental Surveillance

Off-Site Surface Water

\begin{tabular}{|c|c|c|c|c|c|c|c|c|}
\hline $\begin{array}{l}\text { Sample Location } \\
\text { Code }\end{array}$ & $\begin{array}{l}\text { Monitoring/Reporting } \\
\text { Requirements }\end{array}$ & $\begin{array}{c}\text { Sampling } \\
\text { Type/Medium }\end{array}$ & & $\begin{array}{l}\text { Collection } \\
\text { Frequency }\end{array}$ & & $\begin{array}{c}\text { Total Annual } \\
\text { Sample Collections }\end{array}$ & & $\begin{array}{l}\text { Analyses Performed/ } \\
\text { Composite Frequency }\end{array}$ \\
\hline $\begin{array}{l}\text { WFBCTCB* } \\
\text { Buttermilk Creek } \\
\text { Upstream of } \\
\text { Confluence With } \\
\text { Cattaraugus Creek at } \\
\text { Thomas Corners Road }\end{array}$ & $\begin{array}{l}\text { Restricted surface waters } \\
\text { receiving plant effluents } \\
\text { Reported in: } \\
\text { - MTAR } \\
\text { - SER }\end{array}$ & $\begin{array}{l}\text { Timed } \\
\text { continuous } \\
\text { composite } \\
\text { liquid }\end{array}$ & $\rightarrow$ & Weekly & $\rightarrow$ & $\begin{array}{l}52 \\
\text { Weekly samples } \\
\text { composited to } 12 \\
\text { Weekly samples } \\
\text { composited to } 4\end{array}$ & $\begin{array}{l}\rightarrow \\
\rightarrow\end{array}$ & $\begin{array}{l}\mathrm{pH} \text {, conductivity } \\
\text { Monthly composite for } \\
\text { gross alpha/beta, } \mathrm{H}-3 \\
\text { Quarterly composite } \\
\text { for gamma isotopic } \\
\text { and } \mathrm{Sr}-90\end{array}$ \\
\hline $\begin{array}{l}\text { WFFELBR* } \\
\text { Cattaraugus Creek at } \\
\text { Felton Bridge }\end{array}$ & $\begin{array}{l}\text { Unrestricted surface } \\
\text { waters receiving plant } \\
\text { effluents } \\
\text { Reported in: } \\
\text { - MTAR } \\
\text { - SER }\end{array}$ & $\begin{array}{l}\text { Timed } \\
\text { continuous } \\
\text { composite } \\
\text { liquid }\end{array}$ & $\rightarrow$ & Weekly & $\rightarrow$ & $\begin{array}{l}52 \\
\text { Weekly samples } \\
\text { composited to } 12\end{array}$ & $\rightarrow$ & $\begin{array}{l}\text { Gross alpha/beta, H-3, } \\
\text { pH } \\
\text { Flow-weighted } \\
\text { monthly composite } \\
\text { for gamma isotopic, } \\
\text { H-3, Sr-90, and gross } \\
\text { alpha/beta }\end{array}$ \\
\hline $\begin{array}{l}\text { WFBCBKG* } \\
\text { Buttermilk Creek Near } \\
\text { Fox Valley } \\
\text { (Background) }\end{array}$ & $\begin{array}{l}\text { Unrestricted surface } \\
\text { water, background } \\
\text { Reported in: } \\
\text { - MTAR } \\
\text { - SER } \\
\text { - Reported to } \\
\text { NYSERDA }\end{array}$ & $\begin{array}{l}\text { Timed } \\
\text { continuous } \\
\text { composite } \\
\text { liquid }\end{array}$ & $\rightarrow$ & Semiannual & $\rightarrow$ & $\begin{array}{l}52 \\
\text { Weekly samples } \\
\text { composited to } 12 \\
\text { Weekly samples } \\
\text { composited to } 4\end{array}$ & $\rightarrow$ & 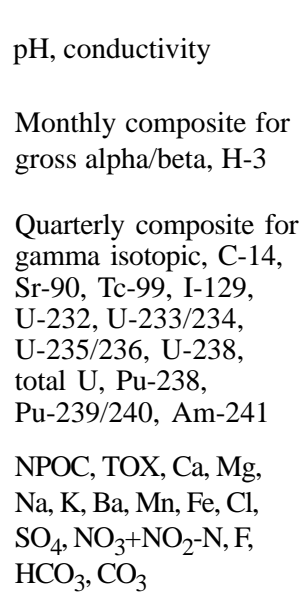 \\
\hline $\begin{array}{l}\text { WFBIGBR } \\
\text { Cattaraugus Creek at } \\
\text { Bigelow Bridge } \\
\text { (Background) }\end{array}$ & $\begin{array}{l}\text { Unrestricted surface } \\
\text { water, background } \\
\text { Reported in: } \\
\text { - MTAR } \\
\text { - SER }\end{array}$ & Grab liquid & $\rightarrow$ & Monthly & $\rightarrow$ & 12 & $\rightarrow$ & $\begin{array}{l}\text { Gross alpha/beta, } \mathrm{H}-3 \text {, } \\
\text { Sr-90, gamma isotopic }\end{array}$ \\
\hline
\end{tabular}

* Monthly composites are also sent to NYSDOH.

B - 29

WVDP Site Environmental Report

Calendar Year 2001 


\section{Sampling Rationale}

WFBCTCB DOE/EH-0173T, 5.10.1.1

Buttermilk Creek is the surface water that receives all WVDP effluents. WFBCTCB monitors the potential influence of WVDP drainage into Buttermilk Creek upstream of Buttermilk Creek's confluence with Cattaraugus Creek.

WFFELBR DOE/EH-0173T, 5.10.1.1

Because Buttermilk Creek empties into Cattaraugus Creek, WFFELBR monitors the potential influence of WVDP drainage into Cattaraugus Creek directly downstream of the Cattaraugus Creek confluence with Buttermilk Creek.

WFBCBKG DOE/EH-0173T, 5.10.1.1

Monitors background conditions of Buttermilk Creek upstream of the WVDP; allows comparison to downstream conditions.

WFBIGBR $\quad$ DOE/EH-0173T, 5.10.1.1

Monitors background conditions of Cattaraugus Creek at Bigelow Bridge, upstream of the WVDP; allows comparison to downstream conditions.

Sampling locations are shown on Figure A-3 (p. A-5). 
2001 Monitoring Program

Environmental Surveillance

Off-Site Drinking Water

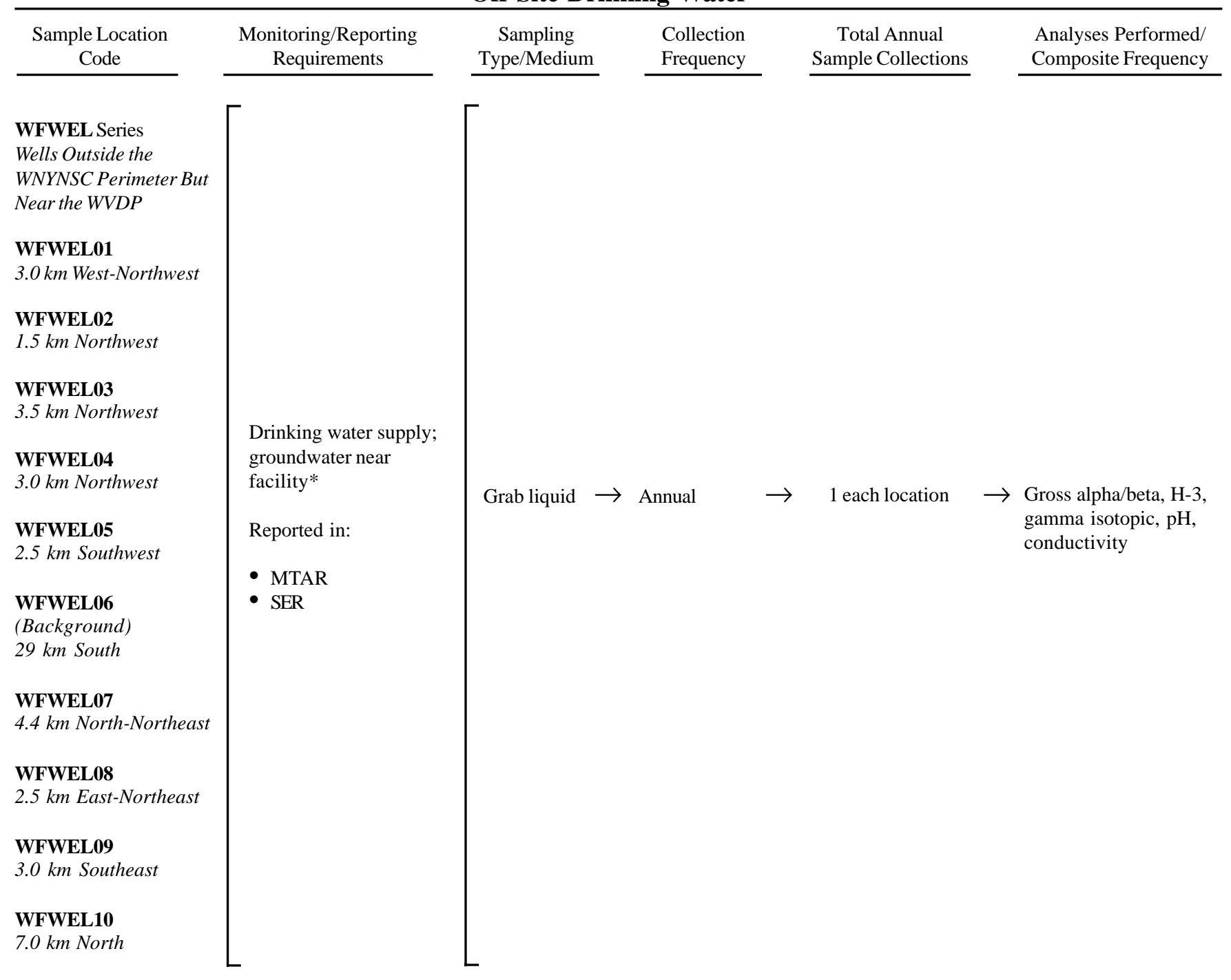

* No drinking water wells are located in hydrogeological units affected by site activity.

$$
B-31
$$




\section{Sampling Rationale}

Off-Site DOE 5400.1, IV.9; DOE/EH-0173T, 5.10.1.2

Drinking Water

WFWEL Series

Eight of the ten listed off-site private residential drinking water wells represent the nearest unrestricted uses of groundwater close to the WVDP. The ninth sample (WFWEL10) is taken from a public water supply from deep wells. The tenth drinking water well, WFWEL06, is located 29 kilometers south of the Project and is considered a background drinking water source.

Sampling locations are shown on Figures A-9, A-12, and A-13 (pp. A-11, A-14, and A-15).

$$
B-32
$$




\section{Monitoring Program}

\section{Environmental Surveillance}

\section{Off-Site Air}

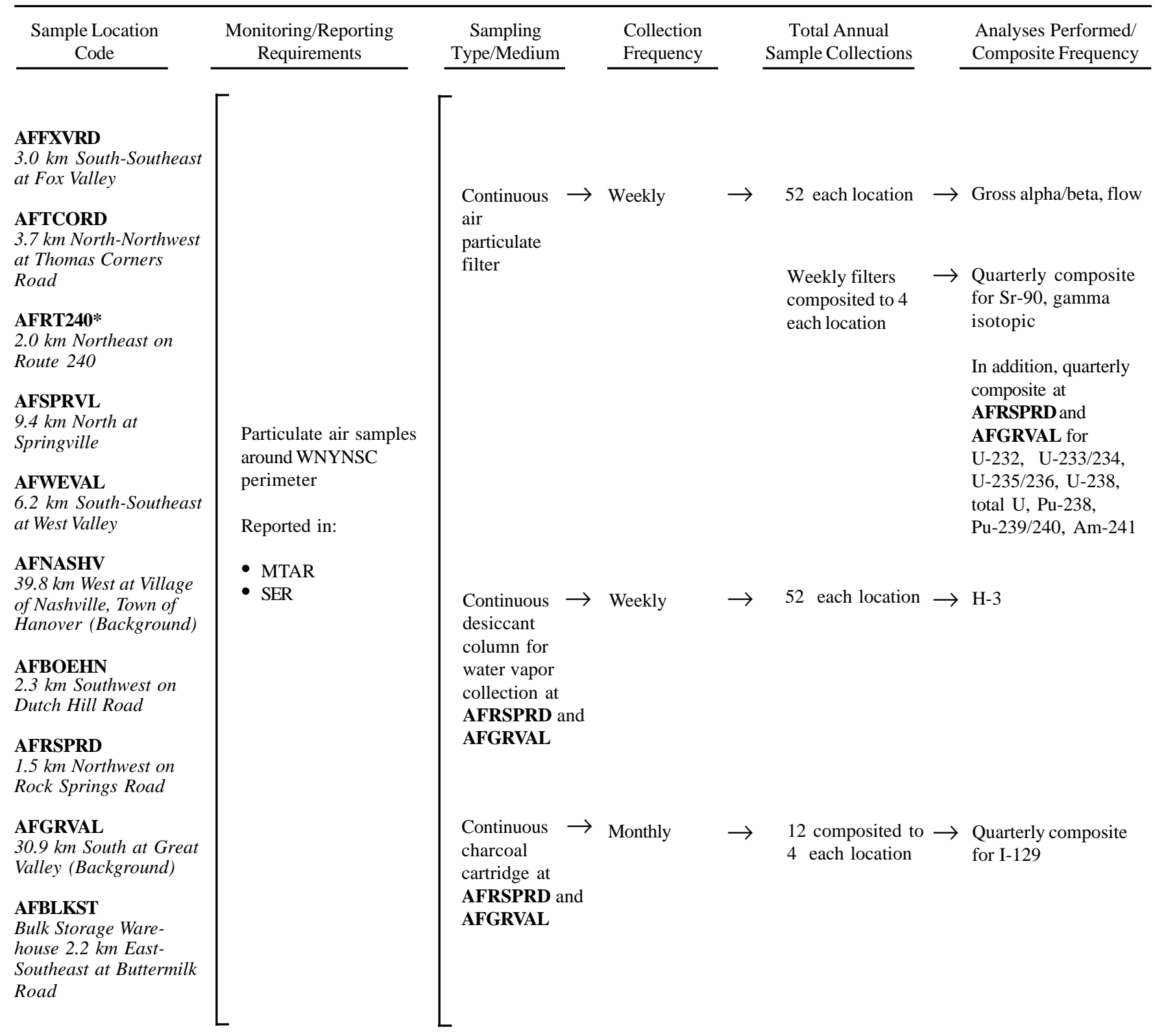

* Filter from duplicate sampler sent to NYSDOH.

$$
\text { B - } 33
$$




\title{
Sampling Rationale
}

\begin{abstract}
AFFXVRD DOE/EH-0173T, 5.7.4
AFTCORD

AFRT240

Air samplers put into service by NFS as part of the site's original monitoring program at perimeter locations chosen to obtain data from places most likely to provide highest concentrations. Choice of location based on meteorological data.
\end{abstract}

AFSPRVL DOE/EH-0173T, 5.7.4; DOE/EP-0023, 4.2.3

Off-site (remote) sampler located on private property in a nearby community within 15 kilometers of the site (north).

AFWEVAL DOE/EH-0173T, 5.7.4; DOE/EP-0023, 4.2.3

Off-site (remote) sampler located in a nearby community within 15 kilometers of the site (southeast).

AFNASHV DOE/EH-0173T, 5.7.4; DOE/EP-0023, 4.2.3

Off-site (remote) sampler considered representative of natural background radiation. Located 39.8 kilometers west of the site (upwind) on privately owned property.

AFBOEHN DOE/EH-0173T, 5.7.4; DOE/EP-0023, 4.2.3

Perimeter location chosen to obtain data from the place most likely to provide the highest elevated release concentrations. AFBOEHN is located on NYSERDA property at the perimeter. Choice of location based on meteorological data.

AFRSPRD DOE/EH-0173T, 5.7.4

Perimeter location chosen to obtain data from the place most likely to provide the highest ground-level release concentrations. AFRSPRD is on WNYNSC property outside the main plant operations fenceline. H-3 and I-129 are sampled here because the sampling trains were easy to incorporate and the location was most likely to receive effluent releases. Choice of location based on meteorological data.

AFGRVAL DOE/EH-0173T, 5.7.4; DOE/EP-0023, 4.2 .3

Off-site (remote) sampler considered representative of natural background radiation. Located on privately owned property 30.9 kilometers south of the site (typically upwind). H-3 and I-129 sampled here also.

AFBLKST

DOE/EH-0173T, 5.7.4

Off-site monitoring of bulk storage warehouse, near the site perimeter.

Sampling locations are shown on Figures A-5, A-12, and A-13 (pp. A-7, A-14, and A-15).

WVDP Site Environmental Report

$$
B-34
$$

Calendar Year 2001 
2001 Monitoring Program

Environmental Surveillance

Fallout, Sediment, and Soil

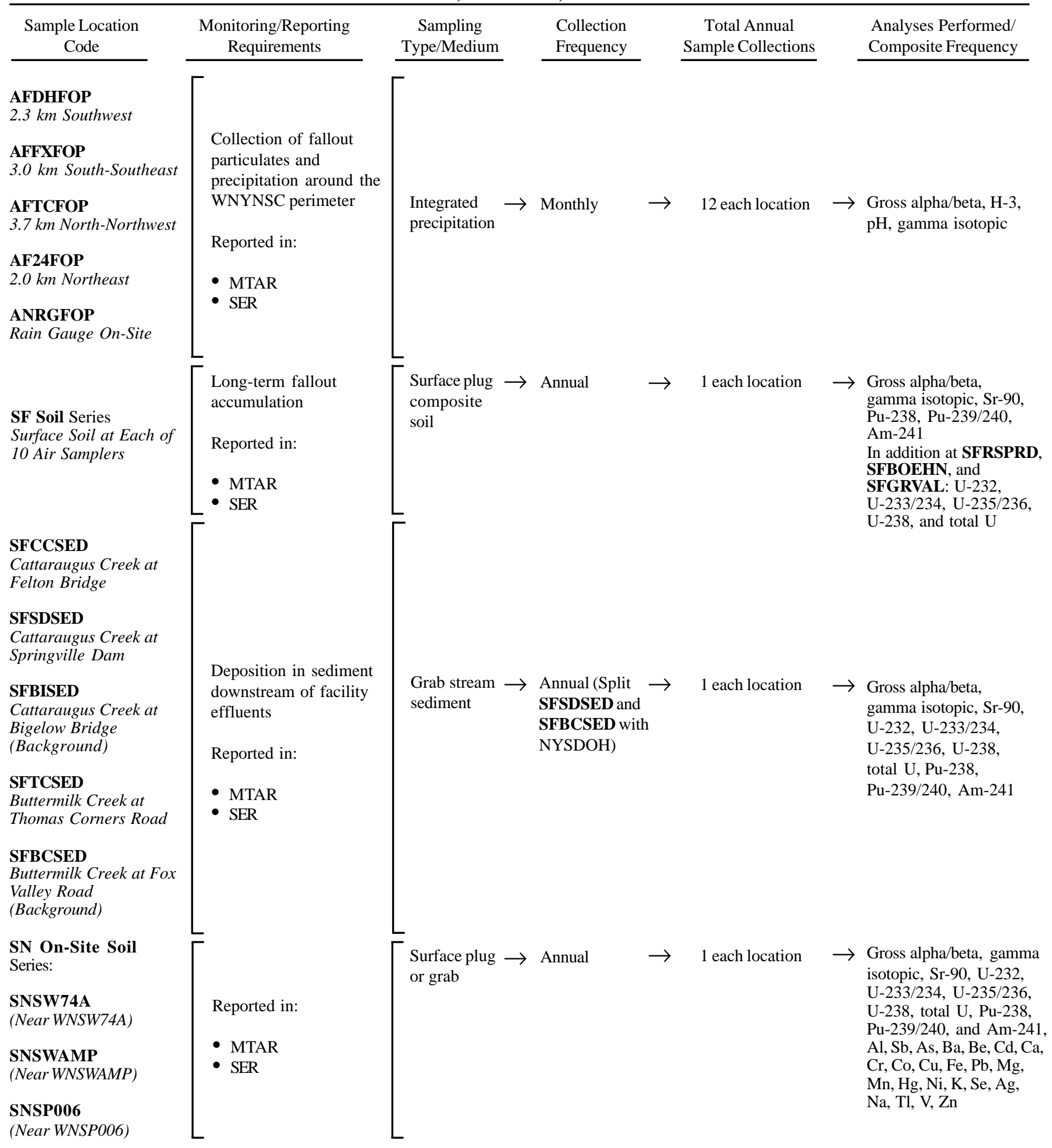

$$
\text { B - } 35
$$




\begin{abstract}
AFDHFOP DOE/EP-0023, 4.7
AFFXFOP

AFTCFOP

AF24FOP

Collection of fallout particles and precipitation around the site perimeter at established air sampling locations: AFDHFOP (Dutch Hill at Boehn Road), AFFXFOP (Fox Valley Road), AFTCFOP (Thomas Corners), AF24FOP (Route 240). Indicates short-term effects.
\end{abstract}

ANRGFOP Fallout particles and precipitation collected on-site by the Environmental Laboratory at the rain gauge. Indicates short-term effects.

SF Soil Series $\quad$ DOE/EH-0173T, 5.9.1

Off-site soils collected at air sampling locations. SFWEVAL (West Valley), SFFXVRD (Fox Valley Road), SFSPRVL (Springville), SFTCORD (Thomas Corners), SFRT240 (Route 240), SFNASHV (Nashville), SFBOEHN (Boehn Road-Dutch Hill), SFGRVAL (Great Valley), SFRSPRD (Rock Springs Road), SFBLKST (bulk storage warehouse): Collection of long-term fallout data at established air sampler locations via soil sampling.

SFCCSED $\quad$ DOE/EH-0173T, 5.12.1

Sediment deposition at Cattaraugus Creek at Felton Bridge. Location is first point of public access to Cattaraugus Creek downstream of its confluence with Buttermilk Creek.

SFSDSED

DOE/EH-0173T, 5.12.1

Sediment deposition in Cattaraugus Creek at Springville Dam. Reservoir provides ideal settling and collection location for sediments downstream of Buttermilk Creek confluence with Cattaraugus Creek. Located downstream of SFCCSED.

SFBISED $\quad$ DOE/EH-0173T, 5.12 .1

Sediment deposition in Cattaraugus Creek at Bigelow Bridge. Location is upstream of the Buttermilk Creek confluence and serves as the Cattaraugus Creek background location.

SFTCSED

DOE/EH-0173T, 5.12.1

Sediment deposition in Thomas Corners in Buttermilk Creek immediately downstream of all facility liquid effluents.

SFBCSED $\quad$ DOE/EH-0173T, 5.12.1

Sediment deposition in Buttermilk Creek upsteam of facility effluents (background).

SN Soil Series

DOE/EH-0173T, 5.9.1.

On-site soil. (Samples may be partially composed of sediments.) SNSW74A (surface soil near WNSW74A), SNSWAMP (surface soil near WNSWAMP), and SNSP006 (surface soil near WNSP006): Locations to be specifically defined by geographic coordinates. Correspond to site drainage pattern flows (i.e., most likely area of radiological deposition/accumulation).

Sampling locations are shown on Figures A-2 through A-5, A-12, and A-13 (pp. A-4 through A-7, A-14, and A-15).

WVDP Site Environmental Report

$$
\text { B }-36
$$

Calendar Year 2001 


\section{Monitoring Program \\ Environmental Surveillance}

\section{Off-Site Biological}

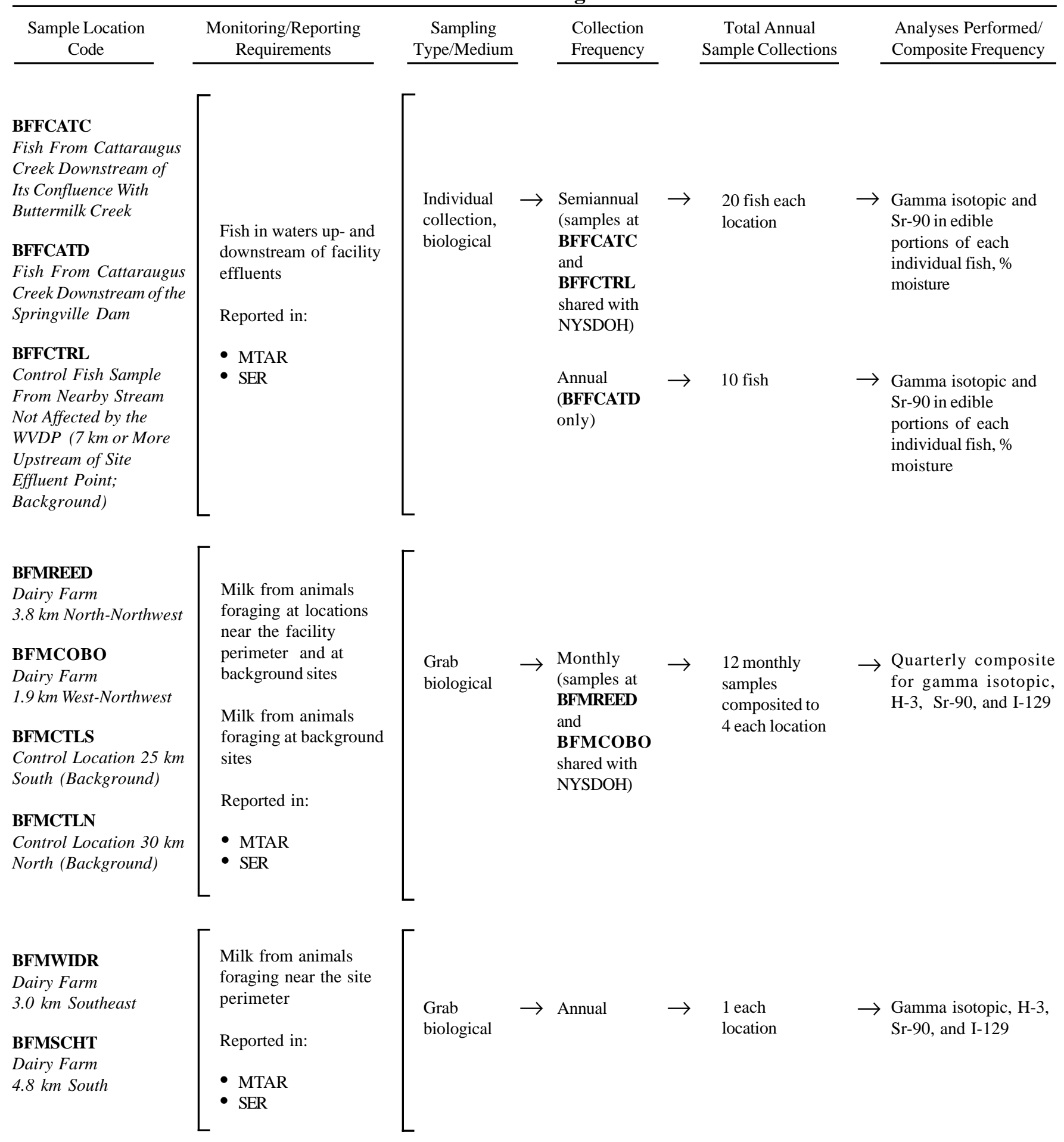

$$
\text { B }-37
$$




\title{
Sampling Rationale
}

\author{
BFFCATC DOE/EH-0173T, 5.11.1.1 \\ BFTCATD \\ Radioactivity may enter a food chain in which fish are a major component and are consumed by the local \\ population.
}

BFFCTRL Control fish sample; provide background data for comparison with data from fish caught downstream of facility effluents.

BFMREED

BFMCOBO

DOE/EH-0173T, 5.8.2.1

Milk is consumed by all age groups and is frequently the most important food that could contribute to the radiation dose. Dairy animals pastured near the site and at two background locations allow adequate monitoring. Control milk samples are collected far from the site to provide background data for comparison with data from near-site milk samples.

BFMWIDR

Milk from animals foraging around facility perimeter.

BFMSCHT

Sampling locations are shown on Figures A-9, A-12, and A-13 (pp. A-11, A-14, and A-15). 


\section{Monitoring Program \\ Environmental Surveillance}

Off-Site Biological

\begin{tabular}{|c|c|c|c|c|c|c|c|c|}
\hline $\begin{array}{l}\text { Sample Location } \\
\text { Code }\end{array}$ & $\begin{array}{l}\text { Monitoring/Reporting } \\
\text { Requirements }\end{array}$ & $\begin{array}{c}\text { Sampling } \\
\text { Type/Medium }\end{array}$ & & $\begin{array}{l}\text { Collection } \\
\text { Frequency }\end{array}$ & & $\begin{array}{c}\text { Total Annual } \\
\text { Sample Collections }\end{array}$ & & $\begin{array}{l}\text { Analyses Performed/ } \\
\text { Composite Frequency }\end{array}$ \\
\hline $\begin{array}{l}\text { BFVNEAR* } \\
\text { Nearby Locations } \\
\text { BFVCTRL* } \\
\text { Remote Locations (16 } \\
\text { km or More From } \\
\text { Facility; Background) }\end{array}$ & $\begin{array}{l}\text { Fruit and vegetables } \\
\text { grown near facility } \\
\text { perimeter, downwind if } \\
\text { possible, and at back- } \\
\text { ground locations } \\
\text { Reported in: } \\
\text { - MTAR } \\
\text { - SER }\end{array}$ & $\begin{array}{l}\text { Grab } \\
\text { biological } \\
\text { (fruits and } \\
\text { vegetables) }\end{array}$ & $\rightarrow$ & $\begin{array}{l}\text { Annual } \\
\text { (at harvest) }\end{array}$ & $\rightarrow$ & $\begin{array}{l}3 \text { each (split with } \\
\text { NYSDOH) }\end{array}$ & $\rightarrow$ & $\begin{array}{l}\text { Gamma isotopic and } \\
\text { Sr-90 analysis of } \\
\text { edible portions, H-3 in } \\
\text { free moisture, \% } \\
\text { moisture }\end{array}$ \\
\hline $\begin{array}{l}\text { BFHNEAR } \\
\text { Forage for Beef Cattle/ } \\
\text { Milk Cows From Near- } \\
\text { Site Location } \\
\text { BFHCTLS or } \\
\text { BFHCTLN } \\
\text { Forage for Beef Cattle/ } \\
\text { Milk Cows From Control } \\
\text { Location South or North } \\
\text { (Background) }\end{array}$ & $\begin{array}{l}\text { Forage (hay) grown } \\
\text { near facility perimeter, } \\
\text { downwind if possible, } \\
\text { and at background } \\
\text { locations } \\
\text { Reported in: } \\
\text { - MTAR } \\
\text { - SER }\end{array}$ & $\begin{array}{l}\text { Grab } \\
\text { biological }\end{array}$ & $\rightarrow$ & Annual & $\rightarrow$ & 1 each location & $\rightarrow$ & Gamma isotopic, $\mathrm{Sr}-90$ \\
\hline $\begin{array}{l}\text { BFBNEAR } \\
\text { Beef Animal From } \\
\text { Nearby Farm in } \\
\text { Downwind Direction } \\
\text { BFBCTRL } \\
\text { Beef Animal From } \\
\text { Control Location } 16 \mathrm{~km} \\
\text { or More From Facility } \\
\text { (Background) }\end{array}$ & $\begin{array}{l}\text { Meat (beef foraging } \\
\text { near facility perim- } \\
\text { eter, downwind if } \\
\text { possible, and a } \\
\text { background location) } \\
\text { Reported in: } \\
\text { - MTAR } \\
\text { - SER }\end{array}$ & $\begin{array}{l}\text { Grab } \\
\text { biological }\end{array}$ & $\rightarrow$ & Semiannual & $\rightarrow$ & 2 each location & $\rightarrow$ & $\begin{array}{l}\text { Gamma isotopic and } \\
\text { Sr- } 90 \text { analysis of } \\
\text { meat, } \mathrm{H}-3 \text { in free } \\
\text { moisture, } \% \text { moisture }\end{array}$ \\
\hline $\begin{array}{l}\text { BFDNEAR } \\
\text { Deer in Vicinity of the } \\
\text { Site }\end{array}$ & $\begin{array}{l}\text { Venison (deer foraging } \\
\text { near facility perimeter } \\
\text { and at background } \\
\text { locations) }\end{array}$ & $\begin{array}{l}\text { Individual } \\
\text { collection, } \\
\text { biological }\end{array}$ & $\rightarrow$ & $\begin{array}{l}\text { Annual, during } \\
\text { hunting season } \\
\text { (BFDNEAR } \\
\text { sample split } \\
\text { with NYSDOH) }\end{array}$ & $\rightarrow$ & 3 & $\rightarrow$ & $\begin{array}{l}\text { Gamma isotopic and } \\
\text { Sr-90 analysis of } \\
\text { meat, H-3 in free } \\
\text { moisture, \% moisture }\end{array}$ \\
\hline $\begin{array}{l}\text { BFDCTRL } \\
\text { Control Deer } 16 \mathrm{~km} \text { or } \\
\text { More From the Facility } \\
\text { (Background) }\end{array}$ & $\begin{array}{l}\text { Reported in: } \\
\text { - } \text { MTAR } \\
\text { - SER }\end{array}$ & & & $\begin{array}{l}\text { During year as } \\
\text { available } \\
\text { (BFDCTRL } \\
\text { sample split } \\
\text { with NYSDOH) }\end{array}$ & $\rightarrow$ & 3 & & \\
\hline
\end{tabular}

* Near-site and control corn, apple, and bean samples are identified specifically as follows: corn = BFVNEAC and BFVCTRC; apples = BFVNEAAF and BFVCTRA; beans = BFVNEAB and BFVCTRB.

$$
B-39
$$




\section{Sampling Rationale}

BFVNEAR

BFHNEAR

BFHCTLS BFHCTLN

BFBNEAR

BFBCTRL

BFDNEAR

BFDCTRL
DOE/EH-0173T, 5.8.2.2

Fruits and vegetables (corn, apples, and beans or leafy vegetables, if available) collected from areas near the site. These samples are collected, if possible, from areas near the site predicted to have worst-case downwind concentrations of radionuclides in air and soil. Sample analysis reflects steady state/chronic uptake or contamination of foodstuffs as a result of site activities. Possible pathway directly to humans or indirectly through animals.

DOE/EH-0173T, 5.8.2.2

Fruits and vegetables collected from an area remote from the site. Background fruits and vegetables collected for comparison with near-site samples. Collected in area(s) of no possible site effects.

DOE/EH-0173T, 5.8.2.2

Hay collected from area near the site. Same as for near-site fruits and vegetables (BFVNEAR). Indirect pathway to humans through animals. Collected from same location as beef or milk sample.

DOE/EH-0173T, 5.8.2.2

Hay collected from areas remote from the site. Background hay collected for comparison with near-site samples. Collected in area(s) of no possible effects from the site.

DOE/EH-0173T, 5.8.2.3

Beef collected from animals raised near the site and foraging downwind of the site in areas of maximum probable effects. Following the rationale for vegetable matter collected near the site (BFVNEAR and BFHNEAR), edible flesh portion of beef animals is analyzed to determine possible radionuclide content passable directly to humans.

DOE/EH-0173T, 5.8.2.3

Beef collected from animals raised far from the site. Background beef collected for comparison with near-site samples. Collected in area(s) of no possible site effects.

DOE/EH-0173T, 5.8.3

Venison from near-site deer. Samples are taken from deer killed in collisions with vehicles. Sample rationale is similar to BFBNEAR.

DOE/EH-0173T, 5.8.3

Venison from deer living far from the site. Background deer meat collected for comparison with near-site samples. Collected in area(s) of no possible site effects.

Sampling locations are shown on Figures A-9, A-12, and A-13 (pp. A-11, A-14, and A-15). 
2001 Monitoring Program

Environmental Surveillance

Off-Site Direct Radiation

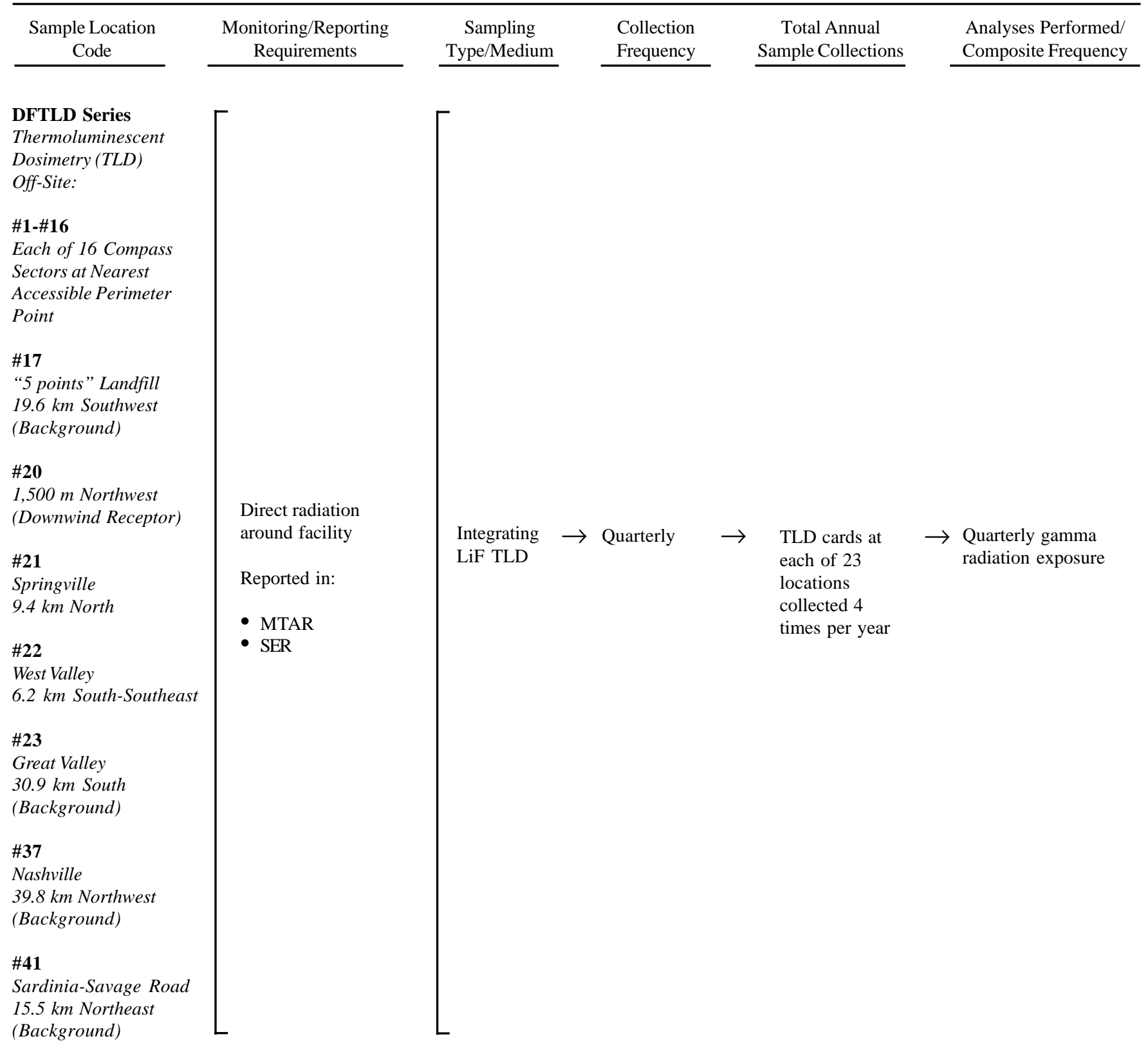

$B-41$ 


\section{Sampling Rationale}

Direct Radiation DOE/EH-0173T, 5.5; DOE/EP-0023, 4.6.3

Off-Site

TLDs offer continuous integrated environmental gamma-ray monitoring and have been deployed systematically about the site. Off-site TLDs are used to verify that site activities have not adversely affected the surrounding environs.

An annual high-pressure ion chamber (HPIC) gamma radiation measurement is completed at all locations in order to confirm TLD measurements.

Sampling locations are shown on Figures A-11 through A-13 (pp. A-13 through A-15).

$$
B-42
$$




\section{Monitoring Program}

\section{Environmental Surveillance}

On-Site Direct Radiation

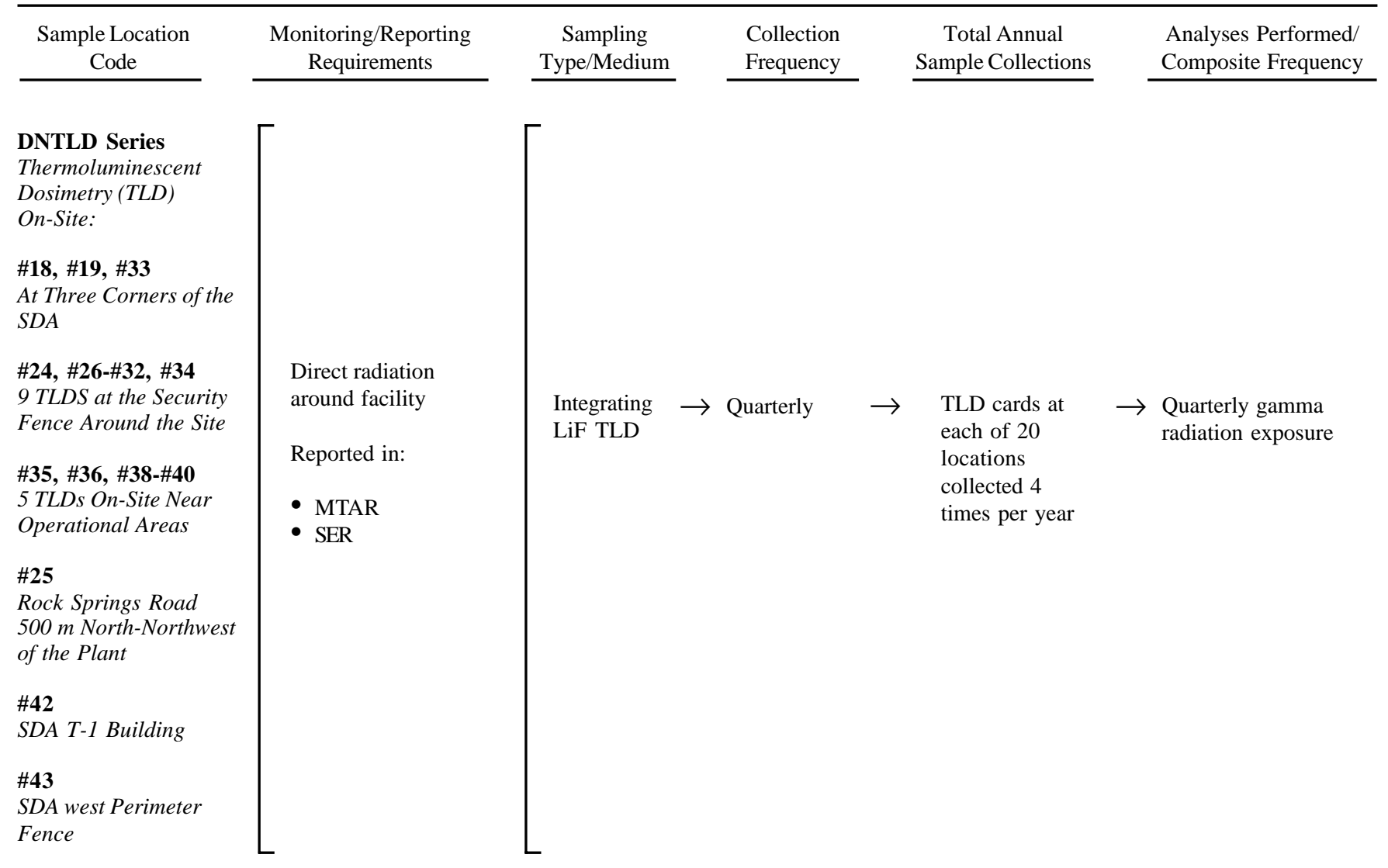

$B-43$ 


\section{Sampling Rationale}

\section{Direct Radiation DOE/EH-0173T, 5.4 and 5.5}

On-Site

On-site TLDs monitor waste management units and verify that the potential dose rate to the general public (i.e., at Rock Springs Road) is below 100 mrem/year ( $1 \mathrm{mSv} / \mathrm{year}$ ) from site activities.

An annual high-pressure ion chamber (HPIC) gamma radiation measurement is completed at all locations in order to confirm TLD measurements.

Potential TLD sampling locations are continually evaluated with respect to site activities.

Sampling locations are shown on Figure A-10 (p. A-12).

$B-44$ 
This page intentionally left blank

$$
B-45
$$




\section{Appendix $C$ \\ Summary of Water, Sediment, and Soil Monitoring Data}

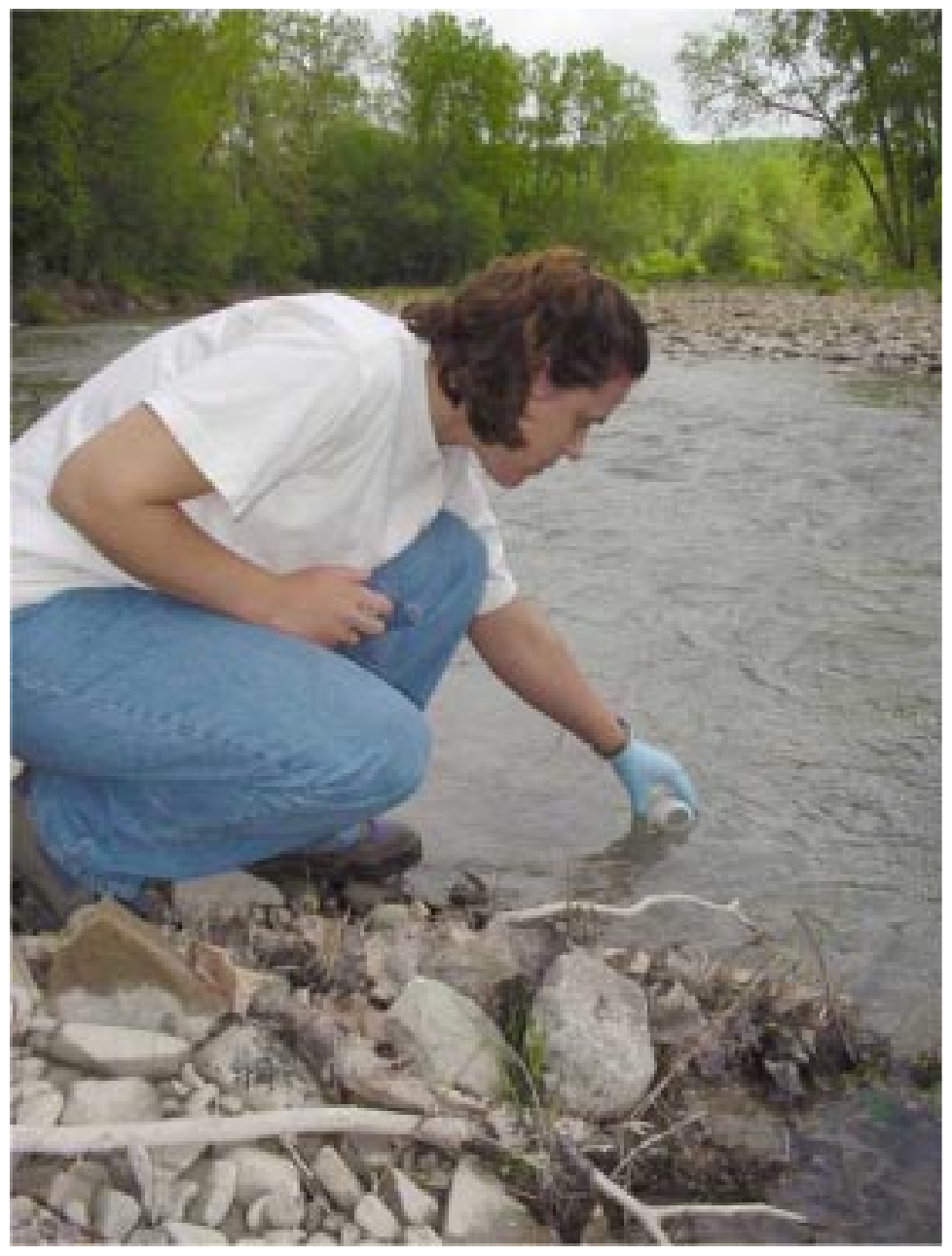

Collecting a Sample at a WVDP Stream Sampling Location

$$
C-1
$$


The following tables contain a bolding convention devised to help the reader, when viewing the data, to quickly see the range of detectable measurements within a data series. A data series is a set of chemical or radionuclide measurements (e.g., gross alpha, gross beta, tritium) from a single location or from similar locations. Note that some tables contain data that should not be technically evaluated under this convention.

\section{Key to bolding convention:}

Results for each constituent constitute a single data series. If a radiological result is larger than the uncertainty term, the measurement is considered positive. Otherwise, a result is considered non-detectable. Chemical results preceded by “less than" $(<)$ are considered nondetectable.

If all results in a data series are positive, the lowest and highest values are bolded.

If a data series contains some positive results, the highest value is bolded.

If all values in a data series are nondetectable, no values are bolded.

\section{$C-2$}




\section{Table C-1}

\section{Total Radioactivity (curies) of Liquid Effluents Released From Lagoon 3 (WNSP001) in 2001}

\begin{tabular}{|c|c|c|c|c|c|}
\hline Isotope & 1st Quarter & 2nd Quarter & 3rd Quarter & 4th Quarter & Annual Total \\
\hline Gross Alpha & $2.53 \pm 0.30 \mathrm{E}-04$ & $1.03 \pm 0.18 \mathrm{E}-04$ & $4.34 \pm 1.50 \mathrm{E}-05$ & $1.16 \pm 0.21 \mathrm{E}-04$ & $5.16 \pm 0.43 \mathrm{E}-04$ \\
\hline Gross Beta & $7.19 \pm 0.11 E-03$ & $1.33 \pm 0.05 E-03$ & $1.37 \pm 0.05 \mathrm{E}-03$ & $2.83 \pm 0.07 \mathrm{E}-03$ & $1.27 \pm 0.01 \mathrm{E}-02$ \\
\hline H-3 & $3.78 \pm 0.12 \mathrm{E}-02$ & $2.59 \pm 0.11 \mathrm{E}-02$ & $1.79 \pm 0.07 \mathrm{E}-02$ & $3.09 \pm 0.13 \mathrm{E}-02$ & $1.12 \pm 0.02 \mathrm{E}-01$ \\
\hline C-14 & $2.85 \pm 1.61 \mathrm{E}-04$ & $0.37 \pm 1.87 \mathrm{E}-04$ & $1.27 \pm 0.21 \mathrm{E}-04$ & $2.08 \pm 0.45 \mathrm{E}-04$ & $6.56 \pm 2.52 \mathrm{E}-04$ \\
\hline K-40 & $1.18 \pm 4.73 \mathrm{E}-04$ & $1.11 \pm 3.62 \mathrm{E}-04$ & $0.13 \pm 1.55 \mathrm{E}-04$ & $2.27 \pm 4.95 \mathrm{E}-04$ & $4.70 \pm 7.90 \mathrm{E}-04$ \\
\hline Co-60 & $1.14 \pm 3.30 \mathrm{E}-05$ & $-0.50 \pm 1.70 \mathrm{E}-05$ & $-0.25 \pm 1.53 \mathrm{E}-05$ & $0.34 \pm 1.95 \mathrm{E}-05$ & $0.72 \pm 4.46 \mathrm{E}-05$ \\
\hline Sr-90 & $2.79 \pm 0.10 \mathrm{E}-03$ & $4.64 \pm 0.39 \mathrm{E}-04$ & $5.33 \pm 0.27 \mathrm{E}-04$ & $1.24 \pm 0.06 \mathrm{E}-03$ & $5.02 \pm 0.13 \mathrm{E}-03$ \\
\hline Tc-99 & $2.79 \pm 0.54 \mathrm{E}-04$ & $1.23 \pm 0.22 E-04$ & $1.77 \pm 0.13 \mathrm{E}-04$ & $4.25 \pm 0.30 \mathrm{E}-04$ & $1.00 \pm 0.07 \mathrm{E}-03$ \\
\hline I-129 & $2.45 \pm 1.12 \mathrm{E}-05$ & $7.40 \pm 5.70 \mathrm{E}-06$ & $1.11 \pm 0.56 \mathrm{E}-05$ & $6.94 \pm 2.30 \mathrm{E}-05$ & $1.12 \pm 0.27 \mathrm{E}-04$ \\
\hline Cs-137 & $1.91 \pm 0.10 \mathrm{E}-03$ & $3.45 \pm 0.42 \mathrm{E}-04$ & $1.81 \pm 0.34 E-04$ & $2.97 \pm 0.41 \mathrm{E}-04$ & $2.73 \pm 0.12 \mathrm{E}-03$ \\
\hline U-232 & $1.65 \pm 0.17 E-04$ & $6.86 \pm 0.70 \mathrm{E}-05$ & 3.44 $\pm 0.35 E-05$ & $8.26 \pm 0.94 \mathrm{E}-05$ & $3.51 \pm 0.21 \mathrm{E}-04$ \\
\hline U-233/234 & $1.05 \pm 0.11 E-04$ & $4.14 \pm 0.43 \mathrm{E}-05$ & $1.95 \pm 0.20 \mathrm{E}-05$ & $4.38 \pm 0.43 \mathrm{E}-05$ & $2.09 \pm 0.13 \mathrm{E}-04$ \\
\hline U-235/236 & $5.03 \pm 1.82 E-06$ & $2.36 \pm 0.60 \mathrm{E}-06$ & 8.21 $\pm 2.21 E-07$ & $2.62 \pm 0.56 \mathrm{E}-06$ & $1.08 \pm 0.20 \mathrm{E}-05$ \\
\hline U-238 & $7.31 \pm 0.86 \mathrm{E}-05$ & $3.26 \pm 0.35 \mathrm{E}-05$ & $1.46 \pm 0.16 E-05$ & $2.79 \pm 0.29 \mathrm{E}-05$ & $1.48 \pm 0.10 \mathrm{E}-04$ \\
\hline Total U (g) & $2.07 \pm 0.05 E+02$ & $8.92 \pm 0.29 \mathrm{E}+01$ & $3.82 \pm 0.06 \mathrm{E}+01$ & $7.02 \pm 0.11 \mathrm{E}+01$ & $4.05 \pm 0.06 \mathrm{E}+02$ \\
\hline Pu-238 & $1.14 \pm 0.53 E-06$ & $2.54 \pm 2.10 \mathrm{E}-07$ & $2.79 \pm 1.39 \mathrm{E}-07$ & $4.65 \pm 2.24 \mathrm{E}-07$ & $2.14 \pm 0.63 \mathrm{E}-06$ \\
\hline Pu-239/240 & $8.18 \pm 4.91 E-07$ & $1.27 \pm 1.48 \mathrm{E}-07$ & $1.64 \pm 1.15 \mathrm{E}-07$ & $2.84 \pm 2.22 \mathrm{E}-07$ & $1.39 \pm 0.57 \mathrm{E}-06$ \\
\hline Am-241 & $1.24 \pm 0.64 \mathrm{E}-06$ & $1.50 \pm 2.12 \mathrm{E}-07$ & $1.82 \pm 1.20 \mathrm{E}-07$ & $6.09 \pm 2.46 \mathrm{E}-07$ & $2.18 \pm 0.73 \mathrm{E}-06$ \\
\hline
\end{tabular}

Note: Bolding convention applied to these data. See page C-2.

WVDP Site Environmental Report

$$
C-3
$$




\section{Table C-2}

\section{Comparison of 2001 Lagoon 3 (WNSP001) Liquid Effluent Radioactivity Concentrations With Department of Energy Guidelines}

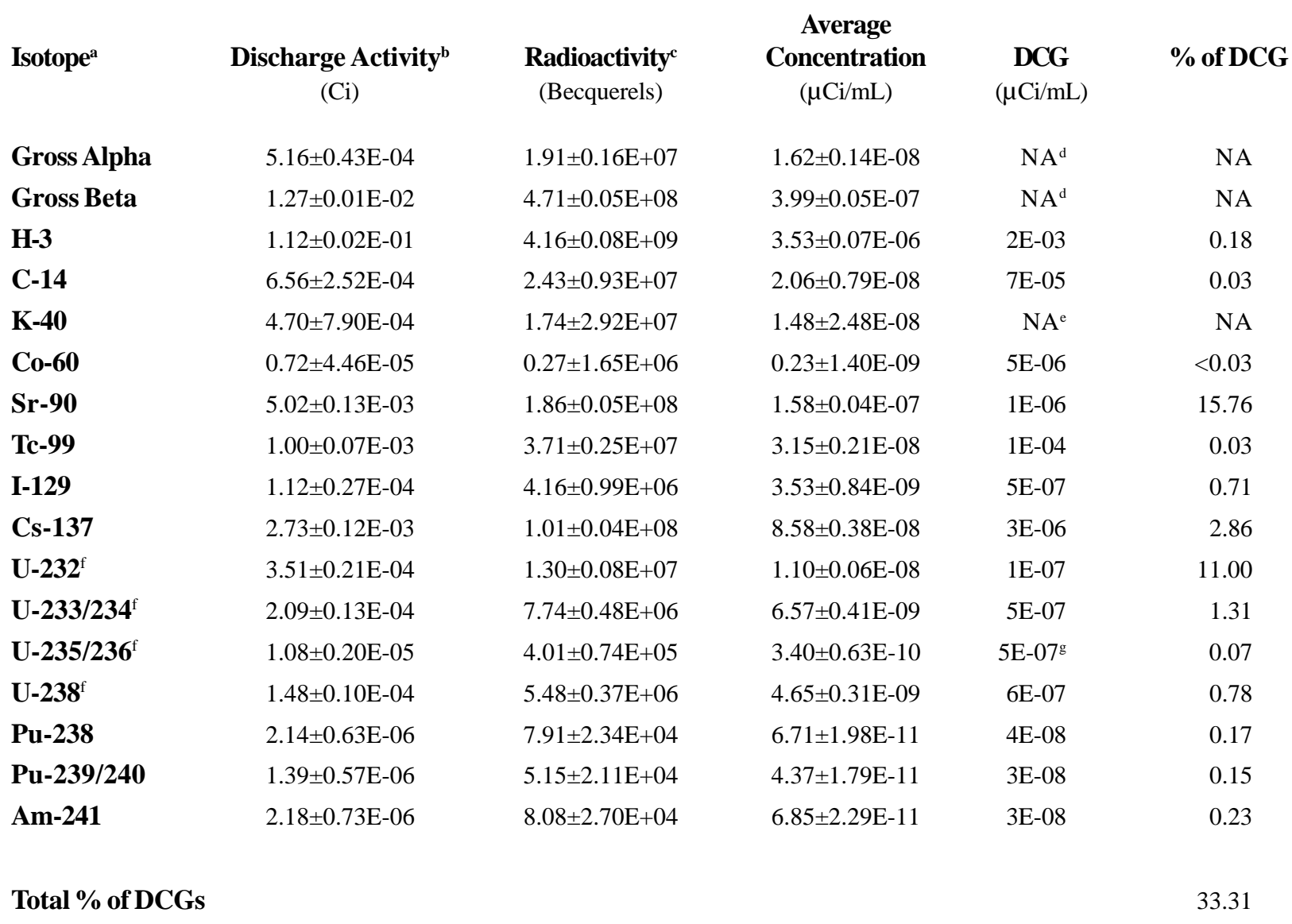

${ }^{a}$ Half-lives are listed in Table $K-1$.

${ }^{b}$ Total volume released: $3.19 E+10 \mathrm{~mL}(8.42 \mathrm{E}+06 \mathrm{gal})$.

${ }^{c} 1$ curie $(\mathrm{Ci})=3.7 \mathrm{E}+10$ becquerels $(\mathrm{Bq}) ; 1 \mathrm{~Bq}=2.7 \mathrm{E}-11 \mathrm{Ci}$.

${ }^{d}$ Derived concentration guides (DCGs) are not applicable (NA) to gross alpha and gross beta.

${ }^{e}$ Potassium-40 activity is not applicable because of its natural origin.

${ }^{f}$ Total $U(\mathrm{~g})=4.05 \pm 0.06 E+02$; Average $U(\mu \mathrm{g} / \mathrm{mL})=1.27 \pm 0.02 E-02$.

${ }^{8}$ DCG for U-236 is used for this comparison.

Note: Bolding convention not applicable to these data.

$$
\text { C- } 4
$$




\section{Table C-3 \\ 2001 Radioactivity Concentrations $(\mu \mathrm{Ci} / \mathrm{mL})$ and $\mathrm{pH}$ in Surface Water Facility Yard Drainage (WNSP005)}

$\begin{array}{lrrrc}\text { Month } & \text { Gross Alpha } & \text { Gross Beta } & \text { H-3 } & \begin{array}{c}\text { pH } \\ \text { (standard units) }\end{array} \\ & & & & \\ \text { January } & 2.81 \pm 3.33 \mathrm{E}-09 & \mathbf{2 . 7 3} \pm \mathbf{0 . 1 2 E}-\mathbf{0 7} & -0.23 \pm 7.98 \mathrm{E}-08 & \mathbf{7 . 7 9} \\ \text { February } & -0.20 \pm 2.83 \mathrm{E}-09 & 1.55 \pm 0.09 \mathrm{E}-07 & -0.48 \pm 8.44 \mathrm{E}-08 & 7.31 \\ \text { March } & 2.10 \pm 4.74 \mathrm{E}-09 & 1.28 \pm 0.10 \mathrm{E}-07 & -2.99 \pm 8.28 \mathrm{E}-08 & 7.22 \\ \text { April } & -2.38 \pm 2.62 \mathrm{E}-09 & 1.64 \pm 0.11 \mathrm{E}-07 & 1.36 \pm 8.13 \mathrm{E}-08 & \mathbf{6 . 8 5} \\ \text { May } & 0.74 \pm 1.53 \mathrm{E}-09 & 2.56 \pm 0.47 \mathrm{E}-08 & 7.12 \pm 8.28 \mathrm{E}-08 & 6.99 \\ \text { June } & -0.14 \pm 1.79 \mathrm{E}-09 & 4.61 \pm 0.34 \mathrm{E}-08 & -3.88 \pm 8.38 \mathrm{E}-08 & 7.22 \\ \text { July } & 0.75 \pm 2.86 \mathrm{E}-09 & 7.07 \pm 0.78 \mathrm{E}-08 & 6.38 \pm 8.10 \mathrm{E}-08 & 6.96 \\ \text { August } & -0.77 \pm 1.57 \mathrm{E}-09 & 8.36 \pm 0.48 \mathrm{E}-08 & -5.46 \pm 8.21 \mathrm{E}-08 & 7.35 \\ \text { September } & 2.59 \pm 1.65 \mathrm{E}-09 & 1.32 \pm 0.06 \mathrm{E}-07 & -8.25 \pm 8.13 \mathrm{E}-08 & 7.62 \\ \text { October } & \mathbf{3 . 6 9} \pm \mathbf{2 . 8 7 E - 0 9} & 1.16 \pm 0.07 \mathrm{E}-07 & 3.22 \pm 8.26 \mathrm{E}-08 & 6.99 \\ \text { November } & -1.67 \pm 1.59 \mathrm{E}-09 & \mathbf{2 . 2 6} \pm \mathbf{0 . 5 7 E}-\mathbf{0 8} & \mathbf{1 . 3 6} \pm \mathbf{0 . 8 1 E}-\mathbf{0 7} & 7.03 \\ \text { December } & 2.34 \pm 2.36 \mathrm{E}-09 & 1.40 \pm 0.09 \mathrm{E}-07 & 0.25 \pm 5.94 \mathrm{E}-08 & 7.19\end{array}$

Note: Bolding convention applied to these data. See page C-2.

$C-5$

WVDP Site Environmental Report

Calendar Year 2001 


\section{Table C-4}

\section{Radioactivity Concentrations $(\mu \mathrm{Ci} / \mathrm{mL})$ in Surface Water Downstream of the WVDP at Frank's Creek (WNSP006)}

\begin{tabular}{|c|c|c|c|c|c|}
\hline Month & Gross Alpha & Gross Beta & H-3 & Sr-90 & Cs-137 \\
\hline January* & $1.37 \pm 1.35 \mathrm{E}-09$ & $5.68 \pm 0.46 \mathrm{E}-08$ & $2.64 \pm 0.84 \mathrm{E}-07$ & $2.60 \pm 0.48 \mathrm{E}-08$ & $0.67 \pm 1.07 \mathrm{E}-08$ \\
\hline February & $-0.36 \pm 1.20 \mathrm{E}-09$ & $2.39 \pm 0.34 \mathrm{E}-08$ & $6.84 \pm 7.79 \mathrm{E}-08$ & $1.24 \pm 0.31 \mathrm{E}-08$ & $-0.12 \pm 1.09 \mathrm{E}-08$ \\
\hline March* & $0.96 \pm 1.68 \mathrm{E}-09$ & $3.98 \pm 0.41 \mathrm{E}-08$ & $1.45 \pm 0.83 \mathrm{E}-07$ & $1.93 \pm 0.29 \mathrm{E}-08$ & $-0.26 \pm 1.22 \mathrm{E}-08$ \\
\hline April & $0.31 \pm 1.10 \mathrm{E}-09$ & $2.16 \pm 0.32 \mathrm{E}-08$ & $-0.78 \pm 7.63 \mathrm{E}-08$ & $1.10 \pm 0.23 \mathrm{E}-08$ & $7.26 \pm 7.86 \mathrm{E}-09$ \\
\hline$M a y^{*}$ & $4.34 \pm 2.09 \mathrm{E}-09$ & $5.79 \pm 0.40 \mathrm{E}-08$ & $3.09 \pm 0.88 \mathrm{E}-07$ & $2.38 \pm 0.30 \mathrm{E}-08$ & $6.26 \pm 1.74 \mathrm{E}-08$ \\
\hline June & $-0.47 \pm 1.80 \mathrm{E}-09$ & $4.02 \pm 0.41 \mathrm{E}-08$ & $-2.11 \pm 7.00 \mathrm{E}-08$ & $2.00 \pm 0.37 \mathrm{E}-08$ & $0.81 \pm 5.76 \mathrm{E}-09$ \\
\hline July & $0.26 \pm 2.39 \mathrm{E}-09$ & $5.45 \pm 0.48 \mathrm{E}-08$ & $8.19 \pm 7.64 \mathrm{E}-08$ & $2.29 \pm 0.32 \mathrm{E}-08$ & $-0.66 \pm 7.44 \mathrm{E}-09$ \\
\hline August* & $0.96 \pm 2.32 \mathrm{E}-09$ & $5.54 \pm 0.47 \mathrm{E}-08$ & $2.56 \pm 0.83 \mathrm{E}-07$ & $2.80 \pm 0.33 \mathrm{E}-08$ & $9.56 \pm 7.82 \mathrm{E}-09$ \\
\hline September & $0.76 \pm 1.75 \mathrm{E}-09$ & $5.02 \pm 0.43 \mathrm{E}-08$ & $1.26 \pm 0.77 \mathrm{E}-07$ & $2.26 \pm 0.33 \mathrm{E}-08$ & $-6.09 \pm 7.92 \mathrm{E}-09$ \\
\hline October & $-0.50 \pm 1.61 \mathrm{E}-09$ & $5.09 \pm 0.44 \mathrm{E}-08$ & $-3.78 \pm 8.34 \mathrm{E}-08$ & $2.46 \pm 0.31 \mathrm{E}-08$ & $3.18 \pm 7.42 \mathrm{E}-09$ \\
\hline November* & $0.82 \pm 1.32 \mathrm{E}-09$ & $5.36 \pm 0.45 \mathrm{E}-08$ & $3.66 \pm 0.87 \mathrm{E}-07$ & $2.74 \pm 0.40 \mathrm{E}-08$ & $-0.10 \pm 1.18 \mathrm{E}-08$ \\
\hline December & $7.40 \pm 9.75 \mathrm{E}-10$ & $1.97 \pm 0.28 \mathrm{E}-08$ & $-3.71 \pm 7.70 \mathrm{E}-08$ & $8.18 \pm 2.18 \mathrm{E}-09$ & $-1.41 \pm 1.33 \mathrm{E}-08$ \\
\hline Quarter & C-14 & Tc-99 & I-129 & U-232 & U-233/234 \\
\hline 1st Quarter & $-0.78 \pm 2.75 \mathrm{E}-08$ & $-0.17 \pm 1.65 \mathrm{E}-09$ & $-1.09 \pm 6.68 \mathrm{E}-10$ & $5.47 \pm 1.27 \mathrm{E}-10$ & $3.67 \pm 1.12 \mathrm{E}-10$ \\
\hline 2nd Quarter & $2.06 \pm 1.35 \mathrm{E}-08$ & $0.77 \pm 1.77 \mathrm{E}-09$ & $2.31 \pm 9.03 \mathrm{E}-10$ & $3.42 \pm 1.00 \mathrm{E}-10$ & $4.66 \pm 1.10 \mathrm{E}-10$ \\
\hline 3rd Quarter & $-0.37 \pm 8.98 \mathrm{E}-09$ & $2.98 \pm 2.17 \mathrm{E}-09$ & $2.89 \pm 3.17 \mathrm{E}-10$ & $1.90 \pm 0.66 \mathrm{E}-10$ & $2.79 \pm 0.78 \mathrm{E}-10$ \\
\hline \multirow[t]{2}{*}{ 4th Quarter } & $0.90 \pm 1.30 \mathrm{E}-08$ & $2.28 \pm 1.87 \mathrm{E}-09$ & $9.21 \pm 9.40 \mathrm{E}-10$ & $3.06 \pm 1.58 \mathrm{E}-10$ & $3.36 \pm 1.20 \mathrm{E}-10$ \\
\hline & U-235/236 & U-238 & $\begin{array}{l}\text { Total U } \\
(\mu \mathrm{g} / \mathrm{mL})\end{array}$ & Pu-238 & $\mathrm{Pu}-239 / 240$ \\
\hline 1st Qua & $5.57 \pm 6.78 \mathrm{E}-11$ & $2.88 \pm 0.92 \mathrm{E}-10$ & $1.14 \pm 0.01 \mathrm{E}-03$ & $1.36 \pm 0.74 \mathrm{E}-10$ & $2.81 \pm 2.82 \mathrm{E}-11$ \\
\hline 2nd Quarter & $9.48 \pm 4.61 \mathrm{E}-11$ & $3.43 \pm 0.92 E-10$ & $1.50 \pm 0.02 \mathrm{E}-03$ & $2.62 \pm 2.34 \mathrm{E}-11$ & $2.45 \pm 2.37 \mathrm{E}-11$ \\
\hline 3rd Quarter & $1.53 \pm 2.80 \mathrm{E}-11$ & $2.51 \pm 0.74 \mathrm{E}-10$ & $7.58 \pm 0.20 \mathrm{E}-04$ & $0.46 \pm 2.32 \mathrm{E}-11$ & $-1.50 \pm 2.90 \mathrm{E}-11$ \\
\hline 4th Quarter & $2.62 \pm 3.11 \mathrm{E}-11$ & $1.80 \pm 0.80 \mathrm{E}-10$ & $9.28 \pm 0.26 \mathrm{E}-04$ & $0.00 \pm 2.28 \mathrm{E}-11$ & $0.56 \pm 2.42 \mathrm{E}-11$ \\
\hline
\end{tabular}

Am-241

1st Quarter 2nd Quarter 3rd Quarter 4th Quarter
8.33 $\pm 5.61 E-11$

$4.75 \pm 3.51 \mathrm{E}-11$

$6.26 \pm 3.78 \mathrm{E}-11$

$3.04 \pm 3.84 \mathrm{E}-11$

* Lagoon 3 discharged through WNSP0O1 during these months. See Table C-27 for a summary of water quality data at WNSPOO6.

Note: Bolding convention applied to these data. See page C-2.

$$
\text { C- } 6
$$




\section{Table C-5}

2001 Radioactivity Concentrations $(\mu \mathrm{Ci} / \mathrm{mL})$ in Surface Water Sewage Treatment Facility (WNSP007)

$\begin{array}{lr}\text { Month } & \text { Gross Alpha } \\ & \\ \text { January } & -0.02 \pm 2.87 \mathrm{E}-09 \\ \text { February } & 0.44 \pm 2.97 \mathrm{E}-09 \\ \text { March } & 0.34 \pm 3.08 \mathrm{E}-09 \\ \text { April } & -2.17 \pm 3.38 \mathrm{E}-09 \\ \text { May } & 0.41 \pm 2.80 \mathrm{E}-09 \\ \text { June } & -1.85 \pm 2.56 \mathrm{E}-09 \\ \text { July } & -1.45 \pm 2.59 \mathrm{E}-09 \\ \text { August } & -0.12 \pm 2.17 \mathrm{E}-09 \\ \text { September } & 1.42 \pm 2.30 \mathrm{E}-09 \\ \text { October } & 0.03 \pm 4.26 \mathrm{E}-09 \\ \text { November } & 0.08 \pm 4.18 \mathrm{E}-09 \\ \text { December } & 2.10 \pm 2.85 \mathrm{E}-09 \\ & \\ \text { Quarter } & \text { Cs-137 } \\ & \\ \text { 1st Quarter } & -0.56 \pm 4.51 \mathrm{E}-09 \\ \text { 2nd Quarter } & 0.35 \pm 2.31 \mathrm{E}-09 \\ \text { 3rd Quarter } & 2.56 \pm 3.86 \mathrm{E}-09 \\ \text { 4th Quarter } & 0.81 \pm 2.56 \mathrm{E}-09\end{array}$

H-3

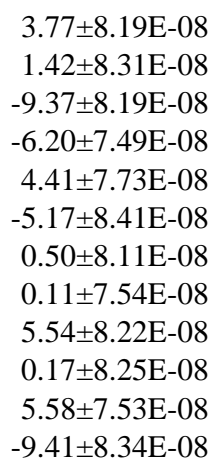

\section{Table C-6 \\ 2001 Radioactivity Concentrations $(\mu \mathrm{Ci} / \mathrm{mL})$ in Surface Water French Drain (WNSP008)}

$\begin{array}{lrrc}\text { Month } & \text { Gross Alpha } & \text { Gross Beta } & \text { H-3 } \\ \text { January } & 0.35 \pm 2.65 \mathrm{E}-09 & \mathbf{7 . 6 6} \pm \mathbf{0 . 6 9 E}-\mathbf{0 8} & 1.63 \pm 0.11 \mathrm{E}-06 \\ \text { February } & 1.05 \pm 1.87 \mathrm{E}-09 & 7.01 \pm 0.46 \mathrm{E}-08 & 1.46 \pm 0.11 \mathrm{E}-06 \\ \text { March } & -0.38 \pm 2.75 \mathrm{E}-09 & 6.17 \pm 0.51 \mathrm{E}-08 & 1.47 \pm 0.11 \mathrm{E}-06 \\ \text { April } & -0.99 \pm 2.30 \mathrm{E}-09 & \mathbf{5 . 1 6} \pm \mathbf{0 . 4 6 E}-\mathbf{0 8} & \mathbf{9 . 5 1} \pm \mathbf{0 . 9 3 E - 0 7} \\ \text { May } & 0.93 \pm 2.66 \mathrm{E}-09 & 6.29 \pm 0.51 \mathrm{E}-08 & \mathbf{1 . 7 7} \pm \mathbf{0 . 1 1 E - 0 6} \\ \text { June }^{*} & & & \\ \text { July }^{*} & & & \\ \text { August } & & & \\ \text { September } & & & \\ \text { October }^{*} & & & \\ \text { November }^{*} & & & \\ \text { December* } & & & \end{array}$

* No discharge from the french drain since May 10, 2001.

Note: Bolding convention applied to these data. See page C-2.

WVDP Site Environmental Report

$$
\text { C- } 7
$$


Table C-7

\section{Radioactivity Concentrations $(\mu \mathrm{Ci} / \mathrm{mL})$ and $\mathrm{pH}$ in Surface Water Northeast Swamp (WNSWAMP)}

\begin{tabular}{|c|c|c|c|c|c|c|}
\hline Month & Gross Alpha & Gross Beta & H-3 & Sr-90 & Cs-137 & $\begin{array}{c}\mathbf{p H} \\
\text { (standard units) }\end{array}$ \\
\hline January & $-0.45 \pm 1.35 \mathrm{E}-09$ & $3.36 \pm 0.03 \mathrm{E}-06$ & $1.25 \pm 0.82 \mathrm{E}-07$ & $1.71 \pm 0.02 \mathrm{E}-06$ & $0.84 \pm 4.12 \mathrm{E}-09$ & 7.13 \\
\hline February & $0.54 \pm 1.29 \mathrm{E}-09$ & $2.96 \pm 0.03 E-06$ & $3.22 \pm 8.24 \mathrm{E}-08$ & $1.48 \pm 0.03 E-06$ & $0.53 \pm 2.73 \mathrm{E}-09$ & 7.03 \\
\hline March & $0.36 \pm 1.34 \mathrm{E}-09$ & $3.43 \pm 0.03 \mathrm{E}-06$ & $8.92 \pm 8.23 \mathrm{E}-08$ & $1.69 \pm 0.03 \mathrm{E}-06$ & $1.12 \pm 3.56 \mathrm{E}-09$ & 6.90 \\
\hline April & $1.48 \pm 1.70 \mathrm{E}-09$ & $3.21 \pm 0.03 \mathrm{E}-06$ & $8.57 \pm 8.09 \mathrm{E}-08$ & $1.60 \pm 0.03 \mathrm{E}-06$ & $-1.63 \pm 2.90 \mathrm{E}-09$ & 6.86 \\
\hline May & $0.91 \pm 2.20 \mathrm{E}-09$ & $4.27 \pm 0.03 \mathrm{E}-06$ & $9.30 \pm 7.15 \mathrm{E}-08$ & $1.68 \pm 0.03 \mathrm{E}-06$ & 2.48 $\pm 2.29 \mathrm{E}-09$ & 7.03 \\
\hline June & $1.17 \pm 2.33 \mathrm{E}-09$ & $5.07 \pm 0.04 \mathrm{E}-06$ & $7.15 \pm 8.37 \mathrm{E}-08$ & $2.67 \pm 0.05 \mathrm{E}-06$ & $0.79 \pm 7.84 \mathrm{E}-09$ & 7.05 \\
\hline July & $0.87 \pm 2.21 \mathrm{E}-09$ & $6.34 \pm 0.04 \mathrm{E}-06$ & $1.67 \pm 0.82 \mathrm{E}-07$ & $3.34 \pm 0.04 \mathrm{E}-06$ & $1.04 \pm 3.70 \mathrm{E}-09$ & 7.06 \\
\hline August & $-0.20 \pm 3.02 E-09$ & $7.80 \pm 0.05 \mathrm{E}-06$ & $2.59 \pm 0.78 E-07$ & $4.04 \pm 0.05 E-06$ & $-1.24 \pm 3.03 \mathrm{E}-09$ & 7.12 \\
\hline September & $1.24 \pm 2.46 \mathrm{E}-09$ & $8.02 \pm 0.05 E-06$ & $2.48 \pm 0.85 \mathrm{E}-07$ & $3.91 \pm 0.05 \mathrm{E}-06$ & $-3.74 \pm 3.06 \mathrm{E}-09$ & 7.27 \\
\hline October & $0.62 \pm 1.77 \mathrm{E}-09$ & $5.47 \pm 0.04 \mathrm{E}-06$ & $1.22 \pm 0.82 \mathrm{E}-07$ & $2.70 \pm 0.03 \mathrm{E}-06$ & $-0.16 \pm 2.43 \mathrm{E}-09$ & 7.07 \\
\hline November & $-1.46 \pm 1.90 \mathrm{E}-09$ & $3.95 \pm 0.03 \mathrm{E}-06$ & $3.53 \pm 8.42 \mathrm{E}-08$ & $2.00 \pm 0.03 \mathrm{E}-06$ & $3.76 \pm 4.59 \mathrm{E}-09$ & 6.96 \\
\hline December & $-0.43 \pm 1.70 \mathrm{E}-09$ & $3.39 \pm 0.03 \mathrm{E}-06$ & $1.41 \pm 0.77 \mathrm{E}-07$ & $1.74 \pm 0.04 \mathrm{E}-06$ & $-0.80 \pm 2.27 \mathrm{E}-09$ & 7.10 \\
\hline Quarter & C-14 & I-129 & U-232 & U-233/234 & U-235/236 & \\
\hline 1st Quarter & $2.32 \pm 2.89 \mathrm{E}-08$ & $1.68 \pm 7.06 \mathrm{E}-10$ & $2.15 \pm 4.82 \mathrm{E}-11$ & $1.81 \pm 0.86 \mathrm{E}-10$ & $3.78 \pm 4.16 \mathrm{E}-11$ & \\
\hline 2nd Quarter & $3.72 \pm 2.84 \mathrm{E}-08$ & $0.22 \pm 1.07 \mathrm{E}-09$ & $3.47 \pm 5.02 \mathrm{E}-11$ & $1.31 \pm 0.59 \mathrm{E}-10$ & $5.89 \pm 3.82 \mathrm{E}-11$ & \\
\hline 3rd Quarter & $-2.35 \pm 8.91 \mathrm{E}-09$ & $1.18 \pm 1.21 \mathrm{E}-09$ & $0.78 \pm 4.61 \mathrm{E}-11$ & $9.24 \pm 4.97 \mathrm{E}-11$ & $0.13 \pm 1.16 \mathrm{E}-11$ & \\
\hline \multirow[t]{2}{*}{ 4th Quarter } & $8.17 \pm 4.96 \mathrm{E}-09$ & $0.46 \pm 1.27 \mathrm{E}-09$ & $-0.74 \pm 6.46 \mathrm{E}-11$ & $7.63 \pm 6.43 \mathrm{E}-11$ & $0.33 \pm 1.50 \mathrm{E}-11$ & \\
\hline & U-238 & $\begin{array}{l}\text { Total U } \\
(\mu \mathrm{g} / \mathrm{mL})\end{array}$ & Pu-238 & Pu-239/240 & Am-241 & \\
\hline 1st Quarter & $1.19 \pm 0.72 \mathrm{E}-10$ & $2.37 \pm 0.06 \mathrm{E}-04$ & $0.00 \pm 4.11 \mathrm{E}-11$ & $3.02 \pm 4.29 \mathrm{E}-11$ & $1.79 \pm 0.87 E-10$ & \\
\hline 2nd Quarter & $9.79 \pm 4.90 \mathrm{E}-11$ & $6.39 \pm 0.11 \mathrm{E}-04$ & $-0.38 \pm 3.97 \mathrm{E}-11$ & $2.14 \pm 2.51 \mathrm{E}-11$ & $3.71 \pm 3.73 \mathrm{E}-11$ & \\
\hline 3rd Quarter & $5.17 \pm 3.16 \mathrm{E}-11$ & $4.35 \pm 0.16 \mathrm{E}-04$ & $1.49 \pm 1.93 \mathrm{E}-11$ & $-0.67 \pm 2.82 \mathrm{E}-11$ & $2.19 \pm 3.91 \mathrm{E}-11$ & \\
\hline 4th Quarter & $7.00 \pm 5.10 \mathrm{E}-11$ & $2.76 \pm 0.09 \mathrm{E}-04$ & $6.27 \pm 4.99 \mathrm{E}-11$ & $1.44 \pm 0.57 E-10$ & $0.87 \pm 3.22 \mathrm{E}-11$ & \\
\hline
\end{tabular}

See Table C-27 for a summary of water quality data at WNSWAMP.

Note: Bolding convention applied to these data. See page C-2.

$C-8$ 


\section{Table C-8 \\ 2001 Radioactivity Concentrations $(\mu \mathrm{Ci} / \mathrm{mL})$ in Surface Water North Swamp (WNSW74A)}

\begin{tabular}{|c|c|c|c|c|c|}
\hline Month & Gross Alpha & Gross Beta & H-3 & Sr-90 & Cs-137 \\
\hline January & $1.40 \pm 4.92 \mathrm{E}-09$ & $9.23 \pm 5.36 \mathrm{E}-09$ & $-2.11 \pm 7.48 \mathrm{E}-08$ & $5.56 \pm 1.61 \mathrm{E}-09$ & $0.03 \pm 5.39 \mathrm{E}-09$ \\
\hline February & $1.33 \pm 4.33 \mathrm{E}-09$ & $1.21 \pm 0.52 \mathrm{E}-08$ & $-2.34 \pm 8.29 \mathrm{E}-08$ & $6.41 \pm 2.55 \mathrm{E}-09$ & $2.38 \pm 9.70 \mathrm{E}-09$ \\
\hline March & $0.23 \pm 4.50 \mathrm{E}-09$ & $1.47 \pm 0.69 \mathrm{E}-08$ & $1.04 \pm 7.28 \mathrm{E}-08$ & $6.30 \pm 2.26 \mathrm{E}-09$ & $-1.68 \pm 8.70 \mathrm{E}-09$ \\
\hline April & $-0.48 \pm 2.91 \mathrm{E}-09$ & $1.06 \pm 0.43 \mathrm{E}-08$ & $-1.35 \pm 8.14 \mathrm{E}-08$ & $6.37 \pm 1.88 \mathrm{E}-09$ & $-5.56 \pm 7.10 \mathrm{E}-09$ \\
\hline May & $0.99 \pm 2.76 \mathrm{E}-09$ & $1.29 \pm 0.38 \mathrm{E}-08$ & $0.16 \pm 8.28 \mathrm{E}-08$ & $6.39 \pm 1.81 \mathrm{E}-09$ & $4.01 \pm 6.07 \mathrm{E}-09$ \\
\hline June & $-0.27 \pm 2.19 \mathrm{E}-09$ & $1.09 \pm 0.41 \mathrm{E}-08$ & $-2.02 \pm 7.85 \mathrm{E}-08$ & $6.35 \pm 2.05 \mathrm{E}-09$ & $1.98 \pm 7.84 \mathrm{E}-09$ \\
\hline July & $0.68 \pm 2.47 \mathrm{E}-09$ & $9.48 \pm 2.95 \mathrm{E}-09$ & $4.42 \pm 7.61 \mathrm{E}-08$ & $3.92 \pm 1.58 \mathrm{E}-09$ & $0.36 \pm 1.14 \mathrm{E}-08$ \\
\hline August & $0.98 \pm 2.36 \mathrm{E}-09$ & $9.24 \pm 3.98 \mathrm{E}-09$ & $5.08 \pm 7.69 \mathrm{E}-08$ & $2.90 \pm 1.57 \mathrm{E}-09$ & $0.05 \pm 1.17 \mathrm{E}-08$ \\
\hline September & $0.27 \pm 2.01 \mathrm{E}-09$ & $1.20 \pm 0.39 \mathrm{E}-08$ & $3.88 \pm 8.20 \mathrm{E}-08$ & $4.98 \pm 2.00 \mathrm{E}-09$ & $0.91 \pm 1.46 \mathrm{E}-08$ \\
\hline October & $-0.62 \pm 1.95 \mathrm{E}-09$ & $1.37 \pm 0.35 \mathrm{E}-08$ & $-9.45 \pm 7.65 \mathrm{E}-08$ & $6.77 \pm 2.12 \mathrm{E}-09$ & $1.78 \pm 7.76 \mathrm{E}-09$ \\
\hline November & $0.44 \pm 1.80 \mathrm{E}-09$ & $1.68 \pm 0.37 E-08$ & $7.41 \pm 8.16 \mathrm{E}-08$ & $1.05 \pm 0.27 \mathrm{E}-08$ & $-2.02 \pm 6.14 \mathrm{E}-09$ \\
\hline December & $0.47 \pm 1.48 \mathrm{E}-09$ & $1.41 \pm 0.35 \mathrm{E}-08$ & $-0.18 \pm 8.23 \mathrm{E}-08$ & $4.96 \pm 1.90 \mathrm{E}-09$ & $-0.24 \pm 1.22 \mathrm{E}-08$ \\
\hline Quarter & C-14 & I-129 & U-232 & U-233/234 & U-235/236 \\
\hline 1st Quarter & $-1.45 \pm 2.71 \mathrm{E}-08$ & $2.48 \pm 7.52 \mathrm{E}-10$ & $3.17 \pm 3.89 \mathrm{E}-11$ & $2.04 \pm 0.76 \mathrm{E}-10$ & $-0.41 \pm 3.26 \mathrm{E}-11$ \\
\hline 2nd Quarter & $1.50 \pm 1.30 \mathrm{E}-08$ & $9.72 \pm 9.1$ & $1.71 \pm 4.92 \mathrm{E}-11$ & $3.54 \pm 0.98 \mathrm{E}-10$ & $1.38 \pm 0.63 \mathrm{E}-10$ \\
\hline 3rd Quarter & $0.32 \pm 9.00 \mathrm{E}-09$ & $1.44 \pm 7.62 \mathrm{E}-10$ & $0.24 \pm 3.18 \mathrm{E}-11$ & $1.60 \pm 0.70 \mathrm{E}-10$ & $-4.08 \pm 5.39 \mathrm{E}-11$ \\
\hline \multirow[t]{2}{*}{ 4th Quarter } & $0.48 \pm 1.26 \mathrm{E}-08$ & $0.56 \pm 8.16 \mathrm{E}-10$ & $0.14 \pm 1.00 \mathrm{E}-10$ & $1.40 \pm 0.84 E-10$ & $0.72 \pm 3.78 \mathrm{E}-11$ \\
\hline & U-238 & $\begin{array}{l}\text { Total U } \\
(\mu \mathrm{g} / \mathrm{mL})\end{array}$ & Pu-238 & Pu-239/240 & Am-241 \\
\hline 1st Quarter & $7.58 \pm 4.75 \mathrm{E}-11$ & $5.10 \pm 0.07 \mathrm{E}-04$ & $2.62 \pm 3.03 \mathrm{E}-11$ & $1.26 \pm 2.52 \mathrm{E}-11$ & $1.73 \pm 2.12 \mathrm{E}-11$ \\
\hline 2nd Quarter & $1.45 \pm 0.62 \mathrm{E}-10$ & $4.14 \pm 0.07 \mathrm{E}-04$ & $4.69 \pm 9.39 \mathrm{E}-12$ & $0.13 \pm 1.15 \mathrm{E}-11$ & $1.45 \pm 1.68 \mathrm{E}-11$ \\
\hline 3rd Quarter & $1.32 \pm 0.66 \mathrm{E}-10$ & $9.56 \pm 0.28 E-04$ & $2.04 \pm 1.84 \mathrm{E}-11$ & $-1.60 \pm 2.55 \mathrm{E}-11$ & $1.99 \pm 1.79 \mathrm{E}-11$ \\
\hline 4th Quarter & $1.41 \pm 0.85 \mathrm{E}-10$ & $4.56 \pm 0.14 \mathrm{E}-04$ & $0.86 \pm 2.02 \mathrm{E}-11$ & $2.68 \pm 3.97 \mathrm{E}-11$ & $5.02 \pm 4.29 \mathrm{E}-11$ \\
\hline
\end{tabular}

See Table C-27 for a summary of water quality data at WNSW74A.

Note: Bolding convention applied to these data. See page C-2.

$C-9$

WVDP Site Environmental Report

Calendar Year 2001 
Table C-9

\section{Radioactivity Concentrations $(\mu \mathrm{Ci} / \mathrm{mL})$ and $\mathrm{pH}$ in Surface Water Frank's Creek East of the SDA (WNFRC67)}

$\begin{array}{lrrrc}\text { Month } & \text { Gross Alpha } & \text { Gross Beta } & \text { H-3 } & \begin{array}{c}\text { pH } \\ \text { (standard units) }\end{array} \\ & & & & \\ \text { January } & 0.00 \pm 6.35 \mathrm{E}-10 & 1.96 \pm 1.30 \mathrm{E}-09 & -2.66 \pm 8.24 \mathrm{E}-08 & \mathbf{8 . 0 8} \\ \text { February } & 5.05 \pm 6.16 \mathrm{E}-10 & 3.70 \pm 1.25 \mathrm{E}-09 & -1.00 \pm 0.82 \mathrm{E}-07 & 6.80 \\ \text { March } & -1.92 \pm 6.90 \mathrm{E}-10 & 1.10 \pm 1.23 \mathrm{E}-09 & -7.61 \pm 8.19 \mathrm{E}-08 & 7.26 \\ \text { April } & -4.30 \pm 6.83 \mathrm{E}-10 & \mathbf{5 . 2 7} \pm \mathbf{1 . 3 8 E}-09 & -6.42 \pm 5.72 \mathrm{E}-08 & 6.85 \\ \text { May } & 5.12 \pm 8.41 \mathrm{E}-10 & 2.68 \pm 1.35 \mathrm{E}-09 & 5.08 \pm 8.30 \mathrm{E}-08 & 7.08 \\ \text { June } & -4.17 \pm 8.38 \mathrm{E}-10 & 2.73 \pm 1.27 \mathrm{E}-09 & -1.77 \pm 0.83 \mathrm{E}-07 & 7.21 \\ \text { July } & 1.49 \pm 7.46 \mathrm{E}-10 & 2.68 \pm 1.28 \mathrm{E}-09 & \mathbf{3 . 2 6} \pm \mathbf{0 . 8 5 E}-\mathbf{0 7} & 6.63 \\ \text { August* } & & & & \\ \text { September } & -6.28 \pm 6.95 \mathrm{E}-10 & 3.65 \pm 1.32 \mathrm{E}-09 & 1.24 \pm 0.84 \mathrm{E}-07 & 7.45 \\ \text { October } & -7.68 \pm 7.92 \mathrm{E}-10 & 3.63 \pm 1.39 \mathrm{E}-09 & 1.12 \pm 0.83 \mathrm{E}-07 & \mathbf{6 . 5 7} \\ \text { November } & -1.64 \pm 7.02 \mathrm{E}-10 & 2.84 \pm 1.34 \mathrm{E}-09 & 1.18 \pm 0.80 \mathrm{E}-07 & 6.76 \\ \text { December } & 2.16 \pm 6.70 \mathrm{E}-10 & 3.47 \pm 1.26 \mathrm{E}-09 & -3.44 \pm 8.28 \mathrm{E}-08 & 6.96\end{array}$

\section{Table C-10}

\section{Radioactivity Concentrations $(\mu \mathrm{Ci} / \mathrm{mL})$ and $\mathrm{pH}$ in Surface Water Erdman Brook (WNERB53)}

$\begin{array}{lrrrc}\text { Month } & \text { Gross Alpha } & \text { Gross Beta } & \text { H-3 } & \begin{array}{c}\text { pH } \\ \text { (standard units) }\end{array} \\ & & & & \\ \text { January } & 0.37 \pm 1.37 \mathrm{E}-09 & \mathbf{2 . 4 6} \pm \mathbf{0 . 3 5 E}-\mathbf{0 8} & \mathbf{9 . 8 2} \pm \mathbf{7 . 6 4 E - 0 8} & 7.20 \\ \text { February } & 0.36 \pm 1.62 \mathrm{E}-09 & \mathbf{2 . 4 6} \pm \mathbf{0 . 3 5 E}-\mathbf{0 8} & 8.71 \pm 8.31 \mathrm{E}-08 & 6.88 \\ \text { March } & 0.09 \pm 2.25 \mathrm{E}-09 & 2.19 \pm 0.40 \mathrm{E}-08 & 4.47 \pm 7.80 \mathrm{E}-08 & 6.79 \\ \text { April } & -0.15 \pm 1.34 \mathrm{E}-09 & 1.54 \pm 0.28 \mathrm{E}-08 & 1.10 \pm 8.16 \mathrm{E}-08 & \mathbf{6 . 6 1} \\ \text { May } & 0.27 \pm 1.56 \mathrm{E}-09 & \mathbf{1 . 1 0} \pm \mathbf{0 . 2 9 E}-\mathbf{0 8} & 1.89 \pm 8.29 \mathrm{E}-08 & 7.01 \\ \text { June } & -0.71 \pm 1.96 \mathrm{E}-09 & 1.16 \pm 0.35 \mathrm{E}-08 & -2.82 \pm 8.28 \mathrm{E}-08 & \mathbf{7 . 3 3} \\ \text { July } & -0.82 \pm 1.80 \mathrm{E}-09 & 1.29 \pm 0.27 \mathrm{E}-08 & 5.58 \pm 7.60 \mathrm{E}-08 & 7.06 \\ \text { August } & 0.32 \pm 1.73 \mathrm{E}-09 & 1.32 \pm 0.30 \mathrm{E}-08 & 7.35 \pm 8.15 \mathrm{E}-08 & 7.13 \\ \text { September } & 0.43 \pm 1.50 \mathrm{E}-09 & 1.57 \pm 0.29 \mathrm{E}-08 & 5.21 \pm 8.19 \mathrm{E}-08 & 7.22 \\ \text { October } & -0.23 \pm 1.69 \mathrm{E}-09 & 2.21 \pm 0.33 \mathrm{E}-08 & 0.23 \pm 7.84 \mathrm{E}-08 & 6.88 \\ \text { November } & 0.33 \pm 1.43 \mathrm{E}-09 & 1.59 \pm 0.27 \mathrm{E}-08 & 6.76 \pm 8.15 \mathrm{E}-08 & 6.69 \\ \text { December } & 0.26 \pm 1.01 \mathrm{E}-09 & 1.37 \pm 0.25 \mathrm{E}-08 & 3.84 \pm 8.29 \mathrm{E}-08 & 6.96\end{array}$

\footnotetext{
* No sample collected as the creek was dry.
}

Note: Bolding convention applied to these data. See page C-2.

$$
C-10
$$




\section{Table C-11 \\ 2001 Radioactivity Concentrations $(\mu \mathrm{Ci} / \mathrm{mL})$ and $\mathrm{pH}$ in Surface Water Cooling Tower Basin (WNCOOLW)}

\begin{tabular}{|c|c|c|c|c|}
\hline Month & Gross Alpha & Gross Beta & H-3 & $\begin{array}{c}\mathbf{p H} \\
\text { (standard units) }\end{array}$ \\
\hline January & $0.18 \pm 1.40 \mathrm{E}-09$ & $2.08 \pm 2.46 \mathrm{E}-09$ & $-4.29 \pm 8.18 E-08$ & 8.01 \\
\hline February & $0.52 \pm 1.30 \mathrm{E}-09$ & $5.60 \pm 2.43 \mathrm{E}-09$ & $-7.35 \pm 8.23 \mathrm{E}-08$ & 8.24 \\
\hline March & $-0.89 \pm 1.78 \mathrm{E}-09$ & $3.28 \pm 3.64 \mathrm{E}-09$ & $-7.92 \pm 8.21 \mathrm{E}-08$ & 7.88 \\
\hline April & $-0.15 \pm 2.56 \mathrm{E}-09$ & $3.67 \pm 3.50 \mathrm{E}-09$ & $0.62 \pm 8.12 \mathrm{E}-08$ & 7.58 \\
\hline May & $0.97 \pm 2.02 \mathrm{E}-09$ & $3.84 \pm 3.70 \mathrm{E}-09$ & $7.33 \pm 8.24 \mathrm{E}-08$ & 8.40 \\
\hline June & $2.94 \pm 2.79 \mathrm{E}-09$ & $9.25 \pm 2.84 \mathrm{E}-09$ & $-1.03 \pm 0.82 \mathrm{E}-07$ & 8.39 \\
\hline July & $1.22 \pm 3.14 \mathrm{E}-09$ & $1.10 \pm 0.41 \mathrm{E}-08$ & $2.82 \pm 8.03 \mathrm{E}-08$ & 8.84 \\
\hline August & $0.26 \pm 2.86 \mathrm{E}-09$ & $1.22 \pm 0.42 \mathrm{E}-08$ & $-7.98 \pm 8.08 \mathrm{E}-08$ & 8.45 \\
\hline September & $2.22 \pm 2.33 \mathrm{E}-09$ & $1.42 \pm 0.30 \mathrm{E}-08$ & $-1.24 \pm 0.82 \mathrm{E}-07$ & 8.66 \\
\hline October & $-1.04 \pm 2.80 \mathrm{E}-09$ & $8.44 \pm 4.07 \mathrm{E}-09$ & $6.57 \pm 8.24 \mathrm{E}-08$ & 8.57 \\
\hline November & $-0.63 \pm 2.68 \mathrm{E}-09$ & $7.76 \pm 4.02 \mathrm{E}-09$ & $8.43 \pm 7.93 E-08$ & 8.61 \\
\hline December & $0.42 \pm 2.16 \mathrm{E}-09$ & $5.59 \pm 4.04 \mathrm{E}-09$ & $-1.04 \pm 0.82 \mathrm{E}-07$ & 8.75 \\
\hline Quarter & Cs-137 & & & \\
\hline 1st Quarter & $1.96 \pm 7.56 \mathrm{E}-09$ & & & \\
\hline 2nd Quarter & $0.98 \pm 1.27 \mathrm{E}-08$ & & & \\
\hline 3rd Quarter & $5.02 \pm 5.57 \mathrm{E}-09$ & & & \\
\hline 4th Quarter & $2.69 \pm 3.54 \mathrm{E}-09$ & & & \\
\hline
\end{tabular}

Table C-12

2001 Radioactivity Concentrations $(\mu \mathrm{Ci} / \mathrm{mL})$ and $\mathrm{pH}$ in Surface Water SDA Drainage (WNSDADR)

$\begin{array}{lrrrrr}\text { Month } & \text { Gross Alpha } & \text { Gross Beta } & \text { H-3 } & \text { Cs-137 } & \begin{array}{c}\text { pH } \\ \text { (standard units) }\end{array} \\ & & & & & 7.27 \\ \text { January } & 6.19 \pm 4.27 \mathrm{E}-10 & 3.08 \pm 0.87 \mathrm{E}-09 & 1.58 \pm 0.58 \mathrm{E}-07 & 0.41 \pm 1.24 \mathrm{E}-08 & 6.79 \\ \text { February } & 2.47 \pm 2.96 \mathrm{E}-10 & 2.31 \pm 0.76 \mathrm{E}-09 & 0.42 \pm 8.32 \mathrm{E}-08 & 0.78 \pm 6.40 \mathrm{E}-09 & 7.02 \\ \text { March } & 7.13 \pm 3.59 \mathrm{E}-10 & 9.94 \pm 7.12 \mathrm{E}-10 & 9.36 \pm 8.09 \mathrm{E}-08 & 4.18 \pm 7.60 \mathrm{E}-09 & 6.46 \\ \text { April } & 3.25 \pm 5.40 \mathrm{E}-10 & 2.67 \pm 0.82 \mathrm{E}-09 & 1.33 \pm 0.83 \mathrm{E}-07 & 3.82 \pm 5.01 \mathrm{E}-09 & 6.36 \\ \text { May } & \mathbf{3 . 4 9} \pm \mathbf{0 . 6 8 E}-\mathbf{0 9} & \mathbf{9 . 5 2} \pm \mathbf{0 . 8 9 E}-\mathbf{0 9} & 2.18 \pm 0.88 \mathrm{E}-07 & 1.42 \pm 6.94 \mathrm{E}-09 & \mathbf{5 . 4 3} \\ \text { June } & 1.14 \pm 0.43 \mathrm{E}-09 & 2.16 \pm 0.80 \mathrm{E}-09 & -3.42 \pm 8.44 \mathrm{E}-08 & \mathbf{1 . 0 7} \pm \mathbf{1 . 0 7 E}-\mathbf{0 8} & 7.10 \\ \text { July } & 4.44 \pm 5.97 \mathrm{E}-10 & 2.09 \pm 0.81 \mathrm{E}-09 & \mathbf{6 . 3 8} \pm \mathbf{0 . 8 8 E}-\mathbf{0 7} & 5.57 \pm 8.38 \mathrm{E}-09 & 7.08 \\ \text { August } & 8.24 \pm 3.96 \mathrm{E}-10 & 3.83 \pm 0.86 \mathrm{E}-09 & 4.30 \pm 0.83 \mathrm{E}-07 & -5.31 \pm 8.02 \mathrm{E}-09 & \mathbf{7 . 7 7} \\ \text { September } & 6.01 \pm 3.62 \mathrm{E}-10 & 2.10 \pm 0.77 \mathrm{E}-09 & 3.03 \pm 0.85 \mathrm{E}-07 & 0.34 \pm 1.08 \mathrm{E}-08 & 7.04 \\ \text { October } & 6.82 \pm 8.31 \mathrm{E}-10 & 2.38 \pm 0.87 \mathrm{E}-09 & 2.67 \pm 0.84 \mathrm{E}-07 & -1.68 \pm 8.23 \mathrm{E}-09 & 6.72 \\ \text { November } & 5.72 \pm 2.82 \mathrm{E}-10 & 3.72 \pm 0.82 \mathrm{E}-09 & 1.13 \pm 0.81 \mathrm{E}-07 & -0.93 \pm 7.05 \mathrm{E}-09 & \end{array}$

Note: Bolding convention applied to these data. See page C-2.

WVDP Site Environmental Report

$$
C-11
$$

Calendar Year 2001 


\section{Table C-13}

\section{Radioactivity Concentrations $(\mu \mathrm{Ci} / \mathrm{mL})$ and $\mathrm{pH}$ in Surface Water Waste Tank Farm Underdrain (WN8D1DR)}

$\begin{array}{lrcrrrr}\text { Month } & \text { Gross Alpha } & \text { Gross Beta } & \text { H-3 } & \text { Sr-90 } & \text { Cs-137 } & \begin{array}{c}\text { pH } \\ \text { (standard units) }\end{array} \\ & & & & & & \\ \text { January } & 3.55 \pm 9.96 \mathrm{E}-09 & 2.73 \pm 0.92 \mathrm{E}-08 & -0.28 \pm 7.99 \mathrm{E}-08 & 5.31 \pm 2.55 \mathrm{E}-09 & -0.66 \pm 9.97 \mathrm{E}-09 & \mathbf{7 . 2 1} \\ \text { February } & 0.29 \pm 1.01 \mathrm{E}-08 & \mathbf{2 . 7 8} \pm \mathbf{0 . 9 2 E - 0 8} & -8.89 \pm 8.13 \mathrm{E}-08 & \mathbf{6 . 9 6} \pm \mathbf{2 . 5 8 E}-\mathbf{0 9} & -3.19 \pm 7.29 \mathrm{E}-09 & 6.98 \\ \text { March } & 0.40 \pm 6.12 \mathrm{E}-09 & 1.92 \pm 0.83 \mathrm{E}-08 & -4.05 \pm 8.21 \mathrm{E}-08 & 3.84 \pm 1.74 \mathrm{E}-09 & -1.09 \pm 1.04 \mathrm{E}-08 & \mathbf{6 . 9 0} \\ \text { April } & 0.33 \pm 3.96 \mathrm{E}-09 & 2.68 \pm 5.64 \mathrm{E}-09 & -3.91 \pm 7.57 \mathrm{E}-08 & 2.43 \pm 1.80 \mathrm{E}-09 & 0.61 \pm 1.15 \mathrm{E}-08 & 7.00 \\ \text { May } & 1.20 \pm 4.16 \mathrm{E}-09 & 1.94 \pm 4.82 \mathrm{E}-09 & -1.66 \pm 7.68 \mathrm{E}-08 & 1.71 \pm 1.28 \mathrm{E}-09 & 1.17 \pm 1.26 \mathrm{E}-08 & 7.03 \\ \text { June } & -1.12 \pm 4.75 \mathrm{E}-09 & 5.02 \pm 5.71 \mathrm{E}-09 & -1.22 \pm 8.28 \mathrm{E}-08 & 2.04 \pm 2.18 \mathrm{E}-09 & 0.41 \pm 6.37 \mathrm{E}-09 & 7.09 \\ \text { July } & -1.21 \pm 4.02 \mathrm{E}-09 & 8.19 \pm 5.25 \mathrm{E}-09 & \mathbf{1 . 0 5} \pm \mathbf{0 . 8 2 E}-\mathbf{0 7} & 1.09 \pm 1.26 \mathrm{E}-09 & \mathbf{6 . 5 2} \pm \mathbf{5 . 5 8 E}-\mathbf{0 9} & 6.99 \\ \text { August } & 1.91 \pm 5.01 \mathrm{E}-09 & 5.94 \pm 5.11 \mathrm{E}-09 & 3.83 \pm 8.04 \mathrm{E}-08 & 2.54 \pm 1.53 \mathrm{E}-09 & -6.65 \pm 9.57 \mathrm{E}-09 & 7.18 \\ \text { September } & 1.10 \pm 4.14 \mathrm{E}-09 & 8.57 \pm 4.64 \mathrm{E}-09 & 0.92 \pm 8.17 \mathrm{E}-08 & 1.04 \pm 1.88 \mathrm{E}-09 & 1.31 \pm 5.67 \mathrm{E}-09 & 7.01 \\ \text { October } & -2.70 \pm 5.04 \mathrm{E}-09 & 7.21 \pm 7.35 \mathrm{E}-09 & -5.34 \pm 7.69 \mathrm{E}-08 & 1.79 \pm 1.42 \mathrm{E}-09 & 1.49 \pm 1.52 \mathrm{E}-08 & 7.01 \\ \text { November } & -0.70 \pm 2.67 \mathrm{E}-09 & 8.54 \pm 5.52 \mathrm{E}-09 & 2.83 \pm 7.72 \mathrm{E}-08 & 1.00 \pm 1.77 \mathrm{E}-09 & -0.44 \pm 1.11 \mathrm{E}-08 & 7.07 \\ \text { December* } & & & & & & \end{array}$

\section{Table C-14}

\section{Radioactivity Concentrations $(\mu \mathrm{Ci} / \mathrm{mL})$ in Surface Water Drum Cell Drainage (WNDCELD)}

\begin{tabular}{|c|c|c|c|c|}
\hline Month & Gross Alpha & Gross Beta & & \\
\hline January & $5.13 \pm 5.80 \mathrm{E}-10$ & $2.15 \pm 1.18 \mathrm{E}-09$ & & \\
\hline February & $7.32 \pm 6.48 \mathrm{E}-10$ & $3.28 \pm 1.26 \mathrm{E}-09$ & & \\
\hline March & $3.15 \pm 6.00 \mathrm{E}-10$ & $2.88 \pm 1.25 \mathrm{E}-09$ & & \\
\hline April & $-0.48 \pm 5.34 \mathrm{E}-10$ & $0.33 \pm 1.21 \mathrm{E}-09$ & & \\
\hline May & $2.73 \pm 9.26 \mathrm{E}-10$ & $2.58 \pm 1.26 \mathrm{E}-09$ & & \\
\hline June & $-5.84 \pm 9.94 \mathrm{E}-10$ & $2.67 \pm 1.30 \mathrm{E}-09$ & & \\
\hline July & $1.93 \pm 1.72 \mathrm{E}-09$ & $5.10 \pm 1.66 \mathrm{E}-09$ & & \\
\hline August & $1.19 \pm 7.71 \mathrm{E}-10$ & $4.74 \pm 1.34 \mathrm{E}-09$ & & \\
\hline September & $4.75 \pm 7.57 \mathrm{E}-10$ & $8.54 \pm 1.10 \mathrm{E}-09$ & & \\
\hline October & $0.00 \pm 7.18 \mathrm{E}-10$ & $2.66 \pm 1.27 \mathrm{E}-09$ & & \\
\hline November & $2.41 \pm 6.30 \mathrm{E}-10$ & $6.55 \pm 1.44 \mathrm{E}-09$ & & \\
\hline December & $-0.42 \pm 4.07 \mathrm{E}-10$ & $1.36 \pm 1.22 \mathrm{E}-09$ & & \\
\hline Quarter & H-3 & Sr-90 & I-129 & Cs-137 \\
\hline 1st Quarter & $1.08 \pm 8.04 \mathrm{E}-08$ & $2.55 \pm 1.02 \mathrm{E}-09$ & $1.10 \pm 4.12 \mathrm{E}-10$ & $1.09 \pm 1.25 \mathrm{E}-08$ \\
\hline 2nd Quarter & $-1.09 \pm 0.83 \mathrm{E}-07$ & $0.26 \pm 1.98 \mathrm{E}-09$ & $0.45 \pm 1.00 \mathrm{E}-09$ & $-0.41 \pm 1.25 \mathrm{E}-08$ \\
\hline 3rd Quarter & $5.06 \pm 8.15 \mathrm{E}-08$ & $2.09 \pm 1.73 \mathrm{E}-09$ & $-0.17 \pm 5.86 \mathrm{E}-10$ & $0.70 \pm 1.01 \mathrm{E}-08$ \\
\hline 4th Quarter & $1.12 \pm 0.82 \mathrm{E}-07$ & $0.74 \pm 1.85 \mathrm{E}-09$ & $-4.18 \pm 9.99 \mathrm{E}-10$ & $1.92 \pm 2.22 \mathrm{E}-09$ \\
\hline
\end{tabular}

* Sampling at WN8D1DR discontinued in December 2001.

Note: Bolding convention applied to these data. See page C-2.

WVDP Site Environmental Report

$$
\text { C }-12
$$


Table C-15

2001 Radioactivity Concentrations ( $\mu \mathrm{Ci} / \mathrm{mL}), \mathrm{pH}$, and Conductivity Environmental Laboratory Potable Water (WNDNKEL)

$\begin{array}{lrrrrr}\text { Month } & \text { Gross Alpha } & \text { Gross Beta } & \text { H-3 } & \begin{array}{c}\text { pH } \\ \text { (standard units) }\end{array} & \begin{array}{c}\text { Conductivity } \\ \left(\mu \mathrm{mhos} / \mathrm{cm} @ 25^{\circ} \mathrm{C}\right)\end{array} \\ \text { January } & 0.30 \pm 4.50 \mathrm{E}-10 & 1.77 \pm 0.82 \mathrm{E}-09 & \mathbf{1 . 3 0} \pm \mathbf{0 . 8 1 E - 0 7} & \mathbf{7 . 9 5} & 191 \\ \text { February } & 0.64 \pm 3.89 \mathrm{E}-10 & 2.08 \pm 0.75 \mathrm{E}-09 & -6.71 \pm 5.69 \mathrm{E}-08 & 7.14 & 218 \\ \text { March } & -0.32 \pm 4.74 \mathrm{E}-10 & \mathbf{9 . 0 2} \pm 7.59 \mathrm{E}-10 & -7.64 \pm 8.13 \mathrm{E}-08 & 7.47 & 192 \\ \text { April } & 0.61 \pm 5.26 \mathrm{E}-10 & 1.48 \pm 0.75 \mathrm{E}-09 & 1.07 \pm 8.04 \mathrm{E}-08 & 7.38 & \mathbf{1 8 4} \\ \text { May } & 0.95 \pm 4.44 \mathrm{E}-10 & 1.42 \pm 0.78 \mathrm{E}-09 & -1.49 \pm 8.08 \mathrm{E}-08 & 7.34 & 247 \\ \text { June } & 3.74 \pm 6.46 \mathrm{E}-10 & 1.66 \pm 0.82 \mathrm{E}-09 & -3.14 \pm 6.05 \mathrm{E}-08 & 7.04 & 247 \\ \text { July } & 4.56 \pm 6.64 \mathrm{E}-10 & 1.62 \pm 0.79 \mathrm{E}-09 & -2.20 \pm 7.92 \mathrm{E}-08 & \mathbf{6 . 9 7} & 266 \\ \text { August } & 1.51 \pm 7.16 \mathrm{E}-10 & \mathbf{2 . 5 4 \pm 0 . 8 7 E - 0 9} & -1.96 \pm 8.12 \mathrm{E}-08 & 7.01 & 267 \\ \text { September } & 0.00 \pm 5.90 \mathrm{E}-10 & 2.28 \pm 0.80 \mathrm{E}-09 & -9.09 \pm 8.01 \mathrm{E}-08 & 7.13 & \mathbf{2 8 7} \\ \text { October } & -3.46 \pm 6.50 \mathrm{E}-10 & 1.95 \pm 0.85 \mathrm{E}-09 & 5.80 \pm 8.20 \mathrm{E}-08 & 6.98 & 269 \\ \text { November } & -5.58 \pm 5.31 \mathrm{E}-10 & 1.42 \pm 0.81 \mathrm{E}-09 & 1.25 \pm 0.80 \mathrm{E}-07 & 7.38 & 247 \\ \text { December } & \mathbf{6 . 0 1} \pm \mathbf{5 . 3 2 E}-\mathbf{1 0} & 1.44 \pm 0.83 \mathrm{E}-09 & 5.38 \pm 8.32 \mathrm{E}-08 & 7.44 & \end{array}$

\section{Table C-16}

\section{Radioactivity Concentrations ( $\mu \mathrm{Ci} / \mathrm{mL}), \mathrm{pH}$, and Conductivity} Maintenance Shop Potable Water (WNDNKMS)

\begin{tabular}{|c|c|c|c|c|c|}
\hline Month & Gross Alpha & Gross Beta & H-3 & $\begin{array}{c}\mathbf{p H} \\
\text { (standard units) }\end{array}$ & $\begin{array}{c}\text { Conductivity } \\
\left(\mu \mathrm{mhos} / \mathrm{cm} @ 25^{\circ} \mathrm{C}\right)\end{array}$ \\
\hline January & $2.34 \pm 4.66 \mathrm{E}-10$ & $8.71 \pm 7.72 \mathrm{E}-10$ & $1.16 \pm 0.81 \mathrm{E}-07$ & 7.98 & 226 \\
\hline February & $2.54 \pm 4.13 \mathrm{E}-10$ & $2.19 \pm 0.75 E-09$ & $-6.00 \pm 8.24 \mathrm{E}-08$ & 7.09 & 446 \\
\hline March & $2.74 \pm 4.87 \mathrm{E}-10$ & $1.22 \pm 0.77 \mathrm{E}-09$ & $-4.10 \pm 8.20 \mathrm{E}-08$ & 6.98 & 195 \\
\hline April & $-3.42 \pm 4.91 \mathrm{E}-10$ & $1.37 \pm 0.75 \mathrm{E}-09$ & $-7.47 \pm 8.06 \mathrm{E}-08$ & 7.00 & 202 \\
\hline May & $-0.33 \pm 4.46 \mathrm{E}-10$ & $8.26 \pm 7.54 \mathrm{E}-10$ & $-0.77 \pm 8.18 \mathrm{E}-08$ & 7.16 & 205 \\
\hline June & $-2.33 \pm 5.54 \mathrm{E}-10$ & $2.16 \pm 0.84 \mathrm{E}-09$ & $-1.82 \pm 0.81 \mathrm{E}-07$ & 7.46 & 257 \\
\hline July & $3.75 \pm 6.58 \mathrm{E}-10$ & $2.14 \pm 0.82 \mathrm{E}-09$ & $-2.96 \pm 7.95 \mathrm{E}-08$ & 6.75 & 249 \\
\hline August & $4.62 \pm 7.01 \mathrm{E}-10$ & $1.52 \pm 0.81 \mathrm{E}-09$ & $-7.23 \pm 8.10 \mathrm{E}-08$ & 7.34 & 271 \\
\hline September & $-2.77 \pm 5.43 \mathrm{E}-10$ & $2.15 \pm 0.79 \mathrm{E}-09$ & $-7.43 \pm 8.08 \mathrm{E}-08$ & 7.78 & 279 \\
\hline October & $-4.22 \pm 6.02 \mathrm{E}-10$ & $1.14 \pm 0.80 \mathrm{E}-09$ & $4.40 \pm 8.20 \mathrm{E}-08$ & 7.37 & 323 \\
\hline November & $-4.24 \pm 5.60 \mathrm{E}-10$ & $1.76 \pm 0.83 \mathrm{E}-09$ & $0.56 \pm 7.85 \mathrm{E}-08$ & 7.27 & 295 \\
\hline December & $1.44 \pm 5.56 \mathrm{E}-10$ & $1.64 \pm 0.76 \mathrm{E}-09$ & $0.62 \pm 8.33 \mathrm{E}-08$ & 6.95 & 274 \\
\hline
\end{tabular}

Note: Bolding convention applied to these data. See page $C-2$.

WVDP Site Environmental Report

$$
\text { C }-13
$$

Calendar Year 2001 


\section{Table C-17 \\ 2001 Radioactivity Concentrations $(\mu \mathrm{Ci} / \mathrm{mL}), \mathrm{pH}$, and Conductivity Main Plant Potable Water (WNDNKMP)}

$\begin{array}{lrrrrr}\text { Month } & \text { Gross Alpha } & \text { Gross Beta } & \text { H-3 } & \begin{array}{c}\text { pH } \\ \text { (standard units) }\end{array} & \begin{array}{c}\text { Conductivity } \\ \left(\mu \mathrm{mhos} / \mathrm{cm} @ 25^{\circ} \mathrm{C}\right)\end{array} \\ \text { January } & 1.75 \pm 4.57 \mathrm{E}-10 & 7.54 \pm 7.64 \mathrm{E}-10 & 2.99 \pm 7.96 \mathrm{E}-08 & \mathbf{7 . 9 8} & 206 \\ \text { February } & 2.22 \pm 4.08 \mathrm{E}-10 & 1.54 \pm 0.72 \mathrm{E}-09 & -5.97 \pm 8.24 \mathrm{E}-08 & 7.17 & 213 \\ \text { March } & 1.30 \pm 5.01 \mathrm{E}-10 & 1.04 \pm 0.77 \mathrm{E}-09 & -4.84 \pm 8.16 \mathrm{E}-08 & 7.20 & \mathbf{1 8 7} \\ \text { April } & -4.80 \pm 4.25 \mathrm{E}-10 & 1.93 \pm 0.77 \mathrm{E}-09 & -0.34 \pm 8.15 \mathrm{E}-08 & 7.05 & 217 \\ \text { May } & 1.01 \pm 4.70 \mathrm{E}-10 & 1.44 \pm 0.80 \mathrm{E}-09 & 2.44 \pm 5.78 \mathrm{E}-08 & 7.34 & 2.08 \\ \text { June } & -4.28 \pm 5.35 \mathrm{E}-10 & 1.36 \pm 0.80 \mathrm{E}-09 & -1.60 \pm 0.81 \mathrm{E}-07 & 7.25 & 261 \\ \text { July } & 0.42 \pm 6.23 \mathrm{E}-10 & 1.85 \pm 0.81 \mathrm{E}-09 & 2.67 \pm 7.98 \mathrm{E}-08 & 6.89 & 261 \\ \text { August } & 4.72 \pm 7.16 \mathrm{E}-10 & 1.47 \pm 0.81 \mathrm{E}-09 & -5.51 \pm 8.12 \mathrm{E}-08 & \mathbf{6 . 7 5} & 272 \\ \text { September } & 2.69 \pm 6.08 \mathrm{E}-10 & 1.87 \pm 0.78 \mathrm{E}-09 & -8.82 \pm 8.02 \mathrm{E}-08 & 7.58 & \mathbf{3 0 0} \\ \text { October } & -5.96 \pm 6.15 \mathrm{E}-10 & 1.87 \pm 0.84 \mathrm{E}-09 & 6.19 \pm 8.21 \mathrm{E}-08 & 7.35 & 282 \\ \text { November } & -4.14 \pm 5.48 \mathrm{E}-10 & 1.69 \pm 0.82 \mathrm{E}-09 & 2.33 \pm 7.84 \mathrm{E}-08 & 7.20 & 258 \\ \text { December } & 0.36 \pm 5.40 \mathrm{E}-10 & \mathbf{2 . 6 3} \pm \mathbf{0 . 8 2 E}-\mathbf{0 9} & 4.98 \pm 8.33 \mathrm{E}-08 & 7.16 & \end{array}$

Note: Bolding convention applied to these data. See page C-2.

WVDP Site Environmental Report

$$
C-14
$$




\section{Table C-18 \\ 2001 Radioactivity Concentrations $(\mu \mathrm{Ci} / \mathrm{mL})$ and Water Quality Parameters Utility Room Potable Water (WNDNKUR)}

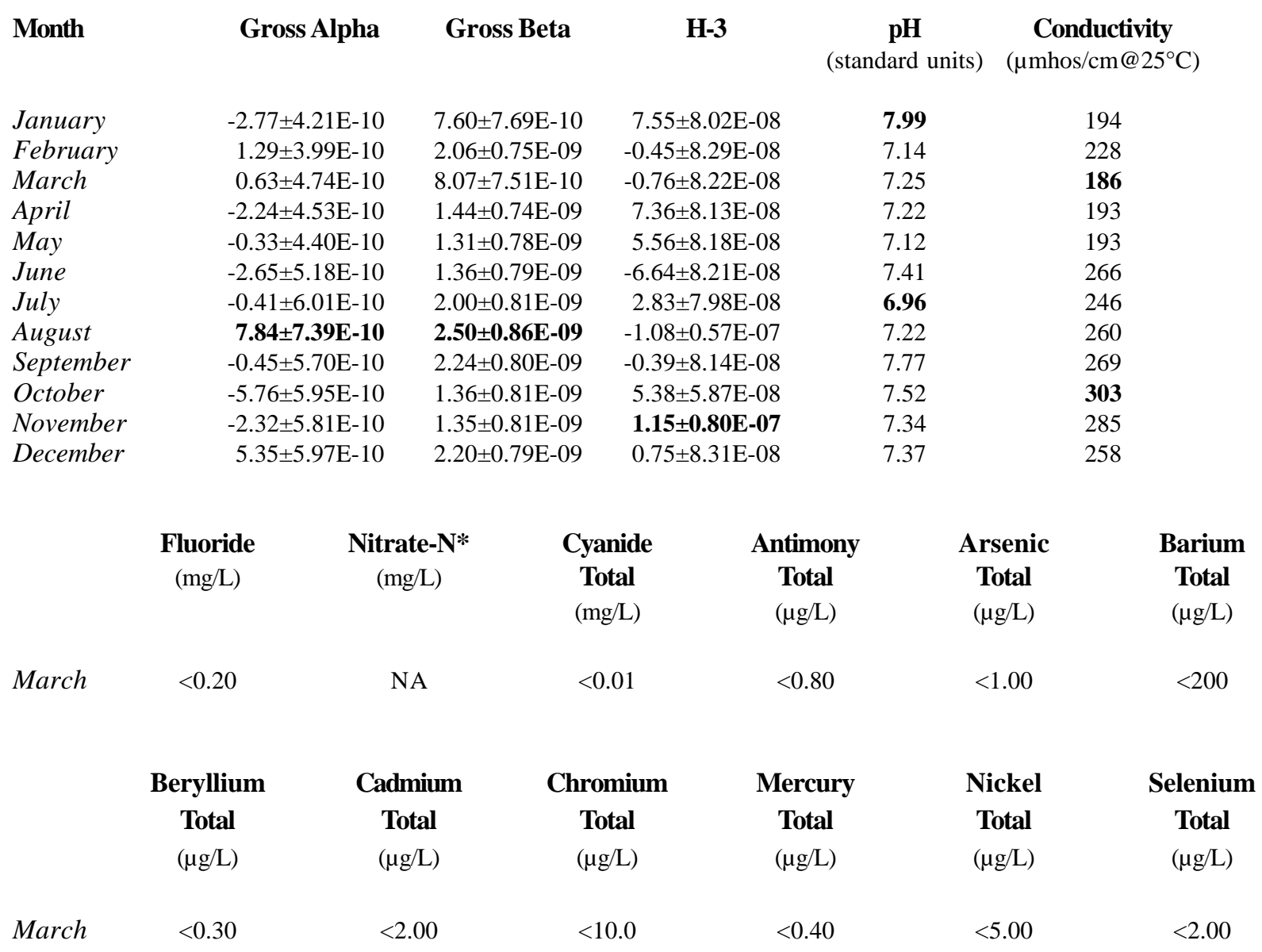

\section{Thallium \\ Total \\ $(\mu \mathrm{g} / \mathrm{L})$}

March

$<0.70$

NA - Not applicable.

* Nitrate-N collected and analyzed by the Cattaraugus County Health Department.

Note: Bolding convention applied to these data. See page C-2.

WVDP Site Environmental Report

$$
\text { C }-15
$$




\section{Table C-19 \\ 2001 Radioactivity Concentrations $(\mu \mathrm{Ci} / \mathrm{mL})$ and Water Quality Parameters Storage and Disposal Area Drainage (WNNDADR)}

\begin{tabular}{|c|c|c|c|c|c|}
\hline Month & Gross Alpha & Gross Beta & H-3 & Cs-137 & $\begin{array}{c}\text { NPOC** } \\
(\mathrm{mg} / \mathrm{L})\end{array}$ \\
\hline January & $1.63 \pm 0.96 \mathrm{E}-09$ & $2.20 \pm 0.06 \mathrm{E}-07$ & $8.46 \pm 0.91 \mathrm{E}-07$ & $1.88 \pm 7.23 \mathrm{E}-09$ & 6.82 \\
\hline February & $-0.61 \pm 1.66 \mathrm{E}-09$ & $3.30 \pm 0.10 \mathrm{E}-07$ & $6.50 \pm 0.90 \mathrm{E}-07$ & $1.72 \pm 8.37 \mathrm{E}-09$ & 5.15 \\
\hline March & $1.15 \pm 0.94 \mathrm{E}-09$ & $2.02 \pm 0.06 \mathrm{E}-07$ & $1.13 \pm 0.10 \mathrm{E}-06$ & $-2.65 \pm 9.29 \mathrm{E}-09$ & 4.48 \\
\hline April & $2.63 \pm 8.79 \mathrm{E}-10$ & $1.65 \pm 0.05 \mathrm{E}-07$ & $7.50 \pm 0.91 \mathrm{E}-07$ & $0.04 \pm 1.12 \mathrm{E}-08$ & 5.88 \\
\hline May & $0.00 \pm 1.57 \mathrm{E}-09$ & $1.68 \pm 0.07 \mathrm{E}-07$ & $2.46 \pm 0.13 \mathrm{E}-06$ & $-2.44 \pm 7.18 \mathrm{E}-09$ & 6.90 \\
\hline June & $0.50 \pm 1.69 \mathrm{E}-09$ & $1.82 \pm 0.07 \mathrm{E}-07$ & $1.46 \pm 0.11 \mathrm{E}-06$ & $-1.97 \pm 6.94 \mathrm{E}-09$ & 6.80 \\
\hline July & $-0.51 \pm 1.80 \mathrm{E}-09$ & $1.67 \pm 0.07 \mathrm{E}-07$ & $2.37 \pm 0.13 \mathrm{E}-06$ & $0.09 \pm 1.17 \mathrm{E}-08$ & 6.65 \\
\hline August & $0.12 \pm 1.52 \mathrm{E}-09$ & $1.61 \pm 0.07 \mathrm{E}-07$ & $2.40 \pm 0.13 \mathrm{E}-06$ & $-5.50 \pm 8.93 \mathrm{E}-09$ & 4.87 \\
\hline September & $0.12 \pm 1.50 \mathrm{E}-09$ & $1.52 \pm 0.07 \mathrm{E}-07$ & $1.60 \pm 0.11 \mathrm{E}-06$ & $0.71 \pm 7.27 \mathrm{E}-09$ & 4.95 \\
\hline October & $0.12 \pm 1.52 \mathrm{E}-09$ & $1.91 \pm 0.08 \mathrm{E}-07$ & $9.61 \pm 0.95 \mathrm{E}-07$ & $3.32 \pm 8.06 \mathrm{E}-09$ & 5.45 \\
\hline November & $1.01 \pm 1.37 \mathrm{E}-09$ & $1.70 \pm 0.07 \mathrm{E}-07$ & $9.11 \pm 0.91 \mathrm{E}-07$ & $0.50 \pm 8.74 \mathrm{E}-09$ & 6.72 \\
\hline \multirow[t]{2}{*}{ December } & $8.78 \pm 9.38 \mathrm{E}-10$ & $1.75 \pm 0.05 \mathrm{E}-07$ & $9.43 \pm 0.93 \mathrm{E}-07$ & $-0.62 \pm 6.88 \mathrm{E}-09$ & 7.55 \\
\hline & $\begin{array}{l}\text { TOX* } \\
(\mu \mathrm{g} / \mathrm{L})\end{array}$ & $\begin{array}{c}\mathbf{p H}^{*} \\
\text { (standard units) }\end{array}$ & & & \\
\hline January & 11.4 & 7.21 & & & \\
\hline February & 13.4 & 7.10 & & & \\
\hline March & 10.3 & 7.03 & & & \\
\hline April & 12.2 & 6.92 & & & \\
\hline May & 8.6 & 7.22 & & & \\
\hline June & 15.2 & 7.30 & & & \\
\hline July & 21.0 & 7.04 & & & \\
\hline August & 16.7 & 6.98 & & & \\
\hline September & 19.7 & 7.26 & & & \\
\hline October & 15.5 & 6.96 & & & \\
\hline November & 16.9 & 6.93 & & & \\
\hline December & 12.7 & 6.97 & & & \\
\hline Quarter & Sr-90 & I-129 & & & \\
\hline 1st Quarter & $1.15 \pm 0.07 E-07$ & $0.60 \pm 1.03 \mathrm{E}-09$ & & & \\
\hline 2nd Quarter & $8.61 \pm 0.62 \mathrm{E}-08$ & $0.51 \pm 1.30 \mathrm{E}-09$ & & & \\
\hline 3rd Quarter & $7.21 \pm 0.54 \mathrm{E}-08$ & $4.18 \pm 8.06 \mathrm{E}-10$ & & & \\
\hline 4th Quarter & $8.44 \pm 0.55 \mathrm{E}-08$ & $1.15 \pm 0.91 E-09$ & & & \\
\hline
\end{tabular}

* Monthly average of weekly measurements.

Note: Bolding convention applied to these data. See page C-2.

WVDP Site Environmental Report

$$
C-16
$$

Calendar Year 2001 


\section{Table C-20}

\section{Radioactivity Concentrations ( $\mu \mathrm{Ci} / \mathrm{mL}), \mathrm{NPOC}$, and TOX in Groundwater at the NDA Interceptor Trench (WNNDATR)}

\begin{tabular}{|c|c|c|c|c|c|c|}
\hline Month & Gross Alpha & Gross Beta & H-3 & Cs-137 & $\begin{array}{c}\mathbf{N P O C} \\
(\mathrm{mg} / \mathrm{L})\end{array}$ & $\begin{array}{c}\text { TOX } \\
(\mu \mathrm{g} / \mathrm{L})\end{array}$ \\
\hline January & $1.55 \pm 2.18 \mathrm{E}-09$ & $1.17 \pm 0.06 \mathrm{E}-07$ & $9.31 \pm 0.32 \mathrm{E}-06$ & $0.24 \pm 5.41 \mathrm{E}-09$ & 9.0 & 18.2 \\
\hline February & $2.85 \pm 1.27 \mathrm{E}-09$ & $1.47 \pm 0.05 \mathrm{E}-07$ & $5.84 \pm 0.23 \mathrm{E}-06$ & $-0.04 \pm 7.85 \mathrm{E}-09$ & 5.0 & 14.5 \\
\hline March & $1.56 \pm 1.70 \mathrm{E}-09$ & $8.36 \pm 0.40 \mathrm{E}-08$ & $1.05 \pm 0.04 \mathrm{E}-05$ & $0.40 \pm 1.20 \mathrm{E}-08$ & 4.4 & 19.0 \\
\hline April & $1.52 \pm 1.06 \mathrm{E}-09$ & $9.75 \pm 0.41 \mathrm{E}-08$ & $2.09 \pm 0.12 \mathrm{E}-06$ & $-1.16 \pm 1.29 \mathrm{E}-08$ & 5.0 & 14.3 \\
\hline May & $3.30 \pm 1.70 \mathrm{E}-09$ & $6.77 \pm 0.36 \mathrm{E}-08$ & $1.98 \pm 0.06 \mathrm{E}-05$ & $-2.78 \pm 7.95 \mathrm{E}-09$ & 4.3 & 7.7 \\
\hline June & $1.00 \pm 2.00 \mathrm{E}-09$ & $1.71 \pm 0.07 \mathrm{E}-07$ & $7.38 \pm 0.27 \mathrm{E}-06$ & $-1.04 \pm 6.70 \mathrm{E}-09$ & 4.7 & 25.8 \\
\hline July & $-0.53 \pm 2.23 \mathrm{E}-09$ & $9.64 \pm 0.59 \mathrm{E}-08$ & $9.94 \pm 0.34 \mathrm{E}-06$ & $5.79 \pm 7.52 \mathrm{E}-09$ & 3.5 & 39.0 \\
\hline August & $4.62 \pm 2.70 \mathrm{E}-09$ & $8.86 \pm 0.56 \mathrm{E}-08$ & $1.38 \pm 0.05 \mathrm{E}-05$ & $-2.62 \pm 8.60 \mathrm{E}-09$ & 3.4 & 37.8 \\
\hline September & $1.61 \pm 1.41 \mathrm{E}-09$ & $1.56 \pm 0.05 \mathrm{E}-07$ & $2.55 \pm 0.13 \mathrm{E}-06$ & $-3.97 \pm 8.80 \mathrm{E}-09$ & 4.7 & 15.8 \\
\hline October & $0.13 \pm 1.35 \mathrm{E}-09$ & $2.51 \pm 0.06 \mathrm{E}-07$ & $1.93 \pm 0.12 E-06$ & $-0.06 \pm 1.24 \mathrm{E}-08$ & 5.4 & 22.5 \\
\hline November & $0.52 \pm 1.80 \mathrm{E}-09$ & $1.59 \pm 0.07 \mathrm{E}-07$ & $3.57 \pm 0.16 \mathrm{E}-06$ & $-2.37 \pm 7.88 \mathrm{E}-09$ & 5.7 & 18.6 \\
\hline December & $1.76 \pm 1.38 \mathrm{E}-09$ & $1.48 \pm 0.05 \mathrm{E}-07$ & $2.63 \pm 0.14 \mathrm{E}-06$ & $0.63 \pm 9.95 \mathrm{E}-09$ & 6.5 & 16.2 \\
\hline Quarter & I-129 & & & & & \\
\hline 1st Quarter & $2.89 \pm 6.44 \mathrm{E}-10$ & & & & & \\
\hline 2nd Quarter & $1.23 \pm 1.07 \mathrm{E}-09$ & & & & & \\
\hline 3rd Quarter & $1.06 \pm 0.55 \mathrm{E}-09$ & & & & & \\
\hline 4th Quarter & $4.24 \pm 9.81 \mathrm{E}-10$ & & & & & \\
\hline
\end{tabular}

Note: Bolding convention applied to these data. See page C-2.

WVDP Site Environmental Report

$$
C-17
$$




\section{Table C-21}

2001 Radioactivity Concentrations $(\mu \mathrm{Ci} / \mathrm{mL})$ and Water Quality Parameters in Surface Water at the Standing Water (WNSTAW-Series) Sampling Locations

\begin{tabular}{|c|c|c|c|c|c|c|c|}
\hline Location & Date & Gross Alpha & Gross Beta & \multicolumn{2}{|c|}{ H-3 } & $\begin{array}{c}\mathbf{p H} \\
\text { (standard units) }\end{array}$ & $\begin{array}{c}\text { Conductivity } \\
\left(\mu \mathrm{mhos} / \mathrm{cm} @ 25^{\circ} \mathrm{C}\right)\end{array}$ \\
\hline WNSTAW4 & $10 / 23$ & $0.82 \pm 4.29 \mathrm{E}-10$ & $6.18 \pm 1.13 \mathrm{E}-09$ & -1.0 & E-07 & 7.47 & 132 \\
\hline WNSTAW5 & $10 / 23$ & $1.66 \pm 3.85 \mathrm{E}-10$ & $3.41 \pm 1.00 \mathrm{E}-09$ & -1.0 & E-07 & 6.96 & 58 \\
\hline WNSTAW6 & $10 / 23$ & $0.00 \pm 6.17 \mathrm{E}-10$ & $4.77 \pm 1.09 \mathrm{E}-09$ & -1.7 & E-08 & 7.32 & 233 \\
\hline WNSTAW9 & $10 / 23$ & $1.09 \pm 6.69 \mathrm{E}-10$ & $2.22 \pm 1.00 \mathrm{E}-09$ & -9.8 & E-08 & 7.56 & 255 \\
\hline \multirow[t]{2}{*}{ WNSTAWB* } & $10 / 23$ & $3.81 \pm 8.86 \mathrm{E}-10$ & $2.29 \pm 1.04 \mathrm{E}-09$ & -1.20 & E-07 & 7.71 & 414 \\
\hline & & $\begin{array}{l}\text { Chloride } \\
(\mathrm{mg} / \mathrm{L})\end{array}$ & $\begin{array}{c}\text { Nitrate } \\
+ \text { Nitrite } \\
(\mathrm{mg} / \mathrm{L})\end{array}$ & $\begin{array}{l}\text { Sulfate } \\
(\mathrm{mg} / \mathrm{L})\end{array}$ & $\begin{array}{l}\text { Iron } \\
\text { Total } \\
(\mu \mathrm{g} / \mathrm{L})\end{array}$ & $\begin{array}{c}\text { Manganese } \\
\text { Total } \\
(\mu \mathrm{g} / \mathrm{L})\end{array}$ & $\begin{array}{c}\text { Sodium } \\
\text { Total } \\
(\mu \mathrm{g} / \mathrm{L})\end{array}$ \\
\hline WNSTAW4 & $10 / 23$ & 15.2 & $<0.05$ & 5.4 & 1,390 & 213 & 8,800 \\
\hline WNSTAW5 & $10 / 23$ & $<1.0$ & $<0.05$ & 5.2 & 607 & 88 & $<1,000$ \\
\hline WNSTAW6 & $10 / 23$ & 11.8 & $<0.05$ & 22.8 & $<100$ & 36 & 1,000 \\
\hline WNSTAW9 & $10 / 23$ & 11.9 & $<0.05$ & 22.9 & 330 & 73 & 8,095 \\
\hline WNSTAWB* & $10 / 23$ & 35.4 & $<0.05$ & 17.6 & 312 & 124 & 21,500 \\
\hline
\end{tabular}

* Background location.

Note: Bolding convention not applicable to these data.

WVDP Site Environmental Report

$$
C-18
$$




\section{Table C-22}

\section{Radioactivity Concentrations $(\mu \mathrm{Ci} / \mathrm{mL}), \mathrm{pH}$, and Conductivity in Surface Water Upstream of the WVDP in Buttermilk Creek at Fox Valley (WFBCBKG)*}

\begin{tabular}{|c|c|c|c|c|c|}
\hline Month & Gross Alpha & Gross Beta & $\mathbf{H}-3$ & $\begin{array}{c}\mathbf{p H} \mathbf{H}^{* *} \\
\text { (standard units) }\end{array}$ & $\begin{array}{c}\text { Conductivity } \\
(\mu \text { * } \\
\left(\mu \mathrm{mhos} / \mathrm{cm} @ 25^{\circ} \mathrm{C}\right)\end{array}$ \\
\hline January & $3.53 \pm 5.73 \mathrm{E}-10$ & $1.70 \pm 1.16 \mathrm{E}-09$ & $1.02 \pm 8.01 \mathrm{E}-08$ & 7.61 & 279 \\
\hline February & $4.22 \pm 5.96 \mathrm{E}-10$ & $2.30 \pm 1.20 \mathrm{E}-09$ & $-3.47 \pm 8.17 \mathrm{E}-08$ & 6.96 & 239 \\
\hline March & $1.30 \pm 0.78 E-09$ & $1.40 \pm 1.20 \mathrm{E}-09$ & $-7.08 \pm 7.91 \mathrm{E}-08$ & 6.84 & 259 \\
\hline April & $-0.45 \pm 5.10 \mathrm{E}-10$ & $0.41 \pm 1.21 \mathrm{E}-09$ & $-6.91 \pm 8.06 \mathrm{E}-08$ & 6.74 & 207 \\
\hline May & $8.00 \pm 8.30 \mathrm{E}-10$ & $1.28 \pm 1.35 \mathrm{E}-09$ & $-5.55 \pm 8.14 \mathrm{E}-08$ & 7.07 & 275 \\
\hline June & $1.14 \pm 1.02 \mathrm{E}-09$ & $2.34 \pm 1.26 \mathrm{E}-09$ & $-7.26 \pm 8.28 \mathrm{E}-08$ & 7.15 & 309 \\
\hline July & $4.77 \pm 9.33 \mathrm{E}-10$ & $1.10 \pm 1.34 \mathrm{E}-09$ & $0.34 \pm 7.96 \mathrm{E}-08$ & 6.86 & 320 \\
\hline August & $1.29 \pm 8.37 \mathrm{E}-10$ & 2.72 $\pm 1.29 \mathrm{E}-09$ & $0.54 \pm 7.92 \mathrm{E}-08$ & 7.42 & 352 \\
\hline September & $-0.65 \pm 8.13 \mathrm{E}-10$ & $2.38 \pm 1.24 \mathrm{E}-09$ & $1.22 \pm 0.82 \mathrm{E}-07$ & 7.10 & 392 \\
\hline October & $-0.67 \pm 8.64 \mathrm{E}-10$ & $2.42 \pm 1.28 \mathrm{E}-09$ & $0.81 \pm 8.23 \mathrm{E}-08$ & 6.98 & 376 \\
\hline November & $5.33 \pm 7.24 \mathrm{E}-10$ & $2.61 \pm 1.25 \mathrm{E}-09$ & $5.28 \pm 7.98 \mathrm{E}-08$ & 6.76 & 319 \\
\hline December & $0.48 \pm 3.67 \mathrm{E}-10$ & $1.47 \pm 1.22 \mathrm{E}-09$ & $5.23 \pm 8.11 \mathrm{E}-08$ & 7.15 & 259 \\
\hline Quarter & C-14 & Sr-90 & Tc-99 & I-129 & Cs-137 \\
\hline 1st Quarter & $0.12 \pm 2.79 \mathrm{E}-08$ & $1.48 \pm 1.49 \mathrm{E}-09$ & $0.51 \pm 1.95 \mathrm{E}-09$ & $2.24 \pm 4.88 \mathrm{E}-10$ & $0.04 \pm 4.61 \mathrm{E}-09$ \\
\hline 2nd Quarter & $1.63 \pm 1.32 E-08$ & $1.58 \pm 1.67 \mathrm{E}-09$ & $-1.22 \pm 1.69 \mathrm{E}-09$ & $1.00 \pm 1.01 \mathrm{E}-09$ & $0.63 \pm 2.32 \mathrm{E}-09$ \\
\hline 3rd Quarter & $-7.18 \pm 8.75 \mathrm{E}-09$ & $-0.85 \pm 1.15 \mathrm{E}-09$ & $-3.90 \pm 1.46 \mathrm{E}-09$ & $0.47 \pm 4.66 \mathrm{E}-10$ & $1.98 \pm 2.33 \mathrm{E}-09$ \\
\hline \multirow[t]{2}{*}{ 4th Quarter } & $0.35 \pm 1.27 \mathrm{E}-08$ & $1.48 \pm 1.36 \mathrm{E}-09$ & $2.27 \pm 1.83 \mathrm{E}-09$ & $0.97 \pm 1.05 \mathrm{E}-09$ & $1.11 \pm 2.43 \mathrm{E}-09$ \\
\hline & $\mathrm{U}-232$ & U-233/234 & $\mathrm{U}-235 / 236$ & $\mathrm{U}-238$ & $\begin{array}{c}\text { Total U } \\
(\mu \mathrm{g} / \mathrm{mL})\end{array}$ \\
\hline 1st Quarter & $3.06 \pm 3.79 \mathrm{E}-11$ & $5.62 \pm 5.08 E-11$ & $0.98 \pm 1.96 \mathrm{E}-11$ & 4.18 $\pm 3.46 E-11$ & $9.72 \pm 0.36 \mathrm{E}-05$ \\
\hline 2nd Quarter & $2.55 \pm 3.41 \mathrm{E}-11$ & $8.93 \pm 4.77 \mathrm{E}-11$ & $1.68 \pm 1.95 \mathrm{E}-11$ & $6.70 \pm 3.94 \mathrm{E}-11$ & $2.55 \pm 0.04 \mathrm{E}-04$ \\
\hline 3rd Quarter & $1.36 \pm 2.47 \mathrm{E}-11$ & $1.55 \pm 0.61 \mathrm{E}-10$ & $3.16 \pm 2.78 \mathrm{E}-11$ & $4.72 \pm 3.99 \mathrm{E}-11$ & $3.42 \pm 0.12 \mathrm{E}-04$ \\
\hline \multirow[t]{2}{*}{ 4th Quarter } & $0.27 \pm 1.16 \mathrm{E}-10$ & $1.40 \pm 0.96 \mathrm{E}-10$ & $-0.47 \pm 4.31 \mathrm{E}-11$ & $7.68 \pm 5.99 \mathrm{E}-11$ & $3.83 \pm 0.15 E-04$ \\
\hline & Pu-238 & Pu-239/240 & Am-241 & & \\
\hline 1st Quarter & $0.46 \pm 2.50 \mathrm{E}-11$ & $1.08 \pm 2.22 \mathrm{E}-11$ & $2.48 \pm 3.28 \mathrm{E}-11$ & & \\
\hline 2nd Quarter & $-6.08 \pm 8.62 \mathrm{E}-12$ & $4.22 \pm 8.45 \mathrm{E}-12$ & $0.65 \pm 1.60 \mathrm{E}-11$ & & \\
\hline 3rd Quarter & $-3.40 \pm 6.80 \mathrm{E}-12$ & $1.21 \pm 2.12 \mathrm{E}-11$ & $2.13 \pm 4.14 \mathrm{E}-11$ & & \\
\hline 4th Quarter & $1.51 \pm 2.14 \mathrm{E}-11$ & $1.94 \pm 2.69 \mathrm{E}-11$ & $2.49 \pm 3.59 \mathrm{E}-11$ & & \\
\hline
\end{tabular}

\footnotetext{
* Background location. See Table C-27 for a summary of water quality data at WFBCBKG.

** Monthly average of weekly results.

Note: Bolding convention applied to these data. See page C-2.
}

$$
\text { C }-19
$$


Table C-23

2001 Radioactivity Concentrations $(\mu \mathrm{Ci} / \mathrm{mL}), \mathrm{pH}$, and Conductivity in Surface Water Downstream of the WVDP in Buttermilk Creek at Thomas Corners Bridge (WFBCTCB)

$\begin{array}{lrr}\text { Month } & \text { Gross Alpha } & \text { Gross Beta } \\ & & \\ \text { January } & 8.57 \pm 6.85 \mathrm{E}-10 & 8.86 \pm 1.55 \mathrm{E}-09 \\ \text { February } & 6.28 \pm 5.11 \mathrm{E}-10 & 5.15 \pm 0.97 \mathrm{E}-09 \\ \text { March } & 1.07 \pm 0.79 \mathrm{E}-09 & 6.65 \pm 1.46 \mathrm{E}-09 \\ \text { April } & 6.73 \pm 6.95 \mathrm{E}-10 & \mathbf{3 . 7 1} \pm \mathbf{1 . 4 0 E}-\mathbf{0 9} \\ \text { May } & 5.82 \pm 8.48 \mathrm{E}-10 & 5.60 \pm 1.56 \mathrm{E}-09 \\ \text { June } & 0.77 \pm 1.11 \mathrm{E}-09 & 7.39 \pm 1.54 \mathrm{E}-09 \\ \text { July } & \mathbf{1 . 4 0} \pm \mathbf{1 . 1 9 E}-\mathbf{0 9} & 6.78 \pm 1.65 \mathrm{E}-09 \\ \text { August } & 1.14 \pm 0.84 \mathrm{E}-09 & 7.28 \pm 1.06 \mathrm{E}-09 \\ \text { September } & 6.76 \pm 9.54 \mathrm{E}-10 & 1.16 \pm 0.17 \mathrm{E}-08 \\ \text { October } & 0.30 \pm 1.03 \mathrm{E}-09 & 1.06 \pm 0.17 \mathrm{E}-08 \\ \text { November } & 4.79 \pm 7.23 \mathrm{E}-10 & \mathbf{1 . 2 6} \pm \mathbf{0 . 1 7 E}-\mathbf{0 8} \\ \text { December } & 7.35 \pm 6.11 \mathrm{E}-10 & 7.78 \pm 1.57 \mathrm{E}-09 \\ & & \\ & & \\ \text { Quarter } & \text { Sr-90 } & \text { Cs-137 } \\ & & \\ \text { 1st Quarter } & 3.73 \pm 1.69 \mathrm{E}-09 & -0.67 \pm 2.91 \mathrm{E}-09 \\ \text { 2nd Quarter } & 3.03 \pm 1.30 \mathrm{E}-09 & 1.00 \pm 3.41 \mathrm{E}-09 \\ \text { 3rd Quarter } & \mathbf{1 . 9 9} \pm \mathbf{1 . 4 2 E}-\mathbf{- 0 9} & -1.24 \pm 3.01 \mathrm{E}-09 \\ \text { 4th Quarter } & \mathbf{5 . 4 0} \pm \mathbf{1 . 9 4 E - 0 9} & 1.66 \pm 4.92 \mathrm{E}-09\end{array}$

$\begin{array}{ccc}\text { H-3 } & \begin{array}{c}\mathbf{p H}^{*} \\ \text { (standard units) }\end{array} & \begin{array}{c}\text { Conductivity } \\ (\mu \mathrm{mhos} / \mathrm{cm} @ 2\end{array} \\ \mathbf{1 . 8 7} \pm \mathbf{0 . 8 2 E - 0 7} & \mathbf{7 . 3 1} & 315 \\ 1.80 \pm 8.26 \mathrm{E}-08 & 6.98 & 306 \\ -2.23 \pm 7.95 \mathrm{E}-08 & 6.88 & 296 \\ -1.18 \pm 0.80 \mathrm{E}-07 & 6.86 & \mathbf{2 1 9} \\ -0.88 \pm 8.14 \mathrm{E}-08 & 6.93 & 309 \\ -1.10 \pm 0.83 \mathrm{E}-07 & 7.18 & 350 \\ -4.19 \pm 7.96 \mathrm{E}-08 & 6.87 & 390 \\ 8.14 \pm 7.82 \mathrm{E}-08 & 7.26 & 407 \\ 1.35 \pm 0.81 \mathrm{E}-07 & 7.07 & 401 \\ 1.93 \pm 8.21 \mathrm{E}-08 & 6.80 & \mathbf{4 1 5} \\ 1.17 \pm 0.80 \mathrm{E}-07 & \mathbf{6 . 7 7} & 353 \\ 7.10 \pm 8.12 \mathrm{E}-08 & 7.06 & 288\end{array}$

\section{Table C-24}

\section{Radioactivity Concentrations $(\mu \mathrm{Ci} / \mathrm{mL})$ and $\mathrm{pH}$ in Surface Water Downstream of the WVDP in Cattaraugus Creek at Felton Bridge} (WFFELBR)

$\begin{array}{lrrrrrr}\text { Month } & \text { Gross Alpha } & \text { Gross Beta } & \text { H-3 } & \text { Sr-90 } & \text { Cs-137 } & \begin{array}{c}\text { pH* } \\ \text { (standard units) }\end{array} \\ & & & & & & \\ \text { January** } & 1.91 \pm 1.10 \mathrm{E}-09 & 3.03 \pm 1.77 \mathrm{E}-09 & -1.17 \pm 0.84 \mathrm{E}-07 & 1.37 \pm 0.85 \mathrm{E}-09 & 0.26 \pm 2.35 \mathrm{E}-09 & \mathbf{7 . 6 0} \\ \text { February } & 3.32 \pm 1.06 \mathrm{E}-09 & 5.30 \pm 1.38 \mathrm{E}-09 & -4.00 \pm 8.54 \mathrm{E}-08 & 1.95 \pm 1.35 \mathrm{E}-09 & 0.20 \pm 3.71 \mathrm{E}-09 & 7.33 \\ \text { March } * * & 2.60 \pm 1.44 \mathrm{E}-09 & 4.00 \pm 1.95 \mathrm{E}-09 & -7.37 \pm 8.09 \mathrm{E}-08 & 2.31 \pm 1.85 \mathrm{E}-09 & -2.25 \pm 2.87 \mathrm{E}-09 & 7.17 \\ \text { April } & 7.41 \pm 1.88 \mathrm{E}-09 & \mathbf{6 . 5 2} \pm \mathbf{1 . 6 2 E}-\mathbf{0 9} & -2.18 \pm 8.15 \mathrm{E}-08 & \mathbf{4 . 9 1} \pm \mathbf{1 . 9 0 E}-\mathbf{0 9} & 0.88 \pm 1.91 \mathrm{E}-09 & 7.07 \\ \text { May** } & 0.67 \pm 1.32 \mathrm{E}-09 & 2.77 \pm 2.10 \mathrm{E}-09 & -0.42 \pm 5.91 \mathrm{E}-08 & 2.61 \pm 1.40 \mathrm{E}-09 & \mathbf{5 . 8 1} \pm \mathbf{3 . 7 1 E}-\mathbf{0 9} & 7.44 \\ \text { June } & \mathbf{6 . 0 6} \pm \mathbf{2 . 3 3 E - 0 9} & 4.75 \pm 1.99 \mathrm{E}-09 & -2.02 \pm 0.84 \mathrm{E}-07 & 1.58 \pm 1.67 \mathrm{E}-09 & 1.22 \pm 2.37 \mathrm{E}-09 & 7.37 \\ \text { July } & 1.70 \pm 1.10 \mathrm{E}-09 & \mathbf{1 . 8 8} \pm \mathbf{1 . 4 3 E}-\mathbf{0 9} & 0.87 \pm 8.15 \mathrm{E}-08 & 1.00 \pm 1.25 \mathrm{E}-09 & 1.74 \pm 3.67 \mathrm{E}-09 & 7.07 \\ \text { August** } & 0.00 \pm 1.26 \mathrm{E}-09 & 3.13 \pm 1.83 \mathrm{E}-09 & \mathbf{1 . 0 1} \pm \mathbf{0 . 8 0 E}-\mathbf{0 7} & 2.36 \pm 1.67 \mathrm{E}-09 & -1.13 \pm 4.82 \mathrm{E}-09 & 7.56 \\ \text { September } & 0.00 \pm 1.21 \mathrm{E}-09 & 5.34 \pm 1.96 \mathrm{E}-09 & 1.68 \pm 8.23 \mathrm{E}-08 & -0.50 \pm 1.47 \mathrm{E}-09 & 0.77 \pm 3.54 \mathrm{E}-09 & 7.41 \\ \text { October } & 0.35 \pm 1.20 \mathrm{E}-09 & 3.22 \pm 1.85 \mathrm{E}-09 & -0.43 \pm 8.13 \mathrm{E}-08 & 2.98 \pm 1.91 \mathrm{E}-09 & -0.68 \pm 2.47 \mathrm{E}-09 & 7.38 \\ \text { November** } & 0.58 \pm 1.16 \mathrm{E}-09 & 5.52 \pm 1.96 \mathrm{E}-09 & -2.30 \pm 0.85 \mathrm{E}-07 & 3.31 \pm 1.66 \mathrm{E}-09 & 1.06 \pm 2.41 \mathrm{E}-09 & \mathbf{7 . 0 6} \\ \text { December } & 2.29 \pm 1.15 \mathrm{E}-09 & 2.11 \pm 1.92 \mathrm{E}-09 & 7.04 \pm 8.51 \mathrm{E}-08 & 2.08 \pm 2.06 \mathrm{E}-09 & -0.49 \pm 4.83 \mathrm{E}-09 & 7.24\end{array}$

\footnotetext{
* Average of weekly results.

** Lagoon 3 discharged through WNSP001 during these months.
}

Note: Bolding convention applied to these data. See page C-2

$$
C-20
$$




\section{Table C-25 \\ 2001 Radioactivity Concentrations $(\mu \mathrm{Ci} / \mathrm{mL})$ in Surface Water Upstream of the WVDP in Cattaraugus Creek at Bigelow Bridge (WFBIGBR)*}

$\begin{array}{lrrrrr}\text { Month } & \text { Gross Alpha } & \text { Gross Beta } & \text { H-3 } & \text { Sr-90 } & \text { Cs-137 } \\ \text { January } & 0.81 \pm 1.18 \mathrm{E}-09 & 2.66 \pm 1.32 \mathrm{E}-09 & -4.65 \pm 5.60 \mathrm{E}-08 & 1.00 \pm 1.16 \mathrm{E}-09 & -0.68 \pm 2.25 \mathrm{E}-09 \\ \text { February } & 6.52 \pm 8.44 \mathrm{E}-10 & 2.65 \pm 1.25 \mathrm{E}-09 & 6.11 \pm 5.87 \mathrm{E}-08 & 1.42 \pm 1.28 \mathrm{E}-09 & -1.17 \pm 2.70 \mathrm{E}-09 \\ \text { March } & 4.19 \pm 9.87 \mathrm{E}-10 & 1.81 \pm 1.27 \mathrm{E}-09 & 0.71 \pm 8.11 \mathrm{E}-08 & 1.47 \pm 1.49 \mathrm{E}-09 & -0.87 \pm 2.84 \mathrm{E}-09 \\ \text { April } & 6.53 \pm 9.31 \mathrm{E}-10 & \mathbf{1 . 3 6} \pm \mathbf{1 . 3 2 E}-\mathbf{0 9} & -9.83 \pm 7.92 \mathrm{E}-08 & 0.69 \pm 1.01 \mathrm{E}-09 & -0.68 \pm 3.59 \mathrm{E}-09 \\ \text { May } & -9.06 \pm 8.36 \mathrm{E}-10 & 2.10 \pm 1.25 \mathrm{E}-09 & -7.12 \pm 8.19 \mathrm{E}-08 & 1.42 \pm 0.97 \mathrm{E}-09 & 2.02 \pm 3.96 \mathrm{E}-09 \\ \text { June } & -0.68 \pm 1.16 \mathrm{E}-09 & 1.60 \pm 1.26 \mathrm{E}-09 & -8.89 \pm 8.34 \mathrm{E}-08 & 1.02 \pm 2.07 \mathrm{E}-09 & \mathbf{2 . 5 3} \pm \mathbf{2 . 2 7 E}-\mathbf{0 9} \\ \text { July } & 0.66 \pm 1.47 \mathrm{E}-09 & 1.55 \pm 1.42 \mathrm{E}-09 & 1.03 \pm 5.69 \mathrm{E}-08 & 1.75 \pm 1.34 \mathrm{E}-09 & 0.79 \pm 2.40 \mathrm{E}-09 \\ \text { August } & -0.31 \pm 1.26 \mathrm{E}-09 & 2.35 \pm 1.33 \mathrm{E}-09 & -1.05 \pm 7.98 \mathrm{E}-08 & 1.45 \pm 0.99 \mathrm{E}-09 & -2.12 \pm 4.85 \mathrm{E}-09 \\ \text { September } & 0.84 \pm 1.02 \mathrm{E}-09 & 2.75 \pm 0.98 \mathrm{E}-09 & -1.22 \pm 8.14 \mathrm{E}-08 & \mathbf{3 . 0 7} \pm \mathbf{1 . 8 2 E}-\mathbf{0 9} & 0.85 \pm 3.10 \mathrm{E}-09 \\ \text { October } & -0.27 \pm 1.12 \mathrm{E}-09 & 2.36 \pm 1.27 \mathrm{E}-09 & \mathbf{6 . 1 8} \pm \mathbf{5 . 7 4 E}-\mathbf{0 8} & -0.33 \pm 1.54 \mathrm{E}-09 & -0.66 \pm 3.00 \mathrm{E}-09 \\ \text { November } & 5.74 \pm 8.49 \mathrm{E}-10 & \mathbf{3 . 7 2} \pm \mathbf{1 . 3 2 E}-\mathbf{0 9} & -6.39 \pm 8.52 \mathrm{E}-08 & 1.37 \pm 2.00 \mathrm{E}-09 & 0.75 \pm 2.26 \mathrm{E}-09 \\ \text { December } & \mathbf{1 . 3 0} \pm \mathbf{0 . 8 0 E}-09 & 1.53 \pm 1.26 \mathrm{E}-09 & 1.71 \pm 8.15 \mathrm{E}-08 & 2.48 \pm 1.82 \mathrm{E}-09 & -3.09 \pm 4.72 \mathrm{E}-09\end{array}$

\section{Table C-26}

\section{Radioactivity Concentrations ( $\mu \mathrm{Ci} / \mathrm{mL}), \mathrm{pH}$, and Conductivity in Potable Well Water Around the WVDP}

$\begin{array}{lrrrrrr}\text { Well } & \text { Gross Alpha } & \text { Gross Beta } & \mathbf{H - 3} & \mathbf{C s - 1 3 7} & \begin{array}{c}\mathbf{p H} \\ \text { (standard units) }\left(\mu \mathrm{mhhos} / \mathrm{cm} @ 25^{\circ} \mathrm{C}\right)\end{array} \\ & & & & & & \\ \text { WFWEL01 } & -0.58 \pm 6.10 \mathrm{E}-10 & \mathbf{4 . 4 9} \pm \mathbf{0 . 9 7 E}-09 & 2.32 \pm 7.92 \mathrm{E}-08 & 0.32 \pm 1.40 \mathrm{E}-08 & 7.04 & 435 \\ \text { WFWEL02 } & -1.60 \pm 7.42 \mathrm{E}-10 & 2.01 \pm 1.10 \mathrm{E}-09 & 5.90 \pm 8.07 \mathrm{E}-08 & -4.16 \pm 8.54 \mathrm{E}-09 & 6.69 & 427 \\ \text { WFWEL03 } & \mathbf{8 . 4 5} \pm \mathbf{7 . 1 4 E}-10 & 2.42 \pm 1.07 \mathrm{E}-09 & -2.25 \pm 0.83 \mathrm{E}-07 & -1.06 \pm 7.35 \mathrm{E}-09 & 7.57 & 431 \\ \text { WFWEL04 } & 1.64 \pm 2.80 \mathrm{E}-09 & 3.92 \pm 3.47 \mathrm{E}-09 & 5.15 \pm 7.93 \mathrm{E}-08 & 4.53 \pm 5.55 \mathrm{E}-09 & \mathbf{8 . 0 7} & \mathbf{1 , 4 9 9} \\ \text { WFWEL05 } & -1.13 \pm 7.36 \mathrm{E}-10 & 2.97 \pm 1.07 \mathrm{E}-09 & 5.13 \pm 5.72 \mathrm{E}-08 & -0.68 \pm 1.56 \mathrm{E}-08 & \mathbf{6 . 3 5} & 354 \\ \text { WFWEL06* } & 0.91 \pm 6.07 \mathrm{E}-10 & 3.92 \pm 8.57 \mathrm{E}-10 & 2.02 \pm 8.15 \mathrm{E}-08 & -0.28 \pm 7.09 \mathrm{E}-09 & 7.39 & \mathbf{2 8 8} \\ \text { WFWEL07 } & 0.48 \pm 7.26 \mathrm{E}-10 & 2.79 \pm 1.02 \mathrm{E}-09 & \mathbf{1 . 0 6} \pm \mathbf{0 . 5 7 E}-\mathbf{0 7} & 2.96 \pm 7.54 \mathrm{E}-09 & 7.51 & 417 \\ \text { WFWEL08 } & -0.89 \pm 9.38 \mathrm{E}-10 & 2.26 \pm 1.47 \mathrm{E}-09 & 5.44 \pm 7.97 \mathrm{E}-08 & -4.67 \pm 9.95 \mathrm{E}-09 & 7.46 & 451 \\ \text { WFWEL09 } & -0.71 \pm 1.25 \mathrm{E}-09 & 2.98 \pm 1.61 \mathrm{E}-09 & 0.13 \pm 5.74 \mathrm{E}-08 & -4.70 \pm 8.59 \mathrm{E}-09 & 8.05 & 697 \\ \text { WFWEL10 } & -0.21 \pm 1.32 \mathrm{E}-09 & 1.23 \pm 1.48 \mathrm{E}-09 & -1.59 \pm 8.14 \mathrm{E}-08 & -1.44 \pm 9.83 \mathrm{E}-09 & 6.95 & 602\end{array}$

\footnotetext{
* Background location.
}

Note: Bolding convention applied to these data. See page C-2.

$$
\text { C- } 21
$$




\section{Table C-27 \\ 2001 Surface Water Quality at Locations WFBCBKG*, WNSP006, WNSWAMP, and WNSW74A}

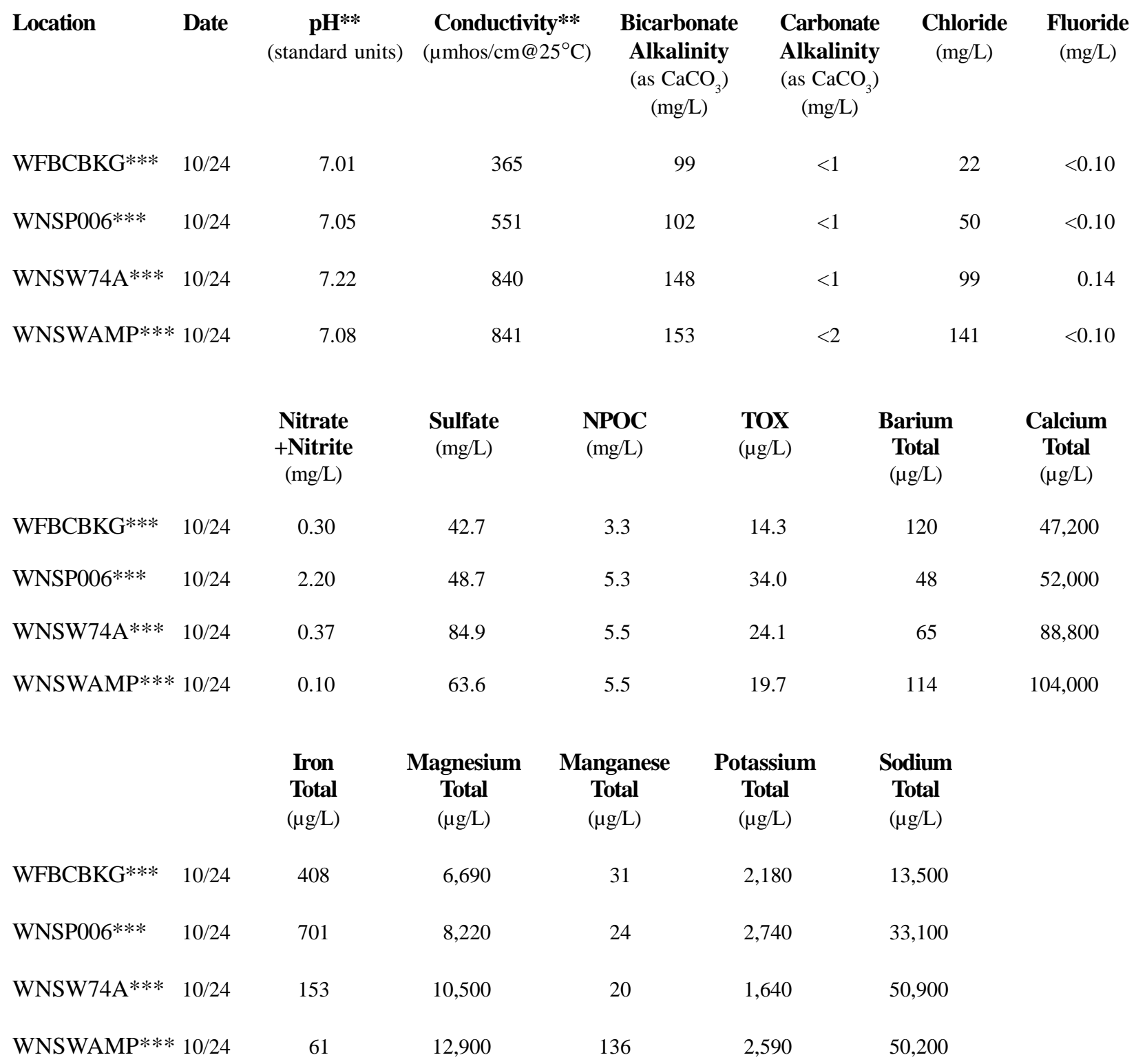

\footnotetext{
* Background location.

** pH and conductivity data are from a separate sample collected within one week of the sample analyzed for other nonradiological parameters.

*** First semi-annual collection data not available.
}

Note: Bolding convention not applicable to these data.

WVDP Site Environmental Report

$$
\text { C - } 22
$$




\section{Table C-28}

\section{Radioactivity Concentrations ( $\mu \mathrm{Ci} / \mathrm{g}$ dry weight from upper $5 \mathrm{~cm}$ ) and Metals Concentrations (mg/kg dry) in On-Site Soils/Sediments}

\begin{tabular}{|c|c|c|c|c|c|}
\hline Location & Gross Alpha & Gross Beta & K-40 & Co-60 & Sr-90 \\
\hline SNSP006 & $9.95 \pm 4.60 \mathrm{E}-06$ & $4.27 \pm 0.61 \mathrm{E}-05$ & $1.57 \pm 0.18 \mathrm{E}-05$ & $0.41 \pm 1.69 \mathrm{E}-08$ & $5.24 \pm 0.59 \mathrm{E}-07$ \\
\hline SNSW74A & $1.12 \pm 0.48 \mathrm{E}-05$ & $2.68 \pm 0.51 \mathrm{E}-05$ & $1.15 \pm 0.14 \mathrm{E}-05$ & $2.65 \pm 8.72 \mathrm{E}-09$ & $3.28 \pm 0.50 \mathrm{E}-07$ \\
\hline \multirow[t]{2}{*}{ SNSWAMP } & $1.83 \pm 0.55 \mathrm{E}-05$ & $6.67 \pm 0.69 \mathrm{E}-05$ & $1.53 \pm 0.07 \mathrm{E}-05$ & $0.92 \pm 1.49 \mathrm{E}-08$ & $1.77 \pm 0.10 \mathrm{E}-06$ \\
\hline & Cs-137 & U-232 & U-233/234 & U-235/236 & U-238 \\
\hline SNSP006 & $1.06 \pm 0.12 \mathrm{E}-05$ & $2.60 \pm 3.17 \mathrm{E}-08$ & $7.16 \pm 1.34 \mathrm{E}-07$ & $5.00 \pm 4.37 \mathrm{E}-08$ & $6.18 \pm 1.26 \mathrm{E}-07$ \\
\hline SNSW74A & $1.75 \pm 0.19 \mathrm{E}-06$ & $2.76 \pm 2.23 \mathrm{E}-08$ & $7.00 \pm 1.40 \mathrm{E}-07$ & $8.15 \pm 4.55 \mathrm{E}-08$ & $5.99 \pm 1.25 \mathrm{E}-07$ \\
\hline \multirow[t]{2}{*}{ SNSWAMP } & $7.76 \pm 0.12 \mathrm{E}-06$ & $0.38 \pm 3.53 \mathrm{E}-08$ & $8.05 \pm 1.45 \mathrm{E}-07$ & $8.28 \pm 4.06 \mathrm{E}-08$ & $7.66 \pm 1.38 \mathrm{E}-07$ \\
\hline & $\underset{(\mu \mathrm{g} / \mathrm{g})}{\text { Total }}$ & Pu-238 & $\mathrm{Pu}-239 / 240$ & Am-241 & \\
\hline SNSP006 & $1.50 \pm 0.02 \mathrm{E}+00$ & $4.00 \pm 2.60 \mathrm{E}-08$ & $2.20 \pm 2.00 \mathrm{E}-08$ & $4.66 \pm 2.58 \mathrm{E}-08$ & \\
\hline SNSW74A & $1.60 \pm 0.02 \mathrm{E}+00$ & $3.79 \pm 2.22 \mathrm{E}-08$ & $8.53 \pm 3.51 \mathrm{E}-08$ & $1.00 \pm 0.35 \mathrm{E}-07$ & \\
\hline SNSWAMP & $1.89 \pm 0.04 \mathrm{E}+00$ & $2.48 \pm 0.72 \mathrm{E}-07$ & $3.30 \pm 0.86 \mathrm{E}-07$ & $6.97 \pm 1.11 \mathrm{E}-07$ & \\
\hline
\end{tabular}

$\begin{array}{llll}\text { Aluminum Antimony } & \text { Arsenic } & \text { Barium } & \text { Beryllium }\end{array}$

SNSP006

SNSW74A

SNSWAMP

Calcium

SNSP006

SNSW74A

SNSWAMP

SNSP006
SNSW74A
SNSWAMP

SNSWAMP

SNSP006

SNSW74A

SNSWAMP

$$
\begin{array}{r}
6,900 \\
9,860 \\
10,700
\end{array}
$$

Calcium

$$
\begin{array}{r}
12,800 \\
32,400 \\
3,310
\end{array}
$$

$$
\begin{aligned}
& 5,155 \\
& 5,850 \\
& 3,990
\end{aligned}
$$

$$
\text { Silver }
$$

Magnesium

$<0.4$
0.4
0.3

63.4
71.7
78.4

$$
\begin{aligned}
& 0.48 \\
& 0.54 \\
& 0.61
\end{aligned}
$$

$$
\begin{aligned}
& <0.04 \\
& <0.05 \\
& <0.04
\end{aligned}
$$

Chromium

Cobalt

10.8
7.6
9.5

$$
\begin{aligned}
& 10.2 \\
& 12.2 \\
& 14.3
\end{aligned}
$$

Manganese

Mercury

Nickel

\begin{tabular}{c} 
Copper \\
\hline 16.8 \\
20.7 \\
26.4
\end{tabular}

Iron

$$
\begin{aligned}
& 18,250 \\
& 20,300 \\
& 25,600
\end{aligned}
$$

$$
\begin{array}{r}
<0.02 \\
0.03
\end{array}
$$$$
0.05
$$

$$
\begin{aligned}
& 21.2 \\
& 18.7 \\
& 22.7
\end{aligned}
$$

Potassium

Selenium

$$
\text { Sodium }
$$

Thallium

Vanadium

$$
\begin{aligned}
& 1,122 \\
& 1,110 \\
& 1,520
\end{aligned}
$$

$<0.37$

$<0.43$

$<0.32$

14.0

16.7

21.8

Lead
14.0
16.7
21.8

$\begin{array}{rrrrr}<0.14 & 94.4 & <0.56 & 13.4 & 55.3 \\ <0.16 & 140 & <0.64 & 17.0 & 97.6 \\ <0.12 & 53.8 & <0.48 & 17.5 & 96.5\end{array}$

Note: Bolding convention not applicable to these data.

WVDP Site Environmental Report

$$
C-23
$$




\section{Table C-29}

\section{Radioactivity Concentrations ( $\mu \mathrm{Ci} / \mathrm{g}$ dry weight from upper $5 \mathrm{~cm}$ ) in Surface Soil Collected at Air Sampling Stations Around the WVDP}

\begin{abstract}
Location
SFBLKST

SFBOEHN

SFFXVRD

SFGRVAL*

SFNASHV*

SFRSPRD

SFRT240

SFSPRVL

SFTCORD

SFWEVAL
\end{abstract}

\section{SFBLKST}

SFBOEHN

SFFXVRD

SFGRVAL*

SFNASHV*

SFRSPRD

SFRT240

SFSPRVL

SFTCORD

SFWEVAL

\begin{tabular}{lr} 
& \multicolumn{1}{c}{ U-232 } \\
& \\
SFBOEHN & $1.50 \pm 3.02 \mathrm{E}-08$ \\
SFGRVAL* & $-1.48 \pm 3.39 \mathrm{E}-08$ \\
SFRSPRD & $0.55 \pm 2.98 \mathrm{E}-08$
\end{tabular}

Gross Beta
$2.95 \pm 0.33 \mathrm{E}-05$
$2.02 \pm 0.32 \mathrm{E}-05$
$\mathbf{1 . 7 5} \pm \mathbf{0 . 3 1 E}-\mathbf{0 5}$
$1.89 \pm 0.28 \mathrm{E}-05$
$2.01 \pm 0.29 \mathrm{E}-05$
$2.14 \pm 0.28 \mathrm{E}-05$
$2.07 \pm 0.30 \mathrm{E}-05$
$1.78 \pm 0.30 \mathrm{E}-05$
$\mathbf{3 . 0 8} \pm \mathbf{0 . 3 4 E}-\mathbf{0 5}$
$2.01 \pm 0.33 \mathrm{E}-05$

\section{Cs-137}

$2.97 \pm 0.62 \mathrm{E}-07$ $3.96 \pm 0.79 \mathrm{E}-07$ $6.83 \pm 1.05 \mathrm{E}-07$ $7.98 \pm 0.54 \mathrm{E}-07$ $5.53 \pm 2.58 \mathrm{E}-08$ 3.32 $\pm 0.36 \mathrm{E}-06$ $3.09 \pm 0.61 \mathrm{E}-07$ $4.28 \pm 0.65 \mathrm{E}-07$ $2.69 \pm 0.54 \mathrm{E}-07$ $4.64 \pm 0.73 \mathrm{E}-07$

Pu-238

$3.07 \pm 7.54 \mathrm{E}-09$
$1.07 \pm 0.94 \mathrm{E}-08$
$4.57 \pm 8.07 \mathrm{E}-09$
$2.94 \pm 4.17 \mathrm{E}-09$
$\mathbf{3 . 7 8} \pm \mathbf{1 . 7 9 E}-08$
$1.27 \pm 2.53 \mathrm{E}-09$
$5.21 \pm 7.38 \mathrm{E}-09$
$2.96 \pm 4.20 \mathrm{E}-09$
$1.85 \pm 1.04 \mathrm{E}-08$
$1.01 \pm 0.80 \mathrm{E}-08$

U-233/234

8.67 $\pm 1.41 E-07$ 8.10 $\pm 1.26 \mathrm{E}-07$

$8.38 \pm 1.35 \mathrm{E}-07$
K-40

$1.86 \pm 0.21 \mathrm{E}-05$

$1.46 \pm 0.19 \mathrm{E}-05$

1.21 $\pm 0.15 E-05$

$1.27 \pm 0.09 \mathrm{E}-05$

$1.88 \pm 0.22 \mathrm{E}-05$

$1.59 \pm 0.19 \mathrm{E}-05$

$1.31 \pm 0.18 \mathrm{E}-05$

$1.40 \pm 0.18 \mathrm{E}-05$

2.04 \pm 0.22E-05

$1.41 \pm 0.18 \mathrm{E}-05$

Pu-239/240

$1.84 \pm 1.24 \mathrm{E}-08$
$1.65 \pm 1.32 \mathrm{E}-08$
$0.30 \pm 1.14 \mathrm{E}-08$
$1.91 \pm 1.54 \mathrm{E}-08$
$1.55 \pm 1.04 \mathrm{E}-08$
$2.02 \pm 1.73 \mathrm{E}-08$
$-0.78 \pm 1.17 \mathrm{E}-08$
$2.07 \pm 1.93 \mathrm{E}-08$
$\mathbf{2 . 1 3} \pm \mathbf{1 . 4 9 E}-08$
$1.76 \pm 1.02 \mathrm{E}-08$

U-235/236

9.21 $\pm 4.16 \mathrm{E}-08$

$5.97 \pm 2.80 \mathrm{E}-08$

$4.06 \pm 4.22 \mathrm{E}-08$
Co-60

$0.86 \pm 2.54 \mathrm{E}-08$

$-1.70 \pm 2.76 \mathrm{E}-08$

$1.26 \pm 2.47 \mathrm{E}-08$

$0.22 \pm 2.16 \mathrm{E}-08$

1.56 $\pm 1.46 \mathrm{E}-08$

$0.12 \pm 1.56 \mathrm{E}-08$

$-0.35 \pm 2.40 \mathrm{E}-08$

$-0.81 \pm 2.13 \mathrm{E}-08$

$0.31 \pm 2.38 \mathrm{E}-08$

$0.03 \pm 3.00 \mathrm{E}-08$

\section{Am-241}

8.46 $\pm 8.99 \mathrm{E}-09$

$2.23 \pm 1.34 \mathrm{E}-08$

$1.48 \pm 0.93 \mathrm{E}-08$

2.57+1.34E-08

$1.04 \pm 0.99 \mathrm{E}-08$

$2.47 \pm 1.35 \mathrm{E}-08$

$0.82 \pm 1.08 \mathrm{E}-08$

$-0.68 \pm 2.04 \mathrm{E}-08$

$1.22 \pm 0.99 \mathrm{E}-08$

$0.53 \pm 1.18 \mathrm{E}-08$

U-238

$8.18 \pm 1.36 \mathrm{E}-07$

8.43 $\pm 1.30 \mathrm{E}-07$

7.42 $\pm 1.24 \mathrm{E}-07$
Sr-90

$6.60 \pm 2.54 \mathrm{E}-08$

$4.86 \pm 2.76 \mathrm{E}-08$

$1.49 \pm 0.35 \mathrm{E}-07$

1.94 \pm 0.35E-07

$1.13 \pm 2.52 \mathrm{E}-08$

$9.82 \pm 2.72 \mathrm{E}-08$

4.65 $\pm 3.26 \mathrm{E}-08$

$1.33 \pm 0.35 \mathrm{E}-07$

$2.03 \pm 1.53 \mathrm{E}-08$

$5.29 \pm 1.90 \mathrm{E}-08$
Total U

$(\mu \mathrm{g} / \mathrm{g})$

$1.78 \pm 0.07 \mathrm{E}+00$

$1.56 \pm 0.07 E+00$

$1.70 \pm 0.06 \mathrm{E}+00$

* Background location.

Note: Bolding convention applied to these data. See page C-2.

WVDP Site Environmental Report

$$
\text { C }-24
$$

Calendar Year 2001 
Table C-30

2001 Radioactivity Concentrations ( $\mu$ Ci/g dry weight from upper $5 \mathrm{~cm}$ ) in Stream Sediments Around the WVDP

\begin{tabular}{|c|c|c|c|c|c|}
\hline Location & Gross Alpha & Gross Beta & K-40 & Co-60 & Sr-90 \\
\hline SFBCSED* & $6.46 \pm 2.42 \mathrm{E}-06$ & $1.45 \pm 0.26 \mathrm{E}-05$ & $1.34 \pm 0.11 \mathrm{E}-05$ & $0.57 \pm 2.74 \mathrm{E}-08$ & $-4.89 \pm 3.61 \mathrm{E}-08$ \\
\hline SFBISED* & $9.46 \pm 2.91 \mathrm{E}-06$ & $1.38 \pm 0.26 \mathrm{E}-05$ & $1.35 \pm 0.18 \mathrm{E}-05$ & $-1.11 \pm 2.03 \mathrm{E}-08$ & $-0.88 \pm 3.89 \mathrm{E}-08$ \\
\hline SFCCSED & $6.80 \pm 2.52 \mathrm{E}-06$ & $1.84 \pm 0.29 \mathrm{E}-05$ & $1.40 \pm 0.18 \mathrm{E}-05$ & $-0.40 \pm 2.05 \mathrm{E}-08$ & $4.40 \pm 4.18 \mathrm{E}-08$ \\
\hline SFSDSED & $6.72 \pm 2.71 \mathrm{E}-06$ & $1.62 \pm 0.31 \mathrm{E}-05$ & $1.43 \pm 0.12 \mathrm{E}-05$ & $0.95 \pm 2.80 \mathrm{E}-08$ & $-2.44 \pm 3.78 \mathrm{E}-08$ \\
\hline \multirow[t]{2}{*}{ SFTCSED } & $7.50 \pm 2.83 \mathrm{E}-06$ & $2.69 \pm 0.34 \mathrm{E}-05$ & $1.63 \pm 0.22 \mathrm{E}-05$ & $-0.08 \pm 3.41 \mathrm{E}-08$ & $1.70 \pm 0.48 \mathrm{E}-07$ \\
\hline & Cs-137 & U-232 & U-233/234 & U-235/236 & U-238 \\
\hline SFBCSED* & $3.02 \pm 3.65 \mathrm{E}-08$ & $1.06 \pm 4.05 \mathrm{E}-08$ & $6.45 \pm 1.05 \mathrm{E}-07$ & $4.62 \pm 2.96 \mathrm{E}-08$ & $6.97 \pm 1.11 \mathrm{E}-07$ \\
\hline SFBISED* & $0.43 \pm 1.86 \mathrm{E}-08$ & $0.82 \pm 5.12 \mathrm{E}-08$ & $5.86 \pm 0.98 \mathrm{E}-07$ & $3.22 \pm 2.03 \mathrm{E}-08$ & $5.33 \pm 0.91 \mathrm{E}-07$ \\
\hline SFCCSED & $2.46 \pm 0.51 \mathrm{E}-07$ & $-1.94 \pm 3.95 \mathrm{E}-08$ & $4.28 \pm 0.82 \mathrm{E}-07$ & $2.38 \pm 2.35 \mathrm{E}-08$ & $4.39 \pm 0.82 \mathrm{E}-07$ \\
\hline SFSDSED & $4.58 \pm 3.63 \mathrm{E}-08$ & $-1.54 \pm 3.78 \mathrm{E}-08$ & $6.89 \pm 1.06 \mathrm{E}-07$ & $3.58 \pm 2.20 \mathrm{E}-08$ & $7.09 \pm 1.08 \mathrm{E}-07$ \\
\hline \multirow[t]{2}{*}{ SFTCSED } & $1.28 \pm 0.19 \mathrm{E}-06$ & $-0.24 \pm 3.99 \mathrm{E}-08$ & $5.82 \pm 1.07 \mathrm{E}-07$ & $2.86 \pm 2.15 \mathrm{E}-08$ & $6.63 \pm 1.16 \mathrm{E}-07$ \\
\hline & $\underset{(\mu \mathrm{g} / \mathrm{g})}{\text { Total }}$ & Pu-238 & Pu-239/240 & Am-241 & \\
\hline SFBCSED* & $2.30 \pm 0.05 \mathrm{E}+00$ & $1.20 \pm 2.40 \mathrm{E}-09$ & $3.59 \pm 5.36 \mathrm{E}-09$ & $5.24 \pm 4.31 \mathrm{E}-09$ & \\
\hline SFBISED* & $2.43 \pm 0.05 \mathrm{E}+00$ & $1.74 \pm 2.47 \mathrm{E}-09$ & $1.74 \pm 5.51 \mathrm{E}-09$ & $1.32 \pm 0.85 \mathrm{E}-08$ & \\
\hline SFCCSED & $2.33 \pm 0.09 \mathrm{E}+00$ & $0.29 \pm 2.69 \mathrm{E}-09$ & $5.62 \pm 4.31 \mathrm{E}-09$ & $-0.56 \pm 7.37 \mathrm{E}-09$ & \\
\hline SFSDSED & $3.06 \pm 0.06 \mathrm{E}+00$ & $0.98 \pm 3.39 \mathrm{E}-09$ & $-0.98 \pm 1.96 \mathrm{E}-09$ & $6.85 \pm 5.93 \mathrm{E}-09$ & \\
\hline SFTCSED & $2.20 \pm 0.10 \mathrm{E}+00$ & $-0.07 \pm 1.04 \mathrm{E}-08$ & $1.48 \pm 5.94 \mathrm{E}-09$ & $1.04 \pm 0.77 \mathrm{E}-08$ & \\
\hline
\end{tabular}

* Background location.

Note: Bolding convention applied to these data. See page C-2.

$$
\text { C }-25
$$

WVDP Site Environmental Report

Calendar Year 2001 
This page intentionally left blank

$$
\text { C - } 26
$$




\section{Appendix D}

\section{Summary of Air Monitoring Data}

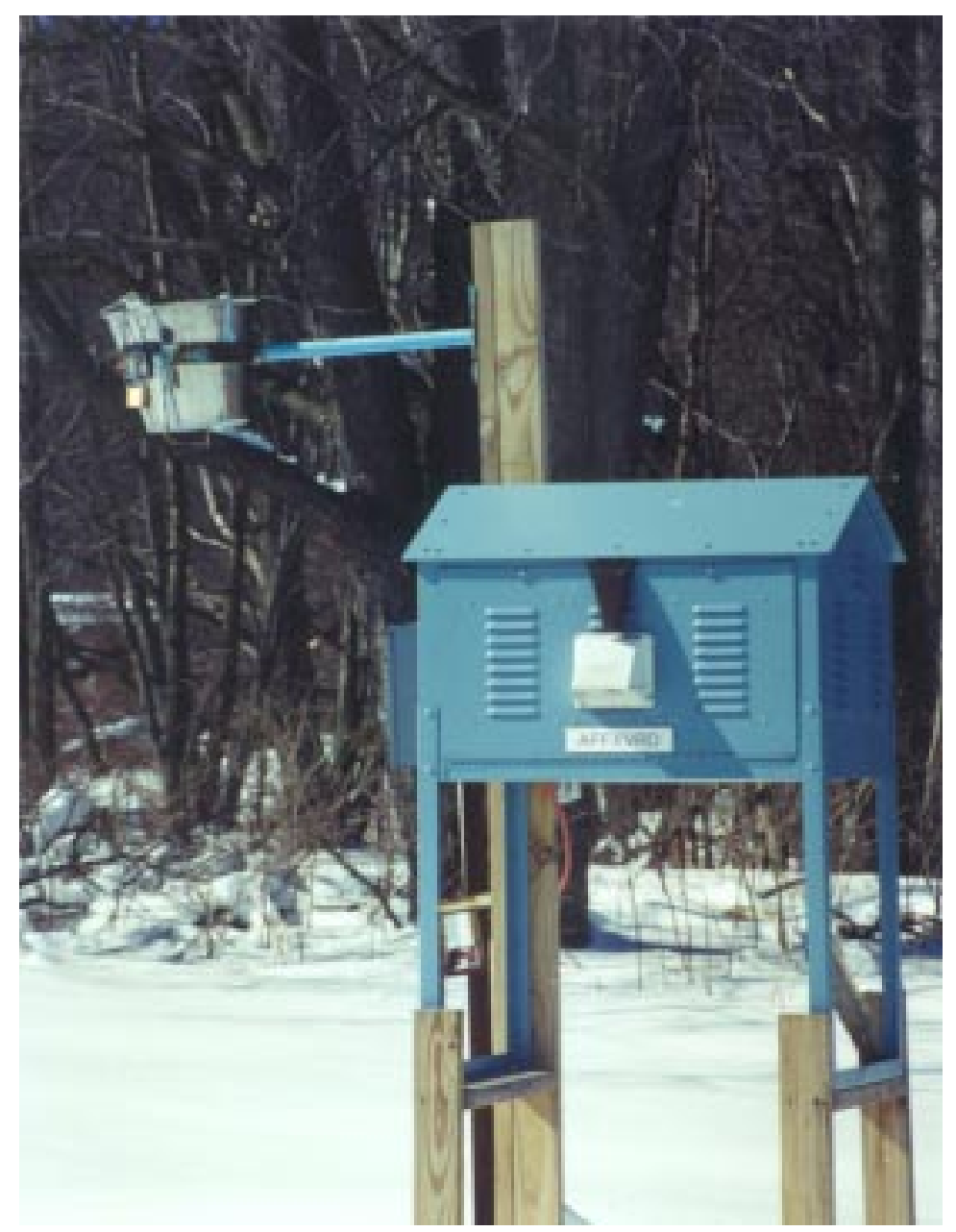

Ambient Air and Atmospheric Fallout Samples are Collected From Numerous Locations in the West Valley Area

$$
D-1
$$


The following tables contain a bolding convention devised to help the reader, when viewing the data, to quickly see the range of detectable measurements within a data series. A data series is a set of chemical or radionuclide measurements (e.g., gross alpha, gross beta, tritium) from a single location or from similar locations. Note that some tables contain data that should not be technically evaluated under this convention.

\section{Key to bolding convention:}

Results for each constituent constitute a single data series. If a radiological result is larger than the uncertainty term, the measurement is considered positive. Otherwise, a result is considered nondetectable. Chemical results preceded by "less than" $(<)$ are considered nondetectable.

If all results in a data series are positive, the lowest and highest values are bolded.

If a data series contains some positive results, the highest value is bolded.

If all values in a data series are nondetectable, no values are bolded.

$D-2$ 


\section{Table D-1 \\ 2001 Airborne Radioactive Effluent Totals (curies) \\ Released From the Main Ventilation Stack (ANSTACK)}

\begin{tabular}{|c|c|c|c|c|c|}
\hline Month & Gross Alpha & Gross Beta & $\mathbf{H}-3$ & & \\
\hline January & $1.77 \pm 2.72 \mathrm{E}-08$ & $2.08 \pm 0.10 \mathrm{E}-06$ & $5.60 \pm 2.96 \mathrm{E}-05$ & & \\
\hline February & $7.89 \pm 2.90 \mathrm{E}-08$ & $4.72 \pm 0.14 \mathrm{E}-06$ & $9.28 \pm 1.13 \mathrm{E}-05$ & & \\
\hline March & $3.14 \pm 0.49 \mathrm{E}-07$ & $2.39 \pm 0.03 \mathrm{E}-05$ & $8.39 \pm 5.22 \mathrm{E}-05$ & & \\
\hline April & $4.60 \pm 2.63 \mathrm{E}-08$ & $4.26 \pm 0.13 \mathrm{E}-06$ & $1.13 \pm 0.04 \mathrm{E}-03$ & & \\
\hline May & $3.45 \pm 2.36 \mathrm{E}-08$ & $1.56 \pm 0.02 \mathrm{E}-05$ & $2.05 \pm 0.04 \mathrm{E}-02$ & & \\
\hline June & $9.33 \pm 3.11 \mathrm{E}-08$ & $8.82 \pm 0.19 \mathrm{E}-06$ & $2.45 \pm 0.13 \mathrm{E}-03$ & & \\
\hline July & $8.19 \pm 3.32 \mathrm{E}-08$ & $2.96 \pm 0.12 \mathrm{E}-06$ & $3.86 \pm 0.32 \mathrm{E}-04$ & & \\
\hline August & $1.30 \pm 0.37 \mathrm{E}-07$ & $9.01 \pm 0.19 \mathrm{E}-06$ & $4.33 \pm 1.15 \mathrm{E}-04$ & & \\
\hline September & $1.50 \pm 0.48 \mathrm{E}-07$ & $2.12 \pm 0.01 \mathrm{E}-04$ & $6.45 \pm 0.48 \mathrm{E}-04$ & & \\
\hline October & $1.02 \pm 0.08 \mathrm{E}-06$ & $7.54 \pm 0.01 E-04$ & $1.70 \pm 0.71 \mathrm{E}-04$ & & \\
\hline November & $1.68 \pm 0.11 E-06$ & $1.44 \pm 0.01 \mathrm{E}-04$ & $2.28 \pm 0.32 \mathrm{E}-04$ & & \\
\hline December & $6.50 \pm 0.65 \mathrm{E}-07$ & $2.62 \pm 0.03 \mathrm{E}-05$ & $3.43 \pm 0.37 \mathrm{E}-04$ & & \\
\hline Annual Total & $4.30 \pm 0.18 \mathrm{E}-06$ & $1.21 \pm 0.01 \mathrm{E}-03$ & $2.65 \pm 0.05 \mathrm{E}-02$ & & \\
\hline Quarter & Co-60 & Sr-90 & I-129 & Cs-137 & Eu-154 \\
\hline 1st Quarter & $0.70 \pm 1.30 \mathrm{E}-08$ & $3.33 \pm 0.20 \mathrm{E}-06$ & $1.08 \pm 0.13 \mathrm{E}-04$ & $6.19 \pm 0.85 \mathrm{E}-06$ & $3.41 \pm 3.59 \mathrm{E}-08$ \\
\hline 2nd Quarter & $0.01 \pm 2.26 \mathrm{E}-08$ & $2.07 \pm 0.09 E-06$ & $1.09 \pm 0.13 \mathrm{E}-04$ & $1.78 \pm 0.24 \mathrm{E}-05$ & $-2.73 \pm 5.33 \mathrm{E}-08$ \\
\hline 3rd Quarter & $0.37 \pm 2.76 \mathrm{E}-08$ & $9.47 \pm 0.42 \mathrm{E}-06$ & $9.61 \pm 1.12 E-05$ & $1.33 \pm 0.13 \mathrm{E}-04$ & $2.34 \pm 8.33 \mathrm{E}-08$ \\
\hline 4th Quarter & $0.92 \pm 5.60 \mathrm{E}-08$ & $3.13 \pm 0.01 E-04$ & $2.06 \pm 0.24 \mathrm{E}-04$ & $6.32 \pm 0.48 \mathrm{E}-04$ & $-0.96 \pm 1.49 \mathrm{E}-07$ \\
\hline \multirow[t]{2}{*}{ Annual Total } & $1.99 \pm 6.77 \mathrm{E}-08$ & $3.28 \pm 0.01 \mathrm{E}-04$ & $5.20 \pm 0.32 \mathrm{E}-04$ & $7.89 \pm 0.50 \mathrm{E}-04$ & $-0.65 \pm 1.83 \mathrm{E}-07$ \\
\hline & U-232 & U-233/234 & $\mathrm{U}-235 / 236$ & U-238 & $\begin{array}{c}\text { Total U } \\
(\mathrm{g})\end{array}$ \\
\hline 1st Quarter & $2.90 \pm 2.40 \mathrm{E}-09$ & $1.21 \pm 0.47 \mathrm{E}-08$ & $1.25 \pm 1.62 \mathrm{E}-09$ & $1.29 \pm 0.46 \mathrm{E}-08$ & $3.28 \pm 0.04 \mathrm{E}-02$ \\
\hline 2nd Quarter & $-1.88 \pm 3.08 \mathrm{E}-09$ & $1.81 \pm 0.55 \mathrm{E}-08$ & $1.83 \pm 1.65 \mathrm{E}-09$ & $1.17 \pm 0.44 E-08$ & $3.08 \pm 0.04 \mathrm{E}-02$ \\
\hline 3rd Quarter & $0.16 \pm 3.09 \mathrm{E}-09$ & $2.98 \pm 0.66 \mathrm{E}-08$ & 3.31 $\pm 2.91 \mathrm{E}-09$ & $2.74 \pm 0.69 \mathrm{E}-08$ & $1.79 \pm 0.03 E-02$ \\
\hline 4th Quarter & $-1.29 \pm 2.33 \mathrm{E}-08$ & $3.45 \pm 1.01 E-08$ & $3.40 \pm 4.41 \mathrm{E}-09$ & $2.37 \pm 0.66 \mathrm{E}-08$ & $6.89 \pm 0.15 E-02$ \\
\hline \multirow[t]{2}{*}{ Annual Total } & $-1.17 \pm 2.38 \mathrm{E}-08$ & $9.45 \pm 1.40 \mathrm{E}-08$ & $9.79 \pm 5.77 \mathrm{E}-09$ & $7.57 \pm 1.15 \mathrm{E}-08$ & $1.50 \pm 0.02 \mathrm{E}-01$ \\
\hline & Pu-238 & $\mathrm{Pu}-239 / 240$ & Am-241 & & \\
\hline 1st Quarter & $5.10 \pm 0.97 \mathrm{E}-08$ & $8.27 \pm 1.21 \mathrm{E}-08$ & $2.19 \pm 0.28 \mathrm{E}-07$ & & \\
\hline 2nd Quarter & $1.84 \pm 0.63 E-08$ & $3.10 \pm 0.83 E-08$ & $3.61 \pm 1.18 E-08$ & & \\
\hline 3rd Quarter & $6.66 \pm 1.02 \mathrm{E}-08$ & $9.62 \pm 1.14 \mathrm{E}-08$ & $2.97 \pm 0.28 \mathrm{E}-07$ & & \\
\hline 4th Quarter & $2.88 \pm 0.25 E-07$ & 4.71 $\pm 0.38 E-07$ & $1.57 \pm 0.12 E-06$ & & \\
\hline Annual Total & $4.24 \pm 0.30 \mathrm{E}-07$ & $6.81 \pm 0.42 \mathrm{E}-07$ & $2.12 \pm 0.12 \mathrm{E}-06$ & & \\
\hline
\end{tabular}

Note: Bolding convention applied to these data. See page D-2.

WVDP Site Environmental Report

$D-3$

Calendar Year 2001 
Table D-2

\section{Comparison of 2001 Main Stack (ANSTACK) Exhaust Radioactivity Concentrations With Department of Energy Guidelines}

$\begin{array}{lcc}\text { Isotope }^{\mathbf{a}} & \begin{array}{c}\text { Exhaust Activity } \\ (\mathrm{Ci})\end{array} & \begin{array}{c}\text { Radioactivity }^{\mathbf{c}} \\ (\mathrm{Bq})\end{array} \\ & & \\ \text { Gross Alpha } & 4.30 \pm 0.18 \mathrm{E}-06 & 1.59 \pm 0.07 \mathrm{E}+05 \\ \text { Gross Beta } & 1.21 \pm 0.01 \mathrm{E}-03 & 4.48 \pm 0.01 \mathrm{E}+07 \\ \text { H-3 } & 2.65 \pm 0.05 \mathrm{E}-02 & 9.81 \pm 0.18 \mathrm{E}+08 \\ \text { Co-60 } & 1.99 \pm 6.77 \mathrm{E}-08 & 0.74 \pm 2.50 \mathrm{E}+03 \\ \text { Sr-90 } & 3.28 \pm 0.01 \mathrm{E}-04 & 1.21 \pm 0.01 \mathrm{E}+07 \\ \text { I-129 } & 5.20 \pm 0.32 \mathrm{E}-04 & 1.92 \pm 0.12 \mathrm{E}+07 \\ \text { Cs-137 } & 7.89 \pm 0.50 \mathrm{E}-04 & 2.92 \pm 0.18 \mathrm{E}+07 \\ \text { Eu-154 } & -0.65 \pm 1.83 \mathrm{E}-07 & -2.42 \pm 6.76 \mathrm{E}+03 \\ \text { U-232 } & -1.17 \pm 2.38 \mathrm{E}-08 & -4.34 \pm 8.81 \mathrm{E}+02 \\ \text { U-233/234 } & 9.45 \pm 1.40 \mathrm{E}-08 & 3.50 \pm 0.52 \mathrm{E}+03 \\ \text { U-235/236 } & 9.79 \pm 5.77 \mathrm{E}-09 & 3.62 \pm 2.13 \mathrm{E}+02 \\ \text { U-238 } & 7.57 \pm 1.15 \mathrm{E}-08 & 2.80 \pm 0.43 \mathrm{E}+03 \\ \text { Pu-238 } & 4.24 \pm 0.30 \mathrm{E}-07 & 1.57 \pm 0.11 \mathrm{E}+04 \\ \text { Pu-239/240 } & 6.81 \pm 0.42 \mathrm{E}-07 & 2.52 \pm 0.16 \mathrm{E}+04 \\ \text { Am-241 } & 2.12 \pm 0.12 \mathrm{E}-06 & 7.84 \pm 0.45 \mathrm{E}+04\end{array}$

$\begin{gathered}\text { Average } \\ \text { Concentration } \\ (\mu \mathrm{Ci} / \mathrm{mL})\end{gathered}$
$5.79 \pm 0.25 \mathrm{E}-15$
$1.63 \pm 0.01 \mathrm{E}-12$
$3.57 \pm 0.07 \mathrm{E}-11$
$2.68 \pm 9.12 \mathrm{E}-17$
$4.42 \pm 0.01 \mathrm{E}-13$
$7.01 \pm 0.43 \mathrm{E}-13$
$1.06 \pm 0.07 \mathrm{E}-12$
$-0.88 \pm 2.46 \mathrm{E}-16$
$-1.58 \pm 3.21 \mathrm{E}-17$
$1.27 \pm 0.19 \mathrm{E}-16$
$1.32 \pm 0.78 \mathrm{E}-17$
$1.02 \pm 0.16 \mathrm{E}-16$
$5.71 \pm 0.40 \mathrm{E}-16$
$9.17 \pm 0.57 \mathrm{E}-16$
$2.85 \pm 0.17 \mathrm{E}-15$

DCG $^{\text {d }}$

$(\mu \mathrm{Ci} / \mathrm{mL})$

$\begin{array}{rr}\mathrm{NA}^{\mathbf{e}} & \mathrm{NA} \\ \mathrm{NA}^{\mathbf{e}} & \mathrm{NA} \\ 1 \mathrm{E}-07 & 0.04 \\ 8 \mathrm{E}-11 & <0.01 \\ 9 \mathrm{E}-12 & 4.91 \\ 7 \mathrm{E}-11 & 1.00 \\ 4 \mathrm{E}-10 & 0.27 \\ 5 \mathrm{E}-11 & <0.01 \\ 2 \mathrm{E}-14 & <0.16 \\ 9 \mathrm{E}-14 & 0.14 \\ 1 \mathrm{E}-13 & 0.01 \\ 1 \mathrm{E}-13 & 0.10 \\ 3 \mathrm{E}-14 & 1.90 \\ 2 \mathrm{E}-14 & 4.59 \\ 2 \mathrm{E}-14 & 14.27\end{array}$

27.40

${ }^{a}$ Half-lives are listed in Table $K-1$ (p. K-3).

${ }^{b}$ Total volume released at $50,000 \mathrm{cfm}=7.42 \mathrm{E}+14 \mathrm{~mL} / \mathrm{year}$.

${ }^{c} 1$ curie $(\mathrm{Ci})=3.7 \mathrm{E}+10$ becquerels $(\mathrm{Bq}) ; 1 \mathrm{~Bq}=2.7 \mathrm{E}-11 \mathrm{Ci}$.

${ }^{d}$ Derived concentration guides (DCGs) are listed for reference only. They are applicable to average concentrations at the site boundary but not to stack concentrations, as might be inferred from their inclusion in this table.

${ }^{e}$ NA - Not applicable: DCGs are not specified for gross alpha and gross beta activity.

${ }^{f}$ Total uranium $=1.50 \pm 0.02 \mathrm{E}-01 \mathrm{~g} ;$ average $=2.03 \mathrm{E}-10 \mu \mathrm{g} / \mathrm{mL}$.

Note: Bolding convention not applicable to these data.

$$
D-4
$$




\section{Table D-3 \\ 2001 Airborne Radioactive Effluent Totals (curies) \\ From the Vitrification System (HVAC) Ventilation Stack (ANVITSK)}

\begin{tabular}{|c|c|c|c|c|c|}
\hline Month & Gross Alpha & Gross Beta & & & \\
\hline January & $-0.87 \pm 1.03 \mathrm{E}-08$ & $-0.06 \pm 1.90 \mathrm{E}-08$ & & & \\
\hline February & $-3.71 \pm 9.25 \mathrm{E}-09$ & $-0.74 \pm 1.86 \mathrm{E}-08$ & & & \\
\hline March & $-0.44 \pm 1.10 \mathrm{E}-08$ & $0.44 \pm 1.98 \mathrm{E}-08$ & & & \\
\hline April & $0.28 \pm 1.03 \mathrm{E}-08$ & $0.00 \pm 1.78 \mathrm{E}-08$ & & & \\
\hline May & $7.00 \pm 9.89 \mathrm{E}-09$ & $-1.59 \pm 1.75 \mathrm{E}-08$ & & & \\
\hline June & $0.43 \pm 1.01 \mathrm{E}-08$ & $0.54 \pm 2.10 \mathrm{E}-08$ & & & \\
\hline July & $0.21 \pm 1.14 \mathrm{E}-08$ & $-0.56 \pm 1.77 \mathrm{E}-08$ & & & \\
\hline August & $-0.43 \pm 1.14 \mathrm{E}-08$ & $2.54 \pm 2.11 \mathrm{E}-08$ & & & \\
\hline September & $-0.84 \pm 1.09 \mathrm{E}-08$ & $-0.41 \pm 1.84 \mathrm{E}-08$ & & & \\
\hline October & $-0.32 \pm 1.05 \mathrm{E}-08$ & $-0.33 \pm 1.92 \mathrm{E}-08$ & & & \\
\hline November & $-0.19 \pm 1.15 \mathrm{E}-08$ & $1.46 \pm 2.07 \mathrm{E}-08$ & & & \\
\hline December & $5.67 \pm 9.26 \mathrm{E}-09$ & $0.81 \pm 2.00 \mathrm{E}-08$ & & & \\
\hline Annual Total & $-1.27 \pm 3.64 \mathrm{E}-08$ & $2.08 \pm 6.67 \mathrm{E}-08$ & & & \\
\hline Quarter & Co-60 & Sr-90 & I-129 & Cs-137 & Eu-154 \\
\hline 1st Quarter & $0.67 \pm 1.43 \mathrm{E}-08$ & $-1.58 \pm 9.45 \mathrm{E}-09$ & $1.72 \pm 1.03 E-07$ & $1.27 \pm 2.44 \mathrm{E}-08$ & $-0.35 \pm 3.79 \mathrm{E}-08$ \\
\hline 2nd Quarter & $0.50 \pm 1.72 \mathrm{E}-08$ & $6.69 \pm 8.95 \mathrm{E}-09$ & $1.39 \pm 0.73 \mathrm{E}-07$ & $0.30 \pm 1.66 \mathrm{E}-08$ & $0.26 \pm 5.30 \mathrm{E}-08$ \\
\hline 3rd Quarter & $0.43 \pm 1.93 \mathrm{E}-08$ & $0.01 \pm 1.07 \mathrm{E}-08$ & $5.38 \pm 7.83 \mathrm{E}-08$ & $-1.59 \pm 1.77 \mathrm{E}-08$ & $4.16 \pm 3.37 \mathrm{E}-08$ \\
\hline 4th Quarter & $1.13 \pm 0.89 \mathrm{E}-08$ & $0.80 \pm 1.54 \mathrm{E}-08$ & $1.38 \pm 0.82 \mathrm{E}-07$ & $-0.07 \pm 1.14 \mathrm{E}-08$ & $1.78 \pm 6.50 \mathrm{E}-08$ \\
\hline \multirow[t]{2}{*}{ Annual Total } & $2.73 \pm 3.09 \mathrm{E}-08$ & $1.32 \pm 2.28 \mathrm{E}-08$ & $5.03 \pm 1.69 \mathrm{E}-07$ & $-0.09 \pm 3.63 \mathrm{E}-08$ & $5.85 \pm 9.80 \mathrm{E}-08$ \\
\hline & U-232 & U-233/234 & U-235/236 & U-238 & $\underset{(\mathrm{g})}{\text { Total U }}$ \\
\hline 1st Quarter & $-0.09 \pm 1.02 \mathrm{E}-09$ & $6.76 \pm 2.08 \mathrm{E}-09$ & $2.89 \pm 4.09 \mathrm{E}-10$ & $3.49 \pm 1.50 \mathrm{E}-09$ & $1.83 \pm 0.02 \mathrm{E}-02$ \\
\hline 2nd Quarter & $2.76 \pm 2.35 \mathrm{E}-09$ & $9.43 \pm 3.19 \mathrm{E}-09$ & $1.26 \pm 1.16 \mathrm{E}-09$ & $7.13 \pm 2.65 \mathrm{E}-09$ & $1.62 \pm 0.02 \mathrm{E}-02$ \\
\hline 3rd Quarter & $3.43 \pm 1.53 \mathrm{E}-09$ & $4.69 \pm 2.04 \mathrm{E}-09$ & $3.91 \pm 6.45 \mathrm{E}-10$ & $6.51 \pm 2.20 \mathrm{E}-09$ & $1.53 \pm 0.03 \mathrm{E}-02$ \\
\hline 4th Quarter & $1.27 \pm 1.53 \mathrm{E}-09$ & $5.75 \pm 2.06 \mathrm{E}-09$ & $1.07 \pm 1.01 \mathrm{E}-09$ & $3.89 \pm 1.83 \mathrm{E}-09$ & $1.38 \pm 0.04 \mathrm{E}-02$ \\
\hline \multirow[t]{2}{*}{ Annual Total } & $7.37 \pm 3.35 \mathrm{E}-09$ & $2.66 \pm 0.48 \mathrm{E}-08$ & $3.01 \pm 1.72 \mathrm{E}-09$ & $2.10 \pm 0.42 \mathrm{E}-08$ & $6.35 \pm 0.06 \mathrm{E}-02$ \\
\hline & Pu-238 & Pu-239/240 & Am-241 & & \\
\hline 1st Quarter & $1.68 \pm 3.37 \mathrm{E}-10$ & $1.21 \pm 4.19 \mathrm{E}-10$ & $1.00 \pm 1.70 \mathrm{E}-09$ & & \\
\hline 2nd Quarter & $1.15 \pm 5.22 \mathrm{E}-10$ & $1.15 \pm 5.21 \mathrm{E}-10$ & $-0.72 \pm 4.66 \mathrm{E}-10$ & & \\
\hline 3rd Quarter & $2.35 \pm 4.71 \mathrm{E}-10$ & $1.17 \pm 5.25 \mathrm{E}-10$ & $2.14 \pm 5.51 \mathrm{E}-10$ & & \\
\hline 4th Quarter & $4.73 \pm 4.75 \mathrm{E}-10$ & $-1.18 \pm 9.15 \mathrm{E}-10$ & $1.46 \pm 1.16 \mathrm{E}-09$ & & \\
\hline Annual Total & $9.91 \pm 9.13 \mathrm{E}-10$ & $0.24 \pm 1.25 \mathrm{E}-09$ & $2.60 \pm 2.18 \mathrm{E}-09$ & & \\
\hline
\end{tabular}

Note: Bolding convention applied to these data. See page D-2.

$D-5$

WVDP Site Environmental Report

Calendar Year 2001 


\section{Table D-4 \\ 2001 Airborne Radioactive Effluent Totals (curies) From the Seismic Sampler (ANSEISK)* for the Vitrification System (HVAC) Ventilation Stack}

$\begin{array}{lrr}\text { Month } & \text { Gross Alpha } & \text { Gross Beta } \\ & & \\ \text { January } & -0.50 \pm 1.08 \mathrm{E}-08 & -0.27 \pm 1.90 \mathrm{E}-08 \\ \text { February } & 1.32 \pm 9.55 \mathrm{E}-09 & -1.11 \pm 1.75 \mathrm{E}-08 \\ \text { March } & -1.14 \pm 1.00 \mathrm{E}-08 & 1.31 \pm 2.00 \mathrm{E}-08 \\ \text { April } & -3.60 \pm 9.53 \mathrm{E}-09 & -0.59 \pm 1.77 \mathrm{E}-08 \\ \text { May } & 3.90 \pm 9.52 \mathrm{E}-09 & -0.87 \pm 1.80 \mathrm{E}-08 \\ \text { June } & 3.78 \pm 9.72 \mathrm{E}-09 & -0.98 \pm 1.98 \mathrm{E}-08 \\ \text { July } & -0.49 \pm 1.07 \mathrm{E}-08 & -1.71 \pm 1.74 \mathrm{E}-08 \\ \text { August } & -1.31 \pm 1.01 \mathrm{E}-08 & 0.09 \pm 1.98 \mathrm{E}-08 \\ \text { September } & -1.05 \pm 1.06 \mathrm{E}-08 & -1.34 \pm 1.79 \mathrm{E}-08 \\ \text { October } & -3.60 \pm 9.88 \mathrm{E}-09 & 1.07 \pm 1.86 \mathrm{E}-08 \\ \text { November } & -0.28 \pm 1.08 \mathrm{E}-08 & 1.20 \pm 1.96 \mathrm{E}-08 \\ \text { December } & 5.40 \pm 8.66 \mathrm{E}-09 & 0.62 \pm 1.86 \mathrm{E}-08\end{array}$

Annual Total $\quad-4.06 \pm 3.47 \mathrm{E}-08 \quad-2.56 \pm 6.47 \mathrm{E}-08$

* ANSEISK provides back-up samples for the primary vitrification sampler (ANVITSK).

Note: Bolding convention applied to these data. See page D-2.

$D-6$ 


\section{Table D-5 \\ 2001 Airborne Radioactive Effluent Totals (curies) From the 01-14 Building Ventilation Exhaust (ANCSSTK)}

\begin{tabular}{|c|c|c|c|c|c|}
\hline Month & Gross Alpha & Gross Beta & & & \\
\hline January & $-0.22 \pm 4.46 \mathrm{E}-09$ & $-1.82 \pm 7.38 \mathrm{E}-09$ & & & \\
\hline February & $-0.84 \pm 3.57 \mathrm{E}-09$ & 3.49+7.32E-09 & & & \\
\hline March & $-1.11 \pm 4.25 \mathrm{E}-09$ & $8.38 \pm 7.84 \mathrm{E}-09$ & & & \\
\hline April & $0.22 \pm 3.83 \mathrm{E}-09$ & $2.20 \pm 6.91 \mathrm{E}-09$ & & & \\
\hline May & $-0.55 \pm 3.71 \mathrm{E}-09$ & $0.94 \pm 7.87 \mathrm{E}-09$ & & & \\
\hline June & $1.74 \pm 4.27 \mathrm{E}-09$ & $3.04 \pm 8.86 \mathrm{E}-09$ & & & \\
\hline July & $-3.42 \pm 4.21 \mathrm{E}-09$ & $9.85 \pm 7.95 \mathrm{E}-09$ & & & \\
\hline August & $-1.22 \pm 4.71 \mathrm{E}-09$ & $0.85 \pm 8.23 \mathrm{E}-09$ & & & \\
\hline September & $-3.96 \pm 4.28 \mathrm{E}-09$ & $8.33 \pm 7.86 \mathrm{E}-09$ & & & \\
\hline October & $-0.43 \pm 3.99 \mathrm{E}-09$ & $4.72 \pm 7.18 \mathrm{E}-09$ & & & \\
\hline November & $-2.43 \pm 4.45 E-09$ & $9.38 \pm 8.52 \mathrm{E}-09$ & & & \\
\hline December & $4.28 \pm 3.93 \mathrm{E}-09$ & $-0.04 \pm 7.69 \mathrm{E}-09$ & & & \\
\hline Annual Total & $-0.79 \pm 1.44 \mathrm{E}-08$ & $4.93 \pm 2.71 \mathrm{E}-08$ & & & \\
\hline Quarter & Co-60 & Sr-90 & I-129 & Cs-137 & Eu-154 \\
\hline 1st Quarter & $4.03 \pm 5.98 \mathrm{E}-09$ & $0.19 \pm 3.39 \mathrm{E}-09$ & $0.97 \pm 1.15 \mathrm{E}-08$ & $2.36 \pm 6.16 \mathrm{E}-09$ & $-0.53 \pm 1.68 \mathrm{E}-08$ \\
\hline 2nd Quarter & $-4.13 \pm 6.25 \mathrm{E}-09$ & $0.09 \pm 2.76 \mathrm{E}-09$ & $1.05 \pm 1.82 \mathrm{E}-08$ & $4.09 \pm 5.58 \mathrm{E}-09$ & $1.08 \pm 1.66 \mathrm{E}-08$ \\
\hline 3rd Quarter & $4.87 \pm 7.90 \mathrm{E}-09$ & $3.48 \pm 5.30 \mathrm{E}-09$ & $1.61 \pm 1.57 \mathrm{E}-08$ & $-1.73 \pm 6.05 \mathrm{E}-09$ & $1.45 \pm 1.95 \mathrm{E}-08$ \\
\hline 4th Quarter & $6.53 \pm 9.83 \mathrm{E}-09$ & $5.28 \pm 5.47 \mathrm{E}-09$ & $2.92 \pm 0.91 E-07$ & $1.36 \pm 4.08 \mathrm{E}-09$ & $0.51 \pm 1.23 \mathrm{E}-08$ \\
\hline \multirow[t]{2}{*}{ Annual Total } & $1.13 \pm 1.53 \mathrm{E}-08$ & $9.04 \pm 8.78 \mathrm{E}-09$ & $3.28 \pm 0.95 \mathrm{E}-07$ & $0.61 \pm 1.11 \mathrm{E}-08$ & $2.52 \pm 3.31 \mathrm{E}-08$ \\
\hline & U-232 & U-233/234 & U-235/236 & U-238 & $\begin{array}{c}\text { Total U } \\
(\mathrm{g})\end{array}$ \\
\hline 1st Quarter & $2.25 \pm 3.28 \mathrm{E}-10$ & $3.16 \pm 0.93 \mathrm{E}-09$ & $1.39 \pm 2.29 \mathrm{E}-10$ & $2.87 \pm 0.90 \mathrm{E}-09$ & $8.46 \pm 0.10 E-03$ \\
\hline 2nd Quarter & $2.78 \pm 8.49 \mathrm{E}-10$ & $3.38 \pm 1.12 E-09$ & $8.87 \pm 5.77 E-10$ & $3.10 \pm 1.05 \mathrm{E}-09$ & $8.39 \pm 0.10 \mathrm{E}-03$ \\
\hline 3rd Quarter & $3.54 \pm 6.62 \mathrm{E}-10$ & $2.85 \pm 0.92 \mathrm{E}-09$ & $1.38 \pm 3.36 \mathrm{E}-10$ & $3.03 \pm 0.94 \mathrm{E}-09$ & $6.38 \pm 0.13 E-03$ \\
\hline 4th Quarter & $-2.29 \pm 7.90 \mathrm{E}-10$ & $2.13 \pm 0.96 E-09$ & $3.05 \pm 4.33 \mathrm{E}-10$ & $3.04 \pm 1.03 E-09$ & $6.99 \pm 0.20 \mathrm{E}-03$ \\
\hline \multirow[t]{2}{*}{ Annual Total } & $0.63 \pm 1.38 \mathrm{E}-09$ & $1.15 \pm 0.20 \mathrm{E}-08$ & $1.47 \pm 0.83 \mathrm{E}-09$ & $1.20 \pm 0.20 \mathrm{E}-08$ & $3.02 \pm 0.03 \mathrm{E}-02$ \\
\hline & Pu-238 & Pu-239/240 & Am-241 & & \\
\hline 1st Quarter & $1.29 \pm 1.83 \mathrm{E}-10$ & $4.65 \pm 9.29 \mathrm{E}-11$ & $6.30 \pm 7.45 \mathrm{E}-10$ & & \\
\hline 2nd Quarter & $1.63 \pm 2.31 \mathrm{E}-10$ & $0.39 \pm 2.70 \mathrm{E}-10$ & $-0.13 \pm 2.96 \mathrm{E}-10$ & & \\
\hline 3rd Quarter & $1.44 \pm 1.66 \mathrm{E}-10$ & $1.91 \pm 1.92 \mathrm{E}-10$ & $5.91 \pm 4.09 \mathrm{E}-10$ & & \\
\hline 4th Quarter & $0.94 \pm 1.33 \mathrm{E}-10$ & $1.41 \pm 3.39 \mathrm{E}-10$ & $3.26 \pm 3.25 \mathrm{E}-10$ & & \\
\hline Annual Total & $5.30 \pm 3.64 \mathrm{E}-10$ & $4.18 \pm 4.83 \mathrm{E}-10$ & $1.54 \pm 0.96 \mathrm{E}-09$ & & \\
\hline
\end{tabular}

Note: Bolding convention applied to these data. See page D-2.

$D-7$

WVDP Site Environmental Report

Calendar Year 2001 


\section{Table D-6}

\section{Airborne Radioactive Effluent Totals (curies) From the Contact Size-Reduction Facility Ventilation Stack (ANCSRFK)}

\begin{tabular}{|c|c|c|c|c|c|}
\hline Month & Gross Alpha & Gross Beta & & & \\
\hline January & NA & NA & & & \\
\hline February & NA & NA & & & \\
\hline March & NA & NA & & & \\
\hline April & NA & NA & & & \\
\hline May & NA & NA & & & \\
\hline June & $0.89 \pm 1.37 \mathrm{E}-09$ & $0.74 \pm 2.87 \mathrm{E}-09$ & & & \\
\hline July & NA & NA & & & \\
\hline August & NA & NA & & & \\
\hline September & $-0.19 \pm 1.55 \mathrm{E}-09$ & $2.33 \pm 2.91 \mathrm{E}-09$ & & & \\
\hline October & NA & NA & & & \\
\hline November & NA & NA & & & \\
\hline December & NA & NA & & & \\
\hline Annual Total & $0.69 \pm 2.07 \mathrm{E}-09$ & $3.08 \pm 4.09 \mathrm{E}-09$ & & & \\
\hline Quarter & Co-60 & Sr-90 & I-129 & Cs-137 & Eu-154 \\
\hline 1st Quarter & NA & NA & NA & NA & NA \\
\hline 2nd Quarter & $1.50 \pm 4.52 \mathrm{E}-09$ & $0.69 \pm 2.18 \mathrm{E}-09$ & $2.14 \pm 5.16 \mathrm{E}-09$ & $-2.79 \pm 4.23 \mathrm{E}-09$ & $0.12 \pm 1.18 \mathrm{E}-08$ \\
\hline 3rd Quarter & $3.80 \pm 5.29 \mathrm{E}-09$ & $-3.93 \pm 3.64 \mathrm{E}-09$ & $-1.29 \pm 3.40 \mathrm{E}-09$ & $-1.52 \pm 5.00 \mathrm{E}-09$ & $0.27 \pm 1.55 \mathrm{E}-08$ \\
\hline 4th Quarter & NA & NA & NA & NA & NA \\
\hline \multirow[t]{2}{*}{ Annual Total } & $5.30 \pm 6.95 \mathrm{E}-09$ & $-3.23 \pm 4.25 \mathrm{E}-09$ & $0.85 \pm 6.18 \mathrm{E}-09$ & $-4.31 \pm 6.55 \mathrm{E}-09$ & $0.39 \pm 1.95 \mathrm{E}-08$ \\
\hline & U-232 & U-233/234 & $\mathrm{U}-235 / 236$ & $\mathrm{U}-238$ & $\begin{array}{c}\text { Total U } \\
(\mathrm{g})\end{array}$ \\
\hline 1st Quarter & NA & NA & NA & NA & NA \\
\hline 2nd Quarter & $2.07 \pm 3.58 \mathrm{E}-10$ & $1.15 \pm 0.54 \mathrm{E}-09$ & $3.93 \pm 3.29 \mathrm{E}-10$ & $3.93 \pm 3.28 \mathrm{E}-10$ & $4.95 \pm 0.07 \mathrm{E}-04$ \\
\hline 3rd Quarter & $4.81 \pm 4.40 \mathrm{E}-10$ & $1.23 \pm 0.51 \mathrm{E}-09$ & $-0.04 \pm 3.67 \mathrm{E}-10$ & $1.29 \pm 0.52 \mathrm{E}-09$ & $4.65 \pm 0.12 \mathrm{E}-04$ \\
\hline 4th Quarter & NA & NA & NA & NA & NA \\
\hline \multirow[t]{2}{*}{ Annual Total } & $6.88 \pm 5.67 \mathrm{E}-10$ & $2.38 \pm 0.74 \mathrm{E}-09$ & $3.89 \pm 4.93 \mathrm{E}-10$ & $1.68 \pm 0.61 \mathrm{E}-09$ & $9.61 \pm 0.14 \mathrm{E}-04$ \\
\hline & Pu-238 & Pu-239/240 & Am-241 & & \\
\hline 1st Quarter & NA & NA & NA & & \\
\hline 2nd Quarter & $-0.89 \pm 1.25 \mathrm{E}-10$ & $0.87 \pm 1.75 \mathrm{E}-10$ & $0.36 \pm 1.86 \mathrm{E}-10$ & & \\
\hline 3rd Quarter & $0.28 \pm 1.49 \mathrm{E}-10$ & $0.00 \pm 1.38 \mathrm{E}-10$ & $1.10 \pm 1.52 \mathrm{E}-10$ & & \\
\hline 4th Quarter & NA & NA & NA & & \\
\hline Annual Total & $-0.60 \pm 1.95 \mathrm{E}-10$ & $0.87 \pm 2.23 \mathrm{E}-10$ & $1.47 \pm 2.40 \mathrm{E}-10$ & & \\
\hline
\end{tabular}

NA - Not applicable. Ventilation off.

Note: Bolding convention not applicable to these data.

WVDP Site Environmental Report

$D-8$ 


\section{Table D-7 \\ 2001 Airborne Radioactive Effluent Totals (curies) From the Supernatant Treatment System Ventilation Stack (ANSTSTK)}

\begin{tabular}{|c|c|c|c|c|c|}
\hline Month & Gross Alpha & Gross Beta & H-3 & & \\
\hline January & $-0.60 \pm 2.37 \mathrm{E}-09$ & $5.87 \pm 0.64 \mathrm{E}-08$ & $5.50 \pm 0.63 \mathrm{E}-06$ & & \\
\hline February & $-0.33 \pm 2.02 \mathrm{E}-09$ & $2.55 \pm 4.13 \mathrm{E}-09$ & $2.94 \pm 0.49 \mathrm{E}-06$ & & \\
\hline March & $-1.22 \pm 2.28 \mathrm{E}-09$ & $4.49 \pm 4.32 \mathrm{E}-09$ & $5.45 \pm 0.67 \mathrm{E}-06$ & & \\
\hline April & $0.17 \pm 2.12 \mathrm{E}-09$ & $1.08 \pm 3.82 \mathrm{E}-09$ & $7.15 \pm 1.02 \mathrm{E}-06$ & & \\
\hline May & $0.15 \pm 1.95 \mathrm{E}-09$ & $-0.31 \pm 3.95 \mathrm{E}-09$ & $4.87 \pm 1.15 \mathrm{E}-06$ & & \\
\hline June & $0.15 \pm 2.11 \mathrm{E}-09$ & $-1.03 \pm 4.49 \mathrm{E}-09$ & $0.60 \pm 1.93 \mathrm{E}-06$ & & \\
\hline July & $0.30 \pm 2.50 \mathrm{E}-09$ & $0.61 \pm 4.01 \mathrm{E}-09$ & $1.63 \pm 1.80 \mathrm{E}-06$ & & \\
\hline August & $-0.62 \pm 2.43 \mathrm{E}-09$ & $-4.27 \pm 4.03 \mathrm{E}-09$ & $7.33 \pm 2.56 \mathrm{E}-06$ & & \\
\hline September & $-1.94 \pm 2.29 \mathrm{E}-09$ & $-0.31 \pm 3.93 \mathrm{E}-09$ & $5.36 \pm 1.73 \mathrm{E}-06$ & & \\
\hline October & $-2.14 \pm 1.88 \mathrm{E}-09$ & $1.01 \pm 3.83 \mathrm{E}-09$ & $5.87 \pm 1.60 \mathrm{E}-06$ & & \\
\hline November & $0.44 \pm 2.53 \mathrm{E}-09$ & $0.47 \pm 4.27 \mathrm{E}-09$ & $1.21 \pm 0.09 \mathrm{E}-05$ & & \\
\hline December & $1.40 \pm 1.95 \mathrm{E}-09$ & $-1.06 \pm 3.92 \mathrm{E}-09$ & $1.55 \pm 0.10 E-05$ & & \\
\hline Annual Total & $-4.24 \pm 7.66 \mathrm{E}-09$ & $6.19 \pm 1.50 \mathrm{E}-08$ & $7.43 \pm 0.49 \mathrm{E}-05$ & & \\
\hline Quarter & Co-60 & Sr-90 & I-129 & Cs-137 & Eu-154 \\
\hline 1st Quarter & $-0.72 \pm 2.92 \mathrm{E}-09$ & $0.63 \pm 2.41 \mathrm{E}-09$ & $1.39 \pm 0.17 \mathrm{E}-06$ & $2.56 \pm 0.67 \mathrm{E}-08$ & $1.98 \pm 8.19 \mathrm{E}-09$ \\
\hline 2nd Quarter & $3.43 \pm 3.06 \mathrm{E}-09$ & $0.33 \pm 1.42 \mathrm{E}-09$ & $6.79 \pm 0.86 \mathrm{E}-07$ & $2.31 \pm 3.31 \mathrm{E}-09$ & $-6.49 \pm 8.25 \mathrm{E}-09$ \\
\hline 3rd Quarter & $-0.88 \pm 3.06 \mathrm{E}-09$ & $-3.83 \pm 2.91 \mathrm{E}-09$ & $1.15 \pm 0.15 \mathrm{E}-06$ & $5.82 \pm 4.10 \mathrm{E}-09$ & $-0.10 \pm 1.03 \mathrm{E}-08$ \\
\hline 4th Quarter & $-1.32 \pm 3.12 \mathrm{E}-09$ & $-2.07 \pm 2.13 \mathrm{E}-09$ & $6.15 \pm 0.74 \mathrm{E}-06$ & $2.60 \pm 8.71 \mathrm{E}-09$ & $5.05 \pm 8.08 \mathrm{E}-09$ \\
\hline \multirow[t]{2}{*}{ Annual Total } & $0.52 \pm 6.08 \mathrm{E}-09$ & $-4.93 \pm 4.56 \mathrm{E}-09$ & $9.36 \pm 0.78 \mathrm{E}-06$ & $3.63 \pm 1.22 \mathrm{E}-08$ & $-0.05 \pm 1.75 \mathrm{E}-08$ \\
\hline & U-232 & U-233/234 & U-235/236 & U-238 & $\begin{array}{c}\text { Total U } \\
(\mathrm{g})\end{array}$ \\
\hline 1st Quarter & $-0.12 \pm 2.71 \mathrm{E}-10$ & $1.16 \pm 0.44 \mathrm{E}-09$ & $-5.15 \pm 7.33 \mathrm{E}-11$ & $9.48 \pm 3.98 \mathrm{E}-10$ & $4.26 \pm 0.05 \mathrm{E}-03$ \\
\hline 2nd Quarter & $1.80 \pm 3.04 \mathrm{E}-10$ & $2.31 \pm 0.71 \mathrm{E}-09$ & $1.02 \pm 0.51 \mathrm{E}-09$ & $2.12 \pm 0.70 \mathrm{E}-09$ & $2.99 \pm 0.08 \mathrm{E}-03$ \\
\hline 3rd Quarter & $-0.45 \pm 2.00 \mathrm{E}-10$ & $1.52 \pm 0.46 \mathrm{E}-09$ & $1.52 \pm 1.37 \mathrm{E}-10$ & $1.28 \pm 0.42 \mathrm{E}-09$ & $2.81 \pm 0.06 \mathrm{E}-03$ \\
\hline 4th Quarter & $0.29 \pm 2.50 \mathrm{E}-10$ & $1.83 \pm 0.77 \mathrm{E}-09$ & $2.55 \pm 4.98 \mathrm{E}-10$ & $7.23 \pm 4.94 E-10$ & $2.48 \pm 0.07 \mathrm{E}-03$ \\
\hline \multirow[t]{2}{*}{ Annual Total } & $1.52 \pm 5.18 \mathrm{E}-10$ & $6.83 \pm 1.22 \mathrm{E}-09$ & $1.37 \pm 0.73 \mathrm{E}-09$ & $5.07 \pm 1.03 \mathrm{E}-09$ & $1.25 \pm 0.01 \mathrm{E}-02$ \\
\hline & Pu-238 & Pu-239/240 & Am-241 & & \\
\hline 1st Quarter & $1.13 \pm 1.31 \mathrm{E}-10$ & $1.62 \pm 1.54 \mathrm{E}-10$ & $2.50 \pm 3.65 \mathrm{E}-10$ & & \\
\hline 2nd Quarter & $0.25 \pm 1.12 \mathrm{E}-10$ & $-1.00 \pm 1.01 \mathrm{E}-10$ & $-0.16 \pm 1.03 \mathrm{E}-10$ & & \\
\hline 3rd Quarter & $2.03 \pm 4.05 \mathrm{E}-11$ & $2.64 \pm 1.48 \mathrm{E}-10$ & $1.07 \pm 1.48 \mathrm{E}-10$ & & \\
\hline 4th Quarter & $2.41 \pm 8.36 \mathrm{E}-11$ & $-0.72 \pm 1.45 \mathrm{E}-10$ & $1.22 \pm 1.90 \mathrm{E}-10$ & & \\
\hline Annual Total & $1.82 \pm 1.95 \mathrm{E}-10$ & $2.53 \pm 2.77 \mathrm{E}-10$ & $4.63 \pm 4.49 \mathrm{E}-10$ & & \\
\hline
\end{tabular}

Note: Bolding convention applied to these data. See page D-2.

WVDP Site Environmental Report

$D-9$

Calendar Year 2001 


\section{Table D-8 \\ 2001 Airborne Radioactive Effluent Totals (curies) From the Container Sorting and Packaging Facility Ventilation Stack (ANCSPFK)}

\begin{tabular}{|c|c|c|c|c|c|}
\hline Month & Gross Alpha & Gross Beta & & & \\
\hline January & $-0.70 \pm 4.53 \mathrm{E}-10$ & $-2.17 \pm 7.32 \mathrm{E}-10$ & & & \\
\hline February & $-0.44 \pm 4.46 \mathrm{E}-10$ & $-0.98 \pm 8.71 \mathrm{E}-10$ & & & \\
\hline March & $-6.38 \pm 4.40 \mathrm{E}-10$ & $4.36 \pm 8.44 \mathrm{E}-10$ & & & \\
\hline April & $-2.04 \pm 4.33 \mathrm{E}-10$ & $5.06 \pm 8.53 \mathrm{E}-10$ & & & \\
\hline May & $-0.36 \pm 4.16 \mathrm{E}-10$ & $-5.07 \pm 8.45 \mathrm{E}-10$ & & & \\
\hline June & $0.05 \pm 4.60 \mathrm{E}-10$ & $-5.30 \pm 9.78 \mathrm{E}-10$ & & & \\
\hline July & $-0.68 \pm 3.51 \mathrm{E}-10$ & $4.14 \pm 6.22 \mathrm{E}-10$ & & & \\
\hline August & $-3.29 \pm 3.41 \mathrm{E}-10$ & $2.88 \pm 7.47 \mathrm{E}-10$ & & & \\
\hline September & $-4.76 \pm 3.40 \mathrm{E}-10$ & $1.54 \pm 6.63 \mathrm{E}-10$ & & & \\
\hline October & $2.78 \pm 5.46 \mathrm{E}-10$ & $7.96 \pm 9.31 \mathrm{E}-10$ & & & \\
\hline November & $0.39 \pm 5.65 \mathrm{E}-10$ & $1.46 \pm 1.03 \mathrm{E}-09$ & & & \\
\hline December & $4.48 \pm 4.14 \mathrm{E}-10$ & $-4.60 \pm 7.83 \mathrm{E}-10$ & & & \\
\hline Annual Total & $-1.10 \pm 1.52 \mathrm{E}-09$ & $2.24 \pm 2.89 \mathrm{E}-09$ & & & \\
\hline Quarter & Co-60 & Sr-90 & I-129 & Cs-137 & Eu-154 \\
\hline 1st Quarter & $1.16 \pm 9.80 \mathrm{E}-10$ & $-0.40 \pm 3.70 \mathrm{E}-10$ & $5.77 \pm 1.00 \mathrm{E}-08$ & $1.21 \pm 0.86 \mathrm{E}-09$ & $0.86 \pm 2.90 \mathrm{E}-09$ \\
\hline 2nd Quarter & $4.73 \pm 9.75 \mathrm{E}-10$ & $1.06 \pm 2.97 \mathrm{E}-10$ & $3.00 \pm 0.52 \mathrm{E}-08$ & $1.24 \pm 9.36 \mathrm{E}-10$ & $1.08 \pm 2.84 \mathrm{E}-09$ \\
\hline 3rd Quarter & $-0.88 \pm 8.58 \mathrm{E}-10$ & $6.59 \pm 6.48 E-10$ & $1.29 \pm 0.35 \mathrm{E}-08$ & $0.31 \pm 1.00 \mathrm{E}-09$ & $-0.89 \pm 2.53 \mathrm{E}-09$ \\
\hline 4th Quarter & $0.84 \pm 5.25 \mathrm{E}-10$ & $-1.15 \pm 7.28 \mathrm{E}-10$ & $6.60 \pm 1.10 \mathrm{E}-08$ & $0.26 \pm 4.87 \mathrm{E}-10$ & $0.21 \pm 1.34 \mathrm{E}-09$ \\
\hline \multirow[t]{2}{*}{ Annual Total } & $0.58 \pm 1.71 \mathrm{E}-09$ & $0.61 \pm 1.08 \mathrm{E}-09$ & $1.67 \pm 0.16 \mathrm{E}-07$ & $1.67 \pm 1.69 \mathrm{E}-09$ & $1.27 \pm 4.97 \mathrm{E}-09$ \\
\hline & U-232 & U-233/234 & U-235/236 & U-238 & $\begin{array}{c}\text { Total U } \\
(\mathrm{g})\end{array}$ \\
\hline 1st Quarter & $2.54 \pm 4.56 \mathrm{E}-11$ & $2.04 \pm 0.73 E-10$ & $3.02 \pm 2.72 \mathrm{E}-11$ & $2.06 \pm 0.75 E-10$ & $6.18 \pm 0.08 \mathrm{E}-04$ \\
\hline 2nd Quarter & $2.57 \pm 5.73 \mathrm{E}-11$ & $4.92 \pm 1.56 \mathrm{E}-10$ & $1.60 \pm 0.85 \mathrm{E}-10$ & $2.70 \pm 1.08 \mathrm{E}-10$ & $6.06 \pm 0.07 \mathrm{E}-04$ \\
\hline 3rd Quarter & $3.85 \pm 4.87 \mathrm{E}-11$ & $4.19 \pm 1.26 \mathrm{E}-10$ & $4.52 \pm 4.64 \mathrm{E}-11$ & $3.12 \pm 1.12 \mathrm{E}-10$ & $4.32 \pm 0.10 \mathrm{E}-04$ \\
\hline 4th Quarter & $3.00 \pm 6.03 \mathrm{E}-11$ & $5.40 \pm 2.01 E-10$ & $0.97 \pm 1.08 \mathrm{E}-10$ & $2.91 \pm 1.52 \mathrm{E}-10$ & $9.10 \pm 0.26 E-04$ \\
\hline \multirow[t]{2}{*}{ Annual Total } & $1.20 \pm 1.07 \mathrm{E}-10$ & $1.66 \pm 0.29 \mathrm{E}-09$ & $3.32 \pm 1.48 \mathrm{E}-10$ & $1.08 \pm 0.23 \mathrm{E}-09$ & $2.57 \pm 0.03 \mathrm{E}-03$ \\
\hline & Pu-238 & Pu-239/240 & Am-241 & & \\
\hline 1st Quarter & $1.94 \pm 2.25 \mathrm{E}-11$ & $1.40 \pm 1.62 \mathrm{E}-11$ & $2.25 \pm 7.52 \mathrm{E}-11$ & & \\
\hline 2nd Quarter & $0.00 \pm 3.13 \mathrm{E}-11$ & $2.60 \pm 3.77 \mathrm{E}-11$ & $1.83 \pm 6.33 \mathrm{E}-11$ & & \\
\hline 3rd Quarter & $1.45 \pm 2.55 \mathrm{E}-11$ & $2.40 \pm 2.55 \mathrm{E}-11$ & $2.54 \pm 2.79 \mathrm{E}-11$ & & \\
\hline 4th Quarter & $0.78 \pm 1.57 \mathrm{E}-11$ & $-1.57 \pm 3.85 \mathrm{E}-11$ & $6.25 \pm 4.76 \mathrm{E}-11$ & & \\
\hline Annual Total & $4.17 \pm 4.89 \mathrm{E}-11$ & $4.83 \pm 6.18 \mathrm{E}-11$ & $1.29 \pm 1.13 \mathrm{E}-10$ & & \\
\hline
\end{tabular}

Note: Bolding convention applied to these data. See page D-2.

WVDP Site Environmental Report

$D-10$

Calendar Year 2001 


\section{Table D-9 \\ 2001 Airborne Radioactive Effluent Totals (curies) From the Former Low-Level Waste Treatment Facility Hot Side Ventilation (ANLLWTVH)}

Ventilation off.

Table D-10

2001 Airborne Radioactive Effluent Totals (curies) From the New Low-Level Waste Treatment Facility Ventilation (ANLLW2V)

$\begin{array}{lcc}\text { Month } & \text { Gross Alpha } & \text { Gross Beta } \\ \text { January } & \text { NA } & \text { NA } \\ \text { February } & \text { NA } & \text { NA } \\ \text { March } & -1.23 \pm 1.47 \mathrm{E}-10 & \mathbf{4 . 3 1} \pm \mathbf{2 . 8 9 E}-10 \\ \text { April } & \text { NA } & \text { NA } \\ \text { May } & \text { NA } & \text { NA } \\ \text { June } & 0.00 \pm 1.56 \mathrm{E}-10 & 3.50 \pm 4.46 \mathrm{E}-10 \\ \text { July } & \text { NA } & \text { NA } \\ \text { August } & \text { NA } & \text { NA } \\ \text { September } & -1.31 \pm 2.39 \mathrm{E}-10 & 0.66 \pm 4.65 \mathrm{E}-10 \\ \text { October } & \text { NA } & \text { NA } \\ \text { November } & \text { NA } & \text { NA } \\ \text { December } & 0.63 \pm 1.52 \mathrm{E}-10 & 1.91 \pm 4.37 \mathrm{E}-10 \\ & & \\ \text { Annual Total } & -1.90 \pm 3.55 \mathrm{E}-10 & 1.04 \pm 0.83 \mathrm{E}-09\end{array}$

NA - Not applicable. Ventilation off.

Note: Bolding convention applied to these data. See page D-2.

WVDP Site Environmental Report

$D-11$ 


\section{Table D-11 \\ 2001 Airborne Radioactive Effluent Totals (curies) From the Laundry Change Room (ANLAUNV)}

\begin{tabular}{lrr} 
Month & Gross Alpha & \multicolumn{1}{c}{ Gross Beta } \\
& & \\
January & $-1.97 \pm 6.70 \mathrm{E}-10$ & $\mathbf{2 . 1 3} \pm \mathbf{1 . 3 9 E}-\mathbf{0 9}$ \\
February & $-4.94 \pm 6.97 \mathrm{E}-10$ & $0.60 \pm 1.33 \mathrm{E}-09$ \\
March & $-0.92 \pm 4.93 \mathrm{E}-10$ & $1.23 \pm 0.86 \mathrm{E}-09$ \\
April & $-4.85 \pm 5.70 \mathrm{E}-10$ & $0.71 \pm 1.21 \mathrm{E}-09$ \\
May & $0.76 \pm 5.35 \mathrm{E}-10$ & $0.82 \pm 1.12 \mathrm{E}-09$ \\
June & $0.71 \pm 3.69 \mathrm{E}-10$ & $3.84 \pm 9.39 \mathrm{E}-10$ \\
July & $0.00 \pm 3.22 \mathrm{E}-10$ & $4.98 \pm 5.25 \mathrm{E}-10$ \\
August & $-3.88 \pm 3.29 \mathrm{E}-10$ & $-1.04 \pm 0.84 \mathrm{E}-09$ \\
September & $0.00 \pm 8.21 \mathrm{E}-10$ & $-0.60 \pm 1.33 \mathrm{E}-09$ \\
October & $4.83 \pm 6.28 \mathrm{E}-10$ & $0.13 \pm 1.30 \mathrm{E}-09$ \\
November & $1.03 \pm 6.68 \mathrm{E}-10$ & $-0.94 \pm 1.16 \mathrm{E}-09$ \\
December & $0.98 \pm 4.27 \mathrm{E}-10$ & $-0.59 \pm 1.23 \mathrm{E}-09$ \\
& & \\
Annual Total & $-0.83 \pm 1.96 \mathrm{E}-09$ & $3.33 \pm 3.92 \mathrm{E}-09$
\end{tabular}

Note: Bolding convention applied to these data. See page D-2.

$$
\text { D }-12
$$




\section{Table D-12}

\section{Radioactivity Concentrations $(\mu \mathrm{Ci} / \mathrm{mL})$ in Airborne Particulates at the Lag Storage Air Sampler (ANLAGAM)}

Month
January
February
March
April
May
June
July
August
September
October
November
December

Quarter
1st Quarter
2nd Quarter
3rd Quarter
4th Quarter

1 st Quarter

2nd Quarter

$3 r d$ Quarter

4th Quarter

\begin{abstract}
Gross Alpha
$8.25 \pm 9.74 \mathrm{E}-16$

$1.21 \pm 0.95 \mathrm{E}-15$

$5.63 \pm 8.39 \mathrm{E}-16$

$8.49 \pm 8.71 \mathrm{E}-16$

$7.89 \pm 8.46 \mathrm{E}-16$

$6.63 \pm 8.02 \mathrm{E}-16$

$5.33 \pm 9.45 \mathrm{E}-16$

$7.64 \pm 9.12 \mathrm{E}-16$

$4.16 \pm 9.12 \mathrm{E}-16$

$6.43 \pm 8.80 \mathrm{E}-16$

$0.83 \pm 1.06 \mathrm{E}-15$

1.41 $\pm 1.04 E-15$
\end{abstract}

\section{Gross Beta}

$2.16 \pm 0.27 \mathrm{E}-14$

$2.38 \pm 0.28 \mathrm{E}-14$

$1.66 \pm 0.24 \mathrm{E}-14$

$1.33 \pm 0.22 \mathrm{E}-14$

$1.80 \pm 0.25 \mathrm{E}-14$

1.26 $\pm 0.23 \mathrm{E}-14$

$1.75 \pm 0.25 \mathrm{E}-14$

$2.20 \pm 0.27 \mathrm{E}-14$

$2.24 \pm 0.27 \mathrm{E}-14$

$2.16 \pm 0.27 \mathrm{E}-14$

2.74 $\pm 0.32 E-14$

$2.47 \pm 0.31 \mathrm{E}-14$

K-40
$0.00 \pm 2.56 \mathrm{E}-15$
$1.31 \pm 5.32 \mathrm{E}-15$
$\mathbf{6 . 8 5} \pm \mathbf{3 . 6 5 E}-15$
$0.83 \pm 3.32 \mathrm{E}-15$

Co-60

Sr-90

Cs-137

U-232

$1.83 \pm 1.99 \mathrm{E}-16$

$-0.56 \pm 2.06 \mathrm{E}-16$

$0.72 \pm 2.31 \mathrm{E}-16$

$0.25 \pm 1.42 \mathrm{E}-16$
$0.83 \pm 1.09 \mathrm{E}-16$
$-4.73 \pm 6.94 \mathrm{E}-17$
$1.28 \pm 1.31 \mathrm{E}-16$
$1.02 \pm 1.93 \mathrm{E}-16$

$0.96 \pm 2.09 \mathrm{E}-16$
$-0.24 \pm 1.71 \mathrm{E}-16$
$-1.07 \pm 1.77 \mathrm{E}-16$
$0.00 \pm 1.52 \mathrm{E}-16$

$-3.11 \pm 9.03 \mathrm{E}-18$

$0.11 \pm 1.46 \mathrm{E}-17$

1.91 $\pm 1.62 \mathrm{E}-17$

$-0.25 \pm 1.86 \mathrm{E}-17$

U-233/234

U-235/236

U-238

Total U

$(\mu \mathrm{g} / \mathrm{mL})$

7.24 $\pm 2.32 \mathrm{E}-17$

$1.31 \pm 6.62 \mathrm{E}-18$

$6.46 \pm 2.19 \mathrm{E}-17$

$1.93 \pm 0.02 E-10$

$1.48 \pm 2.95 \mathrm{E}-18$

$1.36 \pm 1.75 \mathrm{E}-17$

$5.02 \pm 8.26 \mathrm{E}-18$

$7.29 \pm 2.68 \mathrm{E}-17$

$9.08 \pm 3.98 \mathrm{E}-17$

$1.90 \pm 1.72 \mathrm{E}-17$

4.44 $\pm 2.40 \mathrm{E}-17$

$6.19 \pm 2.46 \mathrm{E}-17$

8.71 $\pm 4.05 E-17$

$1.64 \pm 0.02 \mathrm{E}-10$

1.26 \pm 0.03E-10

$1.90 \pm 0.06 \mathrm{E}-10$
$2.35 \pm 4.71 \mathrm{E}-18$

$2.36 \pm 5.79 \mathrm{E}-18$

$4.49 \pm 5.20 \mathrm{E}-18$

\section{Pu-239/240 Am-241}

1 st Quarter

2nd Quarter

$3 r d$ Quarter

4th Quarter
$2.13 \pm 5.21 \mathrm{E}-18$ $0.00 \pm 7.05 \mathrm{E}-18$

$-1.18 \pm 2.36 \mathrm{E}-18$

$0.00 \pm 8.30 \mathrm{E}-18$

\author{
$-0.20 \pm 1.31 \mathrm{E}-17$ \\ $5.47 \pm 8.67 \mathrm{E}-18$ \\ $9.00 \pm 7.39 \mathrm{E}-18$ \\ 1.62 $\pm 1.23 \mathrm{E}-17$
}

Note: Bolding convention applied to these data. See page D-2.

WVDP Site Environmental Report

$$
D-13
$$

Calendar Year 2001 


\section{Table D-13}

\section{Radioactivity Concentrations $(\mu \mathrm{Ci} / \mathrm{mL})$ in Airborne Particulates at the NDA Air Sampler (ANNDAAM)}

\begin{tabular}{|c|c|c|}
\hline Month & Gross Alpha & Gross Beta \\
\hline January & $0.97 \pm 1.07 \mathrm{E}-15$ & $2.21 \pm 0.29 \mathrm{E}-14$ \\
\hline February & $1.13 \pm 0.94 \mathrm{E}-15$ & $2.25 \pm 0.28 \mathrm{E}-14$ \\
\hline March & $3.50 \pm 8.02 \mathrm{E}-16$ & $1.80 \pm 0.25 \mathrm{E}-14$ \\
\hline April & $6.51 \pm 8.29 \mathrm{E}-16$ & $1.20 \pm 0.21 \mathrm{E}-14$ \\
\hline May & $1.18 \pm 0.93 \mathrm{E}-15$ & $1.69 \pm 0.25 \mathrm{E}-14$ \\
\hline June & $3.45 \pm 7.25 \mathrm{E}-16$ & $9.13 \pm 2.05 E-15$ \\
\hline July & $2.96 \pm 8.71 \mathrm{E}-16$ & $1.61 \pm 0.24 \mathrm{E}-14$ \\
\hline August & $1.19 \pm 1.00 \mathrm{E}-15$ & $1.99 \pm 0.26 \mathrm{E}-14$ \\
\hline September & $-3.18 \pm 7.55 \mathrm{E}-16$ & $1.74 \pm 0.25 \mathrm{E}-14$ \\
\hline October & $7.74 \pm 9.50 \mathrm{E}-16$ & $1.91 \pm 0.27 \mathrm{E}-14$ \\
\hline November & $9.41 \pm 9.97 \mathrm{E}-16$ & $2.27 \pm 0.28 \mathrm{E}-14$ \\
\hline December & $8.35 \pm 8.25 \mathrm{E}-16$ & $1.81 \pm 0.26 \mathrm{E}-14$ \\
\hline Quarter & K-40 & Co-60 \\
\hline 1st Quarter & $3.64 \pm 2.09 \mathrm{E}-15$ & $0.42 \pm 1.87 \mathrm{E}-16$ \\
\hline 2nd Quarter & $1.85 \pm 3.91 \mathrm{E}-15$ & $0.23 \pm 1.55 \mathrm{E}-16$ \\
\hline 3rd Quarter & $0.13 \pm 3.49 \mathrm{E}-15$ & $1.10 \pm 1.95 \mathrm{E}-16$ \\
\hline \multirow[t]{2}{*}{ 4th Quarter } & $0.00 \pm 3.69 \mathrm{E}-15$ & $-0.69 \pm 1.77 \mathrm{E}-16$ \\
\hline & U-233/234 & U-235/236 \\
\hline 1st Quarter & 8.21 $\pm 2.59 \mathrm{E}-17$ & $-0.29 \pm 6.90 \mathrm{E}-18$ \\
\hline 2nd Quarter & $6.63 \pm 2.44 E-17$ & $2.86 \pm 1.64 \mathrm{E}-17$ \\
\hline 3rd Quarter & $7.93 \pm 2.74 \mathrm{E}-17$ & $1.28 \pm 1.22 \mathrm{E}-17$ \\
\hline \multirow[t]{2}{*}{ 4th Quarter } & $7.06 \pm 2.77 \mathrm{E}-17$ & $1.04 \pm 1.72 \mathrm{E}-17$ \\
\hline & $\mathrm{Pu}-239 / 240$ & Am-241 \\
\hline 1st Quarter & $0.00 \pm 1.02 \mathrm{E}-17$ & $-0.31 \pm 1.37 \mathrm{E}-17$ \\
\hline 2nd Quarter & $0.00 \pm 6.39 \mathrm{E}-18$ & $-1.57 \pm 3.15 \mathrm{E}-18$ \\
\hline 3rd Quarter & $4.56 \pm 4.59 \mathrm{E}-18$ & $1.86 \pm 4.60 \mathrm{E}-18$ \\
\hline 4th Quarter & $-3.81 \pm 8.44 \mathrm{E}-18$ & $1.89 \pm 1.21 \mathrm{E}-17$ \\
\hline
\end{tabular}

$\begin{array}{crr}\text { Sr-90 } & \text { Cs-137 } & \text { U-232 } \\ & & \\ 3.57 \pm 9.74 \mathrm{E}-17 & 0.69 \pm 1.83 \mathrm{E}-16 & 1.27 \pm 1.29 \mathrm{E}-17 \\ 3.23 \pm 6.02 \mathrm{E}-17 & 0.57 \pm 1.52 \mathrm{E}-16 & -1.15 \pm 6.91 \mathrm{E}-18 \\ 0.63 \pm 1.53 \mathrm{E}-16 & -0.40 \pm 1.90 \mathrm{E}-16 & 1.14 \pm 1.19 \mathrm{E}-17 \\ 0.56 \pm 1.37 \mathrm{E}-16 & -0.55 \pm 1.81 \mathrm{E}-16 & 0.74 \pm 1.38 \mathrm{E}-17 \\ & & \\ & & \\ \mathbf{U}-\mathbf{2 3 8} & \text { Total U } & \mathbf{P u}-\mathbf{2 3 8} \\ & (\mu \mathrm{g} / \mathrm{mL}) & \\ & & \\ \mathbf{5 . 1 6} \pm \mathbf{2 . 0 5 E}-\mathbf{1 7} & \mathbf{1 . 8 5} \pm \mathbf{0 . 0 2 E}-\mathbf{1 0} & 1.85 \pm 3.70 \mathrm{E}-18 \\ \mathbf{5 . 7 2} \pm 2.29 \mathrm{E}-17 & 1.59 \pm 0.02 \mathrm{E}-10 & -1.08 \pm 2.16 \mathrm{E}-18 \\ \mathbf{7 . 4 5} \pm \mathbf{2 . 8 2 E}-\mathbf{1 7} & \mathbf{1 . 2 0} \pm \mathbf{0 . 0 2 E}-\mathbf{1 0} & -1.14 \pm 2.29 \mathrm{E}-18 \\ \mathbf{7 . 2 7} \pm 2.62 \mathrm{E}-17 & 1.84 \pm 0.05 \mathrm{E}-10 & -1.27 \pm 4.40 \mathrm{E}-18\end{array}$

Note: Bolding convention applied to these data. See page D-2.

WVDP Site Environmental Report

$$
D-14
$$

Calendar Year 2001 


\section{Table D-14 \\ 2001 Airborne Radioactivity Concentrations ( $\mu \mathrm{Ci} / \mathrm{mL})$ at the SDA Trench 9 Air Sampler (ANSDAT9)}

$\begin{array}{lcrrr}\text { Month } & \text { Gross Alpha } & \text { Gross Beta } & \text { H-3 } & \\ & & & & \\ \text { January } & 0.33 \pm 1.17 \mathrm{E}-15 & 1.80 \pm 0.31 \mathrm{E}-14 & 1.05 \pm 0.20 \mathrm{E}-12 & \\ \text { February } & 0.50 \pm 1.12 \mathrm{E}-15 & 2.14 \pm 0.34 \mathrm{E}-14 & 1.33 \pm 0.20 \mathrm{E}-12 & \\ \text { March } & 0.32 \pm 1.13 \mathrm{E}-15 & 1.48 \pm 0.30 \mathrm{E}-14 & 1.38 \pm 0.20 \mathrm{E}-12 & \\ \text { April } & 0.92 \pm 1.25 \mathrm{E}-15 & 1.45 \pm 0.30 \mathrm{E}-14 & \mathbf{1 . 5 4} \pm \mathbf{0 . 4 1 E}-12 & \\ \text { May } & 0.80 \pm 1.18 \mathrm{E}-15 & 1.72 \pm 0.33 \mathrm{E}-14 & 1.13 \pm 0.45 \mathrm{E}-12 & \\ \text { June } & 0.70 \pm 1.14 \mathrm{E}-15 & \mathbf{1 . 2 8} \pm \mathbf{0 . 3 0 E}-14 & -3.01 \pm 7.32 \mathrm{E}-13 & \\ \text { July } & 0.27 \pm 1.30 \mathrm{E}-15 & 1.87 \pm 0.34 \mathrm{E}-14 & 7.17 \pm 7.93 \mathrm{E}-13 & \\ \text { August } & 0.51 \pm 1.26 \mathrm{E}-15 & 2.27 \pm 0.35 \mathrm{E}-14 & 7.40 \pm 9.60 \mathrm{E}-13 & \\ \text { September } & 0.27 \pm 1.37 \mathrm{E}-15 & 2.23 \pm 0.36 \mathrm{E}-14 & 1.08 \pm 0.72 \mathrm{E}-12 & \\ \text { October } & 0.40 \pm 1.20 \mathrm{E}-15 & 2.13 \pm 0.34 \mathrm{E}-14 & 2.84 \pm 5.28 \mathrm{E}-13 & \\ \text { November } & 1.17 \pm 1.36 \mathrm{E}-15 & \mathbf{2 . 4 2} \pm \mathbf{0 . 3 6 E}-14 & 7.18 \pm 4.11 \mathrm{E}-13 & \\ \text { December } & 0.78 \pm 1.07 \mathrm{E}-15 & 1.95 \pm 0.33 \mathrm{E}-14 & 4.67 \pm 4.07 \mathrm{E}-13 & \\ & & & & \\ \text { Quarter } & & & & \\ & & & & \\ \text { 1st Quarter } & 2.71 \pm 4.11 \mathrm{E}-15 & 0.71 \pm 2.44 \mathrm{E}-16 & -0.09 \pm 2.54 \mathrm{E}-16 & 0.97 \pm 2.01 \mathrm{E}-16 \\ \text { 2nd Quarter } & 6.15 \pm 3.42 \mathrm{E}-15 & -1.15 \pm 2.69 \mathrm{E}-16 & 0.79 \pm 2.74 \mathrm{E}-16 & 1.56 \pm 2.44 \mathrm{E}-16 \\ \text { 3rd Quarter } & \mathbf{6 . 7 2 \pm 5 . 9 4 E - 1 5} & -2.38 \pm 3.41 \mathrm{E}-16 & 0.30 \pm 1.80 \mathrm{E}-16 & 0.54 \pm 3.14 \mathrm{E}-16 \\ \text { 4th Quarter } & 0.00 \pm 4.90 \mathrm{E}-15 & -0.69 \pm 1.80 \mathrm{E}-16 & -0.17 \pm 2.46 \mathrm{E}-16 & -1.36 \pm 1.79 \mathrm{E}-16\end{array}$

Note: Bolding convention applied to these data. See page D-2.

$$
D-15
$$


NA - Not applicable. Ventilation units not in use.

Note: Bolding convention applied to these data. See page D-2.

WVDP Site Environmental Report

$$
D-16
$$

\begin{tabular}{|c|c|c|}
\hline Month & Gross Alpha & Gross Beta \\
\hline January & NA & NA \\
\hline February & $0.45 \pm 2.95 \mathrm{E}-10$ & $-0.61 \pm 5.67 \mathrm{E}-10$ \\
\hline March & NA & NA \\
\hline April & $-0.49 \pm 1.90 \mathrm{E}-10$ & $2.45 \pm 3.25 \mathrm{E}-10$ \\
\hline May & NA & NA \\
\hline June & NA & NA \\
\hline July & $1.68 \pm 4.28 \mathrm{E}-10$ & $-0.17 \pm 7.56 \mathrm{E}-10$ \\
\hline August & NA & NA \\
\hline September & $0.61 \pm 4.48 \mathrm{E}-10$ & $3.53 \pm 0.89 E-09$ \\
\hline October & NA & NA \\
\hline November & $-1.66 \pm 4.86 \mathrm{E}-10$ & $1.19 \pm 0.99 \mathrm{E}-09$ \\
\hline December & $-6.66 \pm 5.86 \mathrm{E}-10$ & $1.61 \pm 0.84 \mathrm{E}-09$ \\
\hline Annual Total & $-0.61 \pm 1.04 \mathrm{E}-09$ & $6.50 \pm 1.87 \mathrm{E}-09$ \\
\hline Quarter & Co-60 & Sr-90 \\
\hline 1st Quarter & $-0.52 \pm 1.05 E-09$ & $0.09 \pm 5.72 \mathrm{E}-10$ \\
\hline 2nd Quarter & $0.66 \pm 5.83 \mathrm{E}-10$ & $0.05 \pm 2.23 \mathrm{E}-10$ \\
\hline 3rd Quarter & $-6.75 \pm 8.58 \mathrm{E}-10$ & $1.30 \pm 5.70 \mathrm{E}-10$ \\
\hline 4th Quarter & $-5.03 \pm 6.24 \mathrm{E}-10$ & $0.73 \pm 4.81 \mathrm{E}-10$ \\
\hline \multirow[t]{2}{*}{ Annual Total } & $-1.63 \pm 1.60 \mathrm{E}-09$ & $2.17 \pm 9.66 \mathrm{E}-10$ \\
\hline & U-233/234 & U-235/236 \\
\hline 1st Quarter & $1.52 \pm 0.83 \mathrm{E}-10$ & $-1.57 \pm 2.23 \mathrm{E}-11$ \\
\hline 2nd Quarter & $1.70 \pm 0.67 \mathrm{E}-10$ & $6.95 \pm 4.31 \mathrm{E}-11$ \\
\hline 3rd Quarter & $2.09 \pm 0.76 \mathrm{E}-10$ & $2.34 \pm 2.35 \mathrm{E}-11$ \\
\hline 4th Quarter & $3.17 \pm 1.84 \mathrm{E}-10$ & $0.68 \pm 1.20 \mathrm{E}-10$ \\
\hline \multirow[t]{2}{*}{ Annual Total } & $8.49 \pm 2.26 \mathrm{E}-10$ & $1.45 \pm 1.32 \mathrm{E}-10$ \\
\hline & Pu-239/240 & Am-241 \\
\hline 1st Quarter & $1.52 \pm 2.15 \mathrm{E}-11$ & $2.57 \pm 1.91 \mathrm{E}-10$ \\
\hline 2nd Quarter & $0.00 \pm 2.03 \mathrm{E}-11$ & $0.15 \pm 1.31 \mathrm{E}-11$ \\
\hline 3rd Quarter & $2.23 \pm 4.09 \mathrm{E}-11$ & $3.96 \pm 3.48 \mathrm{E}-11$ \\
\hline 4th Quarter & $-4.85 \pm 5.16 \mathrm{E}-11$ & $7.24 \pm 5.99 \mathrm{E}-11$ \\
\hline Annual Total & $-1.10 \pm 7.22 \mathrm{E}-11$ & $3.70 \pm 2.04 \mathrm{E}-10$ \\
\hline
\end{tabular}

$\begin{array}{rrr}\mathbf{9 . 7 8} \pm \mathbf{9 . 4 1 E}-10 & -1.89 \pm 3.00 \mathrm{E}-09 & 2.08 \pm 3.66 \mathrm{E}-11 \\ -0.17 \pm 5.07 \mathrm{E}-10 & 0.12 \pm 1.41 \mathrm{E}-09 & 1.77 \pm 2.75 \mathrm{E}-11 \\ 1.17 \pm 1.98 \mathrm{E}-09 & 1.06 \pm 2.41 \mathrm{E}-09 & 4.32 \pm 5.52 \mathrm{E}-11 \\ -0.14 \pm 5.49 \mathrm{E}-10 & -0.31 \pm 1.64 \mathrm{E}-09 & \mathbf{9 . 7 6} \pm \mathbf{9 . 1 9 E}-11 \\ & & \\ 2.11 \pm 2.31 \mathrm{E}-09 & -1.02 \pm 4.42 \mathrm{E}-09 & 1.79 \pm 1.17 \mathrm{E}-10 \\ & & \\ \mathbf{U}-\mathbf{2 3 8} & \text { Total U } & \mathbf{P u}-\mathbf{2 3 8} \\ & (\mathrm{g}) & \\ 3.26 \pm 3.78 \mathrm{E}-11 & 1.47 \pm 0.03 \mathrm{E}-04 & 1.06 \pm 2.11 \mathrm{E}-11 \\ 7.23 \pm 4.71 \mathrm{E}-11 & \mathbf{6 . 8 7} \pm \mathbf{0 . 1 1 E}-\mathbf{0 5} & -0.01 \pm 2.55 \mathrm{E}-11 \\ \mathbf{1 . 7 5} \pm \mathbf{0 . 6 6 E}-\mathbf{1 0} & 4.07 \pm 0.09 \mathrm{E}-04 & \mathbf{2 . 2 4} \pm \mathbf{2 . 0 1 E}-\mathbf{1 1} \\ 1.58 \pm 1.76 \mathrm{E}-10 & \mathbf{5 . 3 5} \pm \mathbf{0 . 1 6 E}-\mathbf{0 4} & 0.61 \pm 2.71 \mathrm{E}-11 \\ & & \\ 4.38 \pm 1.97 \mathrm{E}-10 & 1.16 \pm 0.02 \mathrm{E}-03 & 3.89 \pm 4.73 \mathrm{E}-11\end{array}$

Eu-154 U-232

\section{Table D-15 \\ 2001 Airborne Radioactive Effluent Totals (curies) \\ From Outdoor Ventilation Enclosures/Portable Ventilation Units}


Table D-16

2001 Airborne Radioactivity Concentrations $(\mu \mathrm{Ci} / \mathrm{mL})$ at the Rock Springs Road Air Sampler (AFRSPRD)

\begin{tabular}{|c|c|c|c|c|c|}
\hline Month & Gross Alpha & Gross Beta & H-3 & & \\
\hline January & $0.07 \pm 1.19 \mathrm{E}-15$ & $1.85 \pm 0.33 \mathrm{E}-14$ & $0.14 \pm 2.09 \mathrm{E}-13$ & & \\
\hline February & $0.67 \pm 1.15 \mathrm{E}-15$ & $2.03 \pm 0.34 \mathrm{E}-14$ & $1.53 \pm 2.33 \mathrm{E}-13$ & & \\
\hline March & $0.32 \pm 1.13 \mathrm{E}-15$ & $1.53 \pm 0.30 \mathrm{E}-14$ & $-0.79 \pm 2.55 \mathrm{E}-13$ & & \\
\hline April & $0.79 \pm 1.22 \mathrm{E}-15$ & $1.21 \pm 0.28 \mathrm{E}-14$ & $2.77 \pm 4.69 \mathrm{E}-13$ & & \\
\hline May & $0.94 \pm 1.20 \mathrm{E}-15$ & $1.98 \pm 0.34 \mathrm{E}-14$ & $3.44 \pm 5.02 \mathrm{E}-13$ & & \\
\hline June & $0.43 \pm 1.15 \mathrm{E}-15$ & $1.35 \pm 0.34 \mathrm{E}-14$ & $-9.56 \pm 8.99 \mathrm{E}-13$ & & \\
\hline July & $0.29 \pm 1.32 \mathrm{E}-15$ & $1.86 \pm 0.34 \mathrm{E}-14$ & $2.25 \pm 9.18 \mathrm{E}-13$ & & \\
\hline August & $0.18 \pm 1.16 \mathrm{E}-15$ & $1.93 \pm 0.33 \mathrm{E}-14$ & $-0.02 \pm 1.09 \mathrm{E}-12$ & & \\
\hline September & $0.20 \pm 1.18 \mathrm{E}-15$ & $1.62 \pm 0.30 \mathrm{E}-14$ & $1.01 \pm 1.78 \mathrm{E}-12$ & & \\
\hline October & $0.78 \pm 1.24 \mathrm{E}-15$ & $1.76 \pm 0.31 \mathrm{E}-14$ & $-5.74 \pm 6.43 \mathrm{E}-13$ & & \\
\hline November & $0.62 \pm 1.29 \mathrm{E}-15$ & $2.11 \pm 0.35 E-14$ & $4.57 \pm 4.73 \mathrm{E}-13$ & & \\
\hline December & $0.61 \pm 1.02 \mathrm{E}-15$ & $1.93 \pm 0.33 \mathrm{E}-14$ & $-1.80 \pm 4.57 \mathrm{E}-13$ & & \\
\hline Quarter & K-40 & Co-60 & Sr-90 & I-129 & Cs-137 \\
\hline 1st Quarter & $1.46 \pm 4.08 \mathrm{E}-15$ & $-1.29 \pm 2.49 \mathrm{E}-16$ & $-0.48 \pm 1.36 \mathrm{E}-16$ & $3.95 \pm 4.01 \mathrm{E}-16$ & $2.00 \pm 2.39 \mathrm{E}-16$ \\
\hline 2nd Quarter & $0.00 \pm 7.44 \mathrm{E}-15$ & $0.38 \pm 2.63 \mathrm{E}-16$ & $0.74 \pm 1.44 \mathrm{E}-16$ & $0.15 \pm 2.99 \mathrm{E}-16$ & $-0.97 \pm 2.75 \mathrm{E}-16$ \\
\hline 3rd Quarter & $7.12 \pm 4.44 \mathrm{E}-15$ & $-0.67 \pm 2.82 \mathrm{E}-16$ & $0.52 \pm 2.05 \mathrm{E}-16$ & $0.97 \pm 2.39 \mathrm{E}-16$ & $0.03 \pm 2.80 \mathrm{E}-16$ \\
\hline \multirow[t]{2}{*}{ 4th Quarter } & $2.48 \pm 3.68 \mathrm{E}-15$ & $-0.79 \pm 1.58 \mathrm{E}-16$ & $1.80 \pm 2.11 \mathrm{E}-16$ & $9.47 \pm 9.39 \mathrm{E}-17$ & $-0.50 \pm 1.52 \mathrm{E}-16$ \\
\hline & U-232 & U-233/234 & U-235/236 & U-238 & $\begin{array}{l}\text { Total U } \\
(\mu \mathrm{g} / \mathrm{mL})\end{array}$ \\
\hline 1st Quarter & $0.47 \pm 1.47 \mathrm{E}-17$ & $1.05 \pm 0.41 \mathrm{E}-16$ & $3.09 \pm 6.17 \mathrm{E}-18$ & $8.98 \pm 3.52 \mathrm{E}-17$ & $2.64 \pm 0.03 E-10$ \\
\hline 2nd Quarter & $0.56 \pm 1.94 \mathrm{E}-17$ & $1.21 \pm 0.50 \mathrm{E}-16$ & $2.20 \pm 2.26 \mathrm{E}-17$ & $8.15 \pm 3.97 \mathrm{E}-17$ & $2.49 \pm 0.03 \mathrm{E}-10$ \\
\hline 3rd Quarter & $-0.26 \pm 1.44 \mathrm{E}-17$ & $7.63 \pm 2.80 \mathrm{E}-17$ & $-0.37 \pm 8.67 \mathrm{E}-18$ & $8.75 \pm 3.11 \mathrm{E}-17$ & $1.69 \pm 0.04 E-10$ \\
\hline \multirow[t]{2}{*}{ 4th Quarter } & $0.00 \pm 9.48 \mathrm{E}-17$ & $1.22 \pm 0.55 \mathrm{E}-16$ & $2.17 \pm 2.94 \mathrm{E}-17$ & $1.27 \pm 0.41 \mathrm{E}-16$ & $2.44 \pm 0.07 \mathrm{E}-10$ \\
\hline & Pu-238 & Pu-239/240 & Am-241 & & \\
\hline 1st Quarter & $7.86 \pm 9.11 \mathrm{E}-18$ & $-1.89 \pm 3.78 \mathrm{E}-18$ & $-1.11 \pm 4.38 \mathrm{E}-17$ & & \\
\hline 2nd Quarter & $1.69 \pm 7.66 \mathrm{E}-18$ & $1.69 \pm 7.64 \mathrm{E}-18$ & $0.80 \pm 1.14 \mathrm{E}-17$ & & \\
\hline 3rd Quarter & $-1.53 \pm 6.86 \mathrm{E}-18$ & $-3.06 \pm 7.51 \mathrm{E}-18$ & $0.62 \pm 1.03 \mathrm{E}-17$ & & \\
\hline 4th Quarter & $-0.41 \pm 1.02 \mathrm{E}-17$ & $0.21 \pm 1.37 \mathrm{E}-17$ & $1.53 \pm 1.26 \mathrm{E}-17$ & & \\
\hline
\end{tabular}

Note: Bolding convention applied to these data. See page D-2.

WVDP Site Environmental Report

$$
D-17
$$

Calendar Year 2001 


\section{Table D-17 \\ 2001 Radioactivity Concentrations $(\mu \mathrm{Ci} / \mathrm{mL})$ in Airborne Particulates at the Dutch Hill Air Sampler (AFBOEHN)}

$\begin{array}{lrr}\text { Month } & \text { Gross Alpha } & \text { Gross Beta } \\ \text { January } & 1.04 \pm 1.33 \mathrm{E}-15 & 2.09 \pm 0.33 \mathrm{E}-14 \\ \text { February } & 0.37 \pm 1.02 \mathrm{E}-15 & 2.33 \pm 0.34 \mathrm{E}-14 \\ \text { March } & 0.54 \pm 1.11 \mathrm{E}-15 & 1.65 \pm 0.29 \mathrm{E}-14 \\ \text { April } & 0.78 \pm 1.17 \mathrm{E}-15 & 1.57 \pm 0.30 \mathrm{E}-14 \\ \text { May } & 1.26 \pm 1.27 \mathrm{E}-15 & 1.90 \pm 0.33 \mathrm{E}-14 \\ \text { June } & 0.97 \pm 1.29 \mathrm{E}-15 & \mathbf{1 . 3 4} \pm \mathbf{0 . 3 2 E}-\mathbf{1 4} \\ \text { July } & 0.36 \pm 1.24 \mathrm{E}-15 & 1.78 \pm 0.32 \mathrm{E}-14 \\ \text { August } & 1.01 \pm 1.30 \mathrm{E}-15 & 2.21 \pm 0.33 \mathrm{E}-14 \\ \text { September } & 0.00 \pm 1.21 \mathrm{E}-15 & 2.20 \pm 0.34 \mathrm{E}-14 \\ \text { October } & 0.52 \pm 1.20 \mathrm{E}-15 & 2.01 \pm 0.33 \mathrm{E}-14 \\ \text { November } & 1.01 \pm 1.34 \mathrm{E}-15 & \mathbf{2 . 4 7} \pm \mathbf{0 . 3 6 E}-14 \\ \text { December } & \mathbf{1 . 1 9} \pm \mathbf{1 . 1 8 E}-15 & 2.21 \pm 0.35 \mathrm{E}-14 \\ & & \\ \text { Quarter } & & \\ & & \text { Sr-90 } \\ \text { 1st Quarter } & 0.88 \pm 1.36 \mathrm{E}-16 & 0.00 \pm 3.78 \mathrm{E}-16 \\ \text { 2nd Quarter } & -0.15 \pm 1.40 \mathrm{E}-16 & 1.55 \pm 2.34 \mathrm{E}-16 \\ \text { 3rd Quarter } & 0.46 \pm 1.66 \mathrm{E}-16 & 0.96 \pm 2.79 \mathrm{E}-16 \\ \text { 4th Quarter } & 0.13 \pm 1.83 \mathrm{E}-16 & -0.64 \pm 1.72 \mathrm{E}-16\end{array}$

Table D-18

2001 Radioactivity Concentrations ( $\mu \mathrm{Ci} / \mathrm{mL}$ ) in Airborne Particulates at the Fox Valley Air Sampler (AFFXVRD)

$\begin{array}{lrr}\text { Month } & \text { Gross Alpha } & \text { Gross Beta } \\ \text { January } & 0.82 \pm 1.32 \mathrm{E}-15 & 1.97 \pm 0.33 \mathrm{E}-14 \\ \text { February } & 0.66 \pm 1.11 \mathrm{E}-15 & 2.39 \pm 0.35 \mathrm{E}-14 \\ \text { March } & 0.38 \pm 1.10 \mathrm{E}-15 & 1.66 \pm 0.30 \mathrm{E}-14 \\ \text { April } & 0.52 \pm 1.15 \mathrm{E}-15 & 1.40 \pm 0.29 \mathrm{E}-14 \\ \text { May } & \mathbf{1 . 5 8} \pm \mathbf{1 . 3 5 E}-15 & 1.71 \pm 0.32 \mathrm{E}-14 \\ \text { June } & 0.48 \pm 1.06 \mathrm{E}-15 & \mathbf{1 . 2 0} \pm \mathbf{0 . 2 9 E}-\mathbf{1 4} \\ \text { July } & 0.30 \pm 1.29 \mathrm{E}-15 & 1.75 \pm 0.33 \mathrm{E}-14 \\ \text { August } & 0.44 \pm 1.23 \mathrm{E}-15 & 2.08 \pm 0.34 \mathrm{E}-14 \\ \text { September } & -0.08 \pm 1.25 \mathrm{E}-15 & 2.12 \pm 0.35 \mathrm{E}-14 \\ \text { October } & 0.60 \pm 1.25 \mathrm{E}-15 & 2.17 \pm 0.35 \mathrm{E}-14 \\ \text { November } & 1.29 \pm 1.41 \mathrm{E}-15 & \mathbf{2 . 4 5} \pm \mathbf{0 . 3 6 E}-\mathbf{1 4} \\ \text { December } & 1.06 \pm 1.16 \mathrm{E}-15 & 2.34 \pm 0.36 \mathrm{E}-14 \\ & & \\ \text { Quarter } & & \\ & & \text { Cr-90 } \\ \text { 1st Quarter } & 0.54 \pm 1.46 \mathrm{E}-16 & -2.33 \pm 2.72 \mathrm{E}-16 \\ \text { 2nd Quarter } & -0.86 \pm 1.13 \mathrm{E}-16 & -0.87 \pm 2.66 \mathrm{E}-16 \\ \text { 3rd Quarter } & -0.42 \pm 2.03 \mathrm{E}-16 & -0.89 \pm 2.98 \mathrm{E}-16 \\ \text { 4th Quarter } & \mathbf{2 . 6 8} \pm \mathbf{1 . 8 4 E}-16 & 0.00 \pm 3.00 \mathrm{E}-16\end{array}$

Note: Bolding convention applied to these data. See page D-2.

WVDP Site Environmental Report

$$
D-18
$$




\section{Table D-19}

\section{Radioactivity Concentrations $(\mu \mathrm{Ci} / \mathrm{mL})$ in Airborne Particulates at the Bulk Storage Warehouse Air Sampler (AFBLKST)}

$\begin{array}{lcr}\text { Month } & \text { Gross Alpha } & \text { Gross Beta } \\ \text { January } & 0.07 \pm 1.16 \mathrm{E}-15 & 1.94 \pm 0.33 \mathrm{E}-14 \\ \text { February } & 0.31 \pm 1.04 \mathrm{E}-15 & 2.28 \pm 0.34 \mathrm{E}-14 \\ \text { March } & 0.69 \pm 1.18 \mathrm{E}-15 & 1.75 \pm 0.31 \mathrm{E}-14 \\ \text { April } & 0.33 \pm 1.09 \mathrm{E}-15 & \mathbf{1 . 3 4} \pm \mathbf{0 . 2 9 E}-14 \\ \text { May } & 1.01 \pm 1.21 \mathrm{E}-15 & 1.74 \pm 0.32 \mathrm{E}-14 \\ \text { June } & 2.68 \pm 9.95 \mathrm{E}-16 & 1.36 \pm 0.30 \mathrm{E}-14 \\ \text { July } & 0.30 \pm 1.28 \mathrm{E}-15 & 1.73 \pm 0.32 \mathrm{E}-14 \\ \text { August } & 0.38 \pm 1.20 \mathrm{E}-15 & 2.16 \pm 0.34 \mathrm{E}-14 \\ \text { September } & 0.23 \pm 1.30 \mathrm{E}-15 & 1.72 \pm 0.32 \mathrm{E}-14 \\ \text { October } & 0.46 \pm 1.22 \mathrm{E}-15 & 1.98 \pm 0.34 \mathrm{E}-14 \\ \text { November } & 0.82 \pm 1.33 \mathrm{E}-15 & \mathbf{2 . 3 0} \pm \mathbf{0 . 3 6 E}-14 \\ \text { December } & 1.09 \pm 1.19 \mathrm{E}-15 & 2.25 \pm 0.36 \mathrm{E}-14 \\ & & \\ \text { Quarter } & & \\ & & \text { Cr-90 } \\ \text { 1st Quarter } & 1.05 \pm 1.59 \mathrm{E}-16 & 0.48 \pm 2.76 \mathrm{E}-16 \\ \text { 2nd Quarter } & 0.00 \pm 2.75 \mathrm{E}-16 & 1.67 \pm 2.26 \mathrm{E}-16 \\ \text { 3rd Quarter } & 0.99 \pm 2.19 \mathrm{E}-16 & -0.25 \pm 3.02 \mathrm{E}-16 \\ \text { 4th Quarter } & -2.51 \pm 2.05 \mathrm{E}-16 & 0.32 \pm 1.73 \mathrm{E}-16\end{array}$

Table D-20

2001 Radioactivity Concentrations ( $\mu \mathrm{Ci} / \mathrm{mL}$ ) in Airborne Particulates at the Route 240 Air Sampler (AFRT240)

$\begin{array}{lcr}\text { Month } & \text { Gross Alpha } & \text { Gross Beta } \\ \text { January } & 0.33 \pm 1.23 \mathrm{E}-15 & 2.05 \pm 0.34 \mathrm{E}-14 \\ \text { February } & \mathbf{1 . 3 0} \pm \mathbf{1 . 2 8 E}-15 & 2.09 \pm 0.34 \mathrm{E}-14 \\ \text { March } & 0.45 \pm 1.14 \mathrm{E}-15 & 1.54 \pm 0.30 \mathrm{E}-14 \\ \text { April } & 0.83 \pm 1.21 \mathrm{E}-15 & 1.39 \pm 0.29 \mathrm{E}-14 \\ \text { May } & 1.36 \pm 1.61 \mathrm{E}-15 & 1.94 \pm 0.40 \mathrm{E}-14 \\ \text { June } & 0.91 \pm 1.16 \mathrm{E}-15 & \mathbf{1 . 2 9} \pm \mathbf{0 . 3 0 E}-\mathbf{1 4} \\ \text { July } & 0.52 \pm 1.31 \mathrm{E}-15 & 1.64 \pm 0.32 \mathrm{E}-14 \\ \text { August } & 0.64 \pm 1.25 \mathrm{E}-15 & 1.99 \pm 0.33 \mathrm{E}-14 \\ \text { September } & 0.30 \pm 1.31 \mathrm{E}-15 & 1.88 \pm 0.33 \mathrm{E}-14 \\ \text { October } & 0.73 \pm 1.29 \mathrm{E}-15 & 1.94 \pm 0.34 \mathrm{E}-14 \\ \text { November } & 0.65 \pm 1.30 \mathrm{E}-15 & 2.30 \pm 0.36 \mathrm{E}-14 \\ \text { December } & 0.88 \pm 1.13 \mathrm{E}-15 & \mathbf{2 . 3 5} \pm \mathbf{0 . 3 6 E}-14 \\ & & \\ \text { Quarter } & & \\ & & \text { Cr-90 }-137 \\ \text { 1st Quarter } & 0.54 \pm 1.38 \mathrm{E}-16 & 0.59 \pm 3.15 \mathrm{E}-16 \\ \text { 2nd Quarter } & 0.74 \pm 1.01 \mathrm{E}-16 & 0.98 \pm 2.18 \mathrm{E}-16 \\ \text { 3rd Quarter } & \mathbf{4 . 0 5} \pm \mathbf{2 . 0 4 E}-16 & -0.90 \pm 2.85 \mathrm{E}-16 \\ \text { 4th Quarter } & 0.23 \pm 2.49 \mathrm{E}-16 & -0.49 \pm 1.91 \mathrm{E}-16\end{array}$

Note: Bolding convention applied to these data. See page D-2.

WVDP Site Environmental Report

$$
D-19
$$




\section{Table D-21}

\section{Radioactivity Concentrations $(\mu \mathrm{Ci} / \mathrm{mL})$ in Airborne Particulates at the Thomas Corners Road Air Sampler (AFTCORD)}

$\begin{array}{lrr}\text { Month } & \text { Gross Alpha } & \text { Gross Beta } \\ \text { January } & 0.32 \pm 1.19 \mathrm{E}-15 & 1.93 \pm 0.32 \mathrm{E}-14 \\ \text { February } & 0.99 \pm 1.18 \mathrm{E}-15 & 2.09 \pm 0.33 \mathrm{E}-14 \\ \text { March } & 0.32 \pm 1.07 \mathrm{E}-15 & 1.64 \pm 0.29 \mathrm{E}-14 \\ \text { April } & 1.16 \pm 1.29 \mathrm{E}-15 & \mathbf{1 . 2 4} \pm \mathbf{0 . 2 8 E}-\mathbf{1 4} \\ \text { May } & 0.91 \pm 1.20 \mathrm{E}-15 & 1.86 \pm 0.33 \mathrm{E}-14 \\ \text { June } & 0.87 \pm 1.17 \mathrm{E}-15 & \mathbf{1 . 2 4} \pm \mathbf{0 . 3 0 E}-14 \\ \text { July } & 0.57 \pm 1.35 \mathrm{E}-15 & 1.82 \pm 0.33 \mathrm{E}-14 \\ \text { August } & 0.83 \pm 1.32 \mathrm{E}-15 & 2.10 \pm 0.34 \mathrm{E}-14 \\ \text { September } & 0.01 \pm 1.27 \mathrm{E}-15 & 2.09 \pm 0.35 \mathrm{E}-14 \\ \text { October } & 0.54 \pm 1.22 \mathrm{E}-15 & 1.96 \pm 0.33 \mathrm{E}-14 \\ \text { November } & 1.06 \pm 1.34 \mathrm{E}-15 & \mathbf{2 . 3 1} \pm \mathbf{0 . 3 5 E}-14 \\ \text { December } & 1.00 \pm 1.13 \mathrm{E}-15 & 2.19 \pm 0.35 \mathrm{E}-14 \\ & & \\ \text { Quarter } & & \\ & & \text { Cr-90 } \\ \text { 1st Quarter } & 0.03 \pm 1.58 \mathrm{E}-16 & 0.20 \pm 3.13 \mathrm{E}-16 \\ \text { 2nd Quarter } & 6.91 \pm 8.12 \mathrm{E}-17 & -0.33 \pm 2.70 \mathrm{E}-16 \\ \text { 3rd Quarter } & 1.51 \pm 1.83 \mathrm{E}-16 & 2.49 \pm 2.62 \mathrm{E}-16 \\ \text { 4th Quarter } & 0.51 \pm 1.85 \mathrm{E}-16 & -0.59 \pm 1.48 \mathrm{E}-16\end{array}$

Table D-22

2001 Radioactivity Concentrations ( $\mu \mathrm{Ci} / \mathrm{mL})$ in Airborne Particulates at the West Valley Air Sampler (AFWEVAL)

$\begin{array}{lcr}\text { Month } & \text { Gross Alpha } & \text { Gross Beta } \\ \text { January } & 0.46 \pm 1.24 \mathrm{E}-15 & 1.85 \pm 0.32 \mathrm{E}-14 \\ \text { February } & 0.35 \pm 1.04 \mathrm{E}-15 & 2.26 \pm 0.34 \mathrm{E}-14 \\ \text { March } & 0.41 \pm 1.11 \mathrm{E}-15 & 1.56 \pm 0.29 \mathrm{E}-14 \\ \text { April } & 0.75 \pm 1.22 \mathrm{E}-15 & 1.42 \pm 0.30 \mathrm{E}-14 \\ \text { May } & 0.96 \pm 1.23 \mathrm{E}-15 & 1.88 \pm 0.34 \mathrm{E}-14 \\ \text { June } & 0.42 \pm 1.37 \mathrm{E}-15 & \mathbf{1 . 2 8} \pm \mathbf{0 . 3 6 E}-14 \\ \text { July } & 0.65 \pm 1.39 \mathrm{E}-15 & 1.70 \pm 0.33 \mathrm{E}-14 \\ \text { August } & 0.36 \pm 1.23 \mathrm{E}-15 & 1.92 \pm 0.33 \mathrm{E}-14 \\ \text { September } & 0.77 \pm 1.45 \mathrm{E}-15 & 1.79 \pm 0.33 \mathrm{E}-14 \\ \text { October } & 0.72 \pm 1.27 \mathrm{E}-15 & 1.91 \pm 0.33 \mathrm{E}-14 \\ \text { November } & 0.93 \pm 1.30 \mathrm{E}-15 & \mathbf{2 . 2 9} \pm \mathbf{0 . 3 5 E}-14 \\ \text { December } & \mathbf{1 . 6 1} \pm \mathbf{1 . 2 6 E}-15 & 2.10 \pm 0.34 \mathrm{E}-14 \\ & & \\ \text { Quarter } & & \\ \text { 1st Quarter } & -0.59 \pm 1.47 \mathrm{E}-16 & 1.72 \pm 2.46 \mathrm{E}-16 \\ \text { 2nd Quarter } & 0.13 \pm 1.10 \mathrm{E}-16 & 0.75 \pm 2.89 \mathrm{E}-16 \\ \text { 3rd Quarter } & 1.77 \pm 2.00 \mathrm{E}-16 & 0.50 \pm 2.75 \mathrm{E}-16 \\ \text { 4th Quarter } & 1.03 \pm 1.72 \mathrm{E}-16 & 1.79 \pm 2.07 \mathrm{E}-16\end{array}$

Note: Bolding convention applied to these data. See page D-2.

WVDP Site Environmental Report

$$
D-20
$$




\section{Table D-23 \\ 2001 Radioactivity Concentrations $(\mu \mathrm{Ci} / \mathrm{mL})$ in Airborne Particulates at the Springville Air Sampler (AFSPRVL)}

$\begin{array}{lcc}\text { Month } & \text { Gross Alpha } & \text { Gross Beta } \\ & & \\ \text { January } & 0.44 \pm 1.28 \mathrm{E}-15 & 2.08 \pm 0.34 \mathrm{E}-14 \\ \text { February } & 0.67 \pm 1.15 \mathrm{E}-15 & 2.20 \pm 0.35 \mathrm{E}-14 \\ \text { March } & 0.86 \pm 1.25 \mathrm{E}-15 & 1.76 \pm 0.31 \mathrm{E}-14 \\ \text { April } & 0.90 \pm 1.23 \mathrm{E}-15 & 1.59 \pm 0.30 \mathrm{E}-14 \\ \text { May } & 1.06 \pm 1.20 \mathrm{E}-15 & 1.67 \pm 0.31 \mathrm{E}-14 \\ \text { June } & 0.70 \pm 1.09 \mathrm{E}-15 & \mathbf{1 . 1 4} \pm \mathbf{0 . 2 8 E}-14 \\ \text { July } & 0.00 \pm 1.18 \mathrm{E}-15 & 1.62 \pm 0.31 \mathrm{E}-14 \\ \text { August } & 0.60 \pm 1.23 \mathrm{E}-15 & 2.04 \pm 0.33 \mathrm{E}-14 \\ \text { September } & 0.23 \pm 1.37 \mathrm{E}-15 & 1.98 \pm 0.35 \mathrm{E}-14 \\ \text { October } & 0.78 \pm 1.30 \mathrm{E}-15 & 1.88 \pm 0.34 \mathrm{E}-14 \\ \text { November } & 0.97 \pm 1.39 \mathrm{E}-15 & \mathbf{2 . 4 1} \pm \mathbf{0 . 3 7 E}-14 \\ \text { December } & 0.83 \pm 1.14 \mathrm{E}-15 & 2.32 \pm 0.37 \mathrm{E}-14 \\ & & \\ \text { Quarter } & & \\ & & \\ \text { 1st Quarter } & 0.60 \pm 1.64 \mathrm{E}-16 & 3.52 \pm 5.05 \mathrm{E}-16 \\ \text { 2nd Quarter } & 4.37 \pm 9.60 \mathrm{E}-17 & 0.23 \pm 1.66 \mathrm{E}-16 \\ \text { 3rd Quarter } & \mathbf{2 . 4 8} \pm \mathbf{1 . 9 1 E}-16 & 1.28 \pm 2.74 \mathrm{E}-16 \\ \text { 4th Quarter } & 0.01 \pm 2.41 \mathrm{E}-16 & 0.65 \pm 1.74 \mathrm{E}-16\end{array}$

Note: Bolding convention applied to these data. See page D-2.

$$
\text { D - } 21
$$




\section{Table D-24 \\ 2001 Airborne Radioactivity Concentrations ( $\mu \mathrm{Ci} / \mathrm{mL})$ at the Great Valley Background Air Sampler (AFGRVAL)}

\begin{tabular}{|c|c|c|c|c|c|}
\hline Month & Gross Alpha & Gross Beta & H-3 & & \\
\hline January & $0.38 \pm 1.30 \mathrm{E}-15$ & $2.18 \pm 0.36 \mathrm{E}-14$ & $0.44 \pm 2.23 \mathrm{E}-13$ & & \\
\hline February & $0.96 \pm 1.25 \mathrm{E}-15$ & $2.40 \pm 0.36 \mathrm{E}-14$ & $1.07 \pm 2.76 \mathrm{E}-13$ & & \\
\hline March & $0.20 \pm 1.12 \mathrm{E}-15$ & $1.63 \pm 0.31 \mathrm{E}-14$ & $-0.32 \pm 4.24 \mathrm{E}-13$ & & \\
\hline April & $1.05 \pm 1.29 \mathrm{E}-15$ & $1.43 \pm 0.30 \mathrm{E}-14$ & $1.59 \pm 4.66 \mathrm{E}-13$ & & \\
\hline May & $1.06 \pm 1.23 \mathrm{E}-15$ & $1.82 \pm 0.33 \mathrm{E}-14$ & $0.11 \pm 3.94 \mathrm{E}-13$ & & \\
\hline June & $0.66 \pm 1.11 \mathrm{E}-15$ & $1.29 \pm 0.30 \mathrm{E}-14$ & $-7.02 \pm 7.51 \mathrm{E}-13$ & & \\
\hline July & $0.34 \pm 1.30 \mathrm{E}-15$ & $1.44 \pm 0.31 \mathrm{E}-14$ & $0.29 \pm 1.00 \mathrm{E}-12$ & & \\
\hline August & $0.51 \pm 1.25 \mathrm{E}-15$ & $2.18 \pm 0.35 \mathrm{E}-14$ & $0.05 \pm 1.10 \mathrm{E}-12$ & & \\
\hline September & $-0.07 \pm 1.25 \mathrm{E}-15$ & $2.00 \pm 0.34 \mathrm{E}-14$ & $3.10 \pm 6.93 \mathrm{E}-13$ & & \\
\hline October & $0.07 \pm 1.13 \mathrm{E}-15$ & $2.01 \pm 0.34 \mathrm{E}-14$ & $-0.70 \pm 5.86 \mathrm{E}-13$ & & \\
\hline November & $1.19 \pm 1.41 \mathrm{E}-15$ & $2.46 \pm 0.37 E-14$ & $4.37 \pm 3.94 \mathrm{E}-13$ & & \\
\hline December & $1.29 \pm 1.24 \mathrm{E}-15$ & $2.23 \pm 0.36 \mathrm{E}-14$ & $-1.33 \pm 4.48 \mathrm{E}-13$ & & \\
\hline Quarter & $K-40$ & Co-60 & Sr-90 & I-129 & Cs-137 \\
\hline 1st Quarter & $3.69 \pm 4.50 \mathrm{E}-15$ & $0.96 \pm 2.67 \mathrm{E}-16$ & $-0.08 \pm 1.62 \mathrm{E}-16$ & $1.91 \pm 2.64 \mathrm{E}-16$ & $-1.58 \pm 1.92 \mathrm{E}-16$ \\
\hline 2nd Quarter & $0.64 \pm 5.90 \mathrm{E}-15$ & $-0.83 \pm 2.22 \mathrm{E}-16$ & $-0.47 \pm 1.25 \mathrm{E}-16$ & $-1.42 \pm 2.77 \mathrm{E}-16$ & $0.40 \pm 2.37 \mathrm{E}-16$ \\
\hline 3rd Quarter & $3.68 \pm 5.90 \mathrm{E}-15$ & $-0.02 \pm 2.88 \mathrm{E}-16$ & $0.34 \pm 2.11 \mathrm{E}-16$ & $-0.41 \pm 1.62 \mathrm{E}-16$ & $-0.20 \pm 2.66 \mathrm{E}-16$ \\
\hline \multirow[t]{2}{*}{ 4th Quarter } & $0.00 \pm 2.25 \mathrm{E}-15$ & $0.03 \pm 1.87 \mathrm{E}-16$ & $2.16 \pm 1.71 E-16$ & $-0.22 \pm 2.71 \mathrm{E}-16$ & $-0.17 \pm 1.59 \mathrm{E}-16$ \\
\hline & U-232 & U-233/234 & U-235/236 & U-238 & $\begin{array}{l}\text { Total U } \\
(\mu \mathrm{g} / \mathrm{mL})\end{array}$ \\
\hline 1st Quarter & $-0.55 \pm 1.60 \mathrm{E}-17$ & $8.42 \pm 3.23 E-17$ & $0.88 \pm 1.14 \mathrm{E}-17$ & $5.94 \pm 2.65 \mathrm{E}-17$ & $2.67 \pm 0.03 \mathrm{E}-10$ \\
\hline 2nd Quarter & $0.77 \pm 1.95 \mathrm{E}-17$ & $1.38 \pm 0.51 \mathrm{E}-16$ & $2.76 \pm 2.49 \mathrm{E}-17$ & $9.92 \pm 4.25 \mathrm{E}-17$ & $2.45 \pm 0.03 \mathrm{E}-10$ \\
\hline 3rd Quarter & $2.20 \pm 2.53 \mathrm{E}-17$ & $1.06 \pm 0.35 \mathrm{E}-16$ & $1.19 \pm 1.48 \mathrm{E}-17$ & $7.69 \pm 2.95 \mathrm{E}-17$ & $1.89 \pm 0.04 E-10$ \\
\hline \multirow[t]{2}{*}{ 4th Quarter } & $0.62 \pm 1.51 \mathrm{E}-17$ & $1.46 \pm 0.51 \mathrm{E}-16$ & $0.64 \pm 2.54 \mathrm{E}-17$ & $1.33 \pm 0.43 E-16$ & $3.04 \pm 0.09 E-10$ \\
\hline & Pu-238 & Pu-239/240 & Am-241 & & \\
\hline 1st Quarter & $2.52 \pm 5.06 \mathrm{E}-18$ & $3.63 \pm 7.27 \mathrm{E}-18$ & $0.25 \pm 2.88 \mathrm{E}-17$ & & \\
\hline 2nd Quarter & $-0.04 \pm 9.33 \mathrm{E}-18$ & $0.57 \pm 1.14 \mathrm{E}-17$ & $2.45 \pm 4.92 \mathrm{E}-18$ & & \\
\hline 3rd Quarter & $1.37 \pm 6.13 \mathrm{E}-18$ & $1.09 \pm 0.78 \mathrm{E}-17$ & $1.40 \pm 1.15 \mathrm{E}-17$ & & \\
\hline 4th Quarter & $6.43 \pm 9.61 \mathrm{E}-18$ & $0.64 \pm 1.42 \mathrm{E}-17$ & $1.05 \pm 1.57 \mathrm{E}-17$ & & \\
\hline
\end{tabular}

Note: Bolding convention applied to these data. See page D-2.

WVDP Site Environmental Report

$D-22$

Calendar Year 2001 


\section{Table D-25}

\section{Radioactivity Concentrations $(\mu \mathrm{Ci} / \mathrm{mL})$ in Airborne Particulates at the Nashville Background Air Sampler (AFNASHV)}

$\begin{array}{lrr}\text { Month } & \text { Gross Alpha } & \text { Gross Beta } \\ & & \\ \text { January } & 0.30 \pm 1.26 \mathrm{E}-15 & 2.14 \pm 0.35 \mathrm{E}-14 \\ \text { February } & 0.66 \pm 1.17 \mathrm{E}-15 & \mathbf{2 . 4 2} \pm \mathbf{0 . 3 6 E}-\mathbf{1 4} \\ \text { March } & 0.55 \pm 1.19 \mathrm{E}-15 & 1.75 \pm 0.31 \mathrm{E}-14 \\ \text { April } & 0.48 \pm 1.15 \mathrm{E}-15 & 1.56 \pm 0.31 \mathrm{E}-14 \\ \text { May } & \mathbf{1 . 3 5} \pm \mathbf{1 . 2 9 E}-15 & 1.77 \pm 0.33 \mathrm{E}-14 \\ \text { June } & 0.72 \pm 1.12 \mathrm{E}-15 & \mathbf{1 . 3 5} \pm \mathbf{0 . 3 0 E}-\mathbf{1 4} \\ \text { July } & 0.19 \pm 1.25 \mathrm{E}-15 & 1.90 \pm 0.33 \mathrm{E}-14 \\ \text { August } & 0.98 \pm 1.34 \mathrm{E}-15 & 2.10 \pm 0.34 \mathrm{E}-14 \\ \text { September } & -0.11 \pm 1.23 \mathrm{E}-15 & 2.02 \pm 0.34 \mathrm{E}-14 \\ \text { October } & 0.38 \pm 1.21 \mathrm{E}-15 & 1.45 \pm 0.31 \mathrm{E}-14 \\ \text { November } & 1.29 \pm 1.44 \mathrm{E}-15 & 2.34 \pm 0.36 \mathrm{E}-14 \\ \text { December } & 1.18 \pm 1.23 \mathrm{E}-15 & \mathbf{2 . 4 2} \pm \mathbf{0 . 3 7 E}-\mathbf{1 4} \\ & & \\ & & \\ \text { Quarter } & \mathbf{S r - 9 0} & \mathbf{C s - 1 3 7} \\ & & \\ \text { 1st Quarter } & -0.80 \pm 1.15 \mathrm{E}-16 & 0.03 \pm 2.55 \mathrm{E}-16 \\ \text { 2nd Quarter } & 4.02 \pm 9.75 \mathrm{E}-17 & 0.45 \pm 2.24 \mathrm{E}-16 \\ \text { 3rd Quarter } & \mathbf{4 . 9 0} \pm \mathbf{2 . 0 3 E}-16 & -1.27 \pm 2.28 \mathrm{E}-16 \\ \text { 4th Quarter } & -0.09 \pm 1.75 \mathrm{E}-16 & 0.14 \pm 1.89 \mathrm{E}-16\end{array}$

Note: Bolding convention applied to these data. See page D-2.

$$
D-23
$$


Table D-26

\section{Radioactivity (nCi/m $/ \mathrm{m}^{2}$ month) and $\mathrm{pH}$ in Fallout Dutch Hill (AFDHFOP)}

$\begin{array}{lcccccc}\text { Month } & \text { Gross Alpha } & \text { Gross Beta } & \begin{array}{c}\text { H-3 } \\ (\mu \mathrm{Ci} / \mathrm{mL})\end{array} & \mathbf{K}-\mathbf{4 0} & \mathbf{C s}-\mathbf{1 3 7} & \begin{array}{c}\text { pH } \\ (\text { standard units) }\end{array} \\ & & & & & \\ \text { January } & \mathbf{1 . 4 7} \pm \mathbf{0 . 3 3 E}-\mathbf{0 2} & 2.84 \pm 0.14 \mathrm{E}-01 & 2.78 \pm 8.05 \mathrm{E}-08 & -1.31 \pm 7.33 \mathrm{E}-01 & 3.08 \pm 6.12 \mathrm{E}-02 & \mathbf{3 . 6 5} \\ \text { February } & 1.79 \pm 0.49 \mathrm{E}-02 & 3.30 \pm 0.20 \mathrm{E}-01 & -2.61 \pm 8.22 \mathrm{E}-08 & 0.51 \pm 3.62 \mathrm{E}+00 & 1.58 \pm 1.94 \mathrm{E}-01 & 4.60 \\ \text { March } & 1.93 \pm 0.69 \mathrm{E}-02 & 3.17 \pm 0.26 \mathrm{E}-01 & 6.09 \pm 8.21 \mathrm{E}-08 & -0.62 \pm 3.84 \mathrm{E}+00 & 1.58 \pm 2.71 \mathrm{E}-01 & 4.02 \\ \text { April } & 1.53 \pm 0.41 \mathrm{E}-02 & 2.27 \pm 0.14 \mathrm{E}-01 & 1.53 \pm 8.23 \mathrm{E}-08 & 3.65 \pm 9.25 \mathrm{E}-01 & 1.40 \pm 7.25 \mathrm{E}-02 & 4.35 \\ \text { May } & 2.42 \pm 0.57 \mathrm{E}-02 & \mathbf{1 . 8 1} \pm \mathbf{0 . 1 3 E}-\mathbf{0 1} & -8.54 \pm 8.40 \mathrm{E}-08 & -1.13 \pm 1.07 \mathrm{E}+00 & -0.77 \pm 8.03 \mathrm{E}-02 & \mathbf{7 . 1 4} \\ \text { June } & \mathbf{5 . 2 0} \pm \mathbf{0 . 8 5 E}-\mathbf{0 2} & 4.38 \pm 0.22 \mathrm{E}-01 & 7.01 \pm 8.25 \mathrm{E}-08 & -1.40 \pm 2.15 \mathrm{E}+00 & 0.29 \pm 1.39 \mathrm{E}-01 & 4.05 \\ \text { July } & 1.55 \pm 0.44 \mathrm{E}-02 & 2.33 \pm 0.15 \mathrm{E}-01 & -1.80 \pm 1.15 \mathrm{E}-07 & -1.02 \pm 0.79 \mathrm{E}+00 & 5.90 \pm 6.69 \mathrm{E}-02 & 5.31 \\ \text { August } & 3.25 \pm 0.72 \mathrm{E}-02 & 4.92 \pm 0.27 \mathrm{E}-01 & \mathbf{1 . 5 4} \pm \mathbf{0 . 8 0 E}-\mathbf{0 7} & -0.33 \pm 4.86 \mathrm{E}+00 & 2.00 \pm 4.00 \mathrm{E}-01 & 4.83 \\ \text { September } & 2.79 \pm 0.78 \mathrm{E}-02 & \mathbf{5 . 2 0} \pm \mathbf{0 . 3 2 E}-\mathbf{0 1} & 6.78 \pm 8.10 \mathrm{E}-08 & 1.20 \pm 3.89 \mathrm{E}+00 & -2.75 \pm 2.89 \mathrm{E}-01 & 4.17 \\ \text { October } & 1.64 \pm 1.00 \mathrm{E}-02 & 2.66 \pm 0.32 \mathrm{E}-01 & -3.34 \pm 8.07 \mathrm{E}-08 & 1.00 \pm 4.18 \mathrm{E}+00 & 2.29 \pm 3.08 \mathrm{E}-01 & 5.11 \\ \text { November } & 1.93 \pm 0.77 \mathrm{E}-02 & 3.04 \pm 0.26 \mathrm{E}-01 & 2.62 \pm 8.69 \mathrm{E}-08 & -1.00 \pm 3.98 \mathrm{E}+00 & 2.00 \pm 3.10 \mathrm{E}-01 & 5.34 \\ \text { December } & 1.55 \pm 0.67 \mathrm{E}-02 & 3.09 \pm 0.34 \mathrm{E}-01 & 4.32 \pm 5.70 \mathrm{E}-08 & -3.26 \pm 7.18 \mathrm{E}+00 & -3.16 \pm 6.08 \mathrm{E}-01 & 4.46\end{array}$

Table D-27

2001 Radioactivity (nCi/m²/month) and $\mathrm{pH}$ in Fallout Rain Gauge (ANRGFOP)

$\begin{array}{lcccccc}\text { Month } & \text { Gross Alpha } & \text { Gross Beta } & \begin{array}{c}\text { H-3 } \\ (\mu \mathrm{Ci} / \mathrm{mL})\end{array} & \mathbf{K}-\mathbf{4 0} & \text { Cs-137 } & \begin{array}{c}\text { pH } \\ \text { (standard units) }\end{array} \\ & & & & & & \\ \text { January } & 4.08 \pm 0.71 \mathrm{E}-02 & 5.05 \pm 0.26 \mathrm{E}-01 & 8.60 \pm 8.05 \mathrm{E}-08 & -0.68 \pm 2.92 \mathrm{E}+00 & 0.58 \pm 1.94 \mathrm{E}-01 & \mathbf{4 . 0 0} \\ \text { February } & \mathbf{5 . 6 9} \pm \mathbf{1 . 5 0 E}-\mathbf{0 2} & \mathbf{6 . 1 9} \pm \mathbf{0 . 5 0 E}-\mathbf{0 1} & -3.62 \pm 8.17 \mathrm{E}-08 & 3.81 \pm 5.70 \mathrm{E}+00 & -2.17 \pm 4.93 \mathrm{E}-01 & 4.98 \\ \text { March } & 3.16 \pm 1.44 \mathrm{E}-02 & 3.07 \pm 0.43 \mathrm{E}-01 & -8.53 \pm 7.94 \mathrm{E}-08 & -6.24 \pm 8.93 \mathrm{E}+00 & -9.10 \pm 9.61 \mathrm{E}-01 & 6.42 \\ \text { April } & 3.08 \pm 1.30 \mathrm{E}-02 & 2.50 \pm 0.21 \mathrm{E}-01 & -6.94 \pm 7.96 \mathrm{E}-08 & -1.86 \pm 2.70 \mathrm{E}+00 & -0.43 \pm 1.79 \mathrm{E}-01 & 6.82 \\ \text { May } & 4.02 \pm 0.81 \mathrm{E}-02 & \mathbf{2 . 3 3} \pm \mathbf{0 . 1 8 E}-\mathbf{0 1} & -5.84 \pm 8.36 \mathrm{E}-08 & -0.52 \pm 2.42 \mathrm{E}+00 & -0.13 \pm 1.65 \mathrm{E}-01 & \mathbf{7 . 4 4} \\ \text { June } & 5.60 \pm 1.23 \mathrm{E}-02 & 5.43 \pm 0.35 \mathrm{E}-01 & -2.44 \pm 8.34 \mathrm{E}-08 & -0.20 \pm 4.35 \mathrm{E}+00 & -0.63 \pm 2.60 \mathrm{E}-01 & 4.88 \\ \text { July } & 3.68 \pm 0.64 \mathrm{E}-02 & 3.18 \pm 0.16 \mathrm{E}-01 & -2.78 \pm 1.28 \mathrm{E}-07 & 1.08 \pm 8.58 \mathrm{E}-01 & -2.13 \pm 7.09 \mathrm{E}-02 & 6.51 \\ \text { August } & 3.13 \pm 0.94 \mathrm{E}-02 & 5.75 \pm 0.36 \mathrm{E}-01 & 3.89 \pm 8.10 \mathrm{E}-08 & -1.58 \pm 5.37 \mathrm{E}+00 & 0.35 \pm 4.39 \mathrm{E}-01 & 6.22 \\ \text { September } & 5.17 \pm 1.27 \mathrm{E}-02 & 6.03 \pm 0.44 \mathrm{E}-01 & \mathbf{2 . 3 5} \pm \mathbf{0 . 8 3 E}-\mathbf{0 7} & 6.40 \pm 7.44 \mathrm{E}+00 & -1.00 \pm 5.25 \mathrm{E}-01 & 5.30 \\ \text { October } & \mathbf{1 . 9 4} \pm \mathbf{1 . 7 2 E}-\mathbf{0 2} & 4.15 \pm 0.57 \mathrm{E}-01 & -0.93 \pm 8.03 \mathrm{E}-08 & -0.14 \pm 1.46 \mathrm{E}+01 & -0.10 \pm 1.21 \mathrm{E}+00 & 6.96 \\ \text { November } & 4.48 \pm 1.21 \mathrm{E}-02 & 3.52 \pm 0.35 \mathrm{E}-01 & -1.51 \pm 0.59 \mathrm{E}-07 & -4.60 \pm 4.79 \mathrm{E}+00 & 1.09 \pm 4.50 \mathrm{E}-01 & 5.94 \\ \text { December } & 3.72 \pm 1.11 \mathrm{E}-02 & 4.75 \pm 0.48 \mathrm{E}-01 & 3.86 \pm 8.03 \mathrm{E}-08 & 4.85 \pm 8.67 \mathrm{E}+00 & 0.13 \pm 6.30 \mathrm{E}-01 & 5.15\end{array}$

Note: Bolding convention applied to these data. See page D-2.

WVDP Site Environmental Report

$D-24$

Calendar Year 2001 
Table D-28

\section{Radioactivity (nCi/m $/ \mathrm{m}^{2}$ month) and $\mathrm{pH}$ in Fallout Route 240 (AF24FOP)}

\begin{tabular}{|c|c|c|c|c|c|c|}
\hline Month & Gross Alpha & Gross Beta & $\begin{array}{c}\mathbf{H}-3 \\
(\mu \mathrm{Ci} / \mathrm{mL})\end{array}$ & K-40 & Cs-137 & $\begin{array}{c}\mathbf{p H} \\
\text { (standard units) }\end{array}$ \\
\hline January & $4.46 \pm 0.53 \mathrm{E}-02$ & $4.71 \pm 0.18 \mathrm{E}-01$ & $1.30 \pm 0.81 \mathrm{E}-07$ & $-0.11 \pm 1.57 \mathrm{E}+00$ & $0.67 \pm 1.28 \mathrm{E}-01$ & 4.17 \\
\hline February & $4.71 \pm 1.05 \mathrm{E}-02$ & $6.95 \pm 0.40 \mathrm{E}-01$ & $-5.11 \pm 8.16 \mathrm{E}-08$ & $-4.96 \pm 4.52 \mathrm{E}+00$ & $2.66 \pm 3.87 \mathrm{E}-01$ & 4.04 \\
\hline March & $4.20 \pm 1.23 \mathrm{E}-02$ & $4.36 \pm 0.39 \mathrm{E}-01$ & $2.03 \pm 8.12 \mathrm{E}-08$ & $-2.81 \pm 7.64 \mathrm{E}+00$ & $1.21 \pm 4.35 \mathrm{E}-01$ & 5.04 \\
\hline April & $4.81 \pm 0.76 \mathrm{E}-02$ & $2.81 \pm 0.15 \mathrm{E}-01$ & $-0.34 \pm 8.33 \mathrm{E}-08$ & $-7.08 \pm 7.13 \mathrm{E}-01$ & $-4.43 \pm 6.22 \mathrm{E}-02$ & 4.91 \\
\hline May & $1.59 \pm 0.44 \mathrm{E}-02$ & $2.13 \pm 0.15 E-01$ & $2.49 \pm 8.30 \mathrm{E}-08$ & $1.14 \pm 2.57 \mathrm{E}+00$ & $1.46 \pm 2.29 \mathrm{E}-01$ & 4.79 \\
\hline June & $2.36 \pm 0.70 \mathrm{E}-02$ & $4.54 \pm 0.26 \mathrm{E}-01$ & $4.89 \pm 5.71 \mathrm{E}-08$ & $0.57 \pm 3.91 \mathrm{E}+00$ & $0.85 \pm 1.91 \mathrm{E}-01$ & 3.68 \\
\hline July & $4.49 \pm 0.64 \mathrm{E}-02$ & $3.66 \pm 0.16 \mathrm{E}-01$ & $1.04 \pm 0.85 \mathrm{E}-07$ & $-1.47 \pm 5.21 \mathrm{E}-01$ & $1.12 \pm 4.27 \mathrm{E}-02$ & 3.53 \\
\hline August & $1.30 \pm 0.52 E-02$ & $3.48 \pm 0.23 \mathrm{E}-01$ & $1.69 \pm 0.80 \mathrm{E}-07$ & $6.60 \pm 4.67 E+00$ & $0.88 \pm 3.17 \mathrm{E}-01$ & 4.19 \\
\hline September & $4.85 \pm 0.99 \mathrm{E}-02$ & $3.99 \pm 0.30 \mathrm{E}-01$ & $1.96 \pm 0.83 E-07$ & $-2.59 \pm 4.80 \mathrm{E}+00$ & $0.67 \pm 3.68 \mathrm{E}-01$ & 5.00 \\
\hline October & $1.89 \pm 1.33 \mathrm{E}-02$ & $4.07 \pm 0.47 \mathrm{E}-01$ & $-5.35 \pm 7.93 \mathrm{E}-08$ & $0.44 \pm 1.15 \mathrm{E}+01$ & $-0.23 \pm 1.16 \mathrm{E}+00$ & 5.40 \\
\hline November & $1.86 \pm 0.71 \mathrm{E}-02$ & $2.82 \pm 0.24 \mathrm{E}-01$ & $-1.10 \pm 0.84 \mathrm{E}-07$ & $-3.78 \pm 4.52 \mathrm{E}+00$ & $1.51 \pm 2.43 \mathrm{E}-01$ & 4.58 \\
\hline December & $3.25 \pm 0.93 \mathrm{E}-02$ & $3.93 \pm 0.39 \mathrm{E}-01$ & $-5.83 \pm 7.92 \mathrm{E}-08$ & $-3.47 \pm 6.00 \mathrm{E}+00$ & $3.41 \pm 4.33 \mathrm{E}-01$ & 5.26 \\
\hline
\end{tabular}

Table D-29

2001 Radioactivity (nCi/m $/ \mathrm{m}^{2}$ month) and $\mathrm{pH}$ in Fallout Thomas Corners Road (AFTCFOP)

$\begin{array}{lcccrrc}\text { Month } & \text { Gross Alpha } & \text { Gross Beta } & \begin{array}{c}\text { H-3 } \\ (\mu \mathrm{Ci} / \mathrm{mL})\end{array} & \mathbf{K}-\mathbf{4 0} & \mathbf{C s}-\mathbf{1 3 7} & \begin{array}{c}\text { pH } \\ \text { (standard units) }\end{array} \\ & & & & & & \\ \text { January } & 2.48 \pm 0.64 \mathrm{E}-02 & \mathbf{2 . 1 8} \pm \mathbf{0 . 1 9 E}-\mathbf{0 1} & 8.64 \pm 8.12 \mathrm{E}-08 & 0.37 \pm 3.40 \mathrm{E}+00 & -0.44 \pm 2.31 \mathrm{E}-01 & 5.18 \\ \text { February } & 3.79 \pm 1.15 \mathrm{E}-02 & \mathbf{5 . 8 6} \pm \mathbf{0 . 4 3 E}-\mathbf{0 1} & -2.12 \pm 8.21 \mathrm{E}-08 & 5.49 \pm 5.39 \mathrm{E}+00 & -1.82 \pm 4.34 \mathrm{E}-01 & 5.98 \\ \text { March } & \mathbf{6 . 0 6} \pm \mathbf{1 . 3 0 E}-\mathbf{0 2} & 3.48 \pm 0.33 \mathrm{E}-01 & -3.97 \pm 7.96 \mathrm{E}-08 & -0.75 \pm 1.10 \mathrm{E}+01 & 7.13 \pm 9.42 \mathrm{E}-01 & 6.81 \\ \text { April } & 2.61 \pm 0.52 \mathrm{E}-02 & 2.47 \pm 0.14 \mathrm{E}-01 & 2.47 \pm 8.09 \mathrm{E}-08 & -0.18 \pm 1.45 \mathrm{E}+00 & -2.59 \pm 8.85 \mathrm{E}-02 & \mathbf{6 . 8 8} \\ \text { May } & 2.75 \pm 0.59 \mathrm{E}-02 & 3.31 \pm 0.20 \mathrm{E}-01 & -0.59 \pm 8.42 \mathrm{E}-08 & -1.63 \pm 2.16 \mathrm{E}+00 & -0.78 \pm 1.40 \mathrm{E}-01 & 6.06 \\ \text { June } & 2.03 \pm 0.73 \mathrm{E}-02 & 5.51 \pm 0.31 \mathrm{E}-01 & \mathbf{1 . 2 6} \pm \mathbf{0 . 8 1 E}-\mathbf{0 7} & -1.60 \pm 5.40 \mathrm{E}+00 & -5.59 \pm 3.71 \mathrm{E}-01 & 3.98 \\ \text { July } & 4.24 \pm 0.58 \mathrm{E}-02 & 4.14 \pm 0.17 \mathrm{E}-01 & 5.65 \pm 8.11 \mathrm{E}-08 & -0.01 \pm 1.53 \mathrm{E}+00 & 0.88 \pm 1.56 \mathrm{E}-01 & \mathbf{3 . 7 7} \\ \text { August } & 2.52 \pm 0.65 \mathrm{E}-02 & 3.80 \pm 0.23 \mathrm{E}-01 & 8.42 \pm 7.95 \mathrm{E}-08 & -0.24 \pm 2.45 \mathrm{E}+00 & -0.81 \pm 2.22 \mathrm{E}-01 & 5.85 \\ \text { September } & 4.39 \pm 1.14 \mathrm{E}-02 & 4.96 \pm 0.39 \mathrm{E}-01 & 1.06 \pm 0.81 \mathrm{E}-07 & -1.61 \pm 6.15 \mathrm{E}+00 & 1.76 \pm 4.23 \mathrm{E}-01 & 4.73 \\ \text { October } & 2.75 \pm 1.55 \mathrm{E}-02 & 3.28 \pm 0.47 \mathrm{E}-01 & 0.11 \pm 8.05 \mathrm{E}-08 & \mathbf{1 . 5 7} \pm \mathbf{1 . 0 6 E}+\mathbf{0 1} & 2.03 \pm 7.92 \mathrm{E}-01 & 6.15 \\ \text { November } & \mathbf{1 . 7 6} \pm \mathbf{0 . 9 3 E}-\mathbf{0 2} & 2.98 \pm 0.32 \mathrm{E}-01 & -1.33 \pm 0.85 \mathrm{E}-07 & -0.80 \pm 5.46 \mathrm{E}+00 & 2.31 \pm 4.11 \mathrm{E}-01 & 4.74 \\ \text { December } & 4.88 \pm 1.18 \mathrm{E}-02 & 4.51 \pm 0.44 \mathrm{E}-01 & 9.75 \pm 8.16 \mathrm{E}-08 & -2.87 \pm 7.27 \mathrm{E}+00 & 0.53 \pm 5.49 \mathrm{E}-01 & 5.23\end{array}$

Note: Bolding convention applied to these data. See page D-2.

WVDP Site Environmental Report

$D-25$

Calendar Year 2001 
Table D-30

2001 Radioactivity (nCi/m²/month) and $\mathrm{pH}$ in Fallout Fox Valley Road (AFFXFOP)

$\begin{array}{lcccrrr}\text { Month } & \text { Gross Alpha } & \text { Gross Beta } & \begin{array}{c}\text { H-3 } \\ (\mu \mathrm{Ci} / \mathrm{mL})\end{array} & \mathbf{K}-\mathbf{4 0} & \mathbf{C s}-\mathbf{1 3 7} & \begin{array}{c}\mathbf{p H} \\ \text { (standard units) }\end{array} \\ & & & & & & \\ \text { January } & 3.65 \pm 0.63 \mathrm{E}-02 & 2.23 \pm 0.16 \mathrm{E}-01 & 1.12 \pm 0.82 \mathrm{E}-07 & 0.83 \pm 2.28 \mathrm{E}+00 & 1.55 \pm 1.84 \mathrm{E}-01 & 4.75 \\ \text { February } & 4.28 \pm 1.09 \mathrm{E}-02 & 3.79 \pm 0.33 \mathrm{E}-01 & -0.93 \pm 8.30 \mathrm{E}-08 & -2.05 \pm 4.47 \mathrm{E}+00 & 0.87 \pm 3.61 \mathrm{E}-01 & 5.46 \\ \text { March } & \mathbf{6 . 6 8} \pm \mathbf{1 . 8 4 E}-\mathbf{0 2} & 4.15 \pm 0.46 \mathrm{E}-01 & 2.13 \pm 8.04 \mathrm{E}-08 & 1.12 \pm 7.13 \mathrm{E}+00 & 2.34 \pm 4.98 \mathrm{E}-01 & 6.60 \\ \text { April } & 4.82 \pm 0.74 \mathrm{E}-02 & 3.58 \pm 0.16 \mathrm{E}-01 & \mathbf{2 . 7 1} \pm \mathbf{0 . 6 1 E}-\mathbf{0 7} & 0.84 \pm 1.90 \mathrm{E}+00 & 1.77 \pm 1.60 \mathrm{E}-01 & 6.03 \\ \text { May } & 3.82 \pm 0.69 \mathrm{E}-02 & 3.60 \pm 0.20 \mathrm{E}-01 & 1.59 \pm 8.35 \mathrm{E}-08 & -1.77 \pm 1.65 \mathrm{E}+00 & 0.77 \pm 1.59 \mathrm{E}-01 & 6.24 \\ \text { June } & 5.56 \pm 1.05 \mathrm{E}-02 & \mathbf{7 . 1 3} \pm \mathbf{0 . 3 4 E}-\mathbf{0 1} & 3.76 \pm 8.33 \mathrm{E}-08 & 1.98 \pm 6.40 \mathrm{E}+00 & \mathbf{4 . 9 5} \pm \mathbf{4 . 5 1 E}-\mathbf{0 1} & \mathbf{3 . 9 5} \\ \text { July } & 3.42 \pm 0.52 \mathrm{E}-02 & 2.84 \pm 0.14 \mathrm{E}-01 & 8.94 \pm 8.65 \mathrm{E}-08 & 0.28 \pm 1.29 \mathrm{E}+00 & -0.23 \pm 1.03 \mathrm{E}-01 & 4.70 \\ \text { August } & 3.71 \pm 0.99 \mathrm{E}-02 & 4.80 \pm 0.34 \mathrm{E}-01 & 4.96 \pm 7.84 \mathrm{E}-08 & 2.46 \pm 3.93 \mathrm{E}+00 & 0.75 \pm 3.76 \mathrm{E}-01 & 5.15 \\ \text { September } & \mathbf{1 . 9 7} \pm \mathbf{0 . 9 3 E}-\mathbf{0 2} & 2.52 \pm 0.30 \mathrm{E}-01 & 9.07 \pm 8.10 \mathrm{E}-08 & -6.83 \pm 5.54 \mathrm{E}+00 & -1.15 \pm 4.83 \mathrm{E}-01 & 4.96 \\ \text { October } & 3.21 \pm 1.47 \mathrm{E}-02 & 3.64 \pm 0.43 \mathrm{E}-01 & 1.98 \pm 8.44 \mathrm{E}-08 & -0.20 \pm 8.85 \mathrm{E}+00 & 3.30 \pm 6.25 \mathrm{E}-01 & \mathbf{7 . 6 3} \\ \text { November } & 2.74 \pm 1.13 \mathrm{E}-02 & \mathbf{2 . 1 8} \pm \mathbf{0 . 3 1 E}-\mathbf{0 1} & -7.57 \pm 8.51 \mathrm{E}-08 & -0.38 \pm 7.26 \mathrm{E}+00 & -3.18 \pm 6.45 \mathrm{E}-01 & 7.09 \\ \text { December } & 4.02 \pm 1.05 \mathrm{E}-02 & 3.77 \pm 0.39 \mathrm{E}-01 & -6.02 \pm 7.91 \mathrm{E}-08 & -5.19 \pm 7.61 \mathrm{E}+00 & 2.06 \pm 5.55 \mathrm{E}-01 & 4.84\end{array}$

Note: Bolding convention applied to these data. See page D-2.

$$
\text { D - } 26
$$




\section{Appendix $E$ Summary of Groundwater Monitoring Data}

$E-1$ 
The tables on pages E-7 through E-19 contain a bolding convention devised to help the reader, when viewing the data, to quickly see the range of detectable measurements within a data series. A data series is a set of chemical or radionuclide measurements (e.g., gross alpha, gross beta, tritium) from a single location or from similar locations. Note that some tables contain data that should not be technically evaluated under this convention.

\section{Key to bolding convention:}

Results for each analyte constitute a single data series. If a radiological result is larger than the uncertainty term, the measurement is considered positive. Otherwise, a result is considered nondetectable. Chemical results preceded by "less than" $(<)$ are considered nondetectable. The bolding convention is not applied to data series consisting of less than three values.

If all results in a data series are positive, the lowest and highest values are bolded.

If a data series contains some positive results, the highest value is bolded.

If all values in a data series are nondetectable, no values are bolded.

$E-2$ 
Table E-1

Groundwater Monitoring Network: Super Solid Waste Management Units

SSWMUS
and
Constituent SWMUs
Well

II

Number $^{1}$
Additional
Analytes
Measured in

$\mathbf{2 0 0 1}^{2}$

Well
ID
Number $^{1}$

Additional

Analytes

Measured in

$2001^{2}$
SSWMU \#1 -

Low-Level Waste Treatment Facilities:

- Former Lagoon 1

- LLWTF Lagoons

- LLWTF Building

- Interceptors

- Neutralization Pit

SSWMU \#2 -

Miscellaneous Small Units:

- Sludge Ponds

- Solvent Dike

202

- Equalization Mixing Basin

- Paper Incinerator

203

204*

205

SSWMU \#3 -

Liquid Waste Treatment System:

- Liquid Waste Treatment System 301*

- Cement Solidification System 302

- Main Process Building (specific areas) 305
(S:D)

(S:C)

(S:C)

(S:D)

(T:D)

(T:D)

(T:D)
$(\mathrm{S}: \mathrm{B})$

(TS:U)

(S:D)

$110^{*}$
$111^{*}$
114
115
$116^{*}$
8604
$8605^{*}$

(T:D)

(S:D)

(T:D)

(T:U)

(S:U)

(S:C)

(S:D)

$\mathrm{V}$
$\mathrm{M} 33, \mathrm{~S}, \mathrm{SV}, \mathrm{V}$
$p$
$p$
$\mathrm{~S}, \mathrm{~V}$
$\mathrm{~V}$
$\mathrm{M} 33, \mathrm{~S}, \mathrm{SV}, \mathrm{V}$
8605

206

207

208

8606

$(\mathrm{TS}: \mathrm{D})$

(S:D)

(TS:D)

(S:D)

$p$

$\mathrm{V}$

307

(S:D)

$p$

${ }^{1}$ Hydrogeologic unit monitored and well position in SSWMU follow the well ID in parentheses. Hydrogeologic units monitored are: WT (weathered Lavery till); $T$ (unweathered Lavery till); $S$ (sand and gravel); $K$ (Kent recessional sequence); TS (till-sand). Well position in SSWMU: U (upgradient); D (downgradient); B (background); $C$ (crossgradient). Example: $401 *(S: B)$ monitors background conditions in the sand and gravel unit.

${ }^{2}$ See Table 3-1 (p. 3-6) for a description of codes and analytes. The parameters listed in this table, Table E-1, are in addition to the contamination indicator parameters (I) and radiological indicator parameters (RI) routinely scheduled at all monitoring locations for 2001. Wells measured for potentiometric (water-level) data only are designated by "p."

* Monitoring for certain parameters is required by the RCRA $\$ 3008(h)$ Order on Consent. (See p. ECS-4.) 


\section{Table E-1 (continued) \\ Groundwater Monitoring Network: Super Solid Waste Management Units}

\author{
SSWMUS \\ and \\ Constituent SWMUs
}

Well
ID
Number $^{1}$

\author{
Additional \\ Analytes \\ Measured in \\ $2001^{2}$
}

\author{
Well \\ ID \\ Number $^{1}$
}

Additional

Analytes

Measured in

2001 $^{2}$
SSWMU \#4 -

HLW Storage and Processing Area:

- Vitrification Facility

- Vitrification Test Tanks

- HLW Tanks

- Supernatant Treatment System

$\begin{array}{lrc}401 * & (\mathrm{~S}: \mathrm{B}) & \mathrm{R} \\ 402 & (\mathrm{TS}: \mathrm{U}) & \\ 403 & (\mathrm{~S}: \mathrm{U}) & \mathrm{V} \\ 404 & (\mathrm{TS}: \mathrm{U}) & p \\ 405 & \text { (T:C) } & \\ 406 * & (\mathrm{~S}: \mathrm{D}) & \mathrm{R}, \mathrm{V}\end{array}$

SSWMU \#5 -

Maintenance Shop Leach Field:

- Maintenance Shop Leach Field

$501 *$

(S:U)

(S:D)

$\begin{array}{ll}601 & (S: D) \\ 602 A & (S: D) \\ 603 & (S: U) \\ 604 & (S: D)\end{array}$

SSWMU \#6 -

Low-level Waste Storage Area:

- Hardstands (old and new)

- Lag Storage

- Lag Storage Additions

(LSAs 1, 2, 3, 4)

SSWMU \#7 -

Chemical Process Cell

(CPC) Waste Storage Area:

- CPC Waste Storage Area

$\begin{array}{lr}701 & \text { (TS:U) } \\ 702 & \text { (T:C) } \\ 703 & \text { (T:D) } \\ 704 & \text { (T:D) }\end{array}$

S, V

$\begin{array}{lcc}407 & (\mathrm{~K}: \mathrm{D}) & p \\ 408^{*} & (\mathrm{~S}: \mathrm{D}) & \mathrm{R}, \mathrm{V} \\ 409 & (\mathrm{~T}: \mathrm{D}) & \\ 410 & (\mathrm{~K}: \mathrm{U}) & p \\ 411 & (\mathrm{~K}: \mathrm{U}) & p\end{array}$

$502 * \quad(S: D)$

S, SM, V

$\begin{array}{llc}605 & (\mathrm{~S}: \mathrm{D}) & \mathrm{S} \\ 8607 * & (\mathrm{~S}: \mathrm{U}) & \mathrm{V} \\ 8608 & (\mathrm{~S}: \mathrm{U}) & p \\ 8609^{*} & (\mathrm{~S}: \mathrm{U}) & \mathrm{S}, \mathrm{V}\end{array}$

$705 \quad(\mathrm{~T}: \mathrm{C})$

$706^{*}$

(S:B)

$707 \quad$ (T:D)

$p$
$p$

$\mathrm{V}$

T:D)

${ }^{1}$ Hydrogeologic unit monitored and well position in SSWMU follow the well ID in parentheses. Hydrogeologic units monitored are: WT (weathered Lavery till); $T$ (unweathered Lavery till); $S$ (sand and gravel); K (Kent recessional sequence); TS (till-sand). Well position in SSWMU: U (upgradient); D (downgradient); B (background); C (crossgradient). Example: $401^{*}(S: B)$ monitors background conditions in the sand and gravel unit.

${ }^{2}$ See Table 3-1 (p. 3-6) for a description of codes and analytes. The parameters listed in this table, Table E-1, are in addition to the contamination indicator parameters (I) and radiological indicator parameters (RI) routinely scheduled at all monitoring locations for 2001. Wells measured for potentiometric (water-level) data only are designated by "p."

* Monitoring for certain parameters is required by the RCRA $\$ 3008(h)$ Order on Consent. (See p. ECS-4.) 
Table E-1 (continued)

\section{Groundwater Monitoring Network: Super Solid Waste Management Units}

$\begin{array}{ccccc}\text { SSWMUS } & \text { Well } & \text { Additional } & \text { Well } & \text { Additional } \\ \text { and } & \text { ID } & \text { Analytes } & \text { ID } & \text { Analytes } \\ \text { Constituent SWMUs } & \text { Number }^{1} & \text { Measured in } & \text { Number }^{1} & \text { Measured in }^{\text {2001 }^{2}} \\ & & \mathbf{2 0 0 1}^{2} & & \end{array}$

\section{SSWMU \#8 - \\ Construction and Demolition \\ Debris Landfill:}

- Former Construction and Demolition Debris Landfill

SSWMU \#9 -

NRC-licensed Disposal Area:

- NRC-licensed Disposal Area

- Container Storage Area

- Trench Interceptor Project

SSWMU \#10 -

IRTS Drum Cell:

- IRTS Drum Cell

- Background (south plateau)

$\begin{array}{lr}901 * & (\mathrm{~K}: \mathrm{U}) \\ 902 * & (\mathrm{~K}: \mathrm{U}) \\ 903 * & (\mathrm{~K}: \mathrm{D}) \\ 904 & (\mathrm{~T}: \mathrm{D}) \\ 905 & (\mathrm{~S}: \mathrm{D}) \\ 906 & (\mathrm{WT}: \mathrm{D}) \\ 907 & (\mathrm{WT}: \mathrm{D})\end{array}$

(S:U)

(S:D)

(S:D)

$\begin{array}{ll}801 * & \text { (S:U) } \\ 802 & \text { (S:D) } \\ 803 & \text { (S:D) }\end{array}$

S, V
V
SV, V

$804^{*}$

8603

$8612 *$
(S:D)
(S:U)
(S:D)

V
S
SV, V

$p$

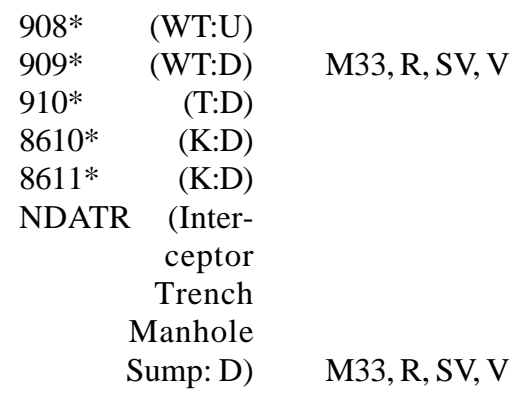

908* (WT:U)

909* (WT:D)

910* $\quad$ (T:D)

$8610 * \quad(\mathrm{~K}: \mathrm{D})$

8611* (K:D)

NDATR (Inter-

ceptor

Trench

Manhole

Sump: D)

M33, R, SV, V

M33, R, SV, V

(n)

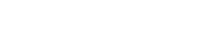

$\begin{array}{lr}1001 & (K: U) \\ 1002 & (K: D) \\ 1003 & (K: D) \\ 1004 & (K: D) \\ 1005^{*} & (\text { WT:U) }\end{array}$

1006* (WT:D)

1007 (WT:D)

1008B (K:B)

1008C* ${ }^{*}$ (WT:B)

\footnotetext{
${ }^{1}$ Hydrogeologic unit monitored and well position in SSWMU follow the well ID in parentheses. Hydrogeologic units monitored are: WT (weathered Lavery till); $T$ (unweathered Lavery till); $S$ (sand and gravel); K (Kent recessional sequence); TS (till-sand). Well position in SSWMU: U (upgradient); D (downgradient); B (background); $C$ (crossgradient). Example: 401* (S:B) monitors background conditions in the sand and gravel unit.

${ }^{2}$ See Table 3-1 (p. 3-6) for a description of codes and analytes. The parameters listed in this table, Table E-1, are in addition to the contamination indicator parameters (I) and radiological indicator parameters (RI) routinely scheduled at all monitoring locations for 2001. Wells measured for potentiometric (water-level) data only are designated by " $p$."

* Monitoring for certain parameters is required by the RCRA $\$ 3008(h)$ Order on Consent. (See p. ECS-4.)
} 
Table E-1 (concluded)

\title{
Groundwater Monitoring Network: Super Solid Waste Management Units
}

$\begin{array}{cc}\text { SSWMUS } & \text { Well } \\ \text { and } & \text { ID } \\ \text { Constituent SWMUs } & \text { Number }^{1}\end{array}$

\author{
Additional \\ Analytes \\ Measured in \\ $\mathbf{2 0 0 1}^{2}$
}
Well
ID
Number $^{1}$

Additional

Analytes

Measured in

2001 $^{2}$

Main Plant Area Well Points:

$\begin{array}{lll}\text { (Monitor groundwater at various } & \text { WP-A } & \text { (S) } \\ \text { locations north and east of the main } & \text { WP-C } & \text { (S) } \\ \text { plant. Not in a SSWMU.) } & \text { WP-H } & \text { (S) }\end{array}$

Former Sand and Gravel Background:

(Well originally used for background; NB1S

replaced by a combination of wells 301,

401, and 706. Not in a SSWMU.)

North Plateau Groundwater Seeps:

(Monitor groundwater emanating from seeps along the north pleateau edge. Not in a SSWMU.)

$\begin{array}{ll}\text { SP04 } & (\text { S }) \\ \text { SP06 } & \text { (S) } \\ \text { SP11 } & \text { (S) }\end{array}$

Note: The SDA is sampled by NYSERDA under an independent monitoring program.

SSWMU \#11 -

State-licensed Disposal Area (SDA)

- State-licensed Disposal Area [NYSERDA]

$\begin{array}{lr}1101 A & (\mathrm{WT}: \mathrm{U}) \\ 1101 \mathrm{~B} & (\mathrm{~T}: \mathrm{U}) \\ 1101 \mathrm{C} & (\mathrm{K}: \mathrm{U}) \\ 1102 \mathrm{~A} & (\mathrm{WT}: \mathrm{D}) \\ 1102 \mathrm{~B} & (\mathrm{~T}: \mathrm{D}) \\ 1103 \mathrm{~A} & (\mathrm{WT}: \mathrm{D}) \\ 1103 \mathrm{~B} & (\mathrm{~T}: \mathrm{D}) \\ 1103 \mathrm{C} & (\mathrm{K}: \mathrm{D}) \\ 1104 \mathrm{~A} & (\mathrm{WT}: \mathrm{D}) \\ 1104 \mathrm{~B} & (\mathrm{~T}: \mathrm{D}) \\ 1104 \mathrm{C} & (\mathrm{K}: \mathrm{D})\end{array}$

$\begin{array}{lr}1105 A & (W T: D) \\ 1105 B & (T: D) \\ 1106 A & (W T: U) \\ 1106 B & (T: U) \\ 1107 A & (W T: D) \\ 1108 A & (W T: U) \\ 1109 A & (W T: U) \\ 1109 B & (T: U) \\ 1110 A & (W T: D) \\ 1111 A & (W T: D)\end{array}$

\footnotetext{
${ }^{1}$ Hydrogeologic unit monitored and well position in SSWMU follow the well ID in parentheses. Hydrogeologic units monitored are: WT (weathered Lavery till); $T$ (unweathered Lavery till); $S$ (sand and gravel); K (Kent recessional sequence); TS (till-sand). Well position in SSWMU: U (upgradient); D (downgradient); B (background); $C$ (crossgradient). Example: 401* (S:B) monitors background conditions in the sand and gravel unit.

${ }^{2}$ See Table 3-1 (p. 3-6) for a description of codes and analytes. The parameters listed in this table, Table E-1, are in addition to the contamination indicator parameters (I) and radiological indicator parameters (RI) routinely scheduled at all monitoring locations for 2001. Wells measured for potentiometric (water-level) data only are designated by "p."
}

\footnotetext{
* Monitoring for certain parameters is required by the RCRA $\$ 3008(h)$ Order on Consent. (See p. ECS-4.)
}

$$
E-6
$$


Table E-2

2001 Contamination Indicator and Radiological Indicator Results

Sand and Gravel Unit

\begin{tabular}{|c|c|c|c|c|c|c|}
\hline $\begin{array}{l}\text { Location } \\
\text { Code }\end{array}$ & $\begin{array}{l}\text { Hydraulic } \\
\text { Position }\end{array}$ & $\begin{array}{c}\mathbf{p H} \\
\text { (standard units) }\end{array}$ & $\begin{array}{c}\text { Conductivity } \\
\left(\mu \mathrm{mhos} / \mathrm{cm} @ 25^{\circ} \mathrm{C}\right)\end{array}$ & $\begin{array}{l}\text { Gross Alpha } \\
(\mu \mathrm{Ci} / \mathrm{mL})\end{array}$ & $\begin{array}{c}\text { Gross Beta } \\
(\mu \mathrm{Ci} / \mathrm{mL})\end{array}$ & $\begin{array}{l}\text { Tritium } \\
(\mu \mathrm{Ci} / \mathrm{mL})\end{array}$ \\
\hline 301 & $\mathrm{UP}(1)$ & 6.93 & 940 & $1.77 \pm 1.63 \mathrm{E}-09$ & $1.10 \pm 0.41 \mathrm{E}-08$ & $5.54 \pm 8.18 \mathrm{E}-08$ \\
\hline 301 & $\mathrm{UP}(2)$ & 7.14 & 1,034 & $1.13 \pm 2.07 \mathrm{E}-09$ & $1.15 \pm 0.39 E-08$ & $9.91 \pm 8.23 E-08$ \\
\hline 301 & $\mathrm{UP}(3)$ & 6.92 & 1,422 & $3.59 \pm 3.28 \mathrm{E}-09$ & $8.54 \pm 3.21 \mathrm{E}-09$ & $-1.32 \pm 0.81 \mathrm{E}-07$ \\
\hline 301 & $\mathrm{UP}(4)$ & 6.73 & 1,389 & $5.20 \pm 3.81 E-09$ & $5.51 \pm 3.78 \mathrm{E}-09$ & $-8.85 \pm 5.76 \mathrm{E}-08$ \\
\hline 401 & $\mathrm{UP}(1)$ & 6.67 & 2,745 & $1.27 \pm 3.62 \mathrm{E}-09$ & $4.08 \pm 7.35 \mathrm{E}-09$ & $-6.42 \pm 5.78 \mathrm{E}-08$ \\
\hline 401 & $\mathrm{UP}(2)$ & 7.07 & 1,740 & $1.55 \pm 0.92 E-08$ & $3.20 \pm 7.39 \mathrm{E}-09$ & $2.33 \pm 0.76 E-07$ \\
\hline 401 & $\mathrm{UP}(3)$ & 7.04 & 2,415 & $2.26 \pm 4.99 \mathrm{E}-09$ & $-0.16 \pm 5.18 \mathrm{E}-09$ & $-1.46 \pm 0.82 \mathrm{E}-07$ \\
\hline 401 & $\mathrm{UP}(4)$ & 6.77 & 2,230 & $0.00 \pm 5.62 \mathrm{E}-09$ & $1.10 \pm 0.74 \mathrm{E}-08$ & $-9.64 \pm 8.16 \mathrm{E}-08$ \\
\hline 403 & $\mathrm{UP}(1)$ & 7.21 & 830 & $1.64 \pm 1.52 \mathrm{E}-09$ & $3.84 \pm 3.66 \mathrm{E}-09$ & $9.62 \pm 8.16 \mathrm{E}-08$ \\
\hline 403 & $\mathrm{UP}(2)$ & 7.33 & 1,013 & $0.81 \pm 1.69 \mathrm{E}-09$ & $6.29 \pm 2.59 \mathrm{E}-09$ & $7.59 \pm 8.22 \mathrm{E}-08$ \\
\hline 403 & $\mathrm{UP}(3)$ & 6.77 & 1,226 & $2.16 \pm 3.00 \mathrm{E}-09$ & $8.25 \pm 3.90 \mathrm{E}-09$ & $-1.30 \pm 0.81 \mathrm{E}-07$ \\
\hline 403 & $\mathrm{UP}(4)$ & 6.89 & 790 & $2.08 \pm 3.36 \mathrm{E}-09$ & $1.06 \pm 0.40 \mathrm{E}-08$ & $-1.11 \pm 0.81 \mathrm{E}-07$ \\
\hline 706 & UP(1) & 6.99 & 776 & $0.72 \pm 1.10 \mathrm{E}-09$ & $1.79 \pm 0.27 E-08$ & $4.71 \pm 8.25 \mathrm{E}-08$ \\
\hline 706 & $\mathrm{UP}(2)$ & 6.78 & 852 & $1.14 \pm 1.64 \mathrm{E}-09$ & $1.49 \pm 0.25 \mathrm{E}-08$ & $-9.77 \pm 7.75 E-08$ \\
\hline 706 & $\mathrm{UP}(3)$ & 6.80 & 849 & $1.29 \pm 2.06 \mathrm{E}-09$ & $1.25 \pm 0.25 E-08$ & $-0.36 \pm 8.28 \mathrm{E}-08$ \\
\hline 706 & $\mathrm{UP}(4)$ & 6.55 & 978 & $-0.29 \pm 2.27 \mathrm{E}-09$ & $1.45 \pm 0.27 \mathrm{E}-08$ & $8.25 \pm 8.26 \mathrm{E}-08$ \\
\hline NB1S & $\mathrm{UP}(1)$ & 6.49 & 586 & $0.15 \pm 1.17 \mathrm{E}-09$ & $4.54 \pm 1.97 \mathrm{E}-09$ & $1.65 \pm 0.57 E-07$ \\
\hline NB1S & $\mathrm{UP}(2)$ & 6.90 & 788 & $0.00 \pm 1.34 \mathrm{E}-09$ & $1.55 \pm 1.32 \mathrm{E}-09$ & $-1.36 \pm 0.80 \mathrm{E}-07$ \\
\hline NB1S & $\mathrm{UP}(3)$ & 6.81 & 809 & $-1.03 \pm 1.53 \mathrm{E}-09$ & $0.36 \pm 1.89 \mathrm{E}-09$ & $0.42 \pm 8.18 \mathrm{E}-08$ \\
\hline NB1S & $\mathrm{UP}(4)$ & 6.76 & 991 & $0.58 \pm 1.63 \mathrm{E}-09$ & $4.58 \pm 2.01 E-09$ & $5.87 \pm 8.06 \mathrm{E}-08$ \\
\hline 201 & $\operatorname{DOWN}(1)$ & 6.48 & 781 & $1.17 \pm 1.72 \mathrm{E}-09$ & $2.20 \pm 0.42 \mathrm{E}-08$ & $-1.11 \pm 0.89 \mathrm{E}-07$ \\
\hline 201 & $\operatorname{DOWN}(2)$ & 6.35 & 1,576 & $0.35 \pm 2.42 \mathrm{E}-09$ & $5.32 \pm 0.47 E-08$ & $-4.98 \pm 9.88 \mathrm{E}-08$ \\
\hline 201 & $\operatorname{DOWN}(3)$ & 6.87 & 587 & $1.33 \pm 1.37 \mathrm{E}-09$ & $1.47 \pm 0.32 E-08$ & $-2.64 \pm 0.92 E-07$ \\
\hline 201 & DOWN(4) & 6.25 & 324 & $-0.49 \pm 1.21 \mathrm{E}-09$ & $1.51 \pm 0.31 \mathrm{E}-08$ & $-1.54 \pm 0.83 \mathrm{E}-07$ \\
\hline 103 & $\operatorname{DOWN}(1)$ & 8.42 & 2,200 & $3.59 \pm 2.94 \mathrm{E}-09$ & $5.99 \pm 0.65 E-08$ & $-0.60 \pm 5.89 \mathrm{E}-08$ \\
\hline 103 & $\operatorname{DOWN}(2)$ & 8.27 & 4,170 & $3.48 \pm 4.28 \mathrm{E}-09$ & $1.55 \pm 0.08 \mathrm{E}-07$ & $1.64 \pm 0.83 E-07$ \\
\hline 103 & DOWN(3) & 7.89 & 6,485 & $5.55 \pm 3.93 E-09$ & $2.84 \pm 0.10 E-07$ & $6.32 \pm 8.16 \mathrm{E}-08$ \\
\hline 103 & DOWN(4) & 7.73 & 5,430 & $2.06 \pm 7.77 \mathrm{E}-09$ & $2.22 \pm 0.12 \mathrm{E}-07$ & $3.02 \pm 8.27 \mathrm{E}-08$ \\
\hline 104 & $\operatorname{DOWN}(1)$ & 7.68 & 1,513 & $5.61 \pm 8.93 \mathrm{E}-09$ & $4.24 \pm 0.02 E-05$ & $3.24 \pm 0.87 \mathrm{E}-07$ \\
\hline 104 & $\operatorname{DOWN}(2)$ & 6.88 & 1,469 & $-1.40 \pm 1.03 \mathrm{E}-08$ & $4.47 \pm 0.02 \mathrm{E}-05$ & $4.05 \pm 0.86 \mathrm{E}-07$ \\
\hline 104 & $\operatorname{DOWN}(3)$ & 7.14 & 1,786 & $7.81 \pm 9.18 \mathrm{E}-09$ & $5.12 \pm 0.02 \mathrm{E}-05$ & $3.58 \pm 0.85 \mathrm{E}-07$ \\
\hline 104 & DOWN(4) & 6.97 & 1,965 & $2.44 \pm 3.02 \mathrm{E}-09$ & $5.80 \pm 0.01 E-05$ & $2.51 \pm 0.60 \mathrm{E}-07$ \\
\hline 111 & $\operatorname{DOWN}(1)$ & 6.64 & 644 & $6.64 \pm 8.62 \mathrm{E}-09$ & $5.81 \pm 0.10 \mathrm{E}-06$ & $7.19 \pm 8.30 \mathrm{E}-08$ \\
\hline 111 & $\operatorname{DOWN}(2)$ & 6.70 & 594 & $-4.04 \pm 8.74 \mathrm{E}-09$ & $4.20 \pm 0.08 E-06$ & $1.75 \pm 0.83 \mathrm{E}-07$ \\
\hline 111 & $\operatorname{DOWN}(3)$ & 6.58 & 794 & $1.03 \pm 0.95 E-08$ & $7.02 \pm 0.11 \mathrm{E}-06$ & $3.91 \pm 0.86 \mathrm{E}-07$ \\
\hline 111 & DOWN(4) & 6.60 & 1,180 & $2.47 \pm 3.09 \mathrm{E}-09$ & $1.04 \pm 0.01 E-05$ & $5.13 \pm 8.27 \mathrm{E}-08$ \\
\hline
\end{tabular}

Sample collection quarter is noted in parentheses next to hydraulic position. Hydraulic position is relative to other wells within the same hydrogeologic unit.

Note: Bolding convention applied to these data. (See p. E-2.)

$E-7$

WVDP Site Environmental Report

Calendar Year 2001 


\section{Table E-2 (continued)}

\section{Contamination Indicator and Radiological Indicator Results Sand and Gravel Unit}

\begin{tabular}{|c|c|c|c|c|c|c|}
\hline $\begin{array}{l}\text { Location } \\
\text { Code }\end{array}$ & $\begin{array}{c}\text { Hydraulic } \\
\text { Position }\end{array}$ & $\begin{array}{c}\mathbf{p H} \\
\text { (standard units) }\end{array}$ & $\begin{array}{c}\text { Conductivity } \\
\left(\mu \mathrm{mhos} / \mathrm{cm} @ 25^{\circ} \mathrm{C}\right)\end{array}$ & $\begin{array}{c}\text { Gross Alpha } \\
(\mu \mathrm{Ci} / \mathrm{mL})\end{array}$ & $\begin{array}{c}\text { Gross Beta } \\
(\mu \mathrm{Ci} / \mathrm{mL})\end{array}$ & $\begin{array}{l}\text { Tritium } \\
(\mu \mathrm{Ci} / \mathrm{mL})\end{array}$ \\
\hline 205 & DOWN(1) & 7.51 & 1,702 & $-0.50 \pm 2.51 \mathrm{E}-09$ & $1.19 \pm 0.47 \mathrm{E}-08$ & $1.11 \pm 0.58 \mathrm{E}-07$ \\
\hline 205 & DOWN(2) & 7.06 & 1,910 & $-0.23 \pm 2.98 \mathrm{E}-09$ & $1.14 \pm 0.42 \mathrm{E}-08$ & $2.25 \pm 8.65 \mathrm{E}-08$ \\
\hline 205 & DOWN(3) & 7.03 & 3,200 & $2.05 \pm 3.97 \mathrm{E}-09$ & $2.59 \pm 0.45 E-08$ & $-9.15 \pm 8.25 \mathrm{E}-08$ \\
\hline 205 & DOWN(4) & 6.59 & $\mathbf{3 , 8 3 5}$ & $-2.96 \pm 6.25 \mathrm{E}-09$ & $2.27 \pm 0.66 \mathrm{E}-08$ & $-9.89 \pm 8.18 \mathrm{E}-08$ \\
\hline 406 & DOWN(1) & 7.01 & 960 & $2.33 \pm 1.61 \mathrm{E}-09$ & $8.65 \pm 2.86 \mathrm{E}-09$ & $1.85 \pm 0.84 \mathrm{E}-07$ \\
\hline 406 & DOWN(2) & 6.58 & 2,065 & $0.95 \pm 2.12 \mathrm{E}-09$ & $1.57 \pm 0.23 \mathrm{E}-08$ & $7.84 \pm 8.05 \mathrm{E}-08$ \\
\hline 406 & DOWN(3) & 6.50 & 2,220 & $1.69 \pm 2.86 \mathrm{E}-09$ & $1.14 \pm 0.32 \mathrm{E}-08$ & $1.17 \pm 0.81 \mathrm{E}-07$ \\
\hline 406 & DOWN(4) & 6.47 & 1,768 & $-1.42 \pm 3.00 \mathrm{E}-09$ & $1.17 \pm 0.33 \mathrm{E}-08$ & $5.69 \pm 8.28 \mathrm{E}-08$ \\
\hline 408 & DOWN(1) & 7.14 & 2,140 & $-3.40 \pm 2.59 \mathrm{E}-09$ & $4.89 \pm 0.01 \mathrm{E}-04$ & $-1.17 \pm 1.14 \mathrm{E}-07$ \\
\hline 408 & DOWN(2) & 6.76 & 2,190 & $6.44 \pm 5.52 \mathrm{E}-09$ & $5.60 \pm 0.01 \mathrm{E}-04$ & $0.95 \pm 1.15 \mathrm{E}-07$ \\
\hline 408 & $\operatorname{DOWN}(3)$ & 6.98 & 2,560 & $0.26 \pm 1.26 \mathrm{E}-08$ & $6.28 \pm 0.02 \mathrm{E}-04$ & $-1.88 \pm 0.92 \mathrm{E}-07$ \\
\hline 408 & DOWN(4) & 7.04 & 2,525 & $0.13 \pm 2.75 \mathrm{E}-09$ & $6.07 \pm 0.01 \mathrm{E}-04$ & $0.00 \pm 1.11 \mathrm{E}-07$ \\
\hline 501 & DOWN(1) & 7.11 & 1,886 & $0.52 \pm 1.44 \mathrm{E}-08$ & $2.66 \pm 0.01 \mathrm{E}-04$ & $1.40 \pm 0.84 \mathrm{E}-07$ \\
\hline 501 & DOWN(2) & 6.90 & 1,693 & $-1.60 \pm 1.88 \mathrm{E}-08$ & $2.22 \pm 0.01 \mathrm{E}-04$ & $1.79 \pm 0.83 \mathrm{E}-07$ \\
\hline 501 & DOWN(3) & 7.08 & 2,230 & $0.85 \pm 1.24 \mathrm{E}-08$ & $3.17 \pm 0.01 \mathrm{E}-04$ & $1.66 \pm 0.83 \mathrm{E}-07$ \\
\hline 501 & DOWN(4) & 6.92 & 2,415 & $2.02 \pm 5.18 \mathrm{E}-09$ & $3.24 \pm 0.01 E-04$ & $8.92 \pm 8.25 \mathrm{E}-08$ \\
\hline 502 & DOWN(1) & 7.18 & 1,867 & $-0.51 \pm 1.00 \mathrm{E}-08$ & $1.93 \pm 0.01 \mathrm{E}-04$ & $5.24 \pm 8.28 \mathrm{E}-08$ \\
\hline 502 & DOWN(2) & 6.82 & 1,764 & $-1.30 \pm 2.02 \mathrm{E}-08$ & $1.93 \pm 0.01 \mathrm{E}-04$ & $1.61 \pm 0.83 \mathrm{E}-07$ \\
\hline 502 & DOWN(3) & 7.04 & 1,891 & $0.62 \pm 1.22 \mathrm{E}-08$ & $2.21 \pm 0.01 \mathrm{E}-04$ & $1.24 \pm 0.82 \mathrm{E}-07$ \\
\hline 502 & DOWN(4) & 7.02 & 2,095 & $1.14 \pm 4.34 \mathrm{E}-09$ & $2.33 \pm 0.01 E-04$ & $9.13 \pm 8.33 \mathrm{E}-08$ \\
\hline $602 \mathrm{~A}$ & DOWN(1) & 6.72 & 550 & $1.55 \pm 1.18 \mathrm{E}-09$ & $9.74 \pm 2.85 \mathrm{E}-09$ & $4.79 \pm 0.85 \mathrm{E}-07$ \\
\hline $602 \mathrm{~A}$ & DOWN(2) & 7.18 & 668 & $1.36 \pm 1.41 \mathrm{E}-09$ & $1.57 \pm 0.25 \mathrm{E}-08$ & $9.17 \pm 8.05 \mathrm{E}-08$ \\
\hline $602 \mathrm{~A}$ & DOWN(3) & 6.83 & 549 & $-0.35 \pm 1.24 \mathrm{E}-09$ & $1.22 \pm 0.29 \mathrm{E}-08$ & $-2.97 \pm 1.11 \mathrm{E}-07$ \\
\hline $602 \mathrm{~A}$ & DOWN(4) & 6.74 & 324 & $-0.12 \pm 1.54 \mathrm{E}-09$ & $1.26 \pm 0.30 \mathrm{E}-08$ & $2.49 \pm 0.84 \mathrm{E}-07$ \\
\hline 604 & DOWN(1) & 6.30 & 1,130 & $1.02 \pm 2.34 \mathrm{E}-09$ & $6.54 \pm 3.78 \mathrm{E}-09$ & $-1.28 \pm 0.58 \mathrm{E}-07$ \\
\hline 604 & DOWN(2) & 6.45 & 928 & $1.09 \pm 1.92 \mathrm{E}-09$ & $5.77 \pm 2.66 \mathrm{E}-09$ & $7.26 \pm 8.05 \mathrm{E}-08$ \\
\hline 604 & DOWN(3) & 6.31 & 956 & $-0.54 \pm 2.27 \mathrm{E}-09$ & $6.77 \pm 3.74 \mathrm{E}-09$ & $5.15 \pm 8.15 \mathrm{E}-08$ \\
\hline 604 & DOWN(4) & 6.43 & 1,059 & $1.53 \pm 1.74 \mathrm{E}-09$ & $5.02 \pm 2.56 \mathrm{E}-09$ & $0.50 \pm 8.14 \mathrm{E}-08$ \\
\hline 8605 & DOWN(1) & 7.43 & 1,311 & $5.30 \pm 9.79 \mathrm{E}-09$ & $1.13 \pm 0.01 \mathrm{E}-05$ & $3.88 \pm 0.88 \mathrm{E}-07$ \\
\hline 8605 & DOWN(2) & 6.78 & 1,104 & $0.20 \pm 1.53 \mathrm{E}-08$ & $1.25 \pm 0.01 \mathrm{E}-05$ & $5.30 \pm 0.88 \mathrm{E}-07$ \\
\hline 8605 & DOWN(3) & 6.76 & 1,463 & $1.42 \pm 1.47 \mathrm{E}-08$ & $1.30 \pm 0.02 E-05$ & $4.90 \pm 0.87 \mathrm{E}-07$ \\
\hline 8605 & DOWN(4) & 6.86 & 1,841 & $1.37 \pm 0.50 \mathrm{E}-08$ & $1.00 \pm 0.01 E-05$ & $0.95 \pm 8.15 \mathrm{E}-08$ \\
\hline 8607 & DOWN(1) & 6.26 & 1,200 & $-0.17 \pm 1.78 \mathrm{E}-09$ & $2.39 \pm 0.43 \mathrm{E}-08$ & $-1.62 \pm 0.86 \mathrm{E}-07$ \\
\hline 8607 & DOWN(2) & 6.65 & 2,115 & $-0.21 \pm 2.76 \mathrm{E}-09$ & $3.44 \pm 0.41 \mathrm{E}-08$ & $0.78 \pm 7.44 \mathrm{E}-08$ \\
\hline 8607 & DOWN(3) & 6.50 & 2,330 & $1.28 \pm 2.84 \mathrm{E}-09$ & $3.92 \pm 0.45 \mathrm{E}-08$ & $-7.84 \pm 8.32 \mathrm{E}-08$ \\
\hline 8607 & DOWN(4) & 6.24 & 1,649 & $-1.30 \pm 3.24 \mathrm{E}-09$ & $2.24 \pm 0.49 \mathrm{E}-08$ & $-4.84 \pm 8.11 \mathrm{E}-08$ \\
\hline
\end{tabular}

Sample collection quarter is noted in parentheses next to hydraulic position. Hydraulic position is relative to other wells within the same hydrogeologic unit.

Note: Bolding convention applied to these data. (See p. E-2.)

WVDP Site Environmental Report

$E-8$

Calendar Year 2001 


\section{Table E-2 (continued) Sand and Gravel Unit}

2001 Contamination Indicator and Radiological Indicator Results

\begin{tabular}{|c|c|c|c|c|c|c|}
\hline $\begin{array}{l}\text { Location } \\
\text { Code }\end{array}$ & $\begin{array}{l}\text { Hydraulic } \\
\text { Position }\end{array}$ & $\begin{array}{c}\mathbf{p H} \\
\text { (standard units) }\end{array}$ & $\begin{array}{c}\text { Conductivity } \\
\left(\mu \mathrm{mhos} / \mathrm{cm} @ 25^{\circ} \mathrm{C}\right)\end{array}$ & $\begin{array}{c}\text { Gross Alpha } \\
(\mu \mathrm{Ci} / \mathrm{mL})\end{array}$ & $\begin{array}{c}\text { Gross Beta } \\
(\mu \mathrm{Ci} / \mathrm{mL})\end{array}$ & $\begin{array}{l}\text { Tritium } \\
(\mu \mathrm{Ci} / \mathrm{mL})\end{array}$ \\
\hline 8609 & DOWN(1) & 7.10 & 1,324 & $-0.51 \pm 2.51 \mathrm{E}-09$ & $1.03 \pm 0.02 \mathrm{E}-06$ & $5.83 \pm 0.90 \mathrm{E}-07$ \\
\hline 8609 & DOWN(2) & 6.95 & 1,340 & $-1.05 \pm 1.62 \mathrm{E}-08$ & $8.18 \pm 0.39 \mathrm{E}-07$ & $4.47 \pm 0.87 \mathrm{E}-07$ \\
\hline 8609 & DOWN(3) & 7.10 & 1,470 & $1.50 \pm 1.55 \mathrm{E}-08$ & $9.93 \pm 0.43 \mathrm{E}-07$ & $4.96 \pm 0.62 \mathrm{E}-07$ \\
\hline 8609 & DOWN(4) & 6.93 & 1,618 & $1.82 \pm 2.90 \mathrm{E}-09$ & $1.07 \pm 0.02 E-06$ & $4.07 \pm 0.86 \mathrm{E}-07$ \\
\hline 105 & DOWN(1) & 7.64 & 1,594 & $0.46 \pm 1.27 \mathrm{E}-08$ & $4.16 \pm 0.09 \mathrm{E}-06$ & $3.84 \pm 0.88 \mathrm{E}-07$ \\
\hline 105 & $\operatorname{DOWN}(2)$ & 6.87 & 1,504 & $-1.07 \pm 1.66 \mathrm{E}-08$ & $3.69 \pm 0.08 \mathrm{E}-06$ & $5.29 \pm 0.87 \mathrm{E}-07$ \\
\hline 105 & DOWN(3) & 7.30 & 1,636 & $2.81 \pm 8.30 \mathrm{E}-09$ & $4.14 \pm 0.07 \mathrm{E}-06$ & $4.13 \pm 0.88 \mathrm{E}-07$ \\
\hline 105 & DOWN(4) & 7.01 & 1,726 & $0.00 \pm 3.42 \mathrm{E}-09$ & $5.40 \pm 0.05 E-06$ & $4.20 \pm 0.87 \mathrm{E}-07$ \\
\hline 106 & DOWN(1) & 6.86 & 1,335 & $2.20 \pm 2.45 \mathrm{E}-09$ & $9.13 \pm 3.58 \mathrm{E}-09$ & $1.18 \pm 0.10 \mathrm{E}-06$ \\
\hline 106 & DOWN(2) & 6.70 & 1,244 & $0.96 \pm 2.30 \mathrm{E}-09$ & $5.43 \pm 3.63 \mathrm{E}-09$ & $1.29 \pm 0.10 \mathrm{E}-06$ \\
\hline 106 & DOWN(3) & 6.83 & 1,400 & $4.61 \pm 3.36 \mathrm{E}-09$ & $4.10 \pm 4.10 \mathrm{E}-09$ & $1.22 \pm 0.10 \mathrm{E}-06$ \\
\hline 106 & DOWN(4) & 6.70 & 1,526 & $2.04 \pm 3.52 \mathrm{E}-09$ & $6.35 \pm 3.41 \mathrm{E}-09$ & $1.82 \pm 0.08 \mathrm{E}-06$ \\
\hline 116 & DOWN(1) & 7.25 & 1,582 & $1.42 \pm 1.67 \mathrm{E}-09$ & $3.18 \pm 0.10 \mathrm{E}-07$ & $2.88 \pm 0.84 \mathrm{E}-07$ \\
\hline 116 & DOWN(2) & 7.32 & 3,260 & $3.28 \pm 5.38 \mathrm{E}-09$ & $4.56 \pm 0.18 E-07$ & $3.03 \pm 0.84 \mathrm{E}-07$ \\
\hline 116 & DOWN(3) & 7.04 & 2,190 & $3.34 \pm 4.86 \mathrm{E}-09$ & $3.13 \pm 0.15 E-07$ & $1.35 \pm 0.82 \mathrm{E}-07$ \\
\hline 116 & DOWN(4) & 6.86 & 1,676 & $1.65 \pm 6.64 \mathrm{E}-09$ & $3.27 \pm 0.15 \mathrm{E}-07$ & $1.51 \pm 0.84 \mathrm{E}-07$ \\
\hline 605 & DOWN(1) & 7.37 & 712 & $1.52 \pm 1.10 \mathrm{E}-09$ & $5.79 \pm 0.40 \mathrm{E}-08$ & $-6.20 \pm 8.20 \mathrm{E}-08$ \\
\hline 605 & DOWN(2) & 7.21 & 861 & $0.53 \pm 1.45 \mathrm{E}-09$ & $7.19 \pm 0.39 \mathrm{E}-08$ & $-9.66 \pm 7.77 \mathrm{E}-08$ \\
\hline 605 & DOWN(3) & 6.38 & 1,038 & $-0.32 \pm 1.70 \mathrm{E}-09$ & $6.24 \pm 0.42 \mathrm{E}-08$ & $-6.82 \pm 8.31 \mathrm{E}-08$ \\
\hline 605 & DOWN(4) & 7.13 & 873 & $1.17 \pm 2.10 \mathrm{E}-09$ & $3.94 \pm 0.35 E-08$ & $5.07 \pm 8.29 \mathrm{E}-08$ \\
\hline 801 & DOWN(1) & 7.63 & 1,119 & $-1.66 \pm 7.29 \mathrm{E}-09$ & $7.30 \pm 0.11 \mathrm{E}-06$ & $1.05 \pm 0.60 \mathrm{E}-07$ \\
\hline 801 & $\operatorname{DOWN}(2)$ & 6.64 & 2,120 & $-0.52 \pm 1.72 \mathrm{E}-08$ & $1.19 \pm 0.01 E-05$ & $8.94 \pm 8.17 \mathrm{E}-08$ \\
\hline 801 & DOWN(3) & 6.61 & 2,350 & $0.37 \pm 1.27 \mathrm{E}-08$ & $1.16 \pm 0.01 \mathrm{E}-05$ & $2.56 \pm 0.84 \mathrm{E}-07$ \\
\hline 801 & DOWN(4) & 6.61 & 1,782 & $-1.07 \pm 3.79 \mathrm{E}-09$ & $9.76 \pm 0.07 \mathrm{E}-06$ & $1.67 \pm 0.82 \mathrm{E}-07$ \\
\hline 802 & DOWN(1) & 7.90 & 589 & $-0.52 \pm 1.25 \mathrm{E}-09$ & $4.44 \pm 3.17 \mathrm{E}-09$ & $-5.48 \pm 5.89 \mathrm{E}-08$ \\
\hline 802 & DOWN(2) & 6.69 & 353 & $1.29 \pm 8.94 \mathrm{E}-10$ & $3.84 \pm 1.85 \mathrm{E}-09$ & $-1.47 \pm 0.78 \mathrm{E}-07$ \\
\hline 802 & DOWN(3) & 7.06 & 468 & $1.52 \pm 1.01 \mathrm{E}-09$ & $2.67 \pm 1.84 \mathrm{E}-09$ & $-6.22 \pm 8.22 \mathrm{E}-08$ \\
\hline 802 & DOWN(4) & 6.96 & 1,230 & $3.31 \pm 3.84 \mathrm{E}-09$ & $1.37 \pm 0.33 E-08$ & $1.74 \pm 0.84 \mathrm{E}-07$ \\
\hline 803 & DOWN(1) & 6.84 & 1,487 & $1.08 \pm 1.89 \mathrm{E}-09$ & $2.04 \pm 0.37 \mathrm{E}-08$ & $3.42 \pm 0.59 \mathrm{E}-07$ \\
\hline 803 & DOWN(2) & 6.98 & 1,298 & $0.57 \pm 2.64 \mathrm{E}-09$ & $1.52 \pm 0.42 \mathrm{E}-08$ & $8.92 \pm 8.32 \mathrm{E}-08$ \\
\hline 803 & DOWN(3) & 6.92 & 772 & $4.09 \pm 3.83 \mathrm{E}-09$ & $1.24 \pm 0.44 \mathrm{E}-08$ & $1.02 \pm 0.84 \mathrm{E}-07$ \\
\hline 803 & DOWN(4) & 6.98 & 1,378 & $-0.38 \pm 3.63 \mathrm{E}-09$ & $1.38 \pm 0.45 \mathrm{E}-08$ & $1.96 \pm 0.84 \mathrm{E}-07$ \\
\hline 804 & DOWN(1) & 6.92 & 853 & $1.07 \pm 1.28 \mathrm{E}-09$ & $3.00 \pm 0.08 \mathrm{E}-07$ & $2.78 \pm 0.82 \mathrm{E}-07$ \\
\hline 804 & DOWN(2) & 7.03 & 1,592 & $0.34 \pm 2.27 \mathrm{E}-09$ & 4.68 $\pm 0.11 E-07$ & $1.45 \pm 0.59 \mathrm{E}-07$ \\
\hline 804 & DOWN(3) & 6.85 & 1,342 & $0.52 \pm 2.58 \mathrm{E}-09$ & $3.37 \pm 0.09 \mathrm{E}-07$ & $1.49 \pm 0.60 \mathrm{E}-07$ \\
\hline 804 & DOWN(4) & 6.69 & 946 & $-0.52 \pm 1.74 \mathrm{E}-09$ & $2.98 \pm 0.07 E-07$ & $6.10 \pm 8.22 \mathrm{E}-08$ \\
\hline
\end{tabular}

Sample collection quarter is noted in parentheses next to hydraulic position. Hydraulic position is relative to other wells within the same hydrogeologic unit.

Note: Bolding convention applied to these data. (See p. E-2.)

$E-9$ 
Table E-2 (concluded)

\section{Contamination Indicator and Radiological Indicator Results Sand and Gravel Unit}

\begin{tabular}{|c|c|c|c|c|c|c|}
\hline $\begin{array}{l}\text { Location } \\
\text { Code }\end{array}$ & $\begin{array}{c}\text { Hydraulic } \\
\text { Position }\end{array}$ & $\begin{array}{c}\mathbf{p H} \\
\text { (standard units) }\end{array}$ & $\begin{array}{c}\text { Conductivity } \\
\left(\mu \mathrm{mhos} / \mathrm{cm} @ 25^{\circ} \mathrm{C}\right)\end{array}$ & $\begin{array}{c}\text { Gross Alpha } \\
(\mu \mathrm{Ci} / \mathrm{mL})\end{array}$ & $\begin{array}{c}\text { Gross Beta } \\
(\mu \mathrm{Ci} / \mathrm{mL})\end{array}$ & $\begin{array}{l}\text { Tritium } \\
(\mu \mathrm{Ci} / \mathrm{mL})\end{array}$ \\
\hline 8603 & DOWN(1) & 7.40 & 1,742 & $-2.28 \pm 9.96 \mathrm{E}-09$ & $2.31 \pm 0.02 \mathrm{E}-05$ & $4.19 \pm 0.89 \mathrm{E}-07$ \\
\hline 8603 & DOWN(2) & 6.88 & 1,615 & $-0.94 \pm 2.03 \mathrm{E}-08$ & $2.04 \pm 0.02 E-05$ & $5.08 \pm 0.62 \mathrm{E}-07$ \\
\hline 8603 & DOWN(3) & 7.42 & 1,754 & $0.30 \pm 1.01 \mathrm{E}-08$ & $2.48 \pm 0.02 \mathrm{E}-05$ & $4.00 \pm 0.85 \mathrm{E}-07$ \\
\hline 8603 & DOWN(4) & 6.98 & 1,802 & $0.77 \pm 3.86 \mathrm{E}-09$ & $2.56 \pm 0.01 E-05$ & $3.50 \pm 0.86 \mathrm{E}-07$ \\
\hline 8604 & DOWN(1) & 7.74 & 1,575 & $0.00 \pm 1.05 \mathrm{E}-08$ & $3.65 \pm 0.03 \mathrm{E}-05$ & $3.48 \pm 0.88 \mathrm{E}-07$ \\
\hline 8604 & DOWN(2) & 6.93 & 820 & $-1.35 \pm 1.59 \mathrm{E}-08$ & $3.77 \pm 0.03 \mathrm{E}-05$ & $3.06 \pm 0.84 \mathrm{E}-07$ \\
\hline 8604 & $\operatorname{DOWN}(3)$ & 7.27 & 1,772 & $0.91 \pm 1.33 \mathrm{E}-08$ & $4.84 \pm 0.03 \mathrm{E}-05$ & $3.78 \pm 0.86 \mathrm{E}-07$ \\
\hline 8604 & DOWN(4) & 6.99 & 1,955 & $2.99 \pm 4.35 \mathrm{E}-09$ & $4.34 \pm 0.01 \mathrm{E}-05$ & $2.62 \pm 0.85 \mathrm{E}-07$ \\
\hline 8612 & DOWN(1) & 7.22 & 1,246 & $1.48 \pm 2.20 \mathrm{E}-09$ & $2.91 \pm 3.17 \mathrm{E}-09$ & $5.18 \pm 0.89 \mathrm{E}-07$ \\
\hline 8612 & DOWN(2) & 7.10 & 1,279 & $1.50 \pm 2.57 \mathrm{E}-09$ & $5.13 \pm 3.64 \mathrm{E}-09$ & $3.84 \pm 0.87 \mathrm{E}-07$ \\
\hline 8612 & $\operatorname{DOWN}(3)$ & 7.17 & 1,274 & $1.68 \pm 2.85 \mathrm{E}-09$ & $0.43 \pm 3.81 \mathrm{E}-09$ & $4.97 \pm 0.88 \mathrm{E}-07$ \\
\hline 8612 & DOWN(4) & 7.28 & 1,284 & $0.52 \pm 3.50 \mathrm{E}-09$ & $0.47 \pm 3.77 \mathrm{E}-09$ & $3.99 \pm 0.87 \mathrm{E}-07$ \\
\hline
\end{tabular}

Sample collection quarter is noted in parentheses next to hydraulic position. Hydraulic position is relative to other wells within the same hydrogeologic unit.

Note: Bolding convention applied to these data. (See p. E-2.)

WVDP Site Environmental Report

$$
\text { E - } 10
$$


Table E-3

2001 Contamination Indicator and Radiological Indicator Results Lavery Till-Sand Unit

\begin{tabular}{|c|c|c|c|c|c|c|}
\hline $\begin{array}{l}\text { Location } \\
\text { Code }\end{array}$ & $\begin{array}{c}\text { Hydraulic } \\
\text { Position }\end{array}$ & $\begin{array}{c}\mathbf{p H} \\
\text { (standard units) }\end{array}$ & $\begin{array}{c}\text { Conductivity } \\
\left(\mu \mathrm{mhos} / \mathrm{cm} @ 25^{\circ} \mathrm{C}\right)\end{array}$ & $\begin{array}{l}\text { Gross Alpha } \\
\qquad(\mu \mathrm{Ci} / \mathrm{mL})\end{array}$ & $\begin{array}{c}\text { Gross Beta } \\
(\mu \mathrm{Ci} / \mathrm{mL})\end{array}$ & $\begin{array}{l}\text { Tritium } \\
(\mu \mathrm{Ci} / \mathrm{mL})\end{array}$ \\
\hline 302 & $\mathrm{UP}(1)$ & 6.69 & 2,565 & $2.76 \pm 4.06 \mathrm{E}-09$ & $7.11 \pm 4.57 \mathrm{E}-09$ & $5.60 \pm 8.15 \mathrm{E}-08$ \\
\hline 302 & $\mathrm{UP}(2)$ & 6.92 & 2,600 & $3.72 \pm 6.10 \mathrm{E}-09$ & $6.57 \pm 5.20 \mathrm{E}-09$ & $1.73 \pm 0.76 E-07$ \\
\hline 302 & $\mathrm{UP}(3)$ & 7.23 & 2,800 & $6.25 \pm 6.32 \mathrm{E}-09$ & $8.21 \pm 5.34 \mathrm{E}-09$ & $-5.42 \pm 8.19 \mathrm{E}-08$ \\
\hline 302 & $\mathrm{UP}(4)$ & 7.04 & 2,530 & $4.61 \pm 5.73 \mathrm{E}-09$ & $2.31 \pm 4.87 \mathrm{E}-09$ & $-6.85 \pm 8.16 \mathrm{E}-08$ \\
\hline 402 & $\mathrm{UP}(1)$ & 7.01 & 2,245 & $0.92 \pm 3.36 \mathrm{E}-09$ & $7.46 \pm 4.53 \mathrm{E}-09$ & $7.44 \pm 8.19 \mathrm{E}-08$ \\
\hline 402 & $\mathrm{UP}(2)$ & 7.18 & 2,140 & $1.56 \pm 3.75 \mathrm{E}-09$ & 4.71 $44.77 \mathrm{E}-09$ & $1.99 \pm 0.76 E-07$ \\
\hline 402 & $\mathrm{UP}(3)$ & 7.00 & 2,140 & $5.55 \pm 4.83 E-09$ & $-0.65 \pm 5.15 E-09$ & $-5.09 \pm 8.29 \mathrm{E}-08$ \\
\hline 402 & $\mathrm{UP}(4)$ & 7.21 & 2,175 & $3.52 \pm 5.67 \mathrm{E}-09$ & $2.93 \pm 4.85 \mathrm{E}-09$ & $-1.26 \pm 0.82 \mathrm{E}-07$ \\
\hline 204 & DOWN(1) & 7.48 & 1,191 & $0.58 \pm 1.65 \mathrm{E}-09$ & $0.90 \pm 3.58 \mathrm{E}-09$ & $5.24 \pm 8.16 \mathrm{E}-08$ \\
\hline 204 & $\operatorname{DOWN}(2)$ & 7.10 & 626 & $0.80 \pm 2.29 \mathrm{E}-09$ & $3.24 \pm 3.49 \mathrm{E}-09$ & $-0.81 \pm 5.92 \mathrm{E}-08$ \\
\hline 204 & $\operatorname{DOWN}(3)$ & 7.35 & 1,212 & $2.14 \pm 2.52 \mathrm{E}-09$ & $2.38 \pm 2.77 \mathrm{E}-09$ & $2.21 \pm 8.05 \mathrm{E}-08$ \\
\hline 204 & DOWN(4) & 7.45 & 1,212 & $0.00 \pm 2.47 \mathrm{E}-09$ & 4.32 $\pm 3.62 \mathrm{E}-09$ & $-6.65 \pm 8.19 \mathrm{E}-08$ \\
\hline 206 & DOWN(1) & 7.52 & 987 & $2.78 \pm 2.15 \mathrm{E}-09$ & $3.09 \pm 3.14 \mathrm{E}-09$ & $1.44 \pm 0.83 E-07$ \\
\hline 206 & $\operatorname{DOWN}(2)$ & 7.62 & 1,020 & $0.15 \pm 2.02 \mathrm{E}-09$ & $2.82 \pm 2.53 \mathrm{E}-09$ & $8.60 \pm 5.73 \mathrm{E}-08$ \\
\hline 206 & DOWN(3) & 7.62 & 1,026 & $0.00 \pm 2.18 \mathrm{E}-09$ & $1.77 \pm 2.44 \mathrm{E}-09$ & $-5.46 \pm 5.85 \mathrm{E}-08$ \\
\hline 206 & DOWN(4) & 7.50 & 1,051 & $0.18 \pm 2.92 \mathrm{E}-09$ & $0.81 \pm 2.59 \mathrm{E}-09$ & $-9.64 \pm 8.18 \mathrm{E}-08$ \\
\hline 208 & $\operatorname{DOWN}(1)$ & 7.67 & 293 & $1.14 \pm 0.88 \mathrm{E}-09$ & $1.80 \pm 1.24 \mathrm{E}-09$ & $5.84 \pm 8.10 \mathrm{E}-08$ \\
\hline 208 & $\operatorname{DOWN}(2)$ & 8.00 & 290 & $6.14 \pm 7.50 \mathrm{E}-10$ & $1.12 \pm 1.19 \mathrm{E}-09$ & $-3.20 \pm 8.03 E-08$ \\
\hline 208 & $\operatorname{DOWN}(3)$ & 8.08 & 281 & $-2.74 \pm 7.66 \mathrm{E}-10$ & $0.50 \pm 1.21 \mathrm{E}-09$ & $-9.96 \pm 8.12 \mathrm{E}-08$ \\
\hline 208 & DOWN(4) & 7.95 & 284 & $1.28 \pm 0.88 E-09$ & $2.19 \pm 1.24 \mathrm{E}-09$ & $-1.38 \pm 0.80 \mathrm{E}-07$ \\
\hline
\end{tabular}

Sample collection quarter is noted in parentheses next to hydraulic position. Hydraulic position is relative to other wells within the same hydrogeologic unit.

Note: Bolding convention applied to these data. (See p. E-2.)

WVDP Site Environmental Report

$$
E-11
$$

Calendar Year 2001 


\section{Table E-4}

\section{Contamination Indicator and Radiological Indicator Results Weathered Lavery Till Unit}

\begin{tabular}{|c|c|c|c|c|c|c|}
\hline $\begin{array}{l}\text { Location } \\
\text { Code }\end{array}$ & $\begin{array}{l}\text { Hydraulic } \\
\text { Position }\end{array}$ & $\begin{array}{c}\mathbf{p H} \\
\text { (standard units) }\end{array}$ & $\begin{array}{c}\text { Conductivity } \\
\left(\mu \mathrm{mhos} / \mathrm{cm} @ 25^{\circ} \mathrm{C}\right)\end{array}$ & $\begin{array}{c}\text { Gross Alpha } \\
(\mu \mathrm{Ci} / \mathrm{mL})\end{array}$ & $\begin{array}{l}\text { Gross Beta } \\
(\mu \mathrm{Ci} / \mathrm{mL})\end{array}$ & $\begin{array}{l}\text { Tritium } \\
(\mu \mathrm{Ci} / \mathrm{mL})\end{array}$ \\
\hline 908 & $\mathrm{UP}(1)$ & 6.83 & 2,960 & $1.36 \pm 0.45 \mathrm{E}-08$ & $9.53 \pm 5.49 \mathrm{E}-09$ & $-9.57 \pm 8.19 \mathrm{E}-08$ \\
\hline 908 & $\mathrm{UP}(3)$ & 6.90 & 3,070 & $4.16 \pm 7.30 \mathrm{E}-09$ & $1.81 \pm 0.85 \mathrm{E}-08$ & $-5.58 \pm 8.11 \mathrm{E}-08$ \\
\hline 1005 & $\mathrm{UP}(1)$ & 7.27 & 810 & $2.20 \pm 1.79 \mathrm{E}-09$ & $4.23 \pm 2.28 \mathrm{E}-09$ & $-1.82 \pm 0.83 \mathrm{E}-07$ \\
\hline 1005 & UP(3) & 7.36 & 770 & $0.89 \pm 2.11 \mathrm{E}-09$ & $3.97 \pm 2.54 \mathrm{E}-09$ & $-1.04 \pm 0.80 \mathrm{E}-07$ \\
\hline $1008 \mathrm{C}$ & UP(1) & 7.31 & 620 & $-0.26 \pm 1.29 \mathrm{E}-09$ & $1.52 \pm 1.82 \mathrm{E}-09$ & $-1.26 \pm 0.81 \mathrm{E}-07$ \\
\hline $1008 \mathrm{C}$ & $\mathrm{UP}(3)$ & 7.00 & 606 & $1.41 \pm 1.52 \mathrm{E}-09$ & $2.10 \pm 1.81 \mathrm{E}-09$ & $4.28 \pm 8.20 \mathrm{E}-08$ \\
\hline 906 & DOWN(1) & 7.31 & 556 & $1.51 \pm 1.45 \mathrm{E}-09$ & $3.66 \pm 1.94 \mathrm{E}-09$ & $-1.24 \pm 0.83 \mathrm{E}-07$ \\
\hline 906 & DOWN(3) & 7.21 & 561 & $0.17 \pm 1.28 \mathrm{E}-09$ & $3.97 \pm 2.03 \mathrm{E}-09$ & $-1.23 \pm 8.25 \mathrm{E}-08$ \\
\hline 1006 & DOWN(1) & 6.99 & 2,280 & $2.63 \pm 4.35 \mathrm{E}-09$ & $1.03 \pm 0.66 \mathrm{E}-08$ & $-6.54 \pm 8.19 \mathrm{E}-08$ \\
\hline 1006 & DOWN(3) & 7.14 & 1,883 & $3.42 \pm 4.77 \mathrm{E}-09$ & $6.17 \pm 6.97 \mathrm{E}-09$ & $-5.47 \pm 8.16 \mathrm{E}-08$ \\
\hline 1007 & DOWN(1) & 6.78 & 1,355 & $4.66 \pm 2.95 \mathrm{E}-09$ & $3.61 \pm 4.92 \mathrm{E}-09$ & $1.81 \pm 0.81 \mathrm{E}-07$ \\
\hline 1007 & DOWN(3) & 6.97 & 1,246 & $1.32 \pm 3.39 \mathrm{E}-09$ & $5.12 \pm 5.09 \mathrm{E}-09$ & $-5.73 \pm 8.05 \mathrm{E}-08$ \\
\hline NDATR & DOWN(1) & 8.13 & 885 & $3.26 \pm 1.64 \mathrm{E}-09$ & $1.18 \pm 0.06 \mathrm{E}-07$ & $3.46 \pm 0.16 \mathrm{E}-06$ \\
\hline NDATR & DOWN(2) & 7.53 & 953 & $3.45 \pm 2.14 \mathrm{E}-09$ & $8.91 \pm 0.56 E-08$ & $1.07 \pm 0.04 \mathrm{E}-05$ \\
\hline NDATR & DOWN(3) & 7.78 & 856 & $1.70 \pm 2.08 \mathrm{E}-09$ & $1.78 \pm 0.07 E-07$ & $7.95 \pm 0.29 \mathrm{E}-06$ \\
\hline NDATR & DOWN(4) & 6.92 & 983 & $-0.16 \pm 2.48 \mathrm{E}-09$ & $1.52 \pm 0.07 \mathrm{E}-07$ & $2.38 \pm 0.13 E-06$ \\
\hline 909 & DOWN(1) & 6.81 & 1,296 & $0.96 \pm 2.10 \mathrm{E}-09$ & $3.84 \pm 0.16 \mathrm{E}-07$ & $7.39 \pm 0.94 \mathrm{E}-07$ \\
\hline 909 & DOWN(3) & 6.77 & 1,359 & $2.41 \pm 3.33 \mathrm{E}-09$ & $4.06 \pm 0.14 \mathrm{E}-07$ & $1.09 \pm 0.10 \mathrm{E}$ \\
\hline
\end{tabular}

Sample collection quarter is noted in parentheses next to hydraulic position. Hydraulic position is relative to other wells within the same hydrogeologic unit.

Note: Bolding convention applied to these data. (See p. E-2.)

WVDP Site Environmental Report

$E-12$

Calendar Year 2001 


\section{Table E-5 \\ 2001 Contamination Indicator and Radiological Indicator Results Unweathered Lavery Till Unit}

\begin{tabular}{|c|c|c|c|c|c|c|}
\hline $\begin{array}{l}\text { Location } \\
\text { Code }\end{array}$ & $\begin{array}{c}\text { Hydraulic } \\
\text { Position }\end{array}$ & $\begin{array}{c}\mathbf{p H} \\
\text { (standard units) }\end{array}$ & $\begin{array}{c}\text { Conductivity } \\
\left(\mu \mathrm{mhos} / \mathrm{cm} @ 25^{\circ} \mathrm{C}\right)\end{array}$ & $\begin{array}{l}\text { Gross Alpha } \\
\quad(\mu \mathrm{Ci} / \mathrm{mL})\end{array}$ & $\begin{array}{c}\text { Gross Beta } \\
(\mu \mathrm{Ci} / \mathrm{mL})\end{array}$ & $\begin{array}{l}\text { Tritium } \\
(\mu \mathrm{Ci} / \mathrm{mL})\end{array}$ \\
\hline 405 & $\mathrm{UP}(1)$ & 7.35 & 728 & $0.55 \pm 2.00 \mathrm{E}-09$ & $8.18 \pm 3.50 \mathrm{E}-09$ & $-0.23 \pm 8.15 \mathrm{E}-08$ \\
\hline 405 & $\mathrm{UP}(2)$ & 7.59 & 1,165 & $0.00 \pm 2.15 \mathrm{E}-09$ & $6.69 \pm 3.70 \mathrm{E}-09$ & $1.56 \pm 0.83 E-07$ \\
\hline 405 & $\mathrm{UP}(3)$ & 7.34 & 966 & $0.60 \pm 1.93 \mathrm{E}-09$ & $1.77 \pm 3.66 \mathrm{E}-09$ & $-1.44 \pm 0.81 \mathrm{E}-07$ \\
\hline 405 & $\mathrm{UP}(4)$ & 6.99 & 2,000 & $1.26 \pm 5.10 \mathrm{E}-09$ & $4.47 \pm 4.17 \mathrm{E}-09$ & $-1.46 \pm 0.82 \mathrm{E}-07$ \\
\hline 110 & $\operatorname{DOWN}(1)$ & 7.56 & 566 & $1.20 \pm 1.45 \mathrm{E}-09$ & $7.92 \pm 2.17 \mathrm{E}-09$ & $1.36 \pm 0.10 \mathrm{E}-06$ \\
\hline 110 & $\operatorname{DOWN}(2)$ & 7.58 & 534 & $1.66 \pm 1.42 \mathrm{E}-09$ & $2.89 \pm 1.58 \mathrm{E}-09$ & $1.38 \pm 0.10 \mathrm{E}-06$ \\
\hline 110 & DOWN(3) & 7.63 & 558 & $0.17 \pm 1.29 \mathrm{E}-09$ & $3.19 \pm 1.98 \mathrm{E}-09$ & $1.34 \pm 0.10 E-06$ \\
\hline 110 & DOWN(4) & 7.46 & 548 & $0.83 \pm 1.34 \mathrm{E}-09$ & $4.20 \pm 1.93 \mathrm{E}-09$ & $1.35 \pm 0.11 \mathrm{E}-06$ \\
\hline 704 & $\operatorname{DOWN}(1)$ & 6.75 & 866 & $1.04 \pm 1.72 \mathrm{E}-09$ & $1.13 \pm 0.36 \mathrm{E}-08$ & $2.60 \pm 8.22 \mathrm{E}-08$ \\
\hline 704 & $\operatorname{DOWN}(2)$ & 6.73 & 875 & $1.17 \pm 1.39 \mathrm{E}-09$ & $8.91 \pm 2.00 \mathrm{E}-09$ & $-3.90 \pm 7.10 \mathrm{E}-08$ \\
\hline 704 & $\operatorname{DOWN}(3)$ & 6.49 & 1,000 & $0.37 \pm 2.14 \mathrm{E}-09$ & $1.08 \pm 0.29 \mathrm{E}-08$ & $-1.41 \pm 0.82 \mathrm{E}-07$ \\
\hline 704 & DOWN(4) & 6.63 & 1,112 & $0.17 \pm 2.23 \mathrm{E}-09$ & $1.02 \pm 0.29 \mathrm{E}-08$ & $0.74 \pm 8.22 \mathrm{E}-08$ \\
\hline 707 & $\operatorname{DOWN}(1)$ & 6.99 & 424 & $0.52 \pm 1.06 \mathrm{E}-09$ & $3.01 \pm 1.86 \mathrm{E}-09$ & $-1.12 \pm 0.83 \mathrm{E}-07$ \\
\hline 707 & $\operatorname{DOWN}(2)$ & 6.60 & 1,118 & $-0.11 \pm 1.47 \mathrm{E}-09$ & $9.84 \pm 1.80 \mathrm{E}-09$ & $-6.15 \pm 7.04 \mathrm{E}-08$ \\
\hline 707 & DOWN(3) & 6.68 & 933 & $0.14 \pm 2.08 \mathrm{E}-09$ & $2.85 \pm 2.04 E-09$ & $-6.19 \pm 8.26 \mathrm{E}-08$ \\
\hline 707 & DOWN(4) & 6.91 & 936 & $1.98 \pm 2.02 \mathrm{E}-09$ & $5.58 \pm 2.10 \mathrm{E}-09$ & $-1.55 \pm 5.89 \mathrm{E}-08$ \\
\hline 107 & $\operatorname{DOWN}(1)$ & 7.24 & 784 & $0.80 \pm 1.13 \mathrm{E}-09$ & $5.71 \pm 1.47 \mathrm{E}-09$ & $9.53 \pm 0.66 E-07$ \\
\hline 107 & $\operatorname{DOWN}(2)$ & 7.41 & 729 & $0.59 \pm 1.14 \mathrm{E}-09$ & $2.42 \pm 1.35 \mathrm{E}-09$ & $7.36 \pm 0.89 \mathrm{E}-07$ \\
\hline 107 & $\operatorname{DOWN}(3)$ & 7.46 & 752 & $0.67 \pm 1.71 \mathrm{E}-09$ & $4.39 \pm 2.09 \mathrm{E}-09$ & $6.80 \pm 0.88 E-07$ \\
\hline 107 & DOWN(4) & 7.10 & 838 & $2.07 \pm 1.45 E-09$ & $5.75 \pm 1.48 \mathrm{E}-09$ & $9.51 \pm 0.95 \mathrm{E}-07$ \\
\hline 108 & $\operatorname{DOWN}(1)$ & 7.61 & 588 & $1.46 \pm 1.40 \mathrm{E}-09$ & $3.99 \pm 1.94 \mathrm{E}-09$ & $-0.50 \pm 8.02 \mathrm{E}-08$ \\
\hline 108 & $\operatorname{DOWN}(2)$ & 7.64 & 569 & $1.50 \pm 1.34 \mathrm{E}-09$ & $2.68 \pm 1.56 \mathrm{E}-09$ & $1.04 \pm 0.81 E-07$ \\
\hline 108 & DOWN(3) & 7.70 & 596 & $1.18 \pm 1.30 \mathrm{E}-09$ & $2.24 \pm 1.91 \mathrm{E}-09$ & $9.04 \pm 8.09 \mathrm{E}-08$ \\
\hline 108 & DOWN(4) & 7.63 & 508 & $1.40 \pm 1.28 \mathrm{E}-09$ & $1.44 \pm 1.75 \mathrm{E}-09$ & $7.12 \pm 8.33 \mathrm{E}-08$ \\
\hline 409 & $\operatorname{DOWN}(1)$ & 7.78 & 376 & $4.79 \pm 8.65 \mathrm{E}-10$ & $3.04 \pm 1.32 \mathrm{E}-09$ & $-4.28 \pm 8.02 \mathrm{E}-08$ \\
\hline 409 & $\operatorname{DOWN}(2)$ & 8.03 & 364 & $1.08 \pm 0.92 \mathrm{E}-09$ & $3.48 \pm 1.35 \mathrm{E}-09$ & $-1.03 \pm 0.77 \mathrm{E}-07$ \\
\hline 409 & $\operatorname{DOWN}(3)$ & 7.97 & 352 & $8.54 \pm 8.63 \mathrm{E}-10$ & $2.57 \pm 1.26 \mathrm{E}-09$ & $-1.71 \pm 0.81 \mathrm{E}-07$ \\
\hline 409 & DOWN(4) & 8.15 & 347 & $1.30 \pm 0.99 \mathrm{E}-09$ & $2.41 \pm 1.26 \mathrm{E}-09$ & $-5.29 \pm 8.06 \mathrm{E}-08$ \\
\hline 910 & $\operatorname{DOWN}(1)$ & 7.59 & 1,368 & $3.45 \pm 2.54 \mathrm{E}-09$ & $2.33 \pm 0.43 \mathrm{E}-08$ & $-2.43 \pm 0.81 \mathrm{E}-07$ \\
\hline 910 & $\operatorname{DOWN}(3)$ & 7.27 & 1,304 & $3.20 \pm 2.99 \mathrm{E}-09$ & $1.90 \pm 0.46 \mathrm{E}-08$ & $-1.39 \pm 0.80 \mathrm{E}-07$ \\
\hline
\end{tabular}

Sample collection quarter is noted in parentheses next to hydraulic position. Hydraulic position is relative to other wells within the same hydrogeologic unit.

Note: Bolding convention applied to these data. (See p. E-2.)

$$
\text { E- } 13
$$


Table E-6

2001 Contamination Indicator and Radiological Indicator Results Kent Recessional Sequence

$\begin{array}{ccccccc}\begin{array}{c}\text { Location } \\ \text { Code }\end{array} & \begin{array}{c}\text { Hydraulic } \\ \text { Position }\end{array} & \begin{array}{c}\text { pH } \\ (\text { standard units })\end{array} & \begin{array}{c}\text { Conductivity } \\ \left(\mu \mathrm{mhos} / \mathrm{cm} @ 25^{\circ} \mathrm{C}\right)\end{array} & \begin{array}{c}\text { Gross Alpha } \\ (\mu \mathrm{Ci} / \mathrm{mL})\end{array} & \begin{array}{c}\text { Gross Beta } \\ (\mu \mathrm{Ci} / \mathrm{mL})\end{array} & \begin{array}{c}\text { Tritium } \\ (\mu \mathrm{Ci} / \mathrm{mL})\end{array} \\ 901 & \text { UP(1) } & 7.63 & 382 & 4.22 \pm 9.66 \mathrm{E}-10 & 3.50 \pm 1.56 \mathrm{E}-09 & -1.79 \pm 0.81 \mathrm{E}-07 \\ 901 & \text { UP(3) } & 7.56 & 371 & 7.77 \pm 7.68 \mathrm{E}-10 & 2.79 \pm 1.12 \mathrm{E}-09 & -1.18 \pm 0.57 \mathrm{E}-07 \\ 902 & \text { UP(1) } & 7.86 & 456 & 1.44 \pm 1.27 \mathrm{E}-09 & 3.78 \pm 1.92 \mathrm{E}-09 & -2.02 \pm 0.81 \mathrm{E}-07 \\ 902 & \text { UP(3) } & 8.02 & 438 & 1.46 \pm 1.19 \mathrm{E}-09 & 1.46 \pm 1.30 \mathrm{E}-09 & -8.81 \pm 8.20 \mathrm{E}-08 \\ 1008 \mathrm{~B} & \text { UP(1) } & 7.77 & 397 & 7.18 \pm 6.53 \mathrm{E}-10 & 3.77 \pm 0.96 \mathrm{E}-09 & -2.14 \pm 7.79 \mathrm{E}-08 \\ 1008 \mathrm{~B} & \text { UP(3) } & 7.67 & 383 & 4.76 \pm 9.31 \mathrm{E}-10 & 1.06 \pm 1.27 \mathrm{E}-09 & -1.39 \pm 0.79 \mathrm{E}-07 \\ 903 & \text { DOWN(1) } & 7.54 & 932 & 0.49 \pm 1.93 \mathrm{E}-09 & 0.94 \pm 2.36 \mathrm{E}-09 & -2.20 \pm 0.81 \mathrm{E}-07 \\ 903 & \text { DOWN(3) } & 7.55 & 886 & 1.00 \pm 2.01 \mathrm{E}-09 & 2.44 \pm 2.42 \mathrm{E}-09 & -1.00 \pm 0.82 \mathrm{E}-07 \\ 8610 & \text { DOWN(1) } & 7.74 & 1,090 & 0.90 \pm 2.07 \mathrm{E}-09 & 4.64 \pm 2.60 \mathrm{E}-09 & -1.85 \pm 0.81 \mathrm{E}-07 \\ 8610 & \text { DOWN(3) } & 7.55 & 870 & 1.16 \pm 1.61 \mathrm{E}-09 & 3.61 \pm 2.62 \mathrm{E}-09 & -1.38 \pm 0.81 \mathrm{E}-07 \\ 8611 & \text { DOWN(1) } & 7.64 & 971 & 1.90 \pm 1.54 \mathrm{E}-09 & 2.73 \pm 2.54 \mathrm{E}-09 & -1.76 \pm 0.81 \mathrm{E}-07 \\ 8611 & \text { DOWN(3) } & 7.56 & 907 & 1.93 \pm 1.98 \mathrm{E}-09 & -0.61 \pm 2.42 \mathrm{E}-09 & -1.09 \pm 0.56 \mathrm{E}-07\end{array}$

\section{Table E-7}

\section{Contamination Indicator and Radiological Indicator Results North Plateau Seep Monitoring Locations}

$\begin{array}{ccccccc}\begin{array}{c}\text { Location } \\ \text { Code }\end{array} & \begin{array}{c}\text { Hydraulic } \\ \text { Position }\end{array} & \begin{array}{c}\text { pH } \\ (\text { standard units })\end{array} & \begin{array}{c}\text { Conductivity } \\ \left(\mu \mathrm{mhos} / \mathrm{cm} @ 25^{\circ} \mathrm{C}\right)\end{array} & \begin{array}{c}\text { Gross Alpha } \\ (\mu \mathrm{Ci} / \mathrm{mL})\end{array} & \begin{array}{c}\text { Gross Beta } \\ (\mu \mathrm{Ci} / \mathrm{mL})\end{array} & \begin{array}{c}\text { Tritium } \\ (\mu \mathrm{Ci} / \mathrm{mL})\end{array} \\ & & & & & & \\ \text { GSEEP } & \text { DOWN(1) } & \mathbf{6 . 6 3} & 1,006 & 0.68 \pm 1.53 \mathrm{E}-09 & \mathbf{9 . 4 1} \pm \mathbf{2 . 5 8 E}-\mathbf{0 9} & 6.39 \pm 0.87 \mathrm{E}-07 \\ \text { GSEEP } & \text { DOWN(2) } & \mathbf{6 . 8 5} & \mathbf{8 6 8} & 0.55 \pm 1.58 \mathrm{E}-09 & \mathbf{5 . 7 9} \pm \mathbf{2 . 5 5 E}-\mathbf{0 9} & \mathbf{4 . 1 4 \pm 0 . 8 7 E - 0 7} \\ \text { GSEEP } & \text { DOWN(3) } & 6.67 & 1,094 & \mathbf{2 . 9 8} \pm 2.47 \mathrm{E}-\mathbf{0 9} & 6.15 \pm 2.81 \mathrm{E}-09 & 5.21 \pm 0.89 \mathrm{E}-07 \\ \text { GSEEP } & \text { DOWN(4) } & 6.65 & \mathbf{1 , 1 8 0} & -0.18 \pm 2.83 \mathrm{E}-09 & 5.90 \pm 2.92 \mathrm{E}-09 & \mathbf{8 . 0 8} \pm \mathbf{0 . 6 3 E}-\mathbf{0 7} \\ \text { SP04 } & \text { DOWN(1) } & \text { NS } & \text { NS } & 0.97 \pm 1.30 \mathrm{E}-09 & 2.73 \pm 2.53 \mathrm{E}-09 & 4.84 \pm 0.85 \mathrm{E}-07 \\ \text { SP04 } & \text { DOWN(3) } & \text { NS } & \text { NS } & 0.69 \pm 1.60 \mathrm{E}-09 & 6.92 \pm 1.93 \mathrm{E}-09 & 2.71 \pm 0.85 \mathrm{E}-07 \\ \text { SP06 } & \text { DOWN(1) } & \text { NS } & \text { NS } & -0.44 \pm 1.07 \mathrm{E}-09 & 1.84 \pm 1.80 \mathrm{E}-09 & 3.00 \pm 0.83 \mathrm{E}-07 \\ \text { SP06 } & \text { DOWN(3) } & \text { NS } & \text { NS } & 0.28 \pm 1.59 \mathrm{E}-09 & 2.75 \pm 1.89 \mathrm{E}-09 & 1.82 \pm 0.84 \mathrm{E}-07 \\ \text { SP11 } & \text { DOWN(1) } & \text { NS } & \text { NS } & 1.09 \pm 1.66 \mathrm{E}-09 & 1.57 \pm 0.44 \mathrm{E}-08 & 3.22 \pm 0.82 \mathrm{E}-07 \\ \text { SP11 } & \text { DOWN(3) } & \text { NS } & \text { NS } & -0.88 \pm 2.27 \mathrm{E}-09 & 2.67 \pm 0.48 \mathrm{E}-08 & 1.64 \pm 0.83 \mathrm{E}-07 \\ \text { SP12 } & \text { DOWN(1) } & 7.11 & 1,005 & -0.08 \pm 1.56 \mathrm{E}-09 & 3.78 \pm 2.28 \mathrm{E}-09 & 4.26 \pm 0.87 \mathrm{E}-07 \\ \text { SP12 } & \text { DOWN(3) } & 7.03 & 1,028 & 2.30 \pm 2.35 \mathrm{E}-09 & 0.41 \pm 2.66 \mathrm{E}-09 & 2.98 \pm 0.87 \mathrm{E}-07\end{array}$

NS - Not sampled.

Sample collection quarter is noted in parentheses next to hydraulic position. Hydraulic position is relative to other wells within the same hydrogeologic unit.

Note: Bolding convention applied to these data. (See p. E-2.)

WVDP Site Environmental Report

E - 14

Calendar Year 2001 
Table E-8

2001 Contamination Indicator and Radiological Indicator Results North Plateau Well Points

$\begin{array}{ccccccc}\begin{array}{c}\text { Location } \\ \text { Code }\end{array} & \begin{array}{c}\text { Hydraulic } \\ \text { Position }\end{array} & \begin{array}{c}\text { pH } \\ (\text { standard units })\end{array} & \begin{array}{c}\text { Conductivity } \\ \left(\mu \mathrm{mhos} / \mathrm{cm} @ 25^{\circ} \mathrm{C}\right)\end{array} & \begin{array}{c}\text { Gross Alpha } \\ (\mu \mathrm{Ci} / \mathrm{mL})\end{array} & \begin{array}{c}\text { Gross Beta } \\ (\mu \mathrm{Ci} / \mathrm{mL})\end{array} & \begin{array}{c}\text { Tritium } \\ (\mu \mathrm{Ci} / \mathrm{mL})\end{array} \\ \text { WP-A } & \text { DOWN(4) } & 8.41 & 89 & 0.42 \pm 2.83 \mathrm{E}-10 & 4.83 \pm 0.21 \mathrm{E}-08 & 1.12 \pm 0.04 \mathrm{E}-05 \\ \text { WP-C } & \text { DOWN(4) } & 6.86 & 167 & 1.13 \pm 3.16 \mathrm{E}-10 & 1.54 \pm 0.13 \mathrm{E}-08 & 5.70 \pm 0.17 \mathrm{E}-05 \\ \text { WP-H } & \text { DOWN(4) } & 6.74 & 1,142 & 2.66 \pm 1.89 \mathrm{E}-09 & 9.07 \pm 0.04 \mathrm{E}-06 & 6.80 \pm 0.25 \mathrm{E}-06\end{array}$

Table E-9

2001 Detections of Volatile Organic Compounds at Selected Groundwater Monitoring Locations

$\begin{array}{ccccccccc}\begin{array}{c}\text { Location } \\ \text { Code }\end{array} & \begin{array}{c}\text { Sampling } \\ \text { Quarter }\end{array} & \begin{array}{c}\mathbf{1 , 1 - D C A} \\ (\mu \mathrm{g} / \mathrm{L})\end{array} & \begin{array}{c}\text { DCDFMeth } \\ (\mu \mathrm{g} / \mathrm{L})\end{array} & \begin{array}{c}\mathbf{1 , 1 - D C E} \\ (\mu \mathrm{g} / \mathrm{L})\end{array} & \begin{array}{c}\mathbf{1 , 2}-\mathrm{DCE}(\text { total }) \\ (\mu \mathrm{g} / \mathrm{L})\end{array} & \begin{array}{c}\mathbf{1 , 2}-\mathbf{D C E}(\operatorname{trans}) \\ (\mu \mathrm{g} / \mathrm{L})\end{array} & \begin{array}{c}\mathbf{1 , 1 , 1 - T C A} \\ (\mu \mathrm{g} / \mathrm{L})\end{array} & \begin{array}{c}\text { TCE } \\ (\mu \mathrm{g} / \mathrm{L})\end{array} \\ \mathrm{SP} 12 & 1 & <5.0^{*} & <5.0^{*} & <5.0 & \mathrm{NS} & <5.0 & <5.0 & <5.0 \\ & 3 & <5.0^{*} & <5.0^{*} & <5.0 & \mathrm{NS} & <1.0 & <5.0 & <5.0 \\ & & & & & & & & \\ 803 & 1 & <5.0^{*} & <5.0^{*} & <5.0 & \mathrm{NS} & <5.0 & <5.0 & <5.0 \\ & 2 & \mathbf{0 . 5} & \mathbf{0 . 9} & <5.0 & \mathrm{NS} & <5.0 & <5.0 & <5.0 \\ & 3 & <5.0^{*} & <5.0^{*} & <5.0 & \mathrm{NS} & <1.0 & <5.0 & <5.0 \\ & 4 & <5.0^{*} & <5.0^{*} & <5.0 & \mathrm{NS} & <1.0 & <5.0 & <5.0 \\ & & & & & & & & \\ 8609 & 1 & <5.0^{*} & <1.0 & <5.0 & \mathrm{NS} & <5.0 & <5.0^{*} & <5.0 \\ & & & & & & & & \\ 8612 & 1 & \mathbf{2 0 . 5} & \mathbf{5 . 2} & <5.0^{*} & \mathbf{3 0 . 3} & <5.0 & <5.0^{*} & <5.0 \\ & 2 & 15.0 & 3.4 & <5.0^{*} & \mathbf{2 6 . 0} & <5.0 & <5.0^{*} & <5.0 \\ & 3 & \mathbf{1 4 . 5} & \mathbf{2 . 9} & \mathbf{0 . 4 5} & \mathbf{2 6 . 0} & <1.0 & \mathbf{2 . 2} & <5.0 \\ & 4 & 16.0 & 3.5 & <5.0^{*} & 29.5 & \mathbf{1 . 4} & <5.0^{*} & <5.0\end{array}$

NS - Not sampled.

* Compound was reported at an estimated concentration less than the practical quantitation limit.

Sample collection quarter is noted in parentheses next to hydraulic position. Hydraulic position is relative to other wells within the same hydrogeologic unit.

Note: Bolding convention applied to these data. (See p. E-2.)

WVDP Site Environmental Report

$$
\text { E- } 15
$$

Calendar Year 2001 


\section{Table E-10 \\ 2001 Tributyl Phosphate Sampling Results at Selected Groundwater Monitoring Locations}

$\begin{array}{ccc}\begin{array}{c}\text { Location } \\ \text { Code }\end{array} & \begin{array}{c}\text { Sampling } \\ \text { Quarter }\end{array} & \begin{array}{c}\text { Tributyl phosphate (TBP) } \\ (\mu \mathrm{g} / \mathrm{L})\end{array} \\ 111 & 1 & <10.0^{*} \\ & 3 & 16.0 \\ 8605 & 1 & 130 \\ & 3 & 220\end{array}$

Practical quantitation limit is $10 \mu \mathrm{g} / \mathrm{L}$.

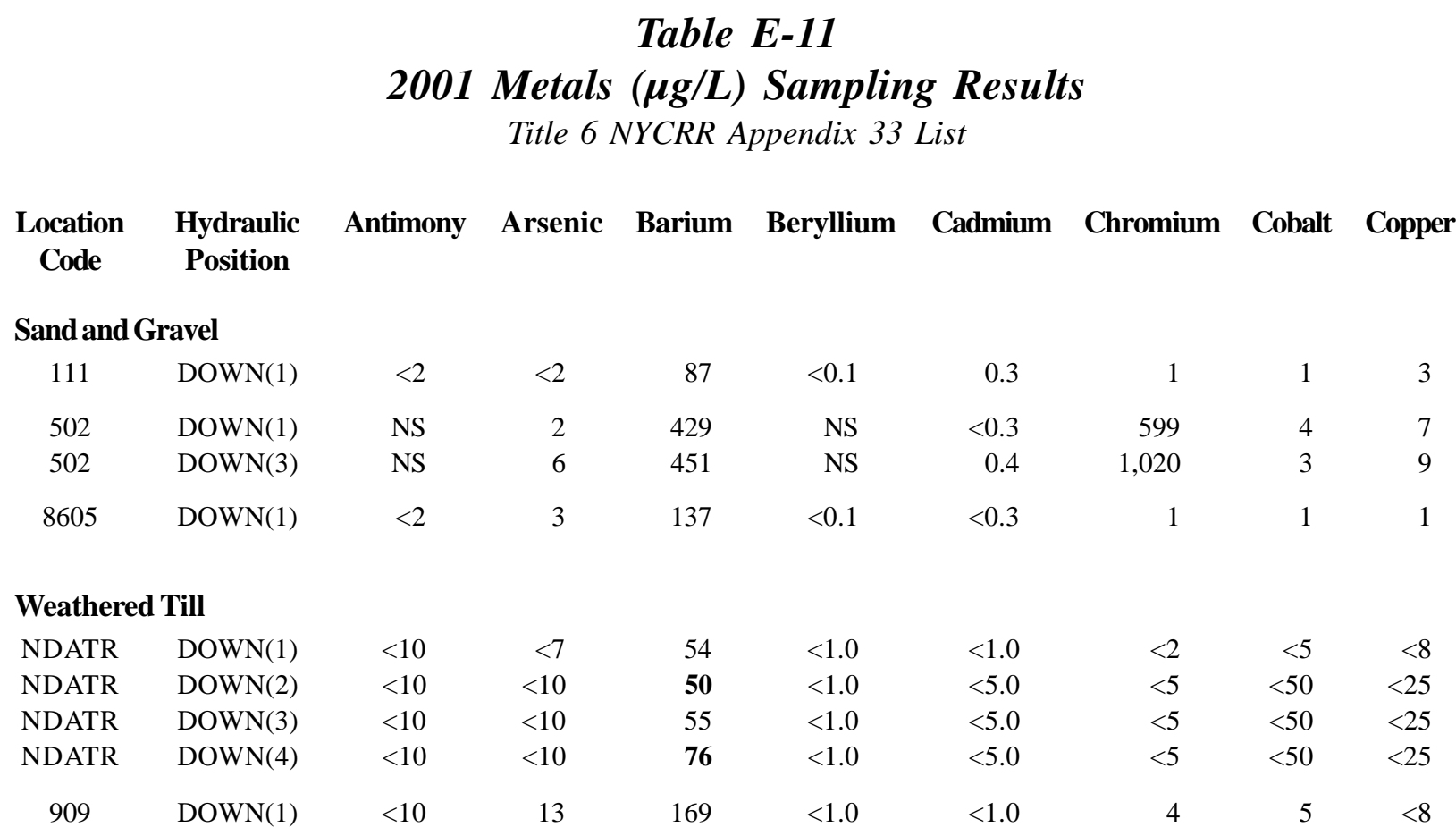

NS - Not sampled.

* Compound was reported at an estimated concentration less than the practical quantitation limit.

Sample collection quarter is noted in parentheses next to hydraulic position. Hydraulic position is relative to other wells within the same hydrogeologic unit.

Note: Bolding convention applied to these data. (See p. E-2.)

WVDP Site Environmental Report

E - 16

Calendar Year 2001 


\section{Table E-11 (concluded)

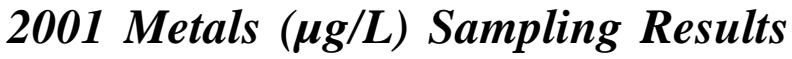 \\ Title 6 NYCRR Appendix 33 List}

\begin{tabular}{|c|c|c|c|c|c|c|c|c|c|c|}
\hline $\begin{array}{c}\text { Location } \\
\text { Code }\end{array}$ & $\begin{array}{l}\text { Hydraulic } \\
\text { Position }\end{array}$ & Lead & Mercury & Nickel & Selenium & Silver & Thallium & Tin & Vanadium & Zinc \\
\hline \multicolumn{11}{|c|}{ Sand and Gravel } \\
\hline 111 & DOWN(1) & $<2$ & $<0.1$ & 4 & $<3$ & $<1$ & $<4$ & $<3$ & $<1$ & 7 \\
\hline 502 & DOWN(1) & 2 & $<0.1$ & 44 & $<3$ & $<1$ & NS & NS & 2 & 6 \\
\hline 502 & DOWN(3) & $<3$ & $<0.1$ & 34 & $<2$ & $<1$ & NS & NS & 3 & 7 \\
\hline 8605 & DOWN(1) & $<2$ & $<0.1$ & 2 & $<3$ & $<1$ & $<4$ & $<3$ & $<1$ & 12 \\
\hline \multicolumn{11}{|c|}{ Weathered Till } \\
\hline NDATR & DOWN(1) & $<3$ & $<0.1$ & $<10$ & $<5$ & $<3$ & $<6$ & $<5$ & $<5$ & $<20$ \\
\hline NDATR & DOWN(2) & $<3$ & $<0.2$ & $<40$ & $<5$ & $<10$ & $<10$ & $<3,000$ & $<50$ & $<20$ \\
\hline NDATR & DOWN(3) & $<3$ & $<0.2$ & $<40$ & $<5$ & $<10$ & $<10$ & $<3,000$ & $<50$ & $<20$ \\
\hline NDATR & DOWN(4) & $<3$ & $<0.2$ & $<40$ & $<5$ & $<10$ & $<10$ & $<3,000$ & $<50$ & $<20$ \\
\hline 909 & DOWN(1) & 6 & $<0.1$ & 12 & $<5$ & $<3$ & $<6$ & $<5$ & $<5$ & 62 \\
\hline
\end{tabular}

Table E-12

2001 Sampling Parameters at Early Warning Monitoring Wells $(\mu g / L)$

$\begin{array}{ccccc}\begin{array}{c}\text { Location } \\ \text { Code }\end{array} & \begin{array}{c}\text { Sample } \\ \text { Quarter }\end{array} & \begin{array}{c}\text { Aluminum } \\ \text { Total }\end{array} & \begin{array}{c}\text { Iron } \\ \text { Total }\end{array} & \begin{array}{c}\text { Manganese } \\ \text { Total }\end{array} \\ 502 & (1) & 69.6 & 6,290 & 33.0 \\ & (3) & 104 & 9,640 & 23.7\end{array}$

NS - Not sampled.

Sample collection quarter is noted in parentheses next to hydraulic position. Hydraulic position is relative to other wells within the same hydrogeologic unit.

Note: Bolding convention applied to these data. (See p. E-2.)

WVDP Site Environmental Report

$$
E-17
$$

Calendar Year 2001 


\section{Table E-13 \\ 2001 Alpha-, Beta-, and Gamma-Emitting Radioisotopic Results ( $\mu$ Ci/mL) for Selected Groundwater Monitoring Locations}

\begin{tabular}{|c|c|c|c|c|}
\hline $\begin{array}{c}\text { Location } \\
\text { Code }\end{array}$ & $\begin{array}{l}\text { Hydraulic } \\
\text { Position }\end{array}$ & C-14 & Sr-90 & Tc-99 \\
\hline \multicolumn{5}{|c|}{ Sand and Gravel } \\
\hline 401 & $\mathrm{UP}(1)$ & $0.88 \pm 2.44 \mathrm{E}-08$ & $2.23 \pm 1.49 \mathrm{E}-09$ & $0.19 \pm 1.45 \mathrm{E}-09$ \\
\hline 111 & DOWN(1) & NS & $2.90 \pm 0.05 \mathrm{E}-06$ & NS \\
\hline 406 & DOWN(1) & $2.72 \pm 2.64 \mathrm{E}-08$ & $1.44 \pm 1.43 \mathrm{E}-09$ & $8.50 \pm 2.60 \mathrm{E}-09$ \\
\hline 408 & DOWN(1) & $-0.16 \pm 2.40 \mathrm{E}-08$ & $2.15 \pm 0.01 \mathrm{E}-04$ & $2.35 \pm 0.37 \mathrm{E}-08$ \\
\hline 501 & DOWN(1) & NS & $1.33 \pm 0.01 \mathrm{E}-04$ & NS \\
\hline 502 & DOWN(1) & NS & $1.05 \pm 0.01 \mathrm{E}-04$ & NS \\
\hline $602 \mathrm{~A}$ & DOWN(1) & NS & $5.98 \pm 1.88 \mathrm{E}-09$ & NS \\
\hline $602 \mathrm{~A}$ & DOWN(3) & NS & $9.48 \pm 2.22 \mathrm{E}-09$ & NS \\
\hline 8605 & DOWN(1) & NS & $5.59 \pm 0.06 \mathrm{E}-06$ & NS \\
\hline 8609 & DOWN(1) & NS & $4.41 \pm 0.14 \mathrm{E}-07$ & NS \\
\hline 8609 & DOWN(3) & NS & $5.04 \pm 0.14 \mathrm{E}-07$ & NS \\
\hline 116 & DOWN(1) & NS & $1.64 \pm 0.08 \mathrm{E}-07$ & NS \\
\hline 116 & DOWN(3) & NS & $1.56 \pm 0.08 \mathrm{E}-07$ & NS \\
\hline 605 & DOWN(1) & NS & $2.70 \pm 0.32 \mathrm{E}-08$ & NS \\
\hline 605 & DOWN(3) & NS & $2.94 \pm 0.47 \mathrm{E}-08$ & NS \\
\hline 801 & DOWN(1) & NS & $3.35 \pm 0.03 \mathrm{E}-06$ & NS \\
\hline 801 & DOWN(2) & NS & $6.24 \pm 0.06 \mathrm{E}-06$ & NS \\
\hline 801 & DOWN(3) & NS & $5.59 \pm 0.07 \mathrm{E}-06$ & NS \\
\hline 801 & DOWN(4) & NS & $5.09 \pm 0.06 \mathrm{E}-06$ & NS \\
\hline 8603 & DOWN(1) & NS & $1.14 \pm 0.01 \mathrm{E}-05$ & NS \\
\hline 8603 & DOWN(3) & NS & $1.28 \pm 0.01 \mathrm{E}-05$ & NS \\
\hline \multicolumn{5}{|c|}{ Weathered Till } \\
\hline NDATR & DOWN(1) & $0.00 \pm 2.41 \mathrm{E}-08$ & $5.50 \pm 0.52 \mathrm{E}-08$ & $-1.14 \pm 2.00 \mathrm{E}-09$ \\
\hline NDATR & DOWN(3) & $-0.16 \pm 1.46 \mathrm{E}-08$ & $7.62 \pm 0.57 \mathrm{E}-08$ & $-0.38 \pm 1.36 \mathrm{E}-09$ \\
\hline 909 & DOWN(1) & $1.86 \pm 2.49 \mathrm{E}-08$ & $1.79 \pm 0.10 \mathrm{E}-07$ & $-0.06 \pm 1.69 \mathrm{E}-09$ \\
\hline
\end{tabular}

NS - Not sampled.

Sample collection quarter is noted in parentheses next to hydraulic position. Hydraulic position is relative to other wells within the same hydrogeologic unit.

Note: Bolding convention applied to these data. (See p. E-2.)

WVDP Site Environmental Report

$E-18$

Calendar Year 2001 


\section{Table E-13 (concluded) \\ 2001 Alpha-, Beta-, and Gamma-Emitting Radioisotopic Results ( $\mu \mathrm{Ci} / \mathrm{mL})$}

\begin{tabular}{ccccccc}
$\begin{array}{c}\text { Location } \\
\text { Code }\end{array}$ & $\begin{array}{c}\text { Hydraulic } \\
\text { Position }\end{array}$ & I-129 & Cs-137 & Ra-226 & Ra-228 & U-232 \\
\multicolumn{2}{c}{ Sand and Gravel } & & & & & \\
401 & UP(1) & $0.01 \pm 4.11 \mathrm{E}-10$ & $1.23 \pm 1.43 \mathrm{E}-08$ & $-1.50 \pm 1.47 \mathrm{E}-10$ & $-0.01 \pm 3.79 \mathrm{E}-10$ & $2.16 \pm 3.19 \mathrm{E}-10$ \\
406 & DOWN(1) & $-0.92 \pm 6.99 \mathrm{E}-10$ & $-0.95 \pm 8.48 \mathrm{E}-09$ & $4.78 \pm 2.99 \mathrm{E}-10$ & $2.06 \pm 4.43 \mathrm{E}-10$ & $-4.27 \pm 1.06 \mathrm{E}-12$ \\
408 & DOWN(1) & $0.58 \pm 1.48 \mathrm{E}-09$ & $1.13 \pm 3.46 \mathrm{E}-09$ & $7.82 \pm 3.91 \mathrm{E}-10$ & $8.00 \pm 0.81 \mathrm{E}-09$ & $3.52 \pm 5.33 \mathrm{E}-10$
\end{tabular}

\section{Weathered Till}

$\begin{array}{ccccccr}\text { NDATR } & \text { DOWN(1) } & 0.00 \pm 3.22 \mathrm{E}-10 & -1.19 \pm 6.45 \mathrm{E}-09 & 5.50 \pm 3.11 \mathrm{E}-10 & -3.96 \pm 5.38 \mathrm{E}-10 & -5.14 \pm 1.08 \mathrm{E}-11 \\ \text { NDATR } & \text { DOWN(3) } & 1.81 \pm 0.94 \mathrm{E}-09 & 2.35 \pm 4.43 \mathrm{E}-09 & 1.82 \pm 2.52 \mathrm{E}-10 & 7.79 \pm 4.53 \mathrm{E}-10 & 1.13 \pm 1.48 \mathrm{E}-10 \\ 909 & \text { DOWN(1) } & 6.21 \pm 1.78 \mathrm{E}-09 & 4.16 \pm 8.18 \mathrm{E}-09 & 5.62 \pm 3.52 \mathrm{E}-10 & 1.04 \pm 3.24 \mathrm{E}-10 & 0.73 \pm 2.96 \mathrm{E}-10\end{array}$

$\begin{array}{llll}\text { U-233/234 U-235/236 } & \text { U-238 } & \text { Total } U\end{array}$

$(\mu \mathrm{g} / \mathrm{mL})$

Sand and Gravel

$\begin{array}{lccccc}401 & \text { UP(1) } & 2.36 \pm 1.35 \mathrm{E}-10 & 1.39 \pm 6.24 \mathrm{E}-11 & 1.25 \pm 1.01 \mathrm{E}-10 & 2.95 \pm 0.06 \mathrm{E}-04 \\ 406 & \text { DOWN(1) } & 2.67 \pm 1.46 \mathrm{E}-10 & 1.57 \pm 7.04 \mathrm{E}-11 & 1.73 \pm 1.05 \mathrm{E}-10 & 3.25 \pm 0.16 \mathrm{E}-04 \\ 408 & \text { DOWN(1) } & 1.27 \pm 0.49 \mathrm{E}-09 & 3.11 \pm 2.31 \mathrm{E}-10 & 4.82 \pm 2.96 \mathrm{E}-10 & 8.17 \pm 0.11 \mathrm{E}-04\end{array}$

Weathered Till

$\begin{array}{cccccc}\text { NDATR } & \text { DOWN(1) } & 1.50 \pm 0.32 \mathrm{E}-09 & 1.09 \pm 0.86 \mathrm{E}-10 & 1.34 \pm 0.30 \mathrm{E}-09 & 3.21 \pm 0.05 \mathrm{E}-03 \\ \text { NDATR } & \text { DOWN(3) } & 1.41 \pm 0.31 \mathrm{E}-09 & 1.70 \pm 1.09 \mathrm{E}-10 & 1.37 \pm 0.30 \mathrm{E}-09 & 3.19 \pm 0.03 \mathrm{E}-03 \\ 909 & \text { DOWN(1) } & 8.20 \pm 2.39 \mathrm{E}-10 & 4.25 \pm 6.35 \mathrm{E}-11 & 4.95 \pm 1.78 \mathrm{E}-10 & 6.85 \pm 0.09 \mathrm{E}-04\end{array}$

Sample collection quarter is noted in parentheses next to hydraulic position. Hydraulic position is relative to other wells within the same hydrogeologic unit.

Note: Bolding convention applied to these data. (See p. E-2.)

WVDP Site Environmental Report

$$
E-19
$$

Calendar Year 2001 


\section{Table E-14 \\ Practical Quantitation Limits (PQLs)}

COMPOUND

NYCRR Appendix 33 Volatiles

$\begin{array}{lc}\text { Acetone } & 10 \\ \text { Acetonitrile } & 100 \\ \text { Acrolein } & 11 \\ \text { Acrylonitrile } & 5 \\ \text { Allyl chloride } & 5 \\ \text { Benzene } & 5 \\ \text { Bromodichloromethane } & 5 \\ \text { Bromoform } & 5 \\ \text { Bromomethane } & 10 \\ \text { Carbon disulfide } & 10 \\ \text { Carbon tetrachloride } & 5 \\ \text { Chlorobenzene } & 5 \\ \text { Chloroethane } & 10 \\ \text { Chloroform } & 5 \\ \text { Chloromethane } & 10 \\ \text { Chloroprene } & 5 \\ \text { 1,2-Dibromo-3-chloropropane } & 5 \\ \text { Dibromochloromethane } & 5 \\ \text { 1,2-Dibromoethane } & 5 \\ \text { Dichlorodifluoromethane } & 5 \\ \text { 1,1-Dichloroethane } & 5 \\ \text { 1,2-Dichloroethane } & 5 \\ \text { 1,1-Dichloroethylene } & 5 \\ \text { 1,2-Dichloropropane } & 5 \\ \text { Ethyl benzene } & 5 \\ \text { Ethyl methacrylate } & 5 \\ \text { 2-Hexanone } & 10\end{array}$

NYCRR Appendix 33 Metals

$\begin{array}{lc}\text { *Aluminum } & 200 \\ \text { Antimony } & 10 \\ \text { Arsenic } & 10 \\ \text { Barium } & 200 \\ \text { Beryllium } & 1 \\ \text { Cadmium } & 5 \\ \text { Chromium } & 10 \\ \text { Cobalt } & 50 \\ \text { Copper } & 25 \\ \text { *Iron } & 100\end{array}$

COMPOUND PQL

$(\mu g / L)$

NYCRR Appendix 33 Volatiles

Isobutyl alcohol $\quad 100$

Methacrylonitrile 5

Methyl ethyl ketone 10

Methyl iodide 5

Methyl methacrylate 5

4-Methyl-2-pentanone 10

Methylene bromide $\quad 10$

Methylene chloride 5

Pentachloroethane 5

Propionitrile 50

Styrene 5

1,1,1,2-Tetrachloroethane 5

1,1,2,2-Tetrachloroethane 5

Tetrachloroethylene 5

Toluene 5

1,1,1-Trichloroethane 5

1,1,2-Trichloroethane 5

1,2,3-Trichloropropane 5

Vinyl acetate $\quad 10$

Vinyl chloride $\quad 10$

Xylene (total) 5

cis-1,3-Dichloropropene 5

trans-1,2-Dichloroethylene 5

trans-1,3-Dichloropropene 5

trans-1,4-Dichloro-2-butene 5

Trichloroethylene 5

Trichlorofluoromethane 5

NYCRR Appendix 33 Metals

$\begin{array}{lc}\text { Lead } & 3 \\ \text { *Manganese } & 15 \\ \text { Mercury } & 0.2 \\ \text { Nickel } & 40 \\ \text { Selenium } & 5 \\ \text { Silver } & 10 \\ \text { Thallium } & 10 \\ \text { Tin } & 3,000 \\ \text { Vanadium } & 50 \\ \text { Zinc } & 20\end{array}$

Note: Specific quantitation limits are highly matrix-dependent and may not always be achievable.

* Not an NYCRR Appendix 33 parameter; sampled for the north plateau early warning program. 


\section{Table E-14 (continued) \\ Practical Quantitation Limits (PQLs)}

COMPOUND

NYCRR Appendix 33 Semivolatiles

Acenaphthene

Acenaphthylene

Acetophenone

2-Acetylaminofluorene 10

4-Aminobiphenyl 10

Aniline 10

Anthracene 10

Aramite 10

Benzo[a]anthracene 10

Benzo[a]pyrene 10

Benzo[b]fluoranthene 10

Benzo[ghi]perylene $\quad 10$

Benzo[k]fluoranthene 10

Benzyl alcohol 10

Bis(2-chlorethyl)ether 10

Bis(2-chloroethoxy)methane $\quad 10$

Bis(2-chloroisopropyl)ether $\quad 10$

Bis(2-ethylhexyl)phthalate $\quad 10$

4-Bromophenyl phenyl ether $\quad 10$

Butyl benzyl phthalate $\quad 10$

Chlorobenzilate 10

2-Chloronaphthalene 10

2-Chlorophenol 10

4-Chlorophenyl phenyl ether $\quad 10$

Chrysene 10

Di-n-butyl phthalate $\quad 10$

Di-n-octyl phthalate $\quad 10$

Diallate 10

Dibenz[a,h]anthracene $\quad 10$

Dibenzofuran 10

3,3-Dichlorobenzidine 10

2,4-Dichlorophenol 10

2,6-Dichlorophenol 10

Diethyl phthalate $\quad 10$

Dimethoate 10

7, 12-Dimethylbenz[a]anthracene $\quad 10$

3,3-Dimethylbenzidine 20

2,4-Dimethylphenol $\quad 10$

Dimethyl phthalate $\quad 10$

4,6-Dinitro-o-cresol 25

2,4-Dinitrophenol 25
COMPOUND PQL

$(\mu g / L)$

NYCRR Appendix 33 Semivolatiles

2,4-Dinitrotoluene 10

2,6-Dinitrotoluene 10

Diphenylamine 10

Ethyl methanesulfonate $\quad 10$

Famphur 10

Fluoranthene $\quad 10$

Fluorene 10

Hexachlorobenzene $\quad 10$

Hexachlorobutadiene $\quad 10$

Hexachlorocyclopentadiene $\quad 10$

Hexachloroethane 10

Hexachlorophene 100

Hexachloropropene $\quad 10$

Indeno(1,2,3,-cd)pyrene $\quad 10$

Isodrin 10

Isophorone 10

Isosafrole 10

Kepone 10

Methapyrilene $\quad 10$

Methyl methanesulfonate $\quad 10$

3-Methylcholanthrene 10

2-Methylnaphthalene 10

1,4-Naphthoquinone 10

1-Naphthylamine 10

2-Naphthylamine 10

Nitrobenzene 10

5-Nitro-o-toluidine 10

4-Nitroquinoline 1-oxide 40

N-Nitrosodi-n-butylamine $\quad 10$

N-Nitrosodiethylamine $\quad 10$

N-Nitrosodimethylamine $\quad 10$

N-Nitrosodipropylamine $\quad 10$

N-Nitrosodiphenylamine $\quad 10$

N-Nitrosomethylethylamine $\quad 10$

N-Nitrosomorpholine 10

N-Nitrosopiperidine 10

N-Nitrosopyrrolidine $\quad 10$

Naphthalene $\quad 10$

0,0,0-Triethyl phosphorothioate $\quad 10$

0,0-Diethyl 0-2-pyrazinyl-phosphorothioate 10

Note: Specific quantitation limits are highly matrix-dependent and may not always be achievable. 


\section{Table E-14 (concluded) \\ Practical Quantitation Limits (PQLs)}

$\begin{array}{ll}\text { COMPOUND } & \text { PQL } \\ (\mu g / L)\end{array}$

NYCRR Appendix 33 Semivolatiles

p-(Dimethylamino)azobenzene $\quad 10$

p-Chloroaniline 10

p-Chloro-m-cresol 10

p-Cresol 10

p-Dichlorobenzene 10

p-Nitroaniline 25

p-Nitrophenol 25

p-Phenylenediamine 10

Parathion 10

Pentachlorobenzene 10

Pentachloronitrobenzene $\quad 10$

Pentachlorophenol 25

Phenacetin 10

Phenanthrene 10

Phenol 10

Pronamide 10

Pyrene 10

Safrole 10

1,2,4,5-Tetrachlorobenzene $\quad 10$ $\begin{array}{ll}\text { COMPOUND } & \text { PQL } \\ (\mu g / L)\end{array}$

NYCRR Appendix 33 Semivolatiles

$\begin{array}{ll}\text { 2,3,4,6-Tetrachlorophenol } & 10 \\ \text { Tetraethyl dithiopyrophosphate } & 10 \\ \text { 1,2,4-Trichlorobenzene } & 10 \\ \text { 2,4,5-Trichlorophenol } & 25 \\ \text { 2,4,6-Trichlorophenol } & 10 \\ \text { alpha,alpha-Dimethylphenethylamine } & 50 \\ \text { m-Cresol } & 10 \\ \text { m-Dichlorobenzene } & 10 \\ \text { m-Dinitrobenzene } & 10 \\ \text { m-Nitroaniline } & 25 \\ \text { o-Cresol } & 10 \\ \text { o-Dichlorobenzene } & 10 \\ \text { o-Nitroaniline } & 25 \\ \text { o-Nitrophenol } & 10 \\ \text { o-Toluidine } & 10 \\ \text { sym-Trinitrobenzene } & 10 \\ \text { 2-Picoline } & 10 \\ \text { Pyridine } & 10 \\ \text { 1,4-Dioxane } & 10\end{array}$

Note: Specific quantitation limits are highly matrix-dependent and may not always be achievable.

$E-22$ 


\section{Groundwater Data Graphs}

Groundwater data for CY 2001 are presented in graphic format on the following pages.

The data point on the nonradiological graphs represents the average for the year and the bracket represents the high and low values for the year.

The graphed data points for the radiological analytes represent the averages for the year and the bracket represents the pooled (i.e., averaged) uncertainty. 


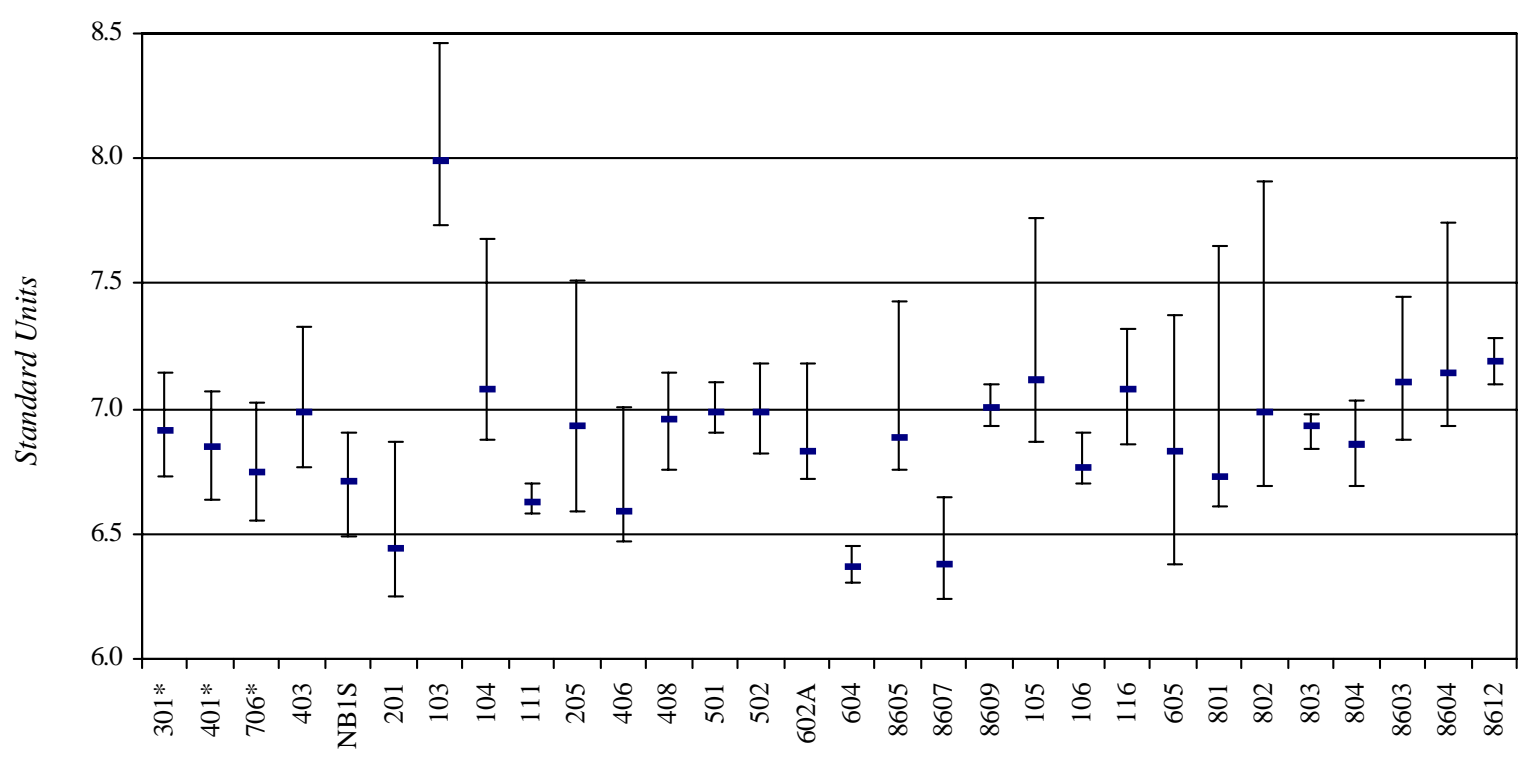

Sampling Locations

* Wells used for background purposes

Figure E-1.pH in Groundwater Samples From the Sand and Gravel Unit

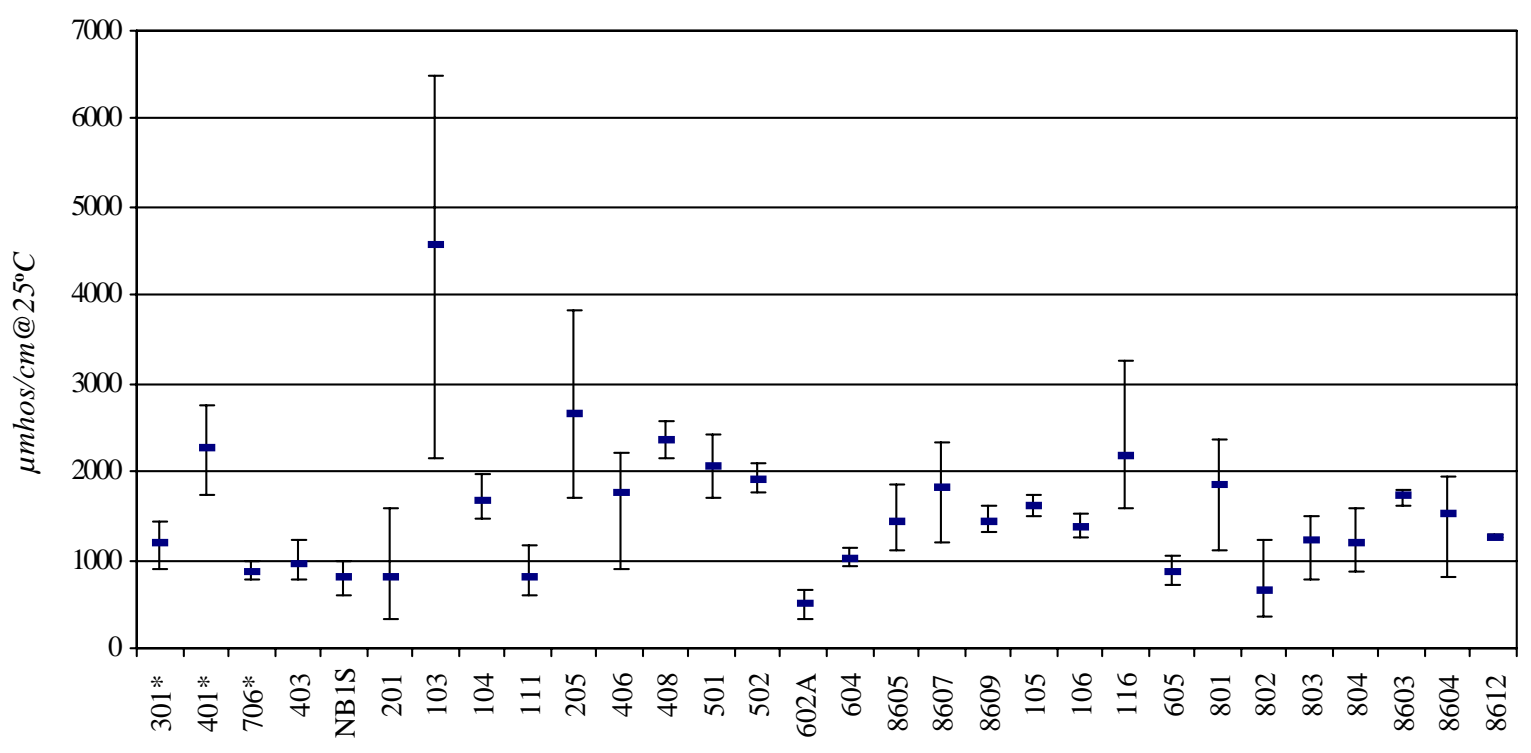

Sampling Locations

* Wells used for background purposes

Figure E-2. Conductivity ( $\mu m h o s / \mathrm{cm}_{2} 5^{\circ} \mathrm{C}$ ) of Groundwater Samples From the Sand and Gravel Unit

$$
\text { E - } 24
$$




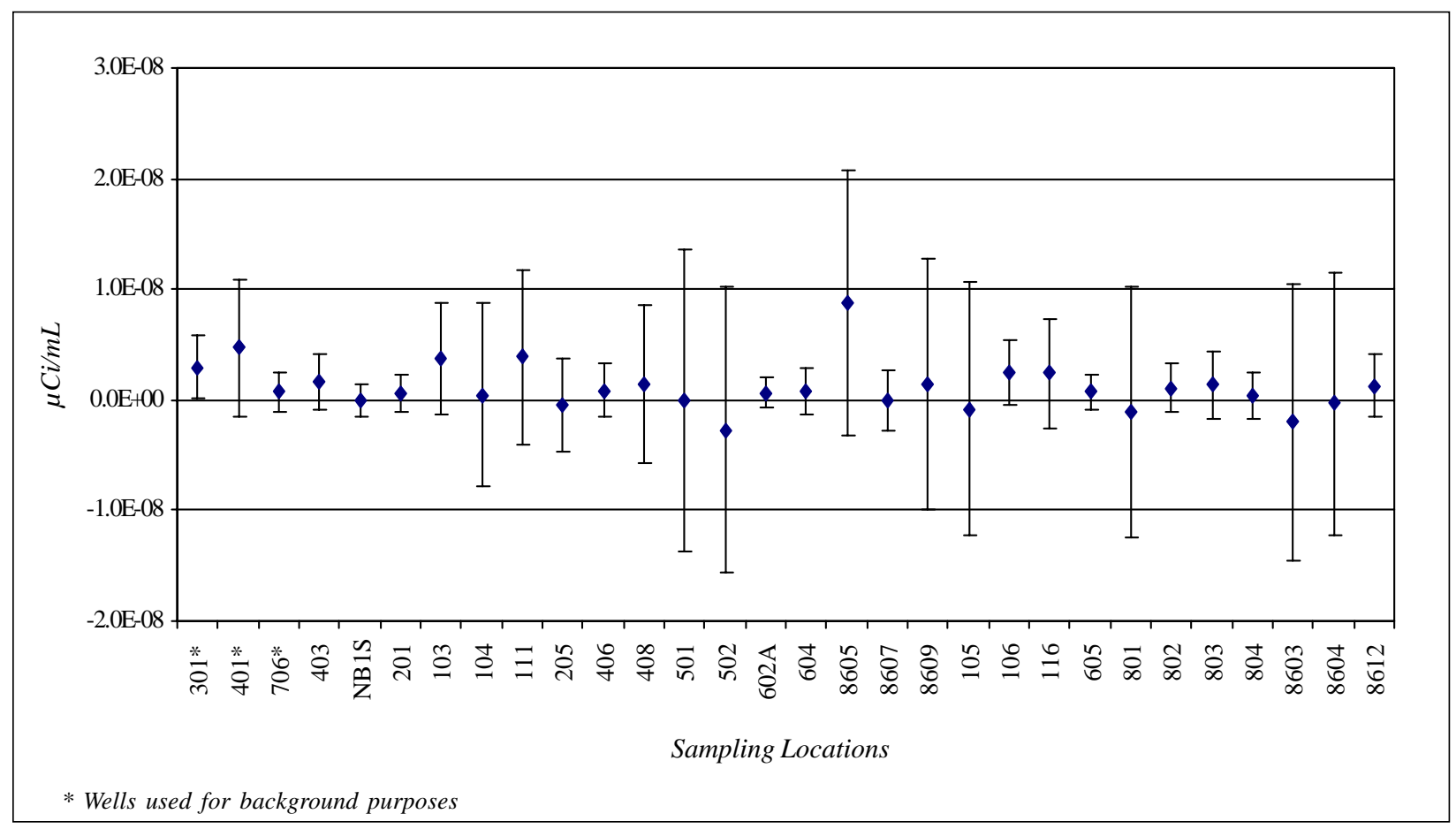

Figure E-3. Gross Alpha $(\mu \mathrm{Ci} / \mathrm{mL})$ in Groundwater Samples From the Sand and Gravel Unit

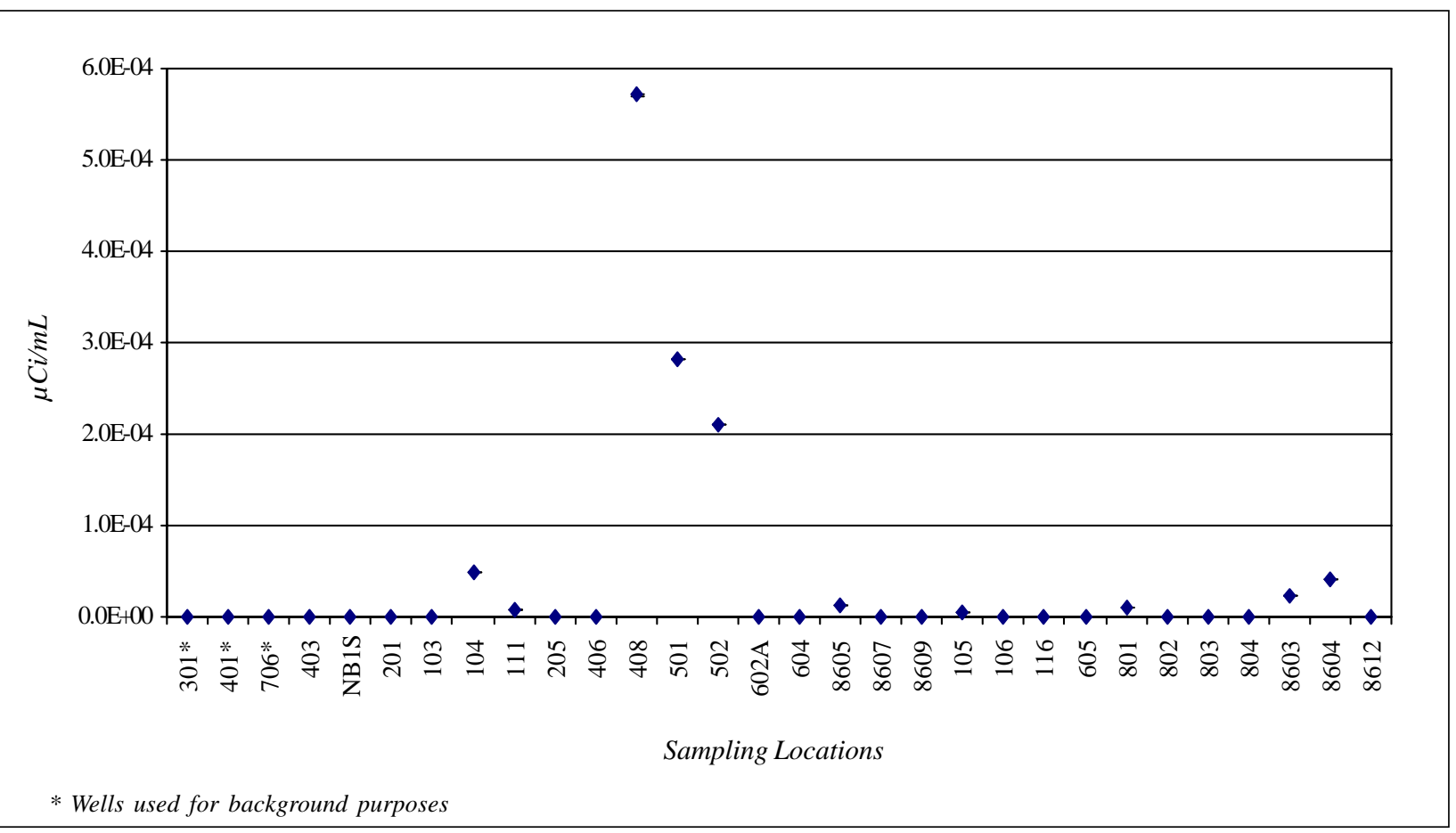

Figure E-4. Gross Beta $(\mu \mathrm{Ci} / \mathrm{mL})$ in Groundwater Samples From the Sand and Gravel Unit

$$
\text { E- } 25
$$




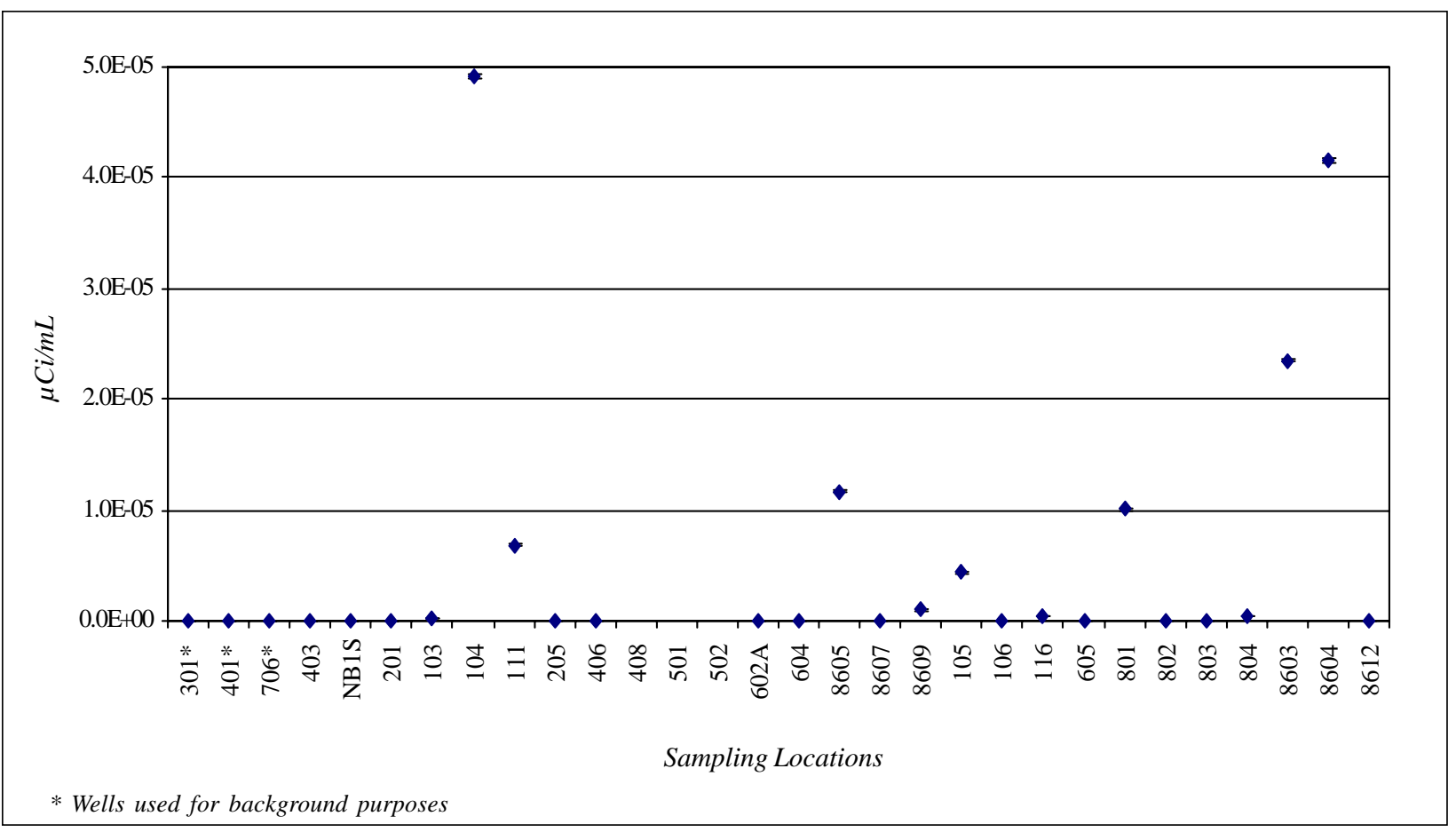

Figure E-4a. Gross Beta $(\mu \mathrm{Ci} / \mathrm{mL})$ in Groundwater Samples From the Sand and Gravel Unit (Magnified Scale of Figure E-4)

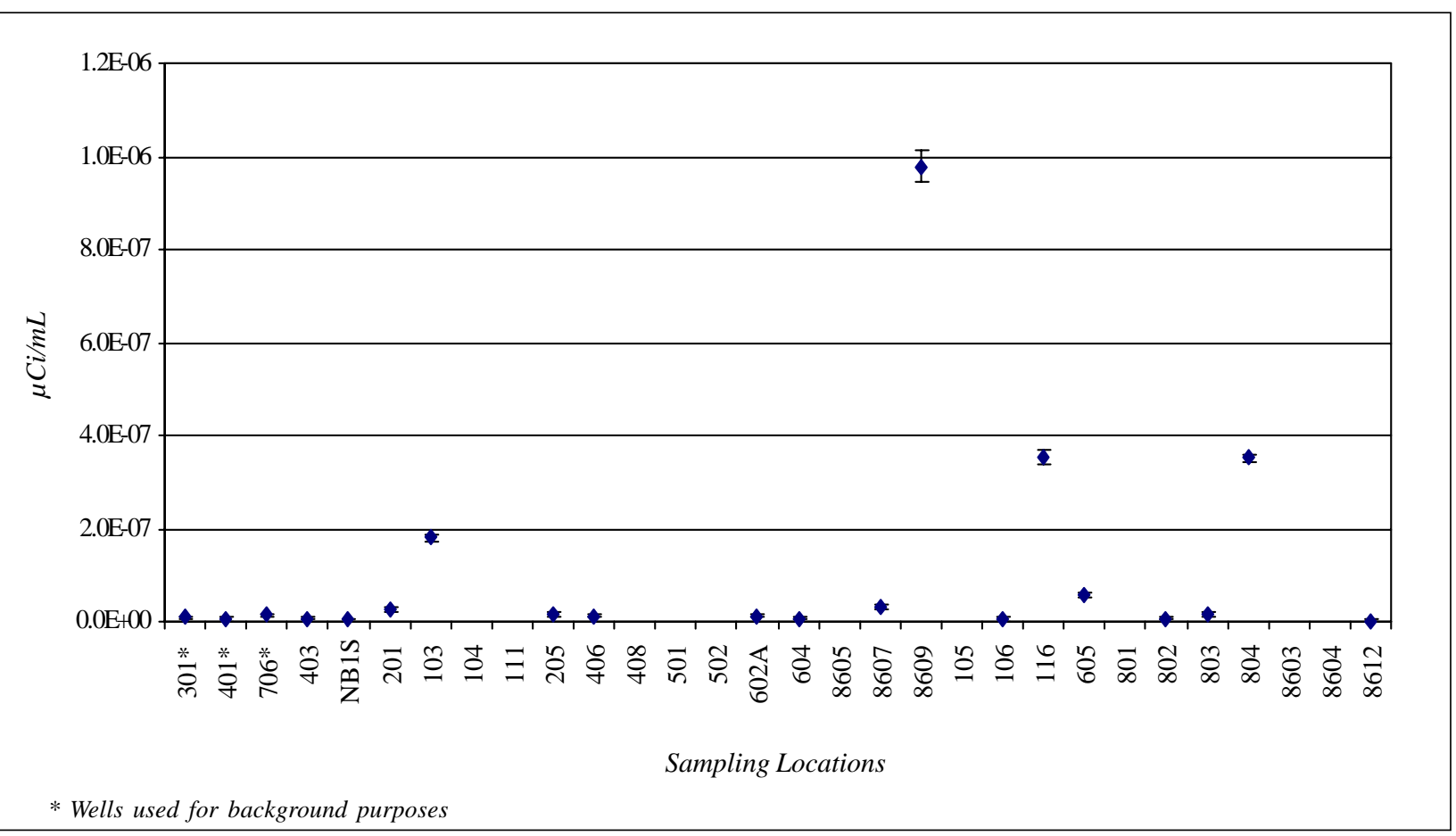

Figure E-4b. Gross Beta $(\mu \mathrm{Ci} / \mathrm{mL})$ in Groundwater Samples From the Sand and Gravel Unit (Magnified Scale of Figure E-4a)

WVDP Site Environmental Report

$E-26$

Calendar Year 2001 


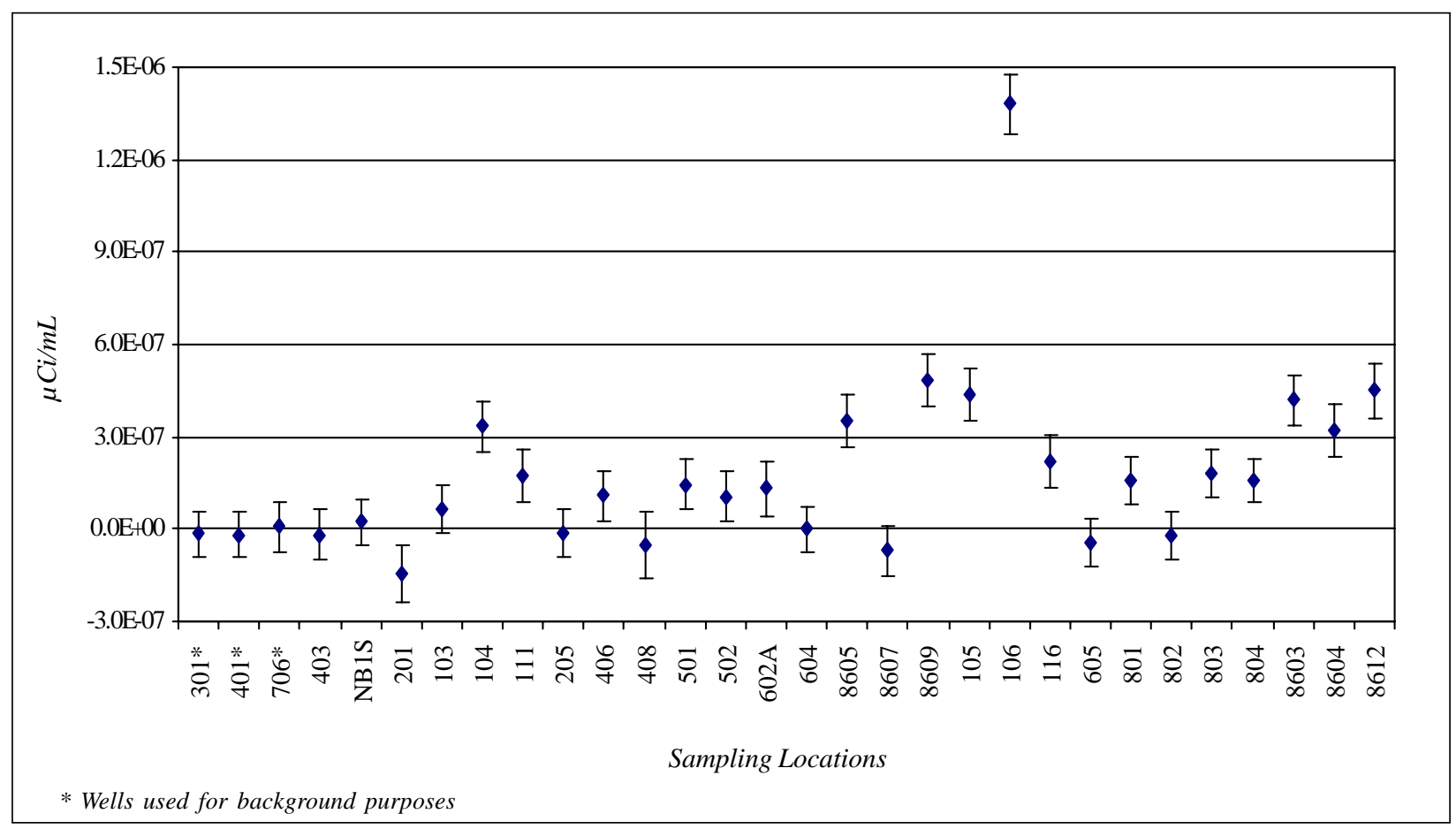

Figure E-5. Tritium ( $\mu \mathrm{Ci} / \mathrm{mL})$ in Groundwater Samples From the Sand and Gravel Unit

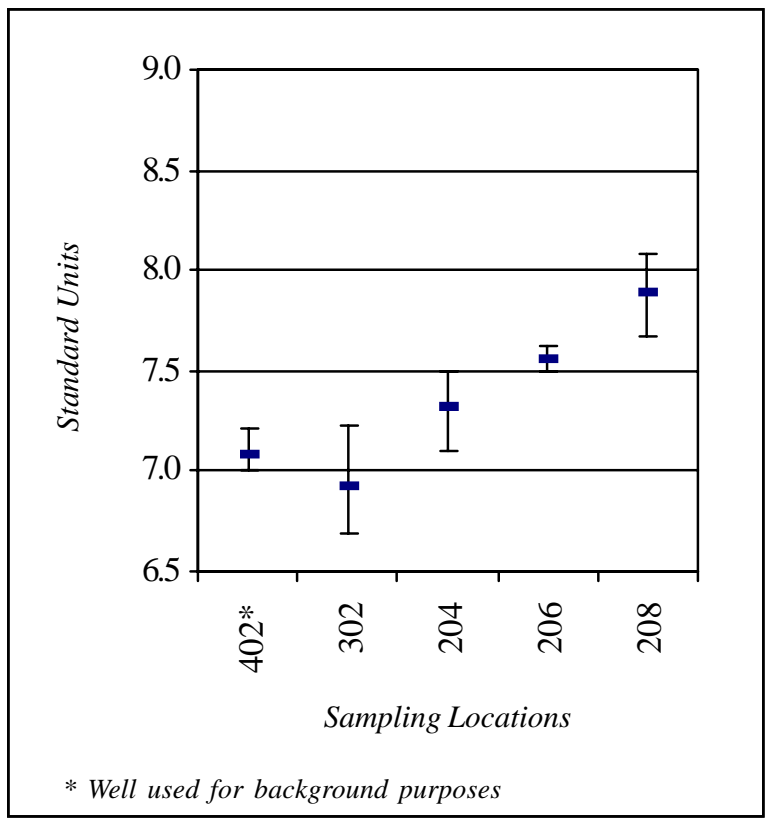

Figure E-6. pH of Groundwater Samples From the Till-Sand Unit

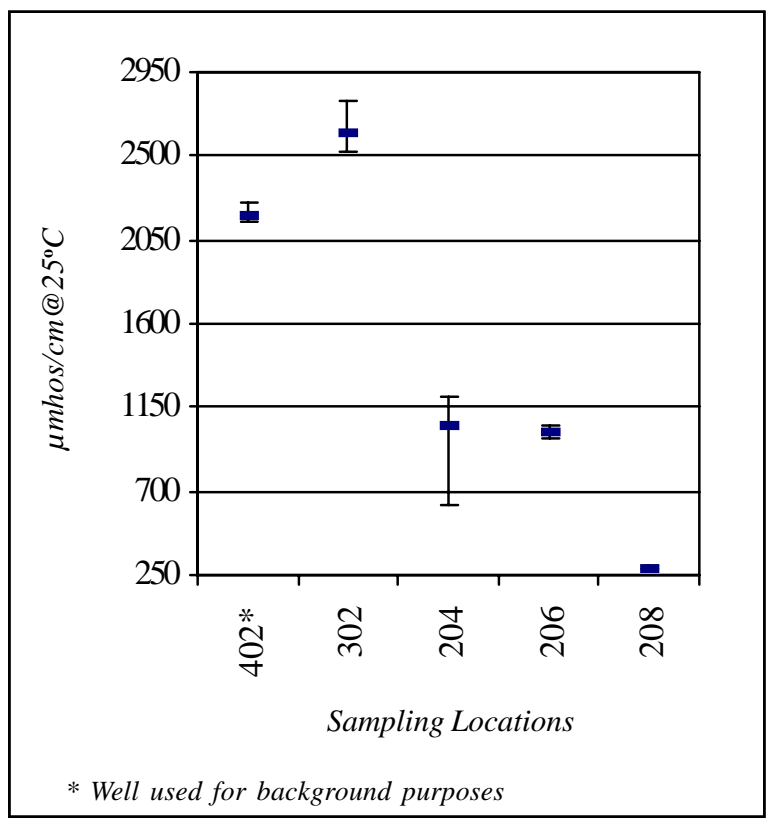

Figure E-7. Conductivity ( $\left.\mu m h o s / \mathrm{cm}_{2} 2^{\circ} \mathrm{C}\right)$ of Groundwater Samples From the Till-Sand Unit 


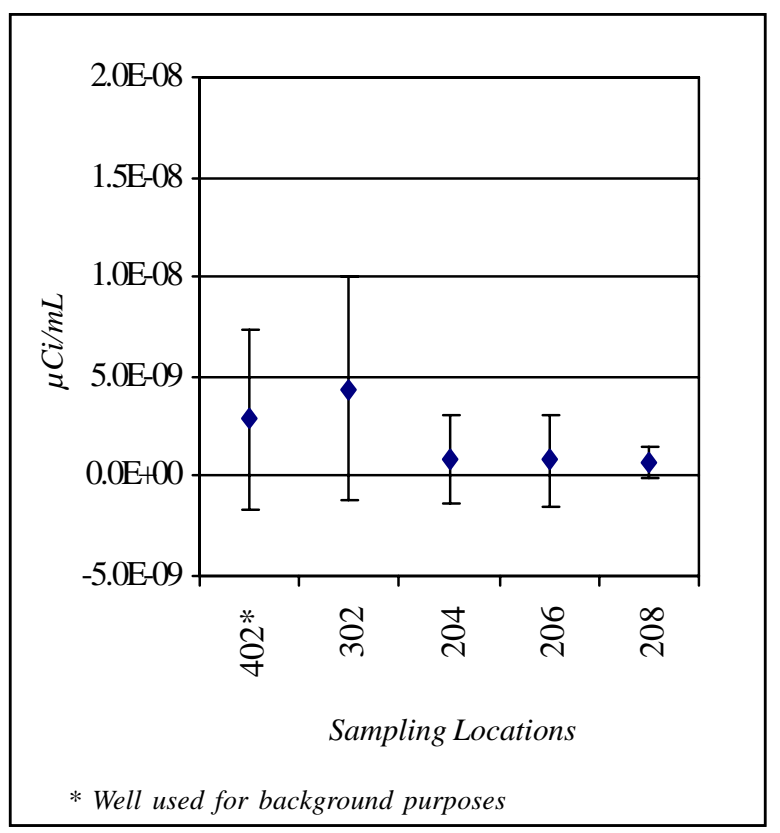

Figure E-8. Gross Alpha ( $\mu$ Ci/mL) in Groundwater Samples From the Till-Sand Unit

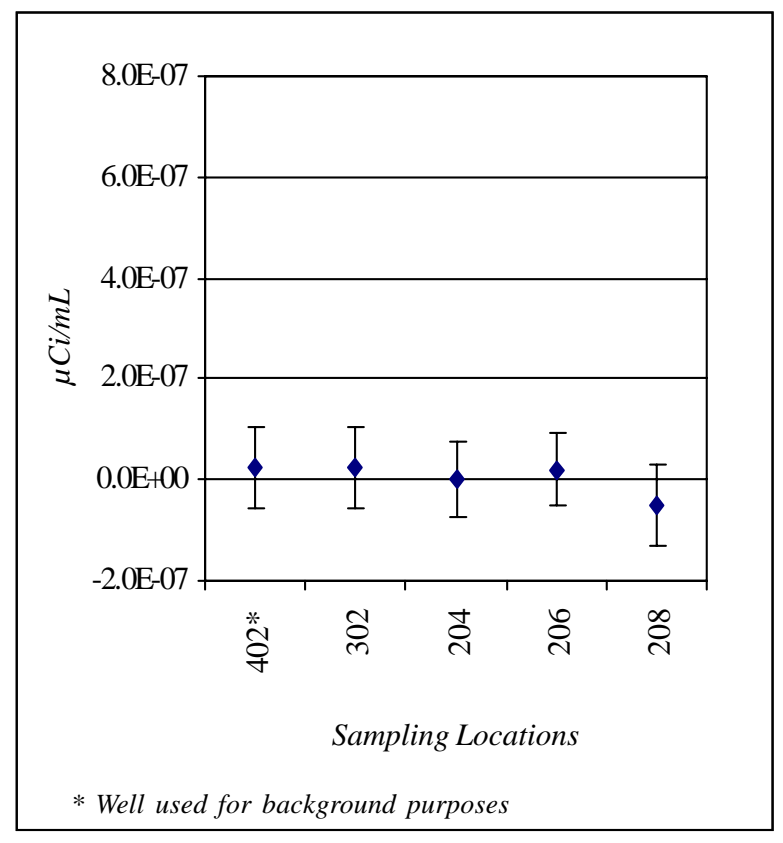

Figure E-10. Tritium ( $\mu$ Ci/mL) in Groundwater Samples From the Till-Sand Unit

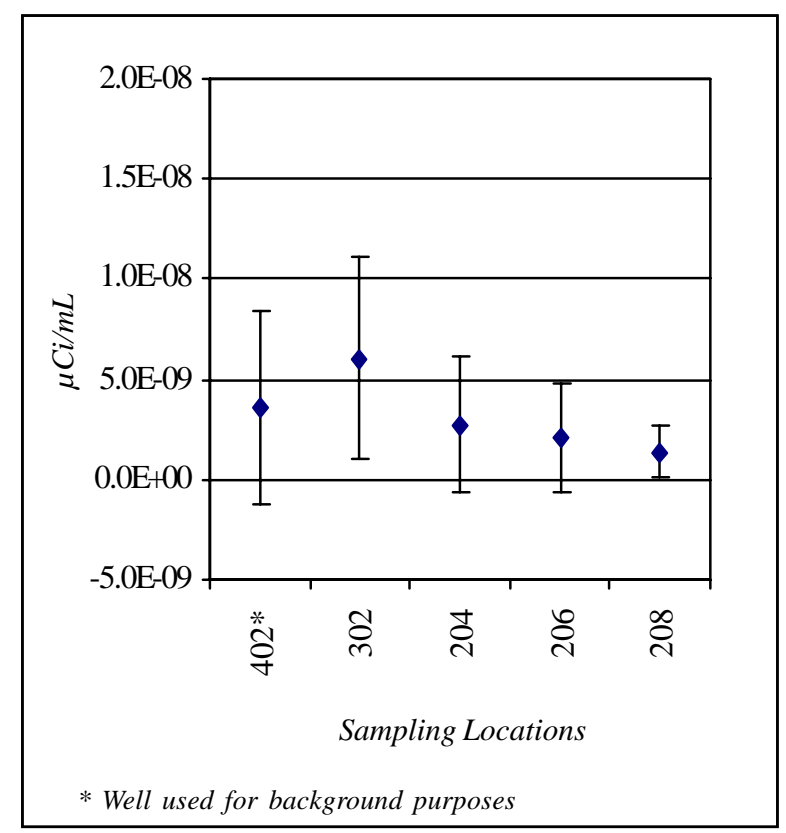

Figure E-9. Gross Beta $(\mu \mathrm{Ci} / \mathrm{mL})$ in Groundwater Samples From the Till-Sand Unit

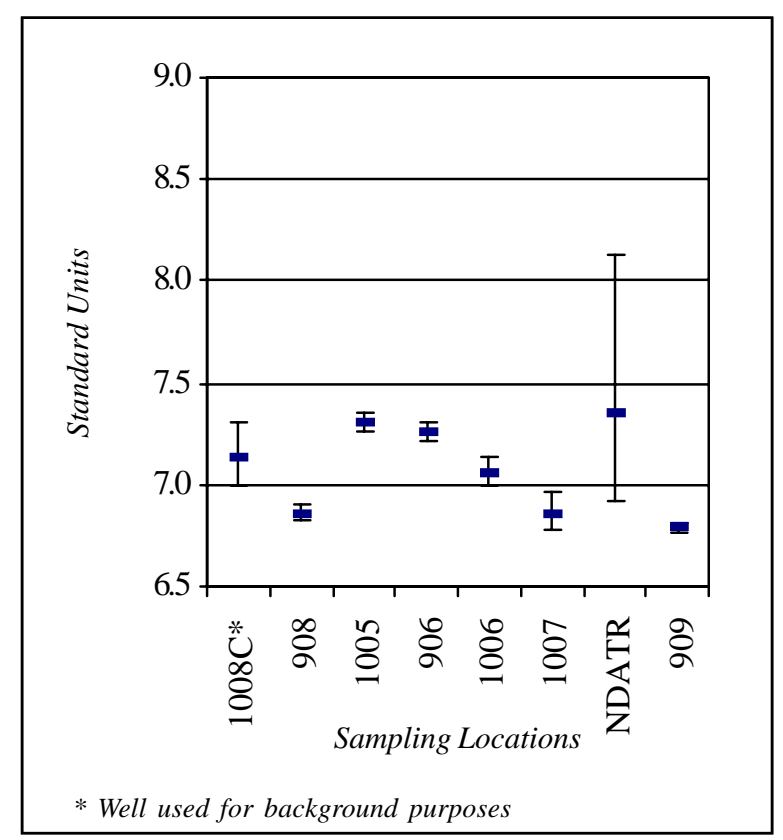

Figure E-11. pH of Groundwater Samples From the Weathered Lavery Till Unit 


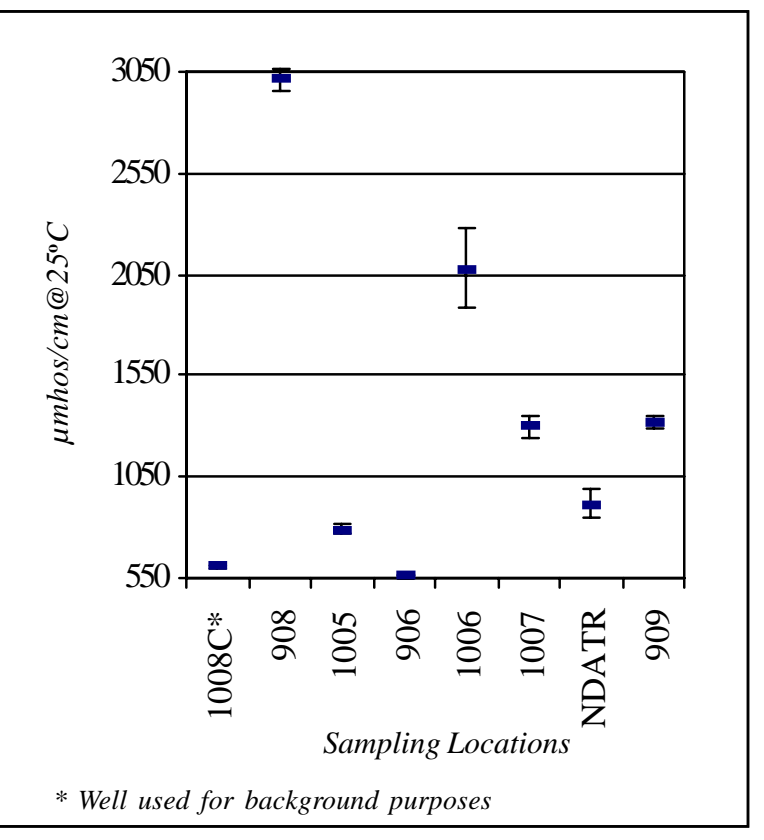

Figure E-12. Conductivity ( $\left.\boldsymbol{\mu m h o s} / \mathbf{c m} @ 25^{\circ} \mathrm{C}\right)$ of Groundwater Samples From the Weathered Lavery Till Unit

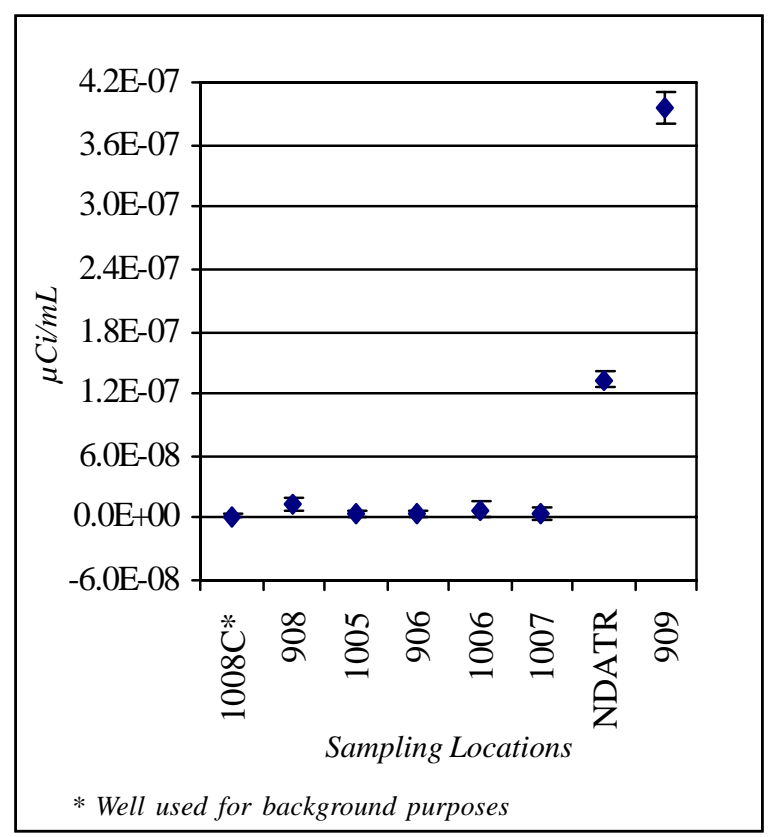

Figure E-14. Gross Beta $(\mu \mathrm{Ci} / \mathrm{mL})$ in Groundwater Samples From the Weathered Lavery Till Unit

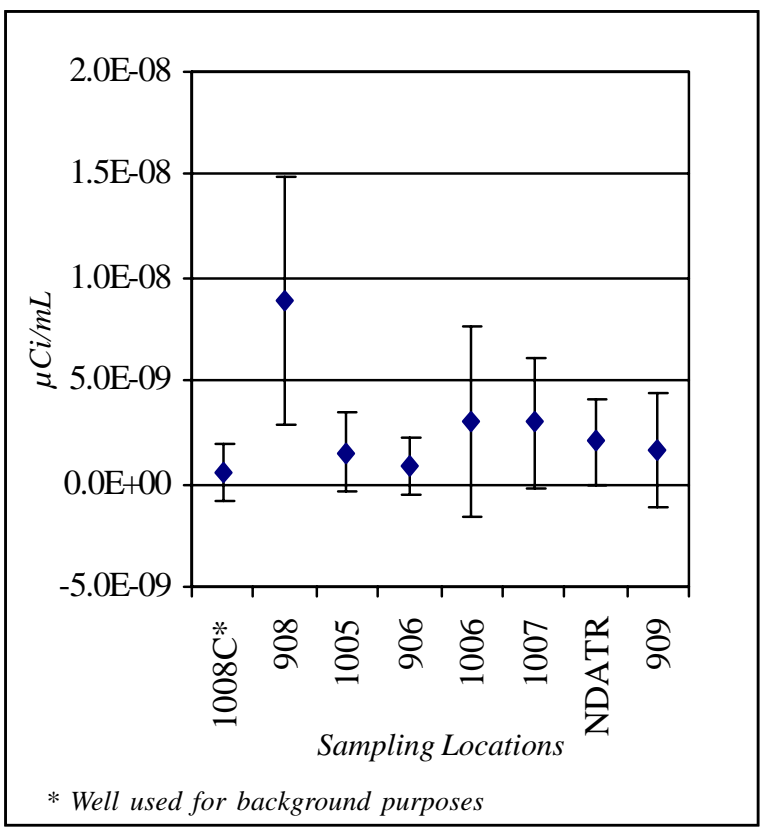

Figure E-13. Gross Alpha ( $\mu \mathrm{Ci} / \mathrm{mL})$ in Groundwater Samples From the Weathered Lavery Till Unit

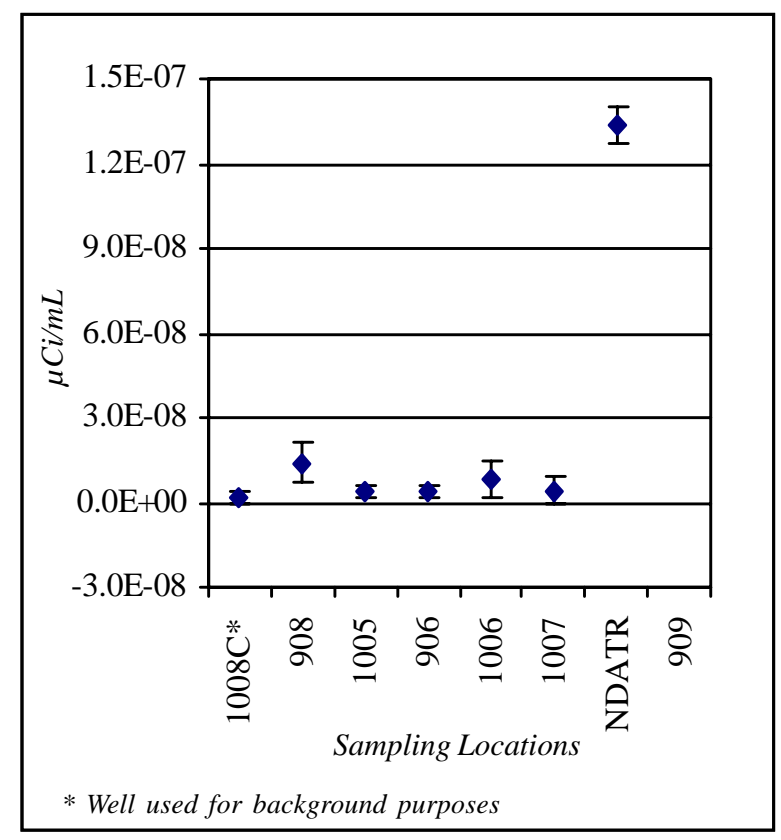

Figure E-14a. Gross Beta $(\mu \mathrm{Ci} / \mathrm{mL})$ in Groundwater Samples From the Weathered Lavery Till Unit (Magnified Scale of Figure E-14) 


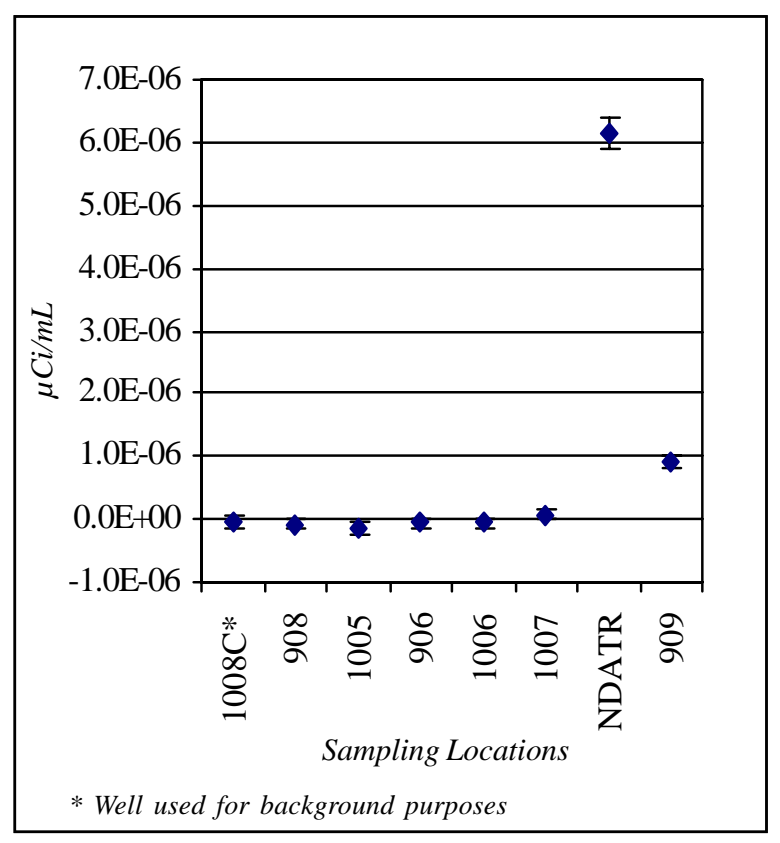

Figure E-15. Tritium $(\mu \mathrm{Ci} / \mathrm{mL})$ in Groundwater Samples From the Weathered Lavery Till Unit

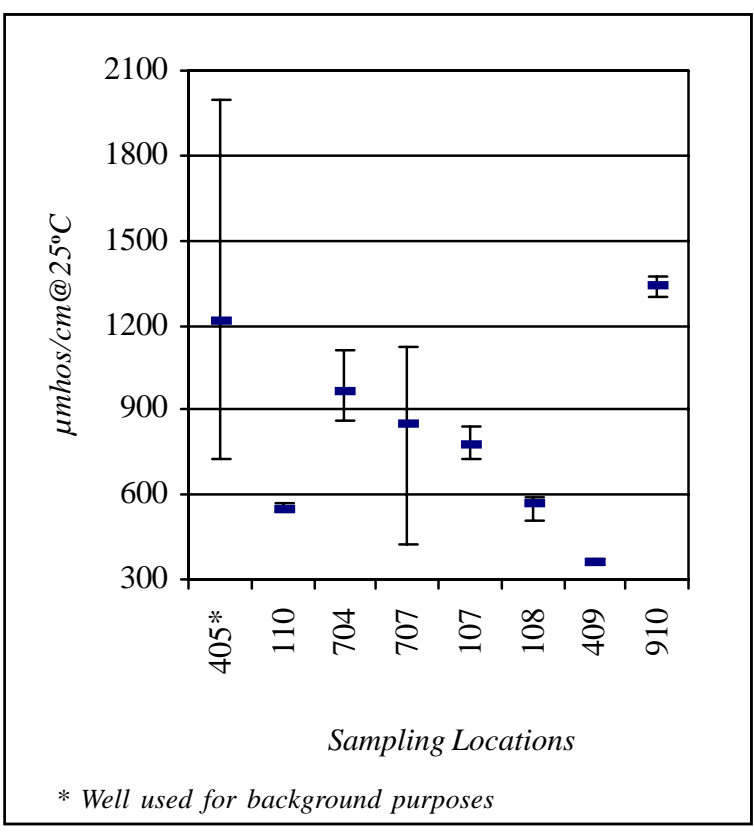

Figure E-17. Conductivity ( $\mu$ mhos/cm @25 $\mathrm{C}$ ) of Groundwater Samples From the Unweathered Lavery Till Unit

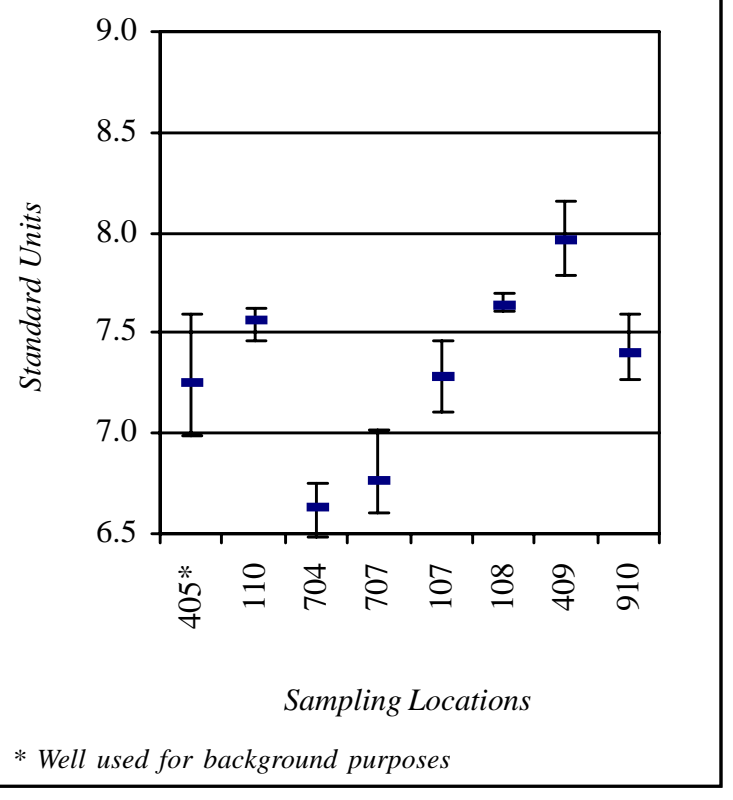

Figure E-16. pH of Groundwater Samples From the Unweathered Lavery Till Unit

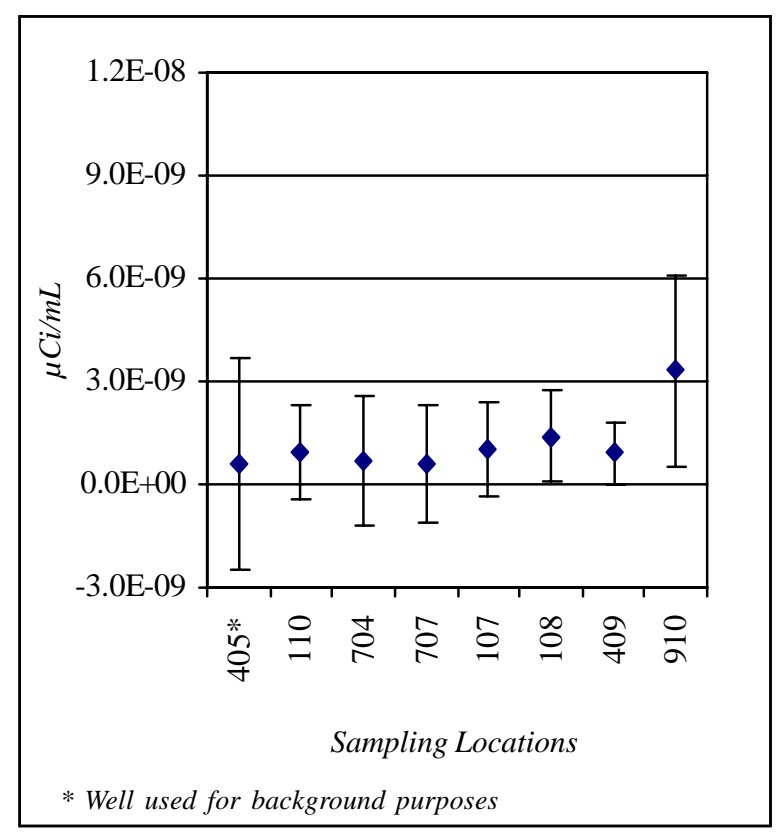

Figure E-18. Gross Alpha ( $\mu$ Ci/mL) in Groundwater Samples From the Unweathered Lavery Till Unit 


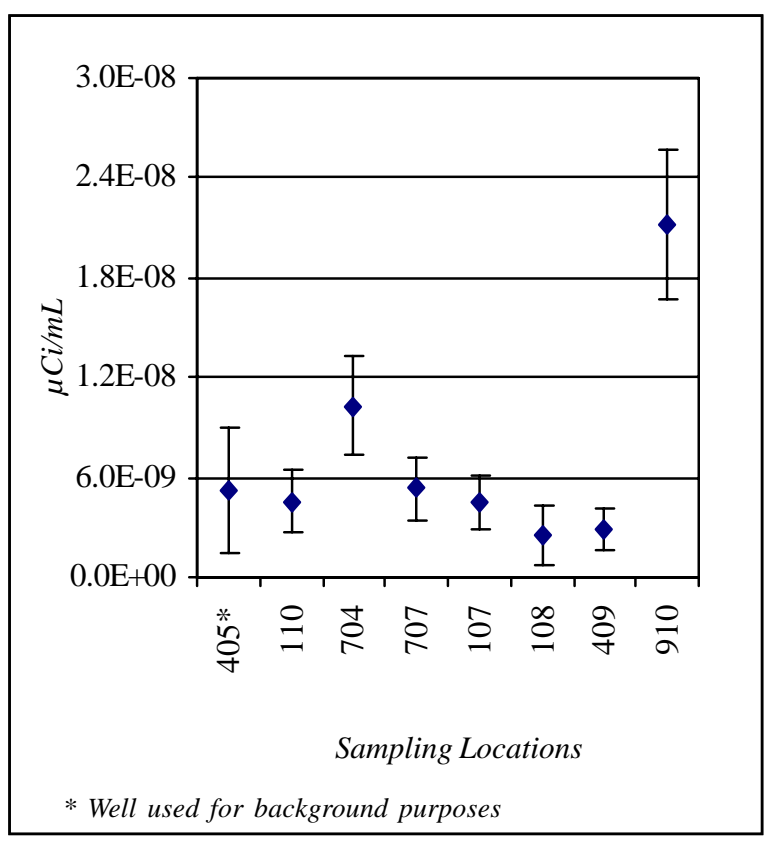

Figure E-19. Gross Beta $(\mu \mathrm{Ci} / \mathrm{mL})$ in Groundwater Samples From the Unweathered Lavery Till Unit

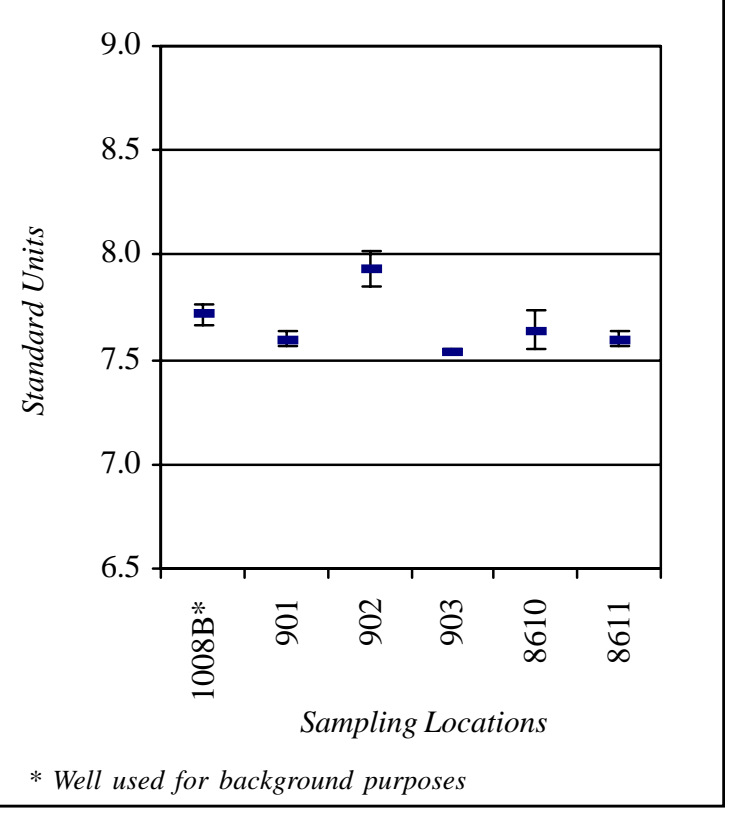

Figure E-21. pH of Groundwater Samples From the Kent Recessional Sequence

WVDP Site Environmental Report

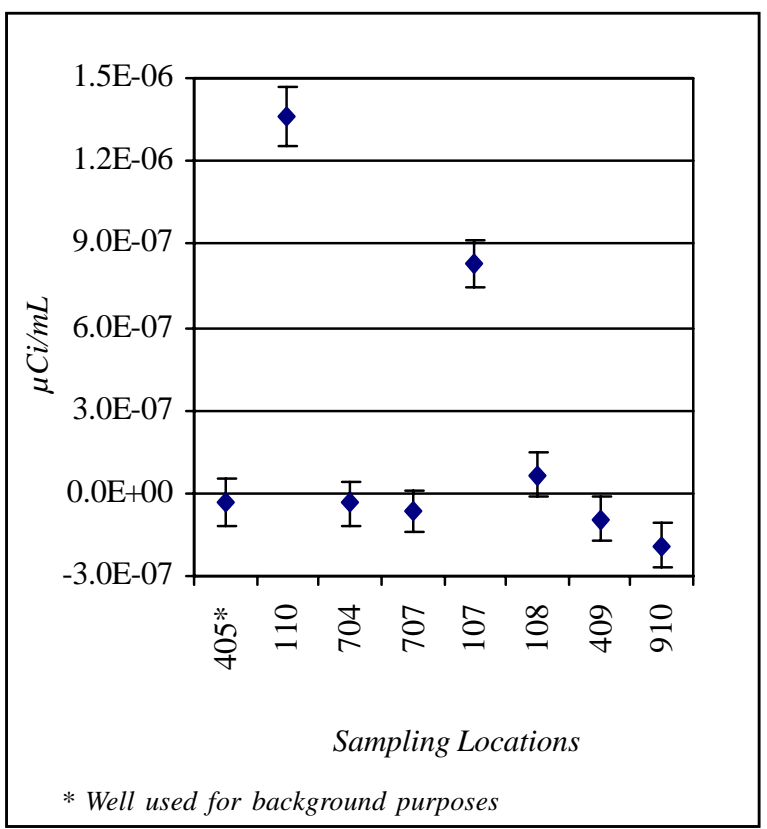

Figure E-20. Tritium ( $\mu \mathrm{Ci} / \mathrm{mL})$ in Groundwater Samples From the Unweathered Lavery Till Unit

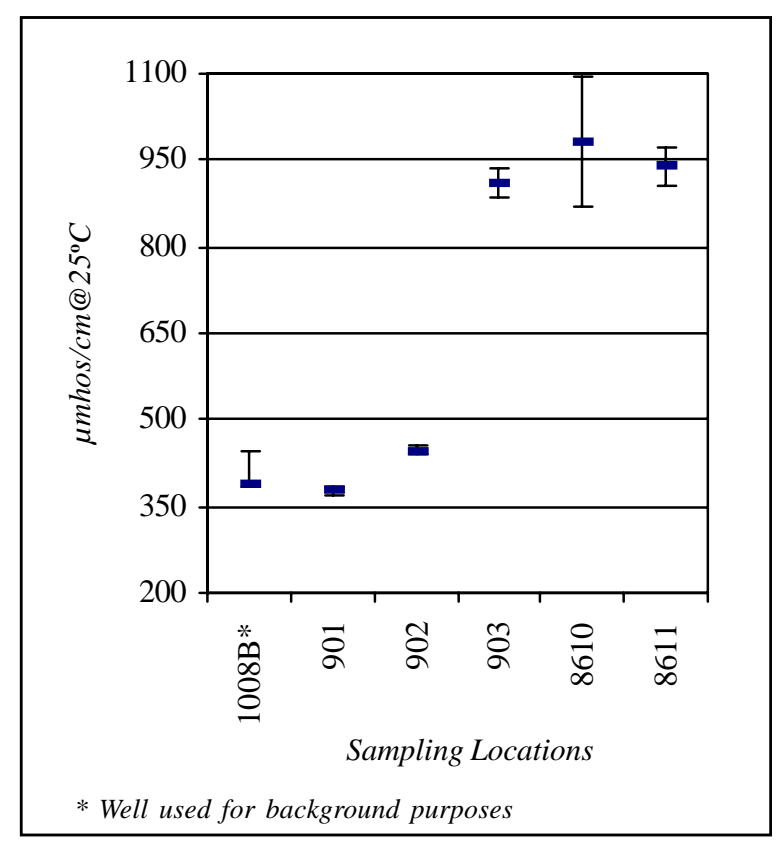

Figure E-22. Conductivity ( $\left.\mu m h o s / \mathrm{cm} @ 25^{\circ} \mathrm{C}\right)$ of Groundwater Samples From the Kent Recessional Sequence

\section{$E-31$}




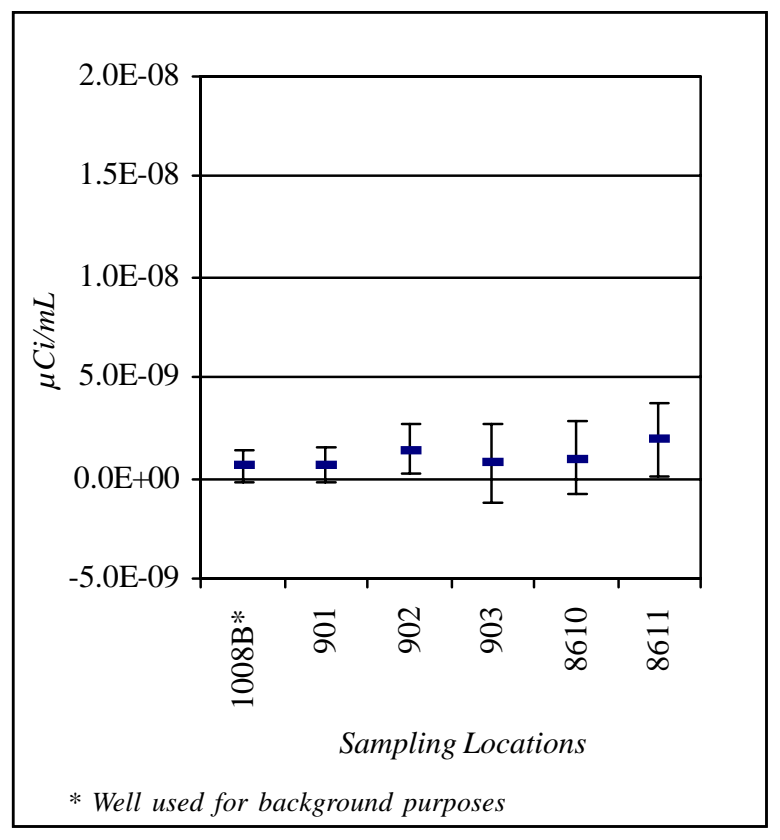

Figure E-23. Gross Alpha ( $\mu \mathrm{Ci} / \mathrm{mL})$ in Groundwater Samples From the Kent Recessional Sequence

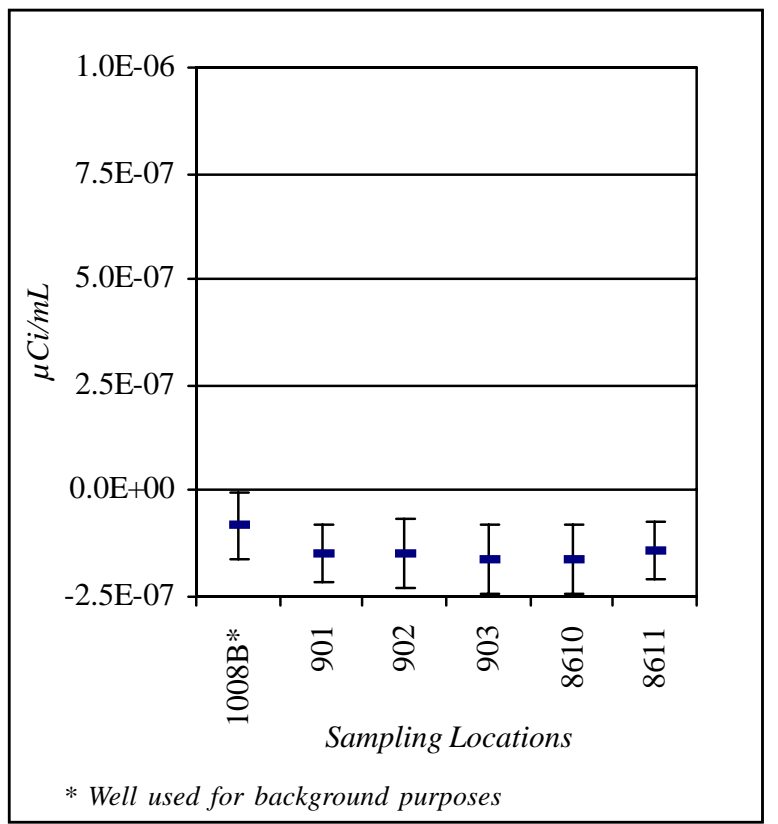

Figure E-25. Tritium ( $\mu \mathrm{Ci} / \mathrm{mL}$ ) in Groundwater Samples From the Kent Recessional Sequence

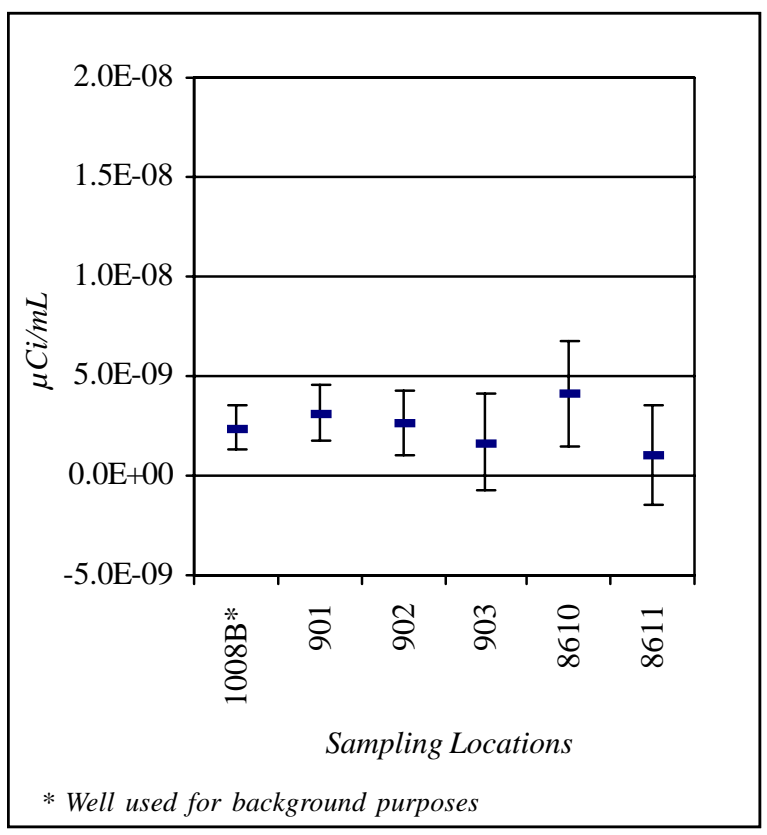

Figure E-24. Gross Beta $(\mu \mathrm{Ci} / \mathrm{mL})$ in Groundwater Samples From the Kent Recessional Sequence
$E-32$

WVDP Site Environmental Report
Calendar Year 2001 


\section{Appendix $F$ \\ Summary of Biological Data}

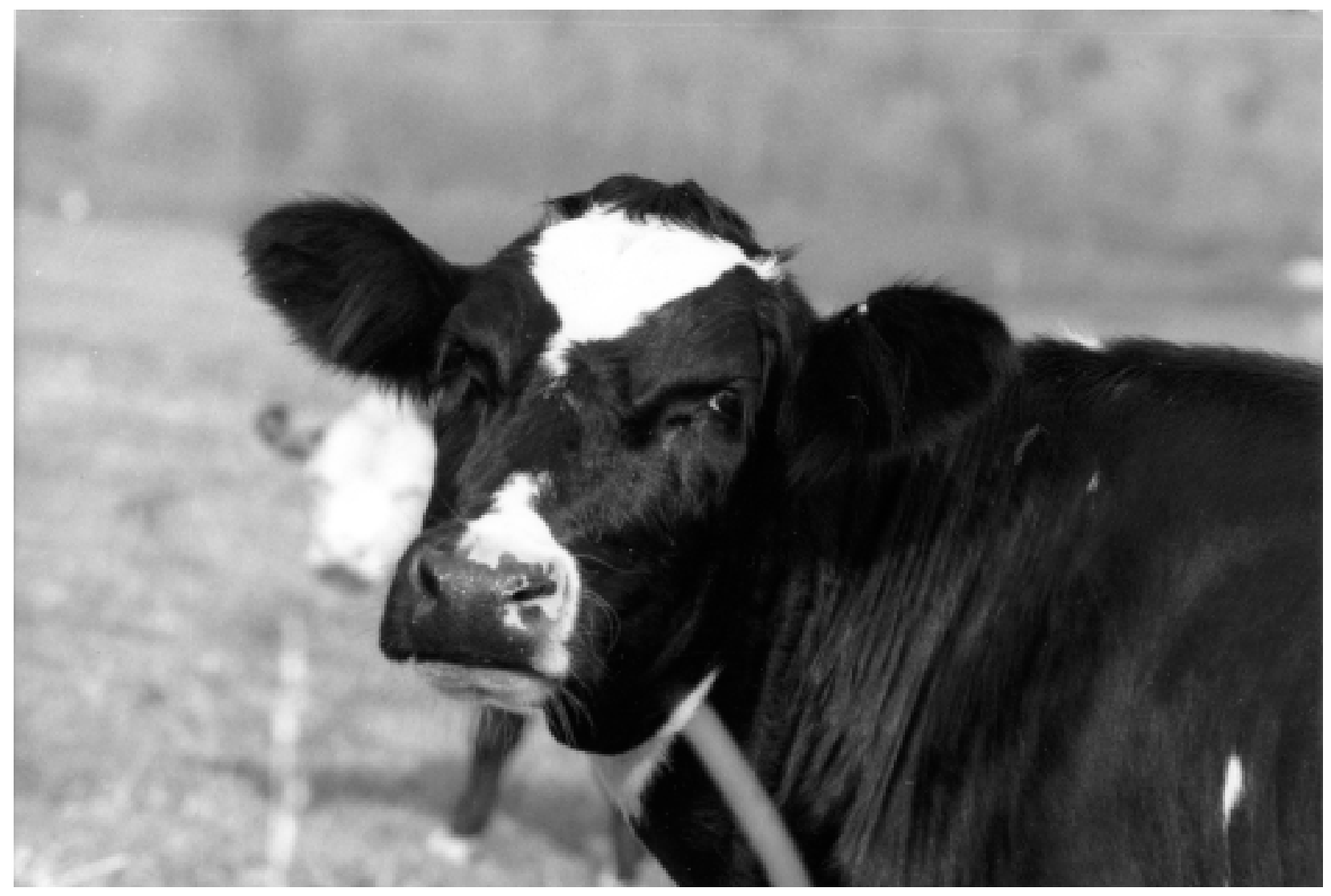

Milk and Meat Samples are Collected from Local Bovine Herds

$$
F-1
$$


The following tables contain a bolding convention devised to help the reader, when viewing the data, to quickly see the range of detectable measurements within a data series. A data series is a set of chemical or radionuclide measurements (e.g., gross alpha, gross beta, tritium) from a single location or from similar locations. Note that some tables contain data that should not be technically evaluated under this convention.

\section{Key to bolding convention:}

Results for each constituent constitute a single data series. If a radiological result is larger than the uncertainty term, the measurement is considered positive. Otherwise, a result is considered non-detectable.

If all results in a data series are positive, the lowest and highest values are bolded.

If a data series contains some positive results, the highest value is bolded.

If all values in a data series are nondetectable, no values are bolded.

$$
F-2
$$




\section{Table F-1 \\ 2001 Radioactivity Concentrations $(\mu \mathrm{Ci} / \mathrm{mL})$ in Milk}

\begin{tabular}{|c|c|c|c|c|c|}
\hline Location & H-3 & K-40 & Sr-90 & I-129 & Cs-137 \\
\hline \multicolumn{6}{|l|}{$\begin{array}{l}\text { BFMCOBO } \\
\text { (WNW Farm) }\end{array}$} \\
\hline 1st Quarter & $0.00 \pm 1.01 \mathrm{E}-07$ & $1.35 \pm 0.10 \mathrm{E}-06$ & $2.00 \pm 0.77 \mathrm{E}-09$ & $1.20 \pm 4.17 \mathrm{E}-10$ & $2.07 \pm 2.07 \mathrm{E}-09$ \\
\hline 2nd Quarter & $-2.87 \pm 9.05 \mathrm{E}-08$ & $1.44 \pm 0.16 \mathrm{E}-06$ & $2.96 \pm 0.74 \mathrm{E}-09$ & $-2.97 \pm 4.02 \mathrm{E}-10$ & $0.00 \pm 1.55 \mathrm{E}-09$ \\
\hline $\begin{array}{l}\text { 3rd Quarter } \\
\text { 4th Quarter* }\end{array}$ & $0.00 \pm 1.08 \mathrm{E}-07$ & $8.92 \pm 2.16 \mathrm{E}-07$ & $3.77 \pm 4.24 \mathrm{E}-10$ & $-1.14 \pm 3.40 \mathrm{E}-10$ & $-1.29 \pm 4.19 \mathrm{E}-09$ \\
\hline \multicolumn{6}{|l|}{$\begin{array}{l}\text { BFMCTLN } \\
\text { (Background) }\end{array}$} \\
\hline 1st Quarter & $1.16 \pm 1.07 \mathrm{E}-07$ & $1.32 \pm 0.19 E-06$ & $6.52 \pm 5.33 E-10$ & $-1.40 \pm 3.42 \mathrm{E}-10$ & $2.50 \pm 3.82 \mathrm{E}-09$ \\
\hline 2nd Quarter & $2.86 \pm 9.29 \mathrm{E}-08$ & $1.46 \pm 0.17 \mathrm{E}-06$ & $7.87 \pm 5.15 \mathrm{E}-10$ & $-0.18 \pm 4.43 \mathrm{E}-10$ & $1.31 \pm 0.98 \mathrm{E}-09$ \\
\hline 3rd Quarter & $1.38 \pm 1.09 \mathrm{E}-07$ & $1.59 \pm 0.25 \mathrm{E}-06$ & $1.04 \pm 0.48 \mathrm{E}-09$ & $-1.21 \pm 3.80 \mathrm{E}-10$ & $4.33 \pm 5.60 \mathrm{E}-09$ \\
\hline 4th Quarter & $1.09 \pm 0.87 \mathrm{E}-07$ & $1.51 \pm 0.19 \mathrm{E}-06$ & $2.61 \pm 0.75 E-09$ & $4.83 \pm 4.08 E-10$ & $1.19 \pm 1.12 \mathrm{E}-09$ \\
\hline \multicolumn{6}{|l|}{$\begin{array}{l}\text { BFMCTLS } \\
\text { (Background) }\end{array}$} \\
\hline 1st Quarter & $0.29 \pm 1.03 \mathrm{E}-07$ & $1.16 \pm 0.17 E-06$ & $1.60 \pm 0.64 \mathrm{E}-09$ & $-0.08 \pm 2.68 \mathrm{E}-10$ & $3.74 \pm 3.50 \mathrm{E}-09$ \\
\hline 2nd Quarter & $0.00 \pm 9.12 \mathrm{E}-08$ & $1.52 \pm 0.19 \mathrm{E}-06$ & $8.60 \pm 4.87 \mathrm{E}-10$ & $2.72 \pm 2.18 \mathrm{E}-10$ & $0.63 \pm 1.14 \mathrm{E}-09$ \\
\hline 3rd Quarter & $-2.73 \pm 9.93 \mathrm{E}-08$ & $1.44 \pm 0.25 \mathrm{E}-06$ & $5.84 \pm 5.39 \mathrm{E}-10$ & $-2.35 \pm 3.45 \mathrm{E}-10$ & $5.62 \pm 4.29 \mathrm{E}-09$ \\
\hline 4th Quarter & $2.69 \pm 8.21 \mathrm{E}-08$ & $1.60 \pm 0.19 E-06$ & $6.96 \pm 7.12 \mathrm{E}-10$ & $0.00 \pm 4.08 \mathrm{E}-10$ & $3.14 \pm 2.39 \mathrm{E}-09$ \\
\hline \multicolumn{6}{|l|}{$\begin{array}{l}\text { BFMREED } \\
\text { (NNW Farm) }\end{array}$} \\
\hline 1st Quarter & $-2.89 \pm 9.83 \mathrm{E}-08$ & $1.10 \pm 0.11 E-06$ & $7.32 \pm 4.69 \mathrm{E}-10$ & $1.04 \pm 3.44 \mathrm{E}-10$ & $0.45 \pm 2.95 \mathrm{E}-09$ \\
\hline 2nd Quarter & $8.57 \pm 9.56 \mathrm{E}-08$ & $1.47 \pm 0.06 \mathrm{E}-06$ & $1.15 \pm 0.50 \mathrm{E}-09$ & $3.10 \pm 3.94 \mathrm{E}-10$ & $1.04 \pm 1.07 \mathrm{E}-09$ \\
\hline 3rd Quarter & $-2.74 \pm 9.98 \mathrm{E}-08$ & $1.42 \pm 0.22 \mathrm{E}-06$ & $8.25 \pm 4.89 \mathrm{E}-10$ & $0.00 \pm 4.11 \mathrm{E}-10$ & $2.95 \pm 5.57 \mathrm{E}-09$ \\
\hline 4th Quarter & $8.14 \pm 8.55 \mathrm{E}-08$ & $1.45 \pm 0.17 \mathrm{E}-06$ & $-0.20 \pm 7.63 \mathrm{E}-10$ & $4.21 \pm 4.07 E-10$ & $-1.42 \pm 1.81 \mathrm{E}-09$ \\
\hline \multicolumn{6}{|l|}{$\begin{array}{l}\text { BFMSCHT } \\
\text { (S Farm) }\end{array}$} \\
\hline Annual & $0.27 \pm 1.18 \mathrm{E}-07$ & $1.37 \pm 0.19 \mathrm{E}-06$ & $2.27 \pm 0.57 \mathrm{E}-09$ & $4.79 \pm 5.91 \mathrm{E}-10$ & $0.40 \pm 2.43 \mathrm{E}-09$ \\
\hline \multicolumn{6}{|l|}{$\begin{array}{l}\text { BFMWIDR } \\
\text { (SEFarm) }\end{array}$} \\
\hline Annual & $-1.88 \pm 1.07 \mathrm{E}-07$ & $1.29 \pm 0.19 \mathrm{E}-06$ & $1.35 \pm 0.57 \mathrm{E}-09$ & $-1.12 \pm 4.75 \mathrm{E}-10$ & $-0.08 \pm 2.23 \mathrm{E}-09$ \\
\hline
\end{tabular}

* Not available, sampling discontinued at this location.

Note: Bolding convention applied to these data. See page F-2.

WVDP Site Environmental Report

$F-3$

Calendar Year 2001 


\section{Table F-2 \\ 2001 Radioactivity Concentrations $(\mu \mathrm{Ci} / \mathrm{g}-\mathrm{dry})$ in Meat}

\begin{tabular}{lccccc} 
& \multicolumn{2}{c}{ 2001 Radioactivity Concentrations in Beef } & \\
Location & \% Moisture & $\begin{array}{c}\text { H-3 } \\
(\mu \mathrm{Ci} / \mathrm{mL})\end{array}$ & K-40 & Sr-90 & Cs-137 \\
$\begin{array}{l}\text { Beef Flesh Background } \\
\text { (BFBCTRL 05/01) }\end{array}$ & 76.7 & $-0.76 \pm 1.16 \mathrm{E}-07$ & $1.51 \pm 0.18 \mathrm{E}-05$ & $0.78 \pm 2.03 \mathrm{E}-09$ & $3.95 \pm 2.88 \mathrm{E}-08$ \\
$\begin{array}{l}\text { Beef Flesh Background } \\
\text { (BFBCTRL 12/01) }\end{array}$ & 68.7 & $5.40 \pm 8.90 \mathrm{E}-08$ & $9.74 \pm 1.18 \mathrm{E}-06$ & $1.26 \pm 1.04 \mathrm{E}-09$ & $9.38 \pm 8.60 \mathrm{E}-09$ \\
\hline $\begin{array}{l}\text { Beef Flesh Near-Site } \\
\text { (BFBNEAR 03/01) }\end{array}$ & 61.4 & $1.01 \pm 1.21 \mathrm{E}-07$ & $6.32 \pm 0.88 \mathrm{E}-06$ & $6.57 \pm 8.19 \mathrm{E}-10$ & $-0.43 \pm 1.62 \mathrm{E}-08$ \\
& & & & \\
$\begin{array}{l}\text { Beef Flesh Near-Site } \\
\text { (BFBNEAR 12/01) }\end{array}$ & 67.9 & $2.70 \pm 8.77 \mathrm{E}-08$ & $9.16 \pm 1.09 \mathrm{E}-06$ & $1.25 \pm 1.13 \mathrm{E}-09$ & $2.28 \pm 1.02 \mathrm{E}-08$
\end{tabular}

2001 Radioactivity Concentrations in Venison

Location

\% Moisture

H-3

K-40

Sr-90

Cs-137

Deer Flesh Background $(\mu \mathrm{Ci} / \mathrm{mL})$

72.1

$0.00 \pm 8.63 \mathrm{E}-08$

$1.10 \pm 0.13 E-05$

$1.99 \pm 1.08 \mathrm{E}-09$

$1.58 \pm 0.55 \mathrm{E}-07$

Deer Flesh Background

(BFDCTRL 11/01)

72.4

$2.69 \pm 8.76 \mathrm{E}-08$

$1.13 \pm 0.13 \mathrm{E}-05$

2.08 $\pm 1.23 E-09$

$2.66 \pm 0.44 \mathrm{E}-07$

Deer Flesh Background (BFDCTRL 12/01)

74.9

$0.00 \pm 8.68 \mathrm{E}-08$

1.18 $\pm 0.14 E-05$

$-1.03 \pm 0.80 \mathrm{E}-09$

$1.30 \pm 1.58 \mathrm{E}-08$

Deer Flesh Near-Site

(BFDNEAR 10/01)

75.5

$0.00 \pm 8.42 \mathrm{E}-08$

$1.06 \pm 0.14 E-05$

$3.66 \pm 1.20 \mathrm{E}-09$

$2.64 \pm 2.07 \mathrm{E}-08$

Deer Flesh Near-Site

(BFDNEAR 11/01)

73.2

$5.42 \pm 8.67 \mathrm{E}-0$

$1.28 \pm 0.18 \mathrm{E}-05$

$0.48 \pm 1.02 \mathrm{E}-09$

$3.28 \pm 3.57 \mathrm{E}-08$

Deer Flesh Near-Site

(BFDNEAR 11/01)

3.72 \pm 2.82 E-08

Note: Bolding convention applied to venison data. See page F-2.

WVDP Site Environmental Report

$$
F-4
$$




\section{Table F-3}

\section{Radioactivity Concentrations ( $\mu \mathrm{Ci} / \mathrm{g}$ - dry) in Food Crops}

Location

$\%$ Moisture

H-3

K-40

Co-60

Sr-90

Cs-137

CORN

Background

(BFVCTRC)

78.6

$-0.43 \pm 1.16 \mathrm{E}-07$

$1.17 \pm 0.20 \mathrm{E}-05$

$-1.79 \pm 3.96 \mathrm{E}-08$

$1.42 \pm 0.53 \mathrm{E}-08$

$1.76 \pm 3.55 \mathrm{E}-08$

Near-Site

(BFVNEAC)

74.8

$0.32 \pm 1.18 \mathrm{E}-07$

$1.22 \pm 0.17 \mathrm{E}-05$

$0.00 \pm 3.83 \mathrm{E}-08$

$3.13 \pm 1.71 \mathrm{E}-09$

$0.35 \pm 2.44 \mathrm{E}-08$

BEANS

Background

(BFVCTRB)

90.9

$0.46 \pm 1.17 \mathrm{E}-07 \quad 3.34 \pm 0.40 \mathrm{E}-05$

$1.91 \pm 5.38 \mathrm{E}-0$

$2.43 \pm 0.22 \mathrm{E}-07$

$-0.70 \pm 4.77 \mathrm{E}-08$

Near-Site

(BFVNEAB)

89.5

$0.68 \pm 1.18 \mathrm{E}-07$

$2.26 \pm 0.30 \mathrm{E}-05$

$0.91 \pm 5.81 \mathrm{E}-08$

$1.24 \pm 0.12 \mathrm{E}-07$

$2.95 \pm 5.02 \mathrm{E}-08$

\section{APPLES}

Background

(BFVCTRA)

86.7

$-1.61 \pm 1.05 \mathrm{E}-07$

$8.30 \pm 1.14 \mathrm{E}-06$

$-1.32 \pm 2.60 \mathrm{E}-08$

6.42 $\pm 1.94 \mathrm{E}-09 \quad-0.04 \pm 1.94 \mathrm{E}-08$

Near-Site

(BFVNEAAF)

$84.8 \quad-0.26 \pm 1.08 \mathrm{E}-07 \quad 7.88 \pm 1.20 \mathrm{E}-06$

$0.13 \pm 1.82 \mathrm{E}-0$

7.72 $\pm 1.37 \mathrm{E}-09 \quad-1.21 \pm 2.19 \mathrm{E}-08$

HAY

Background

(BFHCTLS)

NA

NA

$2.22 \pm 0.26 \mathrm{E}-05$

$-0.74 \pm 3.45 \mathrm{E}-08$

$1.86 \pm 0.10 \mathrm{E}-07$

$0.19 \pm 3.16 \mathrm{E}-08$

Near-Site

(BFHNEAR)

NA

NA

$1.53 \pm 0.27 \mathrm{E}-05$

$1.11 \pm 6.11 \mathrm{E}-08$

$5.73 \pm 1.52 \mathrm{E}-08$

$5.06 \pm 6.23 \mathrm{E}-08$

NA - Not applicable.

Note: Bolding convention not applicable to these data.

$$
F-5
$$




\title{
Table F-4 \\ 2001 Radioactivity Concentrations ( $\mu$ Ci/g - dry) in Fish Flesh From Cattaraugus Creek
}

\author{
Cattaraugus Creek above the Springville Dam (BFFCATC)
}

1st Half 2001

\section{Species}

Hog-nosed Sucker

Hog-nosed Sucker

Hog-nosed Sucker

Hog-nosed Sucker

Hog-nosed Sucker

Brown Trout

Hog-nosed Sucker

Hog-nosed Sucker

Hog-nosed Sucker

Hog-nosed Sucker

Average \% Moisture

Median

Maximum

Minimum
$\%$ Moisture

Sr-90

$5.85 \pm 0.50 \mathrm{E}-08$

$7.09 \pm 0.57 \mathrm{E}-08$

$7.00 \pm 0.65 \mathrm{E}-08$

$1.20 \pm 0.11 \mathrm{E}-07$

$8.75 \pm 0.68 \mathrm{E}-08$

2.18 $\pm 0.32 E-08$

$9.08 \pm 0.63 \mathrm{E}-08$

$7.65 \pm 0.93 \mathrm{E}-08$

1.46 $\pm 0.12 E-07$

$9.08 \pm 0.97 \mathrm{E}-08$
Cs-137

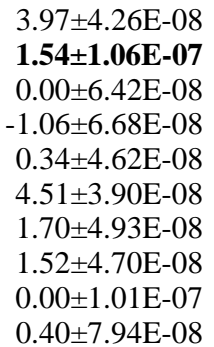

8.20E-08

$1.46 \mathrm{E}-07$

2.18E-08

$<5.68 \mathrm{E}-08$

$1.54 \mathrm{E}-07$

$<4.26 \mathrm{E}-08$

\section{2nd Half 2001}

\section{Species}

\% Moisture

Sr-90

Cs-137

Hog-nosed Sucker

Hog-nosed Sucker

Hog-nosed Sucker

Hog-nosed Sucker

Hog-nosed Sucker

Hog-nosed Sucker

Brook Trout

Hog-nosed Sucker

Hog-nosed Sucker

Hog-nosed Sucker

Average \% Moisture

$\mathbf{8 3 . 2}$
78.9
$\mathbf{7 7 . 6}$
78.0
79.5
82.1
78.6
80.2
80.3
80.4

$2.37 \pm 0.55 \mathrm{E}-08$
$1.33 \pm 5.14 \mathrm{E}-09$
$1.97 \pm 0.56 \mathrm{E}-08$
$8.97 \pm 5.44 \mathrm{E}-09$
$2.32 \pm 0.65 \mathrm{E}-08$
$2.21 \pm 0.96 \mathrm{E}-08$
$5.97 \pm 6.02 \mathrm{E}-09$
$2.16 \pm 0.68 \mathrm{E}-08$
$\mathbf{2 . 5 3} \pm \mathbf{0 . 4 2 E}-08$
$1.68 \pm 0.81 \mathrm{E}-08$

$0.00 \pm 1.04 \mathrm{E}-07$

$0.70 \pm 1.31 \mathrm{E}-07$

$0.05 \pm 1.14 \mathrm{E}-07$

$5.85 \pm 6.44 \mathrm{E}-08$

$1.26 \pm 0.68 \mathrm{E}-07$

1.91 $\pm 0.78 E-07$

$9.19 \pm 5.30 \mathrm{E}-08$

$9.32 \pm 7.42 \mathrm{E}-08$

$0.49 \pm 4.43 \mathrm{E}-08$

$1.88 \pm 0.91 \mathrm{E}-07$

79.9

Median

Maximum

Minimum

1.09E-07

$1.91 \mathrm{E}-07$

$<4.43 \mathrm{E}-08$

Note: Bolding convention applied to these data. See page F-2.

$$
\text { F- } 6
$$




\section{Table F-4 (continued) \\ 2001 Radioactivity Concentrations ( $\mu$ Ci/g - dry) in Fish Flesh From Cattaraugus Creek}

Cattaraugus Creek below the Springville Dam (BFFCATD)

\begin{tabular}{|c|c|c|c|}
\hline \multirow[b]{2}{*}{ Species } & \multirow[b]{2}{*}{ \% Moisture } & \multicolumn{2}{|c|}{ Annual 2001} \\
\hline & & Sr-90 & Cs-137 \\
\hline Steelhead Trout & 72.7 & $9.46 \pm 1.71 \mathrm{E}-09$ & $2.59 \pm 1.67 \mathrm{E}-08$ \\
\hline Steelhead Trout & 74.4 & $0.45 \pm 1.21 \mathrm{E}-09$ & $3.15 \pm 1.81 \mathrm{E}-08$ \\
\hline Steelhead Trout & 75.2 & $-1.93 \pm 9.10 \mathrm{E}-10$ & $2.20 \pm 2.54 \mathrm{E}-08$ \\
\hline Steelhead Trout & 76.2 & $2.59 \pm 8.47 \mathrm{E}-10$ & $0.00 \pm 2.45 \mathrm{E}-08$ \\
\hline Steelhead Trout & 75.2 & $-0.30 \pm 1.40 \mathrm{E}-09$ & $2.75 \pm 2.14 \mathrm{E}-08$ \\
\hline Steelhead Trout & 78.4 & $1.45 \pm 7.07 \mathrm{E}-10$ & $3.36 \pm 1.79 \mathrm{E}-08$ \\
\hline Steelhead Trout & 72.6 & $3.07 \pm 1.09 \mathrm{E}-09$ & $2.84 \pm 1.78 \mathrm{E}-08$ \\
\hline Steelhead Trout & 70.0 & $7.26 \pm 1.49 \mathrm{E}-09$ & $0.07 \pm 2.15 \mathrm{E}-08$ \\
\hline Steelhead Trout & 75.7 & $4.87 \pm 1.19 \mathrm{E}-09$ & $2.51 \pm 1.62 \mathrm{E}-08$ \\
\hline Steelhead Trout & 73.6 & $3.45 \pm 0.98 \mathrm{E}-09$ & $2.10 \pm 1.64 \mathrm{E}-08$ \\
\hline Average $\%$ Moisture & 74.4 & & \\
\hline Median & & 2.24E-09 & $2.56 \mathrm{E}-08$ \\
\hline Maximum & & 9.46E-09 & $3.36 \mathrm{E}-08$ \\
\hline Minimum & & $<7.07 \mathrm{E}-10$ & $2.10 \mathrm{E}-08$ \\
\hline
\end{tabular}

Note: Bolding convention applied to these data. See page F-2.

$$
F-7
$$




\section{Table F-4 (concluded) \\ 2001 Radioactivity Concentrations ( $\mu$ Ci/g - dry) in Fish Flesh From Cattaraugus Creek}

\section{Cattaraugus Creek Background (BFFCTRL)}

\section{1st Half 2001}

\section{Species}

Hog-nosed Sucker

White Sucker

Brown Trout

White Sucker

Brown Trout

White Sucker

White Sucker

Hog-nosed Sucker

Brown Trout

White Sucker

Average \% Moisture

Median

Maximum

Minimum
$\%$ Moisture

75.2
$\mathbf{7 9 . 1}$
76.3
77.6
75.0
77.9
75.1
77.6
$\mathbf{7 0 . 6}$
76.4

76.1

$$
\begin{array}{rr}
9.74 \mathrm{E}-09 & <5.74 \mathrm{E}-08 \\
2.27 \mathrm{E}-08 & 1.24 \mathrm{E}-07 \\
<4.15 \mathrm{E}-09 & <3.84 \mathrm{E}-08
\end{array}
$$

Cs-137

$$
\begin{array}{r}
0.39 \pm 5.97 \mathrm{E}-08 \\
3.74 \pm 4.75 \mathrm{E}-08 \\
-2.08 \pm 4.49 \mathrm{E}-08 \\
0.00 \pm 1.92 \mathrm{E}-07 \\
2.16 \pm 9.69 \mathrm{E}-08 \\
0.31 \pm 3.84 \mathrm{E}-08 \\
1.03 \pm 1.56 \mathrm{E}-07 \\
-2.21 \pm 4.56 \mathrm{E}-08 \\
\mathbf{1 . 2 4} \pm \mathbf{0 . 6 1 E}-07 \\
3.63 \pm 5.51 \mathrm{E}-08
\end{array}
$$

\section{2nd Half 2001}

\section{Species}

$\%$ Moisture

Sr-90

Cs-137

Hog-nosed Sucker

Hog-nosed Sucker

Hog-nosed Sucker

Hog-nosed Sucker

Brown Trout

White Sucker

Hog-nosed Sucker

White Sucker

Brown Trout

White Sucker

Average \% Moisture

Median

Maximum

Minimum

$$
\begin{aligned}
& 79.3 \\
& 79.0 \\
& 79.0 \\
& 78.6 \\
& 79.4 \\
& 78.9 \\
& 77.9 \\
& 79.4 \\
& \mathbf{7 7 . 1} \\
& \mathbf{8 1 . 0}
\end{aligned}
$$

79.0

$\begin{array}{rr}8.21 \pm 3.15 \mathrm{E}-09 & 6.87 \pm 7.36 \mathrm{E}-08 \\ 8.12 \pm 2.05 \mathrm{E}-09 & 0.00 \pm 1.96 \mathrm{E}-07 \\ 6.27 \pm 3.64 \mathrm{E}-09 & 1.11 \pm 4.60 \mathrm{E}-08 \\ 5.87 \pm 2.27 \mathrm{E}-09 & 0.14 \pm 4.82 \mathrm{E}-08 \\ -0.06 \pm 2.75 \mathrm{E}-09 & 1.00 \pm 4.84 \mathrm{E}-08 \\ 5.31 \pm 1.77 \mathrm{E}-09 & 0.00 \pm 5.01 \mathrm{E}-08 \\ 3.85 \pm 2.24 \mathrm{E}-09 & 2.36 \pm 5.48 \mathrm{E}-08 \\ \mathbf{3 . 9 6} \pm \mathbf{0 . 3 3 E}-08 & 0.38 \pm 1.16 \mathrm{E}-07 \\ 8.24 \pm 3.52 \mathrm{E}-09 & \mathbf{8 . 4 3} \pm \mathbf{7 . 2 4 E}-08 \\ 5.69 \pm 2.97 \mathrm{E}-09 & 2.05 \pm 3.44 \mathrm{E}-08\end{array}$

6.07E-09

3.96E-08

$<2.75 \mathrm{E}-09$
$<5.24 \mathrm{E}-08$

$8.43 \mathrm{E}-08$

$<3.44 \mathrm{E}-08$

Note: Bolding convention applied to these data. See page F-2.

$$
F-8
$$




\section{Appendix $G$ \\ Summary of Nonradiological Monitoring Data}

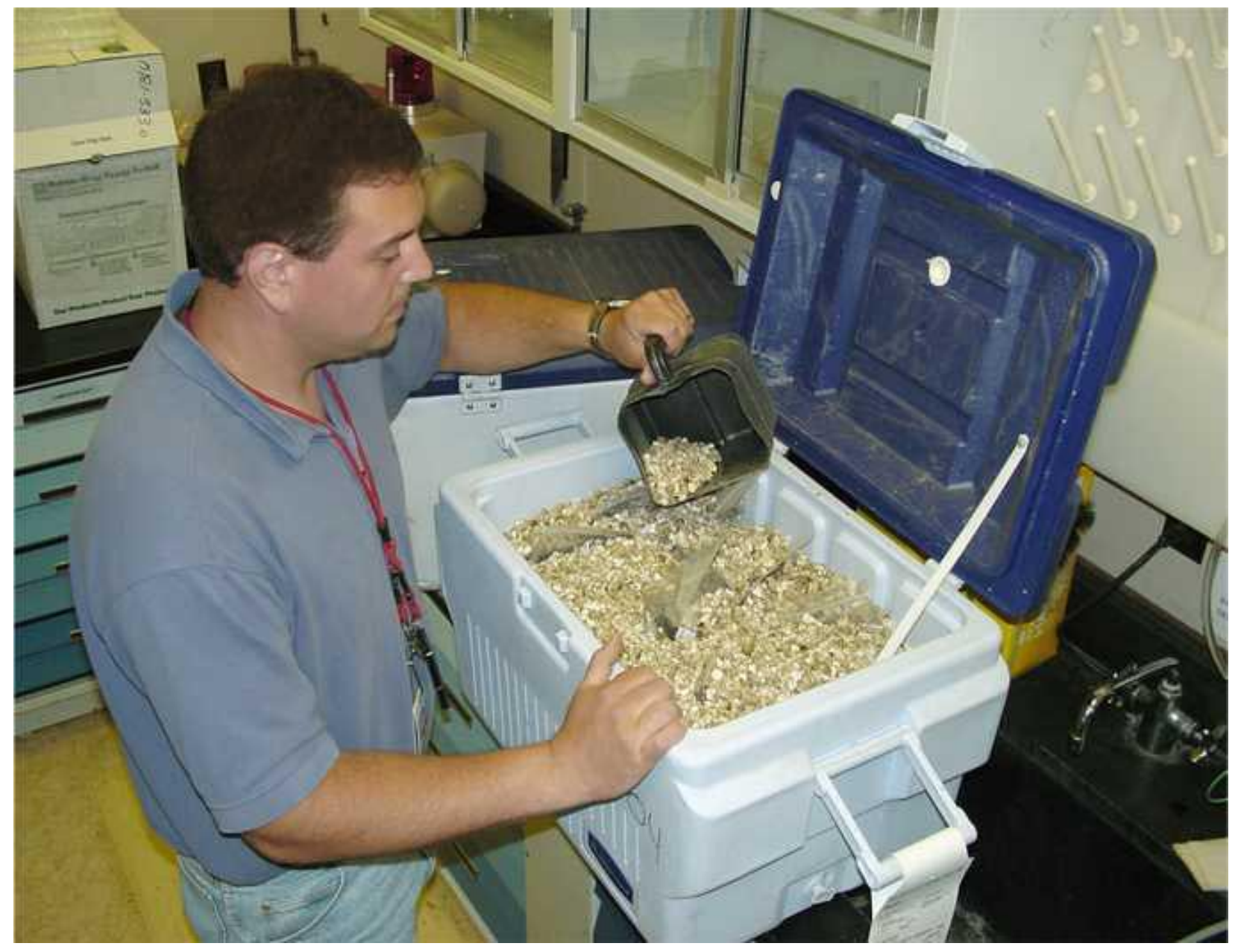

Packaging Samples for Shipment to Off-Site Laboratories 
This page intentionally left blank

$G-2$ 


\section{Table G-1 \\ West Valley Demonstration Project State Pollutant Discharge Elimination System (SPDES) Sampling Program}

\begin{tabular}{|c|c|c|c|}
\hline Outfall & Parameter & Maximum Limit* & Sample Frequency \\
\hline 001 (Process and Storm & Flow & Monitor & 2 per discharge \\
\hline Wastewater) & Aluminum, total & $14.0 \mathrm{mg} / \mathrm{L}$ & 2 per discharge \\
\hline & Ammonia $\left(\mathrm{NH}_{3}\right)$ & Monitor & 2 per discharge \\
\hline & Arsenic, dissolved & $0.15 \mathrm{mg} / \mathrm{L}$ & 2 per discharge \\
\hline & $\mathrm{BOD}_{5}$ & $10.0 \mathrm{mg} / \mathrm{L}$ & 2 per discharge \\
\hline & Iron, total & Monitor & 2 per discharge \\
\hline & Zinc, total recoverable & $0.48 \mathrm{mg} / \mathrm{L}$ & 2 per discharge \\
\hline & Suspended solids & $45.0 \mathrm{mg} / \mathrm{L}$ & 2 per discharge \\
\hline & Cyanide, amenable to chlorination & $0.022 \mathrm{mg} / \mathrm{L}$ & 2 per discharge \\
\hline & Settleable solids & $0.30 \mathrm{~mL} / \mathrm{L}$ & 2 per discharge \\
\hline & $\mathrm{pH}$ (range) & $6.5-8.5$ & 2 per discharge \\
\hline & Oil and grease & $15.0 \mathrm{mg} / \mathrm{L}$ & 2 per discharge \\
\hline & Sulfate (as S) & Monitor & 2 per discharge \\
\hline & Sulfide, dissolved & $0.4 \mathrm{mg} / \mathrm{L}$ & 2 per discharge \\
\hline & Manganese, total & $2.0 \mathrm{mg} / \mathrm{L}$ & 2 per discharge \\
\hline & Nitrate (as N) & Monitor & 2 per discharge \\
\hline & Nitrite (as N) & $0.1 \mathrm{mg} / \mathrm{L}$ & 2 per discharge \\
\hline & Chromium, total recoverable & $0.3 \mathrm{mg} / \mathrm{L}$ & 2 per discharge \\
\hline & Chromium, hexavalent, total recoverable & $0.011 \mathrm{mg} / \mathrm{L}$ & 2 per discharge \\
\hline & Cadmium, total recoverable & $0.002 \mathrm{mg} / \mathrm{L}$ & 2 per discharge \\
\hline & Copper, total recoverable & $0.030 \mathrm{mg} / \mathrm{L}$ & 2 per discharge \\
\hline & Copper, dissolved & Monitor & 2 per discharge \\
\hline & Lead, total recoverable & $0.006 \mathrm{mg} / \mathrm{L}$ & 2 per discharge \\
\hline & Nickel, total recoverable & $0.14 \mathrm{mg} / \mathrm{L}$ & 2 per discharge \\
\hline & Dichlorodifluoromethane & $0.01 \mathrm{mg} / \mathrm{L}$ & 2 per discharge \\
\hline & Trichlorofluoromethane & $0.01 \mathrm{mg} / \mathrm{L}$ & 2 per discharge \\
\hline & 3,3-dichlorobenzidine & $0.01 \mathrm{mg} / \mathrm{L}$ & 2 per discharge \\
\hline & Tributyl phosphate & $32 \mathrm{mg} / \mathrm{L}$ & 2 per discharge \\
\hline & Vanadium, total recoverable & $0.014 \mathrm{mg} / \mathrm{L}$ & 2 per discharge \\
\hline & Cobalt, total recoverable & $0.005 \mathrm{mg} / \mathrm{L}$ & 2 per discharge \\
\hline & Selenium, total recoverable & $0.004 \mathrm{mg} / \mathrm{L}$ & 2 per discharge \\
\hline & Hexachlorobenzene & $0.02 \mathrm{mg} / \mathrm{L}$ & 2 per discharge \\
\hline & Alpha-BHC & $0.00001 \mathrm{mg} / \mathrm{L}$ & 2 per discharge \\
\hline & Heptachlor & $0.00001 \mathrm{mg} / \mathrm{L}$ & 2 per discharge \\
\hline & Surfactants (as LAS) & $0.4 \mathrm{mg} / \mathrm{L}$ & 2 per discharge \\
\hline & Xylene & $0.05 \mathrm{mg} / \mathrm{L}$ & 2 per discharge \\
\hline & 2-butanone & $0.5 \mathrm{mg} / \mathrm{L}$ & 2 per discharge \\
\hline & Total Dissolved Solids & Monitor & 2 per discharge \\
\hline
\end{tabular}

* Daily average limitations are also identified in the permit but require only monitoring for all parameters except total aluminum (daily average limit - $7.0 \mathrm{mg} / \mathrm{L}$ ); suspended solids (daily average limit $-30.0 \mathrm{mg} / \mathrm{L}$ ); $B O D_{5}$ for the sum of outfalls 001, 007, and 008 (daily average limit - $5.0 \mathrm{mg} / \mathrm{L}$ ); and ammonia for the sum of outfalls 001 and 007 (daily average limit $-1.49 \mathrm{mg} / \mathrm{L}$ ).

$$
G-3
$$




\section{Table G-1 (concluded) \\ West Valley Demonstration Project State Pollutant Discharge Elimination System (SPDES) Sampling Program}

\begin{tabular}{|c|c|c|c|}
\hline Outfall & Parameter & Daily Maximum Limit* & Sample Frequency \\
\hline 001 (continued) & $\begin{array}{l}\text { Barium } \\
\text { Antimony } \\
\text { Chloroform } \\
\text { Bis(2-ethylhexyl)phthalate } \\
\text { 4-Dodecene } \\
\text { Titanium }\end{array}$ & $\begin{array}{l}0.5 \mathrm{mg} / \mathrm{L} \\
1.0 \mathrm{mg} / \mathrm{L} \\
0.3 \mathrm{mg} / \mathrm{L} \\
1.6 \mathrm{mg} / \mathrm{L} \\
0.6 \mathrm{mg} / \mathrm{L} \\
0.65 \mathrm{mg} / \mathrm{L}\end{array}$ & $\begin{array}{l}\text { annual } \\
\text { annual } \\
\text { annual } \\
\text { semiannual } \\
\text { semiannual } \\
\text { semiannual }\end{array}$ \\
\hline $\begin{array}{l}007 \text { (Sanitary and } \\
\text { Utility Wastewater) }\end{array}$ & $\begin{array}{l}\text { Flow } \\
\text { Ammonia }\left(\text { as } \mathrm{NH}_{3}\right) \\
\mathrm{BOD}_{5} \\
\text { Iron, total } \\
\text { Solids, suspended } \\
\text { Solids, settleable } \\
\text { pH (range) } \\
\text { Nitrite (as N) } \\
\text { Oil and grease } \\
\text { Chlorine, total residual } \\
\text { Chloroform }\end{array}$ & $\begin{array}{l}\text { Monitor } \\
\text { Monitor } \\
10 \mathrm{mg} / \mathrm{L} \\
\text { Monitor } \\
45.0 \mathrm{mg} / \mathrm{L} \\
0.3 \mathrm{~mL} / \mathrm{L} \\
6.5-8.5 \\
0.1 \mathrm{mg} / \mathrm{L} \\
15 \mathrm{mg} / \mathrm{L} \\
0.1 \mathrm{mg} / \mathrm{L} \\
0.20 \mathrm{mg} / \mathrm{L}\end{array}$ & $\begin{array}{l}3 \text { per month } \\
3 \text { per month } \\
3 \text { per month } \\
3 \text { per month } \\
3 \text { per month } \\
\text { weekly } \\
\text { weekly } \\
3 \text { per month } \\
3 \text { per month } \\
\text { weekly } \\
\text { annual }\end{array}$ \\
\hline $\begin{array}{l}008 \text { (French Drain } \\
\text { Wastewater) }\end{array}$ & $\begin{array}{l}\text { Flow } \\
\text { BOD }_{5} \\
\text { Iron, total } \\
\text { pH (range) } \\
\text { Cadmium, total recoverable } \\
\text { Lead, total recoverable } \\
\text { Silver, total } \\
\text { Zinc, total } \\
\text { Arsenic } \\
\text { Chromium }\end{array}$ & $\begin{array}{l}\text { Monitor } \\
5.0 \mathrm{mg} / \mathrm{L} \\
\text { Monitor } \\
6.5-8.5 \\
0.002 \mathrm{mg} / \mathrm{L} \\
0.006 \mathrm{mg} / \mathrm{L} \\
0.008 \mathrm{mg} / \mathrm{L} \\
0.100 \mathrm{mg} / \mathrm{L} \\
0.17 \mathrm{mg} / \mathrm{L} \\
0.13 \mathrm{mg} / \mathrm{L}\end{array}$ & $\begin{array}{l}3 \text { per month } \\
3 \text { per month } \\
3 \text { per month } \\
3 \text { per month } \\
3 \text { per month } \\
3 \text { per month } \\
\text { annual } \\
\text { annual } \\
\text { annual } \\
\text { annual }\end{array}$ \\
\hline $\begin{array}{l}\text { Sum of Outfalls 001, } \\
007 \text {, and } 008\end{array}$ & $\begin{array}{l}\text { Iron, total } \\
\mathrm{BOD}_{5}\end{array}$ & $\begin{array}{l}0.30 \mathrm{mg} / \mathrm{L} \\
\text { Monitor }\end{array}$ & $\begin{array}{l}3 \text { per month } \\
3 \text { per month }\end{array}$ \\
\hline $\begin{array}{l}\text { Sum of Outfalls } 001 \\
\text { and } 007\end{array}$ & Ammonia $\left(\right.$ as $\left.\mathrm{NH}_{3}\right)$ & $2.1 \mathrm{mg} / \mathrm{L}$ & 3 per month \\
\hline $\begin{array}{l}\text { Pseudo-monitoring } \\
\text { point (116) }\end{array}$ & Solids, total dissolved & $500 \mathrm{mg} / \mathrm{L}$ & 2 per discharge \\
\hline
\end{tabular}

$G-4$

WVDP Site Environmental Report

Calendar Year 2001 


\section{Table G-2}

\section{SPDES Results for Outfall 001 (WNSP001) Water Quality}

\begin{tabular}{|c|c|c|c|c|c|c|c|c|}
\hline \multirow{3}{*}{$\begin{array}{l}\text { Analyte: } \\
\text { Permit limit: } \\
\text { Month }\end{array}$} & \multicolumn{2}{|c|}{$\underset{(\mathrm{mg} / \mathrm{L})}{\operatorname{Ammonia}} \mathbf{N H}_{3}$} & \multicolumn{2}{|c|}{$\underset{(\mathrm{mg} / \mathrm{L})}{\text { BOD }_{5}}$} & \multicolumn{2}{|c|}{$\begin{array}{c}\text { Cyanide } \\
(\mathrm{mg} / \mathrm{L}) \\
\text { (amenable to chlorination) }\end{array}$} & \multicolumn{2}{|c|}{$\begin{array}{c}\text { Discharge Rate } \\
\text { (MGD) }\end{array}$} \\
\hline & \multicolumn{2}{|c|}{ Monitor } & \multicolumn{2}{|c|}{$10.0 \mathrm{mg} / \mathrm{L}$ daily maximum } & \multicolumn{2}{|c|}{$0.022 \mathrm{mg} / \mathrm{L}$ daily maximum } & \multicolumn{2}{|c|}{ Monitor } \\
\hline & Avg & Max & Avg & Max & Avg & Max & Avg & Max \\
\hline $\begin{array}{l}\text { January } \\
\text { February* }\end{array}$ & $<0.016$ & 0.021 & $<2.0$ & $<2.0$ & $<0.013$ & 0.016 & 0.334 & 0.510 \\
\hline $\begin{array}{l}\text { March } \\
\text { April** }^{*}\end{array}$ & 0.18 & 0.19 & $<2.0$ & $<2.0$ & $<0.010$ & $<0.010$ & 0.371 & 0.471 \\
\hline $\begin{array}{l}\text { May } \\
\text { June* } \\
\text { July* }\end{array}$ & $<0.010$ & $<0.010$ & $<2.0$ & $<2.0$ & $<0.010$ & $<0.010$ & 0.241 & 0.647 \\
\hline $\begin{array}{l}\text { August } \\
\text { September* } \\
\text { October* }\end{array}$ & $<0.010$ & $<0.010$ & $<2.0$ & $<2.0$ & $<0.010$ & $<0.010$ & 0.147 & 0.271 \\
\hline $\begin{array}{l}\text { October* } \\
\text { November } \\
\text { December* }\end{array}$ & $<0.011$ & 0.012 & $<2.0$ & $<2.0$ & $<0.010$ & $<0.010$ & 0.225 & 0.357 \\
\hline Analyte: & Nit & , as N & Nitr & $\begin{array}{l}\text { as } \mathbf{N} \\
\mathrm{L})\end{array}$ & Oil & $\begin{array}{l}\text { Grease } \\
\mathrm{g} / \mathrm{L})\end{array}$ & & \\
\hline Permit limit: & & itor & $0.1 \mathrm{mg} / \mathrm{Lc}$ & maximum & $15.0 \mathrm{mg} / \mathrm{L}$ & ily maximum & & \\
\hline Month & Avg & Max & Avg & Max & Avg & Max & & \\
\hline $\begin{array}{l}\text { January } \\
\text { February* }\end{array}$ & 1.1 & 1.1 & $<0.05$ & $<0.05$ & $<5.0$ & $<5.0$ & & \\
\hline $\begin{array}{l}\text { March } \\
\text { April* }\end{array}$ & 1.4 & 1.5 & $<0.05$ & $<0.05$ & $<5.0$ & $<5.0$ & & \\
\hline $\begin{array}{l}\text { May } \\
\text { June* } \\
\text { July* }\end{array}$ & 1.2 & 1.3 & $<0.05$ & $<0.05$ & $<5.0$ & $<5.0$ & & \\
\hline $\begin{array}{l}\text { August } \\
\text { September* } \\
\text { October* }\end{array}$ & $<0.11$ & 0.17 & $<0.05$ & $<0.05$ & $<5.0$ & $<5.0$ & & \\
\hline $\begin{array}{l}\text { November } \\
\text { December* }\end{array}$ & $<0.05$ & $<0.05$ & $<0.05$ & $<0.05$ & $<5.0$ & $<5.0$ & & \\
\hline
\end{tabular}

* No discharge this month.

Note: No results exceeded the permit limits.

WVDP Site Environmental Report

$G-5$ 


\section{Table G-2 (concluded) \\ 2001 SPDES Results for Outfall 001 (WNSP001) \\ Water Quality}

\begin{tabular}{|c|c|c|c|c|c|c|c|c|}
\hline \multirow{3}{*}{$\begin{array}{l}\text { Analyte } \\
\text { Permit limit: } \\
\text { Month }\end{array}$} & \multicolumn{2}{|c|}{$\begin{array}{c}\mathbf{p H} \\
\text { (standard units) }\end{array}$} & \multicolumn{2}{|c|}{$\begin{array}{c}\text { Solids } \\
\text { Settleable } \\
(\mathrm{mL} / \mathrm{L})\end{array}$} & \multicolumn{2}{|c|}{$\begin{array}{c}\text { Solids } \\
\text { Total Dissolved } \\
(\mathrm{mg} / \mathrm{L})\end{array}$} & \multicolumn{2}{|c|}{$\begin{array}{c}\text { Solids } \\
\text { Total Suspended } \\
(\mathrm{mg} / \mathrm{L})\end{array}$} \\
\hline & \multicolumn{2}{|c|}{6.5 to 8.5} & \multicolumn{2}{|c|}{$0.30 \mathrm{ml} / \mathrm{L}$ daily maximum } & \multicolumn{2}{|c|}{ Monitor } & \multicolumn{2}{|c|}{$\begin{array}{c}45.0 \mathrm{mg} / \mathrm{L} \text { daily maximum } \\
30.0 \mathrm{mg} / \mathrm{L} \text { daily average }\end{array}$} \\
\hline & Min & Max & Avg & Max & Avg & Max & Avg & Max \\
\hline $\begin{array}{l}\text { January } \\
\text { February* }\end{array}$ & 7.0 & 7.1 & $<0.1$ & $<0.1$ & 548 & 565 & 25.5 & 44.0 \\
\hline $\begin{array}{l}\text { March } \\
\text { April** }\end{array}$ & 8.0 & 8.1 & $<0.1$ & $<0.1$ & 622 & 629 & 4.8 & 5.5 \\
\hline $\begin{array}{l}\text { May } \\
\text { June* } \\
\text { July* }\end{array}$ & 7.3 & 8.0 & $<0.1$ & $<0.1$ & 690 & 695 & 4.2 & 5.0 \\
\hline $\begin{array}{l}\text { August } \\
\text { September* } \\
\text { October* }\end{array}$ & 7.5 & 7.8 & $<0.1$ & $<0.1$ & 846 & 872 & 5.5 & 8.0 \\
\hline $\begin{array}{l}\text { November } \\
\text { December* }\end{array}$ & 7.6 & 8.1 & $<0.1$ & $<0.1$ & 794 & 830 & $<4.6$ & 7.3 \\
\hline Analyte & \multicolumn{2}{|c|}{$\begin{array}{l}\text { Sulfate, as S } \\
(\mathrm{mg} / \mathrm{L})\end{array}$} & \multicolumn{2}{|c|}{$\begin{array}{c}\text { Sulfide, as S } \\
\text { Dissolved } \\
(\mathrm{mg} / \mathrm{L})\end{array}$} & \multicolumn{2}{|c|}{$\underset{(\mathrm{mg} / \mathrm{L})}{\text { Surfactants as LAS }}$} & & \\
\hline Permit limit: & \multicolumn{2}{|c|}{ Monitor } & \multicolumn{2}{|c|}{$0.4 \mathrm{mg} / \mathrm{L}$ daily maximum } & \multicolumn{2}{|c|}{$0.4 \mathrm{mg} / \mathrm{L}$ daily maximum } & & \\
\hline Month & Avg & Max & Avg & Max & Avg & Max & & \\
\hline $\begin{array}{l}\text { January } \\
\text { February* }\end{array}$ & 99 & 161 & $<0.2$ & $<0.2$ & $<0.1$ & $<0.1$ & & \\
\hline $\begin{array}{l}\text { March } \\
\text { April }^{*}\end{array}$ & 45 & 47 & $<0.2$ & $<0.2$ & $<0.1$ & $<0.1$ & & \\
\hline $\begin{array}{l}\text { May } \\
\text { June* } \\
\text { July* }\end{array}$ & 29 & 45 & $<0.2$ & $<0.2$ & $<0.1$ & $<0.1$ & & \\
\hline $\begin{array}{l}\text { August } \\
\text { September* } \\
\text { October* }\end{array}$ & 62 & 66 & $<0.2$ & $<0.2$ & $<0.1$ & $<0.1$ & & \\
\hline $\begin{array}{l}\text { November } \\
\text { December* }\end{array}$ & 62 & 62 & $<0.2$ & $<0.2$ & $<0.1$ & $<0.1$ & & \\
\hline
\end{tabular}

* No discharge this month.

Note: No results exceeded the permit limits.

$G-6$

WVDP Site Environmental Report

Calendar Year 2001 


\section{Table G-3 \\ 2001 SPDES Results for Outfall 001 (WNSP001) Metals}

\begin{tabular}{|c|c|c|c|c|c|c|c|c|}
\hline Analyte: & & $\begin{array}{l}\text { inum } \\
\text { tal } \\
\text { /L) }\end{array}$ & & $\begin{array}{l}\text { enic } \\
\text { lved } \\
/ L)\end{array}$ & $\begin{array}{r}\text { Ca } \\
\text { Total R } \\
(1\end{array}$ & $\begin{array}{l}\text { lium } \\
\text { overable } \\
\text { (L) }\end{array}$ & Total $\underset{(1}{\mathbf{R}}$ & $\begin{array}{l}\text { alt } \\
\text { overable } \\
\text { /L) }\end{array}$ \\
\hline Permit limit: & $\begin{array}{l}14 \mathrm{mg} / \mathrm{L} \\
7.0 \mathrm{mg} / \mathrm{L}\end{array}$ & $\begin{array}{l}\text { y maximum } \\
\text { ily average }\end{array}$ & $0.15 \mathrm{mg} / \mathrm{L}$ & ily maximum & $0.002 \mathrm{mg} / \mathrm{L}$ & ily maximum & $0.005 \mathrm{mg} / \mathrm{L}$ & ily maximum \\
\hline Month & Avg & Max & Avg & Max & Avg & Max & Avg & Max \\
\hline $\begin{array}{l}\text { January } \\
\text { February* }\end{array}$ & $<0.227$ & 0.254 & $<0.001$ & $<0.001$ & $<0.001$ & $<0.001$ & $<0.004$ & $<0.004$ \\
\hline $\begin{array}{l}\text { March } \\
\text { April* }\end{array}$ & 0.320 & 0.373 & $<0.001$ & $<0.001$ & $<0.001$ & $<0.001$ & $<0.004$ & $<0.004$ \\
\hline $\begin{array}{l}\text { May } \\
\text { June* } \\
\text { July* }\end{array}$ & $<0.200$ & $<0.200$ & $<0.001$ & $<0.001$ & $<0.001$ & $<0.001$ & $<0.004$ & $<0.004$ \\
\hline $\begin{array}{l}\text { August } \\
\text { September* } \\
\text { October* }\end{array}$ & $<0.200$ & $<0.200$ & $<0.003$ & $<0.003$ & $<0.001$ & $<0.001$ & $<0.004$ & $<0.004$ \\
\hline $\begin{array}{l}\text { November } \\
\text { December* }\end{array}$ & $<0.203$ & 0.206 & 0.001 & 0.001 & $<0.001$ & $<0.001$ & $<0.004$ & $<0.004$ \\
\hline Analyte: & $\begin{array}{r}\text { Ch } \\
\text { Total I }\end{array}$ & $\begin{array}{l}\text { nium } \\
\text { overable } \\
\text { /L) }\end{array}$ & $\begin{array}{c}\text { Chr } \\
\text { Total I }\end{array}$ & $\begin{array}{l}\text { lium VI } \\
\text { coverable } \\
\mathrm{g} / \mathrm{L})\end{array}$ & & $\begin{array}{l}\text { per } \\
\text { lved } \\
\text { /L) }\end{array}$ & & \\
\hline Permit limit: & $0.3 \mathrm{mg} / \mathrm{L}$ & ly maximum & $0.011 \mathrm{mg} / \mathrm{l}$ & aily maximum & & iitor & & \\
\hline Month & Avg & Max & Avg & Max & Avg & Max & & \\
\hline $\begin{array}{l}\text { January } \\
\text { February* }\end{array}$ & $<0.002$ & $<0.002$ & $<0.002$ & $<0.002$ & 0.005 & 0.006 & & \\
\hline $\begin{array}{l}\text { March } \\
\text { April* }\end{array}$ & $<0.002$ & $<0.002$ & $<0.010$ & $<0.010$ & $<0.010$ & $<0.010$ & & \\
\hline $\begin{array}{l}\text { May } \\
\text { June* } \\
\text { July* }\end{array}$ & $<0.002$ & $<0.002$ & $<0.010$ & $<0.010$ & $<0.010$ & $<0.010$ & & \\
\hline $\begin{array}{l}\text { August } \\
\text { September* } \\
\text { October* }\end{array}$ & $<0.002$ & $<0.002$ & $<0.010$ & $<0.010$ & $<0.010$ & $<0.010$ & & \\
\hline $\begin{array}{l}\text { November } \\
\text { December* }\end{array}$ & $<0.002$ & $<0.002$ & $<0.010$ & $<0.010$ & $<0.010$ & $<0.010$ & & \\
\hline
\end{tabular}

* No discharge this month.

Note: No results exceeded the permit limits.

$$
G-7
$$

WVDP Site Environmental Report 


\section{Table G-3 (concluded) \\ 2001 SPDES Results for Outfall 001 (WNSP001) Metals}

\begin{tabular}{|c|c|c|c|c|c|c|c|c|}
\hline Analyte: & Total & $\begin{array}{l}\text { per } \\
\text { coverable } \\
\text { (L) }\end{array}$ & & & Total R & $\begin{array}{l}\text { ead } \\
\text { coverable } \\
g / L)\end{array}$ & & $\begin{array}{l}\text { anese } \\
\text { al } \\
\text { L) }\end{array}$ \\
\hline Permit limit: & $\begin{array}{r}0.6 \\
\text { dail }\end{array}$ & $\begin{array}{l}m g / L \\
\text { aximum }\end{array}$ & & itor & $\begin{array}{r}0.0 \\
\text { daily }\end{array}$ & $\begin{array}{l}\mathrm{mg} / \mathrm{L} \\
\text { aximum }\end{array}$ & $\begin{array}{r}2.8 \\
\text { daily }\end{array}$ & $\begin{array}{l}g / L \\
\text { ximum }\end{array}$ \\
\hline Month & Avg & Max & Avg & Max & Avg & Max & Avg & Max \\
\hline $\begin{array}{l}\text { January } \\
\text { February* }\end{array}$ & $<0.012$ & 0.016 & 0.242 & 0.260 & 0.002 & 0.003 & 0.021 & 0.021 \\
\hline $\begin{array}{l}\text { March } \\
\text { April* }\end{array}$ & $<0.010$ & $<0.010$ & 0.290 & 0.342 & $<0.0005$ & $<0.0005$ & 0.018 & 0.019 \\
\hline $\begin{array}{l}\text { May } \\
\text { June* } \\
\text { July* }\end{array}$ & $<0.010$ & $<0.010$ & 0.104 & 0.113 & $<0.003$ & $<0.003$ & 0.0268 & 0.0462 \\
\hline $\begin{array}{l}\text { August } \\
\text { September* } \\
\text { October* }\end{array}$ & $<0.010$ & $<0.010$ & 0.165 & 0.201 & $<0.003$ & $<0.003$ & 0.0662 & 0.0815 \\
\hline $\begin{array}{l}\text { November } \\
\text { December* }\end{array}$ & $<0.010$ & $<0.010$ & 0.183 & 0.187 & $<0.0005$ & $<0.0005$ & 0.0096 & 0.0115 \\
\hline Analyte: & Total I & $\begin{array}{l}\text { kel } \\
\text { coverable } \\
\text { s/L) }\end{array}$ & $\begin{array}{r}\text { Se } \\
\text { Total I }\end{array}$ & $\begin{array}{l}\text { nium } \\
\text { overable } \\
\text { /L) }\end{array}$ & $\begin{array}{r}\text { Va } \\
\text { Total } \\
\text { ( }\end{array}$ & $\begin{array}{l}\text { adium } \\
\text { coverable } \\
\mathrm{g} / \mathrm{L})\end{array}$ & Total F & $\begin{array}{l}\text { nc } \\
\text { overable } \\
\text { /L) }\end{array}$ \\
\hline Permit limit: & $\begin{array}{r}0 . \\
\text { dail }\end{array}$ & $\begin{array}{l}m g / L \\
\text { aximum }\end{array}$ & $\begin{array}{r}0.0 \\
\text { daily }\end{array}$ & $\begin{array}{l}m g / L \\
\text { aximum }\end{array}$ & $\begin{array}{r}0.0 \\
\text { daily }\end{array}$ & $\begin{array}{l}4 \mathrm{mg} / \mathrm{L} \\
\text { naximum }\end{array}$ & $\begin{array}{r}0.4 \\
\text { daily }\end{array}$ & $\begin{array}{l}m g / L \\
\text { aximum }\end{array}$ \\
\hline Month & Avg & Max & Avg & Max & Avg & Max & Avg & $\operatorname{Max}$ \\
\hline $\begin{array}{l}\text { January } \\
\text { February* }\end{array}$ & $<0.010$ & $<0.010$ & $<0.001$ & $<0.001$ & $<0.010$ & $<0.010$ & 0.012 & 0.013 \\
\hline $\begin{array}{l}\text { March } \\
\text { April* }\end{array}$ & $<0.010$ & $<0.010$ & $<0.001$ & $<0.001$ & $<0.010$ & $<0.010$ & $<0.010$ & $<0.010$ \\
\hline $\begin{array}{l}\text { May } \\
\text { June * } \\
\text { July* }\end{array}$ & $<0.010$ & $<0.010$ & $<0.001$ & $<0.001$ & $<0.010$ & $<0.010$ & $<0.010$ & $<0.010$ \\
\hline $\begin{array}{l}\text { August } \\
\text { September* } \\
\text { October* }\end{array}$ & $<0.010$ & $<0.010$ & $<0.002$ & $<0.002$ & $<0.010$ & $<0.010$ & $<0.010$ & $<0.010$ \\
\hline $\begin{array}{l}\text { November } \\
\text { December* }\end{array}$ & $<0.010$ & $<0.010$ & $<0.001$ & 0.001 & $<0.010$ & $<0.010$ & $<0.013$ & 0.016 \\
\hline
\end{tabular}

* No discharge this month.

Note: No results exceeded the permit limits.

$G-8$

WVDP Site Environmental Report 


\section{Table G-4 \\ 2001 SPDES Results for Outfall 001 (WNSP001) Organics}

\section{VOLATILES}

\begin{tabular}{|c|c|c|c|c|c|c|c|c|}
\hline Analyte: & 2-B & $\begin{array}{l}\text { anone } \\
\text { /L) }\end{array}$ & Dichlorof & $\begin{array}{l}\text { romethane } \\
\text { L) }\end{array}$ & Trichloro & $\begin{array}{l}\text { promethane } \\
\text { /L) }\end{array}$ & & $\begin{array}{l}\text { ene } \\
\text { L) }\end{array}$ \\
\hline Permit limit: & $\begin{array}{r}0 . \\
\text { daily }\end{array}$ & $\begin{array}{l}\text { ng/L } \\
\text { aximum }\end{array}$ & $\begin{array}{r}0 . \\
\text { daily }\end{array}$ & $\begin{array}{l}\text { ng/L } \\
\text { ximum }\end{array}$ & $\begin{array}{r}0.6 \\
\text { daily }\end{array}$ & $\begin{array}{l}\mathrm{ng} / \mathrm{L} \\
\text { ximum }\end{array}$ & $\begin{array}{r}0.0 \\
\text { daily }\end{array}$ & $\begin{array}{l}n g / L \\
\text { ximum }\end{array}$ \\
\hline Month & Avg & Max & Avg & Max & Avg & Max & Avg & Max \\
\hline $\begin{array}{l}\text { January } \\
\text { February* }\end{array}$ & $<0.010$ & $<0.010$ & $<0.005$ & $<0.005$ & $<0.005$ & $<0.005$ & $<0.005$ & $<0.005$ \\
\hline $\begin{array}{l}\text { March } \\
\text { April** }\end{array}$ & $<0.010$ & $<0.010$ & $<0.005$ & $<0.005$ & $<0.005$ & $<0.005$ & $<0.005$ & $<0.005$ \\
\hline $\begin{array}{l}\text { May } \\
\text { June* } \\
\text { Julv* }\end{array}$ & $<0.010$ & $<0.010$ & $<0.005$ & $<0.005$ & $<0.005$ & $<0.005$ & $<0.005$ & $<0.005$ \\
\hline $\begin{array}{l}\text { August } \\
\text { September* } \\
\text { October* }\end{array}$ & $<0.010$ & $<0.010$ & $<0.005$ & $<0.005$ & $<0.005$ & $<0.005$ & $<0.005$ & $<0.005$ \\
\hline $\begin{array}{l}\text { November } \\
\text { December* }\end{array}$ & $<0.010$ & $<0.010$ & $<0.005$ & $<0.005$ & $<0.005$ & $<0.005$ & $<0.005$ & $<0.005$ \\
\hline
\end{tabular}

\section{SEMIVOLATILES}

\begin{tabular}{|c|c|c|c|c|c|c|}
\hline \multirow{3}{*}{$\begin{array}{l}\text { Analyte: } \\
\text { Permit limit: } \\
\text { Month }\end{array}$} & \multirow{2}{*}{\multicolumn{2}{|c|}{$\begin{array}{c}\begin{array}{c}\text { Alpha-BHC } \\
(\mathrm{mg} / \mathrm{L})\end{array} \\
0.00001 \mathrm{mg} / \mathrm{L} \\
\text { daily maximum }\end{array}$}} & \multicolumn{2}{|c|}{$\begin{array}{l}\text { 3,3-Dichlorobenzidene } \\
(\mathrm{mg} / \mathrm{L})\end{array}$} & \multicolumn{2}{|c|}{$\begin{array}{c}\text { Hexachlorobenzene } \\
(\mathrm{mg} / \mathrm{L})\end{array}$} \\
\hline & & & & $\begin{array}{l}n g / L \\
\text { ximum }\end{array}$ & $\begin{array}{r}0 . \\
\text { dail }\end{array}$ & mum \\
\hline & Avg & Max & Avg & Max & Avg & Max \\
\hline $\begin{array}{l}\text { January } \\
\text { February* }\end{array}$ & $<0.000009$ & $<0.000009$ & $<0.009$ & $<0.009$ & $<0.010$ & $<0.010$ \\
\hline $\begin{array}{l}\text { March } \\
\text { April** }^{*}\end{array}$ & $<0.000009$ & $<0.000009$ & $<0.0099$ & $<0.0099$ & $<0.010$ & $<0.010$ \\
\hline $\begin{array}{l}\text { May } \\
\text { June* }\end{array}$ & $<0.000009$ & $<0.000009$ & $<0.009$ & $<0.009$ & $<0.010$ & $<0.010$ \\
\hline $\begin{array}{l}\text { July* } \\
\text { August } \\
\text { September* }\end{array}$ & $<0.000009$ & $<0.000009$ & $<0.009$ & $<0.009$ & $<0.010$ & $<0.010$ \\
\hline October* & & & & & & \\
\hline $\begin{array}{l}\text { November } \\
\text { December* }\end{array}$ & $<0.000009$ & $<0.000009$ & $<0.009$ & $<0.009$ & $<0.010$ & $<0.010$ \\
\hline
\end{tabular}

$G-9$

WVDP Site Environmental Report 


\section{Table G-4 (concluded) \\ 2001 SPDES Results for Outfall 001 (WNSP001) \\ Organics}

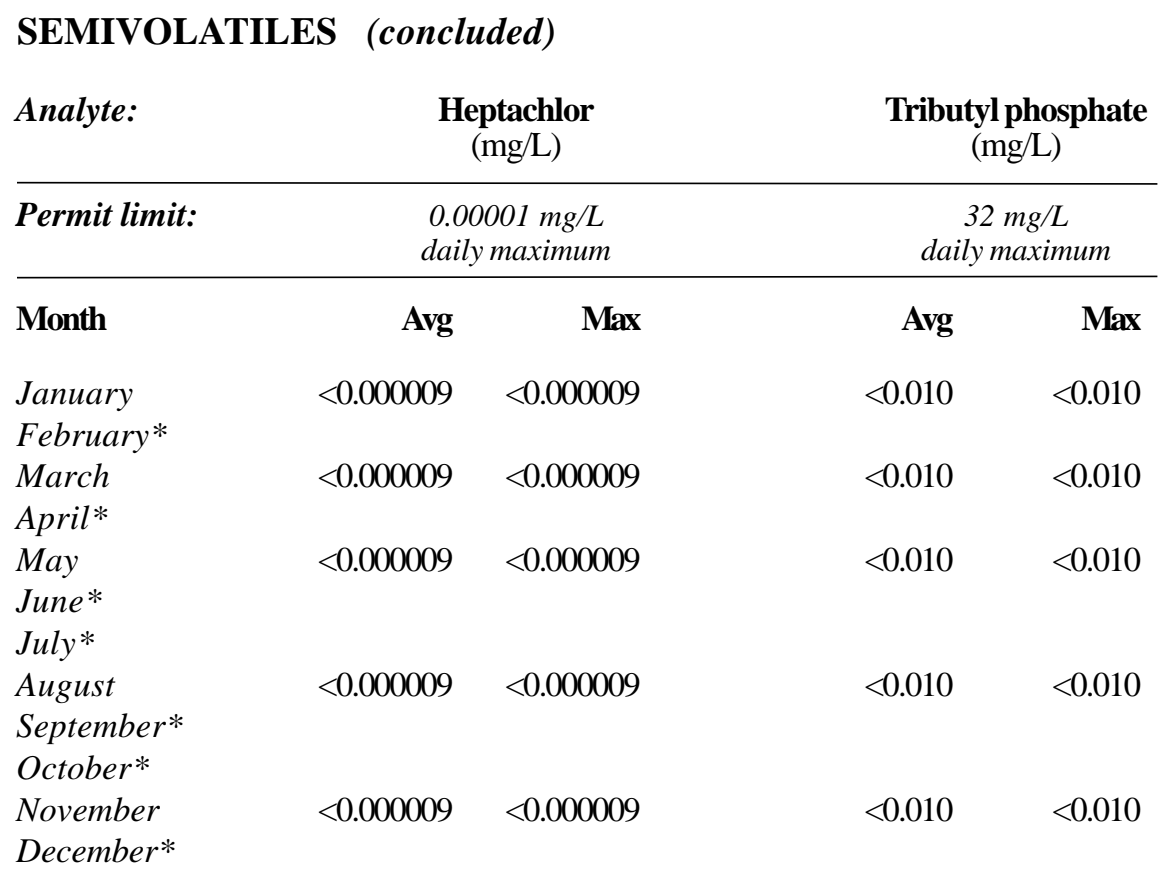

* No discharge this month.

Note: No results exceeded the permit limits.

WVDP Site Environmental Report

$G-10$ 
Table G-5

\section{SPDES Results for Outfall 007 (WNSP007) \\ Water Quality and Iron}

\begin{tabular}{|c|c|c|c|c|c|c|c|c|c|c|}
\hline \multirow{3}{*}{$\begin{array}{l}\text { Analyte: } \\
\text { Permit limit: } \\
\text { Month }\end{array}$} & \multicolumn{2}{|c|}{$\underset{(\mathrm{mg} / \mathrm{L})}{\operatorname{Ammonia}, \mathbf{N H}_{3}}$} & \multicolumn{2}{|c|}{$\begin{array}{l}\text { BOD }_{5} \\
(\mathrm{mg} / \mathrm{L})\end{array}$} & \multicolumn{2}{|c|}{$\begin{array}{c}\text { Chlorine } \\
\text { Total Residual } \\
(\mathrm{mg} / \mathrm{L})\end{array}$} & \multicolumn{2}{|c|}{$\begin{array}{c}\text { Discharge Rate } \\
\text { (MGD) }\end{array}$} & \multicolumn{2}{|c|}{$\begin{array}{l}\text { Iron } \\
\text { Total } \\
(\mathrm{mg} / \mathrm{L})\end{array}$} \\
\hline & \multicolumn{2}{|c|}{ Monitor } & \multicolumn{2}{|c|}{$\begin{array}{c}10 \mathrm{mg} / \mathrm{L} \\
\text { daily maximum }\end{array}$} & \multicolumn{2}{|c|}{$\begin{array}{c}0.1 \mathrm{mg} / \mathrm{L} \\
\text { daily maximum }\end{array}$} & \multicolumn{2}{|c|}{ Monitor } & \multicolumn{2}{|c|}{ Monitor } \\
\hline & Avg & Max & Avg & Max & Avg & Max & Avg & Max & Avg & Max \\
\hline January & $<0.034$ & 0.063 & $<2.2$ & 2.7 & 0.03 & 0.05 & 0.018 & 0.038 & 0.095 & 0.105 \\
\hline February & $<0.010$ & $<0.010$ & $<2.2$ & 2.7 & 0.02 & 0.02 & 0.028 & 0.050 & 0.132 & 0.169 \\
\hline March & $<0.010$ & $<0.010$ & $<2.0$ & $<2.0$ & 0.02 & 0.04 & 0.031 & 0.052 & 0.143 & 0.211 \\
\hline April & $<0.015$ & 0.019 & $<2.1$ & 2.2 & 0.02 & 0.03 & 0.017 & 0.014 & 0.0587 & 0.0798 \\
\hline May & $<0.014$ & 0.022 & $<2.6$ & 3.9 & 0.02 & 0.03 & 0.013 & 0.036 & 0.0701 & 0.0844 \\
\hline June & 0.037 & 0.062 & $<2.1$ & 2.4 & 0.02 & 0.03 & 0.017 & 0.018 & 0.0493 & 0.0557 \\
\hline July & $<0.010$ & $<0.010$ & $<2.0$ & $<2.0$ & 0.04 & 0.08 & 0.013 & 0.023 & 0.0535 & 0.0801 \\
\hline August & $<0.010$ & $<0.010$ & $<2.0$ & $<2.0$ & 0.03 & 0.06 & 0.014 & 0.021 & $<0.053$ & 0.069 \\
\hline September & $<0.010$ & $<0.010$ & $<2.0$ & $<2.0$ & 0.02 & 0.02 & 0.016 & 0.021 & 0.0528 & 0.0583 \\
\hline October & $<0.020$ & 0.040 & $<2.0$ & $<2.0$ & 0.02 & 0.02 & 0.019 & 0.025 & 0.0461 & 0.0471 \\
\hline November & 0.030 & 0.032 & $<2.0$ & $<2.0$ & 0.02 & 0.03 & 0.016 & 0.024 & 0.048 & 0.056 \\
\hline December & $<0.017$ & 0.031 & $<2.0$ & 2.1 & 0.02 & 0.02 & 0.018 & 0.018 & 0.084 & 0.125 \\
\hline Analyte: & \multicolumn{2}{|c|}{$\begin{array}{l}\text { Nitrite, as N } \\
(\mathrm{mg} / \mathrm{L})\end{array}$} & \multicolumn{2}{|c|}{$\begin{array}{c}\text { Oil \& Grease } \\
(\mathrm{mg} / \mathrm{L})\end{array}$} & \multicolumn{2}{|c|}{$\begin{array}{c}\mathbf{p H} \\
\text { (standard units) }\end{array}$} & \multicolumn{2}{|c|}{$\begin{array}{c}\text { Solids } \\
\text { Settleable } \\
(\mathrm{mL} / \mathrm{L})\end{array}$} & \multicolumn{2}{|c|}{$\begin{array}{c}\text { Solids } \\
\text { Total Suspended } \\
(\mathrm{mg} / \mathrm{L})\end{array}$} \\
\hline Permit limit: & \multicolumn{2}{|c|}{$\begin{array}{c}0.1 \mathrm{mg} / \mathrm{L} \\
\text { daily maximum }\end{array}$} & \multicolumn{2}{|c|}{$\begin{array}{c}15 \mathrm{mg} / \mathrm{L} \\
\text { daily maximum }\end{array}$} & \multicolumn{2}{|c|}{6.5 to 8.5} & \multicolumn{2}{|c|}{$\begin{array}{c}0.3 \mathrm{~mL} / \mathrm{L} \\
\text { daily maximum }\end{array}$} & $\begin{array}{l}45.0 \mathrm{mg} / \mathrm{L} \mathrm{da} \\
30.0 \mathrm{mg} / \mathrm{Ld}\end{array}$ & $\begin{array}{l}\text { ly maximum } \\
\text { aily average }\end{array}$ \\
\hline Month & Avg & Max & Avg & Max & Avg & Max & Avg & Max & Avg & Max \\
\hline January & $<0.05$ & $<0.05$ & $<5.0$ & $<5.0$ & 7.5 & 7.9 & $<0.1$ & $<0.1$ & $<2.0$ & $<2.0$ \\
\hline February & $<0.05$ & $<0.05$ & $<5.0$ & $<5.0$ & 7.3 & 7.8 & $<0.1$ & $<0.1$ & $<2.0$ & $<2.0$ \\
\hline March & $<0.05$ & $<0.05$ & $<5.6$ & 6.7 & 7.3 & 7.8 & $<0.1$ & $<0.1$ & $<2.0$ & $<2.0$ \\
\hline April & $<0.05$ & $<0.05$ & $<5.0$ & $<5.0$ & 7.4 & 7.7 & $<0.1$ & $<0.1$ & $<2.5$ & 3.5 \\
\hline May & $<0.05$ & $<0.05$ & $<5.0$ & $<5.0$ & 7.4 & 7.7 & $<0.1$ & $<0.1$ & 5.2 & 6.0 \\
\hline June & $<0.05$ & $<0.05$ & $<5.0$ & $<5.0$ & 7.4 & 7.7 & $<0.1$ & $<0.1$ & $<3.8$ & 7.5 \\
\hline July & $<0.05$ & $<0.05$ & $<5.0$ & $<5.0$ & 7.4 & 7.7 & $<0.1$ & $<0.1$ & $<2.0$ & $<2.0$ \\
\hline August & $<0.05$ & $<0.05$ & $<7.1$ & 11.0 & 7.6 & 7.9 & $<0.1$ & $<0.3$ & $<2.0$ & $<2.0$ \\
\hline September & $<0.05$ & $<0.05$ & $<5.0$ & $<5.0$ & 7.6 & 7.9 & $<0.2$ & $<0.3$ & $<3.0$ & 4.5 \\
\hline October & $<0.05$ & $<0.05$ & $<6.3$ & 8.8 & 7.7 & 8.2 & $<0.1$ & $<0.1$ & $<6.0$ & 12.0 \\
\hline November & $<0.05$ & $<0.05$ & $<5.0$ & $<5.0$ & 7.9 & 8.0 & $<0.1$ & $<0.1$ & $<3.3$ & 6.0 \\
\hline December & $<0.05$ & $<0.05$ & $<5.0$ & $<5.0$ & 7.7 & 8.0 & $<0.1$ & $<0.1$ & $<2.2$ & 2.5 \\
\hline
\end{tabular}

Note: No results exceeded the permit limits.

WVDP Site Environmental Report

$G-11$

Calendar Year 2001 


\section{Table G-6 \\ 2001 SPDES Results for Outfall 008 (WNSP008) \\ Water Quality}

\begin{tabular}{|c|c|c|c|c|c|c|}
\hline Analyte: & & & Disch & Rate & (stanc & units) \\
\hline Permit limit: & $\begin{array}{r}5 \\
\text { dail }\end{array}$ & $\begin{array}{l}\mathrm{g} / \mathrm{L} \\
\text { cimum }\end{array}$ & & & & \\
\hline Month & Avg & Max & Avg & Max & Avg & Max \\
\hline January & $<2.0$ & $<2.0$ & 1,761 & 2,137 & 6.5 & 7.4 \\
\hline February & $<2.0$ & $<2.0$ & 2,214 & 2,622 & 6.9 & 7.2 \\
\hline March & $<2.0$ & $<2.0$ & 1,690 & 2,260 & 7.0 & 7.2 \\
\hline April & $<2.0$ & $<2.0$ & 2,125 & 2,267 & 6.8 & 6.9 \\
\hline May & $<2.0$ & $<2.0$ & 1,152 & 1,226 & 6.9 & 7.3 \\
\hline June* & & & & & & \\
\hline July* & & & & & & \\
\hline August* & & & & & & \\
\hline September* & & & & & & \\
\hline October* & & & & & & \\
\hline November* & & & & & & \\
\hline December* & & & & & & \\
\hline
\end{tabular}

\begin{tabular}{|c|c|c|c|c|c|c|}
\hline Analyte: & Total & $\begin{array}{l}\text { verable } \\
\text { t) }\end{array}$ & & & Total & $\begin{array}{l}\text { verable } \\
\text { C) }\end{array}$ \\
\hline Permit limit: & $\begin{array}{r}0 . \\
d a i\end{array}$ & $\begin{array}{l}g / L \\
\text { imum }\end{array}$ & & & $\begin{array}{r}0 . \\
\text { dail }\end{array}$ & $\begin{array}{l}\text { Ig/L } \\
\text { imum }\end{array}$ \\
\hline Month & Avg & Max & Avg & Max & Avg & Max \\
\hline January & $<0.001$ & $<0.001$ & 0.146 & 0.152 & $<0.0005$ & $<0.0005$ \\
\hline February & $<0.001$ & $<0.001$ & 0.0841 & 0.0979 & $<0.0005$ & $<0.0005$ \\
\hline March & $<0.001$ & $<0.001$ & 0.396 & 0.991 & $<0.002$ & $<0.002$ \\
\hline April & $<0.001$ & $<0.001$ & 0.0534 & 0.0582 & $<0.005$ & 0.010 \\
\hline May & $<0.001$ & $<0.001$ & 0.296 & 0.544 & $<0.003$ & 0.003 \\
\hline June* & & & & & & \\
\hline July* & & & & & & \\
\hline August* & & & & & & \\
\hline September* & & & & & & \\
\hline October* & & & & & & \\
\hline November* & & & & & & \\
\hline December* & & & & & & \\
\hline
\end{tabular}

* No discharge this month; discharge terminated.

WVDP Site Environmental Report

$$
\text { G- } 12
$$




\title{
Table G-7 \\ 2001 SPDES Results for Sums of Outfalls 001, 007, 008, and 116 Water Quality
}

\author{
2001 Sums of Outfalls 001, 007, and 008
}

\begin{tabular}{|c|c|c|c|c|c|}
\hline Analyte: & $\underset{\text { Flow }}{\text { Ammo }}$ & 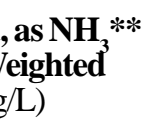 & Flow & ghted & $\begin{array}{c}\text { Iron, Total } \\
\text { Flow-Weighted Net Average } \\
(\mathrm{mg} / \mathrm{L})\end{array}$ \\
\hline Permit limit: & $\begin{array}{l}2.1 \mathrm{mg} / \mathrm{L} \\
1.49 \mathrm{mg} /\end{array}$ & $\begin{array}{l}\text { ily maximum } \\
\text { aily average }\end{array}$ & $5.0 \mathrm{mg} / \mathrm{L}$ & average & $0.30 \mathrm{mg} / \mathrm{L}$ daily average \\
\hline Month & Avg & Max & Avg & Max & Avg \\
\hline January & $<0.020$ & 0.029 & $<2.0$ & $<2.0$ & 0.05 \\
\hline February & $<0.010$ & $<0.010$ & $<2.2$ & $<2.5$ & 0.00 \\
\hline March & $<0.116$ & $<0.169$ & $<2.0$ & $<2.0$ & 0.00 \\
\hline April & $<0.015$ & 0.019 & $<2.1$ & $<2.2$ & 0.00 \\
\hline May & $<0.014$ & 0.022 & $<2.1$ & $<2.2$ & 0.00 \\
\hline June & 0.037 & 0.062 & $<2.1$ & $<2.4$ & 0.00 \\
\hline July & $<0.010$ & $<0.010$ & $<2.0$ & $<2.0$ & 0.00 \\
\hline August & $<0.010$ & $<0.010$ & $<2.0$ & $<2.0$ & 0.00 \\
\hline September & $<0.010$ & $<0.010$ & $<2.0$ & $<2.0$ & 0.00 \\
\hline October & $<0.020$ & 0.040 & $<2.0$ & $<2.0$ & 0.00 \\
\hline November & $<0.019$ & 0.032 & $<2.0$ & $<2.0$ & 0.00 \\
\hline December & $<0.017$ & 0.031 & $<2.0$ & 2.1 & 0.00 \\
\hline
\end{tabular}

2001 Results for Outfall 116

Analyte: $\quad$ Solids, Total Dissolved

$(\mathrm{mg} / \mathrm{L})$

\begin{tabular}{lcc}
\hline Permit limit: & $500 \mathrm{mg} /$ L daily maximu \\
\hline Month & Avg & Max \\
January & 321 & 335 \\
$\begin{array}{l}\text { February* } \\
\text { March }\end{array}$ & 364 & 446 \\
$\begin{array}{l}\text { April * } \\
\text { May } \\
\text { June* } \\
\text { July* }\end{array}$ & 340 & 349 \\
$\begin{array}{l}\text { August } \\
\text { September* }\end{array}$ & & \\
$\begin{array}{l}\text { October } \\
\text { November } \\
\text { December* }\end{array}$ & 378 & 442 \\
* No discharge this month. & \\
** Sum of Outfalls 001 and 007 only.
\end{tabular}

Note: No results exceeded the permit limits.

WVDP Site Environmental Report

$$
\text { G - } 13
$$

Calendar Year 2001 


\section{Table G-8 \\ 2001 Annual/Semiannual SPDES Results for Outfall 001 Water Quality, Metals, and Organics}

\begin{tabular}{|c|c|c|c|c|}
\hline \multirow{2}{*}{$\begin{array}{l}\text { Chloroform } \\
(\mathrm{mg} / \mathrm{L})\end{array}$} & Action Level & Monitoring Frequency & Collection Date & Maximum Measured \\
\hline & $\begin{array}{l}0.3 \mathrm{mg} / \mathrm{L} \text { daily } \\
\text { maximum }\end{array}$ & Annual & March 2001 & $<0.005$ \\
\hline \multirow{2}{*}{$\begin{array}{l}\text { Antimony, Total } \\
(\mathrm{mg} / \mathrm{L})\end{array}$} & Action Level & Monitoring Frequency & Collection Date & Maximum Measured \\
\hline & $\begin{array}{c}1.0 \mathrm{mg} / \mathrm{L} \text { daily } \\
\text { maximum }\end{array}$ & Annual & March 2001 & $<0.020$ \\
\hline \multirow{2}{*}{$\begin{array}{l}\text { Barium, Total } \\
(\mathrm{mg} / \mathrm{L})\end{array}$} & Action Level & Monitoring Frequency & Collection Date & Maximum Measured \\
\hline & $\begin{array}{l}0.5 \mathrm{mg} / \mathrm{L} \text { daily } \\
\text { maximum }\end{array}$ & Annual & March 2001 & 0.022 \\
\hline \multirow{2}{*}{$\begin{array}{l}\text { Titanium, Total } \\
(\mathrm{mg} / \mathrm{L})\end{array}$} & Action Level & Monitoring Frequency & Collection Date & Maximum Measured \\
\hline & $\begin{array}{l}0.65 \mathrm{mg} / \mathrm{L} \text { daily } \\
\text { maximum }\end{array}$ & Semiannual & $\begin{array}{l}\text { March } 2001 \\
\text { August } 2001\end{array}$ & $\begin{array}{l}0.0066 \\
<0.005\end{array}$ \\
\hline \multirow{2}{*}{$\begin{array}{l}\text { bis (2-Ethylhexyl) phthalate } \\
(\mathrm{mg} / \mathrm{L})\end{array}$} & Action Level & Monitoring Frequency & Collection Date & Maximum Measured \\
\hline & $\begin{array}{c}1.6 \mathrm{mg} / \mathrm{L} \text { daily } \\
\text { maximum }\end{array}$ & Semiannual & $\begin{array}{l}\text { March } 2001 \\
\text { August } 2001\end{array}$ & $\begin{array}{l}<0.010 \\
<0.010\end{array}$ \\
\hline \multirow{2}{*}{$\begin{array}{l}\text { 4-dodecene } \\
(\mathrm{mg} / \mathrm{L})\end{array}$} & Action Level & Monitoring Frequency & Collection Date & Maximum Measured \\
\hline & $\begin{array}{l}0.6 \mathrm{mg} / \mathrm{L} \text { daily } \\
\text { maximum }\end{array}$ & Semiannual & $\begin{array}{l}\text { March } 2001 \\
\text { August } 2001\end{array}$ & $\begin{array}{l}<0.060 \\
<0.060\end{array}$ \\
\hline
\end{tabular}




\section{Table G-9 \\ 2001 Annual SPDES Results for Outfall 007 \\ Water Quality}

\begin{tabular}{|c|c|c|c|c|}
\hline \multirow{2}{*}{$\begin{array}{l}\text { Chloroform } \\
(\mathrm{mg} / \mathrm{L})\end{array}$} & Action Level & Monitoring Frequency & Collection Date & Maximum Measured \\
\hline & $\begin{array}{c}0.20 \mathrm{mg} / \mathrm{L} \text { daily } \\
\text { maximum }\end{array}$ & Annual & $*$ & $*$ \\
\hline
\end{tabular}

\section{Table G-10 \\ 2001 Annual SPDES Results for Outfall 008 Water Quality}

\begin{tabular}{|c|c|c|c|c|}
\hline \multirow{2}{*}{$\begin{array}{l}\text { Arsenic, Total } \\
(\mathrm{mg} / \mathrm{L})\end{array}$} & Action Level & Monitoring Frequency & Collection Date & Maximum Measured \\
\hline & $\begin{array}{l}0.17 \mathrm{mg} / \mathrm{L} \text { daily } \\
\text { maximum }\end{array}$ & Annual & $*$ & $*$ \\
\hline \multirow{2}{*}{$\begin{array}{l}\text { Chromium, Total } \\
(\mathrm{mg} / \mathrm{L})\end{array}$} & Action Level & Monitoring Frequency & Collection Date & Maximum Measured \\
\hline & $\begin{array}{l}0.13 \mathrm{mg} / \mathrm{L} \text { daily } \\
\text { maximum }\end{array}$ & Annual & $*$ & * \\
\hline \multirow{2}{*}{$\begin{array}{l}\text { Silver, Total } \\
(\mathrm{mg} / \mathrm{L})\end{array}$} & Action Level & Monitoring Frequency & Collection Date & Maximum Measured \\
\hline & $\begin{array}{l}0.008 \mathrm{mg} / \mathrm{L} \text { daily } \\
\text { maximum }\end{array}$ & Annual & $*$ & $*$ \\
\hline \multirow{2}{*}{$\begin{array}{l}\text { Zinc, Total } \\
(\mathrm{mg} / \mathrm{L})\end{array}$} & Action Level & Monitoring Frequency & Collection Date & Maximum Measured \\
\hline & $\begin{array}{l}0.100 \mathrm{mg} / \mathrm{L} \text { daily } \\
\text { maximum }\end{array}$ & Annual & $*$ & $*$ \\
\hline
\end{tabular}

* Annual collection data not available; discharge terminated.

$$
G-15
$$


This page intentionally left blank

$$
G-16
$$




\section{Appendix $\mathrm{H}$ \\ Summary of Direct Radiation Monitoring Data}

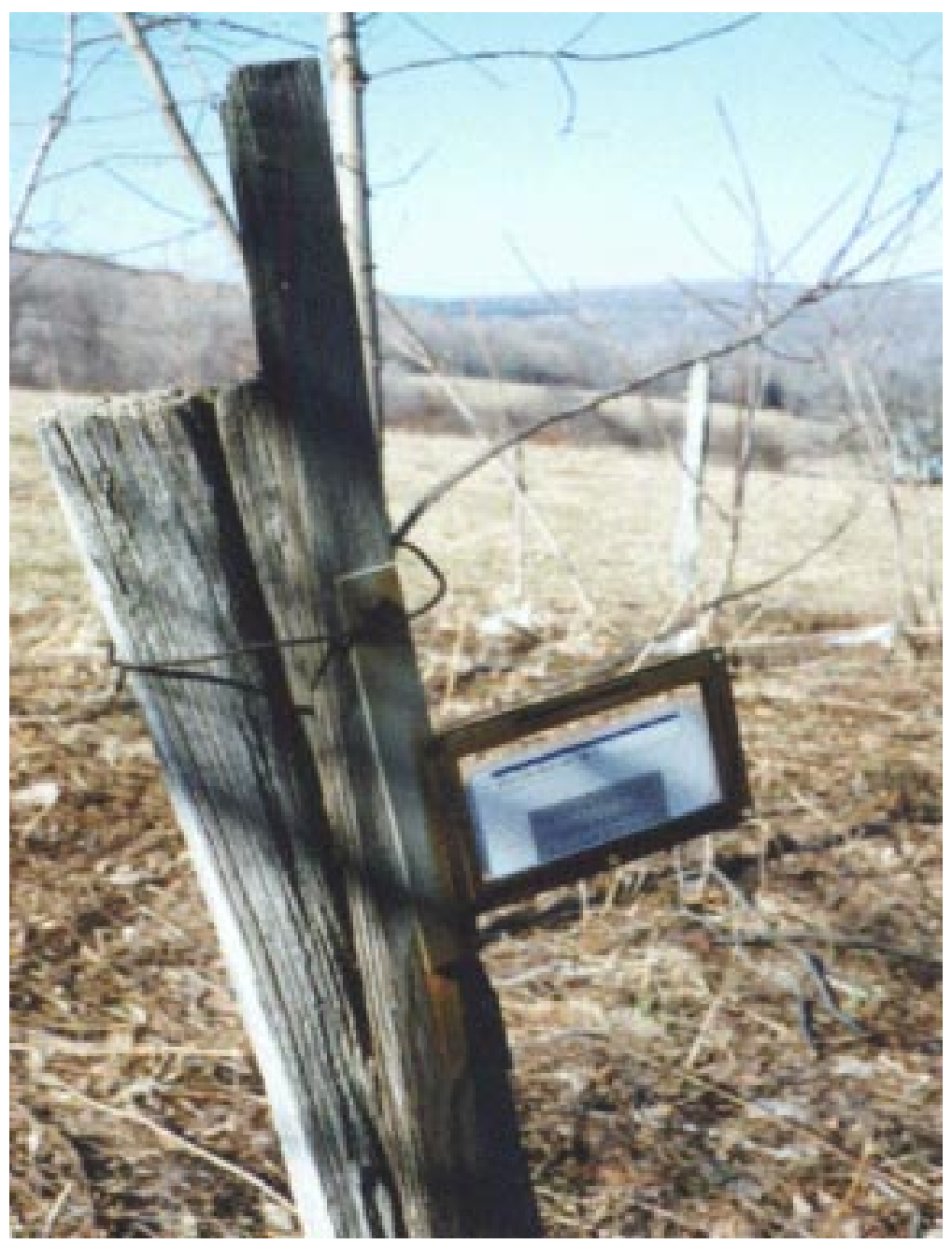

An Environmental TLD Package

$H-1$ 
The following tables contain a bolding convention devised to help the reader, when viewing the data, to quickly see the range of detectable measurements within a data series. A data series is a set of chemical or radionuclide measurements (e.g., gross alpha, gross beta, tritium) from a single location or from similar locations. Note that some tables contain data that should not be technically evaluated under this convention.

\section{Key to bolding convention:}

Results for each constituent constitute a single data series. If a radiological result is larger than the uncertainty term, the measurement is considered positive. Otherwise, a result is considered nondetectable.

If all results in a data series are positive, the lowest and highest values are bolded.

If a data series contains some positive results, the highest value is bolded.

If all values in a data series are nondetectable, no values are bolded.

$H-2$ 
Table $\mathrm{H}-1$

Summary of 2001 Quarterly Averages of Off-Site TLD Measurements (mR $\pm 2 S D / q u a r t e r)$

\begin{tabular}{|c|c|c|c|c|c|}
\hline $\begin{array}{l}\text { Location } \\
\text { Number* }\end{array}$ & 1st Quarter & 2nd Quarter & 3rd Quarter & 4th Quarter & $\begin{array}{l}\text { Location } \\
\text { Average }\end{array}$ \\
\hline DFTLD01 & $19 \pm 3.8$ & $25 \pm 5.3$ & $21 \pm 4.4$ & $18 \pm 3.7$ & $21 \pm 4.3$ \\
\hline DFTLD02 & $19 \pm 3.7$ & $24 \pm 5.1$ & $21 \pm 4.4$ & $18 \pm 3.8$ & $20 \pm 4.3$ \\
\hline DFTLD03 & $17 \pm 3.4$ & $23 \pm 4.9$ & $17 \pm 3.7$ & $15 \pm 3.2$ & $18 \pm 3.9$ \\
\hline DFTLD04 & $18 \pm 3.6$ & $21 \pm 4.5$ & $20 \pm 4.3$ & $17 \pm 3.5$ & $19 \pm 4.0$ \\
\hline DFTLD05 & $18 \pm 3.6$ & $24 \pm 5.2$ & $22 \pm 4.5$ & $18 \pm 3.7$ & $21 \pm 4.3$ \\
\hline DFTLD06 & $18 \pm 3.6$ & $21 \pm 4.6$ & $20 \pm 4.2$ & $18 \pm 3.6$ & $19 \pm 4.0$ \\
\hline DFTLD07 & $16 \pm 3.1$ & $18 \pm 4.1$ & $17 \pm 3.6$ & $15 \pm 3.2$ & $16 \pm 3.5$ \\
\hline DFTLD08 & $17 \pm 3.5$ & $20 \pm 4.4$ & $19 \pm 4.1$ & NA & $19 \pm 4.0$ \\
\hline DFTLD09 & $19 \pm 3.7$ & $20 \pm 4.4$ & $21 \pm 4.4$ & $18 \pm 3.7$ & $19 \pm 4.1$ \\
\hline DFTLD10 & $16 \pm 3.1$ & $20 \pm 4.4$ & $20 \pm 4.2$ & $18 \pm 3.6$ & $18 \pm 3.9$ \\
\hline DFTLD11 & $16 \pm 3.2$ & $19 \pm 4.2$ & $17 \pm 3.7$ & $15 \pm 3.2$ & $17 \pm 3.6$ \\
\hline DFTLD12 & $18 \pm 3.6$ & $21 \pm 4.5$ & $20 \pm 4.2$ & $18 \pm 3.6$ & $19 \pm 4.0$ \\
\hline DFTLD13 & $19 \pm 3.8$ & $22 \pm 4.8$ & $23 \pm 4.7$ & $20 \pm 4.0$ & $21 \pm 4.3$ \\
\hline DFTLD14 & $18 \pm 3.6$ & $21 \pm 4.6$ & $21 \pm 4.4$ & $18 \pm 3.8$ & $20 \pm 4.1$ \\
\hline DFTLD15 & $17 \pm 3.4$ & $20 \pm 4.3$ & $20 \pm 4.2$ & $17 \pm 3.5$ & $18 \pm 3.9$ \\
\hline DFTLD16 & $17 \pm 3.5$ & $21 \pm 4.6$ & $21 \pm 4.4$ & $18 \pm 3.7$ & $19 \pm 4.1$ \\
\hline DFTLD17** & $20 \pm 3.9$ & $23 \pm 4.8$ & $21 \pm 4.4$ & $19 \pm 3.8$ & $21 \pm 4.2$ \\
\hline DFTLD20 & $16 \pm 3.1$ & $18 \pm 4.1$ & $17 \pm 3.7$ & $15 \pm 3.2$ & $16 \pm 3.5$ \\
\hline DFTLD21 & $19 \pm 3.7$ & $22 \pm 4.8$ & $21 \pm 4.4$ & $18 \pm 3.8$ & $20 \pm 4.2$ \\
\hline DFTLD22 & $20 \pm 4.0$ & $22 \pm 4.8$ & $22 \pm 4.5$ & $19 \pm 3.9$ & $21 \pm 4.3$ \\
\hline DFTLD23** & $19 \pm 3.8$ & $22 \pm 4.8$ & $20 \pm 4.2$ & $18 \pm 3.7$ & $20 \pm 4.1$ \\
\hline DFTLD37** & $21 \pm 4.1$ & $23 \pm 5.0$ & $22 \pm 4.5$ & $20 \pm 4.0$ & $21 \pm 4.4$ \\
\hline DFTLD41** & $17 \pm 3.4$ & $19 \pm 4.2$ & $18 \pm 3.8$ & $16 \pm 3.3$ & $17 \pm 3.7$ \\
\hline
\end{tabular}

* Off-site locations are shown on Figures A-11 through A-13 (pp. A-13 through A-15).

** Background measurements are provided by off-site TLDs 17, 23, 37, and 41.

NA - Not available; TLD card missing.

Conversion factor: Milliroentgen $(\mathrm{mR})$ units are used to report exposure rates in air. To convert $m R$ to mrem (dose to humans), a conversion factor of 1.03 must be applied. For example, a reported exposure rate of $18.1 \mathrm{mR} /$ quarter would be equivalent to 18.6 mrem/quarter (based upon dose-equivalent phantom calibration using cesium-137).

Note: Bolding convention applied to these data. See page $\mathrm{H}-2$.

WVDP Site Environmental Report

$H-3$ 
Table $\mathrm{H}-2$

Summary of 2001 Quarterly Averages of On-Site TLD Measurements (mR $\pm 2 S D / q u a r t e r)$

$\begin{array}{lccccc}\begin{array}{l}\text { Location } \\ \text { Number* }\end{array} & \text { 1st Quarter } & \text { 2nd Quarter } & \text { 3rd Quarter } & \text { 4th Quarter } & \begin{array}{c}\text { Location } \\ \text { Average }\end{array} \\ & & & & & \\ \text { DNTLD18 } & 30 \pm 6.0 & 33 \pm 6.7 & 30 \pm 6.1 & 28 \pm 5.6 & 30 \pm 6.1 \\ \text { DNTLD19 } & 21 \pm 4.2 & 24 \pm 5.1 & 23 \pm 4.8 & 21 \pm 4.2 & 22 \pm 4.6 \\ \text { DNTLD24 } & \mathbf{5 6 6} \pm \mathbf{1 1 1 . 0} & \mathbf{5 2 7} \pm \mathbf{1 0 3 . 2} & \mathbf{5 1 5} \pm \mathbf{1 0 1 . 0} & \mathbf{4 8 6} \pm \mathbf{9 5 . 2} & \mathbf{5 2 3} \pm \mathbf{1 0 2 . 8} \\ \text { DNTLD25 } & 23 \pm 4.6 & 26 \pm 5.5 & 25 \pm 5.2 & 22 \pm 4.5 & 24 \pm 5.0 \\ \text { DNTLD26 } & 23 \pm 4.6 & 26 \pm 5.5 & 25 \pm 5.1 & 22 \pm 4.5 & 24 \pm 4.9 \\ \text { DNTLD27 } & \mathbf{2 0} \pm \mathbf{3 . 9} & 23 \pm 4.9 & 22 \pm 4.5 & 19 \pm 3.9 & 21 \pm 4.3 \\ \text { DNTLD28 } & 21 \pm 4.2 & 24 \pm 5.1 & 23 \pm 4.8 & 22 \pm 4.4 & 23 \pm 4.6 \\ \text { DNTLD29 } & 21 \pm 4.2 & 25 \pm 5.2 & 23 \pm 4.9 & 20 \pm 4.1 & 22 \pm 4.6 \\ \text { DNTLD30 } & 22 \pm 4.3 & 25 \pm 5.3 & 24 \pm 5.0 & 22 \pm 4.5 & 23 \pm 4.8 \\ \text { DNTLD31 } & \mathbf{2 0 \pm 3 . 9} & \mathbf{2 2 \pm 4 . 8} & \mathbf{2 1} \pm \mathbf{4 . 5} & \mathbf{1 8} \pm \mathbf{3 . 7} & \mathbf{2 0} \pm \mathbf{4 . 2} \\ \text { DNTLD32 } & 29 \pm 5.7 & 33 \pm 6.7 & 30 \pm 6.1 & 27 \pm 5.5 & 30 \pm 6.0 \\ \text { DNTLD33 } & 30 \pm 6.0 & 34 \pm 7.0 & 34 \pm 6.8 & 28 \pm 5.6 & 32 \pm 6.4 \\ \text { DNTLD34 } & 50 \pm 9.8 & 50 \pm 10.1 & 50 \pm 10.0 & 47 \pm 9.2 & 49 \pm 9.8 \\ \text { DNTLD35 } & 75 \pm 14.7 & 69 \pm 13.7 & 66 \pm 13.1 & 63 \pm 12.4 & 68 \pm 13.5 \\ \text { DNTLD36 } & 36 \pm 7.0 & 36 \pm 7.3 & 36 \pm 7.3 & 33 \pm 6.6 & 35 \pm 7.1 \\ \text { DNTLD38 } & 33 \pm 6.4 & 34 \pm 7.0 & 32 \pm 6.5 & 30 \pm 6.0 & 32 \pm 6.5 \\ \text { DNTLD39 } & 44 \pm 8.7 & 48 \pm 9.7 & 48 \pm 9.6 & 43 \pm 8.4 & 46 \pm 9.1 \\ \text { DNTLD40 } & 116 \pm 22.8 & 117 \pm 22.9 & 116 \pm 22.8 & 106 \pm 20.7 & 114 \pm 22.3 \\ \text { DNTLD42 } & 80 \pm 15.7 & 81 \pm 15.9 & 78 \pm 15.5 & 73 \pm 14.4 & 78 \pm 15.4 \\ \text { DNTLD43 } & 29 \pm 5.8 & 30 \pm 6.2 & 29 \pm 5.9 & 26 \pm 5.2 & 28 \pm 5.8\end{array}$

* On-site locations are shown on Figure A-10 (p. A-12).

Conversion factor: Milliroentgen $(\mathrm{mR})$ units are used to report exposure rates in air. To convert $\mathrm{mR}$ to mrem (dose to humans), a conversion factor of 1.03 must be applied. For example, a reported exposure rate of $18.1 \mathrm{mR} /$ quarter would be equivalent to 18.6 mrem/quarter (based upon dose-equivalent phantom calibration using cesium-137).

Note: Bolding convention applied to these data. See page $\mathrm{H}-2$.

WVDP Site Environmental Report

H - 4

Calendar Year 2001 
Table $\mathrm{H}-3$

3rd-Quarter 2001 TLD Results and Instantaneous Exposure Rate Readings ( $\mu R / h r)$ With a High-Pressure Ion Chamber (HPIC) at Each Monitoring Location

\begin{tabular}{|c|c|c|c|c|c|}
\hline $\begin{array}{l}\text { Off-Site } \\
\text { Location } \\
\text { Number }\end{array}$ & $\begin{array}{c}\text { 3rd-Quarter } \\
\text { TLD Result }\end{array}$ & $\begin{array}{l}\text { August } 2001 \\
\text { HPIC Result }\end{array}$ & $\begin{array}{l}\text { On-Site } \\
\text { Location } \\
\text { Number }\end{array}$ & $\begin{array}{c}\text { 3rd-Quarter } \\
\text { TLD Result }\end{array}$ & $\begin{array}{l}\text { August } 200 \\
\text { HPIC Resul }\end{array}$ \\
\hline DFTLD01 & 9.33 & 10.00 & DNTLD18 & 13.52 & 17.00 \\
\hline DFTLD02 & 9.32 & 9.00 & DNTLD19 & 10.38 & 11.00 \\
\hline DFTLD03 & 7.69 & 9.00 & DNTLD24 & 233.52 & 324.00 \\
\hline DFTLD04 & 9.05 & 9.00 & DNTLD25 & 11.35 & 11.00 \\
\hline DFTLD05 & 9.77 & 9.00 & DNTLD26 & 11.12 & 11.00 \\
\hline DFTLD06 & 8.91 & 10.00 & DNTLD27 & 9.79 & 11.00 \\
\hline DFTLD07 & 7.46 & 10.00 & DNTLD28 & 10.49 & 10.00 \\
\hline DFTLD08 & 8.55 & 10.00 & DNTLD29 & 10.56 & 11.00 \\
\hline DFTLD09 & 9.40 & 9.00 & DNTLD30 & 10.81 & 12.00 \\
\hline DFTLD10 & 8.82 & 9.00 & DNTLD31 & 9.65 & 10.00 \\
\hline DFTLD11 & 7.69 & 9.00 & DNTLD32 & 13.64 & 14.00 \\
\hline DFTLD12 & 8.87 & 10.00 & DNTLD33 & 15.15 & 15.00 \\
\hline DFTLD13 & 10.27 & 9.00 & DNTLD34 & 22.65 & 26.00 \\
\hline DFTLD14 & 9.45 & 9.00 & DNTLD35 & 30.02 & 38.00 \\
\hline DFTLD15 & 8.91 & 9.00 & DNTLD36 & 16.42 & 20.00 \\
\hline DFTLD16 & 9.45 & 9.00 & DNTLD38 & 14.61 & 19.00 \\
\hline DFTLD17 & 9.50 & 10.00 & DNTLD39 & 21.84 & 24.00 \\
\hline DFTLD20 & 7.55 & 9.00 & DNTLD40 & 52.54 & 54.00 \\
\hline DFTLD21 & 9.50 & 11.00 & DNTLD42 & 35.43 & 25.00 \\
\hline DFTLD22 & 9.72 & 11.00 & DNTLD43 & 12.97 & 14.00 \\
\hline DFTLD23 & 8.86 & 9.00 & & & \\
\hline DFTLD37 & 9.72 & 11.00 & & & \\
\hline DFTLD41 & 7.96 & 10.00 & & & \\
\hline
\end{tabular}

Note: Bolding convention not applicable to these data.

$H-5$

WVDP Site Environmental Report

Calendar Year 2001 


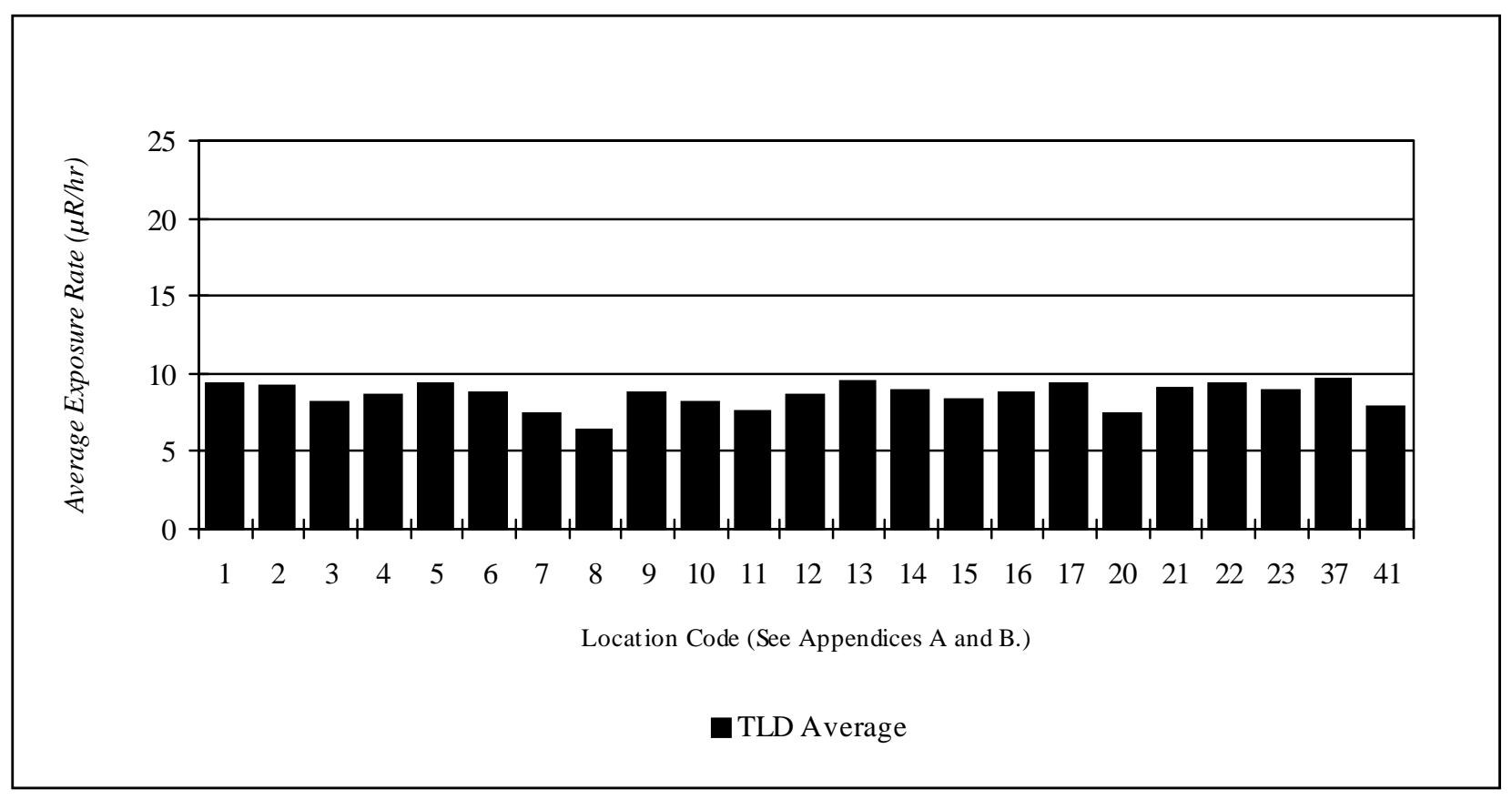

Figure H-1. 2001 Average Yearly Gamma Exposure Rates Around the WVDP

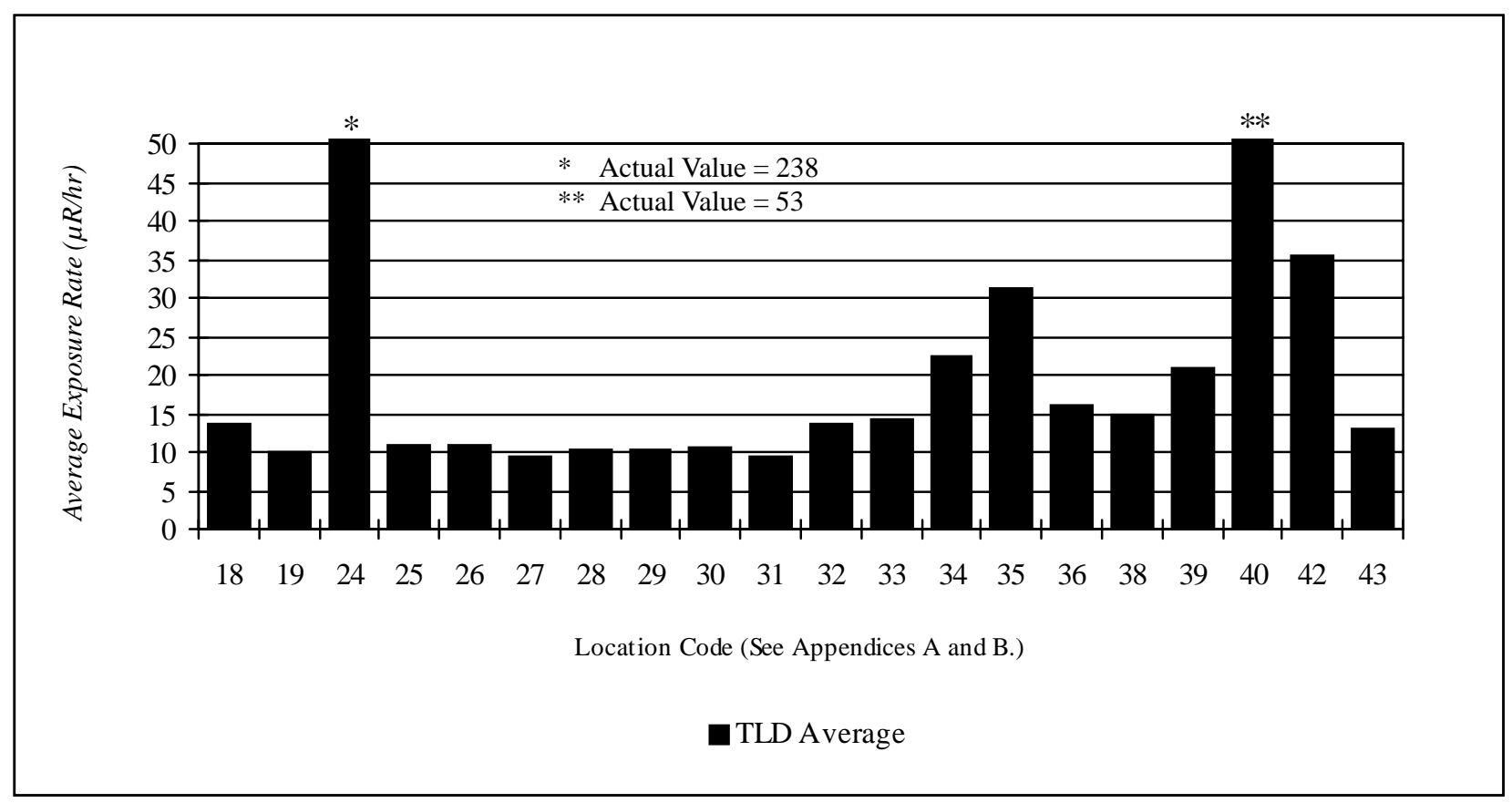

Figure H-2. 2001 Average Yearly Gamma Exposure Rates on the WVDP

$$
H-6
$$




\section{Appendix I}

\section{Summary of Meteorological Data}

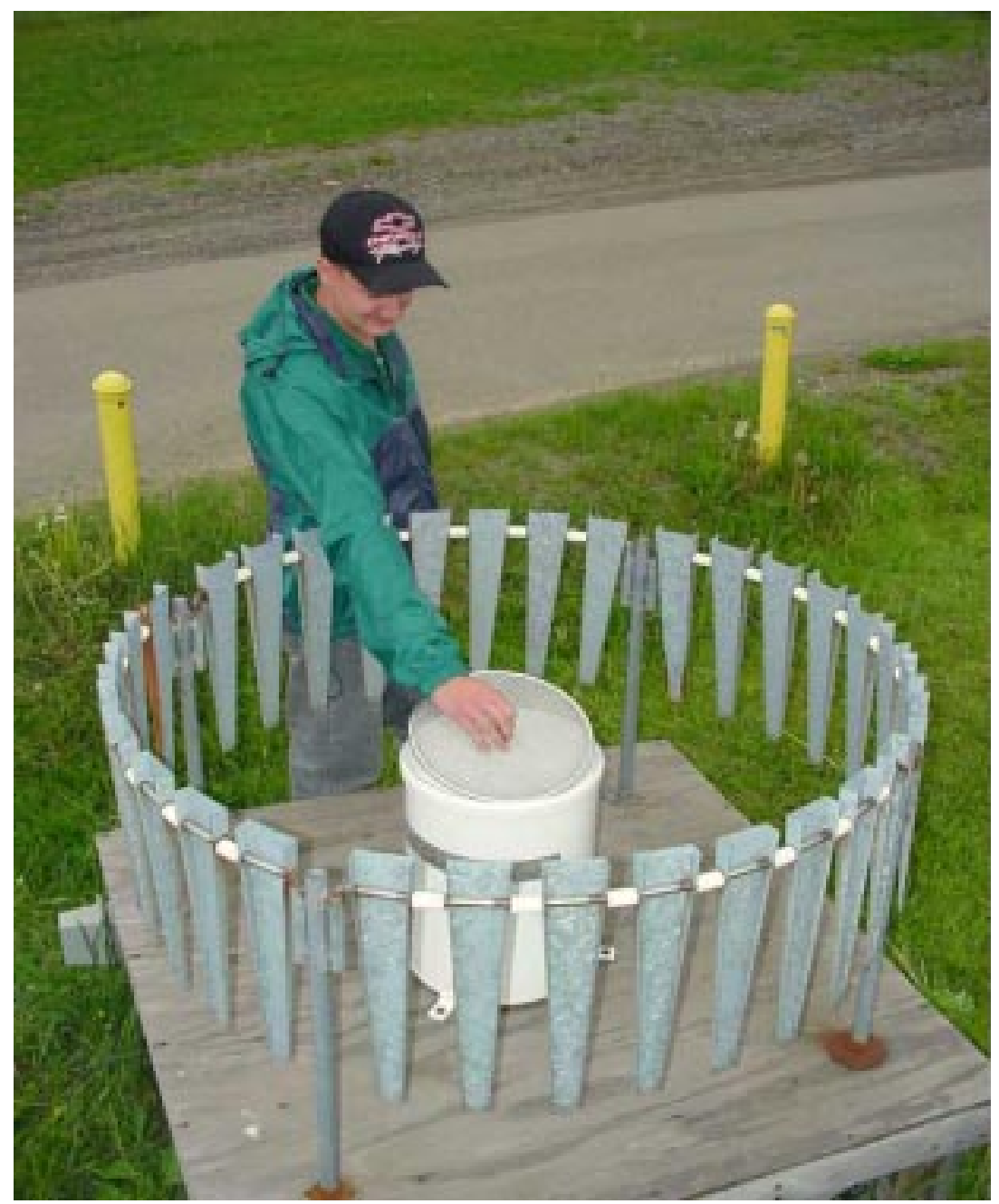

Checking the On-Site Rain Gauge

$$
I-1
$$


This page intentionally left blank

$I-2$ 


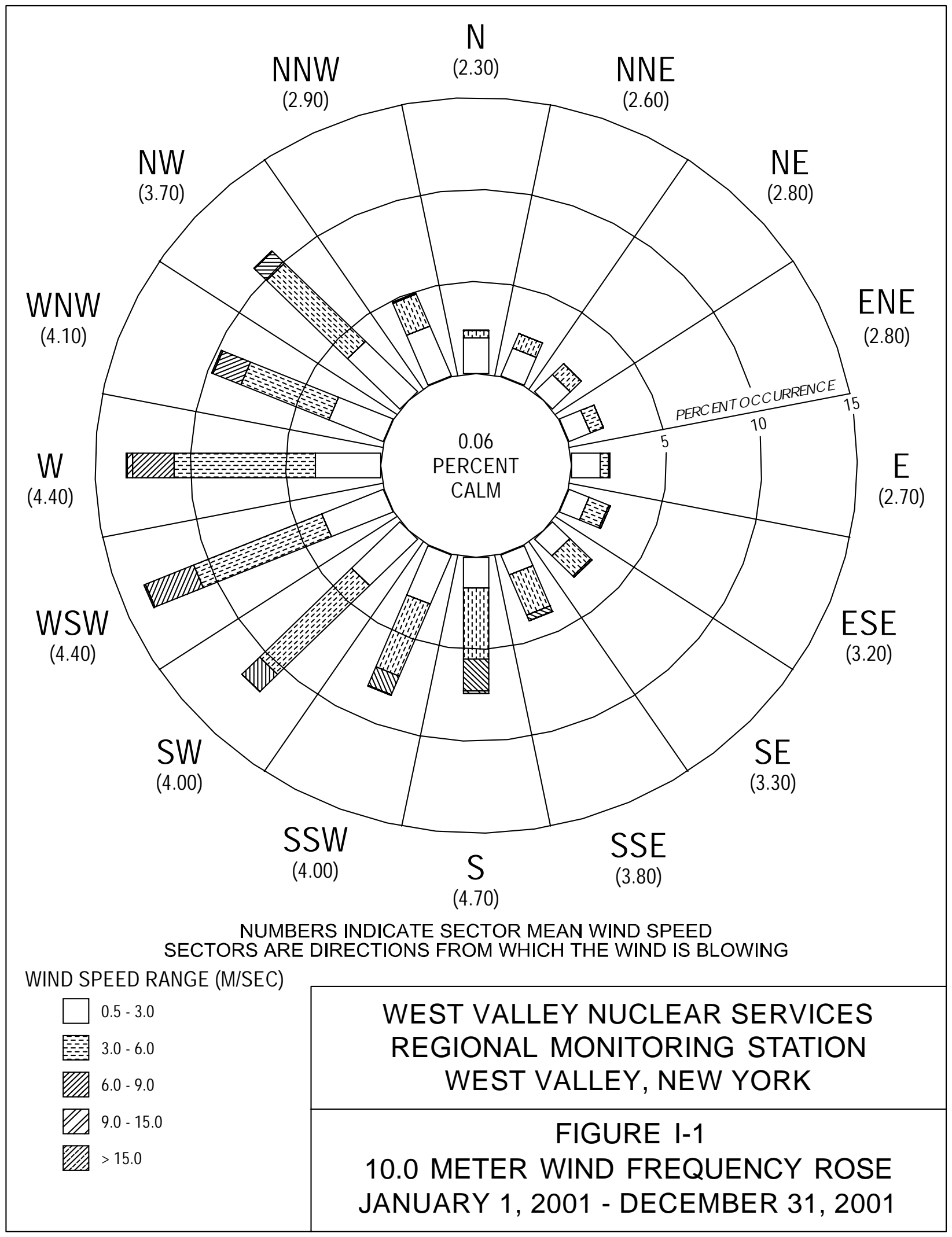

I - 3 


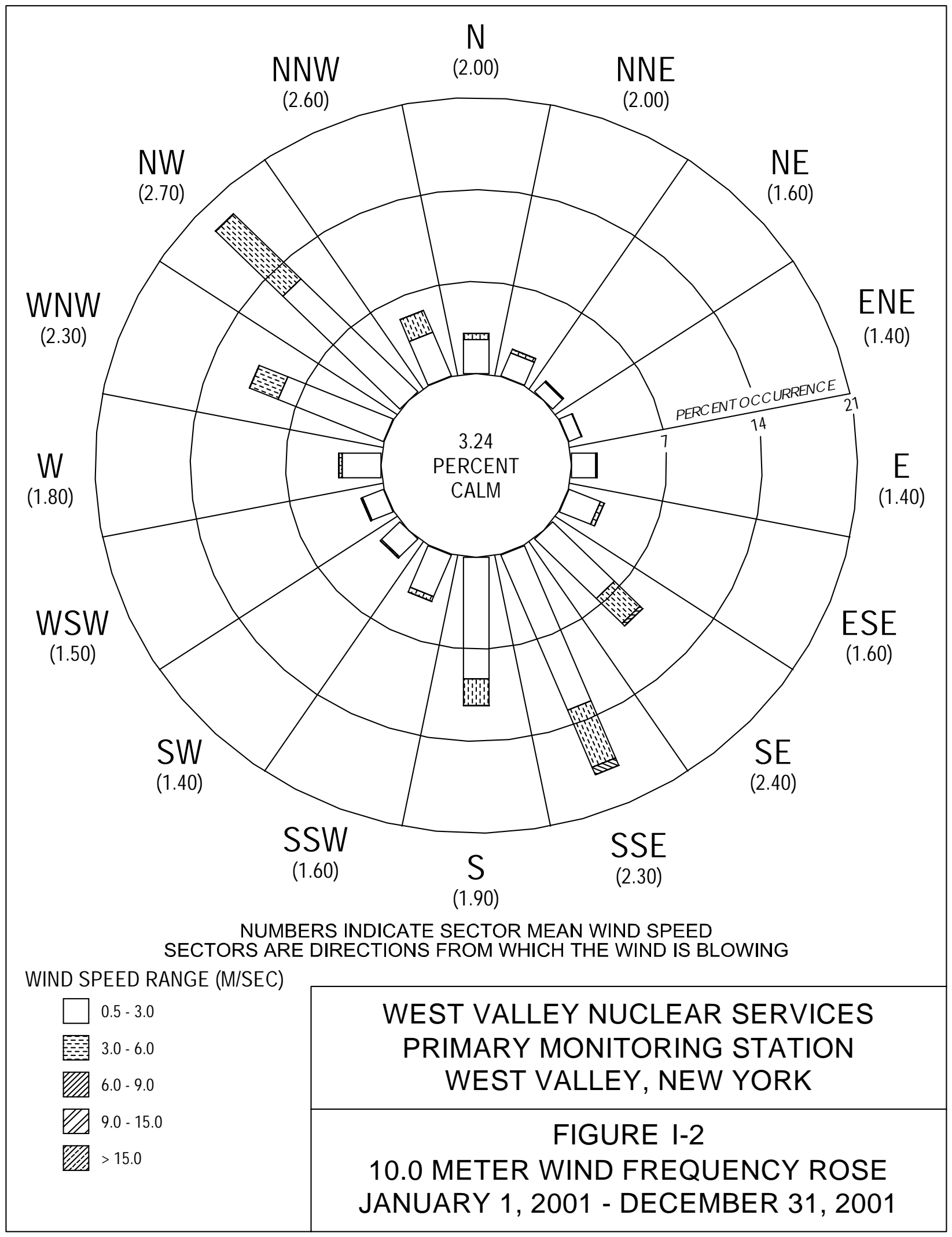

WVDP Site Environmental Report

I - 4

Calendar Year 2001 


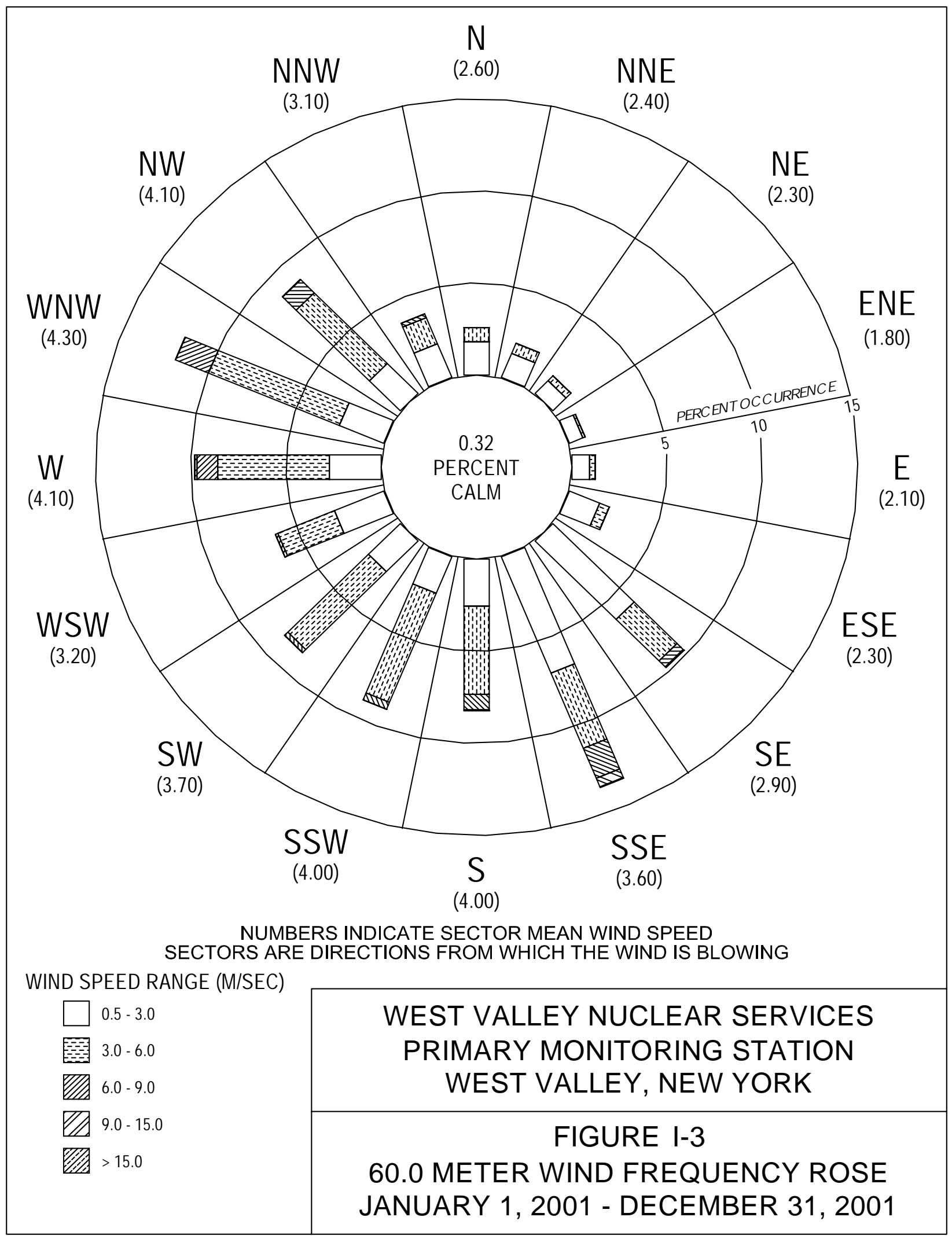

$I-5$ 


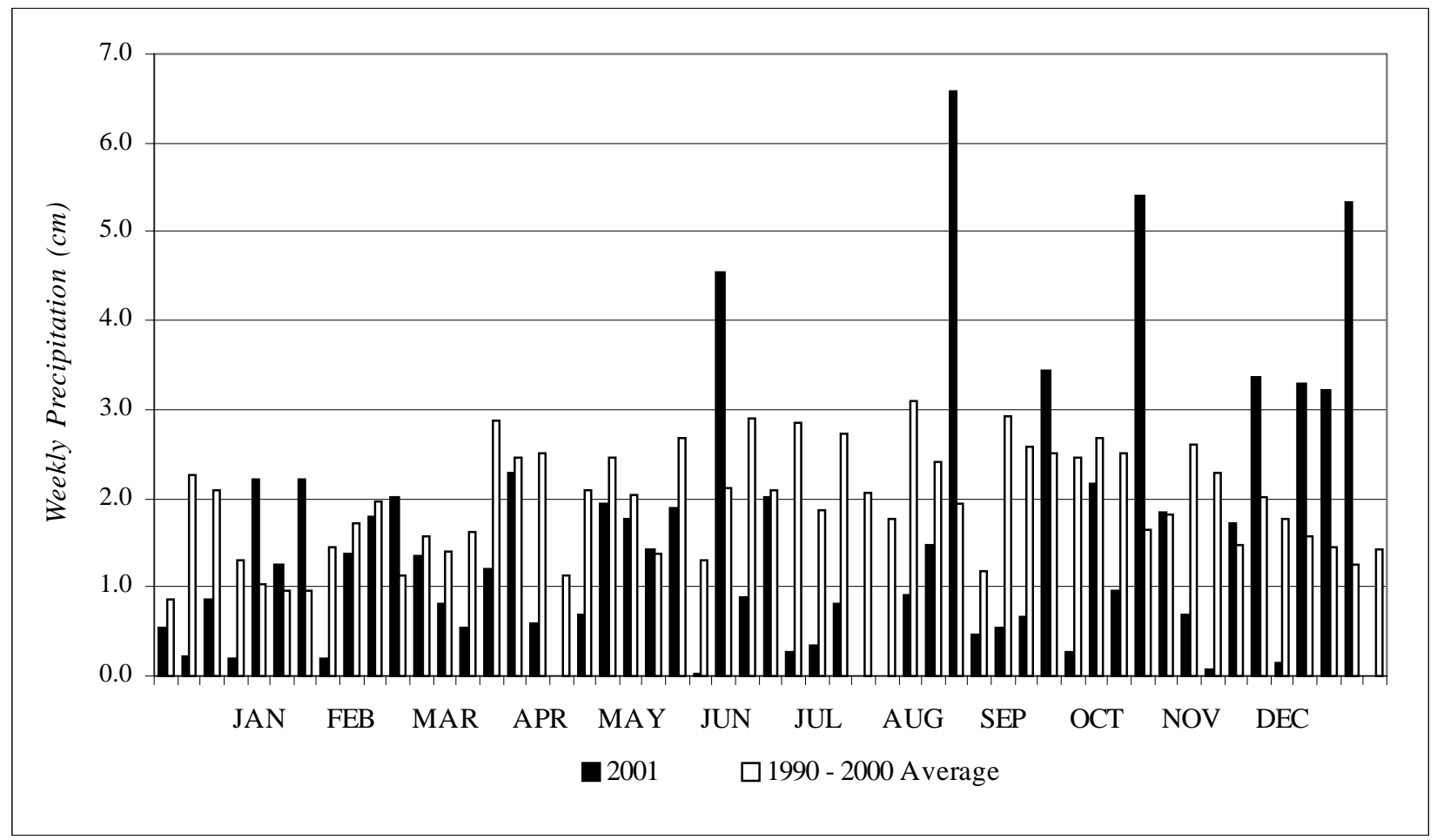

Figure I-4. Calendar Year 2001 Weekly Precipitation

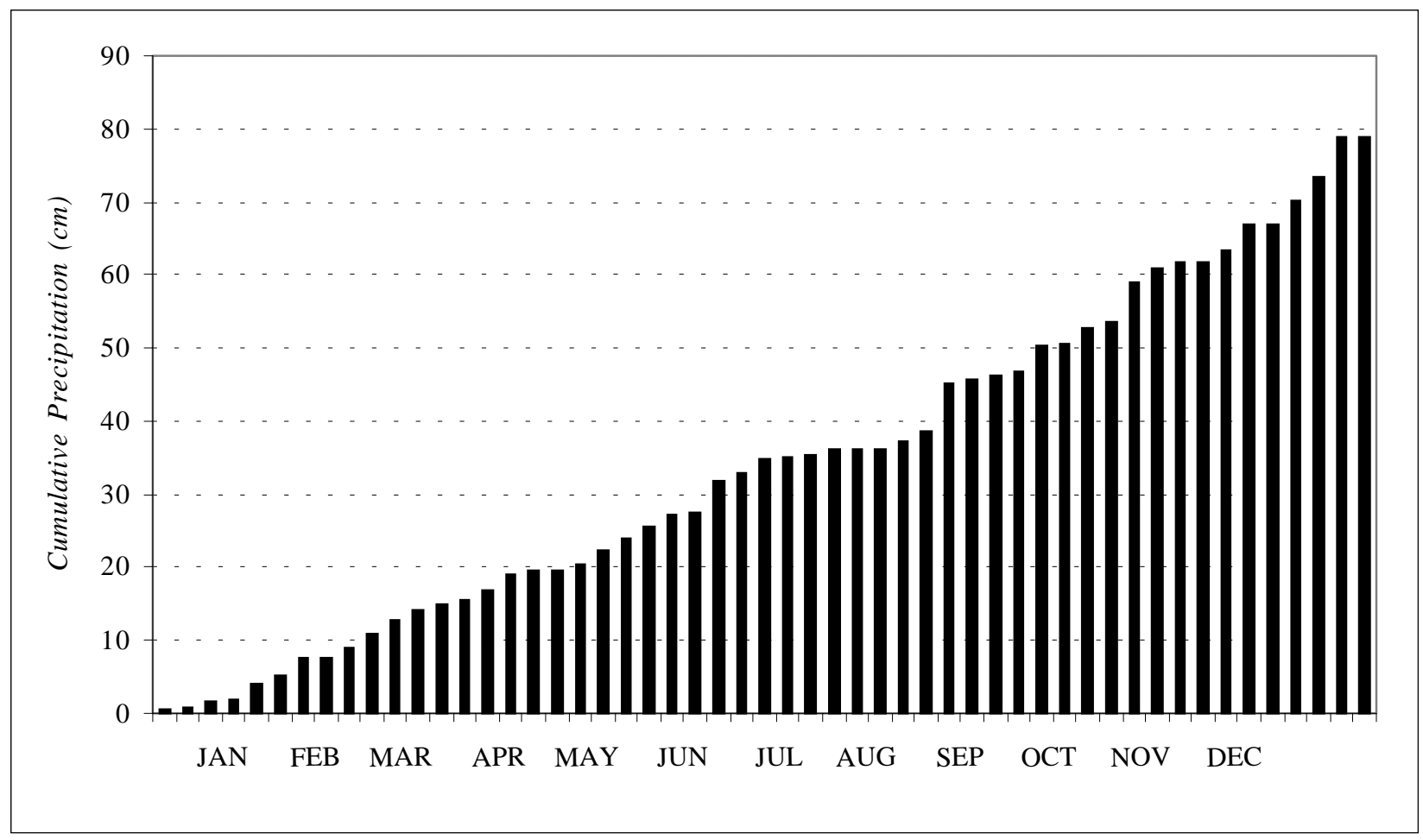

Figure I-5. Calendar Year 2001 Cumulative Precipitation

$$
I-6
$$


Table I-1

2001 Site Precipitation Collection Data

\begin{tabular}{|c|c|c|c|c|c|c|c|c|c|}
\hline \multirow{2}{*}{$\begin{array}{l}\text { Week } \\
\text { Ending: }\end{array}$} & \multicolumn{2}{|c|}{ Weekly } & \multicolumn{2}{|c|}{ Cumulative } & \multirow{2}{*}{$\begin{array}{l}\text { Week } \\
\text { Ending: }\end{array}$} & \multicolumn{2}{|c|}{ Weekly } & \multicolumn{2}{|c|}{ Cumulative } \\
\hline & $(\mathrm{cm})$ & (inches) & $(\mathrm{cm})$ & (inches) & & $(\mathrm{cm})$ & (inches) & $(\mathrm{cm})$ & (inches) \\
\hline Jan 05 & 0.53 & 0.21 & 0.53 & 0.21 & Jul 06 & 2.01 & 0.79 & 34.78 & 13.69 \\
\hline Jan 12 & 0.23 & 0.09 & 0.76 & 0.30 & Jul 13 & 0.28 & 0.11 & 35.06 & 13.80 \\
\hline Jan 19 & 0.86 & 0.34 & 1.63 & 0.64 & Jul 20 & 0.36 & 0.14 & 35.42 & 13.94 \\
\hline Jan 26 & 0.20 & 0.08 & 1.83 & 0.72 & Jul 27 & 0.81 & 0.32 & 36.23 & 14.26 \\
\hline Feb 02 & 2.21 & 0.87 & 4.04 & 1.59 & Aug 03 & 0.00 & 0.00 & 36.23 & 14.26 \\
\hline Feb 09 & 1.24 & 0.49 & 5.28 & 2.08 & Aug 10 & 0.00 & 0.00 & 36.23 & 14.26 \\
\hline Feb 16 & 2.21 & 0.87 & 7.49 & 2.95 & Aug 17 & 0.91 & 0.36 & 37.14 & 14.62 \\
\hline Feb 23 & 0.20 & 0.08 & 7.70 & 3.03 & Aug 24 & 1.47 & 0.58 & 38.62 & 15.20 \\
\hline Mar 02 & 1.37 & 0.54 & 9.07 & 3.57 & Aug 31 & 6.58 & 2.59 & 45.20 & 17.79 \\
\hline Mar 09 & 1.80 & 0.71 & 10.87 & 4.28 & Sep 07 & 0.46 & 0.18 & 45.65 & 17.97 \\
\hline Mar 16 & 2.01 & 0.79 & 12.88 & 5.07 & Sep 14 & 0.53 & 0.21 & 46.19 & 18.18 \\
\hline Mar 23 & 1.35 & 0.53 & 14.22 & 5.60 & Sep 21 & 0.66 & 0.26 & 46.85 & 18.44 \\
\hline Mar 30 & 0.81 & 0.32 & 15.04 & 5.92 & Sep 28 & 3.43 & 1.35 & 50.28 & 19.79 \\
\hline Apr 06 & 0.53 & 0.21 & 15.57 & 6.13 & Oct 05 & 0.28 & 0.11 & 50.56 & 19.90 \\
\hline Apr 13 & 1.19 & 0.47 & 16.76 & 6.60 & Oct 12 & 2.16 & 0.85 & 52.72 & 20.75 \\
\hline Apr 20 & 2.29 & 0.90 & 19.05 & 7.50 & Oct 19 & 0.97 & 0.38 & 53.68 & 21.13 \\
\hline Apr 27 & 0.58 & 0.23 & 19.63 & 7.73 & Oct 26 & 5.41 & 2.13 & 59.09 & 23.26 \\
\hline May 04 & 0.00 & 0.00 & 19.63 & 7.73 & Nov 02 & 1.85 & 0.73 & 60.94 & 23.99 \\
\hline May 11 & 0.69 & 0.27 & 20.32 & 8.00 & Nov 09 & 0.69 & 0.27 & 61.63 & 24.26 \\
\hline May 18 & 1.93 & 0.76 & 22.25 & 8.76 & Nov 16 & 0.08 & 0.03 & 61.71 & 24.29 \\
\hline May 25 & 1.76 & 0.69 & 24.01 & 9.45 & Nov 23 & 1.73 & 0.68 & 63.43 & 24.97 \\
\hline Jun 01 & 1.42 & 0.56 & 25.44 & 10.01 & Nov 30 & 3.35 & 1.32 & 66.79 & 26.29 \\
\hline Jun 08 & 1.88 & 0.74 & 27.32 & 10.75 & $\operatorname{Dec} 07$ & 0.15 & 0.06 & 66.94 & 26.35 \\
\hline Jun 15 & 0.03 & 0.01 & 27.34 & 10.76 & Dec 14 & 3.30 & 1.30 & 70.24 & 27.65 \\
\hline Jun 22 & 4.55 & 1.79 & 31.89 & 12.55 & $\operatorname{Dec} 21$ & 3.23 & 1.27 & 73.47 & 28.92 \\
\hline Jun 29 & 0.89 & 0.35 & 32.78 & 12.90 & $\operatorname{Dec} 28$ & 5.33 & 2.10 & 78.80 & 31.02 \\
\hline & & & & & Dec 31 & 0.00 & 0.00 & 78.80 & 31.02 \\
\hline
\end{tabular}

I - 7 


\section{Table I-2}

\section{Annual Temperature Summary at the 10-Meter Primary Meteorological Tower}

\begin{tabular}{|c|c|c|c|c|c|c|}
\hline \multirow[t]{2}{*}{ Month } & \multicolumn{2}{|c|}{ Average Temperature } & \multicolumn{2}{|c|}{ Maximum Temperature } & \multicolumn{2}{|c|}{ Minimum Temperature } \\
\hline & ${ }^{0} \mathrm{C}$ & ${ }^{0} \mathbf{F}$ & ${ }^{0} \mathbf{C}$ & ${ }^{0} \mathbf{F}$ & ${ }^{\circ} \mathrm{C}$ & ${ }^{\mathbf{O}} \mathbf{F}$ \\
\hline January & -3.7 & 25.3 & 6.1 & 43.0 & -14.7 & 5.5 \\
\hline February & -2.8 & 27.0 & 15.4 & 59.7 & -16.3 & 2.7 \\
\hline March & -1.6 & 29.1 & 10.1 & 50.2 & -14.5 & 5.9 \\
\hline April & 7.8 & 46.0 & 27.8 & 82.0 & -6.6 & 20.1 \\
\hline May & 13.8 & 56.8 & 26.6 & 79.9 & -0.2 & 31.6 \\
\hline June & 17.6 & 63.7 & 31.5 & 88.7 & 5.8 & 42.4 \\
\hline July & 18.4 & 65.1 & 29.8 & 85.6 & 4.6 & 40.3 \\
\hline August & 20.5 & 68.9 & 32.7 & 90.9 & 9.1 & 48.4 \\
\hline September & 14.1 & 57.4 & 29.0 & 84.2 & 0.8 & 33.4 \\
\hline October & 10.0 & 50.0 & 24.6 & 76.3 & -3.5 & 25.7 \\
\hline November & 7.9 & 46.2 & 19.5 & 67.1 & -2.4 & 27.7 \\
\hline December & 1.3 & 34.3 & 19.6 & 67.3 & -10.2 & 13.6 \\
\hline Annual Average & 8.6 & 47.5 & 22.7 & 72.9 & -4.0 & 24.8 \\
\hline
\end{tabular}

\section{Table I-3}

\section{Annual Barometric Pressure Summary}

(station pressure - inches of mercury)

$\begin{array}{lrcr}\text { Month } & \text { Average Pressure } & \text { Maximum Pressure } & \text { Minimum Press } \\ \text { January } & 28.48 & 28.91 & 27.84 \\ \text { February } & 28.59 & 29.09 & 27.92 \\ \text { March } & 28.41 & 28.92 & 27.85 \\ \text { April } & 28.55 & 29.04 & 28.13 \\ \text { May } & 28.51 & 28.86 & 28.18 \\ \text { June } & 28.54 & 28.89 & 28.11 \\ \text { July } & 28.53 & 28.85 & 28.23 \\ \text { August } & 28.53 & 28.84 & 27.68 \\ \text { September } & 28.57 & 28.82 & 28.28 \\ \text { October } & 28.54 & 29.06 & 27.93 \\ \text { November } & 28.61 & 28.94 & 28.25 \\ \text { December } & 28.47 & 28.96 & 27.95 \\ & & & \\ \text { Annual Average } & 28.53 & 28.93 & 28.03\end{array}$

$I-8$ 


\section{Appendix J}

Summary of Quality Assurance Crosscheck Analyses

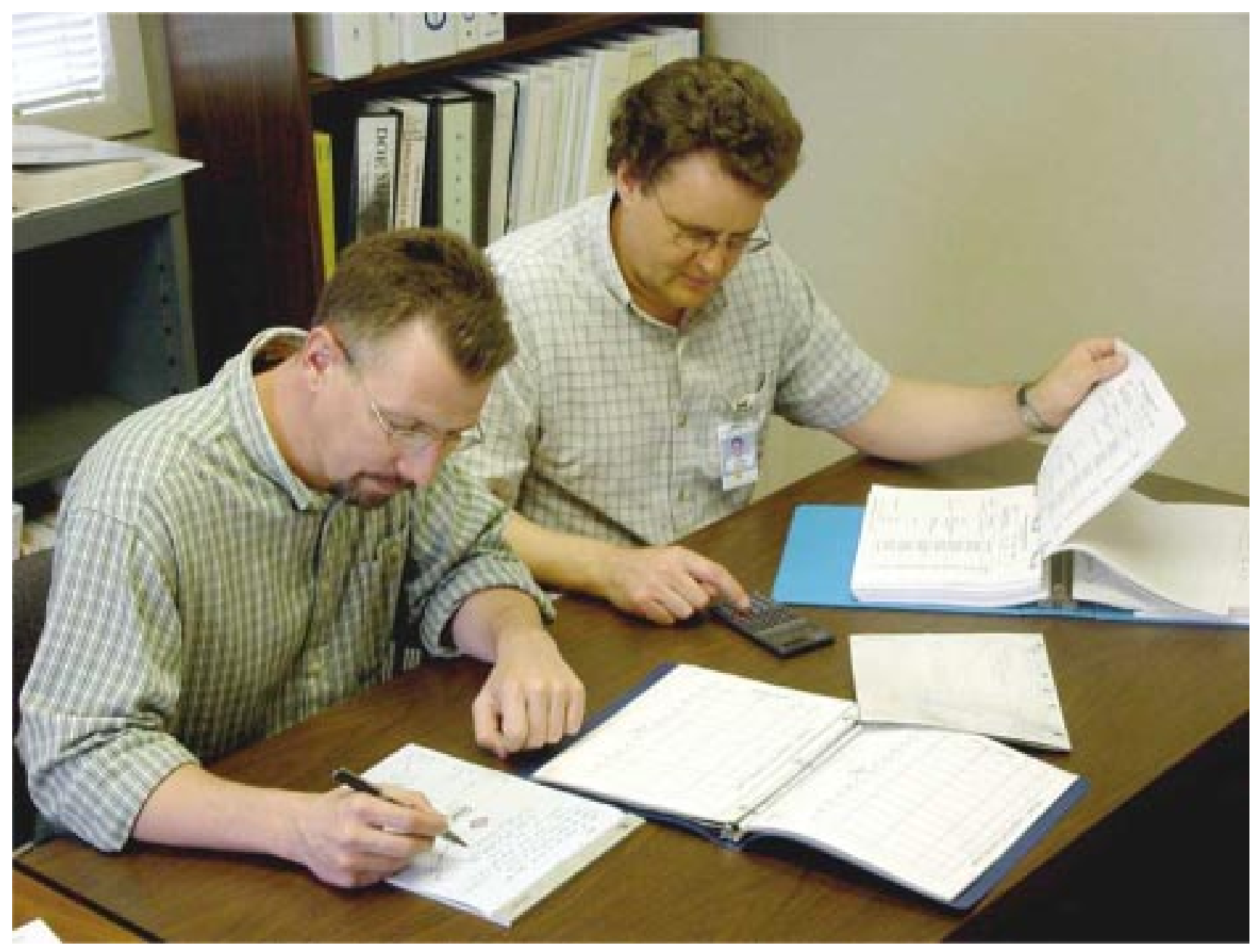

Validating Data

$$
J-1
$$


This page intentionally left blank

$$
J-2
$$


Table J-1

Comparison of Radiological Results With Known Results of Crosscheck Samples From the DOE Environmental Measurements Laboratory (EML) Quality Assessment Program (QAP) 54; EML-613 QAP 0103; June 2001

\begin{tabular}{|c|c|c|c|c|c|c|c|}
\hline Analyte & Matrix & Units & Actual & Reported & Ratio & Accept? & Analyzed by \\
\hline Co-60 & Air filter & Bq/filter & $1.94 \mathrm{E}+01$ & $1.91 \mathrm{E}+01$ & 0.984 & Yes & ELAB \\
\hline Cs-134 & Air filter & $\mathrm{Bq} /$ filter & $2.83 \mathrm{E}+00$ & $2.61 \mathrm{E}+00$ & 0.922 & Yes & ELAB \\
\hline Cs-137 & Air filter & $\mathrm{Bq} / \mathrm{filter}$ & $8.76 \mathrm{E}+00$ & $8.71 E+00$ & 0.994 & Yes & ELAB \\
\hline Gross Alpha & Air filter & $\mathrm{Bq} / \mathrm{filter}$ & $3.97 \mathrm{E}+00$ & $3.17 \mathrm{E}+00$ & 0.798 & Pass & ELAB \\
\hline Gross Beta & Air filter & $\mathrm{Bq} /$ filter & $2.58 \mathrm{E}+00$ & $3.09 \mathrm{E}+00$ & 1.198 & Yes & ELAB \\
\hline Mn-54 & Air filter & $\mathrm{Bq} /$ filter & $6.52 \mathrm{E}+00$ & $7.36 \mathrm{E}+00$ & 1.129 & Yes & ELAB \\
\hline Am-241 & Air filter & $\mathrm{Bq} / \mathrm{filter}$ & $4.86 \mathrm{E}-01$ & $5.19 \mathrm{E}-01$ & 1.068 & Yes & GEL \\
\hline Co-60 & Air filter & $\mathrm{Bq} /$ filter & $1.94 \mathrm{E}+01$ & $1.93 \mathrm{E}+01$ & 0.993 & Yes & GEL \\
\hline Cs-134 & Air filter & $\mathrm{Bq} /$ filter & $2.83 \mathrm{E}+00$ & $2.62 \mathrm{E}+00$ & 0.926 & Yes & GEL \\
\hline Cs-137 & Air filter & $\mathrm{Bq} /$ filter & $8.76 \mathrm{E}+00$ & $8.86 \mathrm{E}+00$ & 1.011 & Yes & GEL \\
\hline Gross Alpha & Air filter & $\mathrm{Bq} /$ filter & $3.97 \mathrm{E}+00$ & $3.59 \mathrm{E}+00$ & 0.904 & Yes & GEL \\
\hline Gross Beta & Air filter & $\mathrm{Bq} / \mathrm{filter}$ & $2.58 \mathrm{E}+00$ & $2.68 \mathrm{E}+00$ & 1.039 & Yes & GEL \\
\hline Mn-54 & Air filter & $\mathrm{Bq} /$ filter & $6.52 \mathrm{E}+00$ & $6.55 \mathrm{E}+00$ & 1.005 & Yes & GEL \\
\hline $\mathrm{Pu}-238$ & Air filter & $\mathrm{Bq} / \mathrm{filter}$ & $2.15 \mathrm{E}-01$ & $2.12 \mathrm{E}-01$ & 0.986 & Yes & GEL \\
\hline $\mathrm{Pu}-239$ & Air filter & $\mathrm{Bq} /$ filter & $1.36 \mathrm{E}-01$ & $1.39 \mathrm{E}-01$ & 1.022 & Yes & GEL \\
\hline Sr-90 & Air filter & $\mathrm{Bq} /$ filter & $7.10 \mathrm{E}+00$ & $8.90 \mathrm{E}+00$ & 1.254 & Yes & GEL \\
\hline U-234 & Air filter & $\mathrm{Bq} /$ filter & $4.60 \mathrm{E}-02$ & $5.90 \mathrm{E}-02$ & 1.283 & Yes & GEL \\
\hline $\mathrm{U}-238$ & Air filter & $\mathrm{Bq} /$ filter & $4.60 \mathrm{E}-02$ & $3.70 \mathrm{E}-02$ & 0.804 & Pass & GEL \\
\hline $\mathrm{U}$ (total) & Air filter & $\mu \mathrm{g} /$ filter & $3.70 \mathrm{E}+00$ & $2.89 \mathrm{E}+00$ & 0.781 & Pass & GEL \\
\hline Ac- 228 & Soil & $\mathrm{Bq} / \mathrm{kg}$ & $4.27 \mathrm{E}+01$ & $4.18 \mathrm{E}+01$ & 0.979 & Yes & GEL \\
\hline Am-241 & Soil & $\mathrm{Bq} / \mathrm{kg}$ & $1.48 \mathrm{E}+01$ & $1.42 \mathrm{E}+01$ & 0.959 & Yes & GEL \\
\hline Bi-212 & Soil & $\mathrm{Bq} / \mathrm{kg}$ & $4.20 \mathrm{E}+01$ & $2.45 \mathrm{E}+01$ & 0.583 & Yes & GEL \\
\hline Bi-214 & Soil & $\mathrm{Bq} / \mathrm{kg}$ & $3.26 \mathrm{E}+01$ & $2.66 \mathrm{E}+01$ & 0.816 & Pass & GEL \\
\hline Cs-137 & Soil & $\mathrm{Bq} / \mathrm{kg}$ & $1.74 \mathrm{E}+03$ & $1.84 \mathrm{E}+03$ & 1.055 & Yes & GEL \\
\hline K-40 & Soil & $\mathrm{Bq} / \mathrm{kg}$ & $4.68 \mathrm{E}+02$ & $5.19 \mathrm{E}+02$ & 1.109 & Yes & GEL \\
\hline $\mathrm{Pb}-212$ & Soil & $\mathrm{Bq} / \mathrm{kg}$ & $4.15 \mathrm{E}+01$ & $4.43 \mathrm{E}+01$ & 1.067 & Yes & GEL \\
\hline $\mathrm{Pb}-214$ & Soil & $\mathrm{Bq} / \mathrm{kg}$ & $3.43 \mathrm{E}+01$ & $3.11 \mathrm{E}+01$ & 0.907 & Yes & GEL \\
\hline $\mathrm{Pu}-239$ & Soil & $\mathrm{Bq} / \mathrm{kg}$ & $2.56 \mathrm{E}+01$ & $2.68 \mathrm{E}+01$ & 1.047 & Yes & GEL \\
\hline Sr-90 & Soil & $\mathrm{Bq} / \mathrm{kg}$ & $6.90 \mathrm{E}+01$ & $6.66 \mathrm{E}+01$ & 0.965 & Yes & GEL \\
\hline Th-234 & Soil & $\mathrm{Bq} / \mathrm{kg}$ & $4.66 \mathrm{E}+01$ & $6.09 \mathrm{E}+01$ & 1.307 & Yes & GEL \\
\hline U-234 & Soil & $\mathrm{Bq} / \mathrm{kg}$ & $4.36 \mathrm{E}+01$ & $3.36 \mathrm{E}+01$ & 0.771 & Pass & GEL \\
\hline $\mathrm{U}-238$ & Soil & $\mathrm{Bq} / \mathrm{kg}$ & $4.61 \mathrm{E}+01$ & $3.48 \mathrm{E}+01$ & 0.775 & Pass & GEL \\
\hline $\mathrm{U}$ (total) & Soil & $\mu \mathrm{g} / \mathrm{g}$ & $3.73 E+00$ & $2.60 \mathrm{E}+00$ & 0.697 & Yes & GEL \\
\hline
\end{tabular}

Acceptance is based on the reported-to-actual ratio, assigned statistically on a case-by-case basis. Yes indicates a ratio within warning limits. Pass indicates a ratio within control limits but outside warning limits. No indicates a ratio outside control limits. Samples were analyzed by either the WVDP Environmental Laboratory (ELAB) or General Engineering Laboratory (GEL).

$$
\text { J - } 3
$$


Table J-1 (concluded)

Comparison of Radiological Results With Known Results of Crosscheck Samples From the DOE Environmental Measurements Laboratory (EML) Quality Assessment Program (QAP) 54; EML-613 QAP 0103; June 2001

\begin{tabular}{|c|c|c|c|c|c|c|c|}
\hline Analyte & Matrix & Units & Actual & Reported & Ratio & Accept? & Analyzed by \\
\hline Am-241 & Veg & $\mathrm{Bq} / \mathrm{kg}$ & $6.17 \mathrm{E}+00$ & $5.81 \mathrm{E}+00$ & 0.942 & Yes & GEL \\
\hline $\mathrm{Cm}-244$ & Veg & $\mathrm{Bq} / \mathrm{kg}$ & $3.69 \mathrm{E}+00$ & $3.85 \mathrm{E}+00$ & 1.043 & Yes & GEL \\
\hline Co-60 & Veg & $\mathrm{Bq} / \mathrm{kg}$ & $3.04 \mathrm{E}+01$ & $3.17 \mathrm{E}+01$ & 1.043 & Yes & GEL \\
\hline Cs-137 & Veg & $\mathrm{Bq} / \mathrm{kg}$ & $8.42 \mathrm{E}+02$ & $8.99 \mathrm{E}+02$ & 1.068 & Yes & GEL \\
\hline $\mathrm{K}-40$ & Veg & $\mathrm{Bq} / \mathrm{kg}$ & $6.03 E+02$ & $6.88 \mathrm{E}+02$ & 1.141 & Yes & GEL \\
\hline $\mathrm{Pu}-239$ & Veg & $\mathrm{Bq} / \mathrm{kg}$ & $9.58 \mathrm{E}+00$ & $9.23 \mathrm{E}+00$ & 0.963 & Yes & GEL \\
\hline Sr-90 & Veg & $\mathrm{Bq} / \mathrm{kg}$ & $1.33 \mathrm{E}+03$ & $1.16 \mathrm{E}+03$ & 0.869 & Yes & GEL \\
\hline Co-60 & Water & $\mathrm{Bq} / \mathrm{L}$ & $9.82 \mathrm{E}+01$ & $1.02 \mathrm{E}+02$ & 1.036 & Yes & ELAB \\
\hline Cs-137 & Water & $\mathrm{Bq} / \mathrm{L}$ & $7.30 \mathrm{E}+01$ & $7.40 \mathrm{E}+01$ & 1.014 & Yes & ELAB \\
\hline Gross Alpha & Water & $\mathrm{Bq} / \mathrm{L}$ & $1.90 \mathrm{E}+03$ & $1.95 \mathrm{E}+03$ & 1.025 & Yes & ELAB \\
\hline Gross Beta & Water & $\mathrm{Bq} / \mathrm{L}$ & $1.30 \mathrm{E}+03$ & $1.68 \mathrm{E}+03$ & 1.297 & Yes & ELAB \\
\hline $\mathrm{H}-3$ & Water & $\mathrm{Bq} / \mathrm{L}$ & $7.93 \mathrm{E}+01$ & $8.63 \mathrm{E}+01$ & 1.088 & Yes & ELAB \\
\hline Sr-90 & Water & $\mathrm{Bq} / \mathrm{L}$ & $4.40 \mathrm{E}+00$ & $4.48 \mathrm{E}+00$ & 1.018 & Yes & ELAB \\
\hline Am-241 & Water & $\mathrm{Bq} / \mathrm{L}$ & $1.67 \mathrm{E}+00$ & $1.57 \mathrm{E}+00$ & 0.940 & Yes & GEL \\
\hline Co-60 & Water & $\mathrm{Bq} / \mathrm{L}$ & $9.82 \mathrm{E}+01$ & $1.03 \mathrm{E}+02$ & 1.049 & Yes & GEL \\
\hline Cs-137 & Water & $\mathrm{Bq} / \mathrm{L}$ & $7.30 \mathrm{E}+01$ & $7.61 \mathrm{E}+01$ & 1.042 & Yes & GEL \\
\hline Gross Alpha & Water & $\mathrm{Bq} / \mathrm{L}$ & $1.90 \mathrm{E}+03$ & $2.08 \mathrm{E}+03$ & 1.093 & Yes & GEL \\
\hline Gross Beta & Water & $\mathrm{Bq} / \mathrm{L}$ & $1.30 \mathrm{E}+03$ & $1.35 \mathrm{E}+03$ & 1.039 & Yes & GEL \\
\hline $\mathrm{H}-3$ & Water & $\mathrm{Bq} / \mathrm{L}$ & $7.93 \mathrm{E}+01$ & $7.64 \mathrm{E}+01$ & 0.963 & Yes & GEL \\
\hline $\mathrm{Pu}-238$ & Water & $\mathrm{Bq} / \mathrm{L}$ & $1.58 \mathrm{E}+00$ & $1.72 \mathrm{E}+00$ & 1.089 & Yes & GEL \\
\hline $\mathrm{Pu}-239$ & Water & $\mathrm{Bq} / \mathrm{L}$ & $1.64 \mathrm{E}+00$ & $1.75 \mathrm{E}+00$ & 1.067 & Yes & GEL \\
\hline Sr-90 & Water & $\mathrm{Bq} / \mathrm{L}$ & $4.40 \mathrm{E}+00$ & $4.36 \mathrm{E}+00$ & 0.991 & Yes & GEL \\
\hline U-234 & Water & $\mathrm{Bq} / \mathrm{L}$ & $1.04 \mathrm{E}+00$ & $8.95 \mathrm{E}-01$ & 0.861 & Pass & GEL \\
\hline U-238 & Water & $\mathrm{Bq} / \mathrm{L}$ & $1.04 \mathrm{E}+00$ & $9.04 \mathrm{E}-01$ & 0.869 & Pass & GEL \\
\hline $\mathrm{U}$ (total) & Water & $\mu \mathrm{g} / \mathrm{mL}$ & $8.00 \mathrm{E}-02$ & $7.50 \mathrm{E}-02$ & 0.935 & Yes & GEL \\
\hline
\end{tabular}

Note: EML did not list acceptance limits for $\mu \mathrm{g}$ of uranium; acceptance criteria for $\mathrm{Bq}$ of uranium were applied to these ratios.

Acceptance is based on the reported-to-actual ratio, assigned statistically on a case-by-case basis. Yes indicates a ratio within warning limits. Pass indicates a ratio within control limits but outside warning limits. No indicates a ratio outside control limits. Samples were analyzed by either the WVDP Environmental Laboratory (ELAB) or General Engineering Laboratory (GEL).

$$
\text { J - } 4
$$




\section{Table J-2}

\section{Comparison of Radiological Results With Known Results of Crosscheck Samples From the DOE Environmental Measurements Laboratory (EML) Quality Assessment Program (QAP) 55; EML-615 QAP 0109; December 2001}

\begin{tabular}{|c|c|c|c|c|c|c|c|}
\hline Analyte & Matrix & Units & Actual & Reported & Ratio & Accept? & Analyzed by \\
\hline Co-60 & Air filter & $\mathrm{Bq} /$ filter & $1.75 \mathrm{E}+01$ & $1.65 \mathrm{E}+01$ & 0.945 & Yes & ELAB \\
\hline Сo-60 & Air filter & $\mathrm{Bq} /$ filter & $1.75 \mathrm{E}+01$ & $1.77 \mathrm{E}+01$ & 1.010 & Yes & ELAB \\
\hline Cs-134 & Air filter & $\mathrm{Bq} /$ filter & $1.30 \mathrm{E}+01$ & $1.21 \mathrm{E}+01$ & 0.933 & Yes & ELAB \\
\hline Cs-134 & Air filter & $\mathrm{Bq} /$ filter & $1.30 \mathrm{E}+01$ & $1.16 \mathrm{E}+01$ & 0.893 & Yes & ELAB \\
\hline Cs-137 & Air filter & $\mathrm{Bq} /$ filter & $1.71 \mathrm{E}+01$ & $1.64 \mathrm{E}+01$ & 0.957 & Yes & ELAB \\
\hline Cs-137 & Air filter & $\mathrm{Bq} /$ filter & $1.71 \mathrm{E}+01$ & $1.72 \mathrm{E}+01$ & 1.003 & Yes & ELAB \\
\hline Gross Alpha & Air filter & $\mathrm{Bq} /$ filter & $5.36 \mathrm{E}+00$ & $3.98 \mathrm{E}+00$ & 0.742 & Pass & ELAB \\
\hline Gross Alpha & Air filter & $\mathrm{Bq} /$ filter & $5.36 \mathrm{E}+00$ & $3.96 \mathrm{E}+00$ & 0.739 & Pass & ELAB \\
\hline Gross Beta & Air filter & $\mathrm{Bq} /$ filter & $1.28 \mathrm{E}+01$ & $1.10 \mathrm{E}+01$ & 0.864 & Pass & ELAB \\
\hline Gross Beta & Air filter & $\mathrm{Bq} /$ filter & $1.28 \mathrm{E}+01$ & $1.09 \mathrm{E}+01$ & 0.851 & Pass & ELAB \\
\hline Mn-54 & Air filter & $\mathrm{Bq} /$ filter & $8.12 \mathrm{E}+01$ & $9.16 \mathrm{E}+01$ & 1.129 & Yes & ELAB \\
\hline $\mathrm{Mn}-54$ & Air filter & $\mathrm{Bq} /$ filter & $8.12 \mathrm{E}+01$ & $8.71 \mathrm{E}+01$ & 1.073 & Yes & ELAB \\
\hline Am-241 & Air filter & $\mathrm{Bq} /$ filter & 8.80E-02 & $1.05 \mathrm{E}-01$ & 1.193 & Yes & GEL \\
\hline Co-60 & Air filter & $\mathrm{Bq} /$ filter & $1.75 \mathrm{E}+01$ & $1.76 \mathrm{E}+01$ & 1.006 & Yes & GEL \\
\hline Cs-134 & Air filter & $\mathrm{Bq} /$ filter & $1.30 \mathrm{E}+01$ & $1.17 \mathrm{E}+01$ & 0.903 & Yes & GEL \\
\hline Cs-137 & Air filter & $\mathrm{Bq} /$ filter & $1.71 \mathrm{E}+01$ & $1.73 \mathrm{E}+01$ & 1.012 & Yes & GEL \\
\hline Gross Alpha & Air filter & $\mathrm{Bq} /$ filter & $5.36 \mathrm{E}+00$ & $5.15 \mathrm{E}+00$ & 0.960 & Yes & GEL \\
\hline Gross Beta & Air filter & $\mathrm{Bq} /$ filter & $1.28 \mathrm{E}+01$ & $1.01 \mathrm{E}+01$ & 0.794 & Pass & GEL \\
\hline Mn-54 & Air filter & $\mathrm{Bq} /$ filter & $8.12 \mathrm{E}+01$ & $8.05 \mathrm{E}+01$ & 0.992 & Yes & GEL \\
\hline $\mathrm{Pu}-238$ & Air filter & $\mathrm{Bq} /$ filter & $7.10 \mathrm{E}-02$ & $6.60 \mathrm{E}-02$ & 0.930 & Yes & GEL \\
\hline $\mathrm{Pu}-239$ & Air filter & $\mathrm{Bq} /$ filter & $2.29 \mathrm{E}-01$ & $2.34 \mathrm{E}-01$ & 1.021 & Yes & GEL \\
\hline Sr-90 & Air filter & $\mathrm{Bq} /$ filter & $3.48 \mathrm{E}+00$ & $3.55 \mathrm{E}+00$ & 1.020 & Yes & GEL \\
\hline U-234 & Air filter & $\mathrm{Bq} /$ filter & $1.08 \mathrm{E}-01$ & $1.09 \mathrm{E}-01$ & 1.007 & Yes & GEL \\
\hline $\mathrm{U}-238$ & Air filter & $\mathrm{Bq} /$ filter & $1.09 \mathrm{E}-01$ & $1.06 \mathrm{E}-01$ & 0.970 & Yes & GEL \\
\hline $\mathrm{U}$ (total) & Air filter & $\mu \mathrm{g} /$ filter & $8.84 \mathrm{E}+00$ & $8.30 \mathrm{E}+00$ & 0.938 & Yes & GEL \\
\hline Am-241 & Soil & $\mathrm{Bq} / \mathrm{kg}$ & $4.43 \mathrm{E}+00$ & $4.92 \mathrm{E}+00$ & 1.110 & Yes & GEL \\
\hline Cs-137 & Soil & $\mathrm{Bq} / \mathrm{kg}$ & $6.12 \mathrm{E}+02$ & $6.55 \mathrm{E}+02$ & 1.070 & Yes & GEL \\
\hline K-40 & Soil & $\mathrm{Bq} / \mathrm{kg}$ & $6.23 \mathrm{E}+02$ & $6.98 \mathrm{E}+02$ & 1.120 & Yes & GEL \\
\hline $\mathrm{Pu}-239$ & Soil & $\mathrm{Bq} / \mathrm{kg}$ & $8.95 \mathrm{E}+00$ & $8.94 \mathrm{E}+00$ & 0.999 & Yes & GEL \\
\hline Sr-90 & Soil & $\mathrm{Bq} / \mathrm{kg}$ & $3.06 \mathrm{E}+01$ & $2.33 \mathrm{E}+01$ & 0.762 & Pass & GEL \\
\hline U-234 & Soil & $\mathrm{Bq} / \mathrm{kg}$ & $9.22 \mathrm{E}+01$ & $7.91 \mathrm{E}+01$ & 0.858 & Pass & GEL \\
\hline $\mathrm{U}-238$ & Soil & $\mathrm{Bq} / \mathrm{kg}$ & $9.83 \mathrm{E}+01$ & $8.39 \mathrm{E}+01$ & 0.853 & Yes & GEL \\
\hline $\mathrm{U}$ (total) & Soil & $\mu \mathrm{g} / \mathrm{g}$ & $7.95 \mathrm{E}+00$ & $5.65 \mathrm{E}+00$ & 0.711 & Yes & GEL \\
\hline
\end{tabular}

Acceptance is based on the reported-to-actual ratio, assigned statistically on a case-by-case basis. Yes indicates a ratio within warning limits. Pass indicates a ratio within control limits but outside warning limits. No indicates a ratio outside control limits. Samples were analyzed by either the WVDP Environmental Laboratory (ELAB) or General Engineering Laboratory (GEL).

$$
J-5
$$


Table J-2 (concluded)

Comparison of Radiological Results With Known Results of Crosscheck Samples From the DOE Environmental Measurements Laboratory (EML) Quality Assessment Program (QAP) 55; EML-615 QAP 0109; December 2001

\begin{tabular}{|c|c|c|c|c|c|c|c|}
\hline Analyte & Matrix & Units & Actual & Reported & Ratio & Accept? & Analyzed by \\
\hline Am-241 & Veg & $\mathrm{Bq} / \mathrm{kg}$ & $6.92 \mathrm{E}+00$ & $7.60 \mathrm{E}+00$ & 1.099 & Yes & GEL \\
\hline $\mathrm{Cm}-244$ & Veg & $\mathrm{Bq} / \mathrm{kg}$ & $4.31 \mathrm{E}+00$ & $4.48 \mathrm{E}+00$ & 1.040 & Yes & GEL \\
\hline Co-60 & Veg & $\mathrm{Bq} / \mathrm{kg}$ & $3.53 \mathrm{E}+01$ & $3.81 \mathrm{E}+01$ & 1.079 & Yes & GEL \\
\hline Cs-137 & Veg & $\mathrm{Bq} / \mathrm{kg}$ & $1.03 \mathrm{E}+03$ & $1.12 \mathrm{E}+03$ & 1.091 & Yes & GEL \\
\hline $\mathrm{K}-40$ & Veg & $\mathrm{Bq} / \mathrm{kg}$ & $8.99 \mathrm{E}+02$ & $1.05 \mathrm{E}+03$ & 1.166 & Yes & GEL \\
\hline $\mathrm{Pu}-239$ & Veg & $\mathrm{Bq} / \mathrm{kg}$ & $1.10 \mathrm{E}+01$ & $9.71 \mathrm{E}+00$ & 0.881 & Yes & GEL \\
\hline Sr-90 & Veg & $\mathrm{Bq} / \mathrm{kg}$ & $1.61 \mathrm{E}+03$ & $1.57 \mathrm{E}+03$ & 0.975 & Yes & GEL \\
\hline Co-60 & Water & $\mathrm{Bq} / \mathrm{L}$ & $2.09 \mathrm{E}+02$ & $2.16 \mathrm{E}+02$ & 1.032 & Yes & ELAB \\
\hline Cs-137 & Water & $\mathrm{Bq} / \mathrm{L}$ & $4.51 \mathrm{E}+01$ & $4.81 \mathrm{E}+01$ & 1.066 & Yes & ELAB \\
\hline Gross Alpha & Water & $\mathrm{Bq} / \mathrm{L}$ & $1.15 \mathrm{E}+03$ & $1.23 \mathrm{E}+03$ & 1.073 & Yes & ELAB \\
\hline Gross Beta & Water & $\mathrm{Bq} / \mathrm{L}$ & $7.97 \mathrm{E}+03$ & $8.20 \mathrm{E}+03$ & 1.028 & Yes & ELAB \\
\hline $\mathrm{H}-3$ & Water & $\mathrm{Bq} / \mathrm{L}$ & $2.07 \mathrm{E}+02$ & $2.23 \mathrm{E}+02$ & 1.076 & Yes & ELAB \\
\hline Sr-90 & Water & $\mathrm{Bq} / \mathrm{L}$ & $3.73 \mathrm{E}+00$ & $3.68 \mathrm{E}+00$ & 0.987 & Yes & ELAB \\
\hline Am-241 & Water & $\mathrm{Bq} / \mathrm{L}$ & $7.60 \mathrm{E}-01$ & $7.78 \mathrm{E}-01$ & 1.024 & Yes & GEL \\
\hline Co-60 & Water & $\mathrm{Bq} / \mathrm{L}$ & $2.09 \mathrm{E}+02$ & $2.16 \mathrm{E}+02$ & 1.035 & Yes & GEL \\
\hline Cs-137 & Water & $\mathrm{Bq} / \mathrm{L}$ & $4.51 \mathrm{E}+01$ & $4.76 \mathrm{E}+01$ & 1.055 & Yes & GEL \\
\hline Gross Alpha & Water & $\mathrm{Bq} / \mathrm{L}$ & $1.15 \mathrm{E}+03$ & $1.31 \mathrm{E}+03$ & 1.139 & Pass & GEL \\
\hline Gross Beta & Water & $\mathrm{Bq} / \mathrm{L}$ & $7.97 \mathrm{E}+03$ & $8.35 \mathrm{E}+03$ & 1.048 & Yes & GEL \\
\hline $\mathrm{H}-3$ & Water & $\mathrm{Bq} / \mathrm{L}$ & $2.07 \mathrm{E}+02$ & $2.23 \mathrm{E}+02$ & 1.075 & Yes & GEL \\
\hline $\mathrm{Ni}-63$ & Water & $\mathrm{Bq} / \mathrm{L}$ & $4.53 \mathrm{E}+01$ & $5.30 \mathrm{E}+01$ & 1.171 & Pass & GEL \\
\hline $\mathrm{Pu}-238$ & Water & $\mathrm{Bq} / \mathrm{L}$ & $1.09 \mathrm{E}+00$ & $1.07 \mathrm{E}+00$ & 0.981 & Yes & GEL \\
\hline $\mathrm{Pu}-239$ & Water & $\mathrm{Bq} / \mathrm{L}$ & $1.63 \mathrm{E}+00$ & $1.72 \mathrm{E}+00$ & 1.059 & Yes & GEL \\
\hline Sr-90 & Water & $\mathrm{Bq} / \mathrm{L}$ & $3.73 \mathrm{E}+00$ & $3.93 \mathrm{E}+00$ & 1.054 & Yes & GEL \\
\hline U-234 & Water & $\mathrm{Bq} / \mathrm{L}$ & $1.17 \mathrm{E}+00$ & $1.02 \mathrm{E}+00$ & 0.877 & Pass & GEL \\
\hline U-238 & Water & $\mathrm{Bq} / \mathrm{L}$ & $1.17 \mathrm{E}+00$ & 9.79E-01 & 0.837 & Pass & GEL \\
\hline $\mathrm{U}$ (total) & Water & $\mu \mathrm{g} / \mathrm{mL}$ & $9.40 \mathrm{E}-02$ & $8.20 \mathrm{E}-02$ & 0.871 & Pass & GEL \\
\hline
\end{tabular}

Acceptance is based on the reported-to-actual ratio, assigned statistically on a case-by-case basis. Yes indicates a ratio within warning limits. Pass indicates a ratio within control limits but outside warning limits. No indicates a ratio outside control limits. Samples were analyzed by either the WVDP Environmental Laboratory (ELAB) or General Engineering Laboratory (GEL).

$$
\text { J - } 6
$$


Table J-3

Comparison of Results From Crosscheck Samples Analyzed for Water Quality Parameters as Part of the EPA's 2001 Discharge Monitoring Report - Quality Assurance (DMR-QA) Study 21 for the National Pollutant Discharge Elimination System (NPDES)

$\begin{array}{llrrrc}\text { Analyte } & \text { Units } & \text { Actual } & \text { Reported } & \text { Accept? } & \text { Analyzed by: } \\ & & & & & \\ \text { Aluminum } & \mu \mathrm{g} / \mathrm{L} & 1,020 & 1,060 & \text { Yes } & \mathrm{STL} \\ \text { Ammonia (as Nitrogen) } & \mathrm{mg} / \mathrm{L} & 14.5 & 14.0 & \text { Yes } & \mathrm{STL} \\ \text { Arsenic } & \mu \mathrm{g} / \mathrm{L} & 709 & 708 & \text { Yes } & \mathrm{STL} \\ \text { Biochemical oxygen demand } & \mathrm{mg} / \mathrm{L} & 45.3 & 68.4 & \text { No } & \mathrm{STL} \\ \text { Cadmium } & \mu \mathrm{g} / \mathrm{L} & 209 & 205 & \text { Yes } & \mathrm{STL} \\ \text { Chlorine, total residual } & \mathrm{mg} / \mathrm{L} & 1.23 & 1.23 & \text { Yes } & \mathrm{WVNS} \\ \text { Chromium } & \mu \mathrm{g} / \mathrm{L} & 309 & 315 & \text { Yes } & \mathrm{STL} \\ \text { Cobalt } & \mu \mathrm{g} / \mathrm{L} & 246 & 251 & \text { Yes } & \mathrm{STL} \\ \text { Copper } & \mu \mathrm{g} / \mathrm{L} & 338 & 334 & \text { Yes } & \mathrm{STL} \\ \text { Cyanide, total } & \mathrm{mg} / \mathrm{L} & 0.193 & 0.158 & \text { Yes } & \mathrm{STL} \\ \text { Grease and oil (Gravimetric) } & \mathrm{mg} / \mathrm{L} & 26.0 & 19.2 & \text { Yes } & \mathrm{STL} \\ \text { Iron } & \mu \mathrm{g} / \mathrm{L} & 457 & 456 & \text { Yes } & \mathrm{STL} \\ \text { Lead } & \mu \mathrm{g} / \mathrm{L} & 198 & 199 & \text { Yes } & \mathrm{STL} \\ \text { Manganese } & \mu \mathrm{g} / \mathrm{L} & 651 & 657 & \text { Yes } & \mathrm{STL} \\ \text { Mercury } & \mu \mathrm{g} / \mathrm{L} & 2.13 & 1.98 & \text { Yes } & \mathrm{STL} \\ \text { Nickel } & \mu \mathrm{g} / \mathrm{L} & 808 & 824 & \text { Yes } & \mathrm{STL} \\ \text { Nitrate (as Nitrogen) } & \mathrm{mg} / \mathrm{L} & 2.58 & 2.84 & \text { Yes } & \mathrm{STL} \\ \text { pH } & \mathrm{SU} & 8.36 & 8.38 & \text { Yes } & \mathrm{WVNS} \\ \text { Phenolics, total } & \mathrm{mg} / \mathrm{L} & 0.372 & 0.30 & \text { Yes } & \mathrm{STL} \\ \text { Selenium } & \mu \mathrm{g} / \mathrm{L} & 597 & 597 & \text { Yes } & \mathrm{STL} \\ \text { Suspended solids, total } & \mathrm{mg} / \mathrm{L} & 68.2 & 66.0 & \text { Yes } & \mathrm{STL} \\ \text { Vanadium } & \mu \mathrm{g} / \mathrm{L} & 439 & 449 & \text { Yes } & \mathrm{STL} \\ \text { Zinc } & \mu \mathrm{g} / \mathrm{L} & 971 & 983 & \text { Yes } & \mathrm{STL}\end{array}$

Samples provided by Environmental Research Associates (ERA).

Analyses were conducted by Severn Trent Laboratories (STL) or WVNSCO, as indicated.

Acceptance limits are determined by ERA or NYSDOH, as applicable. Yes indicates a ratio within warning limits. Pass indicates a ratio within control limits but outside warning limits. No indicates a ratio outside control limits.

$$
J-7
$$

WVDP Site Environmental Report

Calendar Year 2001 
This page intentionally left blank

$$
J-8
$$




\section{Appendix $\mathrm{K}$ \\ Environmental Regulations, Standards, and Orders}

$K-1$ 
This page intentionally left blank

$$
K-2
$$




\section{Table K-1 \\ Department of Energy Radiation Protection Standards and Derived Concentration Guides ${ }^{1}$}

Effective Dose Equivalent Radiation Standard for Protection of the Public

Continuous exposure of any member of the public from routine activities:

All exposure pathways $=100 \mathrm{mrem} / \mathrm{year}(1 \mathrm{mSv} / \mathrm{yr})$ effective dose equivalent

Department of Energy Derived Concentration Guides (DCGs) for Inhaled Air or Ingested Water $(\mu \mathrm{Ci} / \mathrm{mL})$

\begin{tabular}{|c|c|c|c|c|c|c|c|}
\hline Radionuclide & $\begin{array}{c}\text { Half-life } e^{2,3} \\
\text { (years) }\end{array}$ & In Air & In Water & Radionuclide & $\begin{array}{c}\text { Half-life }{ }^{2,3} \\
\text { (years) }\end{array}$ & In Air & In Water \\
\hline H-3* & $1.23 \mathrm{E}+01$ & $1 \mathrm{E}-07$ & $2 \mathrm{E}-03$ & Eu-152 & $1.36 \mathrm{E}+01$ & $5 \mathrm{E}-11$ & $2 \mathrm{E}-05$ \\
\hline C-14* & $5.73 E+03$ & $6 \mathrm{E}-09$ & 7E-05 & Eu-154* & $8.80 \mathrm{E}+00$ & $5 \mathrm{E}-11$ & $2 \mathrm{E}-05$ \\
\hline K-40 & $1.28 \mathrm{E}+09$ & $9 \mathrm{E}-10$ & 7E-06 & Eu-155 & $4.96 \mathrm{E}+00$ & $3 \mathrm{E}-10$ & $1 \mathrm{E}-04$ \\
\hline Fe-55 & $2.70 \mathrm{E}+00$ & $5 E-09$ & $2 \mathrm{E}-04$ & Th-232 & $1.40 \mathrm{E}+10$ & $7 \mathrm{E}-15$ & $5 E-08$ \\
\hline Co-60* & $5.27 \mathrm{E}+00$ & $8 \mathrm{E}-11$ & $5 E-06$ & U-232* & $7.20 \mathrm{E}+01$ & $2 \mathrm{E}-14$ & $1 \mathrm{E}-07$ \\
\hline Ni-59 & $7.50 \mathrm{E}+04$ & $4 \mathrm{E}-09$ & 7E-04 & U-233* & $1.59 \mathrm{E}+05$ & $9 \mathrm{E}-14$ & $5 \mathrm{E}-07$ \\
\hline Ni-63 & $1.00 \mathrm{E}+02$ & 2E-09 & $3 \mathrm{E}-04$ & U-234* & $2.44 \mathrm{E}+05$ & 9E-14 & $5 \mathrm{E}-07$ \\
\hline Sr-90* & $2.86 \mathrm{E}+01$ & 9E-12 & $1 \mathrm{E}-06$ & U-235* & $7.04 \mathrm{E}+08$ & $1 \mathrm{E}-13$ & $6 \mathrm{E}-07$ \\
\hline Y-90 & 7.31E-03 & $1 \mathrm{E}-09$ & $1 \mathrm{E}-05$ & U-236* & $2.34 \mathrm{E}+07$ & $1 \mathrm{E}-13$ & $5 \mathrm{E}-07$ \\
\hline Zr-93 & $1.53 \mathrm{E}+06$ & $4 \mathrm{E}-11$ & 9E-05 & U-238* & $4.47 \mathrm{E}+09$ & $1 \mathrm{E}-13$ & $6 \mathrm{E}-07$ \\
\hline Nb-93m & $1.46 \mathrm{E}+01$ & $4 \mathrm{E}-10$ & $3 \mathrm{E}-04$ & Np-239 & $6.45 \mathrm{E}-03$ & $5 \mathrm{E}-09$ & $5 \mathrm{E}-05$ \\
\hline Tc-99* & $2.13 \mathrm{E}+05$ & 2E-09 & $1 \mathrm{E}-04$ & Pu-238* & $8.78 \mathrm{E}+01$ & $3 \mathrm{E}-14$ & 4E-08 \\
\hline Ru-106 & $1.01 \mathrm{E}+00$ & $3 \mathrm{E}-11$ & $6 \mathrm{E}-06$ & Pu-239* & $2.41 \mathrm{E}+04$ & $2 \mathrm{E}-14$ & $3 \mathrm{E}-08$ \\
\hline Cd-113m & $1.37 \mathrm{E}+01$ & $8 \mathrm{E}-12$ & 9E-07 & Pu-240* & $6.57 \mathrm{E}+03$ & $2 \mathrm{E}-14$ & $3 \mathrm{E}-08$ \\
\hline Sn-126 & $1.00 \mathrm{E}+05$ & $1 \mathrm{E}-10$ & $8 \mathrm{E}-06$ & Pu-241 & $1.44 \mathrm{E}+01$ & $1 \mathrm{E}-12$ & $2 \mathrm{E}-06$ \\
\hline Sb-125 & $2.77 \mathrm{E}+00$ & $1 \mathrm{E}-09$ & $5 \mathrm{E}-05$ & Am-241* & $4.32 \mathrm{E}+02$ & $2 \mathrm{E}-14$ & $3 \mathrm{E}-08$ \\
\hline Te-125m & $1.59 \mathrm{E}-01$ & 2E-09 & $4 \mathrm{E}-05$ & Am-242m & $1.52 \mathrm{E}+02$ & $2 \mathrm{E}-14$ & $3 \mathrm{E}-08$ \\
\hline I-129* & $1.57 \mathrm{E}+07$ & 7E-11 & $5 E-07$ & Am-243 & $7.38 \mathrm{E}+03$ & $2 \mathrm{E}-14$ & $3 \mathrm{E}-08$ \\
\hline Cs-134 & $2.06 \mathrm{E}+00$ & $2 \mathrm{E}-10$ & $2 \mathrm{E}-06$ & Cm-243 & $2.85 \mathrm{E}+01$ & $3 \mathrm{E}-14$ & $5 \mathrm{E}-08$ \\
\hline Cs-135 & $2.30 \mathrm{E}+06$ & $3 \mathrm{E}-09$ & 2E-05 & Cm-244 & $1.81 \mathrm{E}+01$ & $4 \mathrm{E}-14$ & $6 \mathrm{E}-08$ \\
\hline Cs-137* & $3.02 \mathrm{E}+01$ & $4 \mathrm{E}-10$ & $3 \mathrm{E}-06$ & Gross Alpha & NA & $2 \mathrm{E}-14$ & $3 \mathrm{E}-08$ \\
\hline Pm-147 & $2.62 \mathrm{E}+00$ & $3 \mathrm{E}-10$ & $1 \mathrm{E}-04$ & (as Am-241) & & & \\
\hline Sm-151 & $9.00 \mathrm{E}+01$ & $4 \mathrm{E}-10$ & $4 \mathrm{E}-04$ & $\begin{array}{l}\text { Gross Beta } \\
\text { (as Sr-90) }\end{array}$ & NA & $9 \mathrm{E}-12$ & $1 \mathrm{E}-06$ \\
\hline
\end{tabular}

${ }^{1}$ DOE Order 5400.5 (February 8, 1990). Effective May 8, 1990. (See Derived Concentration Guides [p. 1-5] in Chapter 1, Environmental Program Information.)

${ }^{2}$ U.S. Department of Energy. 1981. Radioactive Decay Tables. Washington, D.C.: Technical Information Center, U.S. Department of Energy.

${ }^{3}$ Shleien, B. et al. 1998. Handbook of Health Physics and Radiological Health Safety. 3rd ed. Baltimore, Maryland: Williams \& Wilkins.

* Radionuclides measured in WVDP effluent.

NA - Not applicable.

WVDP Site Environmental Report

K - 3

Calendar Year 2001 


\section{Table K-2 \\ Environmental Regulations, Orders, and Standards}

The following environmental standards and laws are applicable, in whole or in part, to the West Valley Demonstration Project. Although the list covers the major activities at the West Valley Demonstration Project, it does not constitute a complete enumeration.

Atomic Energy Act of 1954, 42 USC $\$ 2011$ et seq.

Clean Air Act (CAA). Pub. L. No. 84-159.42 USC $\$ 7401$ et seq., as amended, and implementing regulations.

Comprehensive Environmental Response, Compensation, and Liability Act (CERCLA). Pub. L. No. 96-510. 42 USC $\$ 9601$ et seq. (including Superfund Amendments and Reauthorization Act of 1986), and implementing regulations.

DOE Order 231.1. September 30, 1995. Environment, Safety, and Health Reporting, including Change 2 (November 7, 1996).

DOE Order 232.1A. August 1, 1997. Occurrence Reporting and Processing of Operations Information.

DOE Order 414.1A. September 29, 1999. Quality Assurance, including Change 1 (July 12, 2001).

DOE Order 435.1. July 9, 1999. Radioactive Waste Management, including Change 1 (August 28, 2001).

DOE Order 451.1B. October 26, 2000. National Environmental Policy Act Compliance Program, including Change 1 (September 28, 2001).

DOE Order 5400.1. November 9, 1988. General Environmental Protection Program, including Change 1 (June 29, 1990).

DOE Order 5400.5. February 8, 1990. Radiation Protection of the Public and the Environment, including Change 2 (January 7, 1993).

DOE Order 5480.4. May 15, 1984. Environmental Protection, Safety, and Health Protection Standards, including Change 4 (January 7, 1993).

DOE Regulatory Guide DOE/EH-0173T. January 1991. Environmental Regulatory Guide for Radiological Effluent Monitoring and Environmental Surveillance.

Emergency Planning and Community Right-to-Know Act (EPCRA) of 1986. Pub. L. No. 99-499. 42 USC $\S 11001$ et seq., and implementing regulations.

$K-4$ 


\section{Table K-2 (concluded) Environmental Regulations, Orders, and Standards}

Endangered Species Act. Pub. L. No. 93-205. 16 USC §1531-1544.

Environmental Conservation Law of New York State and implementing regulations (NYCRR).

Executive Order 11988. Floodplain Management.

Executive Order 11990. Protection of Wetlands.

Executive Order 12856. Federal Compliance with Right-to-Know Laws and Pollution Prevention Requirements.

Executive Order 13101. Greening the Government Through Waste Prevention, Recycling, and Federal Acquisition.

Executive Order 13148. Greening the Government Through Leadership in Environmental Management.

Federal Water Pollution Control Act (Clean Water Act [CWA]). Pub. L. No. 95-217.33 USC \$1251 et seq., as amended, and implementing regulations.

Resource Conservation and Recovery Act (RCRA). Pub. L. No. 94-580. 42 USC $\$ 6901$ et seq., as amended, and implementing regulations.

National Environmental Policy Act (NEPA) of 1969. Pub. L. No. 91-190. 42 USC $\$ 4321$ et seq., as amended, and implementing regulations.

National Historic Preservation Act of 1966. Pub. L. No. 102-575. 16 USC $§ 470$.

Toxic Substances Control Act (TSCA). Pub. L. No. 94-469. 15 USC $\$ 2601$ et seq., as amended, and implementing regulations.

Safe Drinking Water Act (SDWA). Pub.L. No. 93-523.42 USC $\$ 300 f$ et seq., as amended, and implementing regulations.

Water quality standards contained in the State Pollutant Discharge Elimination System(SPDES) permit issued for the facility are listed in Table G-1. Airborne emissions are regulated by the Environmental Protection Agency under the National Emission Standards for Hazardous Air Pollutants (NESHAP), 40 CFR §61 Subpart H(December 15, 1989).

$K-5$ 
This page intentionally left blank

$K-6$ 


\section{Appendix L \\ Summary of NYSERDA Groundwater Monitoring Data}

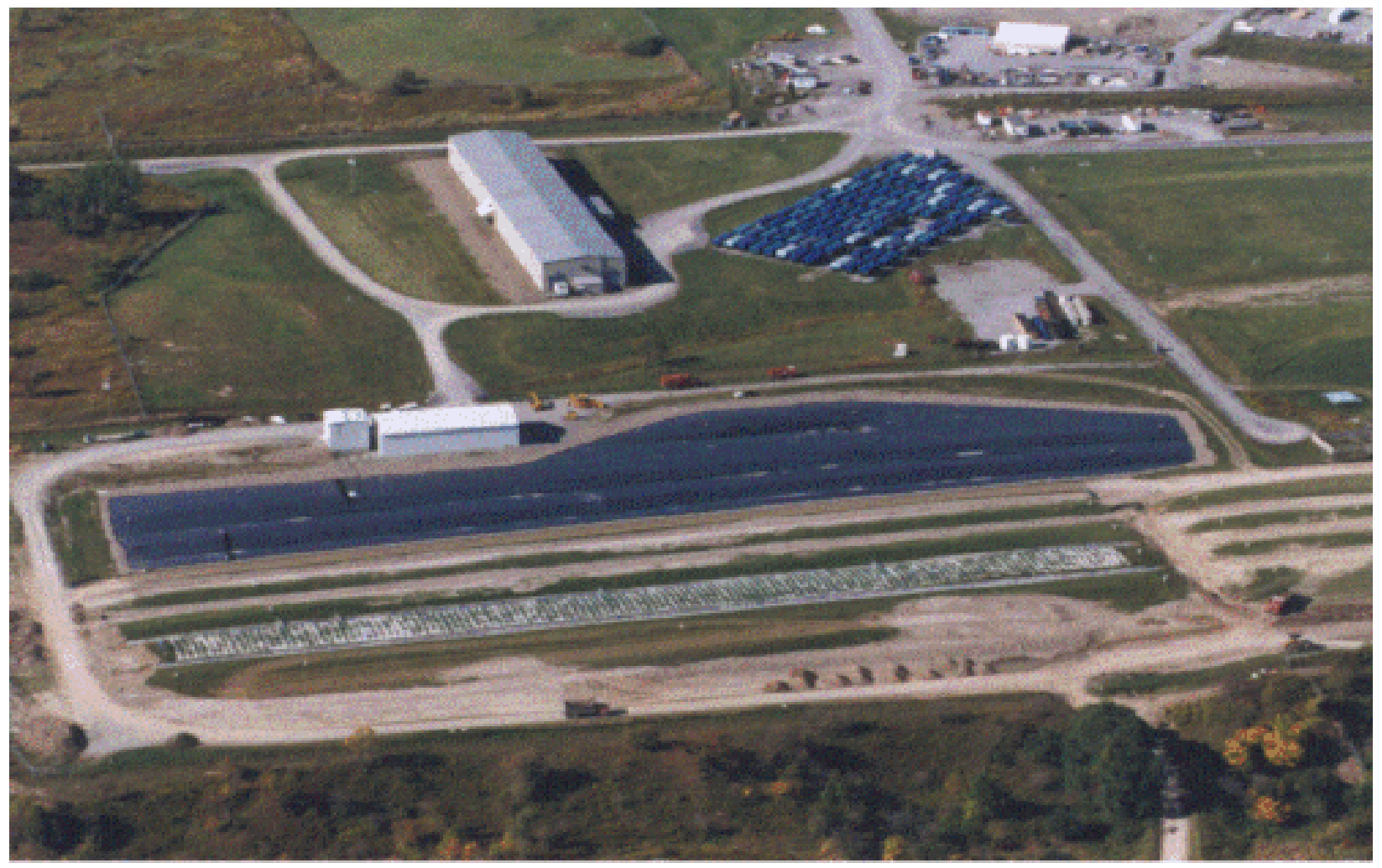

An Aerial View of the New York State-Licensed Disposal Area

$$
L-1
$$


This page intentionally left blank

$L-2$ 
Table L-1

2001 Contamination Indicator Results at SDA Monitoring Wells

\begin{tabular}{|c|c|c|c|c|c|}
\hline $\begin{array}{l}\text { Sample } \\
\text { Location }\end{array}$ & Date & $\begin{array}{c}\text { Conductivity } \\
\left(\mu \mathrm{mhos} / \mathrm{cm} @ 25^{\circ} \mathrm{C}\right)\end{array}$ & $\begin{array}{c}\mathbf{p H} \\
\text { (standard units) }\end{array}$ & $\begin{array}{c}\text { Temperature } \\
\left({ }^{\circ} \mathrm{C}\right)\end{array}$ & $\begin{array}{c}\text { Turbidity } \\
\text { (NTU) }\end{array}$ \\
\hline WNW1101A & June & 643 & 7.57 & 11.5 & 5.21 \\
\hline WNW1101A & December & 615 & 7.68 & 10.8 & 2.94 \\
\hline WNW1101A & December & 615 & 7.68 & 10.8 & 2.94 \\
\hline WNW1101B & June & 651 & 7.73 & 12.5 & 25.30 \\
\hline WNW1101B & December & 536 & 7.59 & 11.0 & 3.27 \\
\hline WNW1101C & June & 370 & 7.90 & 11.2 & 179.00 \\
\hline WNW1101C & December & 374 & 7.93 & 9.2 & $>1,000.00$ \\
\hline WNW1102A & June & 758 & 7.92 & 12.2 & 80.40 \\
\hline WNW1102A & December & 699 & 7.58 & 11.8 & 6.70 \\
\hline WNW1102B & June & 587 & 7.57 & 11.8 & 138.00 \\
\hline WNW1102B & December & 578 & 7.59 & 10.4 & 9.35 \\
\hline WNW1103A & June & 954 & 7.47 & 11.8 & 706.00 \\
\hline WNW1103A & December & 924 & 7.74 & 10.9 & 152.00 \\
\hline WNW1103B & June & 459 & 7.60 & 11.8 & 4.63 \\
\hline WNW1103B & December & 679 & 7.87 & 9.8 & 21.70 \\
\hline WNW1104A & June & 713 & 7.51 & 10.9 & 9.27 \\
\hline WNW1104A & December & 647 & 7.62 & 12.0 & 8.75 \\
\hline WNW1104B & June & 628 & 7.66 & 12.5 & 2.20 \\
\hline WNW1104B & December & 609 & 7.79 & 9.9 & 0.96 \\
\hline WNW1105A & June & 674 & 7.72 & 10.4 & 59.60 \\
\hline WNW1105A & December & 670 & 7.38 & 10.0 & 19.20 \\
\hline WNW1105B & June & 689 & 7.76 & 11.7 & 76.50 \\
\hline WNW1105B & December & 701 & 7.80 & 8.3 & 27.30 \\
\hline WNW1106A & June & 750 & 7.50 & 12.5 & 6.45 \\
\hline WNW1106A & December & 729 & 7.69 & 12.2 & 43.90 \\
\hline WNW1106B & June & 732 & 7.35 & 13.2 & 333.00 \\
\hline WNW1106B & December & 749 & 7.49 & 11.2 & 189.00 \\
\hline WNW1107A & June & 1,898 & 6.80 & 12.4 & 1.73 \\
\hline WNW1107A & June & 1,898 & 6.80 & 12.4 & 1.73 \\
\hline WNW1107A & December & 1,488 & 7.00 & 11.0 & 1.24 \\
\hline
\end{tabular}

All data in Tables L-1 through L-3 have been provided by NYSERDA.

$L-3$

WVDP Site Environmental Report

Calendar Year 2001 
Table L-1 (concluded)

2001 Contamination Indicator Results at SDA Monitoring Wells

$\begin{array}{cccccc}\begin{array}{c}\text { Sample } \\ \text { Location }\end{array} & \text { Date } & \begin{array}{c}\text { Conductivity } \\ \left(\mu \mathrm{mhos} / \mathrm{cm} @ 25^{\circ} \mathrm{C}\right)\end{array} & \begin{array}{c}\mathbf{p H} \\ (\text { standard units })\end{array} & \begin{array}{c}\text { Temperature } \\ \left({ }^{\circ} \mathrm{C}\right)\end{array} & \begin{array}{c}\text { Turbidity } \\ (\mathrm{NTU})\end{array} \\ \text { WNW1108A } & \begin{array}{c}\text { June } \\ \text { December }\end{array} & 898 & 7.65 & 10.7 & 386.00 \\ \text { WNW1108A } & 509 & 6.98 & 11.6 & 1.18 \\ \text { WNW1109A } & \text { June } & 592 & 7.67 & 11.7 & 7.46 \\ \text { WNW1109A } & \text { December } & 566 & 7.31 & 10.9 & 3.41 \\ \text { WNW1109B } & \text { June } & 440 & 7.00 & 11.4 & 42.90 \\ \text { WNW1109B } & \text { December } & 423 & 7.71 & 10.2 & 65.50 \\ \text { WNW1111A } & & & & & \\ \text { WNW1111A } & \text { June } & 1,038 & 7.31 & 11.5 & 2.67 \\ & \text { December } & 1,024 & 7.43 & 10.4 & 2.09\end{array}$

All data in Tables L-1 through L-3 have been provided by NYSERDA.

$$
L-4
$$

WVDP Site Environmental Report 
Table L-2

\section{Radiological Indicator Results at SDA Monitoring Wells $(\mu \mathrm{Ci} / \mathrm{mL})$}

\section{Sample \\ Location}

WNW1101A

WNW1101A

WNW1101A

WNW1101B

WNW1101B

WNW1101C

WNW1101C

WNW1102A

WNW1102A

WNW1102B

WNW1102B

WNW1103A

WNW1103A

WNW1103B

WNW1103B

WNW1103C

WNW1103C

WNW1104A

WNW1104A

WNW1104B

WNW1104B

WNW1104C

WNW1104C

WNW1105A

WNW1105A

WNW1105B

WNW1105B

WNW1106A

WNW1106A

WNW1106B

WNW1106B
Date

June

December

December

June

December

June
December

June

December

June

December

June
December

June

December

June

December

June

December

June

December

June

December

June

December

June

December

June

December

June

December
Gross Alpha

$2.34 \pm 1.70 \mathrm{E}-09$

$2.31 \pm 1.40 \mathrm{E}-09$

$3.14 \pm 1.60 \mathrm{E}-09$

$3.55 \pm 1.30 \mathrm{E}-09$

$3.94 \pm 1.90 \mathrm{E}-09$

$1.64 \pm 1.30 \mathrm{E}-09$

$8.84 \pm 7.60 \mathrm{E}-10$

$0.17 \pm 1.30 \mathrm{E}-09$

$4.87 \pm 2.20 \mathrm{E}-09$

$1.90 \pm 1.10 \mathrm{E}-09$

$7.46 \pm 7.60 \mathrm{E}-10$

$5.53 \pm 3.50 \mathrm{E}-09$

$6.24 \pm 2.80 \mathrm{E}-09$

$4.05 \pm 2.40 \mathrm{E}-09$

$3.68 \pm 1.70 \mathrm{E}-09$

$1.06 \pm 1.50 \mathrm{E}-09$

$1.23 \pm 1.10 \mathrm{E}-09$

$2.63 \pm 1.80 \mathrm{E}-09$

$3.16 \pm 1.70 \mathrm{E}-09$

$2.80 \pm 2.20 \mathrm{E}-09$

$2.87 \pm 1.60 \mathrm{E}-09$

$2.46 \pm 4.30 \mathrm{E}-09$

$6.45 \pm 4.90 \mathrm{E}-09$

$3.40 \pm 1.80 \mathrm{E}-09$

$2.41 \pm 1.50 \mathrm{E}-09$

$3.81 \pm 1.80 \mathrm{E}-09$

$3.06 \pm 1.80 \mathrm{E}-09$

$2.92 \pm 2.30 \mathrm{E}-09$

$3.49 \pm 1.80 \mathrm{E}-09$

$1.36 \pm 1.10 \mathrm{E}-09$

$1.90 \pm 1.30 \mathrm{E}-09$
Gross Beta

$2.46 \pm 1.30 \mathrm{E}-09$

$2.71 \pm 1.20 \mathrm{E}-09$

$3.53 \pm 1.40 \mathrm{E}-09$

$2.87 \pm 1.20 \mathrm{E}-09$

$4.62 \pm 1.50 \mathrm{E}-09$

$3.08 \pm 1.10 \mathrm{E}-09$

$2.44 \pm 0.88 \mathrm{E}-09$

$4.66 \pm 1.60 \mathrm{E}-09$

$3.19 \pm 1.30 \mathrm{E}-09$

$2.87 \pm 1.10 \mathrm{E}-09$

$2.89 \pm 1.20 \mathrm{E}-09$

$4.79 \pm 2.00 \mathrm{E}-09$

$5.20 \pm 2.00 \mathrm{E}-09$

$3.92 \pm 1.50 \mathrm{E}-09$

$2.85 \pm 1.40 \mathrm{E}-09$

NA

8.16 \pm 2.70 E-09

$2.55 \pm 1.50 \mathrm{E}-09$

$3.21 \pm 1.30 \mathrm{E}-09$

$2.48 \pm 1.20 \mathrm{E}-09$

$2.64 \pm 1.20 \mathrm{E}-09$

$8.78 \pm 4.00 \mathrm{E}-09$

$2.01 \pm 0.51 \mathrm{E}-08$

$2.44 \pm 1.10 \mathrm{E}-09$

$3.25 \pm 1.30 \mathrm{E}-09$

$3.48 \pm 1.20 \mathrm{E}-09$

$2.54 \pm 1.20 \mathrm{E}-09$

$2.93 \pm 1.50 \mathrm{E}-09$

$2.84 \pm 1.50 \mathrm{E}-09$

$3.01 \pm 1.30 \mathrm{E}-09$

$3.70 \pm 1.60 \mathrm{E}-09$
H-3

$9.89 \pm 8.00 \mathrm{E}-08$

$5.72 \pm 7.30 \mathrm{E}-08$

$7.70 \pm 7.30 \mathrm{E}-08$

$5.46 \pm 7.20 \mathrm{E}-08$

$-3.63 \pm 6.90 \mathrm{E}-08$

$-1.02 \pm 7.60 \mathrm{E}-08$

$1.03 \pm 7.10 \mathrm{E}-08$

$2.61 \pm 0.87 \mathrm{E}-07$

$2.52 \pm 0.82 \mathrm{E}-07$

$-1.50 \pm 6.90 \mathrm{E}-08$

$-5.61 \pm 6.80 \mathrm{E}-08$

$4.17 \pm 0.94 \mathrm{E}-07$

$4.30 \pm 0.90 \mathrm{E}-07$

$-1.43 \pm 7.50 \mathrm{E}-08$

$-0.99 \pm 7.00 \mathrm{E}-08$

$-4.14 \pm 7.50 \mathrm{E}-08$

$0.00 \pm 7.10 \mathrm{E}-08$

$1.73 \pm 0.83 \mathrm{E}-07$

$1.37 \pm 0.76 \mathrm{E}-07$

$-4.50 \pm 7.40 \mathrm{E}-08$

$-2.96 \pm 6.90 \mathrm{E}-08$

$-0.61 \pm 7.60 \mathrm{E}-08$

$-2.29 \pm 6.90 \mathrm{E}-08$

$1.25 \pm 0.75 \mathrm{E}-07$

$1.10 \pm 0.75 \mathrm{E}-07$

$-2.46 \pm 6.90 \mathrm{E}-08$

$-3.94 \pm 6.90 \mathrm{E}-08$

$4.89 \pm 0.96 \mathrm{E}-07$

$4.77 \pm 0.91 \mathrm{E}-07$

$5.00 \pm 7.20 \mathrm{E}-08$

$-3.92 \pm 6.80 \mathrm{E}-08$

All data in Tables L-1 through L-3 have been provided by NYSERDA.

NA - Not available. Some scheduled analyses could not be performed due to insufficient sample. 
Table L-2 (concluded)

\section{Radiological Indicator Results at SDA Monitoring Wells $(\mu \mathrm{Ci} / \mathrm{mL})$}

$\begin{array}{cc}\begin{array}{c}\text { Sample } \\ \text { Location }\end{array} & \text { Date } \\ \text { WNW1107A } & \text { June } \\ \text { WNW1107A } & \begin{array}{c}\text { June } \\ \text { December }\end{array} \\ \text { WNW1107A } & \\ \text { WNW1108A } & \text { June } \\ \text { WNW1108A } & \text { December } \\ & \\ \text { WNW1109A } & \text { June } \\ \text { WNW1109A } & \text { December } \\ \text { WNW1109B } & \text { June } \\ \text { WNW1109B } & \text { December } \\ & \\ \text { WNW1111A } & \text { June } \\ \text { WNW1111A } & \text { December }\end{array}$

Gross Alpha

7.95+3.50E-09

$5.39 \pm 2.70 \mathrm{E}-09$

$7.02 \pm 3.20 \mathrm{E}-09$

$9.11 \pm 3.50 \mathrm{E}-09$

$2.81 \pm 2.00 \mathrm{E}-09$

$4.41 \pm 1.80 \mathrm{E}-09$

$4.33 \pm 1.90 \mathrm{E}-09$

$0.88 \pm 1.00 \mathrm{E}-09$

$7.49 \pm 7.00 \mathrm{E}-10$

$7.44 \pm 2.50 \mathrm{E}-09$

$4.83 \pm 2.60 \mathrm{E}-09$

\section{Gross Beta}

$3.34 \pm 0.68 \mathrm{E}-08$

$2.10 \pm 0.51 \mathrm{E}-08$

$1.98 \pm 0.43 \mathrm{E}-08$

$4.60 \pm 1.80 \mathrm{E}-09$

$6.23 \pm 2.10 \mathrm{E}-09$

$4.65 \pm 1.30 \mathrm{E}-09$

$2.37 \pm 1.20 \mathrm{E}-09$

$2.23 \pm 1.10 \mathrm{E}-09$

$1.18 \pm 0.84 \mathrm{E}-09$

$2.81 \pm 1.40 \mathrm{E}-09$

$5.82 \pm 2.40 \mathrm{E}-09$
H-3

$1.16 \pm 0.06 \mathrm{E}-05$

$1.17 \pm 0.06 \mathrm{E}-05$

$1.19 \pm 0.06 \mathrm{E}-05$

$9.76 \pm 8.00 \mathrm{E}-08$

$9.95 \pm 7.40 \mathrm{E}-08$

$2.92 \pm 0.82 \mathrm{E}-07$

$2.81 \pm 0.83 \mathrm{E}-07$

$4.44 \pm 0.95 \mathrm{E}-07$

$4.43 \pm 0.90 \mathrm{E}-07$

$2.76 \pm 0.82 \mathrm{E}-07$

$1.57 \pm 0.78 \mathrm{E}-07$

All data in Tables L-1 through L-3 have been provided by NYSERDA.

$$
L-6
$$




\section{Table L-3}

\section{Radioisotopic Results at SDA Monitoring Wells $(\mu \mathrm{Ci} / \mathrm{mL})$}

$\begin{array}{cccccc}\begin{array}{c}\text { Sample } \\ \text { Location }\end{array} & \text { Date } & \text { Actinium-228 } & \text { Bismuth-214 } & \text { Carbon-14 } & \text { Cesium-134 } \\ \text { WNW1101A } & & & & \\ \text { WNW1101B } & \text { June } & 1.73 \pm 1.90 \mathrm{E}-08 & 7.71 \pm 9.50 \mathrm{E}-09 & 4.10 \pm 4.40 \mathrm{E}-09 & -0.10 \pm 5.10 \mathrm{E}-09 \\ & \text { June } & 0.56 \pm 1.30 \mathrm{E}-08 & -4.48 \pm 7.60 \mathrm{E}-09 & -0.27 \pm 1.10 \mathrm{E}-08 & -0.72 \pm 3.60 \mathrm{E}-09 \\ \text { WNW1101C } & \text { June } & -1.84 \pm 2.00 \mathrm{E}-08 & -0.86 \pm 1.20 \mathrm{E}-08 & 0.09 \pm 1.30 \mathrm{E}-08 & -2.63 \pm 5.90 \mathrm{E}-09 \\ \text { WNW1102A } & \text { June } & -1.27 \pm 1.80 \mathrm{E}-08 & 0.36 \pm 1.10 \mathrm{E}-08 & 1.50 \pm 3.60 \mathrm{E}-09 & -1.27 \pm 5.10 \mathrm{E}-09 \\ \text { WNW1102B } & \text { June } & 0.66 \pm 1.20 \mathrm{E}-08 & 1.18 \pm 8.00 \mathrm{E}-09 & 5.09 \pm 5.00 \mathrm{E}-09 & 0.81 \pm 3.40 \mathrm{E}-09 \\ \text { WNW1103A } & \text { June } & 1.62 \pm 1.90 \mathrm{E}-08 & 1.20 \pm 9.20 \mathrm{E}-09 & -0.20 \pm 3.30 \mathrm{E}-09 & 2.47 \pm 4.70 \mathrm{E}-09 \\ \text { WNW1103B } & \text { June } & 0.04 \pm 2.20 \mathrm{E}-08 & 0.91 \pm 1.30 \mathrm{E}-08 & 1.75 \pm 3.30 \mathrm{E}-09 & 3.75 \pm 6.50 \mathrm{E}-09 \\ \text { WNW1104A } & \text { June } & 0.46 \pm 2.10 \mathrm{E}-08 & -0.19 \pm 1.10 \mathrm{E}-08 & 3.51 \pm 3.70 \mathrm{E}-09 & 5.30 \pm 6.00 \mathrm{E}-09 \\ \text { WNW1104B } & \text { June } & 0.30 \pm 1.50 \mathrm{E}-08 & 3.54 \pm 9.20 \mathrm{E}-09 & -0.34 \pm 3.20 \mathrm{E}-09 & -1.60 \pm 5.50 \mathrm{E}-09 \\ \text { WNW1105A } & \text { June } & -0.12 \pm 1.60 \mathrm{E}-08 & 3.26 \pm 7.80 \mathrm{E}-09 & -0.34 \pm 3.60 \mathrm{E}-09 & -5.88 \pm 5.00 \mathrm{E}-09 \\ \text { WNW1105B } & \text { June } & 0.62 \pm 1.70 \mathrm{E}-08 & 1.87 \pm 9.40 \mathrm{E}-09 & -0.18 \pm 3.80 \mathrm{E}-09 & 1.18 \pm 5.40 \mathrm{E}-09 \\ \text { WNW1106A } & \text { June } & 1.15 \pm 1.50 \mathrm{E}-08 & -0.14 \pm 9.60 \mathrm{E}-09 & 3.15 \pm 4.00 \mathrm{E}-09 & -0.99 \pm 3.90 \mathrm{E}-09 \\ \text { WNW1106B } & \text { June } & 0.61 \pm 1.90 \mathrm{E}-08 & 2.93 \pm 8.90 \mathrm{E}-09 & 0.74 \pm 2.70 \mathrm{E}-09 & 1.59 \pm 4.90 \mathrm{E}-09 \\ \text { WNW1107A } & \text { June } & -0.01 \pm 1.70 \mathrm{E}-08 & 2.73 \pm 8.90 \mathrm{E}-09 & 0.58 \pm 4.20 \mathrm{E}-09 & 1.20 \pm 4.80 \mathrm{E}-09 \\ \text { WNW1107A } & \text { June } & 0.75 \pm 1.70 \mathrm{E}-08 & 4.29 \pm 9.90 \mathrm{E}-09 & 0.95 \pm 3.20 \mathrm{E}-09 & 0.45 \pm 5.40 \mathrm{E}-09 \\ \text { WNW1108A } & \text { June } & 1.44 \pm 2.00 \mathrm{E}-08 & 0.66 \pm 1.00 \mathrm{E}-08 & -2.32 \pm 7.60 \mathrm{E}-09 & 7.42 \pm 5.80 \mathrm{E}-09 \\ \text { WNW1109A } & \text { June } & 0.63 \pm 2.20 \mathrm{E}-08 & 0.06 \pm 1.20 \mathrm{E}-08 & -0.17 \pm 3.50 \mathrm{E}-09 & -2.73 \pm 5.70 \mathrm{E}-09 \\ \text { WNW1109B } & \text { June } & 0.00 \pm 1.40 \mathrm{E}-08 & -2.35 \pm 7.20 \mathrm{E}-09 & 1.72 \pm 3.10 \mathrm{E}-09 & -3.25 \pm 4.40 \mathrm{E}-09 \\ \text { WNW1111A } & \text { June } & 1.24 \pm 1.60 \mathrm{E}-08 & 5.14 \pm 8.40 \mathrm{E}-09 & 1.03 \pm 3.90 \mathrm{E}-09 & -4.77 \pm 5.70 \mathrm{E}-09\end{array}$

All data in Tables L-1 through L-3 have been provided by NYSERDA.

$$
L-7
$$




\section{Table L-3 (continued)}

\section{Radioisotopic Results at SDA Monitoring Wells $(\mu \mathrm{Ci} / \mathrm{mL})$}

$\begin{array}{cccccc}\begin{array}{c}\text { Sample } \\ \text { Location }\end{array} & \text { Date } & \text { Cesium-137 } & \text { Cobalt-57 } & \text { Cobalt-60 } & \text { Iodine-129 } \\ \text { WNW1101A } & & & & \\ \text { WNW1101B } & \text { June } & 3.27 \pm 4.40 \mathrm{E}-09 & 0.28 \pm 2.10 \mathrm{E}-08 & 4.33 \pm 6.50 \mathrm{E}-09 & -0.18 \pm 1.40 \mathrm{E}-10 \\ & \text { June } & 0.75 \pm 3.40 \mathrm{E}-09 & 0.46 \pm 1.70 \mathrm{E}-08 & -3.21 \pm 4.00 \mathrm{E}-09 & 0.04 \pm 1.90 \mathrm{E}-10 \\ \text { WNW1101C } & \text { June } & -1.51 \pm 5.30 \mathrm{E}-09 & -0.81 \pm 2.80 \mathrm{E}-08 & 0.35 \pm 6.50 \mathrm{E}-09 & -2.44 \pm 4.00 \mathrm{E}-10 \\ \text { WNW1102A } & \text { June } & 1.85 \pm 4.80 \mathrm{E}-09 & 1.13 \pm 2.40 \mathrm{E}-08 & -1.64 \pm 4.60 \mathrm{E}-09 & 0.49 \pm 1.40 \mathrm{E}-10 \\ \text { WNW1102B } & \text { June } & 5.71 \pm 4.30 \mathrm{E}-09 & 0.95 \pm 1.90 \mathrm{E}-08 & -3.70 \pm 3.90 \mathrm{E}-09 & 1.13 \pm 1.40 \mathrm{E}-10 \\ \text { WNW1103A } & \text { June } & -2.76 \pm 4.50 \mathrm{E}-09 & -1.24 \pm 1.80 \mathrm{E}-08 & 0.58 \pm 3.80 \mathrm{E}-09 & 0.06 \pm 2.60 \mathrm{E}-10 \\ \text { WNW1103B } & \text { June } & 1.72 \pm 5.30 \mathrm{E}-09 & -0.96 \pm 2.70 \mathrm{E}-08 & 2.68 \pm 6.60 \mathrm{E}-09 & 3.98 \pm 4.30 \mathrm{E}-10 \\ \text { WNW1104A } & \text { June } & 1.17 \pm 4.60 \mathrm{E}-09 & 0.63 \pm 2.00 \mathrm{E}-08 & 1.31 \pm 4.90 \mathrm{E}-09 & -1.72 \pm 1.90 \mathrm{E}-10 \\ \text { WNW1104B } & \text { June } & -2.34 \pm 4.50 \mathrm{E}-09 & -1.36 \pm 2.00 \mathrm{E}-08 & -1.86 \pm 4.20 \mathrm{E}-09 & -0.44 \pm 1.30 \mathrm{E}-10 \\ \text { WNW1105A } & \text { June } & 0.65 \pm 4.30 \mathrm{E}-09 & -0.89 \pm 1.70 \mathrm{E}-08 & -1.92 \pm 5.70 \mathrm{E}-09 & 0.56 \pm 2.40 \mathrm{E}-10 \\ \text { WNW1105B } & \text { June } & 2.05 \pm 5.00 \mathrm{E}-09 & 1.03 \pm 1.90 \mathrm{E}-08 & -1.19 \pm 5.10 \mathrm{E}-09 & -0.87 \pm 1.60 \mathrm{E}-10 \\ \text { WNW1106A } & \text { June } & -1.43 \pm 3.80 \mathrm{E}-09 & 0.58 \pm 1.80 \mathrm{E}-08 & -1.93 \pm 5.00 \mathrm{E}-09 & -1.98 \pm 2.90 \mathrm{E}-10 \\ \text { WNW1106B } & \text { June } & -0.63 \pm 4.70 \mathrm{E}-09 & -0.97 \pm 1.70 \mathrm{E}-08 & 2.12 \pm 5.40 \mathrm{E}-09 & 0.11 \pm 1.60 \mathrm{E}-10 \\ \text { WNW1107A } & \text { June } & -0.19 \pm 4.30 \mathrm{E}-09 & -1.04 \pm 1.80 \mathrm{E}-08 & 2.12 \pm 5.10 \mathrm{E}-09 & 0.48 \pm 2.10 \mathrm{E}-10 \\ \text { WNW1107A } & \text { June } & 0.25 \pm 4.40 \mathrm{E}-09 & 0.92 \pm 1.80 \mathrm{E}-08 & -2.31 \pm 4.60 \mathrm{E}-09 & -0.14 \pm 1.50 \mathrm{E}-10 \\ \text { WNW1108A } & \text { June } & -1.22 \pm 4.80 \mathrm{E}-09 & 0.04 \pm 2.40 \mathrm{E}-08 & 1.83 \pm 5.60 \mathrm{E}-09 & 1.43 \pm 1.50 \mathrm{E}-10 \\ \text { WNW1109A } & \text { June } & -0.29 \pm 4.70 \mathrm{E}-09 & 0.10 \pm 2.00 \mathrm{E}-08 & 3.72 \pm 4.70 \mathrm{E}-09 & -0.88 \pm 1.90 \mathrm{E}-10 \\ \text { WNW1109B } & \text { June } & -4.04 \pm 4.10 \mathrm{E}-09 & 0.91 \pm 1.70 \mathrm{E}-08 & -2.66 \pm 4.20 \mathrm{E}-09 & 0.01 \pm 2.00 \mathrm{E}-10 \\ \text { WNW1111A } & \text { June } & -0.55 \pm 4.30 \mathrm{E}-09 & 1.96 \pm 1.80 \mathrm{E}-08 & 0.58 \pm 5.00 \mathrm{E}-09 & -0.03 \pm 1.50 \mathrm{E}-10\end{array}$

All data in Tables L-1 through L-3 have been provided by NYSERDA.

WVDP Site Environmental Report $\quad L$

WVDP Site Environmental Report

Calendar Year 2001 


\section{Table L-3 (continued)}

\section{Radioisotopic Results at SDA Monitoring Wells $(\mu \mathrm{Ci} / \mathrm{mL})$}

$\begin{array}{cc}\begin{array}{c}\text { Sample } \\ \text { Location }\end{array} & \begin{array}{c}\text { Date } \\ \text { WNW1101A }\end{array} \\ \text { June } \\ \text { WNW1101B } & \begin{array}{c}\text { June } \\ \text { WNW1101C }\end{array} \\ \text { June } \\ \text { WNW1102A } & \text { June } \\ \text { WNW1102B } & \text { June } \\ \text { WNW1103A } & \text { June } \\ \text { WNW1103B } & \text { June } \\ \text { WNW1104A } & \text { June } \\ \text { WNW1104B } & \text { June } \\ \text { WNW1105A } & \text { June } \\ \text { WNW1105B } & \text { June } \\ \text { WNW1106A } & \text { June } \\ \text { WNW1106B } & \text { June } \\ \text { WNW1107A } & \begin{array}{l}\text { June } \\ \text { June }\end{array} \\ \text { WNW1107A } & \text { June } \\ \text { WNW1108A } & \text { June } \\ \text { WNW1109B } & \text { June } \\ \text { WNW1111A } & \text { June }\end{array}$

\begin{tabular}{|c|c|c|c|}
\hline Lead-212 & Lead-214 & Potassium-40 & Radium-224 \\
\hline$-6.02 \pm 7.30 \mathrm{E}-09$ & $1.71 \pm 8.30 \mathrm{E}-09$ & $1.44 \pm 9.70 \mathrm{E}-08$ & $-6.19 \pm 7.50 \mathrm{E}-09$ \\
\hline$-2.62 \pm 7.00 \mathrm{E}-09$ & $-1.74 \pm 6.90 \mathrm{E}-09$ & $-0.75 \pm 5.30 \mathrm{E}-08$ & $-2.70 \pm 7.20 \mathrm{E}-09$ \\
\hline $6.08 \pm 8.70 \mathrm{E}-09$ & $1.50 \pm 1.00 \mathrm{E}-08$ & $0.42 \pm 1.10 \mathrm{E}-07$ & $6.26 \pm 9.00 \mathrm{E}-09$ \\
\hline $3.81 \pm 8.20 \mathrm{E}-09$ & $1.30 \pm 1.10 \mathrm{E}-08$ & $0.36 \pm 1.10 \mathrm{E}-07$ & $3.93 \pm 8.40 \mathrm{E}-09$ \\
\hline $0.03 \pm 6.70 \mathrm{E}-09$ & $0.85 \pm 7.30 \mathrm{E}-09$ & $-2.37 \pm 5.20 \mathrm{E}-08$ & $0.03 \pm 6.90 \mathrm{E}-09$ \\
\hline$-2.34 \pm 6.50 \mathrm{E}-09$ & $3.70 \pm 7.20 \mathrm{E}-09$ & $-1.04 \pm 8.80 \mathrm{E}-08$ & $-2.41 \pm 6.70 \mathrm{E}-09$ \\
\hline $8.51 \pm 8.70 \mathrm{E}-09$ & $0.88 \pm 1.00 \mathrm{E}-08$ & $-1.50 \pm 1.00 \mathrm{E}-07$ & $8.76 \pm 8.90 \mathrm{E}-09$ \\
\hline$-5.04 \pm 7.90 \mathrm{E}-09$ & $-1.15 \pm 0.94 \mathrm{E}-08$ & $-1.02 \pm 1.10 \mathrm{E}-07$ & $-5.19 \pm 8.20 \mathrm{E}-09$ \\
\hline$-9.24 \pm 6.90 \mathrm{E}-09$ & $3.63 \pm 8.90 \mathrm{E}-09$ & $8.82 \pm 9.40 \mathrm{E}-08$ & $-9.52 \pm 7.10 \mathrm{E}-09$ \\
\hline$-0.82 \pm 6.80 \mathrm{E}-09$ & $-2.33 \pm 7.80 \mathrm{E}-09$ & $0.73 \pm 9.40 \mathrm{E}-08$ & $-0.84 \pm 7.00 \mathrm{E}-09$ \\
\hline $1.25 \pm 9.50 \mathrm{E}-09$ & $2.80 \pm 8.10 \mathrm{E}-09$ & $-1.64 \pm 9.10 \mathrm{E}-08$ & $1.29 \pm 9.80 \mathrm{E}-09$ \\
\hline$-1.99 \pm 7.10 \mathrm{E}-09$ & $1.22 \pm 0.94 \mathrm{E}-08$ & $6.87 \pm 9.70 \mathrm{E}-08$ & $-2.04 \pm 7.30 \mathrm{E}-09$ \\
\hline $2.24 \pm 8.10 \mathrm{E}-09$ & $0.83 \pm 7.50 \mathrm{E}-09$ & $-5.04 \pm 8.20 \mathrm{E}-08$ & $2.30 \pm 8.30 \mathrm{E}-09$ \\
\hline $4.20 \pm 8.80 \mathrm{E}-09$ & $5.09 \pm 7.20 \mathrm{E}-09$ & $-4.39 \pm 9.00 \mathrm{E}-08$ & $4.32 \pm 9.00 \mathrm{E}-09$ \\
\hline $1.20 \pm 6.50 \mathrm{E}-09$ & $0.50 \pm 7.40 \mathrm{E}-09$ & $-1.44 \pm 9.40 \mathrm{E}-08$ & $1.23 \pm 6.70 \mathrm{E}-09$ \\
\hline$-0.86 \pm 7.40 \mathrm{E}-09$ & $-5.66 \pm 8.90 \mathrm{E}-09$ & $-1.95 \pm 7.50 \mathrm{E}-08$ & $-0.89 \pm 7.60 \mathrm{E}-09$ \\
\hline $9.07 \pm 7.10 \mathrm{E}-09$ & $-1.21 \pm 0.97 \mathrm{E}-08$ & $0.50 \pm 1.20 \mathrm{E}-07$ & $9.34 \pm 7.30 \mathrm{E}-09$ \\
\hline$-4.78 \pm 6.90 \mathrm{E}-09$ & $1.11 \pm 7.50 \mathrm{E}-09$ & $0.10 \pm 5.40 \mathrm{E}-08$ & $-4.91 \pm 7.10 \mathrm{E}-09$ \\
\hline $5.56 \pm 7.10 \mathrm{E}-09$ & 4.21 7.50E-09 & $7.50 \pm 9.50 \mathrm{E}-08$ & $5.73 \pm 7.30 \mathrm{E}-09$ \\
\hline
\end{tabular}

All data in Tables L-1 through L-3 have been provided by NYSERDA.

WVDP Site Environmental Report

$L-9$

Calendar Year 2001 
Table L-3 (continued) 2001 Radioisotopic Results at SDA Monitoring Wells $(\mu \mathrm{Ci} / \mathrm{mL})$

$\begin{array}{cc}\begin{array}{c}\text { Sample } \\ \text { Location }\end{array} & \text { Date } \\ \text { WNW1101A } & \text { June } \\ \text { WNW1101B } & \text { June } \\ \text { WNW1101C } & \text { June } \\ \text { WNW1102A } & \text { June } \\ \text { WNW1102B } & \text { June } \\ \text { WNW1103A } & \text { June } \\ \text { WNW1103B } & \text { June } \\ \text { WNW1104A } & \text { June } \\ \text { WNW1104B } & \text { June } \\ \text { WNW1105A } & \text { June } \\ \text { WNW1105B } & \text { June } \\ \text { WNW1106A } & \text { June } \\ \text { WNW1106B } & \text { June } \\ \text { WNW1107A } & \text { June } \\ \text { WNW1107A } & \text { June } \\ \text { WNW1108A } & \text { June } \\ \text { WNW1109A } & \text { June } \\ \text { WNW1109B } & \text { June } \\ \text { WNW1111A } & \text { June } \\ & \end{array}$

\author{
Radium-226
}

$7.71 \pm 9.50 \mathrm{E}-09$

$-4.50 \pm 7.60 \mathrm{E}-09$

$-0.85 \pm 1.20 \mathrm{E}-08$

$0.36 \pm 1.10 \mathrm{E}-08$

$1.14 \pm 8.00 \mathrm{E}-09$

$1.20 \pm 9.20 \mathrm{E}-09$

$0.91 \pm 1.30 \mathrm{E}-08$

$-0.18 \pm 1.10 \mathrm{E}-08$

$3.46 \pm 9.20 \mathrm{E}-09$

$3.24 \pm 7.80 \mathrm{E}-09$

$1.87 \pm 9.40 \mathrm{E}-09$

$-0.16 \pm 9.60 \mathrm{E}-09$

$2.88 \pm 8.90 \mathrm{E}-09$

$2.76 \pm 8.90 \mathrm{E}-09$

$4.34 \pm 9.90 \mathrm{E}-09$

$0.66 \pm 1.00 \mathrm{E}-08$

$0.06 \pm 1.20 \mathrm{E}-08$

$-2.33 \pm 7.20 \mathrm{E}-09$

$5.17 \pm 8.40 \mathrm{E}-09$
Strontium-90

$-0.37 \pm 3.30 \mathrm{E}-10$

$3.00 \pm 7.10 \mathrm{E}-10$

$1.73 \pm 3.00 \mathrm{E}-10$

$1.72 \pm 2.90 \mathrm{E}-10$

$-0.20 \pm 1.90 \mathrm{E}-10$

$0.84 \pm 3.30 \mathrm{E}-10$

$1.23 \pm 3.00 \mathrm{E}-10$

$1.67 \pm 3.20 \mathrm{E}-10$

$-0.09 \pm 3.40 \mathrm{E}-10$

$-0.23 \pm 2.60 \mathrm{E}-10$

$1.78 \pm 2.50 \mathrm{E}-10$

$1.18 \pm 4.80 \mathrm{E}-10$

$0.56 \pm 3.20 \mathrm{E}-10$

$9.46 \pm 2.40 \mathrm{E}-09$

$4.95 \pm 1.30 \mathrm{E}-09$

$0.58 \pm 3.30 \mathrm{E}-10$

$-0.73 \pm 2.00 \mathrm{E}-10$

$0.90 \pm 2.70 \mathrm{E}-10$

$-0.27 \pm 2.50 \mathrm{E}-10$
Technetium-99

$-1.56 \pm 9.90 \mathrm{E}-10$

$-0.16 \pm 1.10 \mathrm{E}-09$

$0.29 \pm 1.10 \mathrm{E}-09$

$0.54 \pm 1.00 \mathrm{E}-09$

$0.00 \pm 1.60 \mathrm{E}-09$

$0.26 \pm 1.10 \mathrm{E}-09$

$0.70 \pm 1.00 \mathrm{E}-09$

$0.38 \pm 1.00 \mathrm{E}-09$

$-0.03 \pm 1.00 \mathrm{E}-09$

$0.00 \pm 1.20 \mathrm{E}-09$

$-0.39 \pm 1.20 \mathrm{E}-09$

$3.68 \pm 9.80 \mathrm{E}-10$

$-0.17 \pm 1.00 \mathrm{E}-09$

$-3.40 \pm 9.30 \mathrm{E}-10$

$-1.77 \pm 9.40 \mathrm{E}-10$

$0.28 \pm 1.10 \mathrm{E}-09$

$-0.07 \pm 1.00 \mathrm{E}-09$

$4.37 \pm 9.70 \mathrm{E}-10$

$0.04 \pm 1.10 \mathrm{E}-09$
Thallium-208

$-1.82 \pm 5.20 \mathrm{E}-09$

$-1.12 \pm 4.00 \mathrm{E}-09$

$-0.90 \pm 5.50 \mathrm{E}-09$

$7.06 \pm 5.50 \mathrm{E}-09$

4.24+4.00E-09

$-0.53 \pm 4.90 \mathrm{E}-09$

$5.70 \pm 5.90 \mathrm{E}-09$

$-1.96 \pm 6.00 \mathrm{E}-09$

$6.02 \pm 5.00 \mathrm{E}-09$

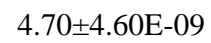

$-2.50 \pm 5.10 \mathrm{E}-09$

$-0.42 \pm 4.60 \mathrm{E}-09$

$0.85 \pm 5.10 \mathrm{E}-09$

$0.01 \pm 5.00 \mathrm{E}-09$

$-4.80 \pm 5.50 \mathrm{E}-09$

$1.73 \pm 4.80 \mathrm{E}-09$

$-2.52 \pm 5.70 \mathrm{E}-09$

$1.03 \pm 3.70 \mathrm{E}-09$

$-1.29 \pm 4.60 \mathrm{E}-09$

All data in Tables L-1 through L-3 have been provided by NYSERDA.

WVDP Site Environmental Report

$$
L-10
$$

Calendar Year 2001 


\section{Table L-3 (continued)}

\section{Radioisotopic Results at SDA Monitoring Wells $(\mu \mathrm{Ci} / \mathrm{mL})$}

\begin{tabular}{|c|c|c|c|}
\hline $\begin{array}{l}\text { Sample } \\
\text { Location }\end{array}$ & Date & Thorium-234 & Uranium-235 \\
\hline WNW1101A & June & $2.54 \pm 9.00 \mathrm{E}-07$ & $0.14 \pm 2.00 \mathrm{E}-08$ \\
\hline WNW1101B & June & $3.79 \pm 4.90 \mathrm{E}-07$ & $1.37 \pm 1.70 \mathrm{E}-08$ \\
\hline WNW1101C & June & $3.93 \pm 7.40 \mathrm{E}-07$ & $-1.22 \pm 2.80 \mathrm{E}-08$ \\
\hline WNW1102A & June & $0.53 \pm 7.60 \mathrm{E}-07$ & $-0.98 \pm 2.50 \mathrm{E}-08$ \\
\hline WNW1102B & June & $-3.77 \pm 5.90 \mathrm{E}-07$ & $0.72 \pm 1.80 \mathrm{E}-08$ \\
\hline WNW1103A & June & $1.40 \pm 7.00 \mathrm{E}-07$ & $0.37 \pm 1.90 \mathrm{E}-08$ \\
\hline WNW1103B & June & $0.64 \pm 8.00 \mathrm{E}-07$ & $1.34 \pm 2.60 \mathrm{E}-08$ \\
\hline WNW1104A & June & $0.09 \pm 7.40 \mathrm{E}-07$ & $0.51 \pm 1.80 \mathrm{E}-08$ \\
\hline WNW1104B & June & $-0.12 \pm 6.30 \mathrm{E}-07$ & $1.63 \pm 1.80 \mathrm{E}-08$ \\
\hline WNW1105A & June & $7.61 \pm 8.10 \mathrm{E}-07$ & $0.66 \pm 1.70 \mathrm{E}-08$ \\
\hline WNW1105B & June & $4.64 \pm 7.50 \mathrm{E}-07$ & $-1.55 \pm 1.90 \mathrm{E}-08$ \\
\hline WNW1106A & June & $0.59 \pm 5.90 \mathrm{E}-07$ & $-0.09 \pm 1.80 \mathrm{E}-08$ \\
\hline WNW1106B & June & $3.19 \pm 7.30 \mathrm{E}-07$ & $-0.17 \pm 1.80 \mathrm{E}-08$ \\
\hline WNW1107A & June & $4.46 \pm 7.80 \mathrm{E}-07$ & $0.68 \pm 1.80 \mathrm{E}-08$ \\
\hline WNW1107A & June & $2.34 \pm 8.80 \mathrm{E}-07$ & $2.46 \pm 2.00 \mathrm{E}-08$ \\
\hline WNW1108A & June & $4.31 \pm 7.20 \mathrm{E}-07$ & $1.43 \pm 2.30 \mathrm{E}-08$ \\
\hline WNW1109A & June & $2.86 \pm 8.10 \mathrm{E}-07$ & $1.12 \pm 1.90 \mathrm{E}-08$ \\
\hline WNW1109B & June & $-3.67 \pm 6.00 \mathrm{E}-07$ & $0.59 \pm 1.70 \mathrm{E}-08$ \\
\hline WNW1111A & June & $4.49 \pm 7.60 \mathrm{E}-07$ & $0.65 \pm 1.80 \mathrm{E}-08$ \\
\hline
\end{tabular}

All data in Tables L-1 through L-3 have been provided by NYSERDA.

WVDP Site Environmental Report

$$
L-11
$$


This page intentionally left blank

$$
L-12
$$




\title{
REFERENCES AND BIBLIOGRAPHY
}

\section{(Some documents listed in this section are basis documents and may not specifically be cited in the text.)}

\begin{abstract}
Albanese, J.R., et al. 1984. Geological and Hydrogeologic Research at the Western New York Nuclear Service Center, West Valley, New York. Final Report, August 1982 - December 1983. U.S. Nuclear Regulatory Commission Report. NUREG/CR-3782.
\end{abstract}

American National Standards Institute/American Society for Quality Control. 1994. Specifications and Guidelines for Quality Systems for Environmental Data Collection and Environmental Technology Programs. ANSI/ASQC E4-1994.

American National Standards Institute, Inc. August 20, 1975. American National Standard: Performance Testing, and Procedural Specifications for Thermoluminescent Dosimetry (Environmental Applications). ANSI N545-1975.

American Society of Mechanical Engineers. 1989. Quality Assurance Program Requirements for Nuclear Facilities. ASME-NQA-1. New York: The American Society of Mechanical Engineers.

Bergeron, M.P., et al. 1987. Geohydrologic Conditions at the Nuclear Fuels Reprocessing Plant and Waste Management Facilities at the Western New York Nuclear Services Center, Cattaraugus County, New York. U.S. Geological Survey Water Resources Investigations Report 85-4145.

Citizen Task Force. July 29, 1998. West Valley Citizen Task Force Final Report.

Dames \& Moore. 1995. Early Warning System for Evaluation of Groundwater Monitoring Results from the Vicinity of the Proposed Groundwater Extraction System. Letter: CDF1004:CDF0.01. AR \# 95-692.

December 22, 1998. 1998 Wetlands Investigation and Delineation of the West Valley Assessment Area. AR \#99-117.

\footnotetext{
WVDP Site Environmental Report
}

$$
R \& B-1
$$


Spur.

December 1999. Wetlands Investigation and Delineation of the West Valley Railroad

Dunning, Donald E. nd. Estimates of Internal Dose Equivalent from Inhalation and Ingestion of Selected Radionuclides. Revised. WIPP-DOE-176.

Executive Order 11988. May 25, 1977. Floodplain Management. 42 FR 26951.

Executive Order 11990. May 25, 1977. Protection of Wetlands. 42 FR 26961.

Executive Order 12856. August 6, 1993. Federal Compliance with Right-to-Know Laws and Pollution Prevention Requirements. 58 FR 41981.

Executive Order 13101. September 16, 1998. Greening the Government through Waste Prevention, Recycling, and Federal Acquisition. 63 FR 49643.

Executive Order 13148. April 26, 2000. Greening the Government through Leadership in Environmental Management. 65 FR 24595.

International Atomic Energy Agency (IAEA). 1992. Effects of Ionizing Radiation on Plants and Animals at Levels Implied by Current Radiation Protection Standards. Technical Report Series No. 332, IAEA, Vienna, Austria.

International Commission on Radiological Protection. 1959. Recommendations of the International Commission on Radiological Protection - Permissible Dose for Internal Radiation. ICRP Publication 2. Oxford: Pergamon Press.

1975. Report of the Task Group on Reference Man. ICRP Publication 23. Oxford: Pergamon Press.

. 1977. Recommendations of the International Commission on Radiological Protection. ICRP Publication 26. Oxford: Pergamon Press.

1979. Recommendations of the International Commission on Radiological Protection - Limits for Intakes of Radionuclides by Workers. ICRP Publication 30. Oxford: Pergamon Press.

1991. 1990 Recommendations of the International Commission on Radiological Protection. ICRP Publication 60. Oxford: Pergamon Press.

International Organization for Standardization. 1996. Environmental Management Systems. ISO 14001:1996.

$R \& B-2$ 
LaFleur, R.G. 1979. Glacial Geology and Stratigraphy of Western New York Nuclear Service Center and Vicinity, Cattaraugus and Erie Counties, New York. U.S. Geological Survey Open File Report 79-989.

Moore, R.E., et al. June 1979. AIRDOS-EPA: A Computerized Methodology for Estimating Environmental Concentrations and Dose to Man from Airborne Releases of Radionuclides. ORNL- 5532.

National Council on Radiation Protection and Measurements. December 1979. Environmental Radiation Measurements. NCRP-50. Washington, D.C.

1987a. Recommendations on Limits for Exposure to Ionizing Radiation. NCRP-91. Bethesda, Maryland.

1987b. Ionizing Radiation Exposure of the Population of the United States. NCRP-93. Bethesda, Maryland.

National Research Council. 1990. Health Effects of Exposure to Low Levels of Ionizing Radiation. BEIR V. Washington: National Academy Press.

New York State Department of Environmental Conservation. 1991. Draft Cleanup Policy and Guidelines, Appendix B - Water Cleanup Criteria. . Environmental Conservation Law of New York State. 6 NYCRR.

. September 3, 1996. Federal Facility Compliance Act: Order on Consent.

. March 19, 1999. Stipulation of Agreement Pursuant to Section 17-0303 of the Environmental Conservation Law and Section 176 of the Navigation Law.

New York State Department of Health. nd. Environmental Laboratory Approval Program (ELAP) Certification Manual.

Nuclear Regulatory Commission. 1998. Decommissioning Criteria for West Valley. SECY-98-251.

1999. Supplement to SECY-98-251, Decommissioning Criteria for West Valley. SECY-99-057.

. December 3, 1999. Decommissioning Criteria for the West Valley Demonstration Project (M-32) and West Valley Site; Draft Policy Statement and Notice of Public Meeting. 64 FR 67952.

. February 1, 2002. Decommissioning Criteria for the West Valley Demonstration Project (M-32) at the West Valley Site; Final Policy Statement. 67 FR 5003.

$$
R \& B-3
$$


Oak Ridge National Laboratory. May 1980. User's Manual for LADTAP II - A Computer Program for Calculating Radiation Exposure to Man from Routine Release of Nuclear Reactor Liquid Effluents. NUREG/CR-1276.

Rickard, L.V. 1975. Correlation of the Silurian and Devonian Rocks in New York State. New York State Museum and Science Service Map and Chart Series No. 24.

Sheppard, M.I., and D.H. Thibault. 1990. Default Soil Solid/Liquid Partition Coefficients, $K_{d}$ s, for Four Major Soil Types: A Compendium. Health Physics. 59 (no. 4): 471-482.

Shleien, B. et al. 1998. Handbook of Health Physics and Radiological Health Safety. 3rd ed. Baltimore, Maryland: Williams \& Wilkens.

Simpson, D.B., and B.L. McGill. 1980. LADTAP II: A Computer Program for Calculating Radiation Exposure to Man from Routine Release of Nuclear Reactor Liquid Effluents. Technical Data Management Center. ORNL/NUREG/TDMC-1.

Spector, H. 2000. WVDP Manual for Radiological Assessment of Environmental Releases at the WVDP. Rev. 3. WVDP-065.

Standish, P.N. 1985. Closure of the Construction Landfill Site. Letter (WD:85:0434) to W.H. Hannum, Department of Energy, West Valley Project Office.

Tesmer, I.H. 1975. Geology of Cattaraugus County, New York. Buffalo Society of Natural Sciences Bulletin, Vol. 27.

Tseng, J.C. November 4, 1975. Clarification of Applicable Radiation Protection Standards for the Public and the Environment. Memorandum from EH-231, Office of Environmental Guidance and Compliance. Washington, D.C.

U.S. Congress. 1954. Atomic Energy Act of 1954. 42 USC $\S 2011$ et seq.

1955. Clean Air Act. 42 USC $\S 7401$ et seq.

1966. National Historic Preservation Act of 1966. 16 USC $\S 470$ et seq.

1969. National Environmental Policy Act of 1969. 42 USC $\S 4321$ et seq.

. 1973. Endangered Species Act. 16 USC § 1531-1544.

. 1974. Safe Drinking Water Act. 42 USC $\S 300 f$ et seq. 
. October 23, 1976. Resource Conservation and Recovery Act of 1976. Public Law 94-580, 90 Stat. 2795, Title 42.

. 1977. Federal Water Pollution Control Act. 33 USC $\S 1251$ et seq. (Also known as the Clean Water Act)

. October 1, 1980. An Act to Authorize the Department of Energy to Carry Out a High-Level Liquid Nuclear Waste Management Demonstration Project at the Western New York Service Center in West Valley, New York. Public Law 96-368 [S.2443]. Congressional Record, Vol. 126. (Also known as the WVDP Act)

. November 1976. Migratory Bird Treaty Act. 16USC $\S 703$ et seq.

. December 11, 1980. Comprehensive Environmental Response, Compensation, and Liability Act of 1980. Public Law 96-150, 94 Stat. 2767, Title 26.

1986. Toxic Substances Control Act. 15 USC $\S 2601$ et seq.

1986. Emergency Planning and Community Right-to-Know Act of 1986. 42 USC $\S$ 11001 et seq.

. October 17, 1986. Superfund Amendments and Reauthorization Act of 1986.

Public Law 99-499, 100 Stat. 1613, Title 10.

U.S. Department of Energy. July 1981. A Guide for Environmental Radiological Surveillance at U.S. Department of Energy Installations. DOE/EP-0023. Washington, D.C.

1981. Radioactive Decay Tables. Washington, D.C.: Technical Information Center, U.S. Department of Energy.

. June 1982. Final Environmental Impact Statement: Long-Term Management of Liquid High-Level Radioactive Wastes Stored at the Western New York Nuclear Services Center, West Valley. DOE/EIS-0081.

July 1983. A Guide for Effluent Radiological Measurements at DOE Installations. DOE/EP-0096. Washington, D.C.

. May 15, 1984. Environmental Protection, Safety, and Health Protection Standards, including Change 4 (January 7, 1993). DOE Order 5480.4. Washington, D.C.

. July 1988. Internal Dose Conversion Factors for Calculation of Dose to the Public. DOE/EH-0071. 
. November 9, 1988. General Environmental Protection Program. DOE Order 5400.1, including Change 1 (June 29, 1990). Washington, D.C.

. February 8, 1990. Radiation Protection of the Public and the Environment. DOE Order 5400.5, including Change 2 (January 7, 1993). Washington, D.C.

January 1991. Environmental Regulatory Guide for Radiological Effluent Monitoring and Environmental Surveillance. DOE/EH-0173T. Washington, D.C.

. ND. Quality Assurance Criteria. 10 CFR 830.122.

September 30, 1995. Environment, Safety, and Health Reporting. DOE Order 231.1, including Change 2 (November 7, 1996). Washington, D.C.

. January 1996. Draft Environmental Impact Statement for Completion of the West Valley Demonstration Project and Closure or Long-Term Management of Facilities at the Western New York Nuclear Services Center. DOE/EIS-0226-D.

May 1997. Final Waste Management Programmatic Impact Statement for Managing Treatment, Storage, and Disposal of Radioactive and Hazardous Waste. DOE/ EIS-0200-F.

. August 1, 1997. Occurrence Reporting and Processing of Operations Information. DOE Order 232.1A. Washington, D.C.

January 23, 1998. Record of Decision for the Department of Energy's Waste Isolation Pilot Plant Disposal Phase.

. June 23, 1998. DOE/EIS-0081. Supplement Analysis II of Environmental Impacts Resulting from Modifications in the West Valley Demonstration Project. WVDP-321.

. August 5, 1998. Record of Decision for the Department of Energy's Waste Management Program: Treatment of Non-Wastewater Hazardous Waste.

. July 9, 1999. Radioactive Waste Management. DOE Order 435.1, including Change 1 (August 28, 2001). Washington, D.C.

August 26, 1999. Record of Decision for the Department of Energy's Waste Management Program: Storage of High-Level Radioactive Waste.

. September 29, 1999. Quality Assurance. DOE Order 414.1A, including Change 1 (July 12, 2001). Washington, D.C.

$R \& B-6$ 
References and Bibliography

December 10, 1999. Identification of Preferred Alternatives for the Department of Energy's Waste Management Program: Low-Level Waste and Mixed Low-Level Waste Disposal Sites.

. February 25, 2000. Record of Decision for the DOE's Waste Management Program: Treatment and Disposal of Low-Level Waste and Mixed Low-Level Waste; Amendment of the Record of Decision for the Nevada Test Site. 65 FR 10061.

. June 2000. A Graded Approach for Evaluating Radiation Doses to Aquatic and Terrestrial Biota. ENVR-0011.

. October 26, 2000. National Environmental Policy Act Compliance Program. DOE Order 451.1B, including Change 1 (September 28, 2001). Washington, D.C.

. March 26, 2001. Revised Strategy for the Environmental Impact Statement for Completion of the West Valley Demonstration Project and Closure or Long-Term Management of Facilities at the Western New York Nuclear Service Center and Solicitation of Scoping Comments. 66 FR 16447.

. November 6, 2001. Advance Notice of Intent to Prepare an Environmental Impact Statement to Evaluate Decommissioning and/or Long-Term Stewardship at the West Valley Demonstration Project and Western New York Nuclear Service Center. 66 FR 56090.

U.S. Environmental Protection Agency. 1976. National Interim Primary Drinking Water Regulations. EPA-570/9-76-003. Washington, D.C.: Office of Water Supply.

. 40 Code of Federal Regulations, Protection of the Environment, Chapter 1, Environmental Protection Agency.

1984a. Drinking Water Guidelines. 40 CFR 141, National Secondary Drinking Water Regulations, Subpart B, Maximum Contaminant Levels.

1984b. Drinking Water Guidelines. 40 CFR 143, National Secondary Drinking Water Regulations, Section 143.3, Secondary Maximum Contaminant Levels.

. September 1986. Groundwater Monitoring Technical Enforcement Guidance Document. OWSER-9950.1. Washington, D.C.

. November 1986. Test Methods for Evaluating Solid Waste. Vol. IA: Laboratory Manual,Physical Chemical Methods. EPA Manual, SW-846, 3rd ed. Update II, September 1994. Washington, D.C.: Office of Solid Waste and Emergency Response.

$R \& B-7$ 
December 15, 1989. National Emission Standards for Hazardous Air Pollutants:

Standards for Radionuclides. 40 CFR 61. Washington, D.C.: U.S. Government Printing Office.

. 1992. Region II Administrative Order on Consent. Docket No. II RCRA 3008(h) -

92-0202. In the Matter of: Western New York Nuclear Service Center.

. March 1992. User's Guide for CAP88-PC. Version 1.0. Las Vegas, NV: U.S.

Environmental Protection Agency Office of Radiation Programs. 402-B-92-001.

1995. Appendix 33 - Groundwater Monitoring List. Title 6 NYCRR Subpart 373-2.

October 16, 1996. Code of Environmental Management Principles. Federal

Register, Vol. 61, No. 201.

U.S. Nuclear Regulatory Commission. July 1977. Regulatory Guide 1.111: Methods for Estimating Atmospheric Transport and Dispersion of Gaseous Effluents in Routine Releases from Light-Water-Cooled Reactors.

October 1977. Regulatory Guide 1.109: Calculation of Annual Doses to Man from Routine Releases of Reactor Effluents for the Purpose of Evaluating Compliance with 10 CFR Part 50, Appendix I.

. February 1, 2002. Decommissioning Criteria for the West Valley Demonstration Project (M-32) at the West Valley Site; Final Policy Statement. 67FR5003.

West Valley Demonstration Project. 1986. WVDP Radioactive Air Emissions Permit Application General Information. Submitted to EPA Region II.

West Valley Nuclear Services Co., Inc. January 1992. Environmental Media Management Plan at the West Valley Demonstration Project.

. December 1993. RCRA Facility Investigation (RFI) Work Plan. West Valley

Demonstration Project. Rev. 0. WVDP-RFI-014.

. May 1, 1995. Subsurface Probing Investigation on the North Plateau at the West Valley Demonstration Project. Rev. 0. WVDP-220.

May 10, 1995. Groundwater Seep Investigation Report: 1,1,1-Trichloroethane Detection. Rev. 0. WVDP-RFI-002.

. March 1996. Environmental Information Document, Volume III: Hydrology, Part 4. WVDP-EIS-009.

$R \& B-8$ 
References and Bibliography

. July 1997. RCRA Facility Investigation Report: Introduction and General Site Overview. Volume 1. WVDP-RFI-017.

. June 23, 1998. Supplement Analysis II of Environmental Impacts Resulting from Modifications in the West Valley Demonstration Project. WVDP-321. (This document is an update to DOE/EIS-0081.)

. August 19, 1998. Documentation and Reporting of Environmental Monitoring Data. Rev. 2. EMP-11.

. June 11, 1999. 1998 Geoprobe ${ }^{\circledR}$ Investigation in the Core Area of the North Plateau Groundwater Plume. Rev. 0. WVDP-346.

. July 8, 1999 (Rev. 4) and December 20, 2001 (Rev. 5). Waste Minimization/Pollution Prevention Awareness Plan. WVDP-087.

. October 26, 1999. Asbestos Management Plan. Rev. 5. WVDP-072.

. February 15, 2000 (Rev. 11) and May 11, 2001 (Rev. 12). WVNS Environmental Management System. WV-980.

. March 6, 2000. Environmental Monitoring Program Plan. Rev. 10. WVDP-098.

. May 2, 2000. WVDP Groundwater Protection Management Program Plan. Rev. 4. WVDP-091.

. March 21, 2001. PCB and PCB-Contaminated Material Management Plan. Rev. 6. WVDP-080.

. June 2001. Hazardous Waste Reduction Program.

. September 27, 2001. Groundwater Monitoring Plan. Rev. 5. WVDP-239.

. February 2002. New York State Department of Environmental Conservation Hazardous Waste Report for 2001.

. February 6, 2002. Site Treatment Plan: Fiscal Year 2001 Update. WVDP-299.

West Valley Nuclear Services Co., Inc. and Dames \& Moore. July 1997. Resource Conservation and Recovery Act Facility Investigation Report, Vol.1: Introduction and General Site Overview. WVDP-RFI-017.

WVDP Site Environmental Report

$R \& B-9$

Calendar Year 2001 
. June 1998. Final Report: Evaluation of the Pilot Program to Investigate

Chromium and Nickel Concentrations in Groundwater in the Sand and Gravel Unit.

West Valley Nuclear Services Co. and URS Group, Inc. January 2001. Results of Corrosion Evaluation in Selected Stainless Steel Monitoring Wells on the North Plateau and Recommendations for Long-Term Management.

August 2001. West Valley Demonstration Project Site Environmental Report Calendar Year 2000.

Yager, R.M. 1987. Simulation of Groundwater Flow near the Nuclear Fuel Reprocessing Facility at the Western New York Nuclear Service Center, Cattaraugus County, New York. 85-4308. Ithaca, New York: U.S. Geological Survey.

$R \& B-10$ 


\section{GLOSSARY}

accuracy. The degree of agreement between a measurement and its true value. The accuracy of a data set is assessed by evaluating results from standards or sample spikes containing known quantities of an analyte.

action plan. An action plan addresses assessment findings and root causes that have been identified in an audit or an assessment report. It is intended to define specific actions that the responsible group will undertake to remedy deficiencies. The plan includes a timetable and funding requirements for implementation of the planned activities.

alluvial fan. A cone-shaped deposit of alluvium made by a stream where it runs out onto a level plain.

alluvium. Sedimentary material deposited by flowing water such as a river.

aquifer. A water-bearing unit of permeable rock or soil that will yield water in usable quantities to wells. Confined aquifers are bounded above and below by less permeable layers. Groundwater in a confined aquifer is under a pressure greater than the atmospheric pressure. Unconfined aquifers are bounded below by less permeable material but are not bounded above. The pressure on the groundwater at the surface of an unconfined aquifer is equal to that of the atmosphere.

as low as reasonably achievable (ALARA). An approach to radiation protection that advocates controlling or managing exposures (both individual and collective) to the work force and the general public and releases of radioactive material to the environment as low as social, technical, economic, practical, and public policy considerations permit. As used in DOE Order 5400.5, ALARA is not a dose limit but, rather, a process that has as its objective the attainment of dose levels as far below the applicable limits of the Order as practicable.

background radiation. Natural and manmade radiation such as cosmic radiation and radiation from naturally radioactive elements and from commercial sources and medical procedures.

becquerel (Bq). A unit of radioactivity equal to one nuclear transformation per second.

$$
\text { GLO - } 1
$$


categorical exclusion (CX). A proposed action that normally does not require an environmental assessment or an environmental impact statement and that the Department of Energy has determined does not individually or cumulatively have a significant effect on the human environment. See 10 CFR 1021.410.

Class A, B, and C low-level waste. Waste classifications from the Nuclear Regulatory Commission's 10 CFR Part 61 rule. Maximum concentration limits are set for specific isotopes. Class A waste disposal is minimally restricted with respect to the form of the waste. Class B waste must meet more rigorous requirements to ensure physical stability after disposal. Higher concentration limits are set for the same isotopes in Class $\mathrm{C}$ waste, which also must meet physical stability requirements. Moreover, special measures must be taken at the disposal facility to protect against inadvertent intrusion.

compliance findings. Conditions that may not satisfy applicable environmental or safety and health regulations, DOE Orders and memoranda, enforcement actions, agreements with regulatory agencies, or permit conditions.

confidence coefficient or factor. The chance or probability, usually expressed as a percentage, that a confidence interval includes some defined parameter of a population. The confidence coefficients usually associated with confidence intervals are $90 \%, 95 \%$, and $99 \%$.

consistency. The condition of showing steady conformity to practices. In the environmental monitoring program, approved procedures are in place in order to ensure that data collection activities are carried out in a consistent manner so that variability is minimized.

cosmic radiation. High-energy subatomic particles from outer space that bombard the earth's atmosphere. Cosmic radiation is part of natural background radiation.

counting error. The variability caused by the inherent random nature of radioactive disintegration and by the detection process.

curie (Ci). A unit of radioactivity equal to 37 billion $\left(3.7 \times 10^{10}\right)$ nuclear transformations per second.

data set. A group of data (e.g., factual information such as measurements or statistics) used as a basis for reasoning, discussion, or calculation.

decay (radioactive). Disintegration of the nucleus of an unstable nuclide by spontaneous emission of charged particles and/or photons or by spontaneous fission.

derived concentration guide (DCG). The concentration of a radionuclide in air and water that, under conditions of continuous exposure for one year by one exposure mode (i.e., ingestion of water, submersion in air, or inhalation), would result in an effective dose equivalent of $100 \mathrm{mrem}(1 \mathrm{mSv})$. See Table K1 in Appendix K.

$G L O-2$ 
detection limit or level (DL). This term may also be expressed as "method detection limit" (MDL). The smallest amount of a substance that can be distinguished in a sample by a given measurement procedure at a given confidence level. (See lower limit of detection [p. GLO-5].)

dispersion (groundwater). The process whereby solutes are spread or mixed as they are transported by groundwater as it moves through subsurface soil and rock sediments.

dosimeter. A portable device for measuring the total accumulated exposure to ionizing radiation.

downgradient. The direction of water flow from a reference point to a selected point of interest. (See gradient [p. GLO-4].)

effective dose. (See effective dose equivalent under radiation dose [p. GLO-8].)

effluent. Any treated or untreated air emission or liquid discharge, including storm water runoff, at a DOE site or facility.

effluent monitoring. Sampling or measuring specific liquid or gaseous effluent streams for the presence of pollutants.

enhanced work planning. A process that evaluates and improves the program by which work is identified, planned, approved, controlled, and executed. The key elements are line management ownership, a graded approach to work management based on risk and complexity, worker involvement beginning at the earliest phases of work management, organizationally diverse teams, and organized, institution-wide communication.

environmental assessment. An evaluation that provides sufficient evidence and analysis for determining whether to prepare an environmental impact statement or a finding of no significant impact. Detailed information found in 40 CFR 1508.9.

Environmental Impact Statement. A detailed statement that includes the environmental impact of the proposed action, any adverse environmental effects that cannot be avoided should the proposal be implemented, and alternatives to the proposed action. Detailed information found in Section 102 (2) (C) of the National Environmental Policy Act.

environmental management system. The systematic application of business management practices to environmental issues, including defining the organizational structure, planning for activities, identifying responsibilities, and defining practices, procedures, processes, and resources.

environmental monitoring. The collection and analysis of samples or the direct measurement of environmental media. Environmental monitoring consists of two major activities: effluent monitoring and environmental surveillance.

$G L O-3$ 
environmental surveillance. The collection and analysis of samples or the direct measurement of air, water, soil, foodstuff, and biota in order to determine compliance with applicable standards and permit requirements.

erg. One-billionth (1E-09) of the energy released by a 100-watt bulb in 1 second.

evapotranspiration. The combined total precipitation returned to the air through direct evaporation and by transpiration of vegetation.

exposure. The subjection of a target (usually living tissue) to radiation.

fallout. The settling to earth of radioactive materials mixed into the earth's atmosphere.

finding. A Department of Energy compliance term. A finding is a statement of fact concerning a condition in the Environmental, Safety, and Health program that was investigated during an appraisal. Findings include best management practice findings, compliance findings, and noteworthy practices. A finding may be a simple statement of proficiency or a description of deficiency (i.e., a variance from procedures or criteria). (See also self-assessment [p. GLO-9].)

fission. The act or process of splitting into parts. A nuclear reaction in which an atomic nucleus splits into fragments (i.e., fission products, usually fragments of comparable mass) with the evolution of approximately 100 million to several hundred million electron volts of energy.

gamma isotopic (also gamma scan). An analytical method by which the quantity of several gamma rayemitting radioactive isotopes may be determined simultaneously. Typical nuclear fuel cycle isotopes determined by this method include but are not limited to cobalt- 60 , zirconium- 95 , ruthenium- 106 , silver- $110 \mathrm{~m}$, antimony-125, cesium-134, cesium-137, and europium-154. Naturally occurring isotopes for which samples also often are analyzed are beryllium-7, potassium-40, radium-224, and radium-226.

gradient. Change in value of one variable with respect to another variable, especially over a vertical or horizontal distance.

groundwater. Subsurface water in the pore spaces and fractures of soil and bedrock units.

half-life. The time in which half the atoms of a radionuclide disintegrate into another nuclear form. The halflife may vary from a fraction of a second to thousands of years.

hazardous waste. A waste or combination of wastes that because of quantity, concentration, or physical, chemical, or infectious characteristics may: a) cause or significantly contribute to an increase in mortality or an increase in serious irreversible or incapacitating reversible illness; or (b) pose a substantial present or potential hazard to human health or the environment when improperly treated, stored, transported, disposed of, or otherwise managed.

$G L O-4$ 
high-level waste (HLW). The highly radioactive waste material that results from the reprocessing of spent nuclear fuel, including liquid waste produced directly in reprocessing and any solid waste derived from the liquid, that contains a combination of transuranic waste and fission products in concentrations sufficient to require permanent isolation. (See also transuranic waste [p. GLO-10].)

hydraulic conductivity. The ratio of flow velocity to driving force for viscous flow under saturated conditions of a specified liquid in a porous medium; the ratio describing the rate at which water can move through a permeable medium.

integrated safety management system (ISMS). The ISMS describes the programs, policies, and procedures used by WVNSCO and the DOE to ensure that WVNSCO establishes a safe workplace for the employees, the public, and the environment. The guiding principles of ISMS are line management responsibility for safety; clear roles and responsibilities; competence commensurate with responsibilities; balanced priorities; identification of safety standards and requirements; hazard controls; and operations authorization.

interim status. The status of any currently existing facility that becomes subject to the requirement to have a RCRA permit because of a new statutory or regulatory amendment to RCRA.

interstitial. The (annular) space between the inner and outer tank walls in a double-walled storage tank.

ion. An atom or group of atoms with an electric charge.

ion exchange. The reversible exchange of ions contained in solution with other ions that are part of the ionexchange material.

isotope. Different forms of the same chemical element that are distinguished by having the same number of protons but a different number of neutrons in the nucleus. An element can have many isotopes. For example, the three isotopes of hydrogen are protium, deuterium, and tritium, with one, two, and three neutrons in the nucleus, respectively.

kame delta. A conical hill or short irregular ridge of gravel or sand deposited in contact with glacier ice.

lacustrine sediments. A sedimentary deposit consisting of material pertaining to, produced by, or formed in a lake or lakes.

land disposal restrictions (LDR). Regulations promulgated by the U.S. EPA (and by NYSDEC in New York State) governing the land disposal of hazardous wastes. The wastes must be treated using the best demonstrated available technology or must meet certain treatment standards before being disposed.

lower limit of detection (LLD). The lowest limit of a given parameter that an instrument is capable of detecting. A measurement of analytical sensitivity.

$$
G L O-5
$$


low-level waste (LLW). Radioactive waste not classified as high-level waste, transuranic waste, spent fuel, or uranium mill tailings. (See Class A, B, and C low-level waste [p. GLO-2].)

maximally exposed individual (MEI). On-site (occupational) or off-site (non-occupational) person that receives the highest dose from a release scenario.

maximally exposed off-site individual (MEOSI). Member of the general public receiving the highest dose from the effluent release.

mean. The average value of a series of measurements.

metric ton. (See ton, metric [p. GLO-10].)

millirem (mrem). A unit of radiation dose equivalent that is equal to one one-thousandth of a rem. An individual member of the public can receive up to 500 millirems per year according to DOE standards. This limit does not include radiation received for medical treatment or the roughly $360 \mathrm{mrem}$, on average, that people receive annually from background radiation.

minimum detectable concentration (MDC). Depending on the sample medium, the smallest amount or concentration of a radioactive or nonradioactive analyte that can be reliably detected using a specific analytical method. Calculations of the minimum detectable concentrations are based on the lower limit of detection.

mixed waste (MW). A waste that is both radioactive and hazardous.

n-Dodecane/tributyl phosphate. An organic solution composed of 30\% tributyl phosphate (TBP) dissolved in n-dodecane used to first separate the uranium and plutonium from the fission products in the dissolved fuel and then to separate the uranium from the plutonium.

neutron. An electrically neutral subatomic particle in the baryon family with a mass 1,839 times that of an electron, stable when bound in an atomic nucleus, and having a mean lifetime of approximately 16.6 minutes as a free particle.

notice of violation (NOV). A letter of notice from a regional water engineer in response to an instance of significant noncompliance with a SPDES permit. Generally, an official notification from a regulatory agency of noncompliance with permit requirements.

nucleus. The positively charged central region of an atom, made up of protons and neutrons and containing almost all of the mass of the atom.

outfall. The end of a drain or pipe that carries wastewater or other effluents into a ditch, pond, or river.

$$
G L O-6
$$


parameter. Any of a set of physical properties whose values determine the characteristics or behavior of something (e.g., temperature, pressure, density of air). In relation to environmental monitoring, a monitoring parameter is a constituent of interest. Statistically, the term "parameter" is a calculated quantity, such as a mean or variance, that describes a statistical population.

particulates. Solid particles and liquid droplets small enough to become airborne.

person-rem. The sum of the individual radiation dose equivalents received by members of a certain group or population. It may be calculated by multiplying the average dose per person by the number of persons exposed. For example, a thousand people each exposed to one millirem would have a collective dose of one person-rem.

plume. The distribution of a pollutant in air or water after being released from a source.

precision. The degree of reproducibility of a measurement under a given set of conditions. Precision in a data set is assessed by evaluating results from duplicate field or analytical samples.

proglacial lake. A lake occupying a basin in front of a glacier, generally in direct contact with the ice.

proton. A stable, positively charged subatomic particle in the baryon family with a mass 1,836 times that of an electron.

pseudo-monitoring point. A theoretical monitoring location rather than an actual physical location; a calculation based on analytical test results of samples obtained from other associated, tributary, monitored locations. (Point 116 at the WVDP is classified as a "pseudo" monitoring point because samples are not actually physically collected at that location. Rather, using analytical results from samples collected from "real" upstream outfall locations, compliance with the total dissolved solids limit in the WVDP's SPDES permit is calculated for this theoretical point.)

quality factor (QF). The extent of tissue damage caused by different types of radiation of the same energy. The greater the damage, the higher the quality factor. More specifically, the factor by which absorbed doses are multiplied to obtain a quantity that indicates the degree of biological damage produced by ionizing radiation. See radiation dose [p. GLO-8].) The factor is dependent upon radiation type (alpha, beta, gamma, or $\mathrm{x}$-ray) and exposure (internal or external).

rad. Radiation absorbed dose. One hundred ergs of energy absorbed per gram.

radiation. The process of emitting energy in the form of rays or particles that are thrown off by disintegrating atoms. The rays or particles emitted may consist of alpha, beta, or gamma radiation.

alpha radiation. The least penetrating type of radiation. Alpha radiation can be stopped by a sheet of paper or the outer dead layer of skin.

$$
\text { GLO - } 7
$$


beta radiation. Electrons emitted from a nucleus during fission and nuclear decay. Beta radiation can be stopped by an inch of wood or a thin sheet of aluminum.

gamma radiation. A form of electromagnetic, high-energy radiation emitted from a nucleus. Gamma rays are essentially the same as x-rays and require heavy shielding such as lead, concrete, or steel to be stopped.

internal radiation. Radiation originating from a source within the body as a result of the inhalation, ingestion, or implantation of natural or manmade radionuclides in body tissues.

radiation dose:

absorbed dose. The amount of energy absorbed per unit mass in any kind of matter from any kind of ionizing radiation. Absorbed dose is measured in rads or grays.

collective dose equivalent. The sum of the dose equivalents for all the individuals comprising a defined population. The per capita dose equivalent is the quotient of the collective dose equivalent divided by the population. The unit of collective dose equivalent is person-rem or personsievert.

collective effective dose equivalent. The sum of the effective dose equivalents for the individuals comprising a defined population. Units of measurement are person-rems or person-sieverts. The per capita effective dose equivalent is obtained by dividing the collective dose equivalent by the population. Units of measurement are rem or sievert.

committed dose equivalent. A measure of internal radiation. The predicted total dose equivalent to a tissue or organ over a fifty-year period after a known intake of a radionuclide into the body. It does not include contributions from sources of external penetrating radiation. Committed dose equivalent is measured in rem or sievert.

committed effective dose equivalent. The sum of the committed dose equivalents to various tissues in the body, each multiplied by the appropriate weighting factor. Committed effective dose equivalent is measured in rem or sievert.

effective dose equivalent. The summation of the products of the dose equivalent received by specified tissues of the body and the appropriate weighting factors. It includes the dose from radiation sources internal and/or external to the body. The effective dose equivalent is expressed in units of rem or seivert.

radioactivity. A property possessed by some elements (such as uranium) whereby alpha, beta, or gamma rays are spontaneously emitted.

$G L O-8$ 
radioisotope. A radioactive isotope of a specified element. Carbon-14 is a radioisotope of carbon. Tritium is a radioisotope of hydrogen. (See isotope [p. GLO-5].)

radionuclide. A radioactive nuclide. Radionuclides are variations (isotopes) of elements. They have the same number of protons and electrons but different numbers of neutrons, resulting in different atomic masses. There are several hundred known nuclides, both manmade and naturally occurring.

rem. An acronym for Roentgen Equivalent Man. A unit of radiation exposure that indicates the potential effect of radiation on human cells.

remote-handled waste. At the WVDP, waste that has an external surface dose rate that exceeds 100 millirem per hour or a high level of alpha and/or beta surface contamination.

self-assessment. Appraisals of work at the WVDP by individuals, groups, or organizations responsible for overseeing and/or performing the work. Self-assessments are intended to provide an internal review of performance to determine that specific functional areas are in programmatic and site-specific compliance with applicable DOE directives, WVDP procedures, and regulations.

finding. A direct and significant violation of applicable Department of Energy, regulatory, or other procedural or programmatic requirements. A finding requires documented corrective action.

observation. A condition that, while not a direct and significant violation of applicable Department of Energy, regulatory, or other procedural or programmatic requirements, could result in a finding if not corrected. An observation requires documented corrective action.

good practice. A statement of proficiency or confirmed excellence worthy of documenting.

sievert. A unit of dose equivalent from the International System of Units (Systeme Internationale). Equal to one joule per kilogram.

solid waste management unit (SWMU). Any discernible unit at which solid wastes have been placed at any time, irrespective of whether the unit was intended for the management of solid or hazardous waste. Such units include any area at a facility at which solid wastes have been routinely and systematically released. (See also super solid waste management unit [p. GLO-10].)

spent fuel. Nuclear fuel that has been used in a nuclear reactor; this fuel contains uranium, activation products, fission products, and plutonium.

spill. A spill or release is defined as "any spilling, leaking, pumping, pouring, emitting, emptying, discharging, injecting, escaping, leaching, dumping, or otherwise disposing of substances from the ordinary containers employed in the normal course of storage, transfer, processing, or use."

GLO - 9 
stakeholder. A person or group that has an investment, share, or interest in something. At the WVDP stakeholders include Project management, scientists, other employees, politicians, regulatory agencies, local and national interest groups, and members of the general public.

standard deviation. An indication of the dispersion of a set of results around their average.

super solid waste management unit (SSWMU). Individual solid waste management units that have been grouped and ranked into larger units - super solid waste management units - because some individual units are contiguous or so close together as to make monitoring of separate units impractical. (See also solid waste management unit [p. GLO-9].)

surface water. Water that is exposed to the atmospheric conditions of temperature, pressure, and chemical composition at the surface of the earth.

surveillance. The act of monitoring or observing a process or activity to verify conformance with specified requirements.

thermoluminescent dosimeter (TLD). A device that luminesces upon heating after being exposed to radiation. The amount of light emitted is proportional to the amount of radiation to which the luminescent material has been exposed.

ton, metric (also tonne). A unit of mass equal to 1,000 kilograms.

ton (short ton). A unit of weight equal to $2,000 \mathrm{lbs}$ or 907.1847 kilograms.

transuranic waste. Waste containing transuranic elements, that is, those elements with an atomic number greater than 92, including neptunium, plutonium, americium, and curium.

universal wastes. Wastes subject to special management provisions that are intended to ease the management burden and facilitate recycling of such materials. Four types of waste are currently covered under the universal waste regulations: hazardous waste batteries, hazardous waste pesticides that are either recalled or collected in waste pesticide collection programs, hazardous waste thermostats, and hazardous waste lamps.

upgradient. Referring to the flow of water or air, "upgradient" is analogous to upstream. Upgradient is a point that is "before" an area of study that is used as a baseline for comparison with downstream data. (See gradient [p. GLO-4] and downgradient [p. GLO-3].)

watershed. The area contained within a drainage divide above a specified point on a stream or river.

water table. The upper surface in a body of groundwater; the surface in an unconfined aquifer or confining bed at which the pore water pressure is equal to atmospheric pressure. 
x-ray. Penetrating electromagnetic radiations having wave lengths shorter than those of visible light. They are usually produced by bombarding a metallic target with fast electrons in a high vacuum. In nuclear reactions it is customary to refer to photons originating in the nucleus as gamma rays and those originating in the extranuclear part of the atom as x-rays. These rays are sometimes called roentgen rays after their discoverer, W.C. Roentgen. 
This page intentionally left blank

$G L O-12$ 


\section{ACRONYMS AND ABBREVIATIONS}

\begin{tabular}{|c|c|}
\hline ACM & Asbestos-containing Material \\
\hline ALARA & As Low As Reasonably Achievable \\
\hline ANSI & American National Standards Institute \\
\hline ASME & American Society of Mechanical Engineers \\
\hline $\mathbf{A S Q}$ & $\begin{array}{l}\text { American Society for Quality (formerly American Society for Quality Control } \\
{[\mathrm{ASQC}] \text { ) }}\end{array}$ \\
\hline BCG & Biota Concentration Guide \\
\hline BEIR & Committee on Biological Effects of Ionizing Radiation \\
\hline BOD $_{5}$ & Biochemical Oxygen Demand (5-day) \\
\hline BSW & Bulk Storage Warehouse \\
\hline CAA & Clean Air Act \\
\hline CDDL & Construction and Demolition Debris Landfill \\
\hline CEDE & Committed Effective Dose Equivalent \\
\hline CEMP & Code of Environmental Management Principles for Federal Agencies \\
\hline CERCLA & Comprehensive Environmental Response, Compensation, and Liability Act \\
\hline CFR & Code of Federal Regulations \\
\hline CO & Certificate-to-Operate \\
\hline CPC & Chemical Process Cell \\
\hline CPC-WSA & Chemical Process Cell Waste Storage Area \\
\hline CSPF & Container Sorting and Packaging Facility \\
\hline CSRF & Contact Size-Reduction Facility \\
\hline CSS & Cement Solidification System \\
\hline CWA & Clean Water Act \\
\hline CWAP & Clean Water Action Plan \\
\hline $\mathbf{C X}$ & Categorical Exclusion \\
\hline CY & Calendar Year \\
\hline D\&D & Decontamination and Decommissioning \\
\hline DCG & Derived Concentration Guide \\
\hline DL & Detection Limit or Detection Level \\
\hline DMR & Discharge Monitoring Report \\
\hline
\end{tabular}

$A \& A-1$ 


\begin{tabular}{|c|c|}
\hline DOE & (U.S.) Department of Energy \\
\hline DOE-EM & Department of Energy, Office of Environmental Restoration and Waste Management \\
\hline DOE-HQ & Department of Energy, Headquarters Office \\
\hline DOE-OH & Department of Energy, Ohio Field Office \\
\hline DOT & (U.S.) Department of Transportation \\
\hline EA & Environmental Assessment \\
\hline EDE & Effective Dose Equivalent \\
\hline EHS & Extremely Hazardous Substance \\
\hline EIS & Environmental Impact Statement \\
\hline ELAB & (WVDP) Environmental Laboratory \\
\hline EML & Environmental Measurements Laboratory \\
\hline EMS & Environmental Management System \\
\hline EPA & (U.S.) Environmental Protection Agency \\
\hline EPCRA & Emergency Planning and Community Right-to-Know Act \\
\hline ERA & Environmental Research Associates \\
\hline ES\&H & Environmental Safety and Health \\
\hline ESR & (WVDP) Effluent Summary Report \\
\hline EWP & Enhanced Work Planning \\
\hline FFC Act & Federal Facility Compliance Act \\
\hline FONSI & Finding of No Significant Impact \\
\hline FR & Federal Register \\
\hline FRS & Fuel Receiving and Storage \\
\hline FSFCA & Federal and State Facility Compliance Agreement \\
\hline FY & Fiscal Year \\
\hline GEL & General Engineering Laboratory \\
\hline HEPA & High-Efficiency Particulate Air (filter) \\
\hline HLW & High-Level (radioactive) Waste \\
\hline HLWTF & High-Level (radioactive) Waste Treatment Facility \\
\hline HPIC & High-Pressure Ion Chamber \\
\hline HTO & Hydrogen Tritium Oxide \\
\hline HVAC & Heating, Ventilation, and Air Conditioning \\
\hline ICRP & International Commission on Radiological Protection \\
\hline INEEL & Idaho National Engineering and Environmental Laboratory \\
\hline IRTS & Integrated Radwaste Treatment System \\
\hline ISMS & Integrated Safety Management System \\
\hline ISO & International Organization for Standardization \\
\hline LAS & Linear Alkylate Sulfonate \\
\hline LDR & Land Disposal Restriction \\
\hline LIMS & Laboratory Information Management System \\
\hline LLD & Lower Limit of Detection \\
\hline LLW & Low-Level (radioactive) Waste \\
\hline LLW2 & Low-Level (liquid) Waste Treatment Facility (new) \\
\hline LLWTF & Low-Level (liquid) Waste Treatment Facility (old) \\
\hline
\end{tabular}

$A \& A-2$ 


\begin{tabular}{|c|c|}
\hline LPS & Liquid Pretreatment System \\
\hline LSA & Lag Storage Area \\
\hline LTR & License Termination Rule \\
\hline LWTS & Liquid Waste Treatment System \\
\hline MDC & Minimum Detectable Concentration \\
\hline MDL & Method Detection Limit \\
\hline MEOSI & Maximally Exposed Off-Site Individual \\
\hline MSDS & Material Safety Data Sheet \\
\hline MTAR & Monthly Trend Analysis Report \\
\hline MW & (Radioactive) Mixed Waste \\
\hline NCRP & National Council on Radiation Protection and Measurements \\
\hline NDA & Nuclear Regulatory Commission-Licensed Disposal Area \\
\hline NEPA & National Environmental Policy Act \\
\hline NESHAP & National Emission Standards for Hazardous Air Pollutants \\
\hline NFS & Nuclear Fuel Services, Inc. \\
\hline NGVD & National Geodetic Vertical Datum \\
\hline NIST & National Institute of Standards and Technology \\
\hline NOI & Notice of Intent \\
\hline NOV & Notice of Violation \\
\hline NO $_{x}$ & Nitrogen Oxides \\
\hline NPDES & National Pollutant Discharge Elimination System \\
\hline NPGRS & North Plateau Groundwater Recovery System \\
\hline NPOC & Nonpurgeable Organic Carbon \\
\hline NRC & (U.S.) Nuclear Regulatory Commission \\
\hline NTS & Nevada Test Site \\
\hline NTU & Nephelometric Turbidity Unit \\
\hline NYCRR & New York Official Compilation of Codes, Rules, and Regulations \\
\hline NYS & New York State \\
\hline NYSDEC & New York State Department of Environmental Conservation \\
\hline NYSDOH & New York State Department of Health \\
\hline NYSDOL & New York State Department of Labor \\
\hline NYSERDA & New York State Energy Research and Development Authority \\
\hline NYSGS & New York State Geological Survey \\
\hline OH/WVDP & Department of Energy, West Valley Demonstration Project \\
\hline OSHA & Occupational Safety and Health Act \\
\hline OVE & Outdoor Ventilated Enclosure \\
\hline $\mathbf{P 2}$ & Pollution Prevention \\
\hline PCB & Polychlorinated Biphenyl \\
\hline PQL & Practical Quantitation Limit \\
\hline PTW & Permeable Treatment Wall \\
\hline PVS & Permanent Ventilation System \\
\hline PVU & Portable Ventilation Unit \\
\hline QA & Quality Assurance \\
\hline
\end{tabular}

$A \& A-3$ 


$\begin{array}{ll}\text { QAP } & \text { Quality Assessment Program (also Quality Assurance Program) } \\ \text { QC } & \text { Quality Control } \\ \text { QF } & \text { Quality Factor } \\ \text { RCRA } & \text { Resource Conservation and Recovery Act } \\ \text { RFI } & \text { RCRA Facility Investigation } \\ \text { RHWF } & \text { Remote-Handled Waste Facility } \\ \text { SAR } & \text { Safety Analysis Report } \\ \text { SARA } & \text { Superfund Amendments and Reauthorization Act } \\ \text { SD } & \text { Standard Deviation } \\ \text { SDA } & \text { (New York) State-Licensed Disposal Area } \\ \text { SDWA } & \text { Safe Drinking Water Act } \\ \text { SER } & \text { Site Environmental Report } \\ \text { SI } & \text { Systeme Internationale (International System of Units) } \\ \text { SO } & \text { Sulfur Dioxide } \\ \text { SPDES } & \text { State Pollutant Discharge Elimination System } \\ \text { SSWMU } & \text { Super Solid Waste Management Unit } \\ \text { STL } & \text { Severn Trent Laboratories } \\ \text { STS } & \text { Supernatant Treatment System } \\ \text { SVOC } & \text { Semivolatile Organic Compound } \\ \text { SWMU } & \text { Solid Waste Management Unit } \\ \text { TBP } & \text { Tributyl Phosphate } \\ \text { TDS } & \text { Total Dissolved Solids } \\ \text { TLD } & \text { Thermoluminescent Dosimetry } \\ \text { TOC } & \text { Total Organic Carbon } \\ \text { TOX } & \text { Total Organic Halogens } \\ \text { TRI } & \text { Toxic Release Inventory } \\ \text { TRU } & \text { Transuranic } \\ \text { TSCA } & \text { Toxic Substances Control Act } \\ \text { TSDF } & \text { Treatment, Storage, and Disposal Facility } \\ \text { USGS } & \text { United States Geological Survey } \\ \text { VEMP } & \text { Vitrification Expended Material } \\ \text { VOC } & \text { Volatile Organic Compound } \\ \text { VPP } & \text { (U.S. DOE) Voluntary Protection Program } \\ \text { WNYNSC } & \text { Western New York Nuclear Service Center } \\ \text { WVDP } & \text { West Valley Demonstration Project } \\ \text { WVNSCO } & \text { Wastewater Treatment Facility } \\ \text { WWTF } & \end{array}$

$A \& A-4$ 


\section{Units of Measure}

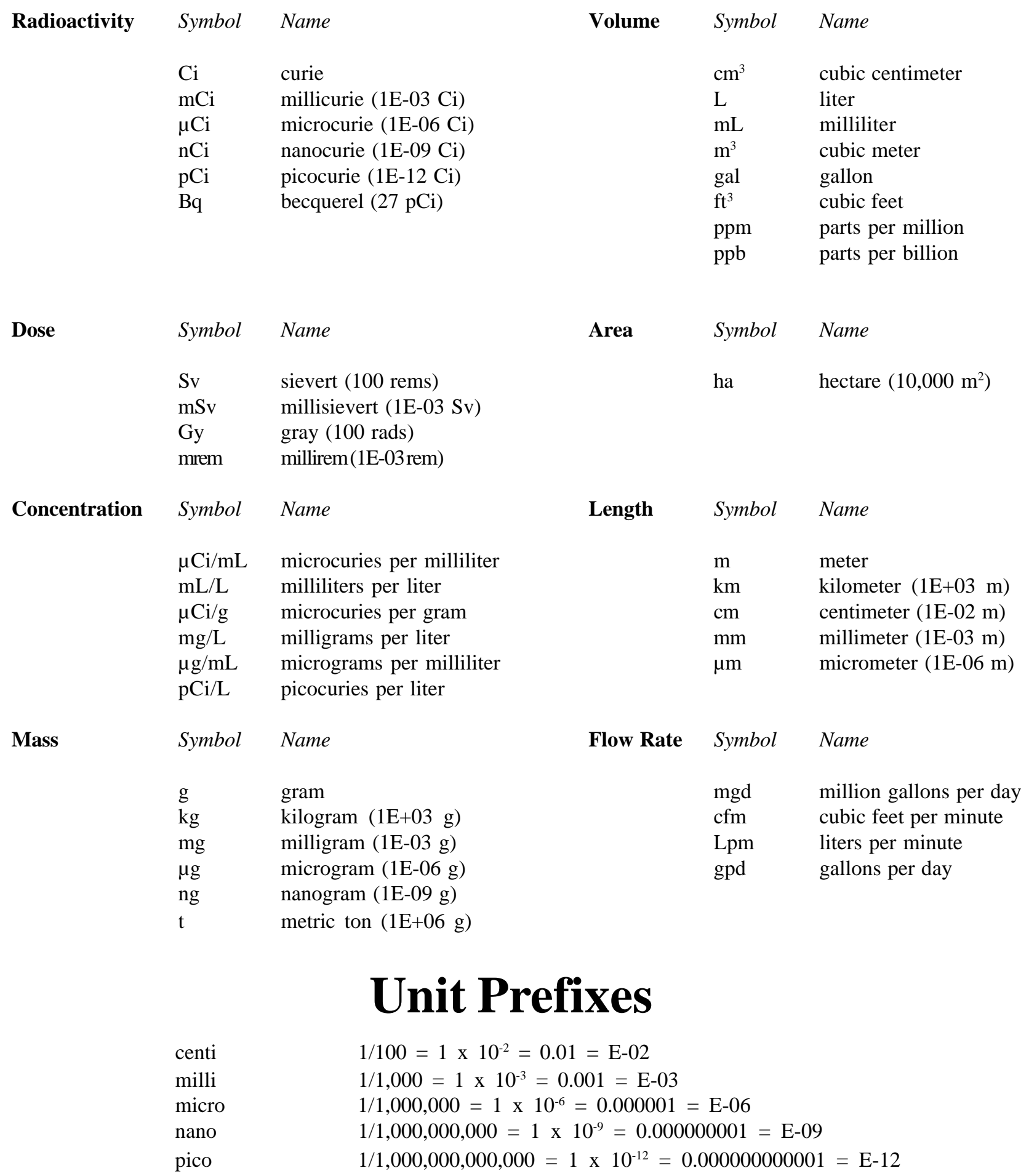

$U O M-1$ 


\section{Scientific Notation}

Scientific notation may be used to express very large or very small numbers. A number smaller than 1 is expressed with a negative exponent (e.g., $1.3 \times 10^{-6}$ ). To convert this number to decimal form, the decimal point is moved left by the number of places equal to the exponent. Thus, $1.3 \times 10^{-6}$ becomes 0.0000013 .

A number larger than 10 is expressed with a positive exponent (e.g., $\left.1.3 \times 10^{6}\right)$. To convert this number to decimal form, the decimal point is moved right by the number of places equal to the exponent. Thus, $1.3 \times 10^{6}$ becomes 1,300,000.

The power of 10 also is expressed as E. For example, $1.3 \times 10^{-6}$ also can be written as $1.3 \mathrm{E}-06$. The chart below shows equivalent exponential and decimal values.

$$
\begin{array}{lllll}
1.0 \times 10^{2}= & 1 \mathrm{E}+02= & 100 \\
1.0 \times 10^{1}= & 1 \mathrm{E}+01= & 10 \\
1.0 \times 10^{0}= & 1 \mathrm{E}+00= & 1 \\
1.0 \times 10^{-1}= & 1 \mathrm{E}-01= & 0.1 \\
1.0 \times 10^{-2}= & 1 \mathrm{E}-02= & 0.01 \\
1.0 \times 10^{-3}= & 1 \mathrm{E}-03= & 0.001 & \\
1.0 \times 10^{-4}= & 1 \mathrm{E}-04= & 0.0001 & \\
1.0 \times 10^{-5}= & 1 \mathrm{E}-05= & 0.00001 & \\
1.0 \times 10^{-6}= & 1 \mathrm{E}-06= & 0.000001 & \text { One Millionth } \\
1.0 \times 10^{-7}= & 1 \mathrm{E}-07= & 0.0000001 & \\
1.0 \times 10^{-8}= & 1 \mathrm{E}-08= & 0.00000001 & \\
& & & &
\end{array}
$$

\section{Conversion Chart}

Both traditional radiological units (curie, roentgen, rad, rem) and the Systeme Internationale (S.I.) units (becquerel, gray, sievert) are used in this report. Nonradiological measurements are presented in metric units with the English equivalent noted in parentheses.

$\begin{array}{lll}1 \text { centimeter }(\mathrm{cm}) & = & 0.3937 \text { inches }(\mathrm{in}) \\ 1 \text { meter }(\mathrm{m}) & = & 39.37 \text { inches }(\mathrm{in})=3.28 \text { feet }(\mathrm{ft}) \\ 1 \text { kilometer }(\mathrm{km}) & = & 0.62 \text { miles }(\mathrm{mi}) \\ 1 \text { milliliter }(\mathrm{mL}) & = & 0.0338 \text { ounces }(\mathrm{oz}) \\ & = & 0.061 \text { cubic inches }\left(\mathrm{in}^{3}\right) \\ & = & 1 \text { cubic centimeter }\left(\mathrm{cm}^{3}\right) \\ 1 \text { liter }(\mathrm{L}) & = & 1.057 \text { quarts }(\mathrm{qt}) \\ & = & 61.02 \text { cubic inches }\left(\mathrm{in}^{3}\right) \\ 1 \text { gram }(\mathrm{g}) & = & 0.0353 \text { ounces }(\mathrm{oz}) \\ & = & 0.0022 \text { pounds }(\mathrm{lbs}) \\ 1 \text { kilogram }(\mathrm{kg}) & = & 2.2 \text { pounds }(\mathrm{lbs}) \\ 1 \text { curie }(\mathrm{Ci}) & = & 3.7 \times 10^{10} \text { disintegrations per second }(\mathrm{d} / \mathrm{s}) \\ 1 \text { becquerel }(\mathrm{Bq}) & = & 1 \text { disintegration per second }(\mathrm{d} / \mathrm{s}) \\ & = & 27 \text { picocuries }(\mathrm{pCi}) \\ 1 \text { roentgen }(\mathrm{R}) & = & 2.58 \times 10^{-4} \text { coulombs per kilogram of air }(\mathrm{C} / \mathrm{kg}) \\ 1 \text { rad } & = & 0.01 \text { gray }(\mathrm{Gy}) \\ 1 \text { rem } & = & 0.01 \text { sievert }(\mathrm{Sv}) \\ 1 \text { millirem }(\mathrm{mrem}) & = & 0.001 \text { rem } \\ & & \end{array}$




\section{Distribution}

Recipient

Federal Organization

DOE Office of Scientific and Technical Information

R. Natoli

M. Rawlings

V. Crawford

W. Best

J. Craig

J. Ebersole

R. Grandfield

R. Tormey

C. Glenn

J. Greeves

J. Cottan

R. Chaput

J. Eng

P. Giardina

S. Venezia

F. Galpin

W. Kappel

T. Reynolds

J. Quinn

A. Houghton

H. Clinton

C. Schumer
DOE-HQ

DOE-HQ

DOE-HQ (OA-50)

DOE-OH

DOE-OH

DOE-OH

DOE-OH

DOE-OH

NRC - HQ

NRC - HQ

NRC - Region 1

USEPA - Region II

USEPA - Region II

USEPA - Region II

USEPA - Region II

USEPA - Washington, D.C.

USGS

U.S. Congressman, 27th Dist.

U.S. Congressman, 30th Dist.

U.S. Congressman, 31st Dist.

U.S. Senator, New York

U.S. Senator, New York
Recipient

M. O’Donahue

P. Counterman

P. Merges

R. Murphy

T. Rice

M. Wang

B. Bartz

S. Doleski

J. Sciascia

M. Jackson

J. Krajewski

J. Strickland

T. DiGiulio

J. Huang

G. Baker

B. Ignatz

A. Salame Alfie

P. Piciulo

H. Brodie

E. Dassatti

R. Fakundiny

D. Burling

C. Young

P. McGee

W. Stachowski

D. Volker
State Organization

Executive Chamber, State Capitol, Albany

NYSDEC - Albany

NYSDEC - Albany

NYSDEC - Albany

NYSDEC - Albany

NYSDEC - Albany

NYSDEC - Buffalo

NYSDEC - Buffalo

NYSDEC - Buffalo

NYSDEC - Region 9

NYSDEC - Region 9

NYSDEC - Region 9

NYSDEC - Syracuse

NYSDOH - Albany

NYSDOH - Buffalo

NYSDOH - Buffalo

NYSDOH - Troy

NYSERDA

NYSERDA - Albany

NYSERDA - Albany

\section{NYSGS}

New York Assemblyman, 147th Dist.

New York Assemblywoman, 149th Dist.

New York Senator, 56th Dist.

New York Senator, 58th Dist.

New York Senator, 59th Dist.

\section{Recipient}

\section{Local Organization}

\section{Recipient}

\section{Local Organization}

W. Penman

Director, Cattaraugus County Health Dept.

E. Wohlers

Cattaraugus County Health Dept.

G. Felton

G. Fitzpatrick

E. Helms

Cattaraugus County Legislator

Cattaraugus County Legislator

P. McCrea

Cattaraugus County Legislator

Cattaraugus County Legislator

\section{G. Eppolito \\ W. King \\ M. Steffan}

Mayor, Village of Springville

Supervisor, Town of Ashford

Supervisor, Town of Concord
A. Billittier IV
Erie County Health Department
C. Schindler
President, Seneca Nation of Indians
L. Maybee
Seneca Nation of Indians Environmental Protection Department 


\section{Distribution}

\section{Publication}

Buffalo News, Buffalo, New York*

Salamanca Republican Press, Salamanca, New York *

Springville Journal, Springville, New York*

\section{Library}

Olean Public Library, Olean, New York

West Valley Central School Library, West Valley, New York

Town of Concord Hulbert Library, Springville, New York

Central Buffalo Public Library, Buffalo, New York

Seneca Nation of Indians Library, Cattaraugus Reservation, Irving, New York

Seneca Nation of Indians Library, Allegheny Reservation, Salamanca, New York

http://www.wv.doe.gov

* Notice of public availability

DST - 2 


\section{Acknowledgments}

This report was compiled and edited by N.A. McNeil, P.J. Hadden-Carter, and E.D. Picazo (team leader) of the URS West Valley Demonstration Project staff. J.M. Wilcox, also of the URS WVDP staff, provided editing support and desktop publishing services. Other technical preparers and reviewers are listed below.

Adams, T.G.

Atkinson, C.E.

Balsdon, P.K.

Banzer, C.B.

Biedermann, C.A.

Bird, A.M.

Bleech, J.P.

Boada-Clista, L.

Carter, R.A.

Centrich, G.F.

Chilson, L.J.

Coco, L.M.

Cohen, F.J.

Eigenbrod, E.M.

Fox, J.R.

Garcia, J.M.

Gerber, J.R.

Heim, B.F.

Hoch, J.J.

Jackson, J.P.

Kean, W.N.

Keller, K.D.

Klenk, D.P.

Komasara, S.M.

Lenter, C.M.

Loop, M.C.

Lowes, E.A.
Maloney, M.N.

Marvin, V.S.

MacVean, S.A.

McGetrick, L.B.

Moore, H.R.

Moran, R.E.

Nagel, A.S.

Paskuly, S.J.

Pendl, M.P.

Pillittere, J.T.

Rizzo, J.R.

Roesch, C.T.

Scalise, D.M.

Schalberg, T.E.

Scharf, R.L.

Shukla, A.K.

Skiba, K.S.

Spector, H.L.

Steiner, A.F.

Steiner, D.R.

Steiner, R.E.

Valenti, P.J.

Walnicki, S.A.

Westcott, D.R.

Wierzbicki, W.M.

Wrotniak, C.M.

Zadins, Z.Z. 
